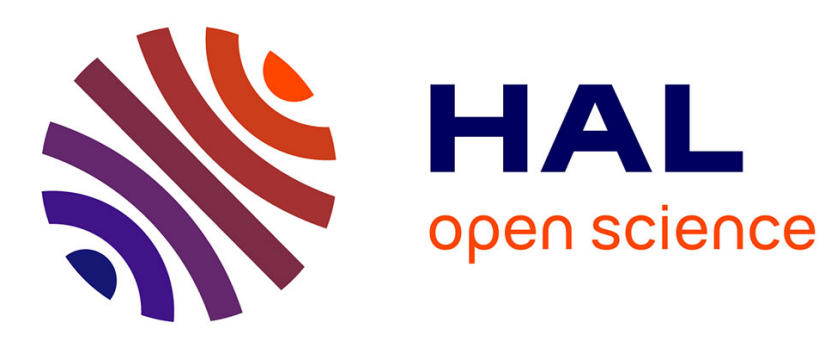

\title{
Financialization and its Implications on the Determination of Exchange Rates of Emerging Market Economies
}

\author{
Raquel Almeida Ramos
}

\section{- To cite this version:}

Raquel Almeida Ramos. Financialization and its Implications on the Determination of Exchange Rates of Emerging Market Economies. Economics and Finance. Université Sorbonne Paris Cité; Universidade estadual de Campinas (Brésil), 2016. English. NNT : 2016USPCD056 . tel-02115942

\section{HAL Id: tel-02115942 \\ https://theses.hal.science/tel-02115942}

Submitted on 30 Apr 2019

HAL is a multi-disciplinary open access archive for the deposit and dissemination of scientific research documents, whether they are published or not. The documents may come from teaching and research institutions in France or abroad, or from public or private research centers.
L'archive ouverte pluridisciplinaire HAL, est destinée au dépôt et à la diffusion de documents scientifiques de niveau recherche, publiés ou non, émanant des établissements d'enseignement et de recherche français ou étrangers, des laboratoires publics ou privés. 


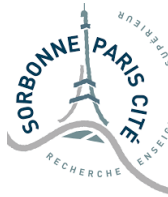

\section{unIVERSITE PARIS 13}

Univesité Sorbonne Paris Cité

Univesité Paris 13

Universidade Estadual de

Campinas

"U.F.R des Sciences Économiques et

"Instituto de Economia"

de Gestion"

\section{THESIS}

in order to become

PhD from Univesités Paris 13 \& from Unicamp

academic field: economics

publicly defended by

Raquel Almeida Ramos

on December 2, 2016

Title

Financialization and its Implications on the Determination of Exchange Rates of Emerging Market Economies

Thesis Advisors

Defense Committee
Daniela Magalhães Prates

Dany Lang

Dominique Plihon

Annina Kaltenbrunner

Antonio Carlos Macedo e Silva

Barbara Fritz

Bruno De Conti

Marc Lavoie, Président

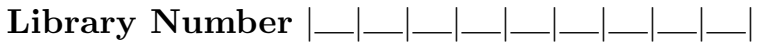




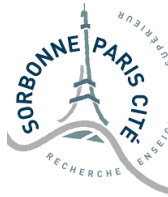

\section{université PARIS 13}

Univesité Sorbonne Paris Cité

Univesité Paris 13

"U.F.R des Sciences Économiques et

de Gestion"

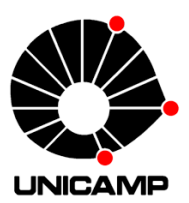

Universidade Estadual de

Campinas

"Instituto de Economia"

\section{THÈSE}

pour obtenir le grade de

Docteur de l'Univesités Paris 13 \& de l'Unicamp

discipline: Sciences Économiques

présentée et soutenue publiquement par

Raquel Almeida Ramos

le 2 décembre 2016

Titre

La financiarisation et ses conséquences dans la détermination du taux de change des pays émergents

Directeurs de thèse

Jury
Daniela Magalhães Prates

Dany Lang Dominique Plihon

Annina Kaltenbrunner Antonio Carlos Macedo e Silva

Barbara Fritz

Bruno De Conti

Marc Lavoie, Président

Numéro attribué par la bibliothèque

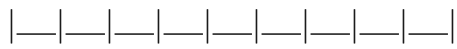




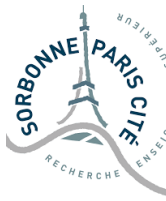

\section{université PARIS 13}

Univesité Sorbonne Paris Cité

Univesité Paris 13

"U.F.R des Sciences Économiques et

de Gestion"

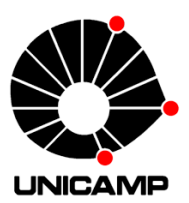

Universidade Estadual de

Campinas

"Instituto de Economia"

\section{TESE}

para obtenção do título de

Doutora da Univesité Paris 13 \& da Unicamp

disciplina: Ciências Econômicas

apresentada e defendida publicamente por

Raquel Almeida Ramos

dia 2 de dezembro de 2016

Título

A financeirização e suas implicações para a determinação da taxa de câmbio das economias emergentes

Orientadores

Banca

\section{Daniela Magalhães Prates \\ Dany Lang \\ Dominique Plihon}

Annina Kaltenbrunner

Antonio Carlos Macedo e Silva

Barbara Fritz

Bruno De Conti

Marc Lavoie, Presidente

Número da biblioteca

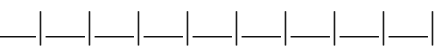




\begin{abstract}
This thesis investigates the impacts of financialization on exchange rates of emerging market economies (EMEs). With financialization, finance follows a patrimonial and increasingly speculative logic at the international level, reflecting innovations of products and practices such as FX derivatives and carry trading by money managers. Through their portfolio allocation decisions, these portfolio investors bridge markets and currencies across the globe, their decisions being key to exchange rate determination. Simultaneously, some EMEs have been facing high exchange rate volatility, especially in moments of turbulence in international financial markets.

The thesis seeks to answer whether these dynamics are associated with financialization and why they are stronger in some EMEs. Specifically, it raises the hypothesis that the use of an EME's assets and currency in those innovative strategies increases emerging currencies' fragility to money managers' decisions, thus to conditions of financial markets worldwide. To test this hypothesis an indicator of financialized integration is suggested and compared to countries' exchange-rate features.

Results demonstrate a strong association of financialization with higher exchange rate volatility, more frequent extreme depreciations, closer association with international financial conditions, and high correlation with other emerging currencies. Apart from scrutinizing emerging currencies' special dynamics and their reasons, the thesis suggests a Minskyan open-economy framework that details the underlying mechanisms and forms of modeling key elements to explain exchange rate dynamics in the SFC framework.
\end{abstract}




\section{Résumé}

Cette thèse étudie les impacts de la financiarisation sur le taux de change des pays émergents. La financiarisation entraine la finance vers une logique patrimoniale et plus spéculative au niveau international comme l'indique l'utilisation de produits et pratiques innovantes par les gestionnaires de portefeuille internationaux. Parallèlement, on constate une volatilité élevée des taux de change dans certains pays émergents, notamment lors de turbulences sur les marchés financiers internationaux.

La thèse analyse la relation entre la financiarisation et cette dynamique du taux de change et pourquoi le taux de change est plus volatile dans certainas pays. La thèse émet l'hypothèse que l'inclusion d'actifs des pays émergents et de leur monnaie dans les stratégies innovantes de gestion de portefeuille soumet leurs taux de change aux décisions des money managers et les rend dépendant aux variations des marchés financiers mondiaux. Pour tester cette hypothèse, la thèse propose l'utilisation d'un indicateur d'intégration financiarisée et le compare aux caractéristiques de chaque taux de change.

Les résultats démontrent une forte relation entre le niveau de financiarisation de l'intégration d'un pays et la volatilité de son taux de change, la fréquence des dépréciations extrêmes, la corrélation avec les conditions financières internationales ainsi qu'avec d'autres monnaies émergentes. La thèse propose une analyse dans une approche Minskyenne d'économie ouverte qui détaille les mécanismes sous-jacents à ces résultats et des modélisations des éléments importants pour la détermination du taux de change dans un cadre SFC. 


\section{Resumo}

A tese estuda o impacto da financeirização nas taxas de câmbio das economias emergentes (EMEs). Com a financeirização, as finanças, no nível internacional, seguem uma lógica partimonial onde a especulação tem espaço cada vez maior, como reflexo de inovações de produtos e práticas como derivativos cambiais e carry trading por parte dos money managers. Através de suas escolhas de alocação de portfolio, esses investidores de portfolio conectam mercados e moedas ao redor do globo, o que faz de suas decisẽes elementos-chave da determinação da taxa de câmbio. Ao mesmo tempo, algumas economias emergentes têm se deparado com uma alta volatilidade cambial, especialmente em momentos de turbulência em mercados financeiros internacionais.

Essas dinâmicas cambiais seriam associadas ao processo de financeirização? Por qual motivo elas seriam mais importantes em algumas economias do que em outras? Essas são algumas das questões às quais essa tese busca responder. Especificamente, a tese sugere a hipótese de que o uso de ativos e de moedas dessas economias nas atividades inovadoras mencionadas torna as taxas de câmbio das mesmas vulneráveis às decisões dos money managers - e assim às condições de mercados financeiros ao redor do mundo. Para testar essa hipótese, um indicador de integração financerizada é proposto e comparado às características das taxas de câmbio do país em questão.

Os resultados demonstram uma forte associação da financeirização com uma volatilidade cambial mais elevada, uma relação mais próxima com as condições dos mercados financeiros globais e uma maior correlação com outras moedas de economias emergentes. Além de examinar as dinâmicas específicas às moedas emergentes e suas razões de forma empírica, a tese sugere um arcabouço Minskyano de economia aberta que detalha os mecanismos subjacentes aos resultados encontrados e formas de modelar elementos-chave para a compreensão da dinâmica cambial em modelos de consistência de fluxos e estoques (SFC). 
Keywords Exchange Rates; Financialization; Emerging Market Economies; Financial Integration; Minsky; Stock-Flow Consistent Models

Mots-clés Taux de change; Financiarisation; Pays émergents; Intégration financière internationale; Minsky; Modèles stock flux cohérents

Palavras-chave Taxas de câmbio; Financeirização; Economias emergentes; Integração financeira internacional; Minsky; Modelos de consistência de fluxos e estoques 
This thesis was written at

Centre d'Economie de Paris Nord (UMR CNRS 7234-CEPN)

Université Paris 13

99 avenue Jean-Baptiste Clément

93430 Villetaneuse

France

+33149403255 / 0149403527

cepn-secretariat@univ-paris13.fr

https://cepn.univ-paris13.fr
Instituto de Economia

Universidade Estadual de Campinas

R. Pitágoras, 353

Cidade Universitária 13083-857 Campinas, SP

Brésil

+ 551935215707

contato@eco.unicamp.br

http://www.eco.unicamp.br 
Para Heloisa, Lucy, e Ondina. 


\section{Acknowledgements}

I would like to express my deepest gratitude to my husband, Max, whose endless support and encouragement throughout these years were key in accomplishing this project. A special thanks to my son, André, for making the thesis period a delight.

I am deeply grateful to my thesis supervisors, Daniela Magalhães Prates, Dany Lang, and Dominique Plihon for their guidance, mentoring and knowledge which deeply enhanced this thesis. It was an honor and great privilege to have you as advisors.

I further extent my thanks to the different professors who helped me with enlightening discussions on different subjects studied in the thesis, specially Bruno De Conti, Philip Arestis, Jan Priewe, Eric Tymoigne, Jan Kregel and Pedro Rossi. Thanks Marc Lavoie, Genaro Zezza, Antoine Godin and Federico Bassi for the SFC and ABM courses. I am thankful to the École doctorale Erasme and the CFDIP for the multidisciplinary workshops organized.

I also take this opportunity to express my appreciation for the incentives of Sebastian Dullien, Jan Priewe, Rathin Roy and Frederico Gonzaga Jayme Jr, who were key in prior moments in my academic carrier.

I must thanks my friends at Paris 13 and Unicamp for the cheerful days, specially Louison, Serge, João, Federico, Luís, Idir, Léonard and Jamel.

Finally, I would like to acknowledge with gratitude the support and love of my parents, Heloisa and Luís Otávio, and of Luís Felipe, Henrique, Sofia, Carlos and Sandra. 


\section{Contents}

List of Figures $\quad$ xii

List of Tables $\quad$ xiv

List of Abbreviations $\quad$ xvi

1 Introduction $\quad 1$

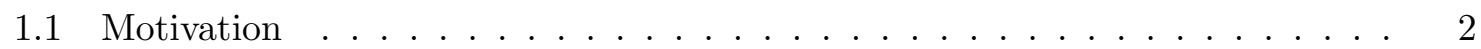

1.1.1 Exchange Rate's Relevance . . . . . . . . . . . . . . . . 2

1.1.2 Emerging Currencies: a Constant Upheaval . . . . . . . . . . . . . 2

1.1.3 Policy Makers' Concerns . . . . . . . . . . . . . . . . . 5

1.1.4 The Exchange-Rate Literature . . . . . . . . . . . . . . 6

1.2 The Purpose of the Study, Theoretical Framework and Methodology . . . . . 8

1.3 The Structure of the Thesis . . . . . . . . . . . . . . . . . . . 10

2 Financialization and its Potential Impact on Emerging Currencies $\quad 16$

2.1 The Rise of Financialization . . . . . . . . . . . . . . . 20

2.1 .1 Concluding Remarks . . . . . . . . . . . . . . . . 26

2.2 The Three Developments That Characterize Financialization . . . . . . . . . 26

2.2.1 Increasing Importance of Finance at the International Level . . . . . . 28

2.2 .2 Transformations of Finance . . . . . . . . . . . . . . . . . 31

2.2.3 The Changing Relationship Between Finance and Other Sectors . . . 43

2.3 Potential Impacts of Financialization on Exchange Rates . . . . . . . . . . . . . 46

2.3.1 The Financialization Literature on Exchange Rates . . . . . . . . . . . 46

2.3.2 Studying Money Managers' Balance-Sheets . . . . . . . . . . . . . . . . . . 48

2.4 Conclusions . . . . . . . . . . . . . . . . . . . . . . . . . . . 49

3 Exchange Rate Theories for Times of Financialization $\mathbf{5 2}$

3.1 Exchange Rate Determination . . . . . . . . . . . . . . . . . . 53

3.1.1 Theories From Before the Collapse of the Bretton Woods System . . . 55

3.1.2 First-Generation Models . . . . . . . . . . . . . . . . . . . . . 62

3.1.3 Second-Generation Models . . . . . . . . . . . . . . . . . . 67

3.1.4 Third-Generation Models . . . . . . . . . . . . . . . . 70

3.1.5 Fourth-Generation Models . . . . . . . . . . . . . . . . . . 71

3.1.6 Fifth-Generation Models . . . . . . . . . . . . . . . . . . 75

3.1 .7 Concluding Remarks . . . . . . . . . . . . . . . . . . . . . 77

3.2 Exchange-Rate Crisis Theories . . . . . . . . . . . . . . . . 79 
$3.2 .1 \quad$ First-Generation Models . . . . . . . . . . . . . . . . . . . . 80

3.2.2 Second-Generation Models . . . . . . . . . . . . . . . . . . . . . 81

3.2 .3 Third-Generation Models . . . . . . . . . . . . . . . . . . 84

3.2 .4 Concluding Remarks . . . . . . . . . . . . . . . . . . . . . . . . . . . . . . . . . 88

3.3 Heterodox Views . . . . . . . . . . . . . . . . . . . . . . . 89

3.3.1 The Evolving Financial Convention . . . . . . . . . . . . . . 90

3.3.2 Foreign Exchange as a 'Trending Market' . . . . . . . . . . . . . . . . 92

3.3.3 Foreign Investor's 'Mental Model' . . . . . . . . . . . . . . . . . . . . . 96

3.3.4 Emerging Currencies' Specificities and Dynamics . . . . . . . . . . . . 104

3.3.5 Exchange-rate dynamics in SFC Models . . . . . . . . . . . . . . . 117

3.3.6 Adding post-Keynesian Features to SFC Portfolio Equations . . . . . 126

3.3 .7 Concluding Remarks . . . . . . . . . . . . . . . . . . . . . 135

3.4 Conclusions . . . . . . . . . . . . . . . . . . . . 137

4 Emerging Countries' Foreign Liabilities and Vulnerabilities 139

4.1 Who are the Emerging Market Economies? . . . . . . . . . . . . . . . . . . . 142

4.1.1 Operationally Defining Emerging Market Economies . . . . . . . . . . 142

4.1.2 General Features of Emerging Market Economies . . . . . . . . . . . . 143

4.2 Emerging Market Economies' Foreign Liabilities: an Overview . . . . . . . . . 147

4.2 .1 Main Data Used . . . . . . . . . . . . . . . . . . . . . . . . 148

4.2.2 Emerging Market Economies' Foreign Liabilities . . . . . . . . . . . . 149

4.2.3 The Most Important Increases of Foreign Liabilities: BRICs . . . . . . 152

4.2.4 Different Types of Liabilities in Different Countries . . . . . . . . . . . . 154

4.3 The Volatility of the Different Types of Liabilities . . . . . . . . . . . . . . . 156

4.3.1 On the Measure of Volatility of a Time-Series . . . . . . . . . . . 159

4.4 The Evolution of the Stock of Foreign Liabilities . . . . . . . . . . . . 160

4.4.1 Equities' Special Pattern . . . . . . . . . . . . . . . . . . 160

4.4 .2 The Pattern of FDI Liabilities . . . . . . . . . . . . . . . . . . . 164

4.4.3 The Pattern of Debt Liabilities . . . . . . . . . . . . . . . . . 165

4.5 The Similarity of the Pattern of Liabilities: a PCA Analysis . . . . . . . . . . . 166

4.5.1 Theoretical Considerations . . . . . . . . . . . . . . 166

4.5 .2 The Results . . . . . . . . . . . . . . . . . . . 167

4.6 Stock Prices and Exchange Rate Dynamics . . . . . . . . . . . . . . 169

4.6.1 Theoretical Considerations . . . . . . . . . . . . . . . . 171

4.6 .2 The Model . . . . . . . . . . . . . . . . . . . . . . 175

4.6.3 Comparing the Results With the Empirical Literature . . . . . . . . . 180

4.6.4 The determination of impact from stock exchange to exchange rates . 181

4.7 Conclusions . . . . . . . . . . . . . . . . . . . . . . . . . . . 184

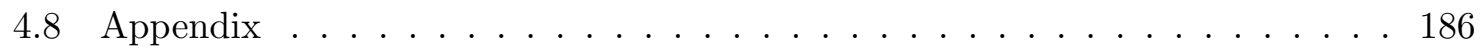

5 The Concept of Financialized Integration 198

5.1 Measuring Financial Integration . . . . . . . . . . . . . . . . . . . . 201

5.1.1 De Facto Measures of Integration . . . . . . . . . . . . . . . . . . . . 203

5.2 From Financial to Financialized Integration . . . . . . . . . . . . . . . . 207

5.2 .1 The Weight of Reserves . . . . . . . . . . . . . . . . . . . . 207

5.2 .2 Liabilities . . . . . . . . . . . . . . . . . . . . . . 211

5.2 .3 The Assets-to-Liabilities Ratio . . . . . . . . . . . . . . . . 211

5.2 .4 Absolute Financial Integration . . . . . . . . . . . . . . . . 214 
5.2.5 Financial Integration Relative to GDP . . . . . . . . . . . . . . . . . 214

5.2 .6 Financial-to-Trade Integration . . . . . . . . . . . . . . . . . . . 216

5.2 .7 Concluding Remarks . . . . . . . . . . . . . . . . . . . . . . . . 219

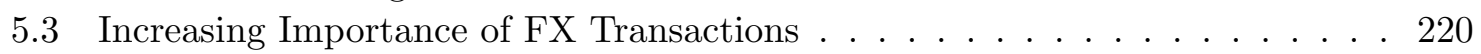

5.3 .1 Total FX Market . . . . . . . . . . . . . . . . . . . . . 221

5.3.2 FX Markets Relative to the Productive Economy . . . . . . . . . . . . 223

5.3 .3 Spot and Derivatives Markets . . . . . . . . . . . . . . . 226

5.3 .4 Concluding Remarks . . . . . . . . . . . . . . . . . . . . . . . . 230

5.4 Measuring Financialized Integration _ . . . . . . . . . . . . . 230

5.5 Characterizing Financial Integration: a Principal Components Analysis . . . 233

5.6 Conclusions . . . . . . . . . . . . . . . . . . . . . . . 240

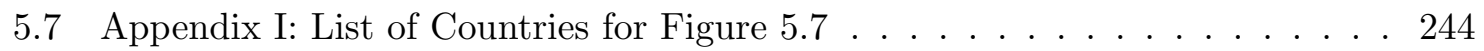

5.8 Appendix II: Additional Statistics and Figures . . . . . . . . . . . . . . . . 245

6 Emerging Countries' Exchange Rate Dynamics 255

6.1 The Expected Impacts of Integration _ . . . . . . . . . . . . . . . . . . 260

6.2 Exchange Rate Volatility . . . . . . . . . . . . . . . . . . . . . . . . . 264

6.2.1 Measuring Volatility: the Standard Deviation . . . . . . . . . . . . 265

6.2.2 Measuring Volatility: Frequency of Extreme Exchange Rate Changes . 274

6.2 .3 Concluding Remarks . . . . . . . . . . . . . . . . . . . . . . . 289

6.3 Influence From International Liquidity Cycles . . . . . . . . . . . . . . 290

6.3.1 International Liquidity Cycles and Capital Flows to EMEs . . . . . . 290

6.3 .2 Liquidity Preference and the VIX Index . . . . . . . . . . . . . . . . . . . 292

6.3.3 The VIX and Capital Flows . . . . . . . . . . . . . . . . . . 295

6.3.4 The VIX Index and Emerging Currencies . . . . . . . . . . . . . . . 297

6.3.5 The VIX Index, Stock Exchange, and Exchange Rates . . . . . . . . . 303

6.3.6 Concluding Remarks . . . . . . . . . . . . . . . . . . . . . 307

6.4 Comovement and Correlation of Different Currencies . . . . . . . . . . . . . . 309

6.4.1 Comovement of Currencies . . . . . . . . . . . . . . . . . 310

6.4.2 Correlation of Currencies . . . . . . . . . . . . . . . . . . 313

6.4.3 Concluding Remarks . . . . . . . . . . . . . . . . . . . . 314

6.5 Other Important Elements in Explaining Emerging Currencies . . . . . . . . 316

6.5.1 Exchange Rate Regimes and Monetary Policy Frameworks . . . . . . . 318

6.5.2 Other Elements . . . . . . . . . . . . . . . . . . . . 318

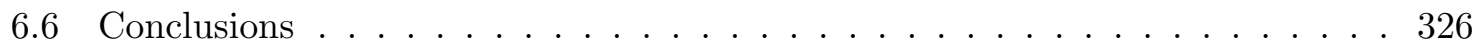

6.7 Appendix I: Information on Interest Rate Differential . . . . . . . . . . . . . 334

6.8 Appendix II: Information on Exchange Rate Regimes . . . . . . . . . . . . . . 335

6.9 Appendix III: Other Data . . . . . . . . . . . . . . . . . . . . . . 339

7 The Fragility of Emerging Currencies: a Minskyan Analysis $\quad \mathbf{3 5 2}$

7.1 The Financial Instability Hypothesis . . . . . . . . . . . . . . . . . . . . 354

7.1.1 Minsky's Framework Applied to an International Context . . . . . . . 357

7.2 Emerging Currencies' Fragility . . . . . . . . . . . . . . . . . . . 364

7.2.1 The Economic Units: Money Managers . . . . . . . . . . . . . . . . . 364

7.2.2 Exchange Rates and Margins of Safety . . . . . . . . . . . . . . . . . 366

7.2.3 Self-Feeding Interactions, Tranquility and the Build-up of Fragility . . 367

7.2.4 The end of the Boom Phase: Fragility and Exchange Rate Turbulence 376

7.2.5 Policy Responses and Implications . . . . . . . . . . . . . . . . . . . 378 
7.3 Conclusions . . . . . . . . . . . . . . . . . . . . . . . . 384

8 Conclusions $\quad 389$

8.1 Financialization and EMEs' Integration . . . . . . . . . . . . . . . . 390

8.2 Integration and Emerging Currencies' Dynamics . . . . . . . . . . . . . . . . 392

8.3 Policy Implications . . . . . . . . . . . . . . . . . . . . . . . 397

$\begin{array}{ll}\text { Bibliography } & 400\end{array}$ 


\section{List of Figures}

1.1 Emerging Currencies, 2000 to $2013 \ldots \ldots \ldots \ldots \ldots$

2.1 Global Network of Cross-Border Equity Holdings and Liabilities Issued . . . . 31

3.1 Harvey's 'Augmented Mental Model' . . . . . . . . . . . . . . . . . . . . . 100

4.1 Cross-Border Equity Holdings . . . . . . . . . . . . . . . . . . . . . 140

4.2 EMEs' GDP and Foreign Trade . . . . . . . . . . . . . . . . . . . . . . . 144

4.3 Capital Account Openness and Financial Integration . . . . . . . . . . . . . . 145

4.4 EMEs' Foreign Exchange Market: Size and Derivatives-to-Spot Ratio . . . . . 147

4.5 EMEs' Stock Market Capitalization _ . . . . . . . . . . . . . . . . . . . 148

4.6 Change in Stocks of Foreign Liabilities . . . . . . . . . . . . . . . 151

4.7 Average Increase in Stocks . . . . . . . . . . . . . . . . . . . . . . 153

4.8 Weight of Equity, Debt and FDI . . . . . . . . . . . . . 155

4.9 Stocks of Foreign Assets in EMEs: Equities . . . . . . . . . . . . . . . 161

4.10 Stocks of Foreign Assets in EMEs: FDI, 1990-2011 . . . . . . . . . . . . . . 164

4.11 Stocks of Foreign Assets in EMEs: Debt, 1990-2011 . . . . . . . . . . . . . . 165

4.12 Equity Liabilities Over Stock Market Capitalization . . . . . . . . . . . . . . 170

4.13 Stock Exchange and Exchange Rates . . . . . . . . . . . . . . . . . . . 171

4.14 Stocks-Exchange-Rate Interaction: Capital Account Openness and Trade . . 182

4.15 Stocks-Exchange-Rate Interaction: Equities Share and Stock Market . . . . . 184

4.16 The Weight of Reserves, Assets and Liabilities . . . . . . . . . . . . . . . 195

4.17 Equity Shares on Total Liabilities and Stock Market Capitalization . . . . . . 197

5.1 Openness and Integration of EMEs . . . . . . . . . . . . . . . . . 204

5.2 Financial Integration: Absolute and Relative Measures . . . . . . . . . . . . . 206

5.3 Assets and Liabilities . . . . . . . . . . . . . . . . . . . . . . . 210

5.4 Assets-to-Liabilities Ratio . . . . . . . . . . . . . . . . . . . . . . 212

5.5 Assets-to-Liabilities Ratio: Different Instruments . . . . . . . . . . . . . . . 213

5.6 Assets Plus Liabilities . . . . . . . . . . . . . . . . . . . . 215

5.7 Assets Plus Liabilities Over GDP: Long-Term Development . . . . . . . . . . 216

5.8 Assets Plus Liabilities Over GDP: Two Points in Time . . . . . . . . . . . . . 217

5.9 Assets Plus Liabilities Over Exports . . . . . . . . . . . . . . . . . . 218

5.10 Foreign Exchange Market . . . . . . . . . . . . . . . . . . . . . 222

5.11 Foreign Exchange Market Over GDP . . . . . . . . . . . . . . . . . . . . . 224

5.12 Foreign Exchange Markets Over Trade . . . . . . . . . . . . . . . . . . 225

5.13 Daily Exchange Rate Transactions . . . . . . . . . . . . . . . . . . . . . . 227

5.14 Total Foreign Exchange Contracts . . . . . . . . . . . . . . 228 
5.15 Derivatives-to-Spot Ratios . . . . . . . . . . . . . . . . . . . 229

5.16 Financialization Level: Five Indicators . . . . . . . . . . . . . . . . 233

5.17 Country Scores on the Four Principal Components on the Four Principal Components . . . . . . . . . . . . . . . . . 237

5.18 Country Scores on the Four Principal Components: EMEs . . . . . . . . . . . 238

5.19 Loadings on PC1 and PC3: Advanced and EMEs . . . . . . . . . . . . . . 247

5.20 Loadings on PC2 and PC3: Advanced and EMEs . . . . . . . . . . . . . . . 248

5.21 Loadings on PC2 and PC4: Advanced and EMEs . . . . . . . . . . . . . . . 249

5.22 Loadings on PC3 and PC4: Advanced and EMEs . . . . . . . . . . . . . . 250

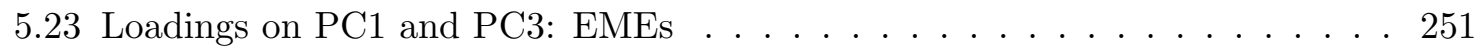

5.24 Loadings on $\mathrm{PC} 2$ and $\mathrm{PC} 3$ : EMEs . . . . . . . . . . . . . . 252

5.25 Loadings on PC2 and PC4: EMEs . . . . . . . . . . . . . . . 253

5.26 Loadings on PC3 and PC4: EMEs . . . . . . . . . . . . . . . 254

6.1 Emerging currencies' exchange rates, 2000-2013 . . . . . . . . . . . . . . 256

6.2 Volatility of Emerging Currencies . . . . . . . . . . . . . . . . . 266

6.3 Exchange Rate Volatility and Financial-to-Trade Integration . . . . . . . . 269

6.4 Exchange Rate Volatility and Financialized Integration . . . . . . . . . . . . 271

6.5 Histogram of Emerging Currencies' Changes . . . . . . . . . . . . . . . . . . 277

6.6 Frequency of Exchange Rate Change . . . . . . . . . . . . . . . . . . 281

6.7 Frequency of Exchange Rate Depreciation . . . . . . . . . . . . . . . . . 282

6.8 Index of Frequency of Extreme Change and Depreciation . . . . . . . . . . . 283

6.9 Frequency of Extreme Depreciation and Standard Deviation . . . . . . . . . . 284

6.10 Frequency of Extreme Depreciation and Financialized Integration . . . . . . . 286

6.11 Frequency of Extreme Depreciation and Financial-to-Trade Integration . . . . 288

6.12 Liquidity Preference: VIX and VSTOXX . . . . . . . . . . . . . . . . . 294

6.13 Capital Flows to Emerging Countries . . . . . . . . . . . . . . . . 296

6.14 The VIX Index and Emerging Currencies . . . . . . . . . . . . . . . . . . . . 298

6.15 The VIX Index and Financialized Integration . . . . . . . . . . . . . . . . 301

6.16 EMEs' Stock Exchange indices . . . . . . . . . . . . . . . . . . . . 304

6.17 EMEs' Stock Exchange indices and the VIX . . . . . . . . . . . . . . . 305

6.18 EMEs' Stock Exchange and the VIX indices, Correlation . . . . . . . . . . . . 306

6.19 Stock Exchange, the VIX indices and Financialized Integration . . . . . . . . 308

6.20 Exchange Rate Comovement . . . . . . . . . . . . . . . . . . 313

6.21 Exchange-Rate Features and Monetary and Exchange-Rate Regimes . . . . . 319

6.22 Exchange Rate Volatility and Explanatory Variables . . . . . . . . . . . . . . 321

6.23 Frequency of Extreme Depreciation and Explanatory Variables . . . . . . . . 324

6.24 Correlation with the VIX and Explanatory Variables . . . . . . . . . . . . . 328

6.25 Interest Rate Differential . . . . . . . . . . . . . . . . . . . . . . . . . . . . . . . . . 334

6.26 Interest Rates and Interest Rate Differential . . . . . . . . . . . . . . . . . . . 335

6.27 Financial-to-Trade and Financialized Integration . . . . . . . . . . . . . . . 339

6.28 Emerging Currencies' Daily Changes . . . . . . . . . . . . . . . . . . . . 341

6.29 Volatility: Standard Deviation and Index of Non-Stability . . . . . . . . . . . 342

6.30 Capital Account Openness . . . . . . . . . . . . . . . . . 350

7.1 EMBI+, Selected EMEs _ . . . . . . . . . . . . . . . . . . 373

7.2 Foreign Equity Liabilities and Stock Exchanges . . . . . . . . . . . . . . . . . 374

7.3 Foreign Portfolio Liabilities and Exchange Rates . . . . . . . . . . . . . . . 375 


\section{List of Tables}

3.1 Exchange Rate Puzzles . . . . . . . . . . . . . . . . . . . . . . . . 54

3.2 Harvey's 'Mental Model': Three Layers . . . . . . . . . . . . . . . . . . . . . 98

3.3 Modeling Exchange-Rate Expectations . . . . . . . . . . . . . . . . . . 123

4.1 Exchange Rate, Monetary Regimes, and Interest Rate Differential . . . . . . 146

4.2 Weight of Different Types of Liabilities, $2011 \ldots \ldots$. . . . . . . . . . 150

4.3 Volatility of the Stocks of Foreign Liabilities . . . . . . . . . . . . . . . . 158

4.4 PCA Stock of Liabilities: Individual Series . . . . . . . . . . . . . . . . . 168

4.5 Results of the VAR Model $(1 / 2) \ldots \ldots \ldots \ldots$. . . . . . . . . . . . . . . . . . . . . . . . . . . . .

4.6 Results of the VAR Model $(2 / 2) \ldots \ldots \ldots \ldots$. . . . . . . . . . 179

4.7 Stock Exchange and Exchange Rates: Granger Causality Test . . . . . . . . 180

4.9 Change in and Variability of the Stock of Foreign Liabilities . . . . . . . . . . 186

4.10 Cross-Country Average, Yearly Variation of Stocks: Different Instruments . . 193

5.1 Indicators of Financialization . . . . . . . . . . . . . . . . . 232

5.2 PCA Variables ... . . . . . . . . . . . . . . . . . . . . 234

5.3 Principal Components and Eigenvalues . . . . . . . . . . . . . . . . . 234

5.4 Component Loadings . . . . . . . . . . . . . . . . . . . . . 235

5.5 Total FX Markets, Advanced Economies . . . . . . . . . . . . . . . . 245

5.6 Total FX Markets, EMEs . . . . . . . . . . . . . . . . . . . . . 245

5.7 Country Scores . . . . . . . . . . . . . . . . . . . 246

6.1 Distribution of Daily Exchange Rate Percent Changes . . . . . . . . . . . . 278

6.2 Integration and Volatility: Correlation Coefficients . . . . . . . . . . . . . . 287

6.3 Correlation Exchange Rate \& VIX . . . . . . . . . . . . . . . . . . . . 299

6.4 Integration and International Influence: Correlation Coefficients . . . . . . . . 302

6.5 EMEs' Stock indices and VIX: Correlation Coefficients . . . . . . . . . . . . . 307

6.6 PCA: Exchange Rate Changes . . . . . . . . . . . . . . . . . . . . 310

6.7 Emerging Currencies With Relevant "out of the Region" Correlation . . . . . 314

6.8 EMEs' Exchange Rate and other Characteristics . . . . . . . . . . . . . . 317

6.9 Standard Deviation and Explanatory Factors: Correlation . . . . . . . . . . 322

6.10 Extreme Depreciations and Explanatory Factors: Correlation . . . . . . . . . 326

6.11 Correlation With the VIX and Explanatory Factors: Correlation . . . . . . . 327

6.12 EMEs' Exchange Rate Arrangements . . . . . . . . . . . . . . . . . . . . . 338

6.13 Details on Countries Currencies and Stock Exchange indices . . . . . . . . . . 340

6.14 Vulnerability and Fragility . . . . . . . . . . . . . . . . . . . 343

6.15 Exchange Rate Volatility: Summary . . . . . . . . . . . . . . . . . . . . . 344

6.16 PCA: Exchange Rate Changes, 2000 to $2003 \ldots \ldots$. . . . . . . . . . 345 
6.17 PCA: Exchange Rate Changes, 2003 to Aug, 2008 . . . . . . . . . . . . 346

6.18 PCA: Exchange Rate Changes, Aug, 2008 to 2013 . . . . . . . . . . . . . 347

6.19 Correlation of Emerging Currencies (1/2) . . . . . . . . . . . . . . 348

6.20 Correlation of Emerging Currencies (2/2) . . . . . . . . . . . . . . 349

6.21 Regression Coefficients: Explaining Exchange Rate Patterns . . . . . . . . . 351 


\title{
List of Abbreviations
}

\section{List of Countries}

\author{
ARG Argentina \\ BRA Brazil \\ CHL Chile \\ CHN China \\ COL Colombia \\ CZE Czech Republic \\ HKG Hong Kong \\ HUN Hungary \\ IDN Indonesia \\ IND India \\ KOR Korea \\ MEX Mexico \\ MYS Malaysia \\ PER Peru \\ PHL Philippines \\ POL Poland \\ RUS Russia \\ SGP Singapore \\ THA Thailand \\ TUR Turkey \\ TWN Taiwan \\ ZAF South Africa
}

\section{List of Currencies}

ARS Argentine peso

BRL Brazilian real

CLP Chilean peso 
CNY Chinese yuan

COP Colombian peso

CZK Czech koruna

HKD Hong Kong dollar

HUF Hungarian forint

IDR Indonesian rupiah

INR Indian rupee

KRW South Korean won

MXN Mexican peso

MYR Malaysian ringgit

PEN Peruvian nuevo sol

PHP Philippine peso

PLN Polish zloty

RUB Russian ruble

SGD Singapore dollar

THB Thai baht

TRY New Turkish lira

TWD New Taiwan dollar

ZAR South African rand 


\section{Chapter 1}

\section{Introduction}

This thesis investigates the impacts of financialization on the dynamics of exchange rates in emerging market economies (EMEs) - the developing countries that are most integrated to the international financial system. From a focus on the international level, financialization is defined as the patrimonial and increasingly speculative logic of finance at the international level. With financialization, the role of finance at the international level is decoupled from functions related to the productive economy, as financing production or trade. Instead, finance follows an increasingly speculative logic, manifested by innovations of usages and products.

The implications of these developments in EMEs exchange rates (hereafter emerging currencies) vary according to the extent of the use of these countries' assets and currencies in the different strategies of money managers - the portfolio investors funded in advanced countries; they are small in numbers and manage the major amounts of liquidity available in these economies, having a great impact on markets. As it will be demonstrated in the thesis, financialization-related developments are revealed in the characteristics of emerging countries' integration, which are associated with an specific exchange rate pattern, marked by fragility for being vulnerable to the international financial conditions. 


\subsection{Motivation}

\subsubsection{Exchange Rate's Relevance}

This thesis is focused on nominal exchange rates, the relative price of two currencies. From the post-Keynesian (PK) perspective of the thesis (see page 8), the relevance of nominal exchange rates derive from direct impacts and indirect ones through the real exchange rate. First, turbulent exchange rates can be a shock to entrepreneurs' animal spirits for increasing uncertainty thus discouraging trade, investment and growth. This is key in the PK framework given the understanding of uncertainty as fundamental (see page 34), thus the role of expectations. Secondly, nominal exchange rates determine real exchange rates, the relative price of goods in two countries: the latter are the former adjusted for inflation.

The real exchange rate is a key relative price. Pervading an economy in several forms, its effects on growth through trade and investments enjoy better empirical support. Real exchange-rate 'undervaluation' positively impacts growth as it favors trade and investment in tradable sectors, relaxes the foreign exchange constraint on growth, and promotes resource reallocation from the non-tradable to the tradable sector, a locus of learning-by-doing externalities and technological spillovers. 'Overvaluation' has the opposite effect. Exchange rate volatility also negatively impacts growth for discouraging trade and investment (Cottani et al. (1990); Dollar (1992); Eichengreen (2007); Ibarra (2010); Missio et al. (2015); Rapetti et al. (2012); Rapetti (2013); Razmi et al. (2009); Rodrik (2008)).

\subsubsection{Emerging Currencies: a Constant Upheaval}

A new expansionary phase of the international liquidity cycle, with its consequent capital flows to EMEs, started in 2003, only a few years after the implementation of floating exchange-rate regimes in several EMEs in the late 1990s ${ }^{1}$ (Prates, 2015). Since then, exchange rates of EMEs have been 'a constant upheaval'. Moreover, the adoption of these regimes did not bring about monetary policy autonomy. Accordingly, EMEs authorities' policy trilemma is reduced to a dilemma, namely, absence of monetary policy autonomy

\footnotetext{
${ }^{1}$ Exchange-rate regimes since the 2000s are presented in Chapter Six, Table 6.12.
} 
with capital account convertibility independently of the exchange rate regime ${ }^{2}$ (Flassbeck (2001); Rey (2015)).

From 2003 to the outbreak of the Global Financial Crisis (GFC) with the collapse of the investment bank Lehman Brothers in September 2008, many emerging currencies faced strong appreciation trends. The Brazilian real ended the period with an appreciation of $49 \%$, the Czech koruna, 44\%, the Polish zloty, 38\%, the Colombian peso, 28\%. On average, there was a $17 \%$ appreciation of emerging currencies ${ }^{3}$. Note that these estimations include the year prior to the collapse of the Lehman Brothers, when EMEs' assets continued booming despite numerous signs of crisis in the US and Europe (there had been 'illiquidity waves' in the US, U.S. house prices had declined sharply, capital flows among advanced countries had retrenched). This context was marked by a debate on whether emerging economies would have decoupled from advanced countries' outlook (Brunnermeier (2008); Dooley and Hutchison (2009); Frank and Hesse (2009); Gorton (2008); Milesi-Ferretti and Tille (2011)).

The path followed by emerging currencies since the year 2000 is shown in Figure 1.1. The collapse of Lehman Brothers was an immediate and immense shock on emerging currencies as investors across the globe liquidated their holdings abroad (Milesi-Ferretti and Tille (2011); Frank and Hesse (2009)). In many EMEs, the vast exchange rate appreciation since 2003 disappeared within a few weeks. Specifically, daily depreciations peaks as high as $6.2 \%$ were seen in the South African rand, and as high as 5\% in the Polish zloty, the Brazilian real, the Colombian peso and the Chilean peso.

However, these major depreciation shocks were relatively short-lived ${ }^{4}$. In a context that combined a more favorable growth outlook in EMEs than in advanced countries (the 'twospeed recovery'), as well as massive policies of quantitative easing (QE) including historically low interest rates in advanced countries, capital flew back to EMEs and their exchange rates went through major appreciations in the following year (Bernanke (2010); Brunnermeier (2008); Fawley and Neely (2013)). In this period, appreciation hit daily peaks of more than $4 \%$ in the Colombian peso and the Polish zloty, and more than $3 \%$ in the Brazilian real, the

\footnotetext{
${ }^{2}$ This contrasts with the argument of the 'impossible trinity', according o which capital account convertibility and flexible exchange rate regimes result in monetary policy autonomy.

${ }^{3}$ This considers the group as a whole, including countries who follow both floating and non-floating regimes.

${ }^{4}$ For instance, in the case of the Brazilian real it lasted 18 weeks.
} 
Figure 1.1: Emerging currencies: 2000 to 2013
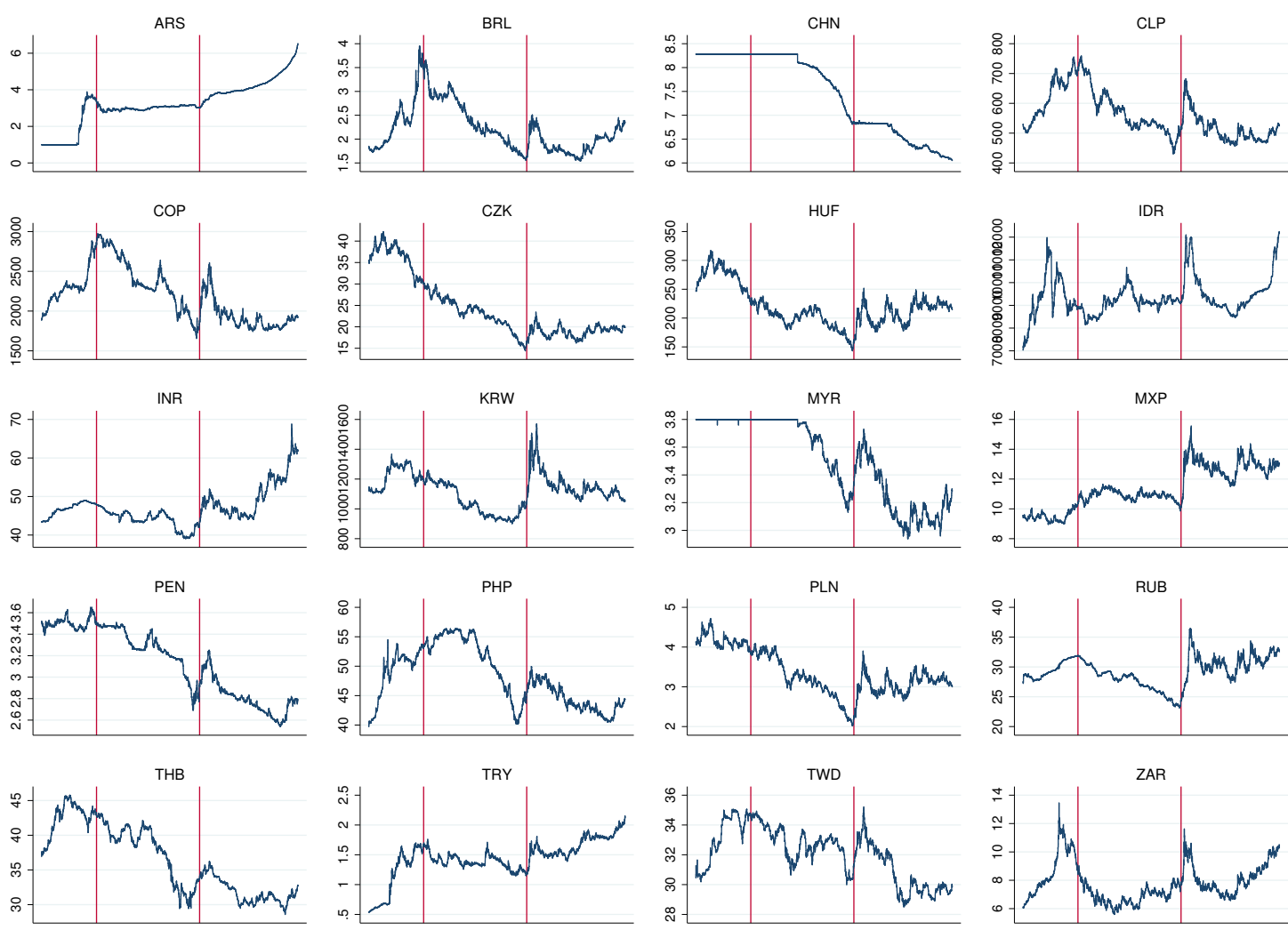

Data source: Ecowin. The vertical lines indicate the new phase of the cycle of capital towards developing countries, January 1st, 2003, and the collapse of the Lehman Brothers, September 15th, 2008. Exchange rates are presented in direct quotation, where a lower value implies that the domestic currency is appreciating. This is the form used throughout the thesis.

Mexican peso, and the South African rand. In about half of the EMEs the total appreciation in this period was greater than the previous, GFC-related, depreciation.

The period from 2010 to 2013 was very turbulent, and the market sentiment guiding emerging currencies was tied to the Euro crisis (that hit peaks in the second half of 2011 and May 2012) and to the fear of tapering with Bernanke's (2013) statement that the Fed could increase interest rates by 2015 (Ahmed and Zlate (2014); Eichengreen and Gupta (2015); Prates and Cunha (2013)). As a result, in the period marked by the Euro crisis, 11 of the 20 emerging currencies depreciated, and in the six months following Bernanke's announcement, 18 currencies depreciated. In the first case, the changes of the Argentinean peso and the South African rand accumulated about $40 \%$ depreciation, those of the Brazilian real, the 
Turkish lira, and the Indian rupee, about 25-30\%. In the six months that followed, marked by the fear of tapering, the Argentinean peso depreciated almost $60 \%$, the Russian ruble, $35 \%$, and the Indonesian rupiah, the Turkish lira, and the Chilean peso depreciated about $15-20 \%$.

The significance of external financial conditions in determining the turbulence of emerging currencies since 2003 is unambiguous. In terms of daily exchange rate depreciation, EMEs were much more impacted by these developments than the advanced economies themselves: Although the US and the Europe were the locus of the crisis, from 2003 to 2013 the daily changes of the U.S. dollar/euro pair were limited to $3 \%^{5}$.

The manifest turbulence of emerging currencies, in addition of being a problem per se might indicate their determination by the conditions of international financial markets, what is also of concern since it demonstrates that these countries' exchange-rate levels are not coherent with their underlying economy. The striking similarity of these currencies' path is an evidence in this sense. These dynamics indicate the fragility of emerging currencies to the conditions prevailing in international financial markets.

\subsubsection{Policy Makers' Concerns}

The repeated cases of turbulence in the aftermath of the GFC have not gone unnoticed by EMEs' policy makers. On the contrary, countries' authorities expressed concern over the impacts of the international context on their currencies to the IMF (Roy and Ramos, 2012) and the two public manifestations of concern by Brazilian authorities became broadly known - over the 'currency war' (in the context of broad implementation of capital controls in 2010) and over the 'monetary tsunami' caused by the QE policies in 2012. In light of the turbulence emanating from the international context, several countries also decided to accumulate reserves of international assets $^{6}$, and to impose capital account management policies.

\footnotetext{
${ }^{5} \mathrm{~A}$ comparison between the distribution of exchange returns of emerging currencies and the U.S. dollar/euro is provided in Chapter Six.

${ }^{6}$ The rise of reserves is studied in Chapter Five, Section 5.2.1. The policy of accumulating reserves is studied in Chapter Seven, Section 7.2.5.2.
} 
The accumulation of reserves started only a few years after the late-1990s crises (whose roots were said to partially rely on the inadequacy of reserves, provoking a change of the related policy recommendations). Reserves were relatively not used during the GFC, a choice that underscores both how treasured they are by policy makers, and the latter's relative contentment with the GFC exchange-rate depreciation after a period marked by appreciation and the fear of these authorities of losing their investment grade (Aizenman and Lee (2007); Aizenman and Hutchison (2012); Garcia and Soto (2004); Feldstein (1999); Fischer (2001); Prates (2015); Rodrik and Velasco (1999)).

Another policy response was the capital account management or regulation. Specially in the form of residency-based taxes in the wake of the return of capital flows to EMEs after the GFC. Not only spot, but also derivatives markets were subject to new regulation, evincing the impact of pressures coming from these markets. At that moment, there was a major debate over the use of capital controls, including a review of IMF's position on the subject $^{7}$ (Ahmed and Zlate (2014); ECLAC (2011); Forbes et al. (2011); Ocampo (2012); Prates and Fritz (2016)).

\subsubsection{The Exchange-Rate Literature}

Mainstream exchange-rate theories are marked by a dichotomy between studies related to exchange-rate determination and others focused on crisis. This very construction of two separate bodies of literature reveals the incapacity of the first strand for accounting for sharp exchange rate movements - that are frequent in EMEs. This literature is indeed focused on long-term dynamics where the exchange rate is a market-clearing price. Whether the exchange rate will be found at its PPP-predicted value after five years of 'misalignment' is irrelevant: It does not provide us with any information on the causes of the turbulence seen in those years that likely affected entrepreneurs' animal spirits.

Because it is focused on fixed exchange rates, most of the dynamics are not present in mainstream crisis literature, and, in these models, internal disequilibrium play an important

\footnotetext{
${ }^{7}$ This subject is covered in Chapter Seven. For studies published inside the IMF that present a change in their view, see Blanchard et al. (2012); Claessens et al. (2010); Ostry et al. (2010); Ostry et al. (2011). For an assessment of the new IMF policy see Fritz and Prates (2014). For a review of the extent of the consideration of the Fund's new position on their policy recommendations to developing countries, see Roy and Ramos (2012).
} 
role, but it was clearly absent in recent emerging currencies' crises. On the contrary, in more recent episodes, capital flew to the countries in crisis (Kohler, 2010) - which can be seen as a no-safe-heaven puzzle, as it is the opposite of what is expected by the usual safe-heaven effect.

Heterodox theories explain that puzzle and have more to add to our understanding of emerging currencies for considering that crises are inherent to these currencies' dynamics. Their patterns emerge from their subordinated place in the hierarchical financial and monetary systems that reflects their inability to perform the functions of money in the international scenario (as it will be seen in Chapter Three). Specifically, two main characteristics of emerging currencies explain why they are massively sold in case of turbulence. First, they are not used as reserve of value, and during crisis, the preference for the most liquid currency increases. Second, they are not used as denominator of financial liabilities, that are needed when crises emerge and financial obligations must be met (Andrade and Prates (2013); Kaltenbrunner (2015); Prates (2005a)).

These explanations are in line with the evidence of fragility of some emerging currencies to the developments of the international financial markets just discussed, but they do not explain why they occurred in some emerging currencies but not in others. They also do not explain why this pattern happens to some emerging currencies but not to currencies of other developing countries that also do not exercise the functions of money in the international sphere. This is the gap in the knowledge that the thesis aims at enlightening. As seen from the brief description of events, exchange rate fragility seems to be concentrated in a few currencies only. Why were the Brazilian real and the Turkish lira frequently mentioned among the most turbulent, but not the Korean won or the Peruvian nuevo sol?

Emerging countries are different from other developing countries for being highly integrated to financial markets. Is it the different magnitude of integration among emerging countries that explains the occurrence of turbulence or would it be associated to a different type of integration? 


\subsection{The Purpose of the Study, Theoretical Framework and Methodology}

The thesis aims at contributing to the exchange-rate literature with the study of why some emerging currencies are more marked by fragility to international conditions than others. Specifically, it suggests different indicators that characterize exchange-rate dynamics - exchange rate volatility, frequency of extreme depreciations, co-movement with international financial scenario and with other emerging currencies - and studies the implications of financialization in determining these features as revealed from the characteristics of EMEs' financial integration.

With financialization, the logic of finance at the international level is associated with capital gains related to the patrimonial decisions of money managers, and the focus on exchange rate returns is a marked feature of its innovations, as observed from the innovations of products (such as FX derivatives) and usages (such as carry trade or currency trading). The analyses assume that the extent of the use of a country's assets or currency in these strategies is revealed from the characteristics of its financial integration. Based on this assumption, the thesis suggests an indicator that characterizes integration with regards to financialization and studies how the level of financialization of countries' integration is associated with exchange rate fragility.

The thesis follows a post-Keynesian framework. As opposed to the orthodox instrumentalism, this framework insists on the importance of the 'realisticness' of theories for understanding the phenomena under study. 'Realisticness' refers to whether a representation is about reality or observables ${ }^{8}$, while 'unrealisticness' defines the oversimplified, implausible, practically irrelevant (Lang and Setterfield (2006); Lavoie (2014)).

Post-Keynesians value 'realisticness' and "believe it is better to develop a model which emphasizes the special characteristics of the economic world in which we live than to continually refine and polish a beautifully precise, but irrelevant model" (Davidson, 1984, as cited

\footnotetext{
${ }^{8}$ According to Mäki (1989, p. 196, as cited by Hodge (2008)): "A representation can be said to be realistic if it is about reality (i.e. it refers factually) or about observables (i.e. it refers observationally) or about essentials (i.e. it refers essentially), or if it represents what it refers to, or if it is true of what it represent".
} 
by Lavoie (2014)). Orthodox frameworks, on the contrary, value a model's ability to provide precise predictions more than the truth of its assumptions ${ }^{9}$.

For valuing realisticness, the thesis underscores the need to understand the structure formed by the rise of money managers as well as the fact that their decisions (key for exchange rates) are constrained by balance-sheet considerations. The focus on balance-sheets is a key feature of Stock Flow Consistent models (used in Chapter Three) and of Minsky's analyses (used in Chapter Seven).

Analyses of balance-sheets of private institutions and the acknowledgment that they are not confined within a country's boarders have also been an increasing feature of studies published by the Bank of International Settlements (Avdjiev et al. (2015); Disyatat (2011); Shin (2016)). Their authors are not associated with post-Keynesian economics, nor with other heterodox schools of thought, but they share a taste for realisticness.

As a reflection of the concern over realisticness, in-depth analyses of the potential effect of financialization on exchange rates at a theoretical level is the methodology used to test this hypothesis, followed by a detailed empirical assessment of the manifestations of financialization in financial integration (as a whole and in the characteristics of countries' integration), and in the exchange-rate dynamics. Most of the analyses start in 2003, the year that marked the beginning of a new expansionary phase of capital flows to developing countries (Prates, 2015) and when most EMEs had already opted for floating exchange rate regimes.

From the empirical analyses of the manifestations of financialization, an index is built to proxy how financialized a country's integration is. It was then compared to the occurrence of the exchange-rate features of concern. To characterize integration and exchange-rate dynamics, the thesis uses graphical analyses, descriptive statistics, correlation coefficients, principal component analyses and a VAR model.

These analyses are done for the 20 EMEs. As mentioned, EMEs are theoretically defined as the most most financially integrated developing countries. As money managers are the

\footnotetext{
${ }^{9}$ This assumption is very clear in Friedman (1953b, p. 8-9, italics in the original): "the only relevant test of the validity of a hypothesis is comparison of its predictions with experience. The hypothesis is rejected if its predictions are contradicted". See Mäki (2003) for a critical assessment of Friedman's (1953b) article and the argument that Friedman deemed the 'unrealisticness' of the assumptions not only irrelevant, but also a virtue.
} 
ones who decide which countries will be integrated, the thesis proposes a financial-markets oriented operational definition of EMEs based on which countries the financial community saw as 'emerging' during the analyzed period (Bibow (2009); Chesnais (1997)).

Major Finding The thesis concludes that a group of emerging currencies is characterized by higher exchange rate volatility, more frequent extreme depreciations than the euro/U.S. dollar pair, closer association with international financial conditions, and high correlation with other emerging currencies. The intensity of these features can be explained by the level of financialization of these economies' financial integration. Financialized integration is more strongly associated with the concerned features than measures of absolute integration or of the weight of financial integration vis-a-vis trade integration, demonstrating the influence of the characteristics of the FX market. Other findings are highlighted in the Thesis Structure Section.

Relevance The thesis' findings raise serious policy concerns: for having its assets used in money managers' innovative strategies, emerging currencies have been presenting higher volatility and frequently passing through major depreciations. For impacting uncertainty and animal spirits and real exchange rates, such exchange rate behavior has negative implications in terms of trade, investment and growth.

The thesis' findings call the attention of regulators to the need of avoiding this development to continue, thus decreasing the vulnerability of emerging economies to international developments and fostering a more stable context that favors these economies' capital and human development. The theoretical relevance of the findings are presented in the thesis' conclusions, and their policy implications, in Chapter Seven.

\subsection{The Structure of the Thesis}

The thesis is divided in six chapters, apart from this introduction (Chapter One) and the Conclusions (Chapter Eight). The first two are focused on the two bodies of literature the thesis discusses the most: financialization and exchange rates. They are followed by three 
empirical chapters. The last chapter provides a framework that explains the transmission channels mentioned in the theoretical chapters and that results in the exchange-rate dynamics seen in the empirical part.

Chapter Two The chapter reviews the literature on the changes of capitalism known as financialization. Its broad tenets are grouped into three main types of developments: i) the increasing importance of finance at the international level with the decoupling from its earlier functions and logic; ii) the changes within the financial system, including the sophistication of finance through major innovations of products and usages; and iii) the changing relationship between finance and other economic sectors. The chapter argues that, in the concerned countries, financialization might have changed exchange rate determination not only through the increasing weight of finance internationally, but also from its patrimonial and strengthened speculative logic, in line with its innovation of products (such as FX derivatives) and usages (such as carry trading). With financialization, capitalism saw the rise of money managers, whose assets and liabilities are located in different markets and labeled in different currencies. The result is an international financial system characterized by a network of different countries' markets, interconnected through money managers' balance-sheets. The chapter argues that exchange-rate dynamics must be analyzed as a result of the dynamics of this broad network, i.e. through money managers' decisions, specifically their balance-sheet constraints.

Chapter Three The chapter analyzes exchange-rate theories on exchange-rate determination and crisis, both from mainstream and heterodox perspectives, including analysis that have a broader focus and that are specific to emerging currencies. The chapter concludes that mainstream models have been gradually taking financialization-related features into account, but without relaxing the idea of exchange rates as a market-clearing price, which is not coherent with the pattern of capital flows (and thus exchange-rate dynamics) in times of financialization. The chapter also points to a dichotomy inside the mainstream exchange rate theories: a set of analyses has emerged to explain exchange rate crisis episodes without much reference to the existing literature on exchange rate determination. Given the frequency of 
turbulence and crisis, this dichotomy reveals the failure of the first set of models to explain exchange-rate dynamics.

Heterodox approaches, on the other hand, provide many insights on the characteristics of FX markets, on investors' decision-making processes and on the specific dynamics of financial flows to EMEs due to the attributes of these countries' currencies. In an attempt to approximate financialization and exchange-rate debates, and to resemble the discussion of heterodox authors on exchange rates through different approaches, the chapter suggests ways to model their main insights on a Stock Flow Consistent framework. The use of the SFC approach echoes the need of considering exchange rates as the result of the decisions of money managers, and their balance-sheet constraints discussed in Chapter Two.

Chapter Four Given the importance of money managers' decisions and the idea of EMEs' assets being interconnected through money manager's balance sheets, Chapter Four analyzes the stock of foreign liabilities of EMEs. It discusses the changing international insertion of EMEs and their associated vulnerabilities with a focus on the implications related to the increasing weight of equities among foreign portfolio investment. It contributes to the literature that studies this trend by highlighting other features of equity, going beyond the discussion of equity's higher volatility. One of the findings is the manifest co-movement of equity liabilities across EMEs, that hints to the relevance of the international scenario in their determination. Due to its price variability, equities are a privileged locus of capital gains, making them attractive to money managers given their increasingly speculative focus. Equities could therefore be not only more volatile, but a type of investment that is more subject to contagion. The chapter also demonstrates that stock markets have an impact on exchange rates in most EMEs. As a consequence, its turbulence is directly transmitted to exchange rates. The interaction between stock prices and exchange rates is also strengthened by the participation of foreign investors, that increase the liquidity of equity markets.

Chapter Five Most of the changes of exchange rate determination due to financialization are related to the greater magnitude and evolving logic of 'finance at the international level' (the first two phenomena of financialization as argued in Chapter Two). Chapter Five studies the different characteristics of financial integration. On a more general level, the chapter 
presents evidence of the decoupling of FX transactions not only from the productive economy (as measured by GDP or trade), but also from the economy's financial integration. This dissociation is found among advanced countries and EMEs. With this evidence, the chapter contributes to the validation of the financialization thesis and argues for the importance of analyzing the implications of financial integration not only through its magnitude, but also from its characteristics.

In this sense, and in line with the analyses of Chapter Two that pointed to the potential implications of the innovative trading strategies on exchange rates, the chapter analyzes how EMEs' assets and currencies are traded as revealed by the characteristics of their integration. After identifying the five most relevant indicators, the chapter proposes a composite index of how financialized the integration of these economies is.

Through the analyses of the different characteristics of integration, the chapter argues that emerging countries' insertion in the IFS is characterized by an asymmetrical type of demand for their assets. While the demand for EMEs' assets is marked by speculative motives, part of the demand for advanced country's assets is marked by the stability and stabilizing features of emerging countries' policies of accumulating reserves. Finally, the chapter also suggests ways of identifying carry trading currencies based on different ratios involving their foreign liabilities and FX markets vis-a-vis their economy's GDP and trade.

Chapter Six The features of emerging currencies and their relationship with the types of integration are the focus of Chapter Six. Exchange rate volatility is a major feature of concern. Its analysis go beyond the use of the standard deviation (that is deemed a partial proxy of volatility and is subject to biases when applied to exchange rates), including analyses of the frequency of extreme exchange rate changes - the latter have proven to be better for characterizing emerging currencies and are more coherent with the theoretical debate (as argued in Chapter Three). The chapter presents a clear differentiation of emerging currencies features from the euro/U.S. dollar pair: exchange rate returns vary significantly across the 20 EMEs, but the most volatile emerging currencies have more frequent extreme changes than the euro/U.S. dollar pair, and most emerging currencies have more frequent modest deviations. 
Two other characteristics analyzed in Chapter Six are the correlation of emerging currencies with the conditions of international financial markets (as proxied by the VIX index) and the co-movement of emerging currencies among themselves. As shown in the chapter, the four characteristics are associated: the group of emerging currencies to present the highest volatility, the highest frequency of extreme depreciations, the highest correlation with the VIX, and correlation with a higher number of emerging currencies is very similar. This result is evidence of the importance of the international financial conditions in determining the volatility of emerging currencies.

Apart from the characterization of emerging currencies dynamics vis-a-vis advanced countries and among EMEs, the second group of findings of Chapter Six concern the reasons behind these features. The occurrence of these features are compared against the level of financialization of the countries integration, as measured in Chapter Five. The chapter concludes that the type of integration is strongly associated with the aforementioned exchangerate features and that this index can better explain exchange-rate features than absolute and relative measures of financial integration. These results underscore the need of analyzing the impacts of integration not only from its magnitude, but also from its characteristics (as also revealed from the analyses of Chapter Five).

Chapter Seven The chapter presents a Minskyan account of the dynamics leading to the exchange rate patterns found in Chapter Six. The contributions of the chapter are around two main axis. The first is related to the utilization of Minsky's framework: it identifies its main elements and suggest how to transpose them not only to an international context, but also to a case where the main decisions are related to assets, not liabilities - in this case, money managers' international portfolio allocation. The second is related to exchange-rate theory: through an empirical analysis of how emerging currencies' fragility was built in the 2000s, the framework proposed details the transmission mechanisms.

In the open economy context, the exchange rate is the additional element of uncertainty that differentiates hedge from speculative and Ponzi units. This allows emphasis on the role of currency mismatch of balance sheets and differentiating investing in assets labeled in a currency from an EME (as Ponzi) or from an advanced country (as speculative) in line with Chapters' Six findings on the higher volatility of emerging currencies. 
The main point of the model is on the build-up of fragility with the appreciation of the emerging currency, that is based on self-feeding mechanisms (appreciation leads to an expectation of further appreciation, higher demand, and further appreciation). As argued in the chapter, this self-feeding mechanism is stronger in a group of EMEs and in times of financialization. It is stronger because of the small size of their markets relative to the capital received and because of the increasing focus on exchange rate returns - that might be even more important for the money managers who invest in the EMEs for their higher exchange rate variability.

With the self-feeding mechanisms, emerging currencies dynamics are best described as a 'deviation amplifying system', backed by money managers' decisions. When the system is fragile, any 'not-unusual' event might trigger a crisis. In times of financialization, given the interconnection of markets across the world through money managers' balance-sheets, the source of shocks are enlarged. When hit, EMEs' assets are sold, in an asset/exchange-rate deflation spiral.

The Minskyan model accurately depicts the pattern of emerging currencies since the implementation of floating exchange rate regimes: fluctuation in cycles according to the international financial scenario. As argued in the chapter, an exchange rate determination based on amplifying deviations that reverses in the advent of an external shock is however markedly different than the view of exchange rates as equilibrium-seeking system with market-clearing properties. Policy alternatives to hinder the self-feeding cycle to emerge are discussed: capital inflow controls, reserves of foreign assets and derivatives management techniques. 


\section{Chapter 2}

\section{Financialization and its Potential Impact on Emerging Currencies}

The thesis discusses whether the determination of exchange rates in emerging market economies (EMEs) could be influenced by the developments that have been characterizing capitalism. A large number of authors name these developments financialization. However, it is a rather elusive term, that has been used to indicate a large set of characteristics. Although they indicate different phenomena, most definitions have a common point: the increasing importance of finance, fitting the broad definition proposed by Epstein (2005, p. 3): "financialization means the increasing role of financial motives, financial markets, financial actors and financial institutions in the operation of the domestic and international economies."

Specifically, the term financialization has been used to designate the following changes:

i) the increasing importance of finance at the international level with the decoupling from its earlier functions and logic;

ii) the changes within the financial system, with the increasing importance of markets, the evolution of banks, and the sophistication of finance through innovations of products and usages; and

iii) the changing relationship between finance and other economic sectors, with the increasing importance of the first and its associated class group, the rentiers. 
Capitalism changes have also been studied by authors who suggested different names for its current phase, including Money Manager capitalism (Minsky, 1986), Patrimonial capitalism (Aglietta, 1999), Finance-led growth regime (Boyer, 2000), Financialized growth regime (Chesnais, 2001), Shareholder capitalism ${ }^{1}$ (Plihon, 2003), and Finance-dominated accumulation regime (Stockhammer, 2008).

When studying the current phase of capitalism, some of these authors have also analyzed prior phases. With an institutionalist perspective, these works analyze the different "types" of capitalism of a specific country and its impact on economic growth. This introduction briefly presents two of these categorizations: the French Regulation school one, and the one done by Minsky².

The regulation modes from the French Regulation school According to the French Regulation school, different regulation modes are observed inside the capitalist system (that is a production mode) based on the different combination of: the monetary constraints (financial and monetary policies); the wage-setting rules; the industries' organization; the form of integration of the economy to the international regime; and its governmental form (Boyer, 2004).

The current regulation mode found in advanced countries is financial ("Capitalisme Financier"). It has succeeded Fordism, that ruled from the 1950s to the 1970s and was marked, in advanced countries, by higher stability based on the different configuration of the above mentioned institutions. For instance, wage-setting during Fordism was done in a common agreement between unions and management, according to productivity gains, which fastly grew, given Taylorism and the scientific organization of work, and enhanced demand.

Demand was also boosted by active fiscal and monetary policies, social protection, and low interest rates (that had, as objective, financing productive capital through banking financing) (Plihon, 2003) $)^{3}$.

\footnotetext{
${ }^{1}$ For Plihon (2003, p. 41), the main characteristics of "Capitalisme actionnarial" are: a new distribution of wealth inside companies; the key role of stock-markets and its institutional investors; the predominance of the shareholder logic leading to new forms of companies' governance; the new financial behavior of non-financial companies; and the loss of autonomy of economic policies in face of financial markets.

${ }^{2}$ Chavance et al. (2007) also cite the "New Institutional economics" of Douglas North, that would have the same object of study.

${ }^{3}$ For a review of the French Regulation school, also see Chavance et al. (2007) and Amable (2005).
} 
Minsky's four stages of capitalism Analyses of the different phases of capitalism (in this case, the U.S. economy) also interested Minsky. His interest in these changes is not dissociated from his financial fragility hypothesis. On the contrary, Minsky's interest in these "main evolutionary changes" (Minsky, 1990, p. 33) might even be seen as the source of the hypothesis, as he saw in these changes the explanation for the behavior of firms and the increase of financial fragility (as in Minsky $(1986)^{4}$ ).

Minsky's characterization is divided into four phases: Commercial, Finance, Managerial, and Money Manager capitalism. The stages are distinguished "by differences between trade and industry; the capital intensity as measured by production; and the balance of economic power between merchants and managers on one side and financing institutions and financial market operators on the other" (Minsky, 1990, p. 27). With respect to finance, these stages are "related to what is financed and who does the proximate financing", representing "the structure of the relations among business, households and finance". Although these stages are understood as consecutive, the last one representing the current period, they can also coexist in an advanced capitalist economy (Minsky, 1992, p. 107).

During Commercial capitalism, funding involved "goods that are being traded or processed", but not durable capital assets used in production. This phase is associated with merchants and has as a main financial instrument a bill of exchange or other instruments that relate credits to specific commodities ${ }^{5}$. The geographic location of the business creation was very important in this period, as those transactions were based upon the knowledge of home bankers about local merchants and distant bankers.

Finance capitalism emerged with the industrial revolution and the requirement of financing expensive and durable capital assets. The period saw the emergence of corporations and of investment bankers as the main institutions in the funding markets. They act as

\footnotetext{
${ }^{4}$ The association between the financial instability hypothesis and the four phases of capitalism is very clear in Minsky (1986, p. 24), where the author begins with a description of the changes in the United States to, based on this historical-analysis, present the financial instability hypothesis. In the book, for instance, the process of debt-deflation of the 1930s is presented as a moment when margins of safety were increased, moving the economy to a more robust situation.

${ }^{5} \mathrm{An}$ important legacy of this stage is the hierarchy of contingent commitments: the banker issues a guarantee of payment that is often reinforced by another financial institution - an acceptance house. Another interesting point of Minsky's analysis of this period is the endogeneity of money supply: contracts create credit, which is later destroyed as the contract is fulfilled.
} 
brokers when facilitating trade in existing issues, and as dealers when underwriting new issues. The 1929 crash saw the end of investment bankers as the dominant institution. In the following stage, Managerial capitalism, government had an important role in adequating aggregate demand and profits through "variations in government deficits [that] offset the effect of variations in private investment upon aggregate profits" (Minsky, 1992, p. 110). As government's deficits allowed the internal cash flows of firms to finance their own investments, firms were more independent from investment bankers and managers were independent from stockholders. "The result was management autonomy, which (...) enabled firms to take long-run views: the short-term bottom line was not the binding constraint upon investment decisions" (p. 110). Corporate management had the freedom to pursue "long range objectives, be 'sociably' responsible, enjoy the easy life of a monopolist, and build conglomerate organization" (p. 31). Firms, rather than bankers, were the central institution in the private economy.

In the public sphere, Managerial capitalism saw a "revolution of government intervention" marked by the combination of Big Government and Big Bank, a Central Bank that intervenes and act as lender-of-last-resort (Minsky, 1990, p. 23). Big government's deficits were related to the rising welfare state, including the state's support to old-age pension, which was supplemented with private pensions. A second important element is broad Central Bank intervention "that prevented a collapse in dollar asset values" and "depression induced dissavings" (Minsky, 1990, p. 30-32). From the working of Big Government and Big Bank, Managerial capitalism "did not exhibit the serious recessions and depressions of Finance capitalism". This evolution is essential in understanding the transition to Money Manager capitalism. The government revolution of this period decreased the downside vulnerability of firms' profits (which became much lower than in a small government capitalist economy) (Minsky, 1986). The margins of safety of firms, that reflected earlier experience, were then deemed excessive; and the new reality allowed firms to change liability structures to accommodate higher indebtedness levels (Minsky, 1992, p. 111). When business, financiers and portfolio managers saw the financial impact of these changes and realized the obsolescence of the regulatory arrangements, put into place prior to World War II, they were "remarkably fecund in developing new instruments, institutions and usages"6 (Minsky, 1990, p. 22-23).

\footnotetext{
${ }^{6}$ Also key for these innovations is the development of communication and computing capabilities. Minsky cites the rise of exotic instruments and activities such as program trading and portfolio insurance as the
} 
During Managerial capitalism, financial innovation (of instruments and usages) emerged in a typical profit-seeking behavior of the different economic units.

The structure of the chapter Apart from this introduction, the chapter is divided as follows. Section 2.1 presents the developments of the last three decades that allowed the emergence of financialization. Section 2.2 discusses the different developments that have been referred to as financialization. Section 2.3 discusses the potential impacts of financialization in terms of exchange-rate determination. Section 2.4 presents the chapters' conclusions.

\subsection{The Developments Leading to the Rise of Financialization}

The emergence of financialization is rooted in a large set of developments. First and most importantly, liberalization policies have a role in allowing financial integration and innovation. Second, the combined changes of monetary policies and socio-demographic evolution also played a role in creating the liquidity that circulates in the enlarged financial sphere. Finally, financialization must be understood in light of prior developments of financial deepening, technological improvements and globalization. Each of these developments will be detailed next.

Liberalization policies Deregulation and liberalization policies ${ }^{7}$ begun in the 1960 s in the US and in France, with the interest equalization tax and the deregulation of banking lending rates, respectively. In the UK, the repeal of foreign exchange (FX) controls in late 1970s is seen as the important mark of liberalization policies (Goldstein and Mussa, 1993), but the lack of government intervention on the rising eurodollar market in the 1960s is also

results of trading activities of money managers (Minsky, 1990, p. 9). Minsky also worked on securitization, as in Minsky (1990, p. 22-23).

${ }^{7}$ Some authors use deregulation and liberalization as synonyms. Bourguinat (1992) differentiate deregulation from other types of liberalization policies. For Goldstein and Mussa (1993) deregulation is a type of liberalization policy. Freitas (1997a, as cited in Prates (2002)) agrees, and adds that deregulation means the elimination of restrictions to the working of markets and the decrease of government integration, while liberalization is a historic process. 
a crucial moment - though not a policy, it is a choice of non-intervention that follow the direction of the liberalization policies ${ }^{8}$ (Prates, 2002).

Liberalization policies are important for allowing finance to overpass not only the barriers between different countries' markets, but also the internal barriers between different national financial markets ${ }^{9}$ (Bourguinat, 1992). Remarkable events in this sense are the softening of the Glass Steagall Act's restrictions ${ }^{10}$ in the US since the 1950s (Cintra, 1998) and the Big Bang of 1986 in the UK, which respectively "removed" the barriers between commercial and investment banks, and between jobbers and brokers (Bourguinat, 1992).

Moreover, the competitive pressures unleashed by the eurodollar market encouraged the imposition of liberalization policies (or the choices for non-intervention) among advanced countries. As put by Helleiner (1996):

When these two states [US and UK] supported growth of the Euro market in the 1960s and then liberalized and deregulated their financial markets in the 1970s and 1980s, foreign financial centers increasingly witnessed their business and capital migrating to these more attractive markets. To compete effectively for this mobile financial business and capital, they were forced to follow the lead of Britain and the United States by liberalizing and deregulating their own financial systems. This 'competitive deregulation' in finance was a central reason for the

\footnotetext{
${ }^{8}$ Following the terms used by Strange (1986) and Helleiner (1994, as cited in Prates (2002)), it is interesting to note that the political influence also manifests through non-actions (or negative decisions) of governments. Actions (or positive decisions) and non-actions (or negative decisions) refer, respectively, to the countries' interventions to influence markets through regulation of financial incentive, and the choices of non-intervention in markets. Apart from the U.K. non-intervention in the rising eurodollar market, another important example of non-action (or negative decision) is the U.S. unilateral rupture of the Breton Wood's agreements (Prates, 2002).

${ }^{9}$ This aspect was highlighted by Bourguinat (1992), which instead of talking about liberalization, uses the term "decloisonement", which could be understood as unification or possibility to communicate. "Decloisonement", "disintermediation", and "deregulation" are the 3D rules of Bourguinat (1992) on the policies leading to financial globalization. Also see Chesnais (1997), Plihon (1997), and Plihon (2003). However, it is important to note that there is a debate on whether direct finance is indeed a form of desintermediation, or another form of finance, as banks are still involved in these transactions. This will be discussed next.

${ }^{10}$ The Glass Steagall Act was only repealed in 1999, but since the 1950s its application has been softened. Cintra (1998) mentions some important acts in this direction. The Bank Holding Company Act of 1956 allowed the formation of bank holding companies that offered services that banks were not allowed to (this was an important step in the creation of the full-service banking, or the financial supermarkets, that characterize the U.S. banking system). Banks also created legally distinct companies, through which they avoided the legal restrictions that separated commercial and investment banking operations. Later, investment banking even merged with banks, in contradiction to the Glass Steagall's legislation. Moreover, since 1987, the Board of the Federal Reserve has allowed banks to trade some types of securities under certain restrictions.
} 
flurry of liberalization activity throughout the advanced industrial world in the 1980s. (p. 12)

Shifting the analysis to developing countries, it was only with the implementation of the Washington Consensus policies of domestic and international liberalization in the 1990s that these countries' integration to the central economies' development was allowed (Epstein and Power, 2003). International organizations are thus key for developing countries' integration given the IMF's and the World Bank's pressure for the implementation of the Washington Consensus policies. More broadly, the IMF also has a role in pushing for capital account liberalization in its Articles of Agreement (see Eichengreen et al. (1998)). The United States has also participated in pushing liberalization policies in its multilateral accords (Guttmann, 2008), and, indirectly, through its influence in the IMF's and the World Bank's decisions.

It should also be mentioned that part of the aspects related to financialization were ideologically backed by economic theories. Palley (2007) and Stockhammer (2010) cite the arguments of Arrow and Debreu (1954) that the expansion of financial markets enhances economic efficiency; Friedman's (1953) case that speculation is stabilizing; Brainard and Tobin's (1977) 'q' ratio that would have helped improve the optimistic view about financial markets by suggesting a simple and clear way of signaling where opportunities exist and where capital lacks (apart from linking the real and the financial sectors); and, finally, Jensen and Meckling's (1976) agency approach that envisages the solution to the corporate governance problem as one of aligning the interest of managers with those of financial market participants (this approach promotes a legal view whereby the sole purpose of corporations is to maximize shareholder returns in the confines of the law $)^{11}$.

Monetary policies Policies that created incentives for the formation of liquid capital searching for investment opportunities were also important, as the change in the monetary regime in the US in the 1970s. With this monetary shock, real interest rates had achieved

\footnotetext{
${ }^{11}$ See Palley (2007) and Stockhammer (2010) for their references.
} 
their highest level since the 1929 crisis, favoring the rise of liquidity (Aglietta (1999); Duménil and Lévy (2003); and Plihon and Ponssard (2002)) $)^{12}$.

This change in the monetary regime reveals the rise of the focus on price stability ${ }^{13}$, instead of the prior one of supporting fiscal policy in the pursuit of economic growth (Plihon, 2003, p. 41) and full employment (Stockhammer, 2009) ${ }^{14}$. With the rise of the monetarist tenet, the growth- and employment-related goals were expected to be achieved with the attainment of price stability (Plihon, 2003). With regards to advanced countries, this new focus was a public and official agreement, sealed in the G5 $5^{15}$ meeting in Tokyo in 1979. It begun in 1979 in the US, spread to other advanced countries (Plihon, 2003, p. 41-43), and is now evident in the increasing use of inflation targeting (Epstein and Power, 2003) ${ }^{16}$. It is also the rule among EMEs, where the vast majority of countries follow an inflation targeting regime. The high interest rates of that time favored the creation of liquidity.

Liquidity availability The existence of a pool of liquidity available, or a reserve of $f$ nancial means (Bourguinat, 1992) is crucial for financialization. This liquidity increased considerably with the emergence of the eurodollar market in the middle 1960s. The market emerged for enabling agents to circumvent regulations, such as U.S. control on capital outflows and interest-rate ceilings, and from the non-repatriated and non-reinvested profits of American international companies. It grew fast, more than doubling from 1950 to 1960,

\footnotetext{
${ }^{12}$ Aglietta (1999) discusses the new monetary regime and Duménil and Lévy (2003) argue that this led to a major change in the power relations between creditors and debtors, with gains to the former. This change was certainly important in creating liquidity at that time, but the balance in power relations is different now that the interest rate level clearly changed, being currently at very low levels in advanced countries. In fact, European companies have recently even taken loans at negative rates ("Société payée pour s'endetter", 2016)

${ }^{13}$ It should be highlighted that the rise of interest rates also reveal open economy concerns - as the important capital outflows in the US in the late-1970s.

${ }^{14}$ Other important policies aimed at controlling inflation were those that concerned limiting wage increases, such as the desindexation of wages from price index in France (Plihon, 2003, p. 43).

${ }^{15}$ In this context, the "G5" was composed of six countries: France, the Federal Republic of Germany, Italy, Japan, the United Kingdom, and the United States.

${ }^{16}$ The GFC triggered interesting reassessments of prior policies, including monetary concerns. Inside the IMF, it was argued that monetary policies can no longer be only focused on one goal, inflation, as price stability would not ensure growth (Blanchard et al., 2010) - also see the discussion in Chapter Six, page 262. Indeed, EMEs and advanced countries have recently been opting for lower interest rates than the values suggested by the Taylor rule (Hofmann and Bogdanova, 2012). Whether this is a real shift of focus of monetary policies, with inflation fighting losing its importance, is yet to be confirmed when inflation rates will be above their unusual low levels in advanced countries. As it will be seen in Chapter Four, from the 20 EMEs, only four (Argentina, China, Malaysia and Russia) do not follow an inflation targeting regime.
} 
and is known for the notorious damages it caused ${ }^{17}$. The exchange-rate crisis of the pound, the spectacular withdraws of the dollar (in 1968, 1971 and 1973) that put an end to the system of fixed exchange rates, and the two oil-price shocks are examples (Chesnais (1997); Guttmann (2008)).

The creation of liquidity is also related to a combination of socio-demographic changes with the change of the monetary regime in advanced countries, where fecundity rates decrease, live expectancy increases, and post-war baby boomers retired (Plihon and Ponssard, 2002 ${ }^{18}$. These developments triggered an increase of savings aiming at retirement (Le Cacheux and Touzé, 2003) and of the demand for financial assets (Aglietta, 1999). In the mid 1970s liquidity also increased due to the stumble of production and the high returns of the circulation sphere (also due to its high productivity) that caused a shift of capital from production to the circulation sphere (Lapavitsas, 2009) ${ }^{19}$.

Looking at more recent developments, the availability of liquidity might also be rooted in the increasing inequality, or the concentration of personal wealth. For instance, Goda et al. (2014) argue that inequality increased asset demand from the rich, which enabled poor and middle-income households to accumulate increasing amounts of debt in the United States and in Europe. Inequality also has a role in the supply of financial products. Goda and Lysandrou (2014) argue that the emergence of financial instruments as CDOs (collateralised debt obligations) on a mass scale before the GFC is rooted in the availability of demand for these products, and the pressure on the American banks to create them. Both demand and supply side being rooted in the increasing unequal distribution of income and wealth ${ }^{20}$.

In this context, the type of investment also changed, with securities and equities taking an increased part of savings (Plihon and Ponssard (2002); Plihon (2003, p. 36) ${ }^{21}$ ). In general,

\footnotetext{
${ }^{17}$ Chesnais (1997) considers this market, in itself, as a phase of financial globalization, not a development leading to it, highlighting its importance.

${ }^{18}$ For Aglietta (1999), liquidity availability and the aging population are the very reasons behind the globalization of finance. Liquidity and pensions are so important for financialization, that Minsky (1990, p. 35) saw the increase of private supplementary pensions as a condition for the continuity of the growth of Money Manager capitalism.

${ }^{19}$ The idea of a shift of capital from production to the circulation sphere is is also present in the works of Crotty (1990), Epstein (2005), and Pollin (2007).

${ }^{20}$ The importance of wealthy citizens in the availability of liquidity is also mentioned by UNCTAD (2007, p. 15), when arguing that the current huge amounts of capital flows depend on the "access to massive pools of capital from pension funds or wealthy citizens".

${ }^{21}$ Plihon (2003) presents the weight of the different types of investment of French households in 1990 and 2007.
} 
wealth holding increasingly took the form of "ownership of liabilities of managed funds" instead of a portfolio of shares of liabilities of firms. The assignment of the management of private pensions and wealth to "fund arrangements" ("mutual, pension and trust funds") is at the core of the development of money managers (Minsky, 1990, p. 4, 9, italics added).

Financial deepening It is also important to acknowledge that financialization has been enabled by the increasing importance of finance as a sector in an economy. Indeed, the first references to the term financialization are associated with the debate that followed McKinnon's (1973) and Shaw's (1973) arguments in favor of financial development. The term "financialization of savings" is used, for example, as a reference to "financial deepening", or the development of a country's financial system (Serieux, 2008). With this meaning, financialization is proxied by the banking system's assets or deposits as a part of GDP (Haseeb and Makdisi, 1982). The connotation of financial deepening is however no longer representative of the financialization debate, that characterizes finance in a more complex way. Financial deepening is however an important step in the developments leading to financialization, as it would probably not occur in under-developed financial systems.

Technological progress The advances in information technology (IT) and in communications were undoubtedly important for allowing the globalization of finance (Plihon and Ponssard, 2002) by reducing the 'natural' barriers to international financial transactions through its dramatic improvements and reductions in costs (Blecker, 2005) 22 .

Globalization Financialization followed globalization of production and trade, that makes the earlier (and ongoing) process of multilateral trade liberalization an important driver of financialization (Blecker, 2005). Arguing that international financial transactions and the rise of instruments to hedge against exchange-rate fluctuations are requirements of the globalization of production, some authors see financialization as part of the globalization of production (see Stockhammer (2010)). Despite the importance of these aspects in a first moment, financialization should not be understood as simply a part of globalization of production. On the contrary, finance and the international financial system have decoupled

\footnotetext{
${ }^{22}$ Also Minsky (1995, p. 25) mentions the importance of technologies in enabling financial integration.
} 
from their earlier functions, starting to follow their own logic (Plihon and Ponssard, 2002) and having only an indirect link with financing trade and investment (Chesnais, 1997), as it will be discussed in Section 2.2.

\subsubsection{Concluding Remarks}

To conclude, it is important emphasize the centrality of governments and money managers in the process of financialization. Financialization is not a natural phenomenon, it was enabled by policy-makers choices of liberalization policies and/or non-intervention in markets and by money managers' decisions to innovate. As put by Minsky (1990), money managers saw profit opportunities from government choices and how to profit from them. Money managers innovated when developing the different financial products, and, in terms of usages, by investing or being funded in another market. They have a crucial role on financial integration, as they are the ones who define which country (and market) will be integrated to international financial markets (Chesnais, 1997).

Developments related to IT, financial deepening, monetary changes and the creation of liquidity only have a secondary role in encouraging financialization. It should also be noted that these developments were also motivated by financialization - in a classical egg-andchicken causality.

\subsection{The Three Developments That Characterize Financializa- tion}

As already mentioned, the term financialization has been used to describe several developments that have been changing the face of capitalism. This section discusses these different transformations according to the three groups mentioned in the introduction, i.e. the increasing importance of finance at the international level; the transformations of finance; and the changing relationship between finance and other economic sectors. 
Before analyzing these phenomena, it is interesting to differentiate this categorization from others found in the related literature. Stockhammer (2004) characterizes financialization by developments that include the globalization of financial markets, the shareholder revolution, and the rise of incomes from financial investment. Compared to what is proposed in this chapter, the first development is common to both classifications, and the latter two are tied to the changing relationship between finance and the other sectors.

Although not directly referring to characteristics of financialization, but to "financial innovations" behind financial crises, Boyer et al. (2004) presents a similar list: deregulation, globalization and sophistication of new (financial) instruments. While the first is seen in this chapter as a development that allowed financialization to occur, globalization is similar to the increased weight of finance internationally, and sophistication is the same as the changes that occurred within finance. We could therefore argue that from the three phenomena used to describe financialization here, the changing (power) relation between finance and the other sectors would be the only one not directly related to crises - which indicates the close relationship between financialization and crisis.

Financial globalization It is also important to mention the use of the term financial globalization $^{23}$. Definitions of financial globalization refer to the important integration of different countries' markets. For instance, Bibow (2009, p. 7) defines it as "the integration of national financial systems through rising cross-border financial flows and asset holdings" and Arestis et al. (2005, p. 507) define it as "the integration of financial markets of all countries of the world into one".

Some references however also include aspects related to financial deregulation or liberalization, as Chesnais et al. (1996, p. 10-11), who add the elimination of internal barriers among different segments of financial markets and the interpenetration of national monetary and financial markets to the definition of financial globalization. That is also the approach of Bresser-Pereira (2010, p. 506), who defines financial globalization as "the liberalization of financial markets and a major increase in financial flows around the world".

\footnotetext{
${ }^{23}$ There are two most important terms in the French literature, "globalisation financière" and "mondialisation du capital". Chesnais (1997) does not use globalization, but "mondialisation", what is close to financial globalization is the "mondialisation" of capital in the financial sphere ("mondialisation du capital dans la sphère financière"). The term financialization is more common in more recent and in Anglophone papers.
} 
However, theoretical discussions are facilitated by differentiating two aspects, integration and what led to integration, into terms. Such a differentiation emphasizing the causalities involved is clear in Arestis et al. (2005, p. 507-508), who state that "financial liberalization provides a necessary, but not a sufficient, condition for financial globalization." This chapter follows this approach: Financial globalization refers to the integration of different national financial systems. Financialization is a broader phenomenon. The emergence of both financial globalization and financialization depends on financial deregulation and liberalization.

\subsubsection{Increasing Importance of Finance at the International Level}

The increasing importance of finance internationally, with its decoupling from its earlier functions, is the first of the three financialization aspects. Financialization is related to financial globalization and integration, but the idea that this integration is of a different logic, no longer determined by its prior function, is keen to financialization. As a result of this concern, both integration (as proxied by capital flows or by the stock of foreign assets and liabilities) ${ }^{24}$, and FX transactions (that would normally be associated to it), are analyzed.

The growth of finance at an international or open-economy level has been broadly detected and much attention is given to the rapid pace in which this process occurred. Part of the proxies used are based on absolute values. Examining financial integration, Chesnais (1997) mentions that the ownership of foreign assets in portfolios of U.S. funds rose significantly - from $0.7 \%$ in 1980 to $5.7 \%$ in 1993. Analyzing FX transactions, Chesnais (1997) and Epstein (2005) demonstrate their rapid growth - in the US, UK and Japan they have six-folded from 1986 to 1992 and, in total, they have almost four-folded from 1989 to 2004. The rapid increase of FX transactions continued in the 2000s. As analyzed in Chapter Five, total transactions four-folded from 2001 to 2013, the ones relative to EMEs' currencies (hereafter emerging currencies) having grown two times faster than those relative to advanced countries' currencies ${ }^{25}$.

To better understand these absolute increases, a discussion on the growth of finance internationally in relative terms - relative to what it was supposed to be considering its

\footnotetext{
${ }^{24}$ Chapter Five discusses these two proxies of de facto financial integration.

${ }^{25}$ The developments of the FX markets and the level of integration are discussed in Chapter Five, respectively on Sections 5.3 and 5.2. A summary of these figures is presented in Table 5.1, page 232 .
} 
prior function of financing production and trade - is required. The most common proxies used are relative to GDP or trade. Analyzing integration, Baker et al. (1998, p. 10) shows that the value of funds raised on international financial markets, as a percentage of world exports, rose from $0.5 \%$ in 1950 to over $20 \%$ in 1996 in OECD $^{26}$ countries.

Plihon (2010) discusses the increasing weight of financial flows on France's balance of payment (from $28.8 \%$ in 1980 to $92.8 \%$ in 2005) and relative to its GDP (from $14 \%$ to $448 \%$ in the same period). The author also compares this dynamic with that of current account transactions, that not only lost its relative space in the balance of payments, but were stable in percentage of GDP (around 35\%). This comparison sheds light on the growing decoupling between financial motives and flows related to the productive economy.

The decoupling of financial integration from GDP and trade has continued to grow rapidly since the 2000s: seen through foreign assets and liabilities, financial integration increased 50\% more than GDP and 40\% more than trade integration among advanced countries from 2001 to 2011. Among EMEs, integration grew on average 40\% more than GDP and as fast as trade. In 2011, financial integration was more than four times greater than GDP among advanced countries and almost as great among EMEs.

Finance has also continuously gained importance internationally when FX transactions are analyzed. FX transactions with advanced countries' currencies grew two times faster than GDP and trade from 2001 to 2013. Among emerging currencies, the decoupling of FX transactions from GDP and trade was even greater. It grew 158\% more than GDP and 136\% more than trade. Note that the growth of FX transactions relative to GDP and trade was greater than the growth of financial integration relative to GDP and trade.

The major magnitude of finance at the international level relative to GDP or trade underlines that the function of the international financial system is no longer to assure the financing of the international trade and of the balance of payments (Chesnais et al., 1996). Instead, it has only indirect links with these functions, following its own logic (Plihon and Ponssard, 2002). The logic of today's international financial market is determined by speculative motives, that gained force with the sophistication of finance - as discussed in the following section. The mentioned decoupling of FX transactions not only from GDP and

\footnotetext{
${ }^{26}$ OCED stands for Organization for Economic Co-operation and Development.
} 
trade, but also from financial integration is evidence of the changing features of integration and finance, and its new logic.

Some features of financial integration must be mentioned before discussing innovations of finance. Financialization is characterized both by a unity of time and place, given that the world is connected through modern communication networks in a non-stop market (Bourguinat (1992); Plihon (1997)), as well as by the fact that money managers across the globe have the same investment possibilities. It is also characterized by the limited ability of governments to intervene against major attacks and currency crises, as the events cited in page 24 (Chesnais, 1997).

The evidence of the rise of finance at the international level shows the evolution of the location of assets and funding of economic units. As Minsky (1990, p. 36) put it, "managed money capitalism is international in both the funds and the assets in the funds." As the integration among different countries' markets increase, the same portfolio becomes available to every investor ("as money managers capitalism grows in importance the same portfolio options will become available to all wealth holders regardless of their national 'base"' (Minsky, 1988)). The result is an interconnection of balance-sheets that is reflected in important capital flows and foreign exchange contracts. The global economy is no longer characterized by individual economies, but "as a closed system of capitalist systems" (Wolfson, 2002).

A very interesting picture of countries in this network with regards to equity holdings can be seen in Figure 2.1 taken from Haldane (2011), where the nodes represent different countries and the arrows represent the gross external equity assets and liabilities ${ }^{27}$. Although this is shown for countries, the units responsible for the interconnections are the money managers.

The limited ability of government intervention is often alluded to in the literature and is of main importance to understand the consequences and the risks associated with financialization. It should not, however, be understood as an argument that governments have a small role to play when crises occur; as argued in the last section, governments are responsible for policy choices that allow financialization to occur in the first place and they have the

\footnotetext{
${ }^{27}$ Figure 2.1 is further debated in Chapter Three, where it is presented for different years since 1980. It is however replicated here for reader's convenience.
} 
Figure 2.1: Global Network of Cross-Border Equity Holdings and Liabilities Issued

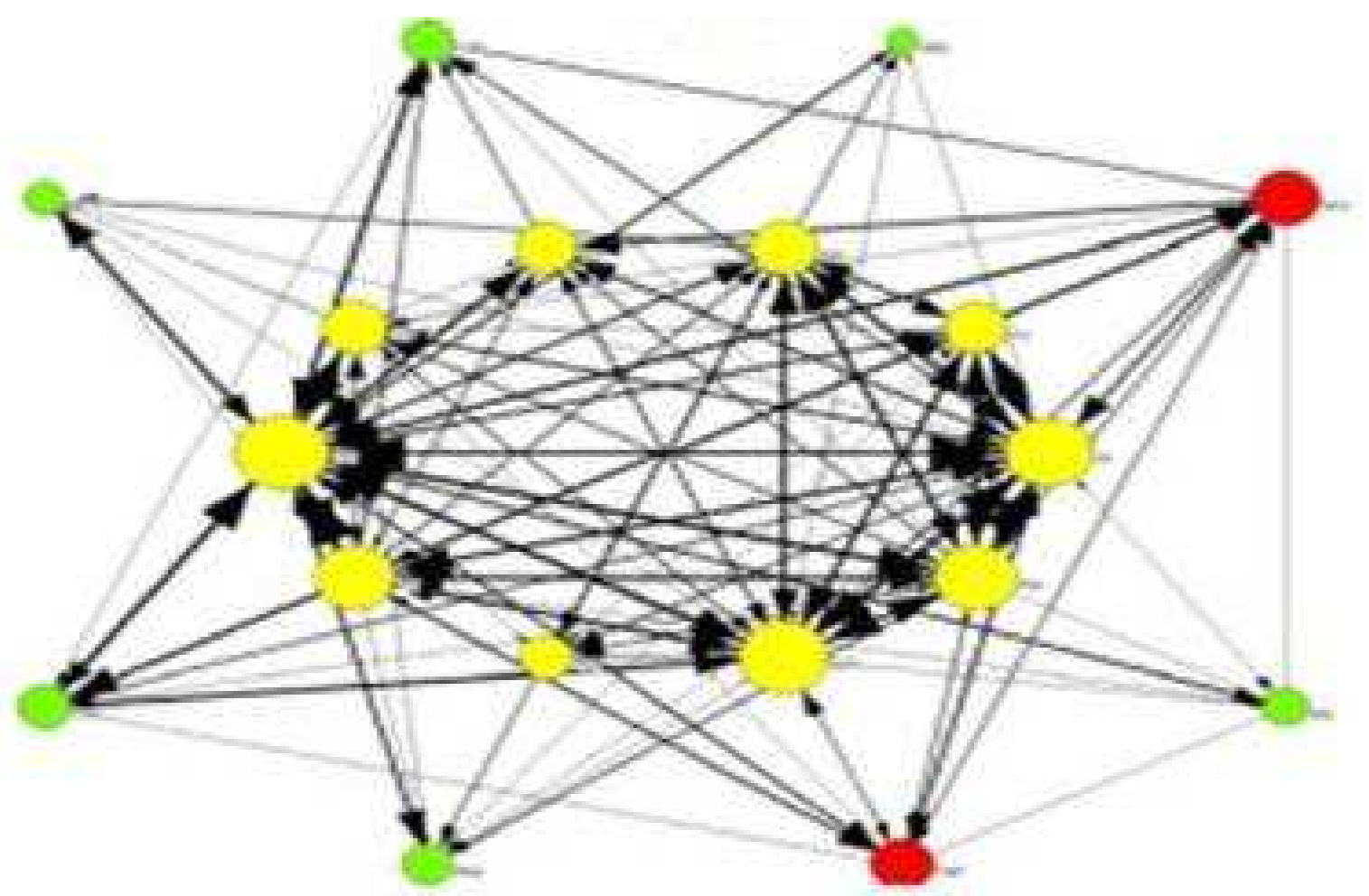

Reprinted from Haldane (2011, p. 17) (with data from Kubelec and Sá (2010) and Bank of England calculations).

Yellow circles represent advanced economies; green ones, emerging countries; red ones, financial centers (Hong Kong and Singapore).

"Widths of links are proportional to the log dollar value of cross-border equity holdings. Each arrow denotes ownership, with the arrow pointing away from the holder of the equity and toward the issuer. Sizes of nodes are proportional to the log dollar value of the sum of all of the country's cross-border equity holdings and liabilities issued" (Haldane, 2011, p. $17)$.

permanent option to counter-act destabilization caused by financialization through capital account management (as it will be discussed in Chapter Seven).

\subsubsection{Transformations of Finance}

A second important phenomenon related to financialization are the changes within the financial system. The rapid pace with which financial markets were able to innovate can be 
explained by the profit prospects of these innovations as well as by their own characteristics. On the profit-making possibilities they provide, Lapavitsas (2009) stresses the different degree of productivity offered by these changes:

Finance might have become neither more efficient nor more productive in terms of intermediation per worker, but it has became capable of operations that were previously completely impossible (...) Not least, finance has become technically capable of dealing with huge numbers of individual borrowers. (p. 110)

Regarding the characteristics of financial innovations, it is interesting to note that unlike industrial innovations, financial innovations are simply contractual arrangements, and are more easily implemented and more readily copied for being devoid of protection by intellectual property rights, resulting in much shorter life cycles (Guttmann, 2008).

The changes of finance analyzed in this section are: the increasing importance of markets, the evolution of banking, and the sophistication of its financial products and usages.

\subsubsection{The increasing importance of markets and the evolution of banking}

The role of banks in credit intermediation changed with the emergence of securities. The development of securities is rooted in the bad solvency-ratios of U.S. banks due to developing countries-debt crises, in the beginning of the 1980s. Securities came as a solution to allow banks to put risky debtors off balance-sheets and to make themselves intermediates only, passing these risks to other institutions. Debt was then fractionated into smaller pieces and constantly renewed; as a result, investors have longer debt maturities and banks intermediation is limited to cases of insufficient liquidity in markets (Bourguinat, 1992).

Observing the increasing role of markets, Aglietta (1999) argued that the financial system would have shifted from being "banking-based" to "market-based". Despite the enlarged role of markets, the financial system is still mainly based on banks, that also have access to markets - characterizing what is called a market-based banking system ${ }^{28}$. In fact,

\footnotetext{
${ }^{28}$ The idea of a system based on markets, as opposed to a system based on banks would stem from Allen's (1999, as cited by Plihon (2003)) observation of the differences between the German/French and the Anglosaxon systems: while the first two countries' systems were based on bank intermediation and private information, the latter is characterized by the central role of financial markets as a source of funding and the quality-level of public information (Plihon, 2003).
} 
the evolution of banks has resulted in a blurry frontier between bank and market-financing. For instance, banks acquire and issue equities in markets, creating a "market intermediation" (Plihon, 1995). Minsky (1990) had also stressed the shifting importance of banking credit to credit in the form of securities and to the blurriness of the frontier between banks and direct markets, highlighting the role of banks as fund managers.

Indeed, fund management is a current function of banks along with commercial banking, investment banking, private wealth management, and insurance. With these new functions, banks evolved to financial institutions called "do-it-all" groups, "financial supermarket", or "full-service" banks. In these new structures, capital markets are used as a source of income along with the traditional functions of commercial banks (Prates and Farhi, 2015). These changes in interaction between banks and markets and the high degree of concentration in the provision of banking services have occurred around the globe (Pastr (2007); Plihon et al. (2006)).

Risk management techniques have also gone through important changes: While banking institutions used to do private evaluations based upon the specific knowledge of each debtor, financial markets use statistical data to infer probability distributions of risk characteristics (Aglietta and Breton, 2001), a kind of risk evaluation that has been included in bank's techniques. This practice has been referred to as the logic of "originate and distribute" its loans to other financial institutions instead of the old "originate and hold" (Brunnermeier, 2008). By doing so, banks have become less cautious about their lending practices as risk is passed to other agents and they do not gain with the return of carrying the operation, but from its fees (Kregel, 2008) ${ }^{29}$.

Among the risks brought by the new structure, Aglietta (1999) stresses the features of market- vis-a-vis banking liquidity. In a bank, liquidity is totally and permanently held because deposits are assured and the bank has access to the ultimate liquidity out of the market, the central bank. Market liquidity, on the other hand, is a collective "imaginary" of participants, not an objective reality, as it is relative to the equilibrium between the diverse expectations of buyers and sellers. In case of doubt about the prevailing collective opinion,

\footnotetext{
${ }^{29}$ Lapavitsas (2009, p. 110) highlights other changes within finance, such as changes in the internal organization of financial institutions, speed of transactions, feasibility of financial engineering, links between financial markets, and pricing techniques.
} 
liquidity deteriorates abruptly, causing a major shift in prices, and instability. This constant risk of losing capital might also oblige market participants to speculate on the future evolution of the assets' prices, that depends on the behavior of other market participants. Speculation is thus a necessity of the functioning of financial markets, making financial fragility inherent to the dynamics of markets ${ }^{30}$.

In the Post-keynesian framework, this dependency on the expectation about collective opinion comes from the very fact that prices change according to the demand, which itself can change abruptly, following participants' expectations. A fundamental issue of financial asset markets is that their high volatility makes participants aware of the high risk, triggering a feeling of necessity to be among the "first to move", generating a herd behavior that then feeds back into volatility. This problem is intrinsic to financial markets due to (Knightian) fundamental uncertainty, that refers to situations in which "at least some essential information about future events cannot be known at the moment of decision because this information does not exist and cannot be inferred from any existing data set" (Dequech, 1999, p. 415-416), as "the future is yet to be created" (Dequech, 2000, p. 41).

The key role of money managers in the dynamics of markets is an important feature to note. Their great impact in prices derive from the fact that they are a limited number of agents, who hold significant amounts of capital, and tend to make similar decisions (as they are guided by the same assets' ratings and tend to simulate important indeces) (Plihon and Ponssard, 2002). Moreover, aware of their impact on prices, other investors also follow money managers. For instance, a better rating might drive important financial flows to a country not only by flows from money managers who follow a rating-based rule, but also from flows of investors that expected the former to do so. Finally, institutional investors' decisions are also important simply for the presence of herd behavior (they have an impact on markets, and the first variation will be followed by trend-following investors, as it will be discussed in Chapter Three).

The trend towards market-based finance has been reinforced by financial innovations as derivatives that reduced different types of risks associated with finance (Guttmann, 2008)

\footnotetext{
${ }^{30}$ Aglietta (1999) also stresses that markets are procyclical and prone to crises. But it should be noted that banks are also procyclical institutions, increasing lending in times of higher economic growth and choosing industries according to their specific growth outlooks.
} 
and by allowing investors to decide which types of risk they want to assume and to what degree (Aglietta and Breton, 2001) ${ }^{31}$. The unbundling of risks associated with different investment vehicles have, for instance, facilitated the growth of private capital flows that led to the East Asia crises in the late-1990s (Dodd, 2002, p. 447). The following section presents some of these innovations that characterize the level of sophistication of finance in times of financialization.

\subsubsection{The sophistication of finance}

In other phases of capitalism (as in Minsky's Finance capitalism) finance also played a central role in the economy, but its current sophistication (seen by the innovations of products and usages) reveals a decoupling from its earlier role of financing production. Minsky and Aglietta defended the changing role of financial markets across different phases of capitalism. While finance currently focuses on a "quick turn of the speculator, upon trading profits", its earlier focus was upon the capital development of the economy (Minsky, 1992, p. 111), or in serving capital accumulation (Aglietta, 1999).

Indeed, it seems hard to defend that the sophistication of finance is strictly tied to prior functions of finance related to capital development, and not to its new patrimonial logic where speculation matters and relies on sophisticated products. As put by Guttmann (2008):

[Finance-led capitalism] has given priority to fictitious capital whose new conduits, such as derivatives or asset-backed securities, are several layers removed from any real economic activity of value creation. In that realm the key objective is to trade paper assets profitably for capital gains, an activity best described as speculation. (para. 23, italics added)

Guttmann (2008) is probably referencing Kaldor's (1939) definition of speculation; where speculation is related to trading with the objective of profiting from change in the price of a good. In Kaldor's words:

\footnotetext{
${ }^{31}$ According to Dodd (2005), the use of derivatives, in general, dates back: it can be traced to some centuries or even to Aristotle's period.
} 
Speculation [...] may be defined by the purchase (or sell) of goods with a view to re-sale (re-purchase) at a later date, where the motive behind such action is the expectation of a change in the relevant prices relatively to the ruling prices and not a gain accruing to their use. (p. 1$)^{32}$

This thesis uses Kaldor's definition as reference.

Innovations of products The rise of financial innovations reveals the changing function of finance. Indeed, speculation gained amplitude with the development or the broad use of sophisticated products as futures, options, forwards, or swaps. These are excellent tools of speculation due to the leveraging possibilities they offer that make risk-taking cheaper and more available (Dodd (2005), Farhi (1999), and Guttmann (2008)). As reminded by Prates and Fritz (2016):

One important characteristic of financial derivatives as a whole is their high degree of leverage, to the extent that they require only a margin requirement or the payment of a premium to be carried out. This specific feature, in turn, makes FX derivatives a privileged instrument for currency speculation and profiting from interest rate differentials. (p. 187)

Apart from favoring speculation, derivatives add pressure on spot markets through arbitrage. Indeed, they are considered an extra conduit of spot exchange-rate determination: as the pricing of forward exchange rate is given by the spot rate plus a cost of carrying the asset ${ }^{33}$ (the interest rate) any change in one of the markets translates into a change in

\footnotetext{
${ }^{32}$ Farhi (1999) questions Kaldor's definition, arguing that acting according to expectations about changing prices is not only a characteristic of speculators, but also common to today's hedgers and arbitrageurs given the high volatility of financial markets. Farhi thus suggests a concise definition of speculation as liquid positions (sold or bought) in a spot or derivatives market that is not hedged by an opposite position in the derivatives or spot market of the same asset. This definition of speculation characterizes one of the four aspects of speculative operations raised by Miotti and Plihon (2001): i) they implicate risk-taking, meaning taking position on interest rates, asset prices, or the exchange rate; ii) they are motivated by expectations of capital gains associated with expectations of increasing price of assets; iii) they are "pure" or "dry", meaning that they are self-sufficient and that they do not have a direct counterpart in the economy's real side (in line with Farhi (1999)); iv) they happen, most of the time, with lent money as speculators aim to leverage their position.

${ }^{33}$ If both the spot prices and the interest rate do not change and the forward price increases, market participants will see an opportunity for arbitrage and buy the asset on the spot and sell it on the derivatives markets. The more liquid the derivatives markets are, the more intense this connection between the three variables will be (Farhi, 1999).
} 
the other ${ }^{34}$. When derivatives markets are insignificant in comparison to spot markets, the influence goes from the spot to the derivatives market. But when derivatives markets gain in weight, the rates in the two markets constantly influence one another (Farhi, 1999). More than being a determinant of the spot rate, derivatives markets can also increase its volatility for being more volatile and subject to changing expectations.

Dodd (2005) also mentions other risks: "derivatives can be used to 'outflank' laws and regulations; they can distort the price discovery process; they can be used to manipulate accounting rules. In short, while they have their benefits, they can also facilitate many 'unproductive' and 'inefficient' activities" 35.

The intensification of business cycles is a different risk associated with financial innovations. Following Schumpeter, Minsky (1990) saw any evolution and innovation as driven by a change in prospective profits. Accordingly, the importance of innovation comes from its ability to change profit prospects and to change behaviors, which results in a pro-cyclicality: innovations allow for more financing to occur, facilitating investment and leading to economic growth; an increase in risk aversion, however, induces a desire to unwind debt financing. As Minsky (1990) concluded: "boom associated with financial innovations is likely to carry the seeds of its own destruction: the fruit of these seeds being a wave of bankruptcies that can lead to a debt deflation process." Brunnermeier (2008) specifically discusses the creation of credit booms in the wake of the GFC. Instead of yielding in a more stable system, as risks are transferred to those who are able to support them, financial innovation led to an unprecedented credit expansion that helped feed the boom in housing prices in the US (before the Global Financial Crisis (GFC)).

Indeed, the consequences of speculation in terms of stability are well known. Differently from Friedman's view of stabilizing speculation on FX markets ${ }^{36}$, speculation led to notorious crises (in advanced and developing countries, discussed in Chapter Three, Section 3.2) and

\footnotetext{
${ }^{34}$ Note that it is a simple arbitrage operation that does not involve any expectation about future exchange rates. It is an arbitrage on the covered interest rate parity (discussed in the next chapter, in Section 3.1.1.3) (Rossi, 2014). Fernandes (2008) argues that in the case of the Brazilian real, whose future market is much more liquid than the spot one, the causality runs from the future to the spot rate.

${ }^{35}$ See Prates and Fritz (2016) on the use of derivatives in circumventing capital controls in Brazil after the GFC.

${ }^{36}$ The concept of stabilizing speculation emerged from Friedman's defense of flexible exchange rate regimes: "Despite the prevailing opinion to the contrary, I am very dubious that in fact speculation in foreign exchange would be destabilizing. Evidence from the earlier experiences of fluctuation in Switzerland, Tangiers, and elsewhere seems to suggest that, in general, speculation is stabilizing rather than the reverse, though the
} 
is the root of the trending pattern of exchange rates (discussed in Chapter Three, Section 3.3.2).

As Plihon and Ponssard (2002) remind us, speculation becomes an issue when its logic becomes the determinant, as financial flows prevail over others which are more connected to the economic reality of a country. The magnitude of FX derivatives markets might raise concerns over the weight of speculation in these markets. Among both EMEs and advanced countries, there were, in 2013, two times more derivatives than spot contracts. In Brazil and Turkey, there were three times more derivatives contracts than spot ones ${ }^{37}$.

More recently, financial innovation also count with high frequency trading and dark pools (Prates and Farhi, 2016, p. 10) ${ }^{38}$. With a combination of the two, investors can trade according to algorithms, benefiting from privileges such as greater or faster access to information in a completely opaque environment - without making their orders public. There are many risks associated with these two instruments, two of them being a very rapid collapse in prices (the 'Flash Crashes' ${ }^{39}$ ) and the determination of market prices at the will of few large international banks - the most notorious one being the manipulation of the Libor (Prates and Farhi, 2016).

Apart from innovation of products, the high level of sophistication of finance in times of financialization is also revealed by the innovation of usages. Carry trading operations and the financialization of commodities and currencies are two examples discussed in what follows.

Commodity and currency financialization A specific financial innovation that is of special interest for this thesis is the creation of asset classes from other assets, or the financialization of these assets; the financialization of commodities and currencies are important examples.

evidence has not yet been analyzed in sufficient detail to establish this conclusion with any evidence" (Friedman, 1953a, p. 175, italics added).

${ }^{37}$ The weight of derivatives markets is discussed in Chapter Five, Section 5.3.3.

${ }^{38}$ High frequency trading is a "class of electronic trading featured by high-speed connections and the use of complex algorithms" (p. 3), while dark pools are "equity-trading systems that do not publicly display orders" (p. 14).

${ }^{39}$ Prates and Farhi (2016, p. 10) define Flash Crash as "a very rapid, deep, and volatile movement in security prices occurring within an extremely short time." There have also been flash rallies of prices. 
Commodities' financialization refers to the observation that commodities are traded as an asset class. UNCTAD (2009) has shown that the price dynamics of commodities has changed since the early 2000s: "these markets follow more the logic of financial markets than that of a typical goods market" (UNCTAD, 2015, p. 24) ${ }^{40}$. Also important for the financialization thesis is the fact that this change of dynamic was associated with a sizable increase of portfolio investors' position on these markets, as revealed by the sizable volumes of exchange-traded derivatives - 20 to 30 times larger than physical production (UNCTAD, 2012).

Tang and Xiong (2010) argue that the financialization of commodities begun in the early 2000s: After the collapse of equity markets in 2001 and the "widely publicized discovery of a small negative correlation between commodity returns and stock returns", commodities were promoted as an interesting asset for reducing portfolio risk. The use of these different commodities as a part of a common portfolio diversification strategy has however resulted in higher volatility, higher correlation between their prices and increasing sensitiveness to international market conditions (Kyle and Xiong (2001); UNCTAD (2009)).

The higher correlation between asset markets is explained by contagion: the need of liquidity in a market calls for withdraws in another (Aglietta, 1999), as the strategy of financial investors is determined by their "own needs" that are related to financial markets in general (UNCTAD, 2009, p. 23) ${ }^{41}$.

Another important type of financialization of assets is the emergence of the financialization of currencies, the consideration of a currency as an asset class per se, with the expectation of incurring gains from the changes in their values (Kaltenbrunner, 2011). Analyzing the trade of the Brazilian real as an asset, Kaltenbrunner (2011) concluded that this process resulted in large exchange rate swings and in a higher vulnerability to international market conditions.

\footnotetext{
${ }^{40}$ Apart of the effect of the macroeconomic conditions of the international economic scenario, it is important to mention the changes related to the productive economy that also explain the steady rise of commodity prices in that period, as the high growth rate of China, and supply shocks that affect the production of some agriculture commodities (Prates, 2007).

${ }^{41}$ Kyle and Xiong (2001) also analyze contagion as the result of a need of liquidity in a market that lead traders to liquidate position in other markets. They call it a wealth effect.
} 
Currency trading is in fact a different process than trading an asset denominated in that currency, due to money's special attributes of the denominator of contractual obligations and the medium with which these are met ${ }^{42}$ (Kaltenbrunner, 2011). This specific feature of money will have important implications on the currency dynamics, as it will be discussed in the next chapter.

Carry trading Another important form of speculation is carry trade. Different definitions of carry trade range from "borrowing in low-interest currencies to fund deposits in highinterest currencies" to "any financial transaction that increases one's high-yielding assets relative to one's low-yielding assets, even when no foreign exchange transaction is involved, such as when a household uses low-interest-bearing short-term deposits to purchase longterm bonds" (Gagnon and Chaboud, 2007, p. 2-3). However, the latter definitions are too broad in describing any attempt to maximize portfolio's returns ${ }^{43}$.

Gagnon and Chaboud (2007) make the debate on carry trade more precise by differentiating carry trade in two types, depending on whether they are done in spot or in derivatives markets. The canonical carry trade involves borrowing in a currency of lower interest rate (the funding currency) and investing in a high-interest-paying currency (the investment or target currency), while the derivatives carry trade, involves being sold in the funding currency and bought in the investment currency, "particularly through currency futures and forward contracts" (p. 10-11) $)^{44}$. Derivatives carry trading is thus a type of currency financialization. An important aspect of the definition of canonical carry trading is that it specifies that the operation is based on borrowing (UNCTAD, 2007).

Carry trading is also a specific type of investment for not being hedged - which is essential in characterizing its objective of gaining with the exchange rate change. This is featured, for instance, in the definition of Burnside et al. (2006, p. 5): carry trading "involves borrowing

\footnotetext{
${ }^{42}$ The consideration of currencies as an asset class can be tracked back to Keynes' General Theory mainly through the liquidity preference theory which, when applied to an international context, explains the demand for different currencies based on its return and liquidity features (Kaltenbrunner, 2011).

${ }^{43}$ An example of broad definition of carry trade is Frankel's (2008): "a useful, still broader definition of the carry trade would cover any investment strategy that involved shifting out of low-interest-rate assets and into anything else - emerging market debt, equities, real estate, commodities, and the like". This might however not help the debate on carry trade for describing a large range of operations.

${ }^{44}$ Gagnon and Chaboud (2007) shows that the two strategies have the same results, precisely because the uncovered interest parity (UIP) does not hold (Prates, 2015). See Section 3.1.1.2 (page 57) for more on the UIP.
} 
low-interest-rate currencies and lending high-interest-rate currencies, without hedging the exchange rate risk" ${ }^{45}$.

Carry trade is difficult to tract in data (Heath et al., 2007), making it difficult to indicate when these operations started. Its use might be found in the early-20th Century ${ }^{46}$, but it certainly gained importance by the end of the century, when it funded the bubbles leading to the Asian crisis. It is also in the late 1990s that Burnside et al. (2006) first find evidence of the consequences of carry trade operations in the yen (a major funding currency) ${ }^{47}$. It would also be in the late 1990s that economists (and international institutions, such as the BIS) begun paying more attention to carry trade, and in the 2000s they begun being referred to in the literature as "famous carry trade". It was also by the end of the 20th Century that the definition of carry trade started centering on investments that involve two different currencies, as revealed by the use of the term currency carry trade (Rossi, 2016).

The importance of carry trading continued throughout the 2000s. Galati and Melvin (2004) cite it as a major reason for the surge seen in FX markets from 2001 to 2004 - when they were favored by the low interest rates of advanced countries since the early 21 st century (Prates, 2015).

Focus on exchange rate returns Both canonical and derivatives carry trade are a type of currency financialization. This is clear in derivatives carry trade where the return is the exchange rate return. However exchange rate returns are also a feature of canonical carry trading: as it is not a hedged operation, part of its returns stem from the exchange rate change (also see Equation 3.24 and the discussion in Chapter Three, Section 3.1.6.1).

The focus on exchange rate return can only exist with flexible exchange rate regimes, being a clearly a dated phenomenon: after the collapse of the Bretton Woods Institutions; and in EMEs, since the late-1990s. It is also revealed from foreign portfolio investment in

\footnotetext{
${ }^{45}$ It should however be noted that although carry trading does not involve hedging, the existence of liquid derivatives markets of the currencies involved facilitate their operation for enabling the "derivatives carry trade".

${ }^{46}$ Eichengreen (2008, as cited in Rossi (2016)) states that: "It had of course been the same carry trade that contributed to the unstable equilibrium of the late 1920s, as investors funded themselves at 3 per cent in New York and Paris in order to lend to Germany at 6 or 8 per cent."

${ }^{47}$ The start date of the empirical analysis of Burnside et al. (2006) is not clear, but it seems to be 1990.
} 
assets labeled in domestic currencies, as equities, that is increasingly used by foreign investors in EMEs (Kaltenbrunner and Painceira, 2014), and by the rise of FX derivatives.

Seen from Kaldor's (1939) definition of speculation, the profit from exchange rate return is an speculative activity, as it is a type of capital gain inferred with the asset. The mentioned innovations of usage and products thus indicate a rise of the speculative logic of finance internationally, what is distinguished from a logic of financing trade and production and simply from a patrimonial logic (it could be a patrimonial logic with a higher focus on speculation).

Kaltenbrunner and Painceira (2014) argue that the focus on exchange rate returns is behind the 'new forms of vulnerabilities' of developing and emerging countries. In Chapter Seven it will be argued that due to the high variability of a group of emerging currencies (presented in Chapter Six), EMEs might attract money managers who are even more focused on exchange rate returns, and aware of exchange rate changes, than others, meaning a bias towards speculative behavior.

Interactions The changes of finance interact with the increasing importance of finance at the international level. The qualitative changes which finance has passed through have certainly impelled the increase of finance at the international level. Derivatives allowed investors to hedge risks related to a large set of assets, reducing the uncertainties related to the volatility of main economic indicators that could hinder cross-national operations (Farhi, 1999). It also made risk-taking cheaper, thus more available, due to the leveraging possibilities offered (Dodd, 2005). In general, by allowing investors to decide which types of risk they wish to assume and to what degree (Aglietta and Breton (2001)), derivatives favor both hedged cross-border investments and currency financialization.

Innovations also played a role for increasing the supply of financial assets, and thus, of investment possibilities. For instance, with securitization, assets are freed from national boundaries, allowing money managers to act internationally (Minsky, 1987, as cited in Wray (2009)) 


\subsubsection{The Changing Relationship Between Finance and Other Economic Sectors}

The third aspect of financialization is the transformation of the interaction between finance and other domestic sectors. It has different nuances, such as the placement of capital or profit-making in the financial rather than in the production sphere (Lapavitsas, 2009) ${ }^{48}$, the focus on share-holder value, and the rise of the rentiers.

Profit-making in the financial sphere The evolution of profit-making forms is the focus of Krippner (2005, p. 173), who defines financialization as a "pattern of accumulation in which profit making occurs increasingly through financial channels rather than through trade and commodity production". This development is also seen among non-financial firms. Epstein and Power (2003) highlight the increasing importance of profits from financial transactions in non-financial companies and Stockhammer (2004, p. 719) defines financialization as "the increased activity of non-financial businesses on financial markets", measuring it by the corresponding income streams.

Share-holder orientation Another main manifestation of this evolving relationship between finance and the other sectors of the economy is the increasing focus on share-holder value inside companies. An important part of the recent research on financialization studies this issue. Stockhammer (2004) even sees the study of corporate governance and labor relations as the first area of debate around financialization.

The increasing focus on shareholder value cannot be dissociated from the increasing use of equities as a form of funding (as mentioned in Section 2.2.1). As shown by Plihon (2003, p. 46), the share of equity funding increased from $2.8 \%$ of external funding in 1980 to $42.6 \%$ in 2008 among French companies. Accordingly, banking financing decreased.

Companies have undertaken changes to maximize shareholder value by adopting sophisticated techniques of financial engineering and by the following practices: i) the broad use

\footnotetext{
${ }^{48} \mathrm{An}$ example of proxy for financialization from a focus on this third aspect is the ratio of financial assets as a percentage of tangible assets, which moved from about $40 \%$ in the mid-1980s to over $100 \%$ in the beginning of the 1990s in the US (Orhangazi, 2008).
} 
of mergers and acquisitions; ii) a greater focus on their core activities; iii) the re-engineering of production chains; and iv) downsizing through stock buyback (Plihon, 2003, p. 58-60).

The main point of the literature is to identify whether the focus on shareholders' interests and the consequent distribution of profits is done at the expense of reinvestment, which would be detrimental to growth ${ }^{49}$. This development is known in the literature as a change in management strategies from "retain and invest" profits to "downsize and distribute" them (Lazonick and O'sullivan, 2000).

This short-termism of management would have decreased "managements' animal spirits with respect to real investment in capital stock and long-run growth of the firm" and the draining of internal means of finance increased dividend payments and share buybacks in order to boost stock prices and thus shareholder value. Two channels that would have negative effects on growth (Hein, 2011, p. 2).

Minsky (1990) had a similar point: The changes in the control of firms triggered the decrease of financial independence of corporate management and its consequent short-termism. In his words: "the capitalism of money managers emphasizes cash flows in the near term to support stock prices and heavily indebted liability structures". While the capital development of the economy "has taken a back seat to the quest for short-run total returns" (p. $34-35)$.

Indeed, Stockhammer (2004) argues that financialization has contributed to the slowdown in accumulation of capital goods since the Golden Age in France, the USA and the UK, as management adopted the preferences of rentiers in the process of institutional changes of financialization ${ }^{50}$.

Although the main focus of the literature is on reinvestment and capital accumulation, financialization could also have negative impacts on growth through a decreased potential to innovate and by worsening distribution. Minsky (1990) calls attention to the former: as liabilities' structures pledge a major part of cash flows, venture capital might be enough for funding smaller innovative efforts, but not the financial investment required by capital needs

\footnotetext{
${ }^{49}$ For an example of the working of "financialized" firms and the potential consequences of growth on a Stock Flow Consistent model, see Reyes and Mazier (2014).

${ }^{50}$ Stockhammer (2004) does not find evidence of such a process in Germany. For an analysis of the impact of financialization on growth through a SFC analysis see Do Nascimento and Macedo e Silva (2016)).
} 
of advanced technology. The author sees it as a decreasing importance of managers vis-a-vis stockholders. Regarding effects on distribution, Epstein and Power (2003) argue that the increase of rentiers' share of national income has not occurred without losses of non-financial institutions and that this increase has happened at the expense of the labor's share. Indeed, as shown by Plihon (2003, p. 44), the wage share as a percentage of GDP has decreased 7 percentage points from the 1970s average to the average of 2001-2008 in Europe. If the profits' from the rentiers were redistributed, a boom in stock markets and in consumption could occur (Boyer, 2000).

The rise of the rentiers Another important feature of financialization is the rise of rentiers: "wealthy people who get most of their incomes from owning financial assets, rather than working or from owning productive assets (factories, natural resources)" (Epstein and Power, 2003, p. 229) ${ }^{51}$. The rise of the rentiers cannot be dissociated from the other aspects of financialization. Rentiers have especially benefited from: i) financial innovations of products and usages and their enlarged profit possibilities; and ii) the prioritization of paying shareholders. These two features are also a consequence of the increasing power of this particular class group. The spiral is clear: with increased economic power, rentiers gained political power, that enabled them to push for policies they have greatly benefited from, increasing their power even more (Epstein and Power (2003); Lapavitsas (2009); Palley (2007)).

Perhaps rentiers' interconectedness with the other aspects of financialization is what has made them so unanmbiguously significant in the financialization literature. Epstein and Power (2003) and Stockhammer (2004) use rentiers' remuneration as indicators of financialization $^{52}$. The definition of financial globalization proposed by Chesnais (1997) has an important focus on rentiers: financial globalization is a new age ruled by a financial capital of "rentier character". The increasing remuneration of rentiers is one of three characteristics

\footnotetext{
${ }^{51}$ See Epstein and Power (2003) for the definitions of rentiers by Keynes and Kalecki.

${ }^{52}$ Epstein and Power (2003) define rentiers' income as profits earned by firms engaged primarily in financial intermediation plus interest income realized by all non-financial non-government resident units, i.e. the rest of the private economy. When data is available, capital gains on financial assets is added. In Stockhammer (2004), income is calculated as interest and dividend income of the non-financial business sector divided by its value added.
} 
of financialization cited by Hein (2011) and the sizable remuneration of savings is a feature of Aglietta's (1999) Patrimonial capitalism.

\subsection{Potential Impacts of Financialization on Exchange Rates}

This section discusses the potential impacts of financialization on exchange-rate determination. It first presents the main points raised by the financialization literature on how it would affect exchange rates and its implications on the global economy. It later suggests an alternative way of analyzing the potential implications of financialization on exchange-rate determination.

\subsubsection{The Financialization Literature on Exchange Rates}

The financialization literature mostly focuses on its impacts on growth. The literature's concerns over exchange-rates are mostly focused on the consequences of the higher weight of financial flows and of the speculation associated to the changes of finance.

As mentioned in Section 2.2.1, with the increasing importance of finance at the international level, the amounts traded on the financial account increased considerably. Hudson (2008) stressed that this development could shift the dynamics, determining the exchange rate to the capital account. Similarly, Eatwell and Taylor (2001) stated that "for industrialized countries at least, the trade account makes up such a tiny fraction of total external transactions that it cannot possibly play a central role in determining the exchange rate". As Minsky (1990) puts it, as a consequence, exchange rates would depend on portfolio choices rather than upon trade imbalances.

Apart from the impacts of greater magnitude of the financial account, its different dynamics must also be considered. The first characteristic of the financial account is its greater volatility, which has different roots. Carvalho (2008) has highlighted the implications of the fact that the financial account reflects trading of assets, that take the form of stocks - differently from the current account, where goods are traded, in flows. As described by the author, the trade of stocks can have more important and rapid implications, because, 
in response to an event, an entire stock of a given asset might be put for sale, substantially increasing the values involved.

Differently from assets markets, transactions in goods markets are decided in advance ${ }^{53}$, with no room for increase in uncertainty or panic at the time of the actual (payment) transaction or change to commitments already made (for contractual reasons and because a seller has financial commitments with the production of those goods). Assets markets, on the other hand, are characterized by a very different timing, given that an important part of this market's investors has as objective and raison d'être, to profit by immediately reacting to changes in the economic or political scene. As a result, repricing under stress happens faster in assets than in goods markets, indicating that substantial changes in prices (or volatility) are more frequent in the capital account than in the current account (Carvalho, 2008) ${ }^{54}$.

The pace of liquidity changes also differs: The trade of assets is subject to extreme movements and features which are traditionally studied with reference to financial markets, as intrinsic instability, proneness to crisis and to being subject to contagion. As financial flows become (quantitatively) more important, financial markets' features are transposed to FX markets. Bibow (2009), for instance, argues that FX markets are characterized by asset-market play of Keynes' beauty contest type ${ }^{55}$ due to the uncertainty about the supposed fundamentals determining exchange rates: FX market volatility would be inherent to volatility in financial markets more generally, and to the fickleness of private capital flows in particular. Eatwell and Taylor (2001) also highlight the role of investors' expectations and conventions in determining exchange rates. Apart from these considerations from the financialization literature, post-Keynesian analyses of exchange-rate determination also call

\footnotetext{
${ }^{53}$ For a few goods, as some commodities, the derivatives price might face higher volatility, but this is not translated into higher volatility in the time the flows are being decided.

${ }^{54}$ Note that the financialization of commodities makes this differentiation between asset and goods markets less clear: commodities markets, supposed to be goods markets, can also be characterized by important share of speculators.

${ }^{55}$ Beauty contest type of expectation refers to building forecasts according to what you expect others' forecast to be, not necessarily according to your own views. It is common in financial markets given potential gains from trading according to what the market will do; or, gains from anticipating the market. It was first discussed by Keynes (1936). Also see the comparison with Orléan's type of auto-referential expectations, on Chapter Three, page 90. A consequence of having participants trading according to what they think others will do is "trending" and volatility, as "every" participant will be trading in the same direction. On "trending", see the work of Schulmeister, especially on the effects of trend-following technical trading systems in Chapter Three, page 94.
} 
attention to the role of expectations and conventions, as it will be discussed in the next chapter.

Implications of the different type of exchange-rate determination The financialization literature also mentions the implications of this different type of exchange-rate determination. With regards to domestic economies, the fact that a currency follows an externally determined dynamic might implicate in loss of policy autonomy, demanding a concern of monetary policy over the exchange rates, instead of domestic objectives, even in a floating exchange rate regime (Flassbeck, 2001). The speculative determination of exchange rates also raises issues for international economics, because trade liberalization policies are based on the purchasing power parity hypothesis, whose persistent violation can be a reason for the trade imbalances (Blecker $(2005)^{56}$; Stockhammer (2010)). These imbalances are also widened by carry trading operations, that, as argued by Flassbeck and La Marca (2007, p. 12 ), would result in "a pattern of real appreciation for deficit economies and real depreciation for surplus economies".

\subsubsection{Studying Money Managers' Balance-Sheets}

The understanding of the exchange-rate determination that emerges with financialization might be enhanced by focusing the analyses on the structure formed by this phenomenon, instead of studying the patterns of capital flows, that are a result of this structure.

With the rise of money managers and the possibilities of investing in different country markets brought by financial liberalization, the international economy is characterized by an important network connected through money managers' balance-sheets. In other words, with financialization, assets and liabilities of money managers' balance-sheets are placed in different countries and labeled in different currencies, tying different country markets and exchange rates, together.

In this context, exchange rates of countries which are part of this network are subject to money managers' investment decisions, and thus vulnerable to changes in funding countries and in different markets where money managers have assets. This explains why, when assets

\footnotetext{
${ }^{56}$ Blecker (2005) also mentions the increasing correlation of business cycles.
} 
become part of money managers' portfolio diversification strategies, their prices become more volatile, more subject to international influence, and correlated with prices of other assets used in the same strategy, as shown by the analyses of commodities and currency financialization.

The second aspect of financialization, i.e. the changes of finance, also have implications on exchange rates. The innovations of product as FX derivatives, as mentioned, favor speculation and are an extra conduit of exchange-rate determination, increasing volatility (for the reasons pointed in page 36). With the innovations of usage and its related focus on exchange rate returns, emerging currencies volatility is also increased from the more speculative behavior of money mangers. Financial innovations also indirectly impact exchange rates by favoring the integration of different countries to this network of money managers' balancesheet, through the innovations of products and usages (as discussed in Section 2.2.2.2).

Emerging countries are supposed to suffer these consequences for having sophisticated FX markets and being, by definition, integrated to international financial systems. This process would have begun when they decided to adopt liberalization policies in the late1990s and increased considerably in the early-2000s (as it will be discussed in Chapter Five).

\subsection{Conclusions}

Capitalism is not a stable system, and understanding its developments is key to understand exchange rate dynamics. Featured from the perspective of the three groups of financializationrelated developments presented in this chapter, and with a focus on the international level, financialization is defined as the patrimonial and increasingly speculative logic of finance at the international level. With financialization, the role of finance at the international level is decoupled from functions related to the productive economy, as financing production or trade. Instead, it follows an increasingly speculative logic, manifested by innovations of usages and products.

Despite the broad range of subjects covered by the financialization literature, exchangerate implications are not so often brought about and the analyses of emerging currencies are rare. As seen in the literature review, financialization would impact exchange rates for 
shifting its determination to the capital account and so yielding in exchange rates behave as asset prices. Exchange rates would be subject to expectation changes and crisis and contagion occur often.

Interesting points come from the studies of the financialization of commodities and currencies: assets used by money managers in portfolio diversification can be more volatile and more closely linked to international financial conditions for being used as portfolio diversification strategies of financial investors that have operations in other markets. These analyses highlight the need to understand the structure formed with the rise of financialization: different countries' markets are interconnected through money managers' balance-sheets, as their assets and liabilities are located in different markets and labeled in different currencies.

With the inclusion of EMEs' assets in this network, these countries' currencies are potentially more volatile, more closely associated to the conditions of international financial markets, and their currencies would move in an increasingly similar path. In other words, emerging currencies would be vulnerable to international markets' conditions due to their insertion in the financialized international financial system. Fragility could thus be a characteristic of emerging currencies in times of financialization, that instead of being based on trade imbalances, are based on money managers' decisions.

The extent of the consideration of these financialization-related developments by the exchange-rate literature is the subject of Chapter Three. In order to be coherent with these developments and to their potential mechanisms of impact on exchange rates, interesting features of exchange rate theories are: i) a patrimonial approach, given the centrality of money managers and their decisions; ii) to count with a sophisticated financial market and speculative practices; iii) the consideration of the constraints of these institutions, and thus of the transmission channels of contagion from a market to another. In addition to that, Chapter Three suggests ways of including main insights from exchange-rate theories on these three points on a Stock Flow Consistent model, providing a framework that associates exchangerate theories to this chapter's debate.

Given the importance of the increasing financial integration to exchange rate-determination, the main features of EMEs' integration are studied in Chapter Four. It is focused on the changes of the characteristics of EMEs' integration from the 1990s to the 2000s and on 
vulnerabilities related to the different types of foreign liabilities. The chapter also analyzes how the function of EMEs in this network of money managers' balance-sheets differs from that of advanced countries.

In subsequent chapters, the hypothesis of different exchange rate-determination among EMEs due to financialization is tested in two steps. Chapter Five presents an index of the type of integration of EMEs, aiming at measuring the level of impact from the financialization process in their integration. In accordance with this chapter's claim that exchange-rate determination depend on EMEs' integration to money manager's balance-sheets and on the change of this integration, a more financialized integration is one where financial integration is relatively important and takes place though sophisticated FX markets. Chapter Six analyzes whether a financialized integration is associated with the presence of the mentioned features of fragile exchange rates - i.e. higher exchange rate volatility, and higher correlation with international financial markets' conditions and with other emerging currencies.

Given the focus on the determination of exchange rates based on EMEs' insertion in this international network of markets connected by money managers' balance-sheets, the interaction of their behavior with EMEs' exchange rates is the focus of Chapter Seven. Following Minsky's analysis of increasing fragility, the chapter provides a model that details the evolution of money managers' choices through an exchange-rate cycle. It explains how their decisions lead to the mentioned exchange rate features (analyzed in Chapter Six). 


\section{Chapter 3}

\section{Exchange Rate Theories for Times of Financialization}

As discussed in Chapter Two, capitalism has undergone significant changes since the 1980s, which is expected to change how exchange rates are determined. This chapter reviews exchange rate theories in light of the recent context of financialization with the aim of highlighting whether its developments have been considered by these studies. Financialization is marked by the centrality of money managers and their decisions; financial flows are of great magnitude, and follow a patrimonial and increasingly speculative logic, as a reflect of innovations of products, such as FX derivatives, and practices, such as carry trading and currency financialization more broadly, by money managers. These portfolio investors funded in advanced countries are small in numbers and manage the major amounts of liquidity available in these economies, having a great impact on markets. Through their international portfolio allocation decisions, these portfolio investors tie together markets and currencies across the globe, their decisions being key to exchange rates of EMEs - that will henceforth be referred to as emerging currencies. The appropriate exchange rate model should take this context into account and account for exchange rate crisis or sudden depreciations - as those seen in emerging currencies since the 2000s, specifically with the Global Financial Crisis (GFC) and the Euro crisis mentioned in the Introduction Chapter. 
Given these objectives, the chapter presents the different models proposed by both mainstream and heterodox approaches, discussing their appropriateness to analyze emerging currencies. The mainstream models of exchange rate determination are presented according to their schools of thought, following Prates (2015), who divide them in six generations. As the author argues, the evolution of mainstream models especially after the collapse of the Bretton Woods system is closely tied to the empirical failures of prior models - the most well-known, Meese and Rogoff (1983), argues that a random walk could outperform exchange rate models in explaining short-run exchange-rate developments. An important mark of these subsequent failures is the emergence of exchange rate puzzles throughout the literature, as presented in Table $3 \cdot 1^{1}$.

It will be discussed that financialization-related aspects are better accounted for by the heterodox literature. However, this is based on different approaches. With the aim of facilitating the dialogue between them, the chapter presents how to model their insights through a common framework, the Stock Flow Consistent (SFC) approach.

The structure of the chapter The remainder of the chapter is organized as following. Section 3.1 looks at mainstream theories of exchange-rate determination. Section 3.2 presents mainstream theories of exchange-rate crisis. Section 3.3 presents the exchange rate theories based on heterodox approaches. Conclusions follow.

\subsection{Exchange Rate Determination}

This section discusses the mainstream theoretical models of exchange rate determination. It first presents the models that emerged before the collapse of the Bretton Woods System. Even if created in a very different scenario, many aspects remain present in most recent mainstream models. The models of the post-Bretton Woods era emerged in a context marked by floating exchange rate regimes and, specially the most recent, in the period of capitalism characterized

\footnotetext{
${ }^{1}$ Table 3.1 presents six main puzzles: five proposed by De Grauwe and Grimaldi (2006a) and the sixth suggested by Prates (2015). Obstfeld and Rogoff (2001, p. 372-373) present six major puzzles on open macroeconomics. Two of them concern exchange rates: the Purchasing-Power-Parity Puzzle and the Exchange-Rate Disconnect Puzzle, that refers to the disconnection between exchange rates and "virtually any macroeconomic aggregates" (similarly to what we here call the first puzzle). The authors present potential elements to solve such puzzles: trade costs and "elements of monopoly and sticky nominal prices for goods and/or labor".
} 
TABLE 3.1 Exchange Rate Puzzles

The exchange-rate determination puzzle The first puzzle refers to the apparent disconnection between exchange rates "from its underlying fundamentals most of the time" (De Grauwe and Grimaldi, 2006b, p. 2) ${ }^{a}$ or from "virtually any macroeconomic aggregates" (Obstfeld and Rogoff, 2001, p. 372-373). This has puzzled economists since the well known results of Meese and Rogoff (1983) that a random walk better predicts exchange rate paths.

The PPP puzzle The second puzzle is based on the difference between exchange rates and the values predicted by the PPP (or the weak connection between exchange rates and national price levels). There is consensus that such deviations can last from three to five years (Rogoff, 1996), but new evidence present long-term support for the PPP (as it will be observed next).

The excess volatility puzzle The third puzzle relates to the volatility of the exchange rate that greatly exceeds the volatility of the underlying economic variables ${ }^{b}$, which led Flood and Rose (1995) to lose faith in models based only on fundamentals.

The adjustment timing puzzle The fourth puzzle is similar to the second one, and it highlights that the timing of the adjustment of nominal exchange rates and prices towards equilibrium (market-clearing) is different. Engel and Morley (2001) contest the PPP-puzzle, arguing that exchange rates and prices do not need to adjust at the same pace, since the PPP should hold in the long term. Thus, it is not whether the two converge, but rather why nominal exchange rates converge so slowly (relatively to prices).

The exchange-rate returns puzzle The fifth puzzle considers that exchange rate returns have fat-tails, as opposed to following a normal distribution as their potential determinants. In fact, exchange rate returns do not follow a normal distribution due to a number of characteristics. Lux and Marchesi (2000) find that i) they present unit root; ii) they have fat-tails ("exhibit more probability mass in the tails and in the centre of the distribution than does the standard normal"); and iii) their volatility is clustered in time. The higher weight of extreme returns (more than $3 \%$ in Westerhoff et al. (2009, who study the $\mathrm{DEM} / \mathrm{USD}$ market $)^{c}$ ) is a related puzzling feature.

The forward premium puzzle The sixth puzzle refers to the fact that the uncovered interest rate parity is not observed. In other words, returns due to interest rate differential between assets of two countries are not compensated by the exchange rate change of a period. Plihon (2010) refers to this as the risk premium puzzle ${ }^{d}$ and provides two possible explanations. A higher risk associated with the U.S. dollar is accepted, for instance, due to its place in the hierarchy of currencies (it plays the role of "habitat préféré") or because agents do not have rational expectations.

\footnotetext{
${ }^{a}$ Fundamentals are not determined by De Grauwe and Grimaldi (2006b). The authors only imply that a divergence from fundamentals would impact exchange rate if its path was predicted by any "observable news".

${ }^{b}$ According to De Grauwe and Grimaldi (2006b) this contradicts the 'news' models "that predicted that the volatility of the exchange rate can only increase when the variability of the underlying fundamental variables increases".

${ }^{c}$ In light of these exchange-rate returns features, Lux and Marchesi (2000, pg.677) conclude that any linear model would be useful in explaining exchange rates: "The reason is that an elementary requirement for any adequate analytical approach is that it must have the potential for bringing about the required behaviour in theoretical time series. Therefore, it seems rather obvious that one has to go beyond linear deterministic dynamics, which of course is insufficient to account for the phenomena under study."

${ }^{d}$ This puzzle is associated with Engel (1996), that coined it "the forward discount anomaly".
} 
by financialization - particularly of sophisticated foreign exchange (FX) markets ${ }^{2}$ (discussed in Chapter Two).

\subsubsection{Theories From Before the Collapse of the Bretton Woods System}

\subsubsection{Purchasing power parity}

The Purchasing Power Parity (PPP) is a main reference in exchange rate theories. In the formalization of Cassel (1916), it meant that the exchange rate would change according to the relative price changes in two countries. The PPP has both absolute and relative forms. In the absolute form, the exchange rate $(E)$ represents the prices prevailing in a country $(P)$ relative to that of a foreign country $\left(P^{*}\right)$, as in Equation $3.1^{3}$ :

$$
E=\frac{P}{P^{*}}
$$

Its relative form implies that the exchange rate changes $(e)$ are determined by the changes of domestic prices $(p)$ relative to changes of international prices $\left(p^{*}\right)$, as in Equation 3.2 :

$$
e=p-p^{*}
$$

Although broadly known and used, the PPP has relevant limitations. First, it supposes the verification of the law of one price (goods would have one unique price in different places), that cannot be achieved given that i) international economic integration is not perfect; ii)

\footnotetext{
${ }^{2}$ As discussed in Chapter Two, finance saw important transformations, with innovations in the sense of products and of usages. What characterizes sophisticated FX markets are the broad use of products as derivatives, and activities including carry trade and currency financialization more broadly (see the discussion that begins on page 35). The operational definition of a sophisticated market is used in Chapter Five: a market that has an important ratio of future-to-spot FX contracts.

${ }^{3}$ In this quotation, the exchange rate $(E)$ is the value of one unit of foreign currency in the domestic currency; a higher rate $(E)$ corresponds to a depreciation of the domestic currency. This type of quotation, known as direct quotation, is the one used throughout this thesis. In French it is called cotation à l'incertain, in opposition to the cotation au certain. In Portuguese it is called cotação direta, as opposed to cotação indireta.
} 
goods are not perfect substitutes as agents do not have the same preferences in different places and companies differentiate their products' prices in different markets ${ }^{4}$ (Plihon, 2010).

Secondly, on the empirical front, the validity of the PPP is questionable, resulting in the presented purchasing power puzzle (Rogoff, 1996). However, recent works that use other econometric techniques, have found long term convergence between exchange rates and values predicted by the PPP. In other words, as the exchange rate and relative prices are co-integrated, the real exchange rate would tend to equilibrium (market-clearing ${ }^{5}$ ) in the long run (See MacDonald (1995) and Taylor (2009b)). Based on this, Taylor and Taylor (2004) state that we currently see the emergence of "some degree of confidence in long-run PPP".

Trade costs are a broadly accepted solution to the PPP puzzle, as they "include transport costs but also tariffs, non-tariff barriers, and possibly other broader factors that impede trade" (Obstfeld and Rogoff, 2001, p. 372-373). Note, however, that this argument still does not solve the problems related to the law of one price.

An intriguing theoretical consideration on the long-run convergence of the PPP is discussed by Priewe (2014, p. 17): if divergence leads to desindustialization and to change in production structure, how can the prices of the new economy be compared to those prevailing before the deviation from PPP? In the author's word: "In this case the statistical approximation to the PPP after correction of the exchange rate is an illusion" - the goods whose prices would have to be the same in different countries, "are no longer produced or are only

\footnotetext{
${ }^{4}$ Isard (1977, p. 4-5) compare domestic (US) and foreign prices of manufactured goods and concludes: "The denial of the law of one price in this context - at the most diaggregated product level for which price data can be readily. matched - provides a strong presumption that it is impossible to assemble available data into aggregate price indeces which can be expected to obey the law of one price (except, perhaps, when product coverage is restricted to primary commodities). Obversely, the notion that aggregate indeces of export or tradable-goods prices will exhibit purchasing power parity - i.e., that the relative home-currency prices of different countries will stay in line with exchange rates - cannot validly lean on the law of one price". Also see Dornbusch (1985) for a review on the law of one price.

${ }^{5}$ In mainstream works equilibrium is used in the market-clearing sense, or to indicate a situation where "quantity demanded exactly equals the quantity supplied" (Davidson, 2011, p. 204). Equilibrium, on the other hand, is a state "where no forces are at work to alter the position of the economy as long as the specified conditions remained unchanged" (p. 203). The concept of equilibrium was brought from physics to economics by Marshal, and meant "a balancing of endogenous forces so that the body under study is at rest" (Rotheim, 2003, p. 23). Market-clearing is a sufficient, but not necessary condition for equilibrium.
} 
produced to minor extent in one or more countries. The production structure then adapts to the distorted exchange rate, instead of the exchange rate adapting to production" ${ }^{6}$.

Drine and Rault (2004) make a similar argument when analyzing why evidence is less favorable to PPP among developing countries, mentioning the role of productivity shocks as one of the reasons for this result. In line with the Balassa (1964)-Samuelson (1964) effect, increasing productivity leads to long term appreciation of exchange rates and thus deviations from the $\mathrm{PPP}^{7}$.

\subsubsection{Uncovered interest rate parity}

With the uncovered interest rate parity (UIP), Keynes emphasized that the exchange rate cannot respond only to developments related to the goods market and shifted the focus towards assets markets. According to the UIP, the expected return of fixed-income assets of two different countries is the same when measured in one currency. In other words, the expected return of a foreign asset $\left(i^{* e}\right)$ should be the same as the return of the domestic asset $\left(i^{e}\right)$ plus the exchange rate change in a given period $\left(E_{t+1}^{e}-E_{t}\right)-$ as shown by Equations 3.3 and 3.4:

$$
\begin{gathered}
i^{* e}=i^{e}+E_{t+1}-E_{t} \\
i^{* e}=i^{e}+e
\end{gathered}
$$

Shifting the focus towards exchange rate determination and expected future exchange rates $\left(E_{t+1}^{e}\right)$, an alternative and common representation of UIP is shown in Equation 3.5 (following Lavoie (2014, p. 479)):

\footnotetext{
${ }^{6}$ It is interesting to note that arguing for the path-dependency of exchange rates, is the same as arguing for the existence of exchange-rate hysteresis, because exchange rates do not come back to their previous trajectory after a shock. Lang and De Peretti (2009, p. 447) defines a hysteretic process as characterized for having a remanence and selective memory: "Remanence occurs when the application of a shock of the same extent as an initial shock, but in the opposite direction, does not bring the system back to its initial position"; in a selective memory, "only the nondominated extreme values of the shocks remain".

${ }^{7}$ Regardless of theoretical limitations and the relative empirical failure, the current practical relevance of the PPP should be noted. It has became an essential tool in global macroeconomic statistics, due to its wide use in international comparison of macro aggregates by international institutions such as the IMF, the World Bank or the OECD.
} 


$$
i^{* e}-i^{e}=E_{t+1}^{e}-E_{t}
$$

The UIP depends on significant hypothesis of perfect arbitrage (implying no transaction costs nor restrictions to capital account transactions) and perfect substitution of assets of different countries, in terms of both risks and liquidity (Prates, 2015, p. 24).

Despite its restrictive assumptions and statistical failure, the UIP is widely used by mainstream economists in the post-Bretton Woods period. According to Burnside et al. (2006), the "UIP is a central feature of virtually all linearized general-equilibrium openeconomy models". These models either ignore the "statistical failure" of the UIP, or try to account for it by introducing a "risk premium shock" in the model.

It is also used by some heterodox authors. Taylor (2009a, p. 333) uses UIP for believing that the "exchange rate must evolve over time subject to rules based on expectations about its future", and the UIP is the best option to take expectations into account ${ }^{8}$. Its use is defended even if it "does not reliably fit the data". For Lavoie (2014, p. 480), this choice reflects an "instrumentalist philosophy (...) according to which it is better to be precisely wrong than vaguely right".

From a theoretical point of view, the advent of the UIP has shifted focus to capital account considerations - essential for an exchange rate analysis in times of financialization. It also considers exchange-rate expectations, which later was neglected by most mainstream models. It is a simple model that has a restrictive hypothesis and does not account for trade-related dynamics, but it is an important shift to capital account considerations that is only revived in portfolio models (analyzed in Section 3.1.2.3) where the hypothesis of perfect substitute assets is relaxed.

\subsubsection{Covered interest parity}

If we consider that the forward exchange rate $(F)$ is a proxy for the expected future exchange rate $\left(E_{t+1}^{e}\right)$, the difference between the forward and the current rate is equal to the interest

\footnotetext{
${ }^{8}$ Taylor (2009a, p. 333) adds that "n a world of shifting and perhaps unstable expectations, no simple dynamic theory is likely to emerge."
} 
rate differential (as shown in Equation 3.6):

$$
i^{* e}-i^{e}=F-E_{t}
$$

In this case, the forward rate is said to be "an unbiased and efficient predictor of the spot rate prevailing in the future" (Moosa, 2004, p. 366). However, this can only be realized in the presence of unbiased expectations (Lavoie, 2014) ${ }^{9}$.

The empirical evidence supports the $\mathrm{CIP}^{10}$. But CIP holds because it is "a definition rather than an equilibrium relationship" (Harvey, 2009, p. 21). Lavoie (2000, p. 172) posits that "the forward exchange rate is not an expectational variable, but rather the result of a simple arithmetic operation": "Banks set the forward rate by adding the interest differential to the spot exchange rate".

The CIP is a rare example of consideration of derivatives markets - along with the ones analyzed in Section 3.1.5 - but because it is a definition rather than an analytical framework it does not add to our understanding of exchange-rate expectations.

\subsubsection{The Keynesian Models: Elasticities, Absorption, Mundell-Fleming}

In the 1940s and 1950s, mainstream economists were challenged by the need to develop an open macroeconomic model that took into account the impacts of exchange rate and foreign income in determining domestic income (Prates, 2015).

Elasticities The elasticity approach presented the effect of an exchange-rate depreciation on the current account. Given that prices were determined by constant monetary incomes,

\footnotetext{
${ }^{9}$ The parity between the forward rate and the realized future exchange rate $\left(F=E_{t+1}\right)$ is known as the forward market unbiasedness hypothesis or the unbiased efficient hypothesis (UEH) (Lavoie, 2014). Note that when both UIP and PPP hold, there is real interest rate parity (RIRP). This relationship suggests that expected adjustments in the real exchange rate are represented by expected real interest rates. Lavoie (2014, p. 478) argues that if the RIRP holds, then central banks are not able "to set real interest rates as it wishes for domestic reasons (...) and are forced to set the real interest rate in line with interest rates that prevail in the biggest economies." Lavoie (2014, p. 478) sees this relationship as "the crucial relation in mainstream openeconomy macroeconomics", and Smithin (2002, p. 224) says that it "transfers the doctrine of the "natural rate of interest' to the international setting."

${ }^{10}$ It should be noted that Shin (2016) argues that the CIP has not hold in turbulent periods, such as in the onset of the Global Financial Crisis and the Euro are crisis of 2011-12 and that it has also not hold recently, although we are living a calm period. Moreover, the deviation from the CIP would be increasing. The author argues that it is related to the strong dollar and the consequent tighter credit condition.
} 
it assumed that nominal and real changes were equivalent ${ }^{11}$. As highlighted by Krueger (1983), it allowed for an analysis based on the opposite direction as that of the elasticity approach: the impact of macroeconomic variables as trade balance and domestic income on the exchange rate.

Absorption Polak (1957) and Alexander (1952) criticized this approach as it did not allow interaction from foreign trade to domestic income given the hypothesis of constant nominal income. The authors highlighted these effects, especially the importance of change in domestic absorption ${ }^{12}$ on the trade balance ${ }^{13}$, developing what became known as the absorption approach. This approach concludes that an exchange-rate depreciation has only a transitory impact and is thus ineffective in enhancing trade balance, while restrictive monetary policies, by decreasing domestic absorption, would solve current account issues. As highlighted by Prates (2015), IMF external adjustment policies were based on this approach, however, Prates (2015) argues that an exchange-rate depreciation does not necessarily has a positive impact on the trade balance but can reduce domestic income, as resource reallocation does not take place immediately. On the theoretical front, the absorption approach has abandoned analyses of the consequences of an exchange-rate change.

Meade's (1951) model combines the elasticity and the absorption approaches: an exchangerate depreciation improves trade balance, but to a lesser extent than in the elasticity approach, as its effects on a country's absorption are taken into account. Because it emerged in the early Bretton-Woods era, some of the model's features differ from today's reality: the exchange rate is considered fixed or exogenous and capital account dynamics are not taken into account (reflecting the lesser importance of capital flows in the period). In light of this, Taylor (2004) considers these models obsolete ${ }^{14}$.

\footnotetext{
${ }^{11}$ Prates (2015) reminds us that this approach is based on a Marshalian framework: as the exchange rate is the price that equals supply and demand for foreign exchange, it analyzes the impact of a change in this relative price on quantities and the stability of the equilibrium.

${ }^{12}$ The total absorption is the sum of consumption, investment, government expenditure and imports.

${ }^{13}$ As reminded by Prates (2015), although these models have also been called current account models (as by (Krueger, 1983)), they focus only on the trade of goods, and overlook services.

${ }^{14}$ According to Taylor (2004), an interesting exchange rate fundamental emerges from a similar model: the traded/non-traded goods price ratio, where a decrease can be interpreted as an overvaluation (referring to the works of Salter (1959) and Swan (1960)).
} 
Mundell-Fleming The Mundell (1963)-Fleming (1962) model incorporates, to the keynesian models just presented, the monetary market, capital flows and the possibility of flexible exchange rates ${ }^{15}$. Mundell's (1963) conclusions differs from Meade's (1951): While the latter argues that a policy conflict exists between the domestic (full employment) and the external (balance-of-payments) equilibrium, the former argues that in the context of free capital movements this trade-off would not take place, with neither floating nor fixed exchange-rates. In fact, appropriate fiscal and monetary policies would allow both objectives to be achieved.

In terms of exchange rate determination, Mundell (1963) incorporates a very simplified form of UIP, where the domestic $(i)$ and foreign $\left(i^{*}\right)$ interest rates are equal (as in Equation 3.7): implying risk-neutral investors with static expectations about the exchange rate the expected rate $\left(E_{t+1}^{e}\right)$ equals the current one $\left(E_{t+1}\right)$ in Equation 3.5. Indeed, this is a simplified form - as put by Krugman (2001a), "nobody believes in static expectations about $e$ ". Consider equations 3.7 to 3.9 as a simplified form of the Mundell-Fleming model (Krugman, 2001a). Equation 3.8 presents the determination of aggregate demand from both domestic demand (that depends on income, $Y$, and interest rates $(i)$ ), and net exports $(N X)$ (that, in turn, depends on the real exchange rate $\left(e P^{*} / P\right)$ and income $(Y)$ ). Equation 3.9 illustrates money demand.

$$
\begin{gathered}
i=i^{*} \\
Y=D(Y, i)+N X\left(e P^{*} / P, Y\right) \\
\frac{M}{P}=L(Y, i)
\end{gathered}
$$

In the Mundell-Fleming model with floating exchange rates, this is the variable that adjusts excess supply and demand in FX markets. Capital account dynamics are extremely simplified: assets are perfect substitutes and expectations are static. The only dynamic taken into account is capital inflows (outflows) when interest rate increases (decreases). Although an important step in understanding exchange rates at the time, this is a simple model, with restrictive assumptions.

\footnotetext{
${ }^{15}$ See Mundell (2001) for the history of the IS-LM-BP model.
} 
The keynesian models are also called balance of payment or flow models, as exchange rate determination arises from the current and the capital accounts of the balance of payments, that are "flow magnitudes" (MacDonald, 2007, p. 7). This is a clear distinction from the focus on stocks characteristic of the monetarist and and portfolio models, presented next.

\subsubsection{First-Generation Models}

The first generation models emerged in the context of flexible exchange rates, with the collapse of the Bretton Woods System. These models shift the focus of exchange rate determination from flows to monetary or financial stocks.

\subsubsection{Monetarist Model}

The monetarist criticism of the keynesian models shifted the focus of exchange rate determination through (mostly) trade-related flows to monetary policy. They can be considered "a monetary approach to the balance of payments" (Taylor, 2004, p. 211). The models start from the traditional equation of the money market equilibrium, given by the equality of the stock of money supply and money demand $\left(M^{s}=M^{d}\right)$. As usual in monetarist models, money supply is exogenous, determined by the Central Bank $\left(\bar{M}^{s}\right)$, and money demand depends on price level $(P)$, real income level $(Y)$ and rate of interest $(i)$. The stock of money $(M)$ can thus be given by Equation 3.10 and 3.11, for domestic and foreign $\left(^{*}\right)$ variables, respectively (Plihon, 2010):

$$
\begin{gathered}
M=P \times L(Y, i) \\
M^{*}=P^{*} \times L\left(Y^{*}, i^{*}\right)
\end{gathered}
$$

Given the use of PPP (shown in Equation 3.1), the exchange rate $(E)$ depends on prices, resulting, in the monetarist view, on exchange rates that depend on the evolution of domestic and foreign money demands, income and interest rates (as in Equation 3.12): 


$$
E=\frac{M}{M^{*}} \times \frac{L\left(Y^{*}, i^{*}\right)}{L(Y, i)}
$$

Therefore, in the monetarist view, the exchange rate is determined by a country's central bank policies and by the behavior of money-holders vis-a-vis these determinants in the other country. In the words of Kouri (1976, p. 1), the behavior of exchange rate, the "relative price of monies", can be explained by "the supplies of various monies and other financial assets, as well as the behaviour of demands for these assets" ${ }^{16}$. The model thus concludes that the central bank can control any potential exchange rate disequilibrium with monetary policies $^{17}$ (which is in line with monetarist models more generally, where the real sphere can be controlled by monetary policies).

According to Plihon (2010), this result was key in providing support the superiority of the floating exchange rate regime, which was the aim of the studies.

It is worth mentioning that these models lead to the conclusion that an increase of domestic revenue lead to an appreciation of the domestic currency, contradicting the findings of the keynesian models, discussed in Section 3.1.1.4 (Plihon, 2010). In fact, combined with a stable stock of money, the higher money demand can only occur when domestic prices are lower; and as the PPP holds, a decrease in domestic prices corresponds to an appreciation.

The fact that the variables used to explain exchange rates and the exchange rate in itself have very different features - the former is stable, while the latter can be volatile - is a main issue of monetarist models. Though the issue is not exclusive to monetarist models, it is worse in them, and originated the excess-volatility puzzle. The monetarist models also receive both PPP-related criticism, as well as criticism related to different financial assets being considered perfect substitutes. Nevertheless, from a PK perspective, it is the very concept of monetary policy based on authorities' changes of money supply and of money as an exogenous variable, that make monetarist models an inadequate framework for exchange rate analysis, not only for EMEs or for a context marked by financialization, but in general.

\footnotetext{
${ }^{16}$ Mussa (1976, p. 229) summarizes the dynamics involved: "When the demand for a particular money rises relative to the supply of that money, either the domestic credit component of the money supply must be expanded, or the exchange rate must appreciate, or the official settlements balance must go into surplus, or some combination of the three."

${ }^{17}$ The impact of change in money supply $(M)$ on the exchange rate $(E)$ is clear on Equation 3.12.
} 
In retrospect, it must be highlighted that monetarist analyses associate stocks (as the money stock) and flows (as the revenue) variables, leading the way to portfolio-models (Plihon, 2010) and to patrimonial approaches that followed (which, in turn, are key to times of financialization and to the crucial role of international portfolio allocation).

\subsubsection{Overshooting models (Dornbusch)}

Dornbusch's (1976) overshooting models is an important monetarist approach focused on explaining exchange rate volatility. It assumes that capital markets' dynamics reflect the UIP, but that the PPP is the long-term determinant of exchange rates. The exchange rate volatility analyzed by the model refers to the deviation from the PPP when UIP dynamics take place. It results from the different adjustment timings of assets' and goods' markets, the first being immediate and the latter fixed (in the short run). In the case of a loose monetary policy, for instance, the adjustment of the monetary market, being immediate, leads to an interest rate decrease. Given that, in the short-term, the FX market is dominated by capital flows which are determined by the UIP, the lower interest rate leads to an expectation of exchange rate depreciation. The name of the model stems from the contrast between the immediate adjustment of both the assets' and the goods' markets. In fact, the adjustment in the latter will only occur with the exchange rate depreciation, the enhancement of the trade balance, resulting in an exchange rate appreciation, back to the PPP-predicted value. Before this occurrence, markets caused overshooting of the exchange rate (Plihon, 2010).

It should be highlighted that Dornbusch's overshooting model implies adaptive expectations: agents action in building the overshooting does not takes into account any consideration that they know that the depreciation will only be temporary - or that the overshoot would later be canceled out.

Although Dornbusch (1976) advances the analysis of exchange rate volatility, since it is the first model to focus on this analysis and to to combine financial and real factors (Plihon, 2010), it must be highlighted that it explains a very specific volatility. It is similar to what is studied as PPP-deviation, a change that is canceled after a relatively long period ${ }^{18}$. It is therefore not the same as weekly or daily volatility from FX markets. The model must

\footnotetext{
${ }^{18}$ As mentioned in Section 3.1.1.1, PPP deviations prevail for 3 to 5 years.
} 
be acknowledged for stressing the need to explain volatility and to indicate negative aspects inherent to flexible exchange rates, but, in light of the most recent models (mainstream and heterodox), it falls far from explaining the volatility phenomenon in all its complexity.

\subsubsection{Portfolio models}

Portfolio Models are inspired by the financial market analyses of Markowitz (1968) and Tobin (1965). In these models the exchange rate is a result of the portfolio allocation among monetary and financial assets of different risk and returns. They therefore reveal a patrimonial approach to exchange rates (Plihon, 2010). McKinnon (1966), Branson (1974) and Kouri (1976) are influential references for these models.

In simple one country models, portfolio equations are written as in Equations 3.13 to 3.16 , where a country's wealth $(W)$ is allocated among domestic assets $(B)$, foreign assets $\left(B^{*}\right)$ in local currency units $\left(B^{*} \times E\right)$, and the money stock $(M)$. Domestic agents cannot hold foreign currency ${ }^{19}$. Portfolio allocation depends on interest rates paid by domestic $(i)$ and foreign $\left(i^{*}\right)$ assets, adjusted for their respective risks $\left(r, r^{*}\right)(\text { Plihon, 2010 })^{20}$.

$$
\begin{gathered}
M=a\left(i, i^{*}, r, r^{*}\right) W \\
B=b\left(i, i^{*}, r, r^{*}\right) W \\
E \times B^{*}=c\left(i, i^{*}, r, r^{*}\right) W \\
W=M+B+E \times B^{*}
\end{gathered}
$$

\footnotetext{
${ }^{19}$ This hypothesis is done in both the monetary and portfolio models, but is relaxed in the monetary models with currency substitution where agents can only hold domestic currency as in Miles (1978) and McKinnon (1982). By allowing agents to hold currencies from different countries, these models achieved two important results: i) the volatility of flexible exchange rates and ii) the importance of changes on relative costs related to holding currencies when determining exchange rates. The result highlights a serious issue: the interdependence of monetary policies in different countries (Plihon, 2010).

${ }^{20}$ The direction of the impact of the risk and return variables on the demand for assets or money is the standard: demand for money (Equation 3.13) is negatively impacted by the return of domestic or foreign interest rates and positively impacted by their risks; demand for domestic assets (Equation 3.14) is positively impacted by their return or by the risk of foreign assets and negatively impacted by its own risks or the return of foreign assets; symmetrically, the demand for foreign assets (Equation 3.14) is positively impacted by its own return or by the risk of domestic assets, and negatively impacted by its own risk or by the return of domestic assets.
} 
Given the budgetary constraint presented in Equation 3.16, the sum of the coefficients $a, b$ and $c$ must equal 1, leading to a reduced form of the model in Equation 3.17 and the exchange rate determination in Equation 3.19:

$$
\begin{gathered}
E \times B^{*}=(1-a-b) W \\
E \times B^{*}=f\left(i, i^{*}, r, r^{*}\right) W \\
E=f\left(i, i^{*}, r, r^{*}\right) \frac{W}{B^{*}}
\end{gathered}
$$

In portfolio models, the exchange rate results from the relative risk and return of domestic vis-a-vis foreign assets and money demand: an interest rate hike increases demand for domestic financial assets, triggering an exchange rate appreciation ( $E$ decreases). Note that this result is the opposite of the monetary models used until then.

Because they are difficult to estimate, portfolio models are often presented in simplified forms ${ }^{21}$. However, some models may include a large set of determinants, such as equities and its rate of return, real capital stock, savings, real investments and its profit rates, exports, imports, and taxes (as in Branson (1974, p. 30)).

Portfolio models present the most suitable features for analyzing the dynamics of EMEs' currencies out of all mainstream models analyzed in this chapter. As mentioned, the fact that financial assets are not perfect substitutes is central in dealing with current exchange rate issues in general (Blanchard et al., 2005), particularly in analysis involving emerging countries' assets due to the specificities of their currencies - to be discussed in Section 3.3.4. In addition, portfolio models put emphasis on the importance of stocks in determining the exchange rate, a patrimonial approach that is key given financialization ${ }^{22}$. This treatment of stocks is also important for two reasons: i) the magnitude of the stock of financial assets that might be converted in another currency at any moment is not comparable to the size of the current account flows, and ii) these two would also differ on the adjustment timing, being much faster in assets markets than in goods markets (Plihon, 2010) (more on capital account adjustment will be seen in the conclusions).

\footnotetext{
${ }^{21}$ See Melitz and Owen (1983) for a discussion on the simplifications in exchange rate modeling.

${ }^{22}$ Branson (1974) specifically considers the effects stemming from "stock-shifts" and "continuing-flow".
} 


\subsubsection{Second-Generation Models (New-Classical)}

The exchange rate models grouped into the second generation consider rational expectations when determining exchange rates, and are, therefore, part of the New-Classical School (Prates, 2015).

\subsubsection{Efficient market models}

As the name indicates, expectations in these models were modeled according to Fama's (1970) efficient market hypothesis: under the assumption that the future can be reduced to probabilistic events and that agents' decisions reflect their rational expectations based on available information, the price of an asset constitutes the best indicator of its intrinsical value, reflecting all information available in a given moment. Thus, exchange rates in period $t$ would reflect all information available in $t$.

Two major assumptions are implied. First, arbitrage are perfect: assets are perfect substitutes and the UIP (Equation 3.4) holds. It means that higher returns in country A than in country B could only hold if agents expect the currency of country A to depreciate until the maturity of the asset by the same amount of the interest rate differential. A deviation from the values predicted by this equation, in turn, would reflect agents' perception of these assets as riskier (and not as substitutes), which calls for a risk-premium (Plihon, 2010).

The second implicit hypothesis is that agents have rational expectations: they use all of available information, know the "real" determinants of exchange rates, and, as a consequence, do not make persistent forecast errors ${ }^{23}$. With such unlikely hypotheses, these models have not directly enhanced our understanding of exchange rates. They have, however, triggered critiques that were further developed into interesting insights.

With rational expectations, the UIP states that the exchange rate change between period $t$ and $t+n\left(E_{t+n}^{e}-E_{t}\right)$ equals the interest rate differential $\left(i_{t}-i_{t}^{*}\right)$ plus an error term $\left(u_{t}\right)$ :

\footnotetext{
${ }^{23}$ This means that their errors have a mathematical average of zero: $E_{t+n}-E_{t}=\left(E_{t+n}^{e}-E_{t}\right) \mid I_{t-1}+u_{t}$ and $E\left(u_{t}\right)=0$.
} 


$$
E_{t+n}-E_{t}=i_{t}-i_{t}^{*}+u_{t}
$$

The empirical tests of the efficient market view thus test if, in Equation 3.21, a can be said to be statistically equal to zero, $b$ equal to 1 , and if the errors terms $\left(u_{t}\right)$ are independent (Plihon, 2010). If this is the case, there is no possibility of higher returns by investing in a foreign country and the exchange rate is determined only by the expectation errors of investors which are only temporary (Prates, 2015).

$$
E_{t+n}-E_{t}=a+b\left(i_{t}-i_{t}^{*}\right)+u_{t}
$$

As expected, these assumptions were rejected by most econometric tests (see MacDonald (2007)), which supports the existence of a risk premium - leading to the emergence of the risk-premium puzzle. Two main explanations for the "puzzle" emerged: a reason for asking for a risk premium might indeed exist, or agents' expectations were not rational. There are two main reasons for the risk-premium: the instability of a currency (Giovannini and Jorion, 1989) or the position of the currency on the hierarchical international monetary market (Frankel and Froot, 1985) - a hypothesis developed in details by the heterodox literature featured in Section 3.3.4. The rejection of the efficient market hypothesis could also indicate that agents are not rational. This hypothesis was further developed by the authors who later created models composed of heterogeneous traders with bounded rationality (discussed in Section 3.1.5).

These studies criticize the efficient market hypothesis that prices always reflect fundamental values by arguing that this is not compatible with fast changing prices. As put by Westerhoff et al. (2009),

The efficient market hypothesis states that prices always reflect their fundamental values. Hence, price changes are due to unexpected fundamental shocks. Clearly, if we observe an exchange rate movement by five percent, then this should correspond to a five percent shock in the fundamentals. Given also the fact that exchange rates change on a second-to-second basis, it is difficult to imagine where all these fundamental shocks should come from. (p. 2) 
These models were criticized when the main features of exchange-rate return distribution (the fifth puzzle) were brought to attention, as the features they reproduced were only partially coherent with what was empirically observed: though they were non-stationary, they were also not simultaneously volatile, random, and with clustered volatility (Lux and Marchesi, 2000). However, these criticisms came later, and the efficient market view of exchange rates profited from relative success at the time (Prates, 2015) ${ }^{24}$.

Despite the fact that exchange rate behavior created in the models only partially fits reality, the main problem with the efficient market view of exchange rates remains its unrealistic hypotheses of an intrinsic value, of rational expectations, of the UIP, and of different country assets as perfect substitutes. Though it allowed for the emergence of interesting discussions over the reasons behind country risk-premiums, it cannot explain exchange-rate dynamics.

\subsubsection{Rational speculative bubbles}

Other important New-Classical models are the rational speculative bubbles, that aimed at explaining markets' development in the 1980s, addressing the puzzle on the exchange rate determination. According to these models, the exchange rate $(E)$ deviates from its equilibrium (meaning market-clearing) value $\left(E^{*}\right)$ due to speculative bubbles $(B)$ (as in Equation 3.22) without relaxing the hypothesis of rational agents and efficient markets: if rumors lead agents to expect an exchange-rate appreciation, their trading creates appreciation, and a bubble. At some point their expectations would change and destroy the bubble, but the fact that expectations were correct (because they were self-fulfilling) is in line with the efficient market hypothesis: that the markets had correctly anticipated the appreciation ${ }^{25}$.

$$
E=E^{*}+B
$$

\footnotetext{
${ }^{24}$ Prates (2015) highlight the potential reasons behind this success: i) they proposed to solve the first exchange rate puzzle, namely the exchange rate determination puzzle, or why exchange rate behavior was a random walk; ii) the role of expectations could not be further denied with financial globalization iii) the new-classical school's rational expectation hypothesis was the mainstream at the time.

${ }^{25}$ Plihon (2010) stresses that markets cannot be efficient given that not all information was taken into account - in the case of the 1980s, agents overlooked the increasing twin (budgetary and external) deficits in the US (showed by Krugman (1985)). Had it been analyzed, the expectation of appreciation would not have been built.
} 
The use of the rational bubbles hypothesis to exchange rate analyses relies on the same assumptions of other efficient market views: efficient markets and rational agents.

\subsubsection{Third-Generation Models (New Keynesians)}

\subsubsection{New open macroeconomics}

The third generation models maintain the hypothesis of rational expectations, but allow rigidities to take place resulting in exchange rates that do not follow fundamentals. These are dynamic models, with maximization of utility and representative agents. They can therefore be called New-Keynesian (Prates, 2015) ${ }^{26}$. They claim to be an alternative to the Mundell-Fleming models (Lane, 2001) - reflecting their closer methodological ties to the eynesian models that emerged before the collapse of the Bretton Woods system than to the Monetarists (Section 3.1.2.1) and the New Classical (Section 3.1.3) models that followed.

Lane (2001) presents the redux exchange rate model of Obstfeld and Rogoff (1995), considered to be the one that initiated this research program ${ }^{27}$. The model makes the relevant hypothesis already discussed on the law of one price and the PPP. It is a two country model with farmers and no capital. It involves the utility functions of farmers that include leisure and the disutility of work effort. Farmers have access to riskfree international bond markets where interest rates are constant. Agents make "optimal choices of consumption, money holding, labor supply" and set their "optimal output price."

Once the steady state of the model is calculated, the authors examine the impact of an increase in money supply (also known as Dornbusch's shock) on welfare. The result is: shock has output effects, and while farmers of one country work more, home and foreign welfare are raised by the same amount, as "the extra revenue is exactly canceled out by the increase in work effort" (Lane, 2001, p. 239).

Lane (2001, p. 240) states the superiority of this framework: "The surprising result that both countries gain equally from an unexpected domestic monetary expansion illustrates the

\footnotetext{
${ }^{26}$ New Open Macroeconomics is defined by Lane (2001, pg.1) as a "new workhorse model for open-economy macroeconomic analysis" that has, as a unifying feature "the introduction of nominal rigidities and market imperfections into a dynamic general equilibrium model with well-specified microfoundations."

${ }^{27}$ Also see Obstfeld and Rogoff (2000) and Obstfeld (2002).
} 
utility-based evaluation offers a non-trivial advantage over traditional ad-hoc loss functions", but acknowledges that the results are highly sensitive to "the precise denomination of price stickiness, the specification of preferences and financial market structure" and concludes that, for these reasons, they should not be used for policy recommendations ${ }^{28}$.

The inappropriateness of these models for exchange-rate dynamics is not due to the sensitiveness of results, but to the unrealistic characteristics they feature on both assumptions - no capital, the law of one price and PPP - and on results - an increase of domestic money supply triggers a fall of the world's real interest rate. Therefore, the inclusion of rigidities has not yielded any further gains on the understanding of exchange-rate dynamics than what the keynesian models had provided. If the latter were said to lack capital account considerations (except for Mundell Fleming), New Keynesian models with no capital (such as Lane's (2001)) are certainly not able to tackle the issue.

\subsubsection{Fourth-Generation Models (Micro-Structure)}

According to Prates (2015) the fourth generation label groups exchange rate models that have abandoned the hypothesis of a representative agent, but are still orthodox for assuming ergodicity - which allows for the use of stochastic models. In these models, the focus is on the micro-structure of FX markets and their participants.

The shift of focus from the mainstream to the microstructure of FX markets is closely tied to the failure of all prior models, that were focused on the role of macro aggregates, and their inadequacy to solve exchange rate puzzles. This is clear in Flood and Rose's (1995) analysis. After presenting what became known as the excess volatility puzzle, Flood and Rose (1995, p. 22-23) conclude that "future research should shy away from macroeconomic fundamentals, and concentrate on more microeconomic detail" (p. 21). Krugman and Miller (1993) introduced stop-loss traders into a model of FX markets, arguing that the microeconomic focus may well provide a future rationalization for the phenomenon of regime-varying volatility.

\footnotetext{
28 "For this reason, any policy recommendations emanating from this literature must be highly qualified. This is an issue of some concern, since the new open economy macroeconomics will be of only limited interest in policy circles unless researchers converge on a 'preferred' specification that is buttressed by extensive supporting empirical evidence. For all that, the many unanswered questions that remain should ensure that this burgeoning field is likely to grow yet further in the coming years" (Lane, 2001, p. 262).
} 
There are two main types of Micro-Structure models: one focused on the flow of buying and selling orders in FX markets (such as Evans and Lyons (1999)) and the other on explaining the behavior of these markets' agents by taking insights from behavior economics (most of which followed De Grauwe and Grimaldi (2006a)). They are presented below.

\subsubsection{Order flow models}

The "order flows models" greatly differ from previously proposed models. Instead of focusing on variables that could directly determine exchange rates (such as money supply on monetary models) or on variables that affect agents' decisions and thus the exchange rates (such as interest rates on portfolio models), order flow models use either orders themselves in their analyses, or the flow of orders of buying or selling foreign exchange ${ }^{29}$. Methodologically speaking, these models present themselves as alternative to the macro-based models that empirically failed, and superior to previously presented alternatives: rational bubbles and irrational agents (Evans and Lyons, 1999) ${ }^{30}$. The framework admits analyses of future markets, as done by Klitgaard and Weir (2004) - however, this it still incomplete, because it does not include the interactions between spot and future markets (Prates, 2015).

Order flow models are successful empirically. Evans and Lyons (2005, p. 1) provide a micro-based model and compare it to both "a standard macro model" and a random walk. Its forecast power is far superior to that of other models (Evans and Lyons, 2005). Their model explains exchange rates from flow of orders and interest rates - an odd combination of the orders themselves and one of their potential determinants (interest rates).

Despite their empirical success, these models have a major limitation: as they do not explain what determines flows, they cannot explain what the determinants of exchange rates

\footnotetext{
${ }^{29}$ In the words of Evans and Lyons (1999, p. 2): "Order flow is a measure of buying/selling pressure. It is the net of buyer-initiated orders and seller-initiated orders. In a dealer market such as spot foreign exchange, it is the dealers who absorb this order flow, and they are compensated for doing so."

${ }^{30}$ As put by Evans and Lyons (1999, p. 1): "If determinants are not macro fundamentals like interest rates, money supplies, and trade balances, then what are they? Two alternatives have attracted attention. The first is that exchange rate determinants include extraneous variables. These extraneous variables are typically modeled as rational speculative bubbles (...) A second alternative to macro fundamentals is irrationality. (...) On a priori grounds, many economists find this second alternative unappealing. Even if one is sympathetic to the presence of irrationality, there is a wide gulf between its presence and accounting for exchange rates empirically. Until it can produce an empirical account, this too will remain an unconvincing alternative."
} 
are. In other words, if we consider that orders are not simply exogenous, it is their determinants that are of interest, and not the orders themselves (Williamson, 2009). In Evans and Lyons (1999), this paradox is clear. The authors claim their study "produces $R^{2}$ statistics above 50 percent" and concludes that for the DM/USD spot market " 1 billion of net dollar purchases increases the DM price of a dollar by about 1 pfennig" - a conclusion that does not add to our understanding of exchange rates determination. They might however prove interesting for central bankers in fine tuning their interventions. The direction of causality, from price to quantities or vice versa, is also an interesting question. Gradojevic et al. (2008, p. 1, italics added) argues that "financial order flow appears to contemporaneously drive the $\mathrm{CAD} / \mathrm{USD}$ while commercial order flow seems to contemporaneously respond to exchange rate movements".

An interesting part of the order/flow approach could be the study of how orders are determined (already suggested rather early by Evans and Lyons (1999)). Gradojevic et al. (2008, p. 20), for instance, analyzes the impact of economic announcements on order flow concluding that: "Several types of U.S. economic announcements housing starts, leading indicators, PPI, CPI and trade balance influence order flow to a statistically significant degree". However, is it an order flow model? Or does it study the importance of news on exchange rate as others that focus on the role of unexpected announcements ${ }^{31}$ on fundamentals or "macro surprises"? 32

If order flows models have limited contributions to our understanding of exchange rate determination, on the methodological front, it is interesting to see that it is a mainstream model that significantly diverges from its peers by completely shifting the focus away from real variables and long-run relations (Harvey, 2009).

\subsubsection{Behavior economics and heterogeneous agents}

The second body of literature that examines the microstructure of FX markets is the one developed from insights of behavior economics, more specifically, from the behavioral heuristic

\footnotetext{
${ }^{31}$ According to the efficient market view of exchange rates, unexpected announcements would cause a deviation as it is not part of the informational set available when decisions were taken.

${ }^{32}$ The author compares his own work to others that study announcements, such as Christie-David and Chaudhry (2001) and Han et al. (1999).
} 
approach of Kahneman and Tversky $(2000)^{33}$. Three heuristic principles that influence how a person makes decisions are relevant from this literature: availability, representativeness, and anchoring.

Availability refers to agents according more weight to most recent events. Representativeness relates to agents' search for causality between two events (especially if they are similar), when both could be the result of a random event. Anchoring relates to how people form expectations about future events: by anchoring any future revision of expectations on the first estimation.

By including these considerations on agents decision-making process (specially on their trading strategies), behavior finance relax the hypothesis of rational expectations. Instead agents would have "bounded rationality" 34 , a feature that would arise from empirical observation of real traders (Westerhoff et al., 2009). Heterogenous-agents models claim to be different from the order-flows models that assume bounded rationality ${ }^{35}$.

De Grauwe and Grimaldi (2006a) suggest a market composed of two types of agents according to their exchange-rate forecasting rule: chartist and fundamentalist traders. Fundamentalists always trade expecting exchange rate to go back to its fundamental value which, in turn, is determined by a stochastic process. Chartists, on the other hand, expect the future change in the exchange rate to be the same as the latest one ${ }^{36}$. This behavior would be related to an anchoring heuristic (Lavoie and Daigle, 2011) according to which agents' new forecast is based on their latest one. The market would, therefore, be composed of stabilizing (fundamentalist) and destabilizing (chartist) trader behavior. Ex-post, traders analyze the result of their operations and choose a new strategy. Thus, the amount of

\footnotetext{
${ }^{33}$ For an overview of their findings in a non-academic text, see Kahneman (2011).

${ }^{34}$ According to Dequech (2001, p. 912-913), bounded rationality is usually used to denote the type of rationality that people resort to "when the environment in which they operate is too complex relative to their limited mental abilities"; due to bounded rationality, "the decision maker adopts a 'satisficing' rather than an optimizing strategy". See also Dequech (2001) for an assessment on the notion of bounded rationality given fundamental uncertainty. Put by the author, "Simon's theory [of bounded rationality] assumes, even if implicitly, that an objectively defined optimal solution exists ex ante, although people may not be able to identify it. This assumption is incompatible with fundamental uncertainty, as unimagined and unimaginable new states may occur in the future, either through the intended or through the unintended consequences of people's actions."

${ }^{35}$ See Westerhoff et al. (2009) for criticisms done by these analyses on the efficient market hypothesis.

${ }^{36}$ Note that the chartist behavior is coherent with only part of the trading rules seen in FX markets, notably the trend-following rules. Section 3.3 will discuss the works of Schulmeister and Harvey that analyze different traders' behaviors.
} 
chartists and fundamentalists is constantly changing. The model result in multiple equilibria and path dependence (Priewe, 2014) ${ }^{37}$.

On the empirical front, models with heterogenous agents were able to respond to the exchange-rate return puzzle. For instance, Lux and Marchesi (2000, p. 675) (a multi-agent framework of speculative activity) can predict the statistical phenomenon of exchange rate returns ("unit roots in levels together with heteroscedasticity and leptokurtosis").

Although models based on heterogenous agents and behavior finance seem to have broadened the mainstream literature for relaxing the rationality assumption, there is a discussion on whether their agents are really far from the traditional rational model (see Frydman (2008), as cited in Kaltenbrunner (2011)). Instead, these models would still adhere to rational expectations and to an ergodic world where the exchange rate is a market-clearing price that has a fundamental value that agents know. A second criticism is that they seem to be constructed for spot exchange rates of advanced countries, although they do not make any reference to the institutional context they aim at explaining ${ }^{38}$ (Kaltenbrunner, 2011).

\subsubsection{Fifth-Generation Models}

\subsubsection{Carry trade}

The exchange rate models grouped as fifth-generation models aim at answering the forward premium puzzle. The question involved is how carry trade operations could be profitable and how the uncovered interest rate parity could hold, simultaneously. As seen in Section 3.1.1.2, the UIP states that an investment in fixed income in different countries should be the same when measured in one currency (as in Equation 3.4, reprinted below), or that interest rate differential should equal the exchange rate change, as in Equation 3.23:

$$
\begin{aligned}
& i^{* e}=i^{e}+e \\
& i^{* e}-i^{e}=e
\end{aligned}
$$

\footnotetext{
${ }^{37}$ See Kaltenbrunner (2011) for a review of the behavior view on exchange rates.

${ }^{38}$ Also in Kaltenbrunner (2011), see the review of another strand of the literature that maintains the assumption that agents are fully rational, but acknowledges that they might not have full knowledge of the underlying structure of the economy, the imperfect knowledge economics.
} 
A carry trade, on the other hand, is an investment strategy based on borrowing in a low interest rate currency and investing in a higher interest rate currency (as seen in Chapter Two). Therefore, it is a bet that "the exchange rate will not change so as to offset the interest rate differential" (Galati and Melvin, 2004, p. 69). It is represented by Equation 3.24. If $i^{*}$ is the interest rate of the target currency and $i$ is the (lower) return paid by the funding currency, a successful carry trade operation is one where the interest rate differential is big enough to accommodate a possible depreciation of the target currency $(\uparrow e)$.

$$
i^{*}-i>e
$$

The very existence of carry trade operations (that is widely documented, as seen in Chapter Two) is therefore an evidence that the UIP does not hold ${ }^{39}$. Brunnermeier et al. (2008) argues that the UIP does not hold due to transaction costs: "the presence of transactions costs and price pressure limits the size of the bets that agents choose to place on these strategies". This argument also features models of the third, fourth and fifth generations (transaction costs are seen as market imperfections). However, transaction costs tend to be small in large financial operations. The authors also argue that, while there is evidence that UIP does not hold, the amount of money that can be made from this "failure seems relatively small". This contradicts the estimations done by UNCTAD (2007) and the Galati and Melvin's (2004) argument that carry trade is the reason behind the major surge in FX markets.

The fourth and fifth generations of models reflect the need to account for features that are manifestly important for exchange rates - especially volatility. While they do not account for all of the financialization-related characteristics, they add features that improve the characterization of speculation, better reflecting the current FX markets. Specifically the modeling of carry trade reflects international markets in the early 21st century. However, the analyses of these fourth and fifth generation models are based on restrictive hypotheses

\footnotetext{
${ }^{39}$ The yields of "currency speculation" would also not be due to country risks. As put by Burnside et al. (2006, p. 23): "in this paper we document that implementable currency-speculation strategies generate very large Sharpe ratios and that their payoffs are uncorrelated with standard risk factors". Note that Sharpe ratios are broadly used in financial markets to estimate the excess amount of returns that would have been due to a potentially different risk level. For examples of carry trade models, see Burnside et al. (2006) on developed-country currencies and its references Bansal (2000) and Lustig (2007) for analyses that include emerging markets.
} 
of homogeneous agents and rational expectations (Prates, 2015). They are able to reproduce exchange-rate features as volatility, but the use of unrealistic assumptions hinder these models from explaining how these feature emerge. Therefore, they offer no insight on exchange rate determination.

\subsubsection{Concluding Remarks}

As discussed in this section, mainstream models have gradually relaxed some assumptions, such as to consider different countries' assets as perfect substitutes (relaxed in portfolio models), to have static expectations (relaxed on behavioral models), and have tried to move away from rational expectations by adding imperfections (New-open economy models) or by considering only bounded rationality (behavior finance). This development might indicate an awareness that these models' empirical failures rely on their unrealistic and restrictive assumptions.

In portfolio models they are presented most completely as the hypothesis of international assets as perfect substitutes is relaxed. Later, behavioral models presented a complex account of how expectations are formed in FX markets by relaxing the hypothesis of representative agents. Most recently, derivatives markets were also included in some models. At first sight, it could be concluded that these models are appropriate to the context of financialization: capital flows are considered, and so are their drivers, the expectations of participants and the sophistication of FX markets. However, these models are not able to account for the very dynamics of capital flows, that unlike trade flows, do not have, in exchange rates, a force pushing to equilibrium.

In a world with only trade flows, the exchange rate favors a movement of convergence (since Cassel (1916)): higher inflows lead to an appreciation of the domestic currency, rising the prices of its products, and, consequently, increasing their demand. Therefore, the exchange rate balances trade flows. However, the dynamics of financial flows are not the same. As a country receives more flows and its exchange rate appreciates, this appreciation increases foreign investors' total return with the country's assets, an incentive for further inflows. This is stronger in the flows to equity markets, where higher inflows increase total returns not only with the exchange rate appreciation, but also by pushing up stock prices (these dynamics 
are studied in Chapter Seven). Therefore, the exchange rate can be a destabilizing force for capital flows.

This specific dynamic of capital flows is not considered by the mainstream literature that has remained grounded to the (trade-related) view of exchange rates as a market-clearing price. The assumption is closely tied to that of rational agents. Even in behavioral models where agents are not considered rational, fundamentalist participants trade knowing the equilibrium (market-clearing) price and expecting the exchange rate to converge to this price at some point.

By considering the exchange rate as a market-clearing price, the mainstream models cannot account for the role of capital flows. Although their drivers and some of the characteristics of traders and of FX markets are considered, the resulting dynamics are not realistic, because the very exchange rate dynamic it aims at elucidating is taken as given in the assumptions. This preconception of the exchange rate as a market-clearing variable and the fact that these model "begins with the conclusions" is seen by Harvey (2001, p. 13) as the "greatest obstacle to understanding currency price determination".

In conclusion, although the most recent models consider some features for analyzing exchange rate analyses in times of financialization, the fact that the exchange rate is exante assumed to clear markets and to converge to equilibrium and market-clearing, reflects a non-consideration of the very characteristics of capital flows - and these characteristics are intensified with financialization. Lacking realistic assumptions, most of these models cannot explain exchange rate determination (as seen by their empirical failure) and those that apply the empirical features do so without explaining the forces behind the exchange rate determination.

The assumption of exchange rates as a market-clearing price has also been rejected for other arguments. Weeks (2012, p. 2) stresses that the notion of equilibrium exchange-rate is based on general equilibrium and its hypothesis (full employment and instantaneously adjusting prices under perfect competition). However, if "one does not accept the analytical validity of Walrasian outcomes, the 'equilibrium exchange rate' and a 'distorted exchange 
rate' are irrelevant." ${ }^{40}$. Taylor (2004, p. 210) also has an insightful remark: how could the exchange rate simultaneously clear two markets (capital and current accounts) that "have their own separate determinants?" (this will be further developed in Section 3.3.5).

Apart from the fundamentals, the models analyzed are also flawed because they are presented as general truths, valid for any country, regardless of their institutional settings. This is not as strong in the exchange rate crisis models (presented in the next section), in which induction plays a larger role, for they are built based on the observation of specific events. It is however in heterodox approaches (presented in Section 3.3) that interesting insights from context-specific analyses are provided.

\subsection{Exchange-Rate Crisis Theories}

A different strand of exchange rate theory is dedicated to crises. These models emerged in the 1980s after speculative attacks against the U.S. dollar, and continued with the crisis of the European Monetary System (EMS) of the early 1990s, and the different crises that affected some EMEs in the late 1990s and early 2000s. Since then, EMEs have been opting for (de jure) floating regimes, but the detachment from fixed regimes has not put an end to the exchange rate turbulence. Although of smaller magnitude and with different implications, the major exchange rate changes observed in some of these countries should be treated as crisis ${ }^{41}$. Could these models enlighten our understanding of emerging currencies behavior during the Global Financial Crisis and the Euro crisis even though they were built for fixed exchange rate regimes? This section reviews the main models proposed guided by this question.

\footnotetext{
${ }^{40}$ It is worth highlighting that regardless of accepting the assumptions of an equilibrium exchange rate, one can still analyze whether an exchange rate level is appropriate or not. Such analyses also concern real exchange rates, but instead of assuming equilibrium in the market-clearing sense, they focus on estimating what we could call "development-oriented" exchange rates. Similarly as the mainstream estimations of real exchange rates, these are also not far from the policy stance: they are frequent in developing countries where the central bank intervenes in FX markets and where there is a question on the appropriate exchange rate level, or on what the central bank should target. Bresser-Pereira (2008, p. 1) discusses an industrial exchange rate, "the one that make viable efficient tradable industries" given the importance of the manufacturing industry for development (as seen during the twentieth century). In Frenkel and Rapetti's (2014) discussion, the call for a stable and competitive exchange rate derives from the importance of high-productivity (that are largely tradable) activities for development and of the role of the exchange rate on trade. Weeks (2012) also estimates a real exchange rate with a focus on trade-induced development as seen by his measures only including trade-related concerns: "purchasing power parity, trade weighted, export competitiveness, import competitiveness, and the ratio of tradables to non-tradables".

${ }^{41}$ The frequency and magnitudes of these exchange rate crises are presented in Chapter Six. Their implications in policy making is discussed in the Introduction.
} 
If the recent theories of exchange rate determination emerged in close dialogue with empirical works that questioned the validity of precedent theories, crisis' analyses tracked these events always considering an added element relevant to the new crisis that had not been considered by prior models. As put by Eichengreen et al. (1994), each wave of crises elicit a new style of model. Or, from another point of view, every model is one crisis too late Plihon $(2010)^{42}$.

There is consensus in dividing the literature in three generations of models : Eichengreen et al. (1994) introduced the "first generation" and "second generation" labels and Krugman (2001a) refers to the models dealing with the 1990s crises in Asia as "third generation". This is the categorization used in this section.

\subsubsection{First-Generation Models: Speculative Attacks}

The canonical model of the first generation is Krugman $(1979)^{43}$, whose motivation are the attacks against the U.S. dollar in the late $1970 \mathrm{~s}^{44}$. In the following models, country fundamentals - fiscal and monetary policies - and central bank's reserves play a crucial role. As Krugman (1979) highlights, with a growing current account deficit and worsening fundamentals a country's reserves level become inadequate to maintain the exchange rate peg. The situation is unbearable: "at some point" there will be a sudden speculative attack eliminating the last of the reserves, demanding an exchange rate devaluation to restore equilibrium. In Krugman's (1979) words: "When the government is no longer able to defend a fixed parity because of the constraints on its actions, there is a 'crisis' in the balance of payments" (p. 311). The author also considers that the government might find extra reserves (from gold or a loan), regain the market's confidence, and postpone the speculative attack, but the attack will take place - it is a model of a unique equilibrium.

Methodologically, Krugman (1979) is a simple model with one good and two assets (domestic and foreign money). Most of the model is taken from Kouri (1976). It has

\footnotetext{
${ }^{42}$ Given that economists have been too late, it is important to discuss the next crisis model. To my knowledge, there has been no study on models focused on the GFC as a coherent body of literature, indicating common points of this crisis. For a discussion on what could be the fourth generation model, that was done before the GFC, see Krugman (2001a).

${ }^{43}$ Another important first-generation model is Flood and Garber (1984).

${ }^{44}$ Krugman (2001a, p. 1) specifically indicates that his motivations in the 1970s were "the speculative attacks that brought down the Bretton Woods system in 1971 and the Smithsonian system in 1973."
} 
restrictive assumptions, such as perfect foresight. It is a balance-of-payment-crisis model with only a current account ${ }^{45}$. This sheds light in the focus of current account dynamics of this "balance of payment" model. The restrictiveness of the hypothesis is acknowledged by Krugman, who, however, does not see it as a limitation to the analysis: "The model involves many special assumptions, and no claims are made for its realism. But it should become clear later that the main points of the analysis would go through in a variety of models" (Krugman, 1979, p. 313).

Thus, it is a model of a balance-of-payments "problem" that, due to a speculative attack become a balance-of-payment "crisis" that obliges an exchange-rate adjustment. Ultimately, the government is responsible for the crisis, that followed their "inappropriate domestic policies" (Obstfeld, 1986, p. 72) 46 $^{46}$ It is interesting to highlight that the label of "balance-ofpayments crises" was later substituted by the "first-generation crises" label. Along with this change, the models began to be more frequently associated to fiscal disequilibrium rather than to external deficits (the balance-of-payment problem). Such shift might be due to the lack of external disequilibrium in (most of the) future cases of crisis.

\subsubsection{Second-Generation Models: Self-Fulfilling Speculative Attacks}

If the first generation models analyzes whether a fixed exchange rate suffers an speculative attack if policies are deemed as unappropriated, those of the second generation are known for alerting that such attacks can occur in a simple, self-fulfilling way, even in the absence of (fiscal and monetary) problems evoked by first-generation models.

Such arguments are first found in models by Obstfeld (1986) and Flood and Garber (1987), but most of this generation's models emerged in the aftermath of the European monetary system crisis, that occurred a few years later, in 1992/93. Indeed, the first and second generations' labels emerged with Eichengreen et al. (1994) ${ }^{47}$, almost a decade after the first two models. The authors differentiate them, respectively, by the "early contributions

\footnotetext{
${ }^{45}$ See Prates (2005b) for a critical analysis of the different hypothesis). There is also no capital account.

${ }^{46}$ As put by Obstfeld (1996, p. 1039, italics added), in these models "a fixed exchange rate contains inflationary pressures which ultimately explode in a sudden balance-of-payments crisis that frees the currency to depreciate."

${ }^{47}$ Before the consensus on the generation categorization, the first generation models were referred to as "balance-of-payments literature" (Obstfeld, 1986, p. 72), "classical theories of rational speculative attack" (Obstfeld, 1996, p. 1039), or simply speculative attacks model (Jeanne, 1996)
} 
to the speculative attack literature" and the "models of self-fulfilling speculative attacks and multiple equilibria in foreign exchange markets" (p. 1-2), arguing that the latter provide an alternative interpretation that better fits the EMS $\operatorname{crises}^{48}$. As a result, the second-generation label is found as a reference for every model that studies the possibility of self-fulfilling crisis, and also as a specific reference to the models that examine the EMS crises ${ }^{49}$.

The models that later became known as second-generation models differ from earlier ones for considering the possibility of speculative attacks that are simply self-fulfilling, not based on bad fundamentals (Jeanne, 1996). It is exactly for not relying on problems with fundamentals that these models are relevant to the context of the SME crises - that took place in countries that did not exhibit any sign of problem ${ }^{50}$; in other words, their success is based on the suggestion that "even sustainable currency pegs may be attacked and even broken" (Obstfeld, 1996, p. 1038).

Obstfeld's early model Obstfeld (1986) compares balance-of-payment crisis with bank runs (in the style of Diamond and Dybvig (1983)), where the result involves "self-fulfilling expectations because banks fail if, and only if, there is a run" (p. 70). Unlike bank runs, balance-of-payment crisis need not be self-ratifying. Instead, they are dependent on expectations relating to authorities' responses. The model, therefore, does not imply that crises are necessarily self-fulfilling; they are only potentially self-fulfilling, effectively taking place only if there is an expectation of change of government policies ${ }^{51}$. In this model, the risk of

\footnotetext{
${ }^{48}$ To be precise, Eichengreen et al. (1994, p. 2) write that they are better fits than the first-generation models, but they do not necessarily fit the event.

${ }^{49}$ Indeed, Obstfeld (1986) is mentioned as a a second-generation model by most of the authors surveyed in this chapter. Prates (2005b) precises that this model (together with Velasco (1987, as citet in Prates (2005b)), is an intermediary model that planted the seeds of the second-generation models - a label she uses as reference to the models that followed the EMS. Jeanne (1996) uses a different categorization, differentiating models of speculative attacks due to bad fundamentals, as Krugman (1979), or self-fulfilling, as Obstfeld (1986); and models that put emphasis on the dynamics that emerge from the fact that a monetary union has irrevocable escape clauses or not, as Obstfeld (1997) and Obstfeld (1996). The latter have more of an institutional focus, differently than Obstfeld (1994) that focuses on government policies.

${ }^{50}$ Krugman (2001a, p. 5) argues that there were no inappropriate policies "in any of the countries involved". More specifically, Eichengreen et al. (1994, p. 3-4) cites references to two strands of the literature, one that emphasizes the "unsustainable policy stances of weak-currency countries" and another that argues that "for several countries concerned, the evidence of lax policies is far from compelling."

${ }^{51}$ Krugman (2001a, p. 6) argues that there is a discussion on whether the second-generation crisis are selffulfilling or not: "There is a question about whether second-generation models necessarily imply that crises are self-fulfilling, or for that matter whether self-fulfilling crises can occur for first-generation reasons. However, the general thrust of the second-generation models is toward the idea that crises may occur suddenly in situations where no crisis seemed inevitable." In Obstfeld (1986, p. 79) the fact that they are only potentially self-fulfilling is clear: "Balance-of-payment crisis, unlike bank runs, need not be self-ratifying. The stability
} 
a self-fulfilling crisis is eliminated if the central bank implements a policy "which implies an exchange rate appreciation" (Eichengreen et al., 1996, p. 11). It is therefore a model with more than one equilibria: with and without crisis, dependent on the government's response, while in Krugman (1979) the speculative attack results in a unique equilibrium, crisis.

Post-EMS-crises models The crises of the EMS raised questions about the power of the models of speculative attacks à la Krugman (1979) to explain the fact that sound currencies could also suffer attacks (Jeanne, 1996). Indeed, the fact that (at least some of) these currencies were sound generated a common assessment of these crises as unexpected. In these exercises of explaining the EMS crises, the models have broadened the understanding of fundamentals, from exclusively focusing on fiscal and monetary policies, to including a large set of circumstances that might affect the stability of an exchange rate peg - because, as put by Flood and Marion (1998, p. 1), "the governments' commitments with a fixed exchange rate is constrained by other policy goals". In this sense, these models incorporate as fundamentals variables that might impact expectations about future monetary policies, such as unemployment rates, monetary policies in other countries that are part of the same exchange rate system (Jeanne, 1996), public deficit, and banking system situation (Prates, 2005b).

The diversity of variables considered reflect these models' focus on the expectations regarding the governments' response. Indeed, following Obstfeld (1994), these models emphasized facts that determine a government's decision to abandon or not a peg, given that the speculative anticipations depend on the expectations relating to government's responses. Note that, since Obstfeld (1986), it is the expectation about government policies that create the multiple equilibria (crisis or not), and differentiate these models from those of the firstgeneration. As highlighted by Prates (2005b), a major contribution of Obstfeld (1986) in relation to first-generation models is indeed the consideration of agents' expectations about government policies (as opposed to the absence of expectations of the first models).

of a peg-regime hinges on the anticipated response of the authorities." But as Krugman puts it, the focus of reviews of this model is that crisis can be self-fulfilling, differently than in the first-generation models. 
Insights from the second-generation models As these are models of fixed exchange rates, expectations are focused on the government's decision as they define the future exchange rate path. Of relevance for investors and, thus, of ultimate importance, is the anticipated exchange rate path. As highlighted by Jeanne (1996, p. 158), these are actually models of contagion of expectations: If there is no problem with a currency, it can suffer an attack only if agents expected an attack to occur. This is also relevant for floating regimes because even with no peg to defend, agents will "attack" if they believe that the value of a currency will change. The expectations of FX market participants is deeply analyzed by heterodox authors, such as Harvey, and the specific role of the expected future exchange rate path for emerging currencies is discussed by Andrade and Prates (2013) (as presented in Section 3.3).

Jeanne (1996) highlights the point that these models suggest an interesting circularity between market expectations and economic policy: The credibility of a rate depends on the government's determination to defend it, which, in turn, depends on the rate itself - if it is not convincing (for instance, very overvalued) it imposes important costs on the government to defend the rate and, thus, it is less likely to be carried on. Such circularity is also observed in cases of flexible exchange rate regimes. When a government intervenes in a sizable exchange rate change, it signalizes to the market that this movement might not continue, which may hinder (or attenuate) a speculative attack by raising doubts about the future exchange rate path. This is indeed a potential impact of capital controls ${ }^{52}$.

\subsubsection{Third-Generation Models: The Balance-Sheet View}

The Asian crisis in the late 1990s led to the evolvement of the mainstream literature (Prates, 2005b). Indeed, the episodes could not be explained by the incompatibility of monetary and fiscal policies and external position (as in the first-generation models), nor were they marked by inappropriate policies in a larger sense that would raise expectations of change of governmental policies (as in the second-generation models). In addition, these currency crises were characterized by the collapse of both the exchange-rate system and the domestic

\footnotetext{
${ }^{52}$ Capital controls, including the expectation channel are discussed in Chapter Seven. Ramos (2010) argues that this channel was effective in capital controls imposed by Brazil in 2009 as the expectations of future exchange rate change of domestic financial market participants changed with the announcement of the policy.
} 
banking systems (Prates, 2005b), and the depreciation of the nominal exchange rate became "more a symptom than a fundamental aspect of these crises" (Krugman, 2001a, p. 8). Accordingly, third-generation models are not limited to exchange-rate crisis, but aim at indicating a broader dynamic of financial instability (Plihon, 2010), especially by analyzing the characteristics of these countries banking or financial systems ${ }^{53}$.

Third-generation models are varied, the first two generation labels aggregating more coherent models (Krugman, 2001a). While some focus on moral hazard, others emphasize the role of panic and runs (similarly as bank runs) in financial markets. There are others that combine both aspects (Prates, 2005b) $)^{54}$.

Krugman (2001b) is an example of considerations of both government inappropriate actions and the behavior of external participants. His analysis claims that due to poor regulation of financial intermediaries, there is moral hazard and overpricing of risky assets, leading in only an apparently better financial condition of the intermediaries. Although these government-led distortions are the focus of his analysis, Krugman also mentions that foreign institutional investors and their herding behavior have some explanatory role to play ${ }^{55}$.

Over-investment fueled by external credit is also the subject of Kaminsky and Reinhart (1999) who argue that these crises were associated with the banking crisis that takes place when an economy enters a recession after a period of boom fueled by credit, capital inflows,

\footnotetext{
${ }^{53}$ In this sense, Dornbusch (2001) distinguishes two types of models: the old style crisis, related to macroeconomic disequilibrium and real exchange rate distortions, and new style balance sheet crisis, related to the vulnerabilities of the banking system. Similarly, Krugman (2001a), underscores the fragility of the banking system and of financial markets' imperfections.Krugman (2001a) concludes that the third-generation models present "the balance-sheet view". It is important to highlight the author's critique that some models might have overseen the real side. To cope with this, the author presents a model that includes the balance-sheet considerations to a simple Mundell-Fleming model (discussed in Section 3.1.1.4). By accounting for the impacts of balance-sheet constrained firms on investment and aggregate demand, the model presents an alternative explanation for crisis: "Something - it could be anything - causes a sudden large currency depreciation; this depreciation creates havoc with balance sheets; and the economy plunges into the crisis equilibrium." This model is however different from the others for focusing on the effects of a currency depreciation, without looking at what causes the exchange rate crisis.

${ }^{54}$ Given these differences, Prates (2005b) divides the third-generation models into three groups. The first associates the Asian crisis with moral hazard that would have emerged from government guarantees. In these models the problem thus arises from inappropriate public policies, as in the first-generation models. The second group focus on the panic in financial markets and self-fulfilling expectations of foreign investors. Analysis of the third group of models would include considerations on both moral hazard and panic as Schneider and Tornell (2004, as cited in Prates (2005b)).

${ }^{55}$ As Krugman (2001b, p. 325) puts: "Finally, it is clearly wrong to blame all of the overinvestment and overvaluation of assets in Asia on domestic financial intermediaries. After all, private individuals - and foreign institutional investors - did buy stocks and even real estate in all the economies now in crisis. This suggests that other kinds of market failure, notably "herding" by investors, still have some explanatory role to play."
} 
and an overvalued currency. The problems in the banking sector would typically precede a currency crisis that, in turn, deepens the banking crisis, creating a vicious spiral.

These are examples of a group of third-generation models that, similarly to the ones from the first generation, recognize the roots of the crises in the government and its guarantees to the residents' liabilities. These would result in distortions to markets' workings, triggering an unsustainable inflow of capital in a context of insufficient regulation and banking supervision (Prates, 2005b),

However, there are also third-generation models whose main point in explaining those crises is on the dynamics concerning foreign investors, as in Chang and Velasco (2001). This model applies Diamond and Dybvig's (1983) bank run model to the open economy context of the Asian crisis, in a mix of a run from domestic agents and panic of foreign investors ${ }^{56}$. As Chang and Velasco (2001) argue, an illiquid position ${ }^{57}$ of domestic banks make them vulnerable to movements of panic of foreign investors (through withdraws or halt of debt rollover). This vulnerability might transform into a crisis or not, depending whether there are coordination failures. As in the second-generation models, these models have therefore more than one equilibrium possibility: crisis or not. In order to avoid this result, the authors conclude that governments should negotiate debt rollovers or reprogrammings. Moreover, this should ideally be coupled with "prudent macro policies, privatization, and other investorfriendly signals" (Chang and Velasco, 2001, p. 504).

Models of financial fragility Third generation models are also seen as models of financial fragility more broadly: Krugman (2001a, p. 2) sees these works as in the spirit of Bernanke and Gertler's (1989) "financial fragility" closed-economies models ${ }^{58}$, where fragility arises from the fact that funding costs are pro-cyclical, depending on the borrowers' balance-sheet

\footnotetext{
${ }^{56}$ The focus on the international sphere is so important that Chang and Velasco (2001, p. 491) even conclude that "financial liberalization may increase financial fragility and the incidence of crises even though it is ex ante welfare-enhancing".

${ }^{57}$ Chang and Velasco (2001, p. 490) define illiquidity as "a situation in which the financial system's potential short-term obligations exceed the liquidation value of its assets".

${ }^{58}$ As Krugman (2001a, p. 2) puts it: "third-generation currency crisis models are actually not very specific to currency crises: the mechanisms for speculative attack and self-fulfilling pessimism that these models identify, while they do make room for an Asian-style crisis in which capital flight leads to plunging currencies that validate the initial loss of confidence, also allow with small modification for other types of financial crisis. In particular, some third-generation crisis models are very close in spirit to the closed-economy "financial fragility" models of Bernanke and Gertler (1989)."
} 
(and net worth) ${ }^{59}$. It is a model in which most of the operations take place in the supply side of the economy (Fazzari et al., 2008) ${ }^{60}$. Also Chang and Velasco's (2001) model is a transposition of Diamond and Dybvig's (1983) domestic model of financial fragility to the open economy level.

The Minskyan closed-economy model of financial fragility has also been translated to the open economy environment to explain the Asian crisis - as Arestis and Glickman (2002) and Wolfson (2002), presented in Chapter Seven. These are obviously very different from the others in many respects, especially because they focus on the demand side and for concluding that fragility is endogenously built ${ }^{61}$.

This transposition of closed-economies models to the open-economy context in both mainstream and heterodox schools bespeak the impossibility of analyzing turbulence in financial markets as limited to a closed-economy context.

Insights from third-generation models The third wave of crisis models raises relevant points as to the vulnerability of countries to international investors that fueled a boom (Kaminsky and Reinhart, 1999), partially in a herd behavior (Krugman, 2001b), and that later stop debt rollover or withdraw (Chang and Velasco, 2001). However, these dynamics of the international financial system are not always considered the main cause of crises, and when that is the case, they derive from the government (whose policies are either distorted and create moral hazard, or lead to market distortions as coordination failures). Thus, because they attribute the crises to governments' decisions, these models are of little help in explaining the recent emerging currencies' crises, that were triggered by the GFC and the Euro crisis, which, surely, are not connected to EMEs' policies or market distortions.

\footnotetext{
59 "Business upturns improve net worth, lower agency costs, and increase investment, which amplifies the upturn; and vice-versa for downturns" (Bernanke and Gertler, 1989, p. 1).

${ }^{60}$ As a new Keynesian model, 'output deviates from its 'natural rate' as the result of nominal rigidity, and faster adjustments of wages and prices stabilize the system" (Fazzari et al., 2008, p. 2).

${ }^{61}$ The Minskyan framework differs greatly from the mainstream third-generation models. On the methodological front, it should be added that in Minskyan models "macroeconomic fluctuations are endogenous and display a true cyclical pattern with identifiable dynamic processes that cause turning points". They differ from New classical macroeconomic models for not relying on stochastic shocks and from New Keynesian models for focusing on the demand-, not the supply-, side of the economy (Fazzari et al., 2008, p. 2). A main result of the Minskyan models is that fragility is endogenous to the capitalist system and will be at higher or lower levels depending on the behavior of economic agents that interact with this system. When fragility is at high levels, the economy is susceptible to entering in a debt-deflation crisis if it is hit by any 'not-unusual' surprise.
} 


\subsubsection{Concluding Remarks}

Governments play a role in a crisis in all of the three generations of exchange-rate crisis models. In the first and the second generations, unappropriated policies (reflected in the fundamentals) lead to crises. In addition to that, in second generation models, governments fail to create the expectation that would ensure the stability of the peg. In the thirdgeneration models, governments are also co-responsible for crises, due to the policies and distortions they create. In an analysis of crises of fixed-exchange rates, the government is expected to have a more important role than in crises of floating regimes. Still, there are features of interest for analyzing recent emerging-currency crises.

The most interesting feature of these models is the role of the financial market participants' expectations: the fact that there is contagion of expectations, and that they are influenced by government's decisions - all features of second-generation models. Also interesting, is the consideration of financial fragility in an open economy level, rather than its being limited to the domestic sphere. Third-generation models are a step in this direction.

In fact, though EMEs were not at the center of the GFC and the Euro crisis, their currencies still depreciated sharply (Kohler, 2010). To be precise, this depreciation was not even a "symptom" (in Krugman's (2001b) words) of domestic financial markets, but a reflection of the problems of a foreign financial market. Therefore, in order to account for these crises, it should be considered that a currency might also fall into crisis from issues taking place in another country's "domestic" market.

Boyer et al. (2004) argued that with liberalization and financial globalization financial instability now results from systemic interactions between different asset markets ${ }^{62}$. As discussed in Chapter Two, different countries' assets markets are indeed connected through money managers' portfolio decisions. The funding conditions, related to where money managers' liabilities are, also have an impact on markets used to allocate the respective assets. In this sense, the network of money managers' balance-sheets can explain the contagion of a market to another, and of a currency to another because the exchange-rate, reflecting these

\footnotetext{
${ }^{62}$ Krugman (2001a, p. 2) also mentioned the interconnection of asset markets in explaining crises as potential characteristic of fourth generation models: “(...) a fourth-generation crisis model may not be a currency crisis model at all; it may be a more general financial crisis model in which other asset prices play the starring role."
} 
patrimonial changes, is always affected. In other words, "domestic" financial markets are tied to each other globally, and when one market is affected the exchange rate necessarily feels the shock.

EMEs and advanced countries are tied together, but the effects are not the same in the two groups of countries ${ }^{63}$ given the asymmetry of the international financial and monetary market $^{64}$ : the U.S. dollar market is too big for the USD/EUR or the EUR/GBP pair to be affected from a crisis in Brazil and changes in the USD/BRL transactions. Crises in the USD/BRL market will however affect any currency pair involving the BRL. Chapter Seven suggests an open economy Minskyan model to study the dynamics of floating emerging currencies where money managers play the central role.

In conclusion, the striking point from the review of the mainstream exchange-rate determination and crisis theories is the clear distinction between the two. The latter literature is a completely independent body of literature that neither references nor is mentioned in the former. There is, for instance, no mention of investors' beliefs on government policies or of financial fragility in the models analyzed in Section 3.1. Crises are also not explained with Dornbusch's overshooting model, nor as a development led by chartists. There is no such dichotomy in the heterodox literature, that will be analyzed next (nor in the model presented in Chapter Seven), in which most theories developed to explain exchange rate developments also account for crises.

\subsection{Heterodox Contributions to Exchange Rates}

As seen in Section 3.1, the mainstream literature is composed of several models that highlight the importance of different variables in determining exchange rates. These variables are referred to as the exchange rate fundamentals, or the drivers that result in exchange rates as

\footnotetext{
${ }^{63}$ Countries smaller than EMEs are not considered here for not being sufficiently inserted in the international financial markets (see the theoretical definition of EMEs in the Introduction, page 10 and see the operational definition in Chapter Four, page 142.

${ }^{64}$ This is discussed in the next section, page 105.
} 
the clearing price of foreign exchange ${ }^{65}$. Despite the discussion on whether fundamentals are "the" exchange rate drivers or not, and whether the exchange rate is a market-clearing price, the consideration of fundamentals inside financial circles, guiding investors' decisions, can make them the de facto drivers. For this reason, fundamentals also have a role to play inside the heterodox literature, that places investors in the center of its exchange rate approach. In this literature, however, fundamentals are mostly seen as a convention, a value, or a set of variables, that result from the social context.

Orléan presents a deep analysis of conventions in asset markets ${ }^{66}$. Specifically, the author highlights the fact that markets are guided by financial conventions that evolve through time. His analysis is presented in what follows. It is then followed by three meaningful heterodox contributions: i) the specific dynamics seen in FX markets by Schulmeister (in Section 3.3.2); ii) the functioning of investors 'mental model' by Harvey (in Section 3.3.3); and iii) the specificities of emerging currencies mostly by Andrade, Prates and Kaltenbrunner (in Section 3.3.4). Finally, the section discusses the use of SFC models as a framework to exchange rate analyses proposing ways to include some of exchange-rate features discussed by the PK literature in this framework (in Section 3.3.5).

\subsubsection{The Evolving Financial Convention}

Fundamentals as a convention based on Keynes' analysis of the beauty contest, Orléan proposes an alternative to the concept of rationality ofthe efficient market hypothesis: agents would be 'auto-referentially rational'. These are strategic investors, that trade according to

\footnotetext{
${ }^{65}$ The concept of fundamentals is very elusive in the mainstream literature, being at best, defined by examples such as inflation, money supply, foreign trade, interest rate differential, output, and income (Harvey, 2001, p. 10) - variables that might be seen as reference to PPP, UIP, the monetarist-, portfolio-, and the keynesian models. Fundamentals are also the very "set of variables guaranteeing the efficient operation of the foreign currency market" (Harvey, 2001, p. 4). To consider that drivers are also the variables making markets efficient, is seen by Harvey (2001) as an indication of the benign approach to markets of mainstream authors.

${ }^{66}$ Note that most of Orléan's work was carried to analyze stock markets. But given the focus on the decision of investors and their importance in determining exchange rates, stock markets and FX markets are simple, specific cases of financial markets, with similar dynamics. The most striking difference is that stock prices are closely tied to investors' expectations, while in FX markets, there are also trade flows and other trading that takes place independently of investors expectations about future price.
} 
what they think others think - the convention of the market - and not according to their personal believes about the trend (Orléan, 1999, p. 89) ${ }^{67}$.

Conventions are to the 'auto-referential' approach as fundamentals are to the mainstream works, but instead of yielding in an objective fundamental value, that is unique and derives from the rarity of the asset, it results in a subjective fundamental value, that depends on the workings of the group itself. Assuming that everybody believes in the convention, to predict the opinion of the others is the same as to predict the result of a model. The model is determined by the conventional rules, that organize private expectations Orléan (1999).

The financial convention and its crisis Orléan's analyses of financial markets are focused on the 'financial convention', or the socially accepted, prevailing quantitative model used to estimate the expected value (Orléan, 1999, p. 88). The dominant financial convention evolves, and so do the variables used in the estimations (Orléan, 2004, p. 264).

Moreover, the fact that a prevailing model exists does not hinder the constitution of different individual expectations. This diversity includes two extra categories of agents: the 'skeptical fundamentalists' that trade values allowed by the conventional model, but that are marginal (their estimations being very closely related to the news); and the 'contrarians', who take positions that are contrary to the conventional one (Orléan, 1999, p. 88-92).

In light of the existence of these other agents, the keynesian convention of continuity becomes only transitory because it would be constantly tested. The stability of the convention will depend on how legitimate it is and, in order to establish itself lastingly, it must display its adequacy to the economy it wants to explain (Orléan, 2004, p. 264).

A convention falls into crisis when a significant deviation from the conventionally estimated value and the observed one emerges, or when these deviations happen too often (Orléan, 2004, p. 264-265). In the period of the 'convention of continuity', conventions are validated by the fact that agents trade according to this convention and, by doing so, they

\footnotetext{
${ }^{67}$ The analysis of Orléan differs from Keynes' beauty contest because Orléan wants to highlight that the convention evolves. For Orléan (1999, p. 87), Keynes convention involves continuity and stability. He quotes Keynes (1936): "The essence of this convention though it does not, of course, work out quite so simply lies in assuming that the existing state of affairs will continue indefinitely, except in so far as we have specific reasons to expect a change."
} 
ensure liquidity to the market (Orléan, 1999, p. 128). But when a convention falls into crisis, liquidity dries up, causing moments of crisis and panic until another convention appears (Orléan, 1999, p. 61) . $^{68}$.

Applied to exchange rates, Orléan's analysis suggests that when investors expect an exchange rate appreciation for following a financial convention that highlights the importance of the variable $x$ (whose trend indicates an appreciation), and the exchange rate depreciates (for being also influenced by variable $y$ that moved in the other direction), the convention falls into crisis: $x$ can no longer explain exchange rates. With the crisis, investors are no longer capable of building forecasts, and will prefer holding more liquid assets, drying liquidity from the market.

Orléan's 'auto-referential' approach has great significance for the study of expectation formation and exchange rates. First, for shifting the focus of convention from the forecast to the financial model used to build the forecast, it indicates how the convention is built: from the academic and financial sector's models. Secondly, for emphasizing that conventions evolve, are not eternal, it opens up the space for different exchange rate determination processes in different periods or places.

Fundamentals do play a role in exchange rate determination as they are the variables that investors consider, but according to the different conventions, they will pay attention to different fundamentals. The role of a fundamental is therefore not static. And with no permanent causal relation between fundamentals and the exchange rate, models based on fundamentals are not empirically successful.

\subsubsection{Foreign Exchange as a 'Trending Market'}

Schulmeister has been analyzing exchange rate patterns and developing theoretical explanations for them since the 1980s. He has an inductive approach, "primarily based on information stemming from markets participants and from empirical investigations into their

\footnotetext{
${ }^{68}$ It is interesting to highlight that these dynamics refer to the change in the convention, not the reverse of the asset's price trend. What can be inferred from Orléan's work is that the convention can be robust to a trend reversal if it is caused by a reversal of the indicators considered by the convention. In this case, when inputted in the dominant conventional model, indicators will reveal a reversal of the asset price, resulting in no deviation from the forecasted value to the observed one.
} 
trading practices" (Schulmeister, 2009, p. 309). Schulmeister (1988, p. 1), analyzed shortand medium-term movements of the DM/USD market from 1973 to 1988, with what he called an "exploratory approach". By observing that these patterns were exploited by technical trading, the author examined the importance of technical analysis for "the formation of expectations and consequently for the determination of exchange rates" 69 . One of the main results from his first studies was that the exchange rate does not simply follow a random walk, as inferred from Meese and Rogoff (1983). Instead, "a systematic pattern in the process of exchange rate determination" exists (Schulmeister, 1987, p. 1, italics added) ${ }^{70}$.

Schulmeister $(2009$, p. 309) presents a synthetic overview of his findings, that he names "a hypothetical picture of expectations formation, trading behaviour and price dynamics." The findings begin with the observation that exchange rates fluctuate around underlying upor downward trends - a phenomenon he calls "trending", that repeats itself across different time scales. Long-term trends result from the accumulation of short-term runs in different directions (for instance, in a bull market, upward trends lasted longer than the countermovements, the downward trends). The determination of the short-term trend is partially autonomous, reflecting the micro-structure of the market, and partially influenced by the "expectational bias", whose determinants are mostly related to the macroeconomy, but also associated with agents' behavior.

How are the short-term trends built? Schulmeister's answer is threefold: what triggers the trend, the mechanisms through which they continue, and how they end. Trends are set off by news, particularly ones concerning "relevant fundamentals" (p. 311). The consequent direction of trade indicated by the news is defined by the market's convention in line with

\footnotetext{
${ }^{69}$ Technical trading is indeed very important in the work of Schulmeister, which he justifies with evidence of the major importance of technical analysis today. Analyzing survey studies, Schulmeister (2008, p. 317) concludes that: "Technical analysis is widely used in the currency markets. Surveys conducted among market participants over the past 20 years document the following. First, roughly $90 \%$ of market participants base their trading at least in part on technical analysis. Second, between $30 \%$ and $40 \%$ of professionals use technical analysis as their most important trading technique. Third, the importance of technical analysis has increased more strongly over the 1990s than other trading practices like the orientation on fundamentals or on customer orders." The author provides a list of references for survey studies.

${ }^{70}$ As argued by Prates (2015), the evolution of exchange rate theories after the collapse of the Bretton woods institutions is driven by the empirical failure of prior theories. The most famous of these studies (and the first) is Meese and Rogoff (1983), who claim that a random walk could better predict the exchange rate behavior than prior models. Schulmeister's work is however very important for dialog with this literature, claiming that, empirically, the exchange rate does not follow a random walk either, but rather a trending, systematic pattern. See Schulmeister (2009, p. 328) on a comparison between a real exchange rate path (the USD/Euro pair from 1999 to 2005) and the path predicted by a random walk. Among other differences, the real path presented marked trending, or "fluctuations around underlying trends".
} 
the keynesian concept of the beauty contest (Keynes, 1936): traders will either buy or sell an specific asset according to what they think other traders will do. Expectations concern only the direction: Traders will not define, for instance, the total impact of the news on the dollar/pound rate, but only assess whether it will cause an appreciation or a depreciation.

After the initial trigger, the exchange rate dynamic is determined by the workings of the trend-following technical trading systems - models that generate signals to buy or sell exclusively based on analysis of previous price changes. Schulmeister (2009, p. 312) refers to two models: the "trend-following models generate signals according to the current trend"; and the "contrarians" "produce sell (buy) signals when prices are still rising (falling), but at a declining speed". Some models generate signals more rapidly than others: based on high frequency data, "fast models" act first. The "slow models", on the other hand, are based on hourly or daily data, and therefore require more time to accumulate the observations needed to generate a buy- or sell signal.

Schulmeister (2009) summarized the dynamics building the trend in the following way:

Subsequent to an initial upward (downward) price movement triggered by news follows a "cascade" of buy (sell) signals stemming from trend-following technical trading systems. At first the most price-sensitive models based on high frequency data ("fast models") produce signals, at last the "slow models" based on hourly or daily data. The execution of the trading signals in turn strengthens and lengthens the price movement. As a consequence, this feedback-mechanism will transform the news-induced price change into a trend. (p. 311)

Apart from the workings of technical trading, the trend is also continued though the trading of amateurs that follow that of professional traders.

How does a trend end? Schulmeister (2009, p. 312) does not - and probably cannot - straightly answer this question. However, he discusses the fact that "the longer an asset price trend lasts the greater becomes the probability that it ends". This phenomenon could be explained by three reasons: i) the decline in the number of traders getting into the bandwagon (in a herd behavior), ii) the higher incentive for cashing-in profits and iii) the increasing amount of "contrarian" traders that will consider the asset overbought or oversold 
and open a position speculating on the reversal of the trend. These reasons explain why an asset price always alternate trends, not following one infinitely.

As mentioned, medium-term trends are formed by short-run trends in one direction that last longer than counter-movements. It is in the explanation of why that is so that Schulmeister (2009) includes the considerations that approximate his approach to those that look into expectations. As argued, there is always an "expectational bias" in favor or against an asset that reflects the market's mood - bullish or bearish (p. 312). A change in the market's mood is said to be determined according to psychological, economic or social factors.

The most important economic factor is the extent of the under- or overvaluation of an asset $^{71}$. In the author's words: "The longer an overshooting process lasts and the more an asset is therefore over(under)valued, the weaker becomes the "bullishness" ("bearishness")" and the higher number of agents will change their expectations and trading behavior ${ }^{72}$.

Among emotional factors, the author mentions "manic" and "depressive" phases (respectively when prices rise or fall strongly) and herd effects. Recommendations from analysts and rating agencies are important to confirm if a boom is sound ${ }^{73}$.

Schulmeister (2009, p. 312) also analyzes "recognition and reaction bias": "News in line with the prevailing expectational bias get higher recognition and reaction than news which contradict the "market mood"." As a result, traders invest more if the news are in line with the direction determined by the market mood, intensifying the trend.

The inductive analyses of Schulmeister resulted in an important picture of the FX market. These analyses are important in Harvey's work - probably because it looks at exchange rates "as they are", which is an important difference from mainstream analyses (Harvey, 2001, p. 13). To summarize, for Schulmeister (2009, p. 313), exchange rates therefore alternate upward (manic) and downward (depressive) trends, that will last longer if they are in line with the "market mood" (expectational bias). Fundamentals play an

\footnotetext{
${ }^{71}$ Although the author refers to exchange rate misalignment, he does not agree with the view of the exchange rate as an equilibrium, market-clearing price.

${ }^{72}$ Schulmeister (2009, p. 312) argues that the impact of the real under- or overvaluation of the exchange rate in an economy can change the expectational bias, as this would "strengthen the expectation of a "correction", i.e., a depreciation of the respective currency".

${ }^{73}$ An interesting note from Schulmeister (2009): as agencies strengthen the market mood when it is sound and recommend not to panic or not to sell in other circumstances, they leave an optimistic bias in the long run.
} 
important role. Firstly, when the short-term trend is triggered, the fundamentals determine in which direction the news will push trading. Secondly, they determine whether the exchange rate is misaligned or not, determining the "expectational bias". The exchange rate will thus be a sequence of ups and downs, according to short-term movements that are highly due to technical trading, and that have the fundamental value as a "center of gravity" or an "attractor" (p. 332), because they determine agents' trading.

Although Schulmeister does not detail his understanding of fundamental values, he argues that they do not serve as equilibrium in the market-clearing sense of the mainstream school and that the exchange rate does not present any tendency of convergence towards the fundamental value (p. 332). From the description of the market dynamics, it can be inferred that the concept of fundamentals in Schulmeister's work is similar to that of Orléan: a subjective value determined by the convention ruling in financial markets. Indeed, fundamentals have a role in defining how agents interpret the news (and thus buy or sell and asset) and on how they interpret an asset's value (as over- or undervalued) (p. 310-312). Moreover, the author's mentioning of the "most relevant fundamentals" (p. 310) indicate that he refers to a set of variables that are subject to evolve. Harvey's analysis is in line with this argument.

\subsubsection{Foreign Investor's 'Mental Model'}

Harvey's analyses derive from a criticism on the view of the exchange rate as a market clearing price in mainstream models, an aspect that would derive from the great role played by trade-flows in mainstream approaches (presumably in the long run $)^{74}$. However, such consideration is not coherent with the reality of large and developed economies where portfolio flows dominate (Harvey, 2009, p. 54), and that call for the need to understand how portfolio investors form their expectations. In the author's words: "portfolio capital flows dominate the market and that within that context market participants forecasts of future currency price movements are the prime movers of foreign exchange rates" (p. 54).

\footnotetext{
${ }^{74}$ As put by Harvey (2009, p. 64), "There is no reason to expect exchange rates to move in a way that restores balanced trade. That exchange rates do just that is a central theme in almost every Neoclassical theory". Note however that, as shown in Section 3.1 financial flows have been considered by mainstream authors since the collapse of the Bretton Woods institutions with the monetarist models.
} 
Harvey's analysis of expectation formation is based on concepts taken from Keynes and from behavior economics (the heuristics). Based on these principles, agents' decision-making process is influenced by forecast-construction biases (or an "unreasonable influence of some factor" (Harvey, 2009, p. 44)). Given these biases, to Harvey, the foreign currency market is characterized by volatility, bandwagons, and agents that employ technical analysis, trading limits and engage in periodic profit taking (cash-in).

Keynesian concepts, heuristics, and forecast-construction biases Harvey (2009, p. 50) indicates five keynesian insights on asset markets that enhance our understanding of why forecast-biases are built. Given fundamental uncertainty, available information has an undue weight in agents' forecasts. For the same reason, there will be low confidence in asset markets, resulting in opinions and forecasts that change rapidly. Convention makes participants take the current valuation of an asset by a market as the correct price. Making quick returns is necessary. And, notably, it is due to animal spirits that agents are able to act despite their ignorance face to fundamental uncertainty.

Apart from these keynesian insights, three heuristics and two biases taken from behavior economics are used to explain forecast-construction biases. According to the availability principle, the more available something is in our memory ("either through imagination or recalling past instances") the more frequent or likely that event is deemed to be. The impact of availability on what Harvey (2009) called forecast-construction biases is evident:

The inherent problem is, however, that there are many things that can make something more available in memory without making it more frequent or likely. An instance may be more easily accessed, for example, simply because it was dramatic, more recent, or falls into the decision maker's area of interest. (p. 47)

As a result, agents overrate the importance of dramatic events, which is a bias on their exchange rate forecast. The representativeness principle is related to the calculation of the probability that event $A$ is a result of event $B$. The more one event resembles the other, the more people will think that this causal relation exists. The impact of the representativeness principle is also great: people will constantly look for explanations about exchange rate movements, whether they can discern it or not. In the anchoring principle, people will make 
new forecasts always having a prior one as reference. As a result, agents will put undue weight on their first forecast, regardless of how it was done.

The forecast-construction bias is also a response to two other problems related to probability-calculation: wishful-thinking, according to which agents believe that outcomes that are more beneficial to them are more likely to occur; and ii) framing, which is how people see and describe events, because in Harvey's (1998) words, "a likelihood is an opinion, not an objective value. Opinion is based not only on the information available to the decision-maker, but also on the framing of that information" (p. 54).

The consequence is the forecast-construction bias in expectation-formation. As put by Harvey (2009):

agents will place undue emphasis on dramatic and more recent events, ignore basic statistical principles, anchor to early estimates, have a tendency to expect events that favor them, and tend to ignore evidence that does not fit their preconceptions. (p. 47)

These forecast-construction biases and their consequences come into play when agents are forming their expectations and trading - presented as "the agents' mental model".

Agents' 'mental model' Harvey proposes a detailed analysis of the agents' 'mental model', based in three layers: the reasons why agents need foreign currency, the base factors that they believe influence these reasons, and the indicators they might use in building expectations concerning changes in these factors. These are presented in Table 3.2. Though the model is shown as diagrams, it will be presented in the form of equations to more easily compare it with the literature. Also refer to Figure 3.1 that presents the 'augmented mental model', which concerns the dynamics that occur up to the exchange rate forecast.

TABle 3.2 Harvey's 'Mental Model': Three Layers

\begin{tabular}{ccc} 
Three Reasons & Four Base Factors & Several Indicators \\
\hline $\begin{array}{c}\text { Net exports, FDI, and } \\
\text { portfolio investment }\end{array}$ & Prices, GDP growth, & Trade account, \\
interest rates, and liquidity & unemployment, etc
\end{tabular}


The exchange rate expectation $\left(E^{e}\right)$ is determined relative to the "three reasons to purchase foreign currency" (Harvey, 2009, p. 83): expected net exports $\left((X-M)^{e}\right)$, expected net direct foreign investments $\left(F D I^{e}\right)$, and expected net portfolio foreign investment $\left(P I^{e}-\right.$ in equation $\left.3.25^{75}\right)$.

$$
E^{e}=f\left((X-M)^{e}, F D I^{e}, P I^{e}\right)
$$

These three reasons depend on four other variables, that Harvey (2009) calls base factors: the expected price differential between the domestic and the foreign $\left(^{*}\right)$ country $\left(\left(P-P^{*}\right)^{e}\right)$, the expected relative "macroeconomic growth and stability" $\left(\left(y-y^{*}\right)^{e}\right)$, the expected relative interest $\operatorname{rates}^{76}\left(\left(i-i^{*}\right)^{e}\right)$, and expected liquidity ${ }^{77}\left(l^{e}\right)$. These are presented in Equations 3.26, 3.27, and 3.28 $8^{78}$.

$$
\begin{gathered}
(X-M)^{e}=f\left(\left(P-P^{*}\right)^{e},\left(y-y^{*}\right)^{e}\right) \\
F D I^{e}=f\left(\left(P-P^{*}\right)^{e},\left(y-y^{*}\right)^{e}\right) \\
P I^{e}=f\left(\left(y-y^{*}\right)^{e},\left(i-i^{*}\right)^{e}, l^{e}\right)
\end{gathered}
$$

Finally, Harvey suggests some of the indicators that impact base factors. These indicators are especially important for forming forecasts when the base factors are not often published. For instance, trade balances are published monthly, but GDP rates are not reported as frequently. In this case, unemployment can be an important indicator for future economic growth. Two other important indicators in the post-Bretton Woods era are interest and inflation rates.

Indicators are expected to evolve with time as "the structure of the mental model is

\footnotetext{
${ }^{75}$ Exchange rates are given in the form of the amount of foreign currency needed to buy an unit of the local currency, where an increase means a depreciation of the domestic currency. Therefore, all the three variables have positive impacts on agents' forecast of exchange rates.

${ }^{76}$ The author does not mention whether these are real or nominal interest rates, but they are probably nominal rates, since prices are not considered as determinants of portfolio investment. The variable used for economic growth $(y)$, on the other hand, seems to be in real terms given that earlier in the book Harvey had used $P y$ to refer to nominal growth.

${ }^{77}$ It is not specified whether liquidity is related to the asset or the currency in which it is labeled, or both.

${ }^{78}$ The impacts of $\left(P-P^{*}\right)^{e}$ and $\left(y-y^{*}\right)^{e}$ on $(X-M)^{e}$ are negative. The impacts of $\left(P-P^{*}\right)^{e}$ and $\left(y-y^{*}\right)^{e}$ on $F D I^{e}$ are, respectively, negative and positive. The impacts of $\left(y-y^{*}\right)^{e},\left(i-i^{*}\right)^{e}$, and $l^{e}$ on $P I^{e}$ are positive. See Harvey (2009, p. 83-84) for details on these causalities.
} 
based on experience and professional and scholarly experience". For instance, monetary aggregates would have lost importance and inflation would now be associated with exchange rate appreciation due to the expectation of interest-rates increases and higher portfolio investment rather than with depreciation due to a decline of purchasing power. In addition, structural changes, due to the increasing role of portfolio flows, are expected to change the weight of indicators in the 'mental model' (in this case, away from determinants of trade to financial ones). In total, four factors are mentioned: regime change, structural change, academic change and professional theory (Harvey, 2009, p. 86-87). In the author's word: "the foci of expectations formation will emerge as a function of the social context in which the agents interpret their experiences and scholars and professionals engage in research" (Harvey, 2009, p. 54) - similarly to Orléan's evolving financial convention.

'Augmented mental model' With his 'mental model', Harvey explains how expectations are built, while with the augmented model he introduces exchange rate determination from portfolio investment (that depends on exchange rate forecasts) and the workings of five of his six "exchange-rate features" - volatility, bandwagons, technical analysis, trading limits and cash-in (as presented in Figure 3.1).

Figure 3.1: Harvey's 'Augmented Mental Model'

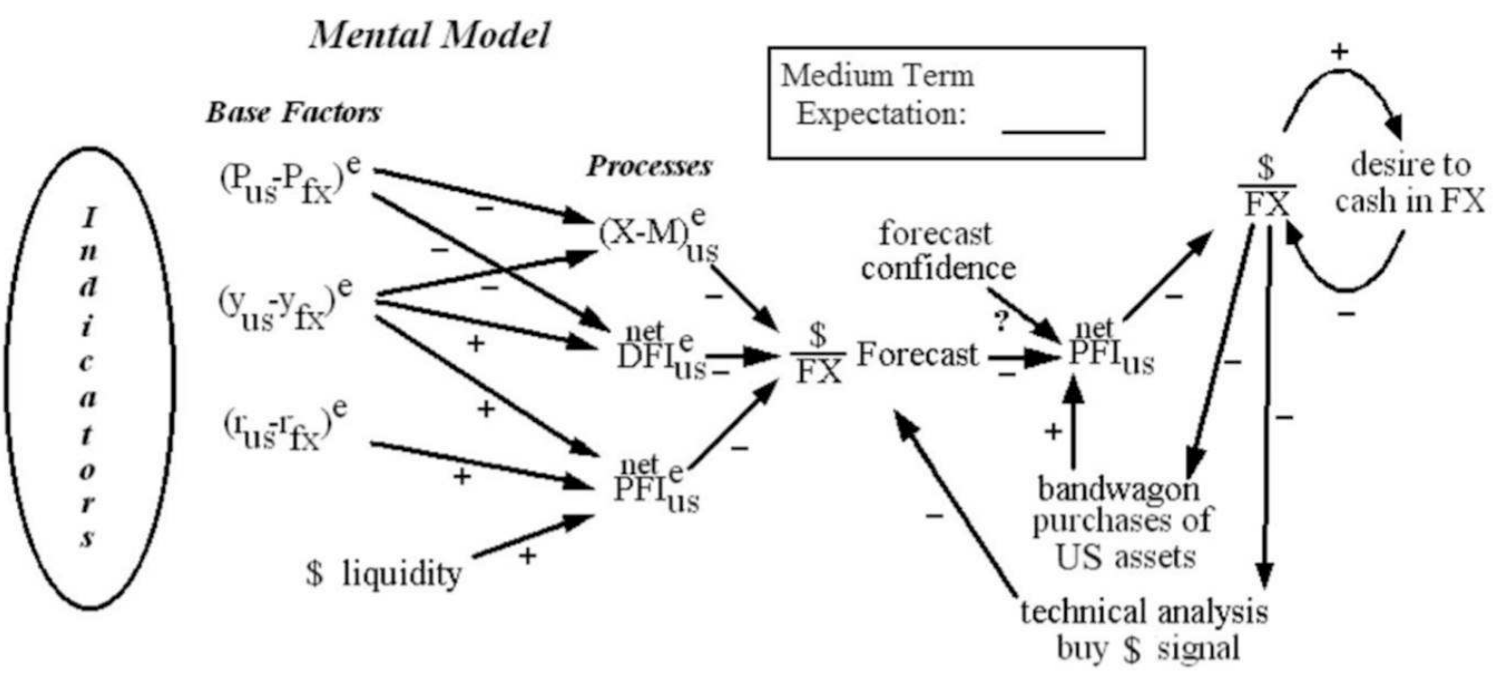

Source: Harvey (2009, p. 88). 
Technical analysis' dynamics based on Schulmeister's work: a sign that follows an exchange rate change has an impact on the forecasts and thus in portfolio flows ${ }^{79}$. With the bandwagon effect, an exchange rate change makes agents increase their net portfolio investments, adding pressure to the currency. Trading limits are not presented in the diagram, but can be thought as a ceiling to both technical analysis and the bandwagon purchases.

While technical analysis and bandwagon purchases are self-feeding cycles, cash-in acts against the trend. It is however said to be just white noise over the trend, having no effect over longer time horizons.

A fourth important element is confidence, that affects different interactions inside the model $^{80}$ : the more confident the participant is, the stronger the response of these mechanisms will be ${ }^{81}$. Finally, Harvey considers the medium-term expectations as "attractors", or "a sort of lens through which agents filter inputs" (as in Schulmeister (1987) and Schulmeister $(1988))^{82}$. These expectations guide how agents see an event: the significance of events that would lead to an exchange rate change in line with the medium-term expectations (be it bullish, bearish or neutral) is magnified. Also confidence is positively affected in the case of an event that is in line with the medium-term expectation.

Harvey's (2009) words well summarize these interactions that determine exchange rates:

In sum, the three feedback loops - cash in, bandwagon effects, and technical analysis - are key to behavior. It is because of them that, in general, currency markets tend to move under their own momentum (due to bandwagon and technical analysis), interrupted by brief reversals caused by cash in. Cash in causes a zigzag pattern; if bandwagon and technical analysis have imparted a particular direction to the market, the zigzag occurs around that vector. As market participants work with their 'mental model' to interpret the impact of events (base factors and

\footnotetext{
${ }^{79}$ In Schulmeister, the sign has a direct impact on trading.

${ }^{80}$ Although, according to Harvey's text confidence seems to affect any kind of expectation formation, in the illustration, it is placed as to affect expected net portfolio investment.

${ }^{81}$ Schulmeister does not directly mention concerns over confidence, but indirectly he mentions that rating agencies' communications "strengthen the market mood" when they "confirm that an ongoing boom is fundamentally sound", Schulmeister (2009, p. 4+), which is very close to increasing confidence on a forecast.

${ }^{82}$ Note that this is consistent with survey analysis, that argues that there is an important skew towards technical analysis at short horizons, that reverses as the length of the considered horizon is increased.
} 
indicators) on the processes (thus generating their short-term and medium-term forecasts), so the zigzagging vector may be turned in new directions (p. 89).

\subsubsection{Concluding remarks}

Similarly to Orléan's and Schulmeister's analyses, Harvey concludes that the exchange rate is determined by social context that, in turn, in longer time horizons, is determined by fundamentals, and that they are relevant "because portfolio investors have decided that there should be [such associations]" (Harvey, 2009, p. 64). While for Orléan decisions are based on financial conventions, Harvey's 'mental model' details the indicators considered by investors in forming their expectations - presenting what, in the terms of Orléan, could be seen as our current financial convention. These details are interesting because they are specifically focused on the forecast of currencies, while Orléan's analysis is directed at assets markets in general.

A more complete picture emerges with the inclusion of FX markets' features (partially proposed by Schulmeister) in Harvey's 'augmented mental model'. FX features complement the financial convention and the description of the indicators for explaining how the manifest zigzag pattern of exchange rates are built.

The definition of the turning points is of major importance. Harvey (implicitly) suggests two explanations of how these are built. The first is cash-in operations (Harvey, 2009, p. 89), and the other (that focuses on a longer time-horizon) is the difference from agents' interpretation and the actual rate:

These [bandwagon effects] can continue unabated until current events (as interpreted by market participants) accumulate against the trend. If the discrepancy between the level to which a currency price has risen due to bandwagons and the interpretation of events is large enough then agents confidence can be shattered and panic and collapse can result. (p. 66, italics added)

Note the similarity with Orléan: the fact that participants are no longer able to explain a trend leads to a crisis, putting an end to the movement. 
Harvey and Orléan's explanation of turning points seem more appropriate for defining the turning points of up-trends, as the lack of liquidity and crisis are associated with sells and not with purchases of the asset. An alternative is to think of turning points of downturn trend as coming from investors buying an asset for perceiving its price as excessively low what maintains the general idea of the divergence of investors' perception and the actual rate.

As in portfolio models (discussed in Section 3.1.2.3), portfolio flows play an important role in Harvey's model. Their determination is surely much more complex in the latter, where exchange-rate expectations are not only included, but deeply discussed and seen in parallel to the specific features of today's FX markets - and assumptions are realistic. Portfolio models, however, include features that are absent from Harvey's model. First, they are based on portfolio allocation strategies that involve investing in one country or another, underscoring that the decision involves several alternative investments. Harvey partially considers the importance of other country's features in its model as base factors are always considered in relative terms (as expected relative macroeconomic growth and stability, $(y-$ $\left.y^{*}\right)^{e}$. However, this is only marginal, and what could be the central issue, the other country's expected exchange rate change $\left(e^{e}\right)$ is not taken into account. In a two-country model, this would not be important as the depreciation of one is the appreciation of the other. But portfolio allocation involves more than two countries and when considering an advanced and an emerging currency, the expected change in the emerging currency might be seen with respect to the advanced country, but the advanced currencies forecasts would probably be estimated with respect to another advanced currency.

Another important point is that, differently to portfolio models, stocks and changes in stocks play no role in Harvey's model. Portfolio flows are considered, but these flows do not accumulate somewhere indicating the potential impact of an investors withdraw from a market - which indicates the great difference between the potential impact of financial and trade-related flows (see Carvalho (2009)). Such consideration enhances our understanding of exchange rate volatility - a feature that manifests not only as the zigzagging behavior nicely explained by Schulmeister and Harvey, but also as sudden depreciations. In this case, the consideration of stocks is central for understanding the vulnerability brought by portfolio flows (as it will be seen in Section 3.3.5, they are considered by SFC models). 
In fact, neither Schulmeister's nor Harvey's models can better explain usual volatility of FX markets than exchange rate crises like the ones faced by emerging currencies since the 2000s. These heterodox models include features as herd behavior, but they do not explain what would have triggered the major depreciations seen in these currencies nor why they are recurrent in some countries. The analyses of emerging currencies presented in the next section shed light in these questions.

Finally, a remark on the absence of impact from other types of flows on the exchange rate in Harvey's analysis. Foreign trade and FDI are included in the model as reasons for trading in foreign exchange markets, but their role is limited to affecting agents' exchange rate forecast, not having a direct impact on the exchange rate. This inclusion would enhance realisticness and is of especial importance for countries that can experience a shock of terms of trade (as due to commodity prices).

\subsubsection{Emerging Currencies' Specificities and Dynamics}

Of special interest for this thesis are the analyses of the specificities of emerging currencies. These are heterodox works, and as the ones presented earlier in this section, they disagree with the view of exchange rates as a market-clearing price. They agree with the role of expectations in driving exchange rates and with the view that expectations are anchored in social conventions given the weight of fundamental uncertainty. As in other heterodox works, expectations impact exchange rates through investors' decisions on financial investments, but these decisions are now conditioned by a currency's liquidity premium associated with the place it occupies on the hierarchical international monetary and financial system (IMFS).

These works are based on structuralists concepts of hierarchy and asymmetries that differentiate the center from the periphery. Institutions play a central role and the analyses are based on the context and dynamics of the post-Bretton Woods era. The broader center-periphery literature analyzes different types of asymmetries, but the most relevant for exchange-rate dynamics are financial and monetary asymmetries ${ }^{83}$. The asymmetries

\footnotetext{
${ }^{83}$ Described by Andrade and Prates (2013), Prebisch's (1949 e 1981, as cited in Andrade and Prates (2013)) work focused on three main types of asymmetries between the center and the periphery: the technical/productive, the macroeconomic, and the financial. The literature emphasized the following asymmetries: the creation and dissemination of technical progress; national innovation systems as the institutional structure
} 
of the IMFS are briefly presented in the following section, followed by an analysis of the exchange-rate per se.

\subsubsection{Asymmetries of the international monetary and financial system (IMFS)}

The international monetary system (IMS) has undergone significant changes in the 20th Century. There were periods of fixed and floating exchange rates, of capital controls and free mobility, and while the Gold-Standard had the pound sterling as key-currency, this lost its space to the U.S. dollar at the emergence of the Bretton-Woods system ${ }^{84}$. It is from historical analysis of its development that authors argue that the IMS is asymmetrical ${ }^{85}$, that a currency's position determines its country's policy autonomy (as Carneiro's (1999)), the dynamics of the capital flows it receives, and thus its exchange rate's main features (as Prates (2002)).

There is consensus that the central ${ }^{86}$ place of the IMS in the post-Bretton Woods system is occupied by the U.S. dollar ${ }^{87}$, followed by currencies of other central economies, with peripheral currencies coming next. But the exact explanations of these layers might diverge. Carneiro (1999) argue that the U.S. dollar was at its center for being the system's reservecurrency, while the other two layers were divided between convertible and non-convertible currencies, but no further development on the concept of convertibility is presented ${ }^{88}$.

leading to technical progress; productive structures; the income-distribution and job creation profiles; the degree of autonomy of the political economy; and the financial and monetary asymmetries.

${ }^{84}$ Note that the period between the two World Wars also has important implications for exchange rate analysis, for being a period of exchange rate flexibility.

${ }^{85}$ De Paula et al. (2016) mention that the hierarchical feature of the IMS and its resulting asymmetries were already pointed out by Keynes in the Treatise on Money and in his preparatory works for the Bretton Woods Conference (Keynes, 1930, 1944, as cited by De Paula et al. (2016).

${ }^{86}$ The idea of centrality is a direct reference to the center-periphery framework that results in a representation of currencies based on circles. Another representation is the currencies pyramid, where the most important currency occupies the highest position (see Cohen (1998) for the concept of the currencies' pyramid).

${ }^{87}$ Indeed, the IMFS that emerged after the collapse of the Bretton Woods institutions is labeled by Prates (2002) as the one based on a "flexible, financial and fiduciary dollar" as the very definition of a IFMS is based, among other features, on the presence of a key-currency and the dynamics that it imposes. In the current IFMS the U.S. dollar is the key and the 'reserve' currency, the one that better incorporates the idea of reserve of value.

${ }^{88}$ Carneiro (1999) analyzes how interest rates of different countries are set in the context of financial globalization, arguing that the interest rate of the reserve currency would work as a floor for the other countries, whose interest rates would increase according to the distance to the center of the system). 
The reasons behind these three layers that differentiate currencies is examined by Prates $(2002)^{89}$ :

The concept of convertibility is based on the acceptance of national currencies as means of payment, unity of account and contract denomination, and store of value in the international monetary system. In other words, a national currency is completely convertible if capable of performing, in the international context, the three functions of money ${ }^{90}$. (p. 148)

The U.S. dollar is the only currency "to fully perform the three functions", as it is the currency mostly used "in monetary (means of change) and financial (unit of contract denomination) transactions, as well as the most liquid and safe asset and therefore the most desired by agents as receptacle of uncertainty", and thus, it is at the system's center. Other currencies from central countries occupy second place in this hierarchy as they are also used to denominate contracts internationally (unit of account) and are relatively demanded as store of value. Currencies from peripheral countries occupy the third place, as they do not exercise any of the three functions internationally (they are not de facto convertible) (Prates, 2002, p. 148).

De Conti (2011, p. 46), following Prates' (2002) three-functions definition, argues for the increasing importance of the euro as store of value and unit of account and suggests an specific layer for the currency, resulting in an IMS with four layers ${ }^{91}$.

Apart from monetary asymmetry, the positioning of countries in the international $f i$ nancial system (IFS) is also important for Andrade and Prates (2013) in determining the liquidity premium of a currency. The hierarchy of the IFS is related to the different magnitudes of capital flows to different countries, those directed at emerging countries being marginal in comparison to total flows ${ }^{92}$.

Although marginal, these flows exercise important pressures on countries' foreign exchange markets due to the smaller size of their economies. Haldane (2011) uses the "Big

\footnotetext{
${ }^{89}$ Note that this definition involved a de facto understanding of convertibility, that differs from de jure convertibility that is associated with the legal possibility of converting a currency into another.

${ }^{90}$ Author's translation from Portuguese.

${ }^{91}$ De Conti (2011, p. 46) also argues for the relative heterogeneity of peripheral currencies, as some are used regionally; but given its still marginal importance, all peripheral currencies are taken as a unique group. Also, on IMS' current configuration, see De Conti and Prates (2014) that analyze the current IMS configuration based on data on the specific usages of money that are associated with each of its three functions.

${ }^{92}$ See Prates (2015) on how the financial and monetary hierarchies reinforce themselves.
} 
Fish Small Content" metaphor to illustrate this issue: "The Big Fish here are the large capital-exporting, advanced countries. The Small Ponds are the relatively modest financial markets of capital-importing emerging countries." The numbers on the size of the 'fish' and the 'pond' are impressive $\mathrm{e}^{93}$ :

For example, a fall of 0.1 in the weighted home bias index for advanced countries in 2007 relative to 2006 would have equated to a portfolio reallocation to foreign markets of around $\$ 4.5$ trillion. That is a big fish. To give some context, the market capitalisation of all G20 emerging market countries in 2007 was $\$ 6.8$ trillion. That is a smallish pond. (p. 5)

\subsubsection{Store of value or unit of account? Assets or liabilities?}

While some authors follow Prates' (2002) definition of a currency's ability to exercise the three functions of money in the international context, others seem to focus exclusively on the store of value function. Kaltenbrunner (2015) cites the German monetary keynesians (GMK) school's ${ }^{94}$ analyses as example. As argued, the school suggests that a currency's position, and thus its liquidity premium, results from its ability to store wealth. The leading currency would be the one at the highest position in the hierarchy, with the greatest ability to store value, followed by intermediate currencies (from other developed countries), and, finally, by developing and emerging countries that have "unstable currencies with a poor reputation concerning their ability to act as a stable store of value" (Kaltenbrunner, 2015, p. 432-433).

In the dynamics described by Andrade and Prates (2013, p. 410) the store of value function also seems particularly important: they refer, for instance, to the incapability of

\footnotetext{
${ }^{93}$ Haldane (2011) uses the 'Big Fish Small Pond' metaphor to refer to the very different magnitudes of international portfolios and emerging countries markets:

Haldane (2011, p. 15) also presents the importance of gross portfolio equity inflows relative to lagged market capitalization for G20 emerging markets in different years, which was about $4 \%$ in 2010 . The ratio of the foreign liabilities in the form of equities over market capitalization might however be a more interesting measure for comparing two stock-values. As presented in Chapter Four, this ratio achieved levels of $45 \%$ in Hungary and $42 \%$ in Mexico in the $2000-2011$ period.

${ }^{94}$ See Kaltenbrunner (2015) for the GMK references.
} 
these currencies to be "a receptacle of uncertainty on a global scale" in moments when investors have "a clear preference for money and its closer substitutes" (p. 402) . $^{95}$.

Kaltenbrunner (2015) argues for the importance of shifting the (GMK's) focus on the store of value function, focusing instead on the currency's ability to settle financial obligations internationally (p. 428), as it determines its ability to be used as a means of meeting outstanding obligations $^{97}$ (p. 436).

This shift of focus from the assets' (store of value) to the liabilities' side (denominate financial obligations) would be an insight taken from Minsky (1975). Specifically, it is based on Minsky's argument that for debtors, "it is convenient to hold liquid assets in the currency in which your debts are denominated". It is also based on the understanding of the concept of liquidity in the international context as the ability to convert assets into "the currency with which positions in these assets have been funded", given that in closed economies, liquidity is associated with the ability to convert an asset at any time, without loss of value, into money, which is "the mean of account and denominator of contractual obligations" (Kaltenbrunner, 2015, p. 436).

Though the store of value function is still important, to Kaltenbrunner (2015), the liquidity premium paid by a currency (and thus its position in the IMS) is ultimately determined by a currency's ability to act as international medium of contractual settlement that, in turn, defines its ability to act as store of value ${ }^{98}$. In this sense, Kaltenbrunner (2015) proposes a causal relation between two of the three functions of money that, according to

\footnotetext{
${ }^{95}$ When discussing periods of uncertainty, Andrade and Prates (2013) refer to the search for the most liquid assets with the idea of saving value for investment in a future moment ${ }^{96}$ : "liquidity is strongly valued in times of higher uncertainty regarding the future, justifying an increased demand for money as an asset, or for its close substitutes, so as to structure a portfolio that is as liquid as possible, while one waits for more auspicious circumstances in which one can hold less liquid assets that may, however, generate higher overall returns. (...) Given the logic of capitalist accumulation and the ubiquitous existence of uncertainty, in particular situations there will be a clear preference for money and its closer substitutes, since they are the liquid assets par excellence, and the postponement of real investment plans" (Andrade and Prates, 2013, p. 402).

${ }^{97}$ The role of the dollar as the currency in which the banking system runs is also highlighted by some mainstream authors. Its importance, however, is rooted on the role of the dollar in international trade (which is the same as arguing that inside the unit of account function, the denomination of trade contracts has led to the denomination of financial obligations). As put by Shin (2016, p. 6): "The consequence of the dollar's international role in transactions is that the global banking system runs on dollars".

98 "It is important to note that in the Minskyan framework presented here a currency's ability to act as international store of value remains a crucial element of its international liquidity premium. It is, however, its inability to act as international medium of contractual settlement that undermines this function in the first place" (Kaltenbrunner, 2015, p. 437).
} 
Prates (2002), would jointly determine a country's position in the $\mathrm{IMS}^{99}$. The causal relation would be from the non-use as denominator of financial contracts to the non-use as store of value: with the inability to denominate financial contracts, a country would have foreign denominated liabilities, demanding investors to sell domestic currency to buy the funding one when external obligations must be met (p. 436), resulting in a latent depreciation pressure and risk of sudden and sharp exchange rate depreciations. It is due to this dynamic that a currency's ability to act as store of value and media of contractual settlement would be undermined, and thus its international liquidity premia (Kaltenbrunner, 2015, p. 440).

It should be highlighted that the unit of account function can manifest in different forms. While the usages cited by De Conti and Prates (2014) ${ }^{100}$ reflect a focus on the ability of a currency to be used in price setting, Kaltenbrunner (2015) suggests the specific use of a currency as denomination of financial contracts. The ability to denominate contracts mentioned by Prates (2002) had a focus on the country's capacity to issue debt in its own currency $^{101}$, which reflects the objective of explaining the late-1990s crises where the public sphere and debt played prominent roles. Kaltenbrunner (2015), on the other hand, focuses on international investors and on any type of external liability (not only debt), reflecting a higher influence of the GFC dynamics, in which the liabilities of emerging countries were more varied (as it will be seen in Chapter Four).

In the last two decades, the analyses of the specificities of emerging currencies and its tendency to crisis have therefore pointed to different aspects featured in different crisis episodes. The (lack of) store of value function is central to dynamics concerning the assets' side of foreign investors and their choices for maintaining the value of their assets. The function of denomination of financial contracts comes into play in the liabilities' dynamics and the implications of having to meet financial obligations. Both are important and cannot be dissociated. As seen in Chapter Two, the different markets, and thus countries, are interconnected by money managers' balance-sheets. Minsky's analysis, discussed in Chapter Seven, is different from others for pointing exactly to this interconnection of balance-sheets (and

\footnotetext{
${ }^{99}$ See De Conti and Prates (2014) for arguments on the opposite causality.

${ }^{100}$ De Conti and Prates (2014) follow Cohen (1971, as cited in De Conti and Prates (2014)) on the specific usages.

${ }^{101}$ Note that the presence of original sin (a country's ability to issue debt in its own currency) is, itself, a dimension of the de facto convertibility of a currency.
} 
the associated fragility that derives from it). Andrade and Prates (2013) and Kaltenbrunner (2015), respectively, focus on the assets' and liabilities' sides, and are therefore, highly complementary.

\subsubsection{The use of Keynes' equation on an assets' own rate of interest}

The different positions in the international monetary and financial system (IMFS) would thus be translated in different levels of liquidity premium: the highest for the U.S. dollar, the lowest for the emerging currencies. The analysis of the implications of this different attribute of emerging currencies is facilitated by the use of Keynes' equation on an asset's own rate of interest. With this equation, Keynes (1936) indicated that in a monetary production economy an asset's own interest rate (or "total expected returns", $r_{a}$ ) is determined by four main attributes $^{102}$ : its expected appreciation $(a)$, its quasi-rent ( $q$, or yield), its carrying costs ${ }^{103}$ (c) and its liquidity premium ( $l$, a power of disposal that confers a potential convenience or security) (Andrade and Prates, 2013, p. 402) - see Equation 3.29:

$$
r=a+q-c+l
$$

The equation was developed by Keynes to estimate the return of domestic economy assets (including money) being built for same currency assets. However, it has been translated to the context of currencies based on the view of a domestic currency as an "international asset class" (Kaltenbrunner, 2011, p. 90) ${ }^{104}$ or, because "currencies are held as a portfolio capital asset" (Andrade and Prates, 2013, p. 404).

The analysis of the implications of the specificities related to the hierarchic nature of the IMFS on a currency's return can therefore be done through its liquidity premium, $l$, that is lower for emerging currencies than for those of central countries.

\footnotetext{
${ }^{102}$ The characteristics of a monetary production economy will be discussed in Chapter Seven.

${ }^{103}$ Capital controls (Andrade and Prates, 2013) and transaction costs, that could be reduced with higher liquidity (Prates, 2015, p. 401-402) are examples of carrying costs. Alternatively, it could be seen as the degree of financial openness of a country (De Paula et al., 2016).

${ }^{104}$ Kaltenbrunner (2015, p. 428) cites several authors that have used some of the variables in this equation in exchange-rate analysis, while Kaltenbrunner (2011), Andrade and Prates (2013), and Kaltenbrunner (2015) are cited as examples of uses of all elements present in Keynes' equation. While it is not clear whether the first group of references focus specifically on emerging-currencies dynamics, this is the case of the latter three papers.
} 
Andrade and Prates (2013) focus on the impact of a country's features in defining capital flow dynamics. Given that $l$ is structurally low, capital flows would mostly be attracted by the other features $-a, q$, or $c$ ). These changes are analyzed in light of the liquidity preference scenario, which is therefore seen as the major determinant of capital flows. For instance, capital will be directed to emerging countries:

in situations marked by an excess of international liquidity and a higher appetite for risk, or eagerness to bet against the uncertain future (lower liquidity preference), when, normally, conventions (and expectations) about the future trajectory of the economy are more optimistic, and interest rates in core countries are lower. (p. 401)

In these moments, there will be an increase of the feature $a$ that compensates for the low $l$, resulting in capital flows.

Conversely, when uncertainty and liquidity preference are high, these countries will face capital outflows: In moments of "reversal of the cycle, of monetary/fiscal policy changes in the center or of increase in the liquidity preference", these countries are the "first victims of the global investors" (Andrade and Prates, 2013, p. 410) due to the lower $l$ and consequent incapability of being "a receptable of uncertainty on a global scale" 105 .

In Andrade and Prates (2013), although the narrative sometimes refers to the features in relative terms, the equation is presented in absolute terms (which might reflect the authors' intent to analyze the desirability of a currency, and not exchange rates (De Paula, Fritz and Prates, 2016)). For exchange rate analyses, however, relative returns are key (as done in traditional portfolio models, discussed in Section 3.1.2.3, and in SFC models, discussed in Section 3.3.5). The explicit consideration of a currency's returns in relative forms is done by Kaltenbrunner (2015) and De Paula et al. $(2016)^{106}$.

\footnotetext{
${ }^{105}$ Andrade and Prates (2013, p. 411) also use the equation to discuss a possible governmental interference: in case of capital outflows and need of stabilizing the currency, policy rate might be raised (thus managing both $q$ and $a$ ) and financial openness can be deepened through a decrease of capital controls (a decrease of c).

${ }^{106}$ In Kaltenbrunner (2011) the importance of relative terms is also seen, as it considers that the assets' return should be equal "to the return offered by the currency with the highest liquidity premium, i.e. the money of the system".
} 
In De Paula et al. (2016), the consideration of relative terms is presented in the form of Equation $3.30^{107}$. The emphasis is put on the alternatives that emerging countries have to compensate for the low liquidity of their currencies $\left(l<l^{*}\right.$, where ${ }^{*}$ denotes a central currency):

to compensate for the lower liquidity premium, those currencies have to offer a higher $q$, which is a policy variable in order to try to achieve a higher $a$ (currency appreciation), creating conditions which are attractive for international investors, and/or to reduce $c$, i.e. the obstacles for capital inflows (or capital outflows), with the withdrawal of capital account regulation. (p. 8)

$$
l^{*}-l=(a+q-c)-\left(a^{*}+q^{*}-c^{*}\right)
$$

Assuming that expected rates of return $(r)$ throughout the world will be driven toward equality ${ }^{108}$ and given that there is a "world reserve currency", Kaltenbrunner (2015, p. 431) presents the following equations (3.31 and 3.32), where $(*)$ denotes the equivalent for the world reserve currency. The expected appreciation $(a)$ is considered with regards to the world's money, and it assumes that carrying costs $(c)$ are negligible for short-term financial instruments ${ }^{109}$ :

$$
\begin{gathered}
r=a+(q-c)+l=\left(q^{*}-c^{*}\right)+l^{*} \\
\left(q-q^{*}\right)+a=\left(l^{*}-l\right)
\end{gathered}
$$

Equation 3.32 is presented by Kaltenbrunner (2015) as a representation of a reason behind the structurally higher interest rates of some emerging countries:

\footnotetext{
${ }^{107}$ De Paula et al. (2016) actually use the subscript ${ }_{n}$ and $s$ as reference to northern and southern (or peripheral emerging) countries. The reference to a central currency instead of a northern currency is done to facilitate a comparison with Kaltenbrunner (2015).

${ }^{108}$ Kaltenbrunner (2015) does not detail the convergence mechanism. If the higher return of a country $(q)$ leads to higher capital inflows, the resulting exchange rate appreciation might lead to an expectation of further appreciation (an increase of $a$ ) and thus an increase of returns, diverging $r$ further, instead of converging. This mechanism of divergence is in line with Kaltenbrunner and Painceira (2009), with the bandwagon effects of Schulmeister and Harvey, and with the model that will be proposed in Chapter Seven. The hypothesis of convergence also assumes that the policy rate is not used as an instrument of inflation control, while most emerging countries follow inflation targeting regimes (as it will be seen in Chapter Four).

${ }^{109}$ Equation 3.31 does not consider that the return of world's reserve currency $\left(r^{*}\right)$ includes an expectation of exchange rate change $\left(a^{*}\right)$. In a two country model, the appreciation of a currency should be the depreciation of the other, in the terms of the equations, $a=-a^{*}$, that could demand the exclusion of $a^{*}$ from Equation 3.32 if $a^{*}$ were considered in Equation 3.31. Kaltenbrunner's choice might have been based on the consideration of the equations not as a two-country model, or on the fact that the relevant $a^{*}$ is not estimated with regards to the emerging currency.
} 
(...) similar to Keyness understanding of interest rate determination in the closed economy, a currency's yield differential $\left(q-q^{*}\right)$ has to compensate for its lower liquidity premium relative to that of the leading currency $\left(l^{*}-l\right)$ if demand for it is to be maintained" ${ }^{110}$. (p. 433)

Emerging currencies would therefore be marked by "latent depreciation pressures and risks of sudden and sharp exchange rate depreciations" that are exogenous to domestic conditions - in moments when "investors have to sell these currencies (and acquire the funding currency) to meet their contractual obligations" (Kaltenbrunner, 2015, p. 440).

\section{Volatility or extreme depreciations? And the role of the international scenario}

Andrade and Prates' (2013) and Kaltenbrunner's (2015) analyses therefore argue that emerging countries' currencies are vulnerable to moments of crisis internationally either for being unable to store value (Andrade and Prates, 2013) or for not being used in contractual obligations (Kaltenbrunner, 2015). The consequent major depreciations would occur in specific moments of turbulence internationally, such as in moments of "reversal of the cycle, of monetary/fiscal policy changes in the center or of increase in the liquidity preference" when "investors [...] reassess their investment decisions" (Andrade and Prates, 2013, p. 410), or "moments of market turmoil" (Kaltenbrunner, 2015, p. 442), or change in international "funding" (p. 439), or "liquidity conditions" (p. 440).

Therefore, it can be asserted that the authors' arguments do not refer to the higher volatility of emerging currencies in general, but to the important depreciations in specific moments. As it will be shown later in the thesis, such argument would be coherent with empirical findings for some emerging currencies since the $2000 \mathrm{~s}^{111}$. This type of volatility is different from that analyzed by Schulmeister and Harvey (depicted as zigzags) that emerge from technical trading, bandwagon and herd behavior. Some emerging countries that count with deep and sophisticated foreign exchange markets, are also subject to this type of volatility,

\footnotetext{
${ }^{110}$ Note that this implies stable expectations about exchange rate developments $(\bar{a})$, either of appreciation or depreciation, but it does not necessarily imply stability, $(a=0)$.

${ }^{111}$ Chapter Six presents findings about the volatility of some emerging countries (specifically those that have a more "financialized integration", a concept suggested and discussed in Chapter Five).

Specifically, the comparison of these emerging countries exchange rates with the Euro/Dollar rate, shows that while the former suffer from more frequent extreme depreciations, the latter presents a higher standard deviation from its trend.
} 
but the analysis presented in this section points to what could be an additional source of volatility: one that emanates from external shocks due to the specificities of their currencies and its use in international portfolio allocation.

In addition, the definition of the exchange rate cycles seen in emerging currencies might be different than those of advanced countries' currencies. Based on an analysis of the Deutsche mark, the euro and the dollar, Schulmeister argues that long-term cycles are the result of short-term cycles, with the trend being determined by whether the short-term 'up' trend is longer than its 'down' trend, combined with the way investors saw fundamentals (the role of their medium-term expectations). On the other hand, the internal dynamics of the foreign exchange market in emerging currencies are dominated by prevailing conditions in international financial markets, resulting in cycles whose length is dependent on the frequency of turmoils in those markets.

These analyses therefore suggest emerging currencies' vulnerability to changes in the international scenario. The idea of emerging currencies being vulnerable to money managers' decisions will be developed in Chapter Seven.

An important explanatory power The explanatory power of the analyses based on the asymmetry of liquidity premia among currencies is considerable. It can account for the appreciation of the Japanese yen after the Fukushima accident in 2011 when Japanese insurance firms and carry-trade investors repatriated their investments ("What is happening to the Japanese yen?", 2011). At that moment, capital flew to Japan because of the financial obligations of insurance firms. As a consequence, knowing that and expecting the yen to appreciate with this inflow of capital, carry-trade investors repatriated their investments to gain with the exchange-rate change. The role of the denomination of financial obligations also explains the GFC-related flows - when investment currencies depreciated sharply, and the funding currencies appreciated, unrelated to their countries' conditions (Kohler, 2010 $)^{112}$. With the Euro crisis, depreciation of emerging currencies are better explained by the non-use of emerging currencies as store of value, as it was more of a crisis of uncertainty than a need of covering losses as the GFC.

\footnotetext{
${ }^{112}$ See Brunnermeier (2008), Hesse et al. (2008), and Milesi-Ferretti and Tille (2011) for a description of the $2007 / 2008$ events and see Tridico (2012) for a review of competing explanations of the crisis.
} 
Irrespective of the reason, if the high liquidity premium is due to the denomination of financial obligations or to the store of value function, liquidity premium asymmetries can also explain why the United States has received so much foreign private-sector investment even with very low interest rates since the GFC. Indeed, Forbes (2010) finds that:

Foreigners have earned substantially lower returns on their U.S. investments over the past five years than U.S. investors have earned abroad, even after removing the effects of exchange rate movements and official sector investments. This return differential against foreigners even exists within individual asset classes (equities, foreign direct investment, and to a lesser extent, bonds) and even after making rough adjustments for risk. (p. 2)

From this framework, the high flows to the United States even with very low interest rates $\left(q^{*}<q\right)$ and "high risk" is no puzzle: they derive from its currency's exceptional place in the international monetary system (and consequent high liquidity premium, $l^{*}>l$ ). This suggests the superiority of the keynesian framework when compared to traditional portfolio models - what derives from their account for the liquidity premium and the fact that it is a more complete concept than risk.

\subsubsection{Including liquidity preference in the equation}

Emerging currencies' l-feature is therefore structurally low to both Andrade and Prates (2013) and Kaltenbrunner (2015). Although $l$ is structurally defined, its impact on a currencies' return might change if there is a change in how agents value this feature: in moments of change in liquidity preference. To account for such possibility in the keynesian-equation, a weight $(\beta)$ can be included on how "preferred" the liquidity attribute is, as in Equation 3.33 and 3.34 that are receptively related to assets denominated in emerging currency $(r)$ and one denominated in the currency of a central economy $\left(r^{*}\right)$, or in Equation 3.35:

$$
\begin{gathered}
r=a+(q-c)+\beta l \\
r^{*}=a^{*}+\left(q^{*}-c^{*}\right)+\beta l^{*} \\
r-r^{*}=(a+q-c)-\left(a^{*}+q^{*}-c^{*}\right)+\beta\left(l-l^{*}\right)
\end{gathered}
$$


Given that $l^{*}$ is higher than $l,\left(l-l^{*}\right)$ has a negative effect on the return differential $\left(r-r^{*}\right)$. An increase in liquidity preference $(\uparrow \beta)$ increases the negative impact of $\left(l-l^{*}\right)$ on the return differential $\left(r^{*}-r\right)$. The consequence is an outflow of capital from the emerging to the central economy, what is in line with the dynamics suggested by Biancareli (2011).

The analysis based on a system of two equations is an option for analyzing exchange rates - "the relation between domestic and foreign money, (...) a manifestation of these differential returns" (Kaltenbrunner, 2015, p. 431) - without assuming the convergence of returns. But the liquidity preference coefficient can also be added to the framework proposed by Kaltenbrunner (2015), as in Equation 3.36:

$$
\left(q-q^{*}\right)+a=\beta\left(l^{*}-l\right)
$$

Equation 3.36 shows that an increase of liquidity preference $(\beta)$ increases the yield differential $\left(q-q^{*}\right)$ needed to maintain the stability of capital flows (given no change in expectations, $\bar{a}$, nor in liquidity premia, $\bar{l}$ and $\bar{l}^{*}$ ). In other words, in moments of higher liquidity preference, emerging countries would have to increase its policy rate to maintain capital flows. This is a clear representation of the lack of autonomy of monetary policies in emerging countries.

\subsubsection{Additional remarks on the use of Keynes' equation}

The use of Keynes' equation on an asset's own rate of interest is a very important step on elucidating the dynamics of emerging currencies for including the significant liquidity feature in the exchange-rate discussion. Having included liquidity concerns, this framework dialogues with the risk-return founding dilemma of portfolio equations. It is however an heterodox alternative, where uncertainty is not reduced to calculable risk (as $r$ in Equation 3.15) ${ }^{113}$. On the contrary, it is a subjective variable, allowing the consideration of expectations and conventions.

While Andrade and Prates (2013) focus on the desirability of a currency, Kaltenbrunner (2015) highlights that such desirability gains on meaning when seen in relation to the attributes of a 'competing' currency, which is an important step in exchange-rate analyses.

\footnotetext{
${ }^{113}$ The discussion on the concepts of risk and liquidity preference is done in Chapter Five.
} 
Still, synthetic and detailed formalization have both positive and negative features. On the one hand, the schematic $(a+q-c)$ versus $(l)$ dilemma in Andrade and Prates (2013) and the $\left(q-q^{*}+a\right)$ versus $\left(l^{*}-l\right)$ dilemma in Kaltenbrunner (2015) allow for rich discussions on the role of international dynamics in emerging countries' exchange rates.

On the other hand, the synthetic form might be unable to account for crucial dynamics. For instance, the analysis based on the currency's return $(q)$ as policy rate is restrictive, given the different dynamics related to equity returns ${ }^{114}$. On a general level, it should be noted that due to not having fixed returns, equities' liabilities are more subject to changes in expectations, increasing "speculative" behavior. But the most significant and specific point is that equities can trigger a self-fulfilling spiral forming bubbles and leading to diverging returns in two markets: as an increase in inflows to stock markets increases its returns, it leads to expectations of exchange rate appreciation and higher returns, leading to more inflows. This is specially important in light of the increasing weight of equities as a form of foreign liabilities in emerging countries (as it will be discussed in Chapter Four).

Another consequence of the very synthetic character of Keynes' equation is the sideby-side consideration of monetary and non-pecuniary variables: $l$ is considered in the same way as monetary variables $(a, q, c)$, as an additional and independent form of return despite its nonpecuniary characteristics (Andrade and Prates, 2013, p. 402). It is therefore a nonpecuniary variable that determines returns ${ }^{115}$. However, having the liquidity feature be a determinant of demand could be more precise, with liquidity and return jointly determining demand. This is suggested in the following session.

\subsubsection{Exchange-rate dynamics in SFC Models}

SFC models are similar to portfolio models presented in Section 3.1.2.3 in that both are inspired by Brainard and Tobin's (1968) method (Godley and Lavoie, 2007, p. 15) $)^{116}$.

\footnotetext{
${ }^{114}$ The variable $q$ should account not only for the public bonds or equities, but also other assets. I want to emphasize, however, the specific dynamics related to equities.

${ }^{115}$ Note that this inconsistency is not eliminated with the inclusion of the liquidity-preference feature $(\beta)$ in Equations 3.33, 3.34 and 3.36 .

${ }^{116}$ Dos Santos (2006) enumerates four features presented by Tobin in his Nobel lecture as features that distinguish his work, that also apply to SFC modeling: the tracking of stocks and precision regarding time; the several assets and rates of return; the modeling of financial and monetary operations; the budget constraint and the adding-up constraint.
} 
SFC models are built from different sectors' (such as households, firms, the government) stock-flows norms with the aim of describing the most important economic relations in an economy ${ }^{117}$. It is based on accounting and behavior equations, the latter being those that determine the causality among the model's variables, thus its assumptions - or how the models are 'closed"118. It is in the behavior equations that heterodox and traditional portfolio models differ: while the latter are labeled neo-classical-Keynesian, SFC models are "essentially postKeynesian or heterodox" (Godley and Lavoie, 2007, p. 15) ${ }^{119}$. SFC models are expected to be more realistic than the standard portfolio models, as the search for realisticness is a characteristic of the school (as opposed to the mainstream's instrumentalism (Lavoie, 2014) ${ }^{120}$ ). For instance, some models have as 'closures' Central Banks that set interest rates, instead of attempting to target money supply or securities' supply ${ }^{121}$ (Godley and Lavoie, 2003, p. 3). Indeed, it is one of the most prominent type of modeling in the Post Keynesian tradition ${ }^{122}$. Macedo e Silva and Dos Santos (2011, p. 105) argue that institutionally rich SFC models are "the ideal tool for rigorous post-Keynesian analyses of the medium run" given its "period by period balance sheet dynamics and throughout description of the short-period behavior of agents. SFC framework is thus "crucial to the consolidation of the broad post-Keynesian research programme".

\footnotetext{
${ }^{117}$ A synthetic description of Godley and Lavoie's (2007) open-economy model by Lavoie and Daigle (2011, p. 438 ) provides a good idea of how comprehensive SFC models can be: "The key features specific to this model are the ability of agents to trade for foreign assets, the dependence of international trade on both domestic and foreign output as well as relative prices, and the endogeneity of prices. The model features a large number of endogenous variables. Import prices, export prices, domestic sales deflators, GDP deflators and the exchange rate are all endogenous variables. So are real quantities such as exports, imports, output, consumption, domestic sales, and disposable income. Other endogenous variables include taxes, interest payments, the supply of money, holdings of foreign and domestic bills, household wealth, and of course the government deficit and the government debt. Standard balance of payment measures, such as the trade balance, the current account balance, the capital account balance and the value of foreign reserves are endogenous as well. Still, simplifying assumptions needed to be made to keep the model under 100 equations. There is no domestic or foreign investment in fixed or working capital. As a consequence, the model, when it converges, tends toward a stationary state. Also there is no wage inflation, no commercial banking, and as pointed out already, the treatment of exchange rate expectations is more than rudimentary."

${ }^{118}$ Taylor provides a good definition of a model 'closure': "Formally, prescribing a closure boils down to stating which variables are endogenous or exogenous in an equation system largely based upon macroeconomic accounting identities, and figuring out how they influence one another" (Taylor, 1991, as cited in Dos Santos (2006)).

${ }^{119}$ See Dos Santos (2006) for a comparison between SFC modeling and mainstream macroeconomics.

${ }^{120}$ See the discussion in the Introduction Chapter.

${ }^{121}$ Godley and Lavoie (2003, p. 3) reminds us that this assumption (or 'closure') is not unique to Postkeynesians. In fact, it is also common to 'New consensus' models, as they are found among central bank practitioners and some New Keynesians.

${ }^{122}$ Path-dependence models, the neo-kaleckian and Minskyan models of income distribution and growth are other important types of economic modeling in the Post Keynesian tradition (Asensio et al., 2011).
} 
Lavoie and Daigle (2011) also highlight the importance of the consideration of time as historical-time, a key feature for post-Keynesian analyses:

"A major difference between standard open-economy portfolio models and stockflow consistent models however is that while the former establish timeless equilibria, the latter track stocks of assets and flow variables through time, in a sequential manner." (p. 244)

For exhibiting historical time, SFC models are also used to study issues of path-dependence or hysteresis (as done by Lavoie and Daigle (2011) for exchange rates).

A very praised characteristic of SFC models is that it has "no black holes", as "all stocks are the result of cumulated flows plus capital appreciation" (Godley and Lavoie, 2005, p. 3). This feature has theoretical and technical advantages - in addition to allowing the construction of applied models to study specific conditions and run economic scenarios ${ }^{123}$ (Dos Santos and Zezza, 2008). On the theoretical front, as reminded by Dos Santos (2005, p. 718), the absence of black holes with all economic sectors tied together make SFC models a perfect framework for analyses of monetary economics, which, in Minsky's words, is characterized by "the set of interrelated balance sheets among the various units", so that "one way every economic unit can be characterized is by its portfolio: the set of tangible and financial assets it owns and the financial liabilities on which it owes" (Minsky, 1975, as cited in Dos Santos $(2005))^{124}$.

\footnotetext{
${ }^{123} \mathrm{SFC}$ models have indeed been built with different goals. In Dos Santos and Zezza's (2008) review, the aim of the different models are as diverse as: "(i) checking the logical consistency of incomplete models; (ii) extending the approach to deal with open economy issues; (iii) discussing the theoretical compatibility of SFC models with the views of important authors who phrased their views in literary form; (iv) producing applied models which can be used to study actual economies; and (v) exploring the properties of models with different financial architectures and supply specifications" (p. 471).

${ }^{124}$ It is interesting to note that the analysis of balance-sheets and the liabilities of a countries' sectors also appears to be gaining importance in mainstream circles. The 'risk-channel' Shin (2016)) and the 'bank lending channel' (Disyatat, 2011) are evidence of great concern with the global banking dynamics and its spillovers on other economies. Indeed, several works from the Bank of International Settlements seem to go in this direction. Shin (2016) criticizes traditional international economy models for their belief on the three-coincidences "where the GDP area, decision-making unit and currency area are one and the same. [...] Textbooks therefore start with the assumption that each GDP area has its own currency and the use of that currency is largely confined to that economic area. The Mundell-Fleming model is a classic example of the triple coincidence, but even in sophisticated macroeconomic models, the triple coincidence is rarely questioned. Currency appreciation or depreciation then acts on the economy through changes in net exports" (see Avdjiev et al. (2015)). Although not posited this way, his reasoning based on these criticisms put light on the liabilities' dynamics. Based on the triple coincidence, pre-GFC US deficits would lead to a dollar depreciation, but instead, U.S. dollar appreciated sharply. In the author's view, the reason for this appreciation is found on a sector's balance-sheet: it is associated with "a deleveraging of financial market participants outside the United States that had used short-term dollar funding to invest in risky long-term dollar assets, with the European banks mentioned above
} 
On the technical side, the no-black-hole constraint, together with the fact that it is a complete model, allows for a detailed examination of economic models proposed by other theoretical approaches and thus, an assessment of its dynamics and of the validity of their conclusions. As argued by Taylor (2009a, p. 2) SFC macro modeling helps to "remove many degrees of freedom from possible configurations of patterns of payments at the macro level, making tractable the task of constructing theories to "close" the accounts into complete models". Differently from literary analyses, in the SFC approach the concerned dynamics are forced to interact with all other variables of the economic system, requiring an explicit recognition of such "system-wide constraints", as well as of the potential limitations of the analyses (Dos Santos, 2006, p. 564).

In this sense, Godley (2012) argues that SFC is an interesting framework for allowing more detailed and precise discussions than the narrative method. Indeed it highlights disagreement in areas where further studies are needed, and is useful in comparing dynamics that might differ from one place to another, through a change in the equations or in the 'closures' of the models. However, it must be noted that the level of details of the discussion might be constrained by the difficulty of running very complex SFC models and of keeping track of their causalities ${ }^{125}$.

Therefore, SFC models have great potential for exchange-rate analyses. By allowing a simultaneous treatment of flows and stocks, and of real and financial variables, both portfolio (stocks) adjustments and trade flows have potential to impact exchange rates (which is especially important in times of financialization, where portfolio adjustments across different global financial assets are of major relevance $)^{126}$.

Moreover, the SFC constraints can be added to an Agent-Based model (ABM) resulting in a (AB-SFC $)^{127}$ model that has heterogeneous agents, with micro-macro interactions.

being the most prominent example. As the crisis erupted, these financial institutions found themselves short the dollar and overleveraged, and sought to reduce their dollar liabilities, bidding up the value of the dollar in the process." (Shin, 2016, p. 13-14).

${ }^{125}$ Godley (2012) argues that one of the intents of the SFC approach is to "supplement the narrative method used perforce by Keynes and his followers before the computer age".

${ }^{126}$ Note that this feature was already present in some mainstream portfolio models such as Branson's (1974).

${ }^{127}$ The ABM provides a bottom up framework where the economy results from agents' decision - relaxing the representative agents' hypothesis. It combines a microeconomic approach with the macroeconomic strictness (Clévenot and Héron, 2014). 
Because they allow the consideration of heterogeneous agents, these models can provide interesting analyses of foreign exchange markets, with traders that follow different rules, as fundamentalists and chartists (similarly as the models discussed in Section 3.1.5).

Being a 'fully interdependent system', exchange rates react to shocks from numerous sources in SFC models. Instead of being analyzed separately, "as stand-alone processes", they are "part of a complete, self-contained, economic system" (Lavoie and Daigle, 2011, p. 244). For instance, usually, in the 'exchange-rate equation', the exchange rate equals a securities supply-and-demand ratio $\left(\frac{B_{\# s}^{\Phi}}{B_{\# d}^{\Phi}}\right)$, as in Equation $3.37^{128}$ :

$$
E^{\#}=\frac{B_{\# s}^{\$}}{B_{\# d}^{\$}}
$$

As an open-economy SFC model can have more than hundred equations, its complete transmission channels cannot be mentioned here. It can however be highlighted that, from the side of the supply of securities $\left(B_{\# s}^{\$}\right)$, exchange rate determination include variables such as "government surplus or deficit, which, itself, is a function of a variety of factors throughout the economy". Securities' demand $\left(B_{\# d}^{\$}\right)$, on the other hand, is "a function of the wealth accumulated in each country which, itself, is also a function of a variety of factors throughout the economy" (Lavoie and Daigle, 2011, p. 445).

Portfolio equations, similar to the ones below, are of highest relevance to this thesis' discussion. In these equations, total wealth $\left(V^{\$}\right)$ of investors based in country $\$$ is allocated among domestic assets $\left(B_{\$}^{\$}\right)$, and foreign financial assets $\left(B_{\$}^{\#}\right)^{129}$. The demand $\left.{ }_{d}\right)$ functions for each of these assets is given by Equations 3.38 and 3.39, where $r$ stands for the assets' respective returns and $e^{\# e}$ the expected exchange rate change $\left(e^{\# e}=E_{t+n}^{\# e}-E_{t}^{\#}\right)^{130}$ :

$$
\begin{aligned}
& B_{\$ d}^{\$}=V^{\$}\left(\lambda_{20}+\lambda_{21}\left(r^{\$}\right)-\lambda_{22}\left(r^{\#}+e^{\# e}\right)\right) \\
& B_{\$ d}^{\#}=V^{\$}\left(\lambda_{30}-\lambda_{31}\left(r^{\$}\right)+\lambda_{32}\left(r^{\#}+e^{\# e}\right)\right)
\end{aligned}
$$

\footnotetext{
${ }^{128}$ This equation presents the ratio between the supply of assets from country $\$$ in country \# over the demand of assets from country $\$$ in country \#. It is used by Lavoie and Daigle (2011).

${ }^{129}$ The subscript $(\$)$ indicates that they are considered in the currency of the country $\$$.

${ }^{130}$ Note that in a two-country model $e^{\# e}=\frac{1}{e^{\$ e}}$.
} 
Similarly, investors based in country \#, allocate their wealth $\left(V^{\#}\right)$ among domestic $\left(B_{\#}^{\#}\right)$ and foreign financial assets $\left(B_{\#}^{\$}\right)$, as in Equations 3.40 and 3.41:

$$
\begin{aligned}
& B_{\# d}^{\#}=V^{\#}\left(\lambda_{50}+\lambda_{51}\left(r^{\#}\right)-\lambda_{52}\left(r^{\$}+e^{\$ e}\right)\right) \\
& B_{\# d}^{\$}=V^{\#}\left(\lambda_{60}-\lambda_{61}\left(r^{\#}\right)+\lambda_{62}\left(r^{\$}+e^{\$ e}\right)\right)
\end{aligned}
$$

For modeling the whole economy, SFC models allow for feedback effects, such as those from the exchange rate to trade balance, domestic income, and thus income effects on the trade balance (Lavoie and Daigle, 2011). Such feedbacks are ignored in mainstream analyses where the focus is on a timeless equilibrium (Godley and Lavoie (2003, p. 2)). Feedback analyses, in turn, are made possible by the treatment of time as historical time (as just presented).

\subsubsection{Exchange rate analyses}

With the SFC framework, some authors conducted interesting analyses of exchange rate theories originally presented within other frameworks. Godley (1196) and Taylor (2004) analyzed mainstream exchange rate theories, especially their stock-flow consistency and results, with significant results. Godley (1996, as cited in Taylor (2004, p. 210)), showed that no equation similar to the balance of payments can be found by looking at an economy's social accounting matrix $(\mathrm{SAM})^{131}$. In other words, regardless of the numerous relationships, not one involves all the cross-border flows with their exchange conversions. This is no surprise to Taylor (2004, p. 210): why should they "add up to some over-riding 'balance', especially since all have their own separate determinants"? The view of exchange rates as a marketclearing price crumbles with this finding. Taylor (2004) concludes that the exchange rate cannot converge to an equilibrium value and any attempt to model it under the assumption that they are moving towards fundamental values is doomed to fail.

\footnotetext{
${ }^{131}$ See second chapter in Godley and Lavoie (2007, p. 24) for details on the SAM and how it differs from Richard Stone's social accounting that was eventually laid out in the 1953 United Nations System of National Accounts, that "left monetary and financial phenomena in the dark" with "no integration between the flows of the real economy and its financial side".
} 
Indeterminancy of exchange rates in the Mundell Fleming and the portfolio balance models is another result from SFC models. Taylor (2004) argues that these models are stock-flow inconsistent: Due to the net foreign asset constraint (total net foreign assets "are constant in the short run"; they "can only change over time due to a surplus or deficit on current account" (Taylor, 2004, p. 213)), there would be only one independently clearing asset market in a country. If the domestic asset market is cleared by local interest rates, portfolio adjustment cannot determine the exchange rate, which is left undetermined.

\subsubsection{Modeling exchange-rate expectations}

Open-economy SFC models are not as numerous as closed economy models ${ }^{132}$ and modeling exchange-rate expectations is still incipient despite its importance for PK exchange-rate analyses. There are four main options - static expectations, expectation of a given exchange rate change (e), expectation of a given exchange rate value (E), expectation that the exchange rate follows some type of fundamental, such as the UIP, as shown in Table $3.3^{133}$. There is also the possibility of having heterogeneous agents, and thus, a market formed of a combination of these expectations.

TABlE 3.3 Modeling Exchange-Rate Expectations

$$
\begin{array}{lcl}
\text { Static expectations } & e^{e}=0 & \begin{array}{l}
\text { Neutral } \\
\text { Exp. of a given } e
\end{array} \\
& e^{e}=x & \left\{\begin{array}{l}
\text { if } x<0, \text { Bullish } \\
\text { if } x>0, \text { Bearish } \\
\text { if } x=e_{t-1}, \text { Chartist }
\end{array}\right. \\
\text { Exp. of a given } E & E^{e}=x & \text { Static Fundamentalist } \\
\text { Exp. of the UIP } & E^{e}=E_{t-1}+\left(r^{*}-r\right) E_{t-1} & \text { Endogenous Fundamentalist }
\end{array}
$$

Looking for an alternative where the exchange rate would "evolve over time subject to rules based on expectations about its values in the future", Taylor (2004, p. 223) chose to use the UIP (discussed in Section 3.1.1.2) to close his model. Note that Taylor refers to the model's exchange rate itself - not to the exchange rate expectation, as considered in Table

\footnotetext{
${ }^{132}$ See Caverzasi and Godin (2015) for a review of open economy models, including purely theoretical models and analysis of occurring world events, both treating exchange-rate dynamics, expectations, and aspects such as foreign reserves, gold reserves, and balances of payments.

${ }^{133}$ Mentioning options for modeling exchange-rate expectations, Godley and Lavoie (2007) indicate: i) a fixed value that traders would have in mind, as a fundamental value, or ii) a rate of exchange-rate change, that can be positive, negative, or zero, representing a neutral case. Note that these are all cases where the exchange rate expectation is exogenous to the economy.
} 
3.3. This means that the exchange rate is modeled according to its own past value and to the interest rate differential (as in Equation 3.42):

$$
E=E_{t-1}+\left(r^{*}-r\right) E_{t-1}
$$

However, the accuracy of such exchange-rate determination is controversial. The equation shows the way that the forward rate is formed by traders (Lavoie, 2000, p. 172), but not the observed exchange rate pattern (as concluded by empirical tests in Moosa (2004)). The UIP can however be an approximation of how foreign exchange market participants form their expectations, if interest rate differentials are to be believed as an important fundamental in traders' mind. In other words, although the exchange rate does not float in this manner, it could be an approximation of how participants expect it to behave in a model where the exchange rate would actually be determined by several contemporary variables, such as through the use of equation 3.37 and portfolio equations (3.38 to 3.41) in a complete SFC model.

To consider that traders expect the exchange rate to remain the same $\left(e^{e}=0\right)$ is a great restriction, but it could be used for simplicity (as Godley and Lavoie (2007) did). Compared to the expectation of an exchange rate change, it is assuming that traders are neutral neither bullish $\left(e^{e}=x ; x<0\right)$, nor bearish $\left(e^{e}=x ; x>0\right)^{134}$.

To consider traders that have in mind a given exchange rate value $\left(E^{e}=x\right)$ might be useful for modeling fundamentalist traders. This is done by Lavoie and Daigle (2011), whose specification of exchange rate expectation is "drawn from the behavioural finance literature" (Lavoie and Daigle, 2011, p. 437) ${ }^{135}$. Similarly to De Grauwe and Grimaldi (2006a), fundamentalists trade expecting the exchange rate to converge to a given fundamental value, while chartists expect the future change in the exchange rate to be the same as the latest one. It creat the following dynamic. When there is a divergence from the fundamental value (or the creation of a 'bubble' in one direction), fundamentalists see it as an increase in the expected future exchange rate change and thus of their profits, investing more in the country facing

\footnotetext{
${ }^{134}$ The exchange rate is given as the amount of local currencies needed to buy a foreign currency unit.

${ }^{135}$ Specifically, the authors apply the idea of a market composed by chartists and fundamentalists of the model presented in chapter 2 of De Grauwe and Grimaldi (2006a) (discussed in the end of Section 3.1) to the SFC model presented in chapter 12 of Godley and Lavoie (2007).
} 
the exchange rate depreciation. This happens up to the point when the trend is reverted. At this moment, chartists change the direction of their trading, bringing the exchange rate back to its fundamental value. From this moment on, a 'bubble' is created in the opposite direction and the mechanism repeats itself. Therefore, the model yields in exchange rates cycles around an exogenously defined fundamental value.

Static vs. endogenous fundamentalist behavior The idea of a foreign market participant that trades knowing the fundamental value of the exchange rate is subject to criticisms related to the very existence of fundamental values and of efficient market models. However a fundamentalist trader may simply be a participant that knows what (part of) the other participants think about future exchange-rate value, coherently with Orléan's concept of an 'auto-referential' market. By expecting the exchange rate to be at a given level, these participants make their forecasts according to the current financial convention. As put by Orléan, to be 'auto-referentially' rational is the same as to estimate the result of a model. Similarly to the mainstream fundamental, their forecast is an external value that does not depend on their own opinion, but on the market's. In both Lavoie and Daigle (2011) and De Grauwe and Grimaldi (2006a), the forecast is an external value (a given value, and a stochastic process, respectively). In this sense, in both cases the modeling of the exchange rate forecast through a 'fundamentalist trader' does not necessarily imply the assumption of the exchange rate as a market clearing price.

Additionally, to consider that participants trade expecting the exchange rate to converge to a (supposedly) market-clearing price (in accordance with the result of mainstream models) is not the same as to assume that such price exists. Indeed, such consideration is realistic, if it is agreed that real world traders believe in market-clearing exchange rates. This is in line with the argument that the exchange rate converges to 'fundamentals' because traders make them behave in this way.

The simplification done by Lavoie and Daigle (2011) is not based on the assumption of fundamentalist traders, but on the fact that the given fundamental value is static and does not evolve with the economy. The use of a stochastic variable as exchange rate expectation has the same drawbacks: they are not associated with the economy's condition. In the different PK analyses discussed in this section, expectations are allowed to change: in Orléan's analysis, 
the financial convention evolves; in Schulmeister and Harvey, expectations "react" either to events, or to base factors and indicators, respectively. Static expectations in a context of important exchange-rate fluctuation are also not in line with the representativeness principle. Instead, traders would look for reasons for these fluctuations and adapt their expectations accordingly.

Modeling such floating fundamentalist expectations is not easy, but can be enabled by tying economic variables already estimated by the model to the exchange rate forecast, creating endogenous fundamentalist behavior - as in the fourth option of Table 3.3.

In conclusion, in light of this section's theoretical discussion, an SFC model in the line of Lavoie and Daigle's (2011) could be made more complex by including a series of features: the behavior of chartists could account for different types of model, as cash-in or contrarian traders, and participants could praise different currencies differently. Providing a framework to which details can be added and opening space for questioning how to model endogenous (and thus floating) fundamental values is a step forward in heterodox exchange rate modeling. This question will be dealt with in the next section, that also suggests ways to model the features that emerged from PK exchange-rate analyses to an SFC model.

\subsubsection{Adding post-Keynesian Features to SFC Portfolio Equations}

This section has presented heterodox views on exchange rate determination, that emerged from different approaches: Schulmeister's work is inductive, based on empirical analysis of the foreign exchange markets; both him and Harvey consider psychological insights into their analysis; analyses of the specificities of emerging currencies are based on historical and institutional analyses of the evolution of the international monetary and financial system; and SFC models are based on transactions matrix that aim to put down in equations domestic or open-economy dynamics in a detailed fashion. The main insights and shortcomings of the different approaches have been analyzed throughout the section. The following analysis aims at suggesting ways to use the different insights brought by these analyses in a SFC model, specifically on its portfolio equations, the locus of most of the discussions presented. 
The intention of discussing how these features could be added to a SFC model is to provide a common basis for theoretical discussion on exchange rate determination. If added to an empirical model (which is probably not an easy task) it might also be used to explain specific past exchange rate patterns ${ }^{136}$. This discussion may also be relevant to the SFC literature in general, for adding realism (or realisticness ${ }^{137}$ ) to the treatment of exchange rates in models that focus on different matters. Indeed, assumptions are simplifications, and "to avoid to avoid cluttering a model with insignificant details" is needed (Lavoie, 2014, p. $13)$.

The choice of SFC framework derives from the following advantages. First, portfolio equations allow adding considerations on the specificities of two (or more) currencies. This can be done within the framework of the keynesian equation (as seen in the last section), but it implies considering liquidity as a determinant of returns, while in SFC models they determine demand, which is more specific. Harvey's 'mental model', On the other hand, does not allow such considerations for being based on one single currency.

Second, in an SFC model financial and real interactions are considered. This is an advantage over Harvey's 'mental model', for instance, that is a partial model where only portfolio investment is considered as a factor adding supply or demand to the foreign exchange market. Third, the stock and flow coherence can be added to an agent-based model (an ABSFC model), allowing for heterogeneous agents and a greater details of agents' decisions. In this way, the investor is at the center of the model, perfectly matching the theoretical background of the rise of financialization and the importance of money managers. Note that this is also a feature of Harvey's 'mental model', but not the heterogeneity of agents. Fourth, in an SFC model the interaction between flows and stocks can be taken into account while none of the PK models discussed consider stocks.

Fifth, due to the flexibility of the SFC model, features that have not yet been discussed or institutional changes can be accommodated. These features are not only restricted to portfolio changes, but can also come from other sectors (as a policy of reserve accumulation or capital control). While different features and complex analysis can also be done by using

\footnotetext{
${ }^{136} \mathrm{It}$ is worth noting that there is no intention to use such a model for exchange rate forecast: the exchange rate is the result of social interactions that cannot be foreseen (whether investors will focus on one fundamental or another is unknowable) and that depend on responses to unpredictable events.

${ }^{137}$ See the discussion on realisticness, as opposed to instrumentalism, in the Introduction Chapter.
} 
literary analysis, they are more explicit when the SFC framework is used, as it demands a high level of precision over assumptions. Finally, the SFC framework allows the simulation of changes in economic variables, presenting its impacts through the economy.

How the different features of PK exchange-rate analyses can be added to the portfolio equations of SFC models will be discussed next. The equations 3.38, 3.39, 3.40, and 3.41 are replicated here for the reader's convenience. This analysis assumes that country $\$$ is a central country issuing a currency that occupies a higher place in the IMFS, and that country \# is an EME whose currency occupies a peripheral position.

$$
\begin{aligned}
& B_{\$ d}^{\$}=V^{\Phi}\left(\lambda_{20}+\lambda_{21}\left(r^{\$}\right)-\lambda_{22}\left(r^{\#}+e^{\# e}\right)\right) \\
& B_{\$ d}^{\#}=V^{\$}\left(\lambda_{30}-\lambda_{31}\left(r^{\$}\right)+\lambda_{32}\left(r^{\#}+e^{\# e}\right)\right) \\
& B_{\# d}^{\#}=V^{\#}\left(\lambda_{50}+\lambda_{51}\left(r^{\#}\right)-\lambda_{52}\left(r^{\$}+e^{\$ e}\right)\right) \\
& B_{\# d}^{\$}=V^{\#}\left(\lambda_{60}-\lambda_{61}\left(r^{\#}\right)+\lambda_{62}\left(r^{\$}+e^{\$ e}\right)\right)
\end{aligned}
$$

Liquidity-premium asymmetry and country bias The dynamics created by Lavoie and Daigle (2011) include country-bias: investors' preference for its own country assets ${ }^{138}$. Liquidity-premium asymmetry is a different phenomenon: as central currencies offer a higher liquidity premium, investors prefer investments in a central, rather than in a peripheral currency, regardless of their country of origin.

Country-bias can be translated in higher demand for its own country's assets $\left(B_{\$ d}^{\$}>B_{\$ d}^{\#}\right.$ and $B_{\# d}^{\#}>B_{\# d}^{\$}$ ) even if the return differential would not predict this (for instance, if

\footnotetext{
${ }^{138}$ Forbes (2010, p. 11) explains home-bias as a puzzle that cannot be explained by portfolio models: "standard portfolio theory shows that if investors care only about the mean and variance of the real return of their invested wealth, if markets are efficient, and the cross-border barriers to investment are small, then investors should hold the world market portfolio of stocks. An extensive literature on home bias, however, shows that investors deviate substantially from this prediction and tend to hold a larger share of domestic assets in their portfolios." Based on Kaltenbrunner (2015) one could argue that country-bias derives from the fact that investors' liabilities are held in their own country's currency. The framework presented in Chapter Seven is consistent with that and suggests that these biases derive from the additional element of uncertainty that affects any foreign investment: the unknown exchange-rate development.
} 
$\left.r^{\$}=r^{\#}+e^{\# e 139}\right)$. Country-bias could be added through the constants in the determination of demand for assets denominated in its own currency: $\lambda_{20}>\lambda_{30}$ and $\lambda_{50}>\lambda_{60}{ }^{140}$.

Different liquidity premiums, in turn, result in a bias in favor of central currencies from investors in the two countries even if central and emerging countries offer the same total expected returns: $B_{\$ d}^{\$}>B_{\$ d}^{\#}$ and $B_{\# d}^{\#}<B_{\# d}^{\$}$ even if $r^{\#}=r^{\$}+e^{\$ e}$.

With regards to the behavior of the central country's investors, both liquidity-premium asymmetry and county-bias result in biases towards their own country's assets, which can be modeled by considering $\lambda_{20}>\lambda_{30}$ or $\frac{\lambda_{20}}{\lambda_{30}}>1^{141}$. Accordingly, the simultaneous consideration of the two biases could be done by increasing the difference between $\lambda_{20}$ and $\lambda_{30}$, or by increasing $\frac{\lambda_{20}}{\lambda_{30}}$ above 1 .

However, with regards to the demand of the emerging-country investor, the two features act in opposite directions: the country-bias favors emerging assets and the liquidity-premium asymmetry favors the asset from the central economy. In terms of the coefficients, these considerations favor, respectively, $\lambda_{50}$ and $\lambda_{60}$. If the two features are considered equally important, $\frac{\lambda_{50}}{\lambda_{60}}=1$. Most likely, country bias is more important ${ }^{142}$ and thus $\frac{\lambda_{50}}{\lambda_{60}}>1$.

Therefore, $\frac{\lambda_{20}}{\lambda_{30}}>1$ and $\frac{\lambda_{50}}{\lambda_{60}}>1$. Since the two biases are working in the same direction in the case of foreign investor's demand, and in opposite directions in the case of emerging country's investors, it can be concluded that $\frac{\lambda_{20}}{\lambda_{30}}>\frac{\lambda_{50}}{\lambda_{60}}$. Distinguishing the lambdas in two is an option to deal with the two features (country bias, ${ }^{c b}$, and liquidity-premium asymmetry, $\left.{ }^{l p m}\right)$, separately:

$$
\lambda_{i 0}=\lambda_{i 0}^{c b}+\lambda_{i 0}^{l p m}
$$

In this case, the higher liquidity premium of central currencies are translated into $\lambda_{20}^{l p m}>$ $\lambda_{50}^{l p m}$ and $\lambda_{60}^{l p m}>\lambda_{30}^{l p m}$. The country bias, on the other hand, leads to $\lambda_{20}^{c b}>\lambda_{30}^{c b}$ and $\lambda_{50}^{c b}>\lambda_{60}^{c b}$.

\footnotetext{
${ }^{139}$ Note that this dynamic must emerge independently from issues of liquidity premium and liquidity preference.

${ }^{140}$ Also see how Lavoie and Daigle (2011, p. 444) calibrate their coefficients for allowing the emergence of country-bias.

${ }^{141}$ For simplicity, the discussion focuses only in the constants $\left(\lambda_{i 0}\right)$, but the coefficients $\lambda_{i 1}$ and $\lambda_{i 2}$ could also be adjusted.

${ }^{142}$ A way to test it would be to compare an emerging country's foreign assets position net of central bank reserves with its country equity and bond markets capitalization net of foreign liabilities.
} 
Liquidity preference Given that the different level of liquidity premium are accounted for, liquidity preference concerns are the most important feature to add to analyze the impacts of the changes of the international financial scenario in emerging currencies. As liquidity preference varies, there is a change on how investors value the liquidity premium of a currency. Its coefficient $\left(\lambda_{i 0}^{l p f}\right)$, must therefore be considered next to liquidity premium $\left(\lambda_{i 0}^{l p m}\right)$ in Equation $3.44^{143}$ :

$$
\lambda_{i 0}^{l p}=\lambda_{i 0}^{l p m} \times \lambda_{i 0}^{l p f}
$$

$\lambda_{i 0}^{l p f}$ is mostly stable. It increases in time of turbulence $\left(\uparrow \lambda_{i 0}^{l p f}\right)$, leading to a shift of demand from emerging $\left(\downarrow B_{\$ d}^{\#}, \downarrow B_{\# d}^{\#}\right)$ to central economy's assets $\left(\uparrow B_{\$ d}^{\$}, \uparrow B_{\# d}^{\$}\right)$, from both types of investors. Such a change in liquidity preference can be analyzed as a shock on $\lambda_{i 0}^{l p f}$, or, in an AB-SFC model, an exogenous series could be used (in the same way that the exchange rate fundamental is modeled in De Grauwe and Grimaldi (2006a)). In the latter case, the series could be modeled to resemble the VIX index, which is currently used as a proxy for uncertainty and thus liquidity preference in the literature (as it will be seen in Chapter Five) $)^{144}$.

Liquidity and liquidity preference The SFC framework allows the analysis of not only changes in liquidity preference $\left(\lambda_{i 0}^{l p f}\right)$, but also of liquidity itself, that can be seen as the hike of wealth in the center or in the periphery $\left(V^{\$}\right.$ and $V^{\#}$, respectively). While liquidity preference acts by shifting demand from assets in one country to another, changes in liquidity change the total demand for assets. Liquidity increase is an important development that led to the rise of financialization (as discussed in Chapter Two) and it is of major relevance to the integration of emerging countries' assets in the international financial system.

Exchange-rate expectations As briefly discussed in Section 3.3.5 and in Table 3.3, there are different ways to model exchange-rate expectations $\left(E^{i e}\right)$. Fundamentalists $(f)$ have a

\footnotetext{
${ }^{143}$ Note that this is the same of considering $\beta$ next to $l$ as in Equations 3.33 to 3.36

${ }^{144}$ As shown in Chapter Five, the behavior of the VIX in the 2000s has been characterized by more or less long stability, of levels close to 20, with peaks that are usually as high as 40, having achieved the 80-level with the GFC. A purely stochastic process would therefore not be the most welcomed. The optimum would be a series that has major hikes that slowly fade.
} 
fixed exchange rate $(x)$ in mind, shown in Equation 3.45. (In a two-country model, $E_{f}^{\$ e}=x$ and $\left.E_{f}^{\# e}=1 / x\right)^{145}$.

$$
E_{f}^{i e}=x
$$

As discussed in Section 3.3.5, such fundamentalist behavior is static and not in line with PK analyses. An option for modeling an endogenous fundamentalist behavior is to think of what traders see as fundamental exchange rates. If traders believe that the exchange rate follows the UIP, their behavior could be modeled as in Equation 3.46: A hike of interest rates in the emerging country $\left(\uparrow r^{\#}\right)$ is expected to lead to an appreciation of the country's currency $\left(\downarrow E^{\#} ; E_{f U I P}^{\# e}<E_{t-1}^{\#}\right)$ :

$$
E_{f U I P}^{\# e}=E_{t-1}^{\#}+\left(r^{\$}-r^{\#}\right) E_{t-1}^{\#}
$$

A PPP-fundamentalist trader could use price differentials in their forecast (as in Equation 3.47, that follows from Equation 3.2): Higher prices in the emerging country ( $\left.\uparrow p^{\#}\right)$ are associated with a loss of competitiveness internationally and an exchange rate depreciation $\left(\uparrow E^{\#} ; E_{f P P P}^{\# e}>E_{t-1}^{\#}\right)^{146}$ :

$$
E_{f P P P}^{\# e}=E_{t-1}^{\#}+\left(p^{\#}-p^{\$}\right) E_{t-1}^{\#}
$$

In complete models as the one presented in the Chapter 12 of Godley and Lavoie (2007), a more specific behavior might be modeled, as a participant that trades according to changes on the trade balance instead of the PPP. In Equation 3.48, a higher trade balance ( $\uparrow X^{\#}-$ $\left.I M^{\# 147}\right)$ is expected to lead to an appreciation of the local currency $\left(\downarrow E^{\#} ; E_{f t r a d e}^{\# e}<E_{t-1}^{\#}\right)$.

$$
E_{\text {ftrade }}^{\# e}=E_{t-1}^{\#}-\gamma\left(X^{\#}-I M^{\#}\right) E_{t-1}^{\#}
$$

\footnotetext{
${ }^{145}$ In all equations where past exchange rate change is a factor in determining future exchange rates, the option to consider $E_{t-1}-E_{t-2}$ instead of $E_{t}-E_{t-1}$ is based on a concern over the simultaneous definitions and the problems that can arise when running a SFC model.

${ }^{146}$ Note that this implies a case with zero inflation. Similarly, $p$ could denote inflation, and a rise of inflation in emerging countries above the one of central countries would have the same effect.

${ }^{147}$ This follows the notations and the variables' definitions of chapter 12 of Godley and Lavoie (2007).
} 
This expectation formation could be made more complex to better represent the impact of changes in indicators in the exchange rate forecast, as described by Harvey in its 'mental model' (presented in Section 3.3.3 and in Figure 3.1) by adding other concerns, as in Equation $3.49^{148}$. Heterogeneous agents with different focus on each of these variables can also be considered by adjusting their respective $\gamma, \epsilon$, and $\theta$.

$$
E_{\text {findic }}^{\# e}=E_{t-1}^{\#}-E_{t-1}^{\#}\left[\gamma\left(X^{\#}-I M^{\#}\right)+\epsilon\left(y^{\#}-y^{\$}\right)+\theta\left(r^{\#}-r^{\$}\right)\right]
$$

Chartists $(c)$, on the other hand, do not look at economic variables, just at the exchange rate itself, expecting the last exchange rate change to repeat in the future, as in Equations 3.50 or 3.51 :

$$
\begin{gathered}
e_{c}^{i e}=e_{t-1}^{i} \\
E_{c}^{i e}=E_{t-1}^{i}+\frac{E_{t-1}^{i}-E_{t-2}^{i}}{E_{t-2}^{i}}
\end{gathered}
$$

More complex chartist behavior, based on Schulmeister's fast and slow technical systems, could also be added. When forming their expectation, slow chartists $\left(_{\text {cslow }}\right)$ look for a longer average change of exchange rates than fast chartists ( cfast ) as shown in Equations 3.53 and 3.52 , where $m>n$ :

$$
\begin{aligned}
& E_{\text {cfast }}^{i e}=E_{t-1}^{i}+\frac{E_{t-1}^{i}-E_{t-n}^{i}}{E_{t-n}^{i}} \\
& E_{\text {cslow }}^{i e}=E_{t-1}^{i}+\frac{E_{t-1}^{i}-E_{t-m}^{i}}{E_{t-m}^{i}}
\end{aligned}
$$

Cash-in Cash-in can be included through a limit in the profits accumulated with an asset. Its modeling asks for the addition of a variable that counts the stock of profits of a given amount of periods and a rule that the agent sells an asset when its stock of profits achieves a

\footnotetext{
${ }^{148}$ The causalities are the ones considered by Harvey. Higher trade is expected to lead to an appreciation (or $\left.\uparrow\left(X^{\#}-I M^{\#}\right), \downarrow E^{\#}\right)$. Higher growth would lead to more portfolio investment and FDI (although less trade), and is thus expected to lead to an exchange rate appreciation (or $\uparrow\left(y^{\#}-y^{\$}\right), \downarrow E^{\#}$.). Higher interest rate differential is expected to have the same impact, $\uparrow\left(r^{\#}-r^{\$}\right), \downarrow E^{\#}$
} 
given percentage of its wealth. It demands an ABM framework. Although a rough approximation, the fact that this feature partly explains the reversal of a trend (which is scarce even in theoretical discussions) makes it an important inclusion.

Forecast errors and crisis Another discussed reason for the end of a trend is the deviation of the actual rate from the expected value. Orléan argues that such deviations lead to panic and crisis in a market as liquidity evaporates with participants' preference for more liquid assets. This could be done by a forecast error variable (that compares past exchange-rate expectation with actual rates) and an impact from this variable in liquidity preference $\left(\lambda_{l p}\right)$, shown in Equations 3.54 and 3.55:

$$
\begin{gathered}
\mu=\frac{E^{e}}{E_{t}} \\
\lambda_{l p f}=f(\mu)
\end{gathered}
$$

Equities The SFC framework also allows the inclusion of equity markets, which is interesting given the different dynamics it triggers (discussed in Chapter Seven) and given its increasing weight among emerging countries (discussed in Chapter Four). The modeling of equity markets is out of the scope of this section, but its impact on portfolio equations asks for a distinction of the return of a countries' assets $\left(r^{i}\right)$ into returns from bonds $\left(r_{b d}^{i}\right)$ and from equities $\left(r_{e q}^{i e}\right)$; and the modeling of the latter depends on dividends and on the expected appreciation of the equity.

Anchoring and medium-term fundamentals Both the anchoring principle, analyzed by Harvey, and the medium-term expectations, analyzed by Schulmeister, have a similar effect: new forecasts depend on past forecasts. The inclusion of such features is enabled by considering the past forecast in the expectation formation rule. The exchange rate expectation of fundamentalist traders that anchors their expectations on past forecasts is shown in Equation 3.56 (where 0.95 is indicated as an arbitrary value to limit the amount of variables):

$$
E_{\text {fanc }}^{i e}=(0.95) x+(0.05) E_{t-1}^{e i}
$$


Representativeness principle As discussed, according to the representativeness principle agents look for causality between two events - in Harvey's application of this principle to foreign exchange markets, agents look for explanations for exchange rate movement. As a result, it can be expected that agents consider the new exchange rate value as somehow reasonable (because they "found" the explanation to it, or according to which fundamentals the exchange rate has moved) and anchor their new forecast to it. In other words, such forecast is a way for traders to adapt their estimations to the changes seen in the economy. The representativeness principle is modeled in Equation 3.57 for an agent that follows an externally defined fundamental value, or in Equation 3.58 for a participant that forms their exchange rate expectation according to the UIP:

$$
\begin{gathered}
E_{f r e p}^{i e}=(0.95) x+(0.05) E_{t-1}^{i} \\
E_{f U I P r e p}^{i e}=E_{t-1}^{i}+(0.95)\left(r^{\$}-r^{\#}\right) E_{t-1}^{\#}
\end{gathered}
$$

Concluding remarks This section presented how to merge different important heterodox contributions to exchange-rate theory on a common approach, the equations of the SFC models. The heterodox contributions considered are complementary, including the workings of foreign exchange (and of assets) markets, analyses of how investors build their exchangerate forecasts, and analyses that differentiate currencies' features. The different frameworks used have advantages and drawbacks that were discussed throughout the section. The SFC framework was chosen for the precision and clarity of its equations as well as for the flexibility it offers to include further considerations. Its first main aim is to be used for enhancing the theoretical debate, but a future implementation of (some of) the equations proposed is an important avenue for further research. It probably would not be an easy task due to the complexity involved in guaranteeing the stability of the model in face of changing prices and the exchange rate, and in keeping track of the specific effects of the numerous mechanisms. However, when implemented, it could enhance our understanding of exchange rate developments, and add realisticness to SFC models in general. The use of this framework for analysis of the vulnerability and the inclusion of the dynamics of derivatives markets is another important agenda. 


\subsubsection{Concluding Remarks}

The role of exchange-rate expectations given the rejection of viewing the exchange rate as a market-clearing price (as discussed in Section 3.1) is a main feature across the heterodox views presented in this section. The treatment of exchange-rate expectations is indeed one of the main differences between the mainstream approaches presented in Sections 3.1 and 3.2 and the heterodox views presented in this section. Exchange-rate expectations were a main feature of one of the first exchange rate analyses, the UIP. After that it was neglected in favor of models focusing on the links between the exchange rate and macro aggregates in the keynesian models (discussed in Section 3.1.1.4). From this moment on, the exchange rate became a variable "supposed to arrive at a level that 'clears' macro balances" (Taylor, 2004 , p. 211). In the mainstream, it was later modeled in behavior finance models, though in a simplified form and still based on a view of exchange rates as a market-clearing price.

The treatment of expectations in a realistic fashion has reemerged in heterodox approaches. While Orléan highlights that expectations are associated with a financial model, an evolving convention, Harvey's 'mental model' describes a convention in a detailed way. The complexity of expectation formation is a main take from his work, where it not only depends on the analysis of relevant indicators, but is also done through behavior biases, and accounts for the specific dynamics of the foreign exchange markets described by Schulmeister.

However, expectations are not the sole determinants of exchange rates. To Harvey, the exchange rate is only determined by portfolio flows, which depend solely on the expected exchange rate - other influencing factors are limited to impacts on the exchange rate forecast. Based on the keynesian equation, Andrade and Prates' and Kaltenbrunner's analyses highlight that currencies are not all the same: they offer different liquidity premium, which also impacts their desirability. The analysis done in the SFC framework is also complementary: it is a patrimonial approach where the exchange rate is not only impacted by the relative return of foreign assets and its expected future value, but also by all the other economic variables accounted for in the model - trade being an important one. Moreover, although the modeling of exchange-rate expectations is still incipient, Lavoie and Daigle have presented it in a way that accounts for heterogeneous agents. 
The SFC framework was used to assemble the different features regarding exchange-rate expectations and determination discussed in the literature: it is a patrimonial approach (coherent with financialization), it is precise and flexible, and simultaneously accounts for stocks and flows, and for financial and productive sectors' variables. Although literary analyses are most relevant for deeply elaborating on a point, thus keen to heterodox works, presentation in a set of equations results in a clearer discussion, where points of divergence and consensus are easily identified.

The modeling of exchange-rate expectations presented in this section is an important outcome of the chapter as it might be the first account for modeling endogenous fundamentalist behavior. A second important outcome is the modeling of emerging currencies specificities (low liquidity premium) and the mechanism that allows realistic emerging currencies dynamics to emerge, through the inclusion of liquidity preference concerns. The addition of the liquidity preference feature, next to the liquidity premium makes it easier to differentiate the several points raised by this literature and the superiority of the heterodox approach to the mainstream restrictive consideration of risk. A third important outcome is the modeling of cash-in and of the divergence of the conventionally estimated value, that can allow the emergence of cycles without recurring to less realistic features such as the expectation of fundamentalist behavior based on an exogenous and stable value. Finally, the details of chartist behavior also adds complexity, and thus realisticness, to exchange rate models. The use of SFC as a common basis for heterodox views on exchange rates opens a large avenue for future research, that includes the modeling of the confidence level and of derivatives markets.

On the theoretical front, this section has argued that emerging currencies are subject to an additional source of exchange rate volatility. International financial cycles influence these currencies behavior due to their low liquidity premium (that are related to both assets and liabilities dynamics, respectively their incapability of being a receptacle of uncertainty (Andrade and Prates, 2013) or for not being used to denominate financial commitments Kaltenbrunner (2015)), and thus, they are subject to major shocks. This configures a different type of volatility that is not associated with daily (small) deviations around the trend, but occasional major depreciations. Therefore, they are vulnerable to the international financial scenario. As it will be seen in Chapter Six, the empirical analysis of the emerging currencies behavior since the 2000s supports this argument. 


\subsection{Conclusions}

The thesis aims at enlightening the behavior of emerging currencies in times of financialization. As seen in Chapter Two, the current phase of capitalism is characterized by the centrality of money managers and their portfolio decisions: financial flows are of great relevance, financial markets are sophisticated (with great derivatives markets, where leveraging allows speculating large amounts), there is a high amount of liquidity in central economies that are allocated worldwide according to the decisions of a few investors. Are these features accounted for by exchange rate theories? As discussed in this chapter, among the mainstream theories, the patrimonial approach of portfolio models is coherent with the financialization context. Additionally, the inclusion of exchange-rate expectations in models with heterogeneous agents should be recognized. However, both approaches are based on assumptions of the exchange rate as a market-clearing price. As argued in this chapter, this is inconsistent with the very dynamics of financial flows in a context of floating exchange rate and financialization, where exchange rate returns are key for attracting financial flows, determining a self-feeding interaction that, instead of leading to equilibrium, is a 'deviation amplifying system'. This is strengthened in the case of equity investment, as also the asset price will pass through the interaction. This dynamic, that will be presented in Chapter Seven, is the opposite of the mainstream idea of exchange rates that tend to equilibrium and clear markets. Note that this dynamic is the opposite to the dynamics related to trade flows, where the exchange rate is a converging force: higher exports put appreciation pressure that discourage exports.

Given the post-Keynesian perspective, the realisticness of theories, specifically with regards to the financialization-related features, is key for understanding exchange rates. The failure of most mainstream models might result from their lack of realisticness. As the section has shown, there is however a search for more realistic features among mainstream approach when they explicitly attempt to answer the exchange-rate puzzles, and thus enhance the explanation power of models - these include heterogeneous agents and derivatives markets; also the third-generation crisis models, that are case specific analyses, are a noteworthy step in this direction. 
On the other hand, heterodox models are based on realistic assumptions, emerging from analyses of the workings of foreign-exchange markets and of the configuration of the international monetary and financial system. For this reason, they result in insights that enhance our understanding of exchange rate behavior. While mainstream analyses deem short-term exchange rate behavior as irrational, concentrating on long-term trends, shortterm fluctuations impact the economy in general (as discussed in the Introduction) and their understanding is crucial for policy concerns. For the same reason, the understanding of crisis is also crucial. In this point, once more, the heterodox approach proves superior as most of the theories discussed account for both exchange rate determination and crisis differently from the mainstream where these are divided in two bodies of literature. This very dichotomy in the mainstream literature is an evidence of the failure of its models to explain exchange rate developments. The ability of heterodox studies to explain exchange rates in its complexity - in both tranquil and turbulent periods - is even more relevant for analyses of emerging currencies, where crises are frequent.

From the literature review on the specificities of emerging currencies, this chapter has argued that the inclusion of EMEs' assets in money managers' portfolios results in important shocks when there is a change in the international financial scenario and in their close association to it. In other words, emerging currencies become more fragile to changes in the international scenario. These hypotheses will be tested in Chapter Six.

Chapter Seven will analyze the dynamics behind this phenomenon, based on the Minskyan framework of analyzing the evolution of agents' behavior throughout the economic cycle and how that creates a fragile system. It differs from the literature analyzed in this chapter by centering on money-managers' decisions, their evolution and the creation of fragility, although a currency's features and behavioral biases are considered in the analysis. 


\section{Chapter 4}

\section{Emerging Countries' Changing}

\section{Foreign Liabilities and}

\section{Vulnerabilities}

As discussed in Chapter Two, the 1990s was a period of important changes in developing countries due to the broad implementation of policies of capital account liberalization in the wake of what became known as the 'Washington Consensus' policies ${ }^{1}$. If financial globalization started in the 1970s and consolidated among advanced countries in the 1980s, it was in the 1990s that some developing countries became part of this process, and, as argued in Chapter Two, became part of a network determined by money managers' balance-sheets ${ }^{2}$. Figure 4.1, taken from Haldane (2011, p. 17), illustrates the changing participation of emerging countries' equity assets ${ }^{3}$ : showing a marginal presence before the 1990s, and the subsequent integration of several EMEs as part of a very complex network in the 2000s.

In fact, there was a massive increase of flows to developing countries in the 1990s, building important stocks of foreign liabilities following domestic reforms and the decrease

\footnotetext{
${ }^{1}$ See Williamson (1990).

${ }^{2}$ See Akyüz and Cornford (2002, p. 10) for the change in capital flows to developing and emerging countries in the period, with regards to the countries GNP, type of flow and geographical area.

${ }^{3}$ Emerging markets in this work are represented by Argentina, Brazil, Mexico, China, India and Korea (Kubelec and Sá, 2010, p. 35).
} 
Figure 4.1: Cross-Border Equity Holdings: Different Years, From 1980 to 2005
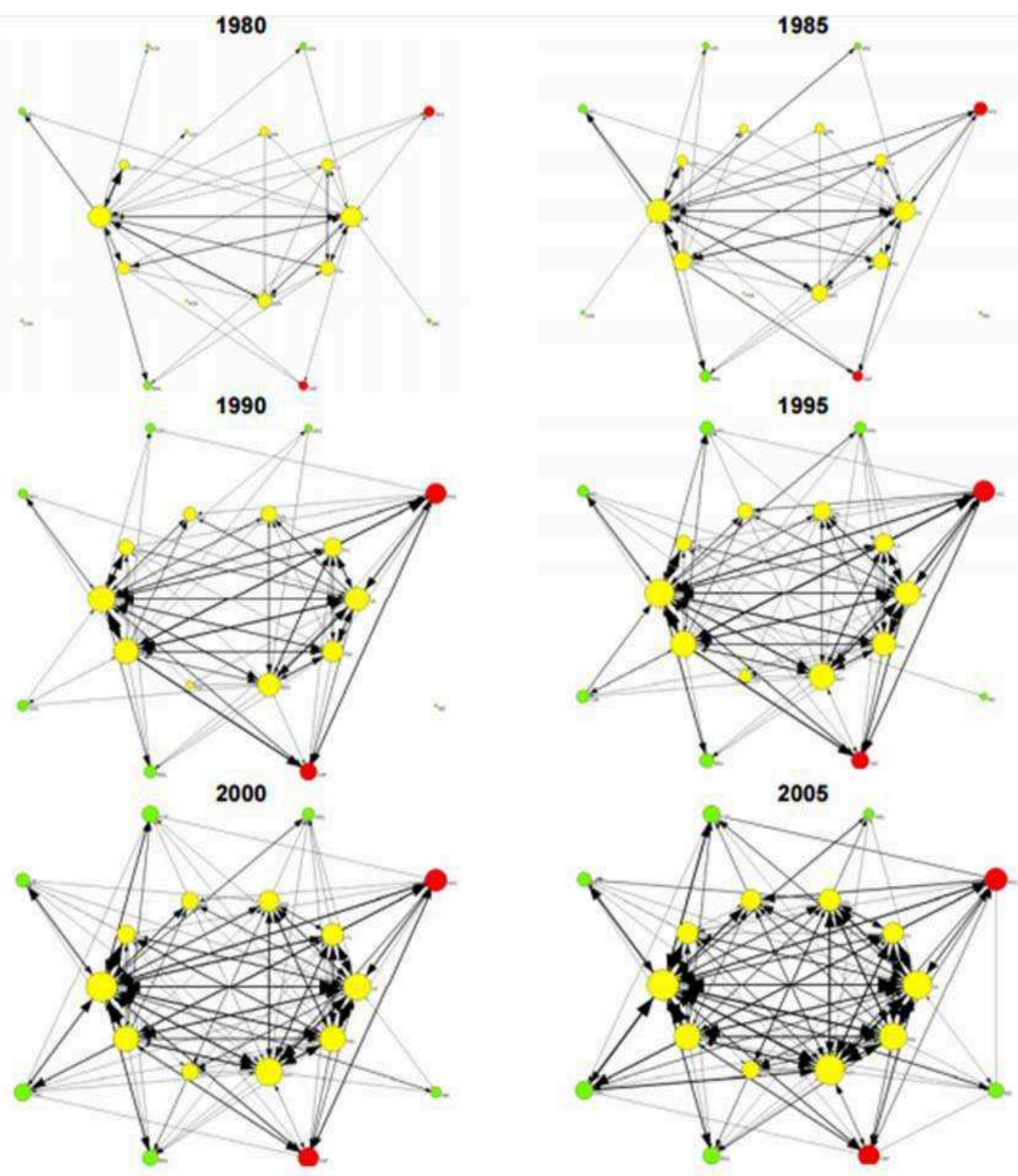

Reprinted from Haldane (2011, p. 17) (with data from Kubelec and Sá (2010) and Bank of England calculations).

Yellow circles represent advanced economies; green ones, emerging countries; red ones, financial centers (Hong Kong and Singapore).

"Widths of links are proportional to the log dollar value of cross-border equity holdings. Each arrow denotes ownership, with the arrow pointing away from the holder of the equity and toward the issuer. Sizes of nodes are proportional to the log dollar value of the sum of all of the countrys cross-border equity holdings and liabilities issued" (Haldane, 2011, p. $17)$. 
of interest rates in the US in the beginning of the decade (Helleiner, 1997) ${ }^{4}$. This boom was followed by crises and outflow in the late-1900s and by a new boom since $2003^{5}$ associated with financialization and with the lower interest rates in the United States. Also important and associated with the increasing liquidity internationally is the boom of commodities.

This "new phase" of financial globalization that included the countries that became known as $\operatorname{EMEs}^{6}$ cannot be dissociated from the other processes that characterize financialization. Especially when it comes to exchange rate determination, the rising importance of finance internationally with its decoupling from earlier functions, and the sophistication of finance are of great importance (as argued in Chapter Two). With the increasing importance of these financialization-related features, and, most importantly, in the context of floating exchange rates that followed the late-1990s currency crises, EMEs' integration in the 2000s took place in a different environment.

The three empirical chapters of this thesis are dedicated to the analysis of whether financialization-related features have an impact on emerging currencies' dynamics. This is the first of these three chapters and is therefore focused on providing a first overview of the integration of EMEs to international financial markets. It also highlights some of the associated potential risks (or "new forms of external vulnerability" (Kaltenbrunner and Painceira, 2014)). It contributes to this literature by suggesting an analysis focused on the pattern of EMEs' foreign liabilities and with different methodologies.

The structure of the chapter Apart from this short introduction, the chapter is divided as follows. Section 4.1 presents this thesis' operational definition of EMEs (based on the theoretical debate presented in Chapter Two), and these economies' main features. Section 4.2 presents the main changes in EMEs' foreign liabilities. The sections that follow analyze the potential risks of the different types of liabilities from different perspectives. Section 4.3 analyzes volatility. Section 4.4 presents a graphical analysis of the similarity of each type of foreign liabilities across EMEs. Section 4.5 presents a similar study, but through a

\footnotetext{
${ }^{4}$ The higher inflows to developing countries is also a result of a decrease of home bias (Bonizzi, 2013). For the definition of home bias see Chapter Three.

${ }^{5}$ See Chapter Six for the literature on the different waves of capital flows to EMEs and Figure 6.13 (in Chapter Six) for the figures of the most recent cycle.

${ }^{6}$ See the discussion on the definition of EME in the Introduction Chapter, page 10.
} 
principal components analysis. Section 4.6 analyzes whether stock prices impact exchange rates. Finally, concluding remarks are presented.

\subsection{Who are the Emerging Market Economies?}

This section operationally defines EMEs and presents country features such as GDP, foreign trade, capital account openness, financial integration, exchange rate regimes, monetary regimes, interest rate, and stock market capitalization.

\subsubsection{Operationally Defining Emerging Market Economies}

As discussed in this thesis' Introduction, this thesis follows Bibow's (2009) definition of EME as the developing countries that actively participate in the process of financial globalization. In line with Chesnais' (1997) point that financial globalization is defined by the decisions of portfolio managers, the thesis proposes to operationally define EME according to which countries the financial community saw as emerging in the period under study. The operational definition of EMEs is based on the countries who are part of the MSCI index ${ }^{7}$, a broadly used indicator of financial returns in $\mathrm{EMEs}^{8}$.

An operational definition of EMEs that could be labeled 'financial-markets-oriented' has also been used by the Bank for International Settlements (BIS) (Hofmann and Takáts (2015, p. 2)). Focused on economies "that are well integrated in the global financial system", the study mentions that its list of EMEs "represent more than $95 \%$ of the weights of the JP Morgan Government Bond-Emerging Market Index (GBI-EM), a key local currency EMEs' government bond index"9.

\footnotetext{
${ }^{7} \mathrm{MSCI}$ is a provider of indeces of different investment opportunities, including equities and fixed income. It is commonly used as a benchmark in the financial markets. It used to stand for Morgan Stanley Capital International.

${ }^{8}$ Note that the use of an index seems sounder than institutional lists of EME given that in their portfolio diversification strategy money managers tend to simulate important financial indeces (Plihon and Ponssard, 2002).

${ }^{9}$ These countries are Brazil, Chile, China, Chinese Taipei, Colombia, the Czech Republic, Hong Kong SAR, Hungary, India, Indonesia, Israel, Korea, Malaysia, Mexico, Peru, the Philippines, Poland, Russia, Singapore, South Africa, Thailand and Turkey. This text, from a footnote in the paper, is a rare example of explanation of the definition of EMEs' in the institution's papers. This list of countries is the one used in their publications.
} 
The list of countries in the MSCI index changes over time. That it evolves through time is in line with the theoretical definition of EMEs and with the characteristics of financial markets more broadly. It can however be an issue when a more structural picture of EMEs is to be drawn. To cope with it, the list was used as a first approximation, but recently-added countries as Egypt and Qatar were not included. Greece was also not considered given the obviously different issues it faces as an Euro Area country. The final list of EMEs used in this thesis includes: Argentina, Brazil, Chile, China, Colombia, Czech Republic, Hungary, India, Indonesia, Korea, Malaysia, Mexico, Peru, the Philippines, Poland, Russia, South Africa, Taiwan, Thailand and Turkey. Please refer to the "List of Abbreviations" of countries and currencies in the Thesis' preamble.

\subsubsection{General Features of Emerging Market Economies}

By definition, these 20 EMEs are similar in respect to their financial integration. However, they differ in many aspects that characterize this integration (as it will be analyzed in this chapter and the in the next one) and their exchange-rate dynamics also present different characteristics (as it will be seen in Chapter Six). Before looking at these inter-related features, it is useful to examine a few characteristics of these economies.

The size of economies is a main difference between EMEs. China's economy is by far the largest among EMEs, almost three times larger than Brazil's, the second largest. The smallest economy, Hungary's, is almost 50 times smaller than China's. Figure 4.2 presents the average GDP and foreign trade (exports plus imports) of EMEs: from 2003 to 2013. China is excluded from the figure for ease of reading. As shown, the countries' economies significantly vary in magnitude. In terms of trade, the graph clearly shows how Asian economies (presented in red with a different marker) are more open - for instance, Thailand and Brazil have similar levels of foreign trade although Brazil's economy is about six times bigger. In general, the foreign trade-to-GDP ratio of Latin American economies is smaller than the ones of other EMEs.

The level of capital account openness also differs among EMEs. Figure 4.3 presents the index developed by Chinn and Ito (2008) based on information from the IMFs Annual Report 
Figure 4.2: EMEs GDP and Foreign Trade, 2003-2013 average

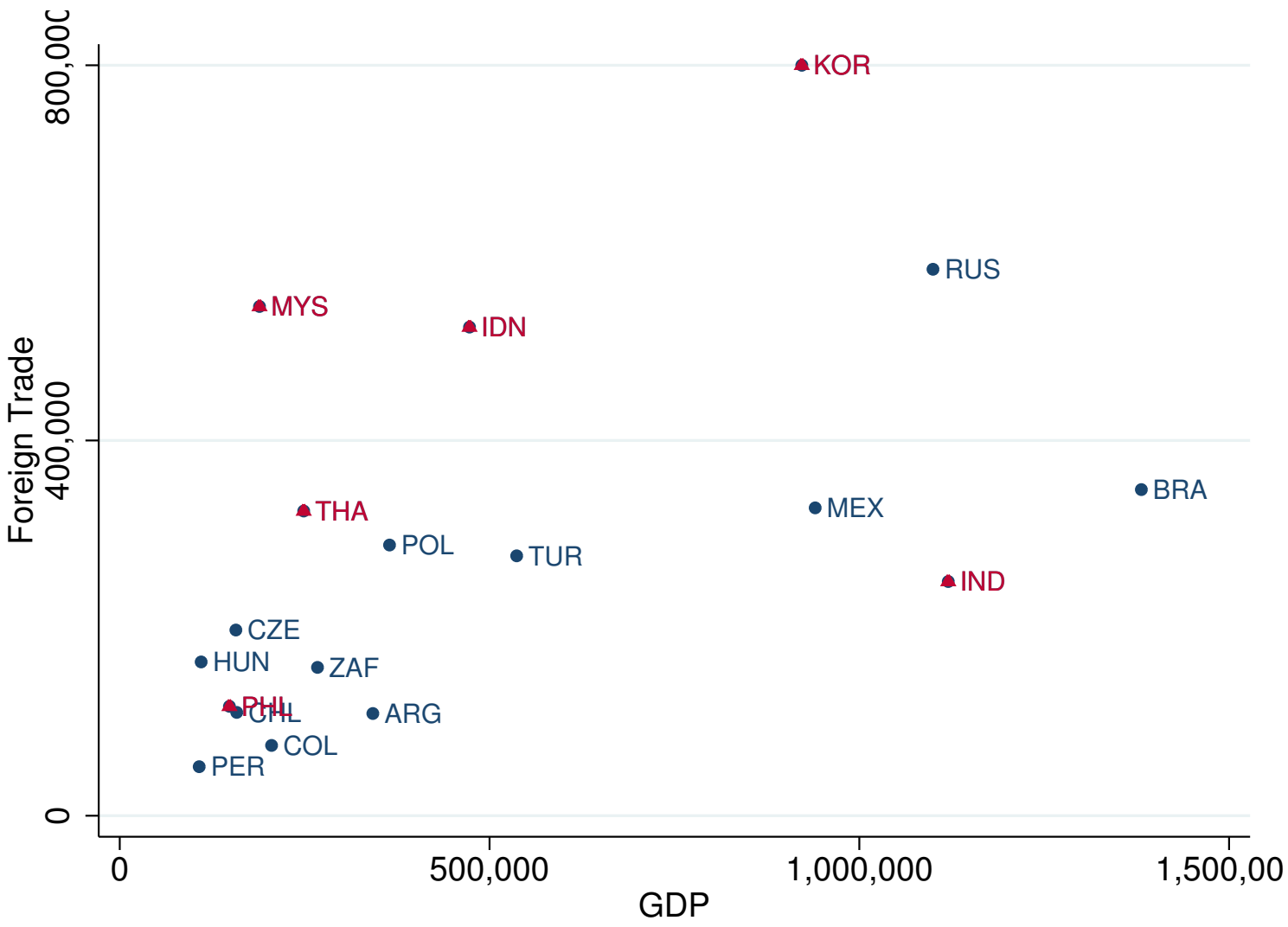

US\$ Millions. Data source: WDI. Data for China is not presented for ease of reading. Its trade level is about three times higher than the one of Korea; its GDP is almost three times higher than the one of Brazil.

on Exchange Arrangements and Exchange Restrictions ${ }^{10}$. Chile, Czech Republic, Hungary, and Peru are among the ones with less impediments for capital account transactions. China, India, and South Africa are on the other end. In terms of absolute financial integration (assets plus liabilities), China has double the integration level of the second country, Russia followed by Brazil, Korea and Mexico (these five countries are also the largest economies). On the other end are Peru, the Philippines, and Colombia. When looking at financial integration relative to GDP (presented as the size of the bubbles), the picture changes. Hungary is by far the most integrated country, with almost twice the integration of the following countries, Malaysia and Chile are almost four times more integrated than the country with the lowest integration level, India ${ }^{11}$.

\footnotetext{
${ }^{10}$ See Chapter Six for details on IMFs Annual Report on Exchange Arrangements and Exchange Restrictions.

${ }^{11}$ The concepts of financial integration and capital account openness are discussed in Chapter Five.
} 
Figure 4.3: EMEs' Capital Account Openness and Financial Integration, 2003-2013 average

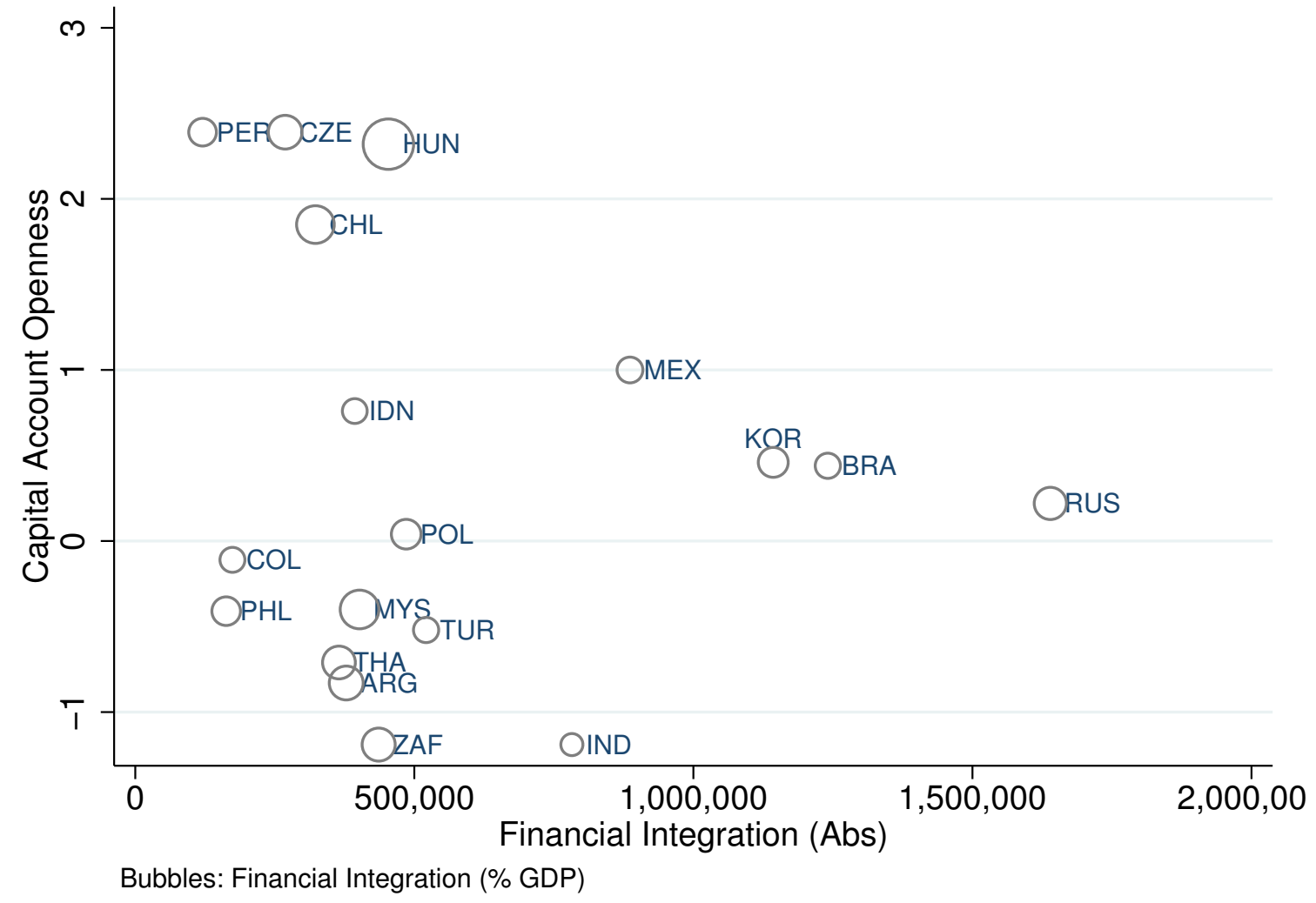

Financial Integration (abs) refers to the absolute value, in US\$ Millions. Capital Account Openness Data source: Chinn and Ito (2006). Financial Integration Data source: updated and extended version of Lane and Milesi-Ferretti (2007). Data for China is not presented for ease of reading. Its absolute financial integration is more than twice of the second biggest one; its capital account openness level is among the smallest; its relative financial integration is rather small, about the same as Peru.

As discussed in the Chapter One, the exchange rate regimes adopted by EMEs have changed in the 2000s, with the (de jure) floating regime becoming the most common one $(\text { IMF, 2014) })^{12}$. Only Argentina, China, Malaysia, Czech Republic and Russia presented, in 2013, regimes which are less flexible than the floating one. With regards to the monetary regime, the most common is the inflation targeting. Table 4.1 presents the monetary and exchange rate regimes prevailing in 2013 and the importance of the interest rate differential with regards to the United States' (US) Fed Fund rates. As it can be seen, there is a higher

\footnotetext{
${ }^{12}$ See more details on EMEs' monetary and exchange rate regimes in the 2000 s in the Table 6.12 , in the Appendix of Chapter Six.
} 
TABLE 4.1 Exchange Rate and Monetary Regimes, and Interest Rate Differential

\begin{tabular}{lcccc} 
& Free Floating & Floating & Ot. Managed & Craw-like \\
\hline Inflation & Chile (M) & Brazil (H), Colombia (M) & Czech R. (L) & \\
Target. & Poland (M) & Hungary (M/H), Indonesia (H) & & \\
& & Korea (M), Mexico (L) & & \\
& & Peru (L), Philippines (M) & & \\
& & Poland (M), Thailand (L) & & \\
\hline Other & Turkey (H), S. Africa (H) & Malaysia (L/M) & Argentina (H) \\
& & India (H) & Russia (M) & China (L)
\end{tabular}

Interest rate differential is measured as the average of the 2003-2013 period - (L) stand for low levels; (M) for mid; (H) for high. The categorization is done with the aim of having a similar amount of individuals in each level. Data source: IMF, International Financial Statistics. The exchange rate regime and the monetary policy framework are presented as of 2013, and according to IMF's de facto classifications. For more details on these classifications and its changes from 2003 to 2013, see Table 6.12 in the Appendix of Chapter Six. Other Monetary Regimes refer to "Monetary Aggregate Target" in Argentina and China; India, Malaysia, and Russia are under IMF's "other" classification. Taiwan is not on IMF's list. India has recently adopted the Inflation Targeting regime. For details, see Chapter Six, Table 6.12.

proportion of EMEs with high interest rate differential $(\mathrm{H})$ among the countries who opt for an inflation targeting regime or with a more flexible exchange rate arrangement.

The size of EMEs' foreign exchange (FX) markets are also very diverse. As it will be discussed in Chapter Five, data on FX markets is available only for a few emerging currencies. Figure 4.4 presents the size of EMEs' FX markets and the ratio of derivatives over spot contracts for them. The Mexican peso, the Chinese yuan and the Russian ruble are the currencies of the countries with the highest GDP and foreign trade levels that also have the most important FX markets. The Brazilian real, the Turkish lira and the Taiwanese dollar are the currencies with the highest share of derivatives markets.

India, Russia, Brazil, Korea and South Africa are a few of the EMEs that have very important stock markets; with the other countries having much smaller ones (Figure 4.5 shows the market capitalization of the most important stock exchange of each EMEs, by region). 
FIGURE 4.4: EMEs' Foreign Exchange Market: Size and Derivatives-to-Spot Ratio, 2013

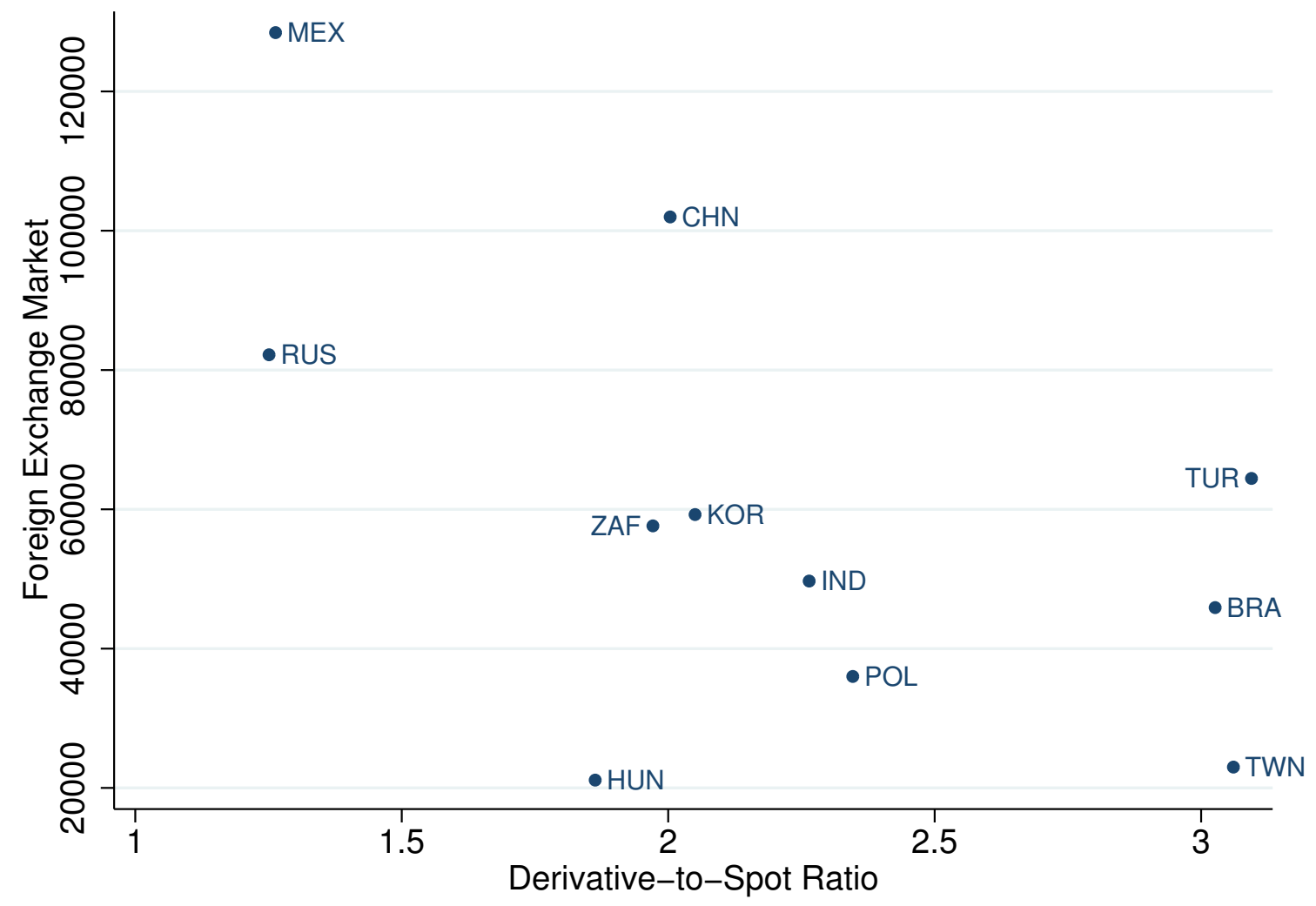

Foreign Exchange Market is given in US\$ Millions. Data source: BIS (2013)

\subsection{Emerging Market Economies' Foreign Liabilities: an Overview}

Given the focus on the operation of international money managers' and EMEs' function of supplying financial assets (as discussed in Chapter Two), this thesis analyzes financial integration based on the liabilities' side of EMEs' external position.

EMEs' foreign private assets are rather small, and only relate to these dynamics to the extent that domestic investors might want to follow international money managers for inferring in capital gains. Depending on a country's policy of accumulation of reserves of international assets, EMEs might hold major amounts of foreign assets. These are however of the realm of public sphere, not being subject to the same dynamics. Reserves represented an average of $41 \%$ of EMEs' assets (in the 2003-to-2011 period), reducing assets to an average of 
Figure 4.5: EMEs' Stock Market Capitalization, 2003-2013 average

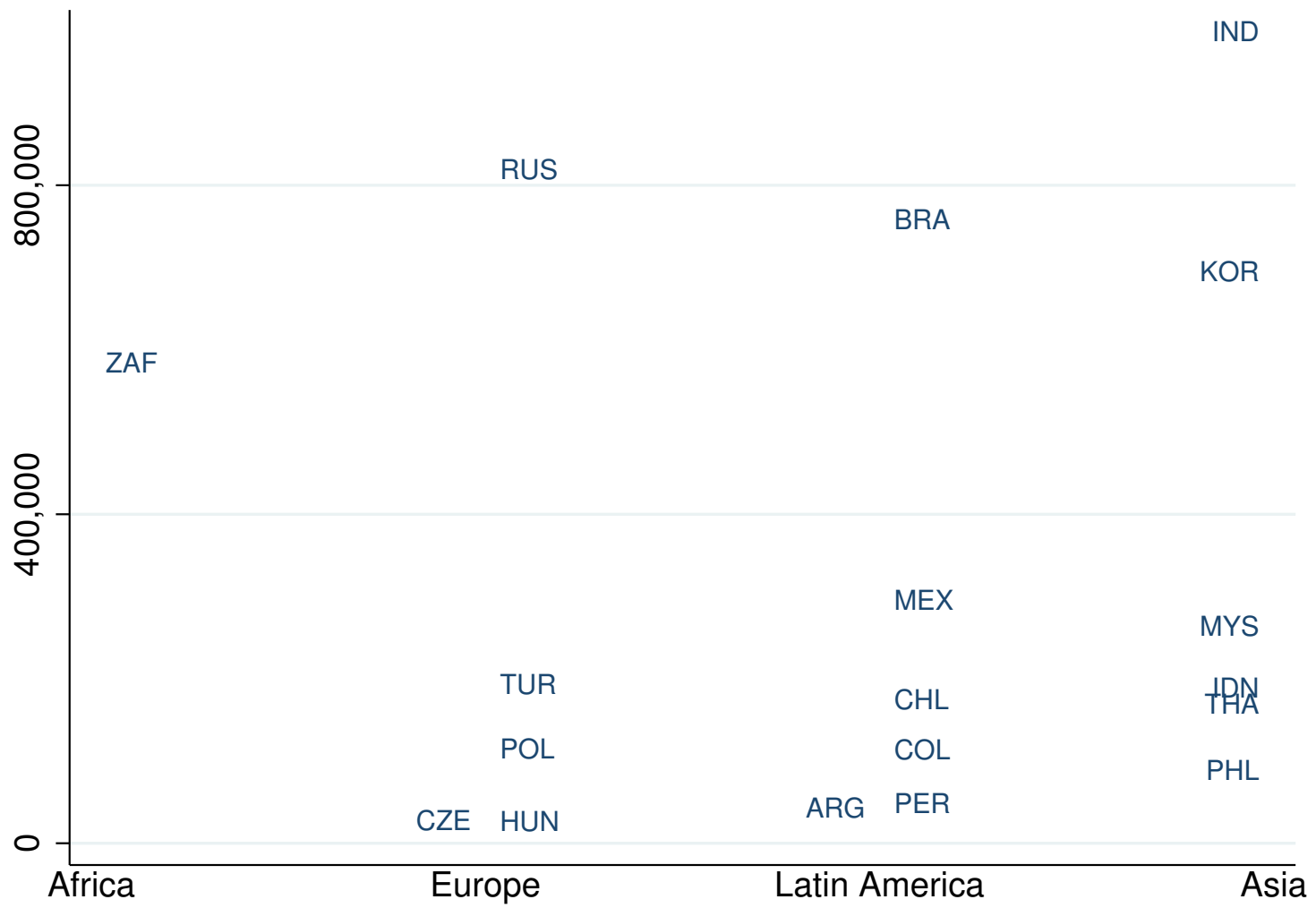

Data source: Bloomberg.

$47 \%$ of liabilities ${ }^{13}$. However, it must be noted that, theoretically, reserves are closely linked to a country's liabilities due to their role in attracting foreign investors and their utility in managing balance of payment crisis and daily exchange rate volatility.

\subsubsection{Main Data Used}

The financial integration data is an updated and extended version of the dataset constructed by Lane and Milesi-Ferretti $(2007)^{14}$. It provides estimates for stocks of external positions taking capital gains into account, thus presenting the vulnerabilities and risks involved more clearly (see Chapter Five, Section 5.2.4 on the advantages of using stock-based measures

\footnotetext{
${ }^{13}$ These figures are presented in Figure 4.16 in the Appendix. Reserves ranged from from $19 \%$ in Argentina to $76 \%$ in Hungary and assets-to-liabilities varied from $13 \%$ in India to $77 \%$ in Argentina (apart of Taiwan's $160 \%$ that is a specific case).

${ }^{14}$ The database can be accessed here: http://www.philiplane.org/EWN.html.
} 
of integration instead of flows measures $)^{15}$. This dataset separates three types of capital: equities, debt and foreign direct investment (FDI). Derivatives are not included due to their very low levels ${ }^{16}$.

\subsubsection{Emerging Market Economies' Foreign Liabilities}

In 2011, foreign liabilities were rather diversified among EMEs: in seven of the 20 countries, any of the three types of foreign capital represented more than $45 \%$ of the total. FDI represented the most important type of liability in half of the countries. Debt represented the most important type in six of them. The importance of equities varied significantly across countries, representing $17 \%$ of total liabilities on average (see Table 4.2). Equities are an important type of foreign assets in Taiwan (43\%), Korea (35\%), South Africa (32\%), India (27\%), Brazil (24\%), and Thailand (23\%). This is a very different picture than ten years before. In 2001, debt was the most important form of liability in over two thirds of the countries, and was at least two times more important than FDI in half of them. Equities were not very significant in most countries, and averaged $9 \%$ of total liabilities (see Table 4.8 in the Appendix).

The remainder of the section analyses the development of foreign liabilities based on two sub-periods: 1990-1999 and 2000-2011. These periods were chosen because they represent two types of integration, distinguished by the rising use of equity instruments and the emergence of floating exchange rate regimes (as mentioned in the introduction).

The increase in the weight of equities as a form of foreign liability (from a cross-country average of $9 \%$ in the 1990 s to $17 \%$ in 2000-2011) results from the much higher increase of equities than debt liabilities. During the first period, debt instruments represented the most important type of foreign capital in EMEs and were the type of capital that grew the most (see Figure 4.6). During the following period, 2000 to 2011, the stock of debt liabilities doubled (from less than US\$ 6 billion per year to US\$ 13.514 Million). However, in relative

\footnotetext{
${ }^{15}$ Regarding IMF databases, the International Financial Statistics provide flow data in this format, what is not the case for the Balance of Payment Statistics, that has net data.

${ }^{16} \mathrm{It}$ is interesting to note that the low levels of derivatives in a country's balance of payments reflects the way derivatives are measured. Their small size in the balance of payments should not lead to an underestimation of their importance, that derives from the high leveraging possibilities they offer (Fritz and Prates, 2014, p. 216).
} 
TABLE 4.2 Weight of Different Types of Liabilities, 2011

\begin{tabular}{lccc} 
& Equities & Debt & FDI \\
\hline ARG & 0.02 & $\mathbf{0 . 5 5}$ & 0.43 \\
BRA & 0.24 & 0.29 & $\mathbf{0 . 4 7}$ \\
CHL & 0.07 & 0.31 & $\mathbf{0 . 6 1}$ \\
CHN & 0.12 & 0.29 & $\mathbf{0 . 5 9}$ \\
COL & 0.08 & 0.41 & $\mathbf{0 . 5 0}$ \\
CZE & 0.04 & 0.39 & $\mathbf{0 . 5 7}$ \\
HUN & 0.03 & 0.36 & $\mathbf{0 . 6 1}$ \\
IDN & 0.22 & 0.40 & 0.38 \\
IND & 0.27 & $\mathbf{0 . 4 5}$ & 0.28 \\
KOR & 0.35 & $\mathbf{0 . 4 8}$ & 0.17 \\
MEX & 0.16 & 0.40 & 0.43 \\
MYS & 0.21 & 0.44 & 0.35 \\
PER & 0.21 & 0.39 & 0.41 \\
PHL & 0.18 & $\mathbf{0 . 6 0}$ & 0.22 \\
POL & 0.05 & $\mathbf{0 . 5 1}$ & 0.44 \\
RUS & 0.16 & 0.42 & 0.42 \\
THA & 0.23 & 0.28 & $\mathbf{0 . 4 9}$ \\
TUR & 0.08 & $\mathbf{0 . 6 4}$ & 0.28 \\
TWD & 0.43 & 0.44 & 0.13 \\
ZAF & 0.32 & 0.27 & 0.41
\end{tabular}

Data source: extended and updated version of Lane and Milesi-Ferretti (2007). Values higher than 0.45 are presented in bold for facilitating the reading of the table.

terms, the period is characterized by a higher increase of equities, whose stock grew two times faster than the stock of debt liabilities (the stock of equities more than four-folded, from US\$1.851 to US\$ 8.844).

FDI was the type of foreign liability to grow the most in absolute numbers (US\$20.874). Indeed, the globalization of production is a major process that continued its pace despite the Global Financial Crisis (GFC). A strong internationalization of firms, allied with the fact that half of the global FDI started to be directed to developing countries in 2009, explains the important increase of FDI in EMEs (UNCTAD, 2010) ${ }^{17}$. In a nutshell, the overall

\footnotetext{
${ }^{17}$ It is interesting to note that the differentiation between equity and FDI investments might be blurry in some cases as an investment that buys more than $10 \%$ of a company is not classified as equity, but as FDI - more precisely, "at least $10 \%$ of the voting power of the direct investment enterprise" (OECD, 2008, p. 17). Also, given the similar definition of FDI and portfolio flows, and the controls imposed on the latter since the Global Financial Crisis (GFC), part of the FDI growth in this period may be attributed to the use of regulation loopholes by investors, who started investing in the form of FDI when before they would have invested in the form of portfolio capital, as happened in Brazil (Corrêa et al., 2012). On the imposition of capital controls since the GFC, see discussion in the Introduction Chapter, page 6.
} 
picture shows an increase in the use of equity instruments among portfolio options, with FDI remaining the most important type of foreign liabilities in these countries.

Figure 4.6: Change in Stocks of Foreign Liabilities: Yearly Cross-Country Average in Different Periods

$1990-1999$

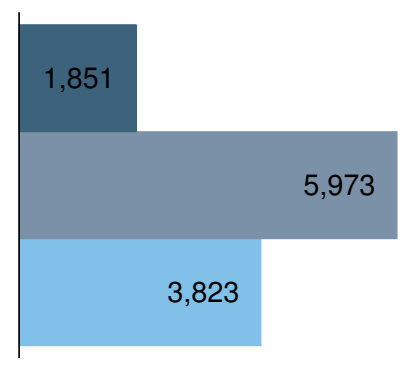

$2000-2011$

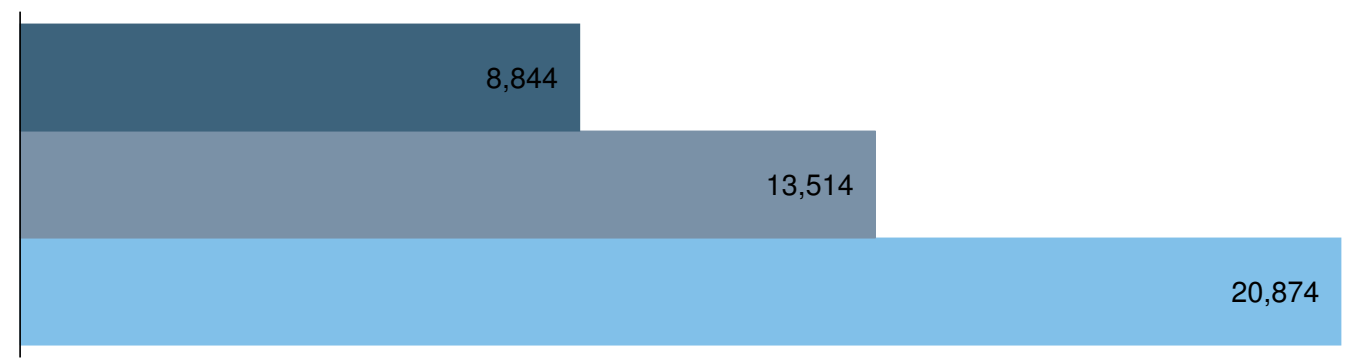

Equities Debt $\quad$ FDI

US\$ Million. Data source: Updated and extended version of dataset constructed by Lane and Milesi-Ferretti (2007)

Mainstream authors regard this relative shift in the reliance on debt to equity-financing as positive. It would be a preferable risk-sharing strategy internationally because it would reduce potential sudden repayment demands (Obstfeld, 2009) and, in the case of crisis, part of the adjustment would be borne by the foreign investor ${ }^{18}$ as the value of equity declines (Lane and Milesi-Ferretti, 2000) ${ }^{19}$. Reducing the impact of crises would also bring gains: in

\footnotetext{
${ }^{18}$ The literature on different types of lending often refers to lenders' and borrowers' risk. However, note that in the case of stock markets there is no lender or borrower risk. In this sense, De Deos (1998) suggests an analysis based on the risks of old-stock holders and future-stock holders (which are associated with the consequences of a new emission of stocks).

${ }^{19}$ Lane and Milesi-Ferretti (2000) also highlights two minor advantages. The first, at the firm level, where "avoiding bankruptcy costs is a powerful motivation to share risk". The second relates to the consequences of debt overhang in potential investment and thus in the desirability of debt-financing: "equity investment by foreign residents has more desirable properties than debt for example, in the case of debt overhang, external
} 
the case of direct financing, a country-run would have no impact on liquidity, as banks would not be involved, and there would also be no need for a lender-of-last-resort (Rogoff, 1999).

Another important factor derives from the absence of currency mismatch: equities are labeled in the country's currency, while EMEs' debt are mostly labeled in foreign currencies ${ }^{20}$. As a consequence, in the case of debt-financing, the exchange rate depreciation (that usually follows crises and capital outflows) could hamper debt repayment, but in the case of equityfinancing its impacts are only beard by the foreign investor.

This shift towards equity-financing can reinforce the importance of international shocks in the domestic economy as it constitutes a new "conduit for foreign investor sentiment": it impacts stock-market prices and, through them, the domestic economy (Obstfeld, 2009). Apart from this type of conduit, equity-financing can increase a country's vulnerability due to its special features, as it will be shown in Sections 4.3, 4.4 and 4.5.

\subsubsection{The Most Important Increases of Foreign Liabilities: BRIC Coun- tries}

As expected, foreign liabilities have grown the most in the largest economies (see Figure 4.7). As seen above, FDI was the type of liability to increase the most in the recent period in many EMEs. Its highest absolute increase was seen in China (an average of US\$152,367 Millions each year), followed by Brazil (US\$ 52,678), Russia (US\$ 38,431), Mexico (US\$ 21,757 ), Hungary (US\$18,368), India (US\$20,829) and Indonesia (US\$15,268).

Debt instruments are the second most important form of foreign liabilities in emerging markets. It has significantly increased in China (average yearly increases of stocks in the 2000-2011 period of US\$71,100), Russia (US\$ 14,992), Korea (US\$22,607), India (US\$ 20,829), Brazil (US\$18,843), Poland (US\$17,639) and Turkey (US\$17,025) 21 .

debt may act as a disincentive to domestic investment, given that foreigners would capture (part of) the benefits of increases in output" (Cole and English, 1992).

${ }^{20}$ Whether EMEs' debt is issued in the country's currencies or not depend on the state of the 'original sin' problem in these countries. See Eichengreen (2007).

${ }^{21}$ Argentina is an exception: there was a decrease in foreign liabilities in the form of debt instruments and of equities in the 2000s. 
Figure 4.7: Average Increase in Stocks, Liabilities in 19 Countries. 1990 to 1999 and 2000 to 2011 , respectively

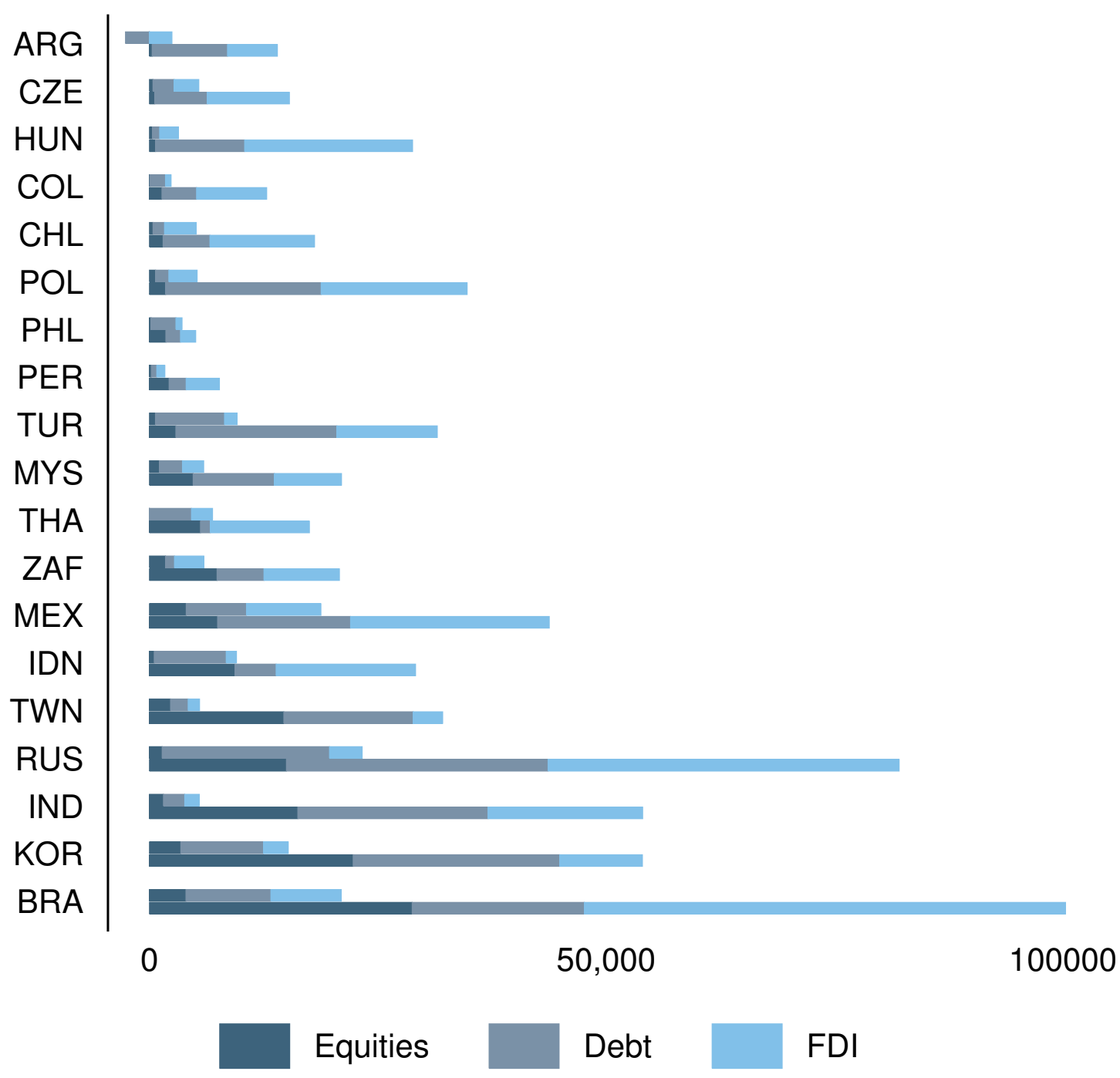

US\$ Million. Data source: Updated and extended version of dataset constructed by Lane and Milesi-Ferretti (2007). Data for China is not presented for better visualization of the others. From 1990 to 1999, Equities: US\$ 1,161 Debt: US\$ 9,156 FDI:US\$ 19,960. 2000 to 2011, Equities: US\$ 32,664 Debt: US\$ 71,100 FDI:US\$ 152,376. 
The highest increases in equity liabilities were seen in China (US\$ 32,664), Brazil (US\$ 28,7575 ), Korea (US\$22,293), India (US\$ 16,239), Russia (US\$14,992), and Taiwan (US\$ 14,707). Among these countries, only in Brazil did the stock of equities increase more than the stock of debt. In Russia and Korea, the increase seen in this two forms of liabilities were very similar.

These different magnitudes reflect the heterogeneity of this group. The biggest economies present the most important increases of external liabilities. It is in fact the BRIC countries (Brazil, Russia, India and China, the four biggest economies) that are among the highest increases of liabilities in all three types of capital.

\subsubsection{Different Types of Liabilities in Different Countries}

As expected, EMEs are heterogeneous with regards to the type of liabilities they hold. The average weight of each type of capital in each country for the 1990-1999 and the 2000-2011 periods are presented in Figure 4.8.

Although it was the stock of FDI that increased the most among EMEs, most of their liabilities are still held in the form of debt instruments. To be precise, debt instruments represented the most important type of foreign liability in 12 of the 20 countries: the Philippines (69\%), Turkey (68\%), India (64\%), Argentina (63\%), Peru (52\%), Poland (51\%), Colombia (50\%), Russia (48\%), Indonesia (47\%), Korea (46\%), Malaysia (45\%), and Brazil (39\%, where FDI is almost as important as debt: $37 \%$ ). On average, debt accounted for $46 \%$ of total foreign liability in the 2000-to-2011 period.

FDI is the second most important form of foreign liability, accounting for an average of $37 \%$ across the 20 countries. However, in seven countries it is the most important type of liability. These are: Chile (58\%), China (56\%), Czech Republic (57\%), Hungary (53\%), Mexico (42\%), Thailand (44\%), and South Africa (40\%).

Equities are the most important form of foreign capital only in Taiwan (44\%), though its weight has increased significantly in many countries. As seen in Figure 4.8, equities are 
Figure 4.8: Weight of Equity, Debt and FDI per Country, in 2000 and 2011, Respectively

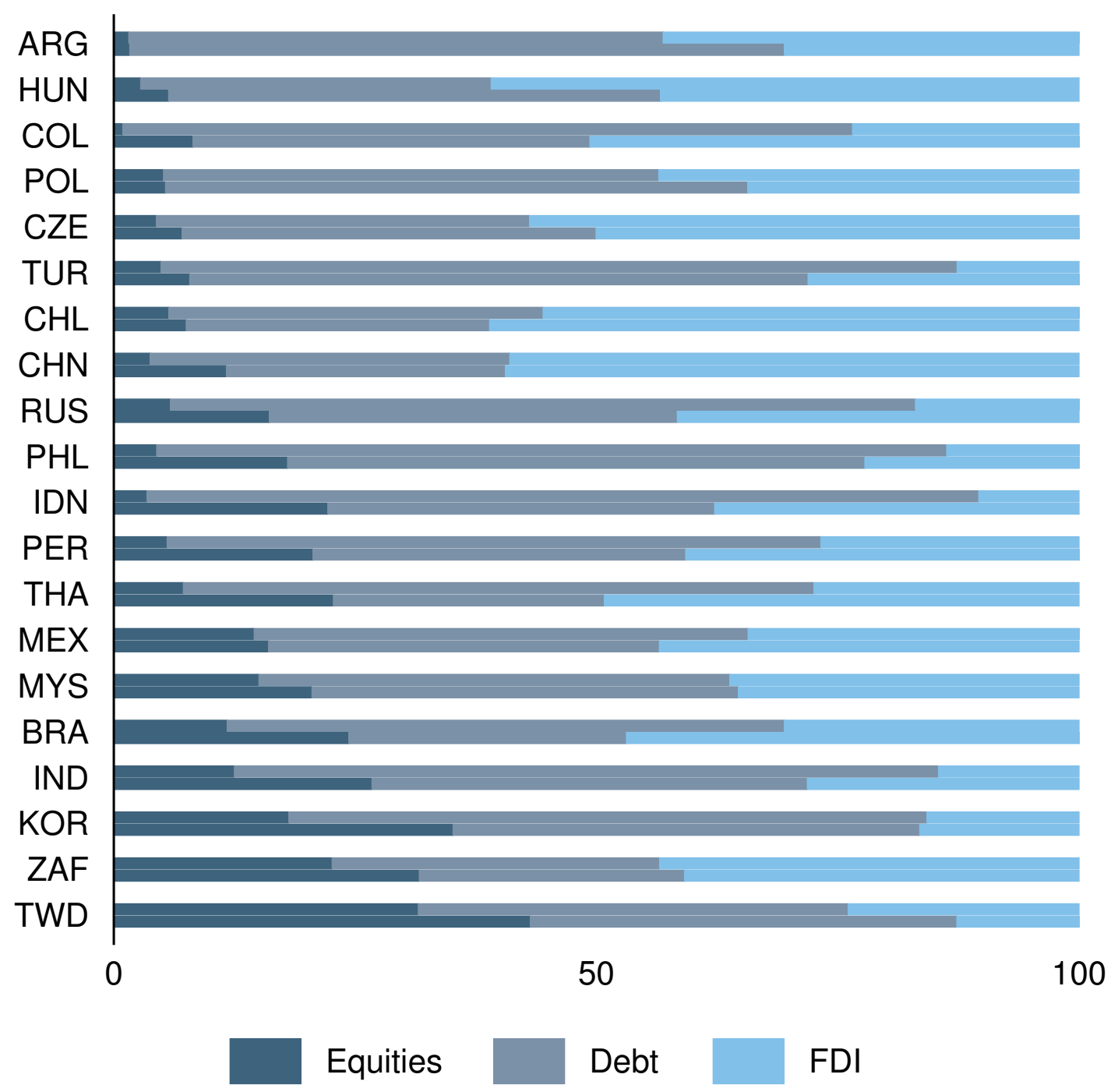

Countries are ordered by the weight of equities in 2011. Data source: Updated and extended version of dataset constructed by Lane and Milesi-Ferretti (2007). 
specially important in Korea (where it account for 35\% of total liabilities), South Africa $(33 \%)$, India (32\%), Brazil (23\%), and Malaysia $(20 \%)^{22}$.

In the following section the volatility of the three types of liabilities will be analyzed, indicating the fragility of the different types of integration among EMEs.

\subsection{The Volatility of the Different Types of Liabilities}

As seen above, there was an important change in the type of foreign liabilities across EMEs, with equities growing in importance among portfolio inflows. In order to study the potential implications of this shift, and of the type of integration of different countries, this subsection looks at the volatility of the different types of capital: FDI, debt and equities. Although technically FDI and equities do not differ greatly (see Footnote 17), portfolio flows are broadly seen as most volatile, and FDI as most stable. This difference should however not be taken for granted: Claessens et al. (1995) and Kregel (1996) have long argued that foreign direct investment can be as volatile as the other types of flows. But others, as Chuhan et al. (1996), Sarno and Taylor (1999), and Moguillansky (2002, p. 57) have reached the opposite conclusion $^{23}$. An interesting point raised by Sula and Willett (2009) is that volatility during inflow periods might not be a good predictor of the size of reversals during crises. From this perspective, the authors analyze the reversibility of the different types of flow and conclude that FDI is the least reversible and portfolio and loans are equally reversible.

The stock of foreign liabilities increased substantially in EMEs since the year 2003 - as Section 4.4 will show. The analysis starts in this point for this reason and to avoid including periods of extreme volatility in some countries due to the late-1990s and early-2000s crises. The yearly change of stocks of the three types of foreign liabilities is seen in Table 4.9 in the Appendix. These values show that the series of equities seem to be the most volatile: there are significant changes in values and alternates periods of increase and periods of decrease of stocks. Table 4.10 (in the Appendix) provides the year-by-year cross-country average.

\footnotetext{
${ }^{22}$ The countries where equities grew considerably are very similar: India (25 p.p.), Taiwan (25 p.p.), Korea (24 p.p), Russia (15 p.p.), Brazil (15 p.p), South Africa (14 p.p.), Indonesia (12 p.p.), Peru (11 p.p.), and China (10 p.p).

${ }^{23}$ There might also be specific factors related to the origins of the crisis. In the Asian crisis, for instance, bank loans were said to be the most important type of outflow (Willett et al., 2001).
} 
The figures confirm that the equity stock varied more than the other stocks of capital, even if these are cross-country average values and can represent an underestimation of volatility in some countries. For instance, between 2003 and 2011, the yearly change in the stocks of equities varied from a decrease of $47 \%$ (in 2008) to an increase of $82 \%$ (in 2003), while changes in FDI varied from a $4 \%$ decrease (in 2008) to a $29 \%$ increase (in 2009) and the stock of debt has increased every year (varying from $2 \%$ in 2008 to $23 \%$ in 2007).

To further analyze volatility, we look at the standard deviation $(\sigma)$ of the series of changes in the stocks of the different types of capital in different countries. The deviation in this case is the difference between the yearly change $\left(x_{i}\right)$ to the period's average change $(\bar{x})$ - shown in Equation 4.1:

$$
\sigma=\sqrt{\frac{1}{N} \sum_{i=1}^{N}\left(x_{i}-\bar{x}\right)^{2}}
$$

The resulting volatility indicators of each type of capital in each of the 20 countries are presented in Table 4.3 for the 2003 to 2011 period. As it can be seen, the stock of equity liabilities is the most volatile in all 20 countries. Only in South Africa does the stock of FDI deviate almost as much as the one of equities. As a result, the cross-country average volatility of the stocks of equities (0.48) is four times higher than the volatility of debt (0.12) and 2.5 times higher than the volatility of FDI (0.19).

It is important to note that the volatility of equities is not only due to the volatility of the flows themselves, but also to the rapidly changing capital gains (and losses) that are characteristic of this type of asset. This is especially important given that in the analyzed period stock markets have sky-rocketed and also suffered large losses in some EMEs (see Figure 4.13). As mentioned earlier, this very characteristic of equities could be seen as a means of improving risk sharing: in times of crisis, creditors would have lower amounts to withdraw from countries due to the losses in capital values. But from a macro perspective, due to the higher volatility of equities, the available withdrawal amounts at a given point, can also be substantially large, because the stock of equities has two relevant sources of volatility: flows and prices. This calls attention to the need of studying the price changes of the different types of capital. Equities surely have the advantage (for the investment country 
TABle 4.3 Standard Deviation of Changes in the Stock of Different Liabilities From 2003 to 2011

\begin{tabular}{lccc} 
Country & Equities & Debt & FDI \\
\hline ARG & 0.60 & 0.14 & 0.03 \\
BRA & 0.59 & 0.14 & 0.22 \\
CHL & 0.26 & 0.05 & 0.10 \\
CHN & 0.74 & 0.13 & 0.10 \\
COL & 0.51 & 0.08 & 0.11 \\
CZE & 0.29 & 0.13 & 0.15 \\
HUN & 0.47 & 0.19 & 0.33 \\
IDN & 0.73 & 0.08 & 0.44 \\
IND & 0.57 & 0.09 & 0.15 \\
KOR & 0.41 & 0.18 & 0.16 \\
MEX & 0.23 & 0.10 & 0.14 \\
MYS & 0.37 & 0.13 & 0.13 \\
PER & 0.44 & 0.08 & 0.10 \\
PHL & 0.41 & 0.06 & 0.06 \\
POL & 0.42 & 0.11 & 0.20 \\
RUS & 0.52 & 0.15 & 0.40 \\
THA & 0.43 & 0.15 & 0.10 \\
TUR & 0.70 & 0.08 & 0.45 \\
TWN & 0.49 & 0.17 & 0.12 \\
ZAF & 0.32 & 0.09 & 0.31 \\
\hline Average & 0.48 & 0.12 & 0.19
\end{tabular}

Data source: extended and updated version of Lane and Milesi-Ferretti (2007). Author's estimations.

and for risk-sharing) of the possibility of negative price changes, but the range of the positive price changes must also be considered.

The volatility levels of the stocks of equities vary across EMEs. The highest levels were seen in China (0.74), Indonesia (0.73), Turkey (0.70), Argentina (0.60), Brazil (0.59) and India (0.57). Mexico (0.23), Chile (0.26) and Czech Republic (0.29) had the lowest levels (see Table 4.3).

In the case of FDI, the highest volatility coefficients are much lower, in the range of 0.30 to 0.45 . The highest levels were seen in Turkey, followed by Indonesia, Russia, Hungary and South Africa. The volatility of the stock of debt is much lower - the highest being 0.19 for Hungary, 0.18 for South Korea, and 0.17 for Taiwan. It is interesting to note that there seems to be no country bias with regards to volatility, as we cannot point to a country where the three types of capital are more volatile than in other places. The same cannot be said 
about types of capital, as the lowest volatility of the stock of equities, for instance, is higher than the highest volatility of the stock of debt.

The volatility of the stock of foreign liabilities in the form of equities was also the highest among the three types of capital when analyzing a longer period, from 1970 to 2011 and in every one of the three sub-periods (1970-1989, 1990-1999 and 2000-2011). From 1970 to 1989, the volatility of equities was four times higher than that of debt and FDI; from 1980 to 1990 this ratio increased to 43 times in relation to FDI and 180 times in relation to debt; it was in the most recent period (from 2000 to 2011) that the volatility of equities was the closest to that of FDI (two times higher) and debt (less than four times higher). The higher volatility level of equities in earlier periods might be a consequence of the very low values of the stocks of equities, making any "small" absolute change be an important deviation.

\subsubsection{On the Measure of Volatility of a Time-Series}

Although equities clearly presented higher volatility than the other types of foreign liabilities, estimating it through the standard deviation results in an underestimation of volatility levels.

The standard deviation cannot differentiate the volatility of a series that is only growing at $\mathrm{x} \%$ from another that alternates increases and decreases of $\mathrm{x} \%$, as is the case of a series of equities, because it is based on absolute values, where the impact of a positive or a negative change is the same.

An option to this underestimation problem could be to look at the standard deviation of the stocks themselves, instead of their changes. However, such measure would also underestimate the variance of the equity series that for alternating increases and decreases of the stock have values that are closer to each other than the values of debt that for having only increased have larger ranges. In other words, the series of equities has values which are closer to their averages than the series of debt, resulting in deviations from the average which are less significant.

Another alternative could be to look at the coefficient of variation $\left(c_{v}\right)$ of the series of changes in stocks, therefore considering the standard deviation $(\sigma)$ relative to the mean $(\bar{x})$ of the series - as in Equation 4.2: 


$$
c_{v}=\frac{\sigma}{\bar{x}}
$$

This option was also rejected. Given that the original values $\left(x_{i}\right)$, and thus their average $(\bar{x})$, represent changes and variability, the higher the average change in stocks $(\bar{x})$, the lower the $\left(c_{v}\right)$, which is the opposite of what one understands of volatility: that its estimator must increase with an increase of the deviation $(\bar{x})$.

\subsection{The Evolution of the Stock of Foreign Liabilities}

Continuing the analysis of the vulnerabilities associated with each type of capital, this section discusses the path followed by the three types of foreign capital since the 2000s. Figures 4.9, 4.10, and 4.11, show the evolution of the stock of foreign capital of equities, FDI, and debt, respectively.

\subsubsection{Equities' Special Pattern}

The recent evolution of the stock of equities present a very similar pattern, forming a Nor M-line across several countries (See Figure 4.9). This striking similarity is unique to the stock of equities, not occurring in the cases of FDI nor debt - with the interesting exceptions of FDI in the cases of Russia and Turkey.

The increase in the stock of equities from the mid-2000s was impressive in most coun$\operatorname{tries}^{24}$. In the first years of the 2000s (the aftermath the late-1990s crises that affected many EMEs), the stocks of foreign equity liability still decreased in most countries. From 2003 onward the situation reversed. This was the expansionary stage of the new cycle of capital

\footnotetext{
${ }^{24}$ A notable exception is Argentina, where the stock of equities was already at very high levels in the 1990 s. To a smaller extend Malaysia, Mexico and Thailand also present different cases. Moreover, it must be noted that in percentage terms the average increase was higher in the early 1990s due to the very small values before this decade.
} 
Figure 4.9: Stocks of Foreign Assets in EMEs, 1990-2011: Equities, 1990-2011
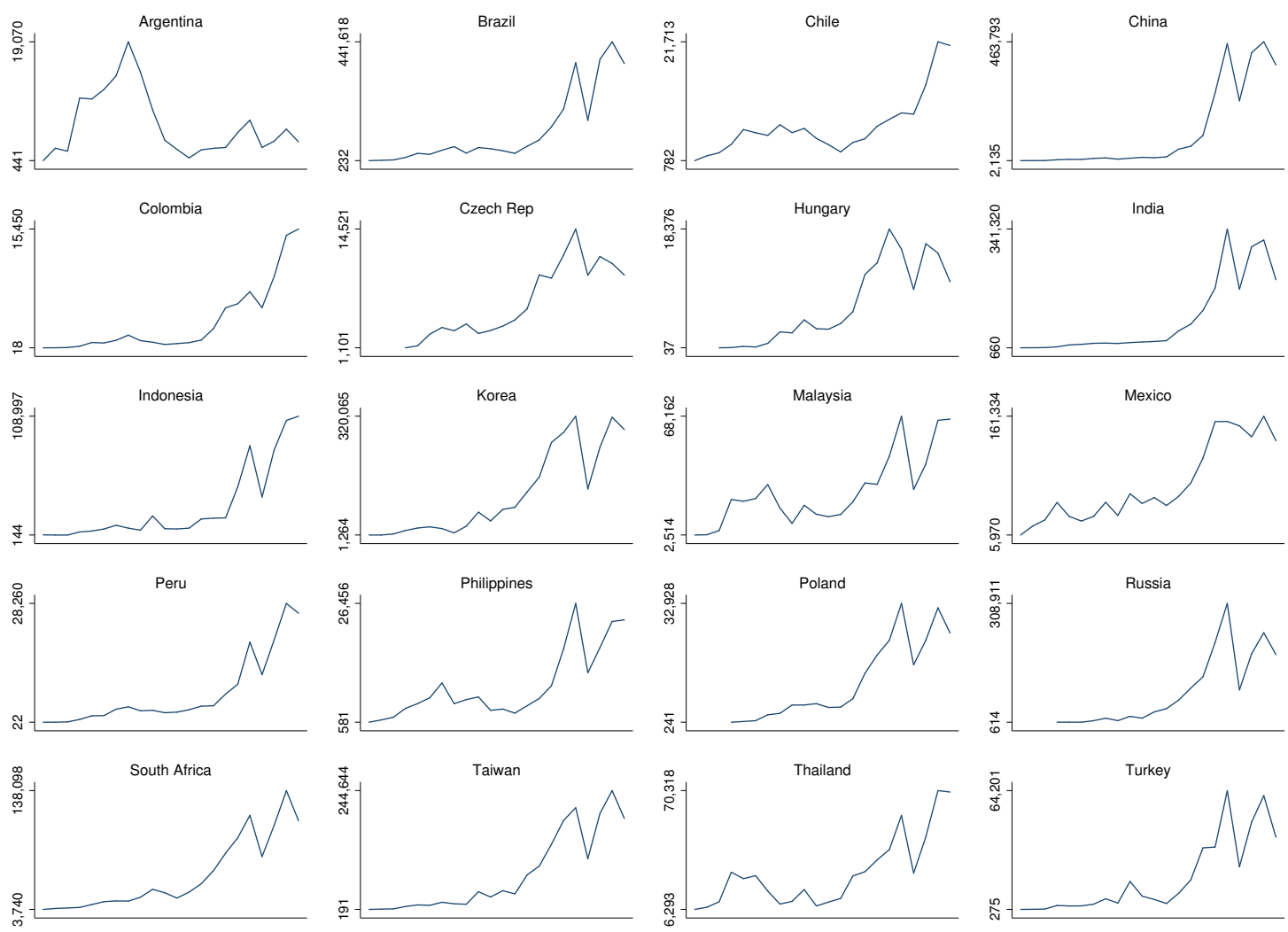

US\$ Million. Data source: Updated and extended version of dataset constructed by Lane and Milesi-Ferretti (2007). The scales are different in each plot, varying according to the countries' range.

flows to EMEs (Prates, 2015) ${ }^{25}$ and of stock prices ${ }^{26}$ and there was an impressive increase of liabilities in most countries. In 2003, the average increase across the 20 countries was of $82 \%$. The following years were also marked by important increases, with liabilities in the form of equities increasing around 50\%. In 2006, right before the first signs of crisis in the housing market in the US, there was an average increase of $53 \%$.

The countries that saw the greatest average increase of liabilities in the form of equities during the 2003 to 2007 period were: China (103\%), Turkey (88\%), Indonesia (80\%), India (78\%), Colombia (68\%), the Philippines (61\%) and Argentina (60\%) (see Table 4.10 in the

\footnotetext{
${ }^{25}$ Studying capital flows to Latin America, Palma (2012) also points 2003 as the starting point of a new cycle of capital flows to these countries. Shin (2014) argues that there has been two liquidity cycles since the 2000s, one from 2003 to the crisis and another one that started after the crisis. The author differentiates these into two cycles for arguing that the main players in these two periods are different.

${ }^{26}$ It is worth remembering that the rise of stock markets were fueled not only by foreign, but also by domestic capital.
} 
Appendix). Specifically looking at the period just before the crisis (2006 and 2007), the stock of equities achieved an increase of $132 \%$ in Indonesia, $119 \%$ in China, $79 \%$ in India, $77 \%$ in the Philippines $73 \%$ in Peru, $71 \%$ in Brazil, $67 \%$ in Argentina, and 62\% Russia. Among the European EMEs, Czech Republic, Hungary, and Poland (and to a smaller extent Turkey) the growth rate from these years was not impressive. In fact, in these countries the stock of equities had already been substantially increasing since the mid-2000s, in the wake of their integration to the European Union. It is interesting to note that in the countries where the stocks of equities grew the most in pre-crisis periods presented the most volatile stock of equity liabilities.

Following the collapse of the Lehman Brothers and the repatriation of capital to advanced economies with the consequent fall of stock prices in EMEs, the stock of equity liabilities decreased considerably in 2008 - an average of $47 \%$ across the 20 countries. The most impacted were Russia (73\%), Turkey (64\%), Argentina (63\%), Korea (61\%), Brazil (59\%), Malaysia (59\%), Indonesia (57\%), Thailand (55\%), India (51\%) and Taiwan (50\%). The falls are represented by the first inflection point of the $\mathrm{N}$ - or M-like lines in the plots of Figure 4.9.

In 2009, the great recession in advanced countries and the relatively quick recovery of EMEs (characterizing the situation known as 'double-speed recovery') resulted in inflows of capital to these countries and the stocks of equities increased significantly, reaching a crosscountry average of $72 \%$. With this increase, by the end of 2009 , the stock of equities achieved end-2007 levels - indicated by the third inflection point of the N- or M-like lines in the plots. More precisely, 2009 level in some countries was even higher than in 2007. These are: Brazil, Indonesia, Peru, South Africa, Taiwan and Thailand.

The years of 2010 and 2011 were characterized by uncertainties related to the Euro crisis. In 2010 the stock of equities still presented an increase (of 31\%, on average), but in 2011 it decreased (16\%). The post-crisis increases were the greatest in Brazil (85\%), Indonesia (79\%), Russia (71\%), Colombia (68\%), Turkey (67\%), Thailand (65\%), and Korea $(62 \%)$. As expected, the group of countries that faced the highest decreases in liabilities is very similar to the one that faced the highest increases some years before, given that the countries where liabilities increased the most are the ones with the highest potential for 
a decrease. This is important to be highlighted because it it indicates the importance of external (push) factors because in determining capital flows and thus foreign liabilities (a subject that will be discussed in Chapter Six).

The fact that the stock of equity liabilities followed a specific N- or M-pattern calls attention to two important aspects. First, the similarity across several countries sheds light on the importance of push factors in their determination. They could only reflect pull factors if all these countries' domestic conditions were similar and had evolved in the same manner, but, as shown by Kaltenbrunner and Painceira (2014), who study six of these EMEs, their fundamentals were markedly different at this moment.

Secondly, this pattern is similar to the evolution of uncertainty in international financial markets, as proxied by the VIX index - presented in Figure 6.12 (in Chapter Six) ${ }^{27}$. As shown from its path and from the academic discussion presented in Chapter Six, the VIX suggests that the 2000s were marked by low level of uncertainty from the dot-com bubble to the GFC, when it hit a historical peak. The period after the GFC was marked by much smaller but frequent peaks of uncertainty (related to crisis in Europe). This similarity of the inflection points of the two series indicates a close association between the stock of equity liabilities in EMEs and the international financial markets ${ }^{28}$.

Moreover, the fact that it is only the stock of equities and not the stocks of debt or FDI that presents a similar pattern across EMEs is in line with the aforementioned "double volatility" characteristic of the equities' liabilities. The "double volatility" could explain why the stock of equities is more sensitive to international financial markets, as exposed in this section: international shocks affect not only its flows, but also its prices.

\footnotetext{
${ }^{27}$ By measuring the expected volatility implied in different S\&P 500 index options, the VIX is a broadly used indicator of uncertainty and stress in financial markets in general. Values lower than 20 are commonly considered as less stressful periods and values higher than 30 are associated with crisis. This index is further discussed in Chapter Six.

${ }^{28}$ Unfortunately an econometric measure of the relationship between the VIX and the countries' equity liabilities is hindered. The data on liabilities is published yearly while the VIX's daily, and an yearly average of the VIX would lose much of its information. For instance, the average of the VIX 2008 values is probably not representative of the uncertainty of that year given that the hike of the VIX was (as they always are) very short-lived.
} 


\subsubsection{The Pattern of FDI Liabilities}

As mentioned, in Russia and Turkey the pattern of FDI is similar to the one of equities, what could result from the closer definition of the two (see Footnote 17). But, as it can be seen in Figure 4.10, this pattern is an exception, not a characteristic of all EMEs.

Figure 4.10: Stocks of Foreign Assets in EMEs: FDI, 1990-2011
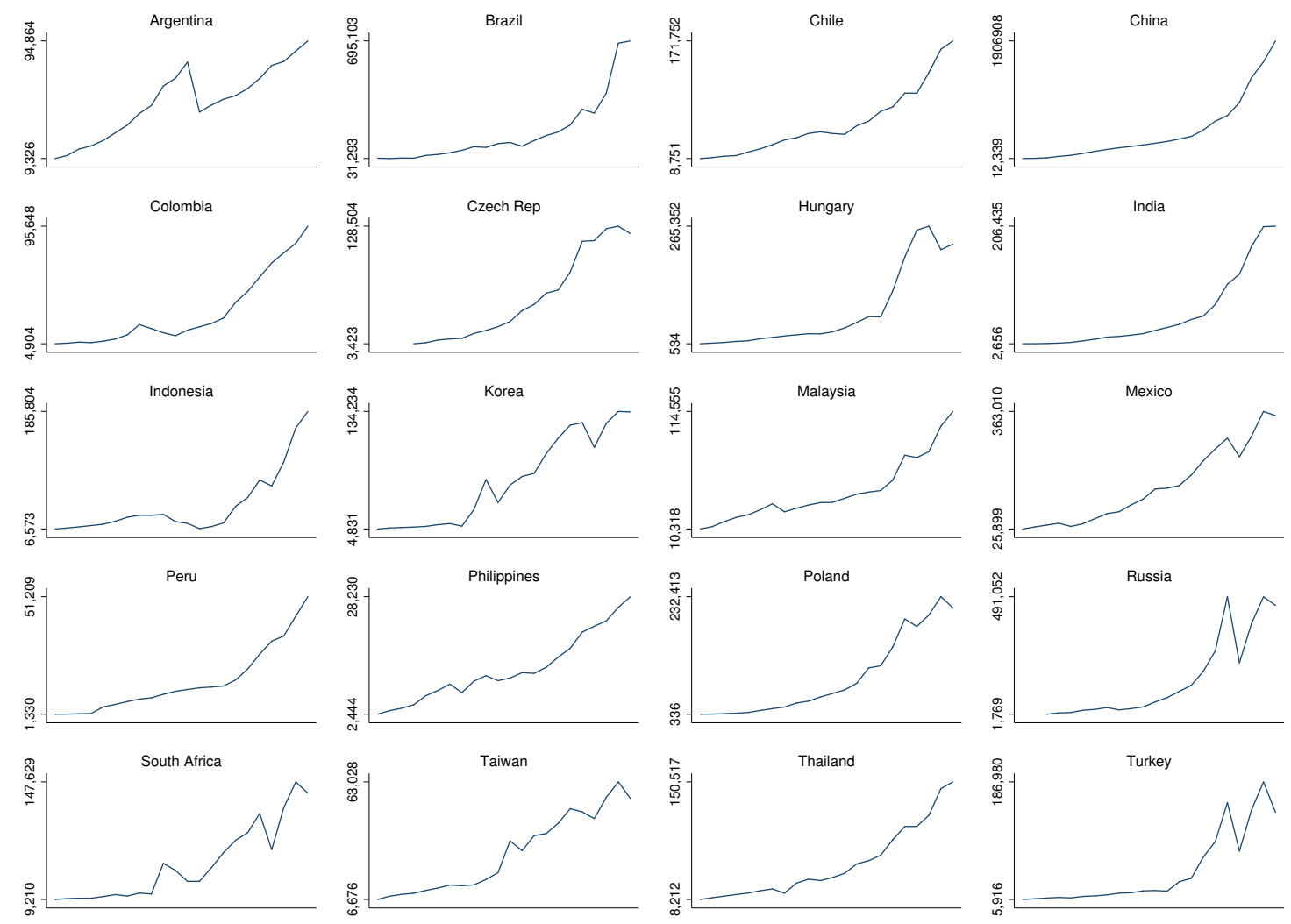

US\$ Million. Data source: Updated and extended version of dataset constructed by Lane and Milesi-Ferretti (2007). The scales are different in each plot, varying according to the countries' range.

Figure 4.10 and Table 4.9 show that FDI liabilities were most impacted by the GFC in Russia (56\% fall in 2008), Turkey (48\%), South Africa (28\%), Korea (22\%), and Indonesia (11\%). Apart from that, there is not a clear association between FDI and the international environment in the most recent period. In many EMEs the stock of FDI even increased in 2008. FDI followed a similar pattern across EMEs, presenting an important and rather stable increase from 2000 to 2011, with small or no impact from the GFC. 


\subsubsection{The Pattern of Debt Liabilities}

Among the three types of liability, the pattern of debt is the least homogeneous (see Figure 4.11). Nevertheless, as the other types of capital, it has been increasing in most EMEs (an important exception being Argentina). A main difference is that in most countries debt did not suffer a great impact during the GFC - except for Hungary, Korea, South Africa and Russia. The absence of a common pattern across countries could indicate that this type of capital is more closely related to each country's pull factors rather than to the international scenario. Such a finding would be in line with the empirical literature, as it will be seen in Chapter Six.

Figure 4.11: Stocks of Foreign Assets in EMEs: Debt, 1990-2011
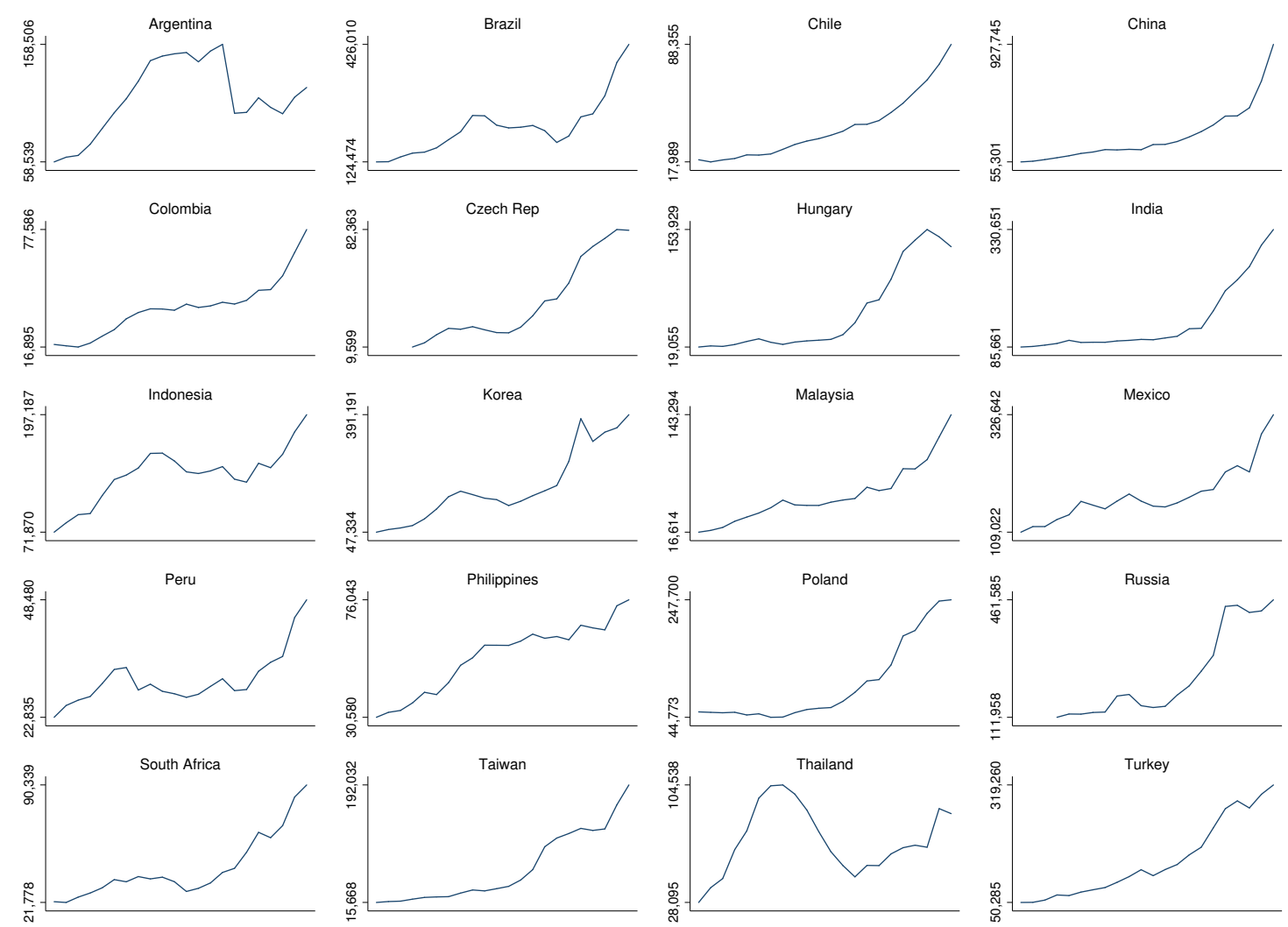

US\$ Million. Data source: Updated and extended version of dataset constructed by Lane and Milesi-Ferretti (2007). The scales are different in each plot, varying according to the countries' range. 


\subsection{The Similarity of the Pattern of Liabilities: a Principal Components Analysis}

In order to further analyze whether the pattern of liabilities is becoming increasingly similar across EMEs - as indicated by the graphical analyses for the case of equities - this section looks at the comovement of stocks of different types of capital across EMEs in different periods through a principal components analysis (PCA).

\subsubsection{Theoretical Considerations}

PCA is a mathematical technique that reduces the dimensions of a dataset into a series of principal components - that, in turn, explain as much of the variance of the original series as possible. As straightly put by Edison and Reinhart (2001), the number of components resulting from the PCA indicates the extent of the variance of the original data series. In their words:

The higher the degree of co-movement that exists among the original series, the fewer the number of principal components that will be needed to explain a large portion of the variance of the original series. In the case where the original series were identical (perfectly collinear), the first principal component would explain 100 percent of the variation of the original series. Alternatively, if all the series are orthogonal to one another, it would take as many principal components as there are series to explain all of the variance in the original series. (p. 23)

The simplicity of the meaning of PCA has made it useful in a variety of cases. It is used by Edison and Reinhart (2001) to assess comovement between stock exchanges and exchange rates in EMEs. The authors conduct estimations of comovement for a control period and for a period when capital controls are imposed, testing whether the comovement decreases with the imposition of capital controls, and, therefore, its success. Comovement was also the focus of Calvo and Reinhart (1996), who studied contagion of crisis between different countries, with an increase in comovement being evidence of contagion. 
Studying the impact of factors on productivity, Loko and Diouf (2009) used PCA to understand how a few selected factors are related to others before adding them to an econometric exercise. Another interesting application is the one of Chinn and Ito (2008), that used PCA to build a financial openness indicator, composed from different data series, allowing the use of one unique series instead of a set of series in their study.

Miotti and Plihon (2001) used factor analysis, a similar technique to PCA, to analyze the different behavior of Argentinean banks before the late-1990s crisis. The analysis resulted in axis that were related to a more or less speculative behavior (built from indicators that were related or not to speculation) against which banks are located. The result is a typology of banks according to their speculative behavior that is then compared to the list of banks that default in 1998 .

\subsubsection{The Results}

In this chapter, PCA is used to study whether the stock of foreign liabilities of a type of capital has been recently following a similar pattern across EMEs - as argued from the graphical analyses to the case of equities. The analysis is done based on the amount of components whose Eigenvalues ${ }^{29}$ is greater than one $\mathrm{e}^{30}$.

The results are presented in Table 4.4. They indicate a higher comovement of the countries' series of equities in the most recent period: while three components were needed to explain $90 \%$ of the variance of the evolution of the stock in different countries for the 1990s period, for the 2000s, two components explained more than that percentage. Seen from another angle, for the series of the 1990s, the first component could explain $52 \%$, while for the 2000 s, the component explained $85 \%^{31}$.

The same exercise was done for the stock of external liabilities in the form of FDI and debt instruments. They suggest that the pattern of the stocks of these two types of

\footnotetext{
${ }^{29}$ As neatly put by Kolenikov and Angeles (2004, p. 8) "the eigenvalues are the variances of the corresponding linear combinations. Then the linear combination that corresponds to the largest eigenvalue is the one that has the greatest variance", in other words, the one that explains the greatest variance from the original dataset, or the one that explains the most of it

${ }^{30}$ This rule for choosing the amount of "relevant" components is known as the Kaiser rule.

${ }^{31}$ A comparison with the 1970 s and 1980 s is not possible due to lack of data for several countries in this period.
} 
TABLE 4.4 PCA Stock of Liabilities of Individual Series

\begin{tabular}{|c|c|c|c|c|c|c|}
\hline & & Component & Eigenvalue & Difference & Proportion & Cumulative \\
\hline \multirow{5}{*}{ Equities } & \multirow{3}{*}{ 1990s } & Comp1 & 10.8491 & 5.39962 & 0.5166 & 0.5166 \\
\hline & & Comp2 & 5.44951 & 2.81514 & 0.2595 & 0.7761 \\
\hline & & Comp3 & 2.63437 & 0.567369 & 0.1254 & 0.9016 \\
\hline & \multirow{2}{*}{$2000 \mathrm{~s}$} & Comp1 & 17.9162 & 16.654 & 0.8532 & 0.8532 \\
\hline & & Comp2 & 1.26223 & 0.412987 & 0.0601 & 0.9133 \\
\hline \multirow{5}{*}{ FDI } & \multirow{3}{*}{$1990 \mathrm{~s}$} & Comp1 & 18.0146 & 16.3953 & 0.8578 & 0.8578 \\
\hline & & Comp2 & 1.61929 & 0.856515 & 0.0771 & 0.9349 \\
\hline & & Comp3 & 0.762777 & 0.328697 & 0.0363 & 0.9713 \\
\hline & \multirow{3}{*}{$2000 \mathrm{~s}$} & Comp1 & 19.0962 & 18.1712 & 0.9093 & 0.9093 \\
\hline & & Comp2 & 0.92498 & 0.499268 & 0.0440 & 0.9534 \\
\hline \multirow{7}{*}{ Debt } & & Comp1 & 13.9813 & 10.8098 & 0.6658 & 0.6658 \\
\hline & \multirow{2}{*}{ 1990s } & Comp2 & 3.17147 & 0.462001 & 0.1510 & 0.8168 \\
\hline & & Comp3 & 2.70947 & 2.03567 & 0.1290 & 0.9458 \\
\hline & & Comp4 & 0.673802 & 0.400872 & 0.0321 & 0.9779 \\
\hline & \multirow{3}{*}{$2000 \mathrm{~s}$} & Comp1 & 17.7722 & 15.8424 & 0.8463 & 0.8463 \\
\hline & & Comp2 & 1.92979 & 1.45642 & 0.0919 & 0.9382 \\
\hline & & Comp3 & 0.473376 & 0.141194 & 0.0225 & 0.9607 \\
\hline
\end{tabular}

Data source: extended and updated version of Lane and Milesi-Ferretti (2007). Author's estimations.

capital have also been moving in an increasingly similar pattern. With regards to FDI, two components were needed to explain the variance of the series of different countries in the 1990s, with the first one explaining $86 \%$. Yet, in the 2000s, only one component explained $91 \%$ of the variance. With regards to debt, four components were used to explain $67 \%$ variance in the 1990s, while in the 2000s only three components explained more than that, $85 \%$. Therefore, when analyzed through the explanatory power of the first component, all three forms of capital have seen a decrease of their variance.

FDI is the form of foreign liability that presents the most similar pattern across EMEs in the 2000 (91\% explained by the first component, against $85 \%$ of equities and debt). Yet, this should not be interpreted as an indicator that FDI is the type of capital that responds the most to external factors ${ }^{32}$. As seen in the descriptive analysis, the stock of equities alternates increases and decreases, while the stocks of debt and FDI tend to increase only. As debt and FDI tend to have longer trends, it is expected that their path present a smaller co-variance

\footnotetext{
${ }^{32}$ If the importance of external factors overcomes the importance of domestic ones, flows, and thus stocks of foreign liabilities would be more similar across different countries.
} 
across countries. The stock of equities saw the greatest increase in the explanatory power of its first component from the 1990s to the 2000s, which could indicate evidence of the increasing use of equities as an instrument of portfolio diversification. Moreover, the overall result of increasing comovement of all three types of stocks of liabilities might be an evidence of the higher importance of external (push) factors in their determination, along with these countries' higher integration to international financial markets.

In summary, the PCA analysis confirmed that the stock of equities is now more similar across EMEs, but not that this similarity is higher than that other types of capital, which might be due to its different characteristics.

\subsection{Stock Prices and Exchange Rate Dynamics}

This section further discusses the potential impacts of equity-financing by adding considerations on the interactions between equity markets and exchange rates. It is expected that the rise of equity-financing and the rise of foreign investors in EMEs' domestic stock exchanges lead to a growth of these markets, making such an interaction more important ${ }^{33}$. Indeed, by comparing the stock of foreign liabilities held in the form of equities to EMEs' stock market capitalization, the importance of foreign investment in these markets is evident. The highest average share in the 2003-2011 period was $45 \%$ in Hungary and $42 \%$ in Mexico. But it also varied significantly, starting with Chile's 6\% - see Figure 4.12 for the average ratio and Figure 4.17 in the Appendix for the behavior of the two series in the period.

Following the same approach used in the thesis, this section first presents the two series before going into a more precise empirical analysis. Figure 4.13 presents EMEs' stock exchange indeces, plotted against the countries' exchange rates (USD per local currency) from 2000 to 2013 .

Figure 4.13 indicates that the relationship between stock exchange and exchange rates is not the same across EMEs. In some countries or in certain periods the two seem to move in tandem, while in others, they go in opposite directions. The case of Brazil from 2003 to the

\footnotetext{
${ }^{33}$ In a similar exercise, Haldane (2011) compares gross portfolio equity flows to emerging markets and the MSCI index in 2010, which seem to be strongly correlated.
} 
Figure 4.12: Equity Liabilities Over Stock Market Capitalization, 2000 to 2011 average

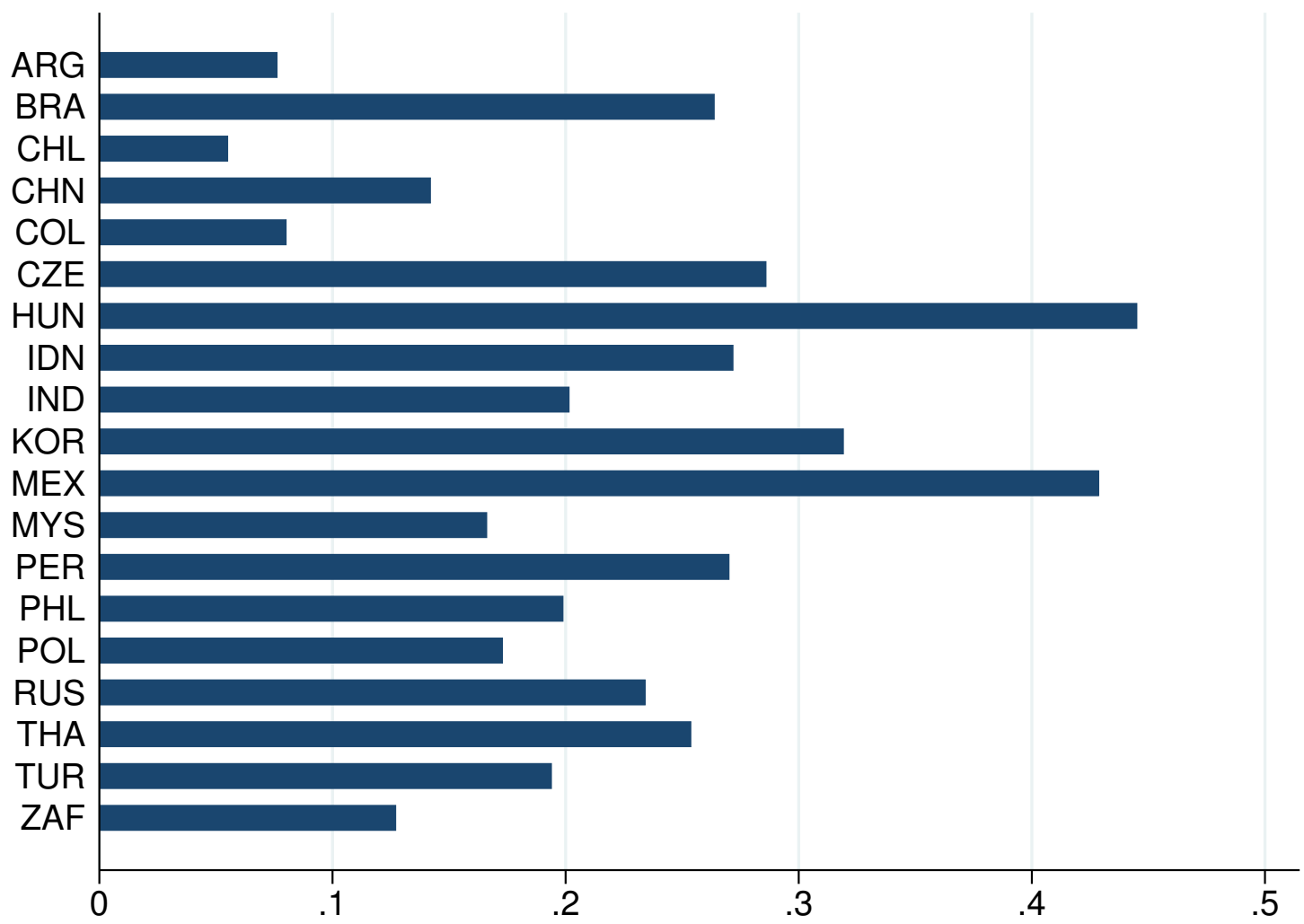

Total liabilities in the form of equities from updated and extended database constructed by Lane and Milesi-Ferretti (2007). Stock Market Capitalization from WB WDI.

GFC is a good example of the latter: the IBOVESPA (the main stock market index) rallied and the exchange rate appreciated (a decrease in the USD value of one Brazilian real); after, with the crisis and capital outflows, the stock exchange index lost value and the exchange rate depreciated. The same pattern is observed with the Korean KOSPI and the won, the Indian BSES and rupee, the Peruvian IGBVL and the nuevo sol, the Polish WIG and the zloty - also in the period around the GFC.

In other countries, the exchange rate and the stock index seem to have moved in tandem. South Africa is a clear example. In the most recent period, for instance, the JSE gained value and the rand depreciated. The same is seen for the Argentinean MERV and the peso. 
Figure 4.13: Stock Exchange and Exchange Rates, 2000 to 2013
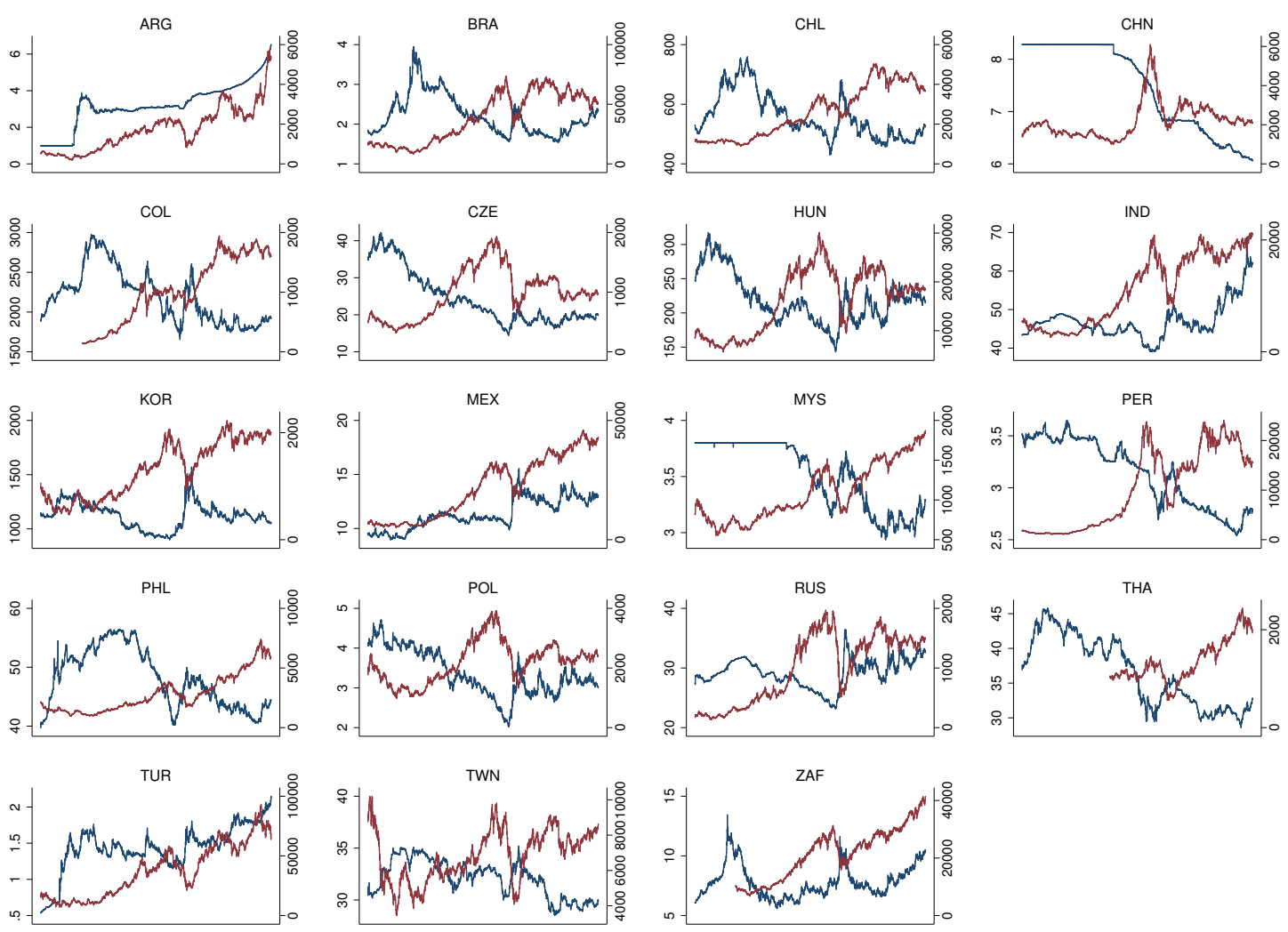

Data Source: Ecowin (exchange rates) and Bloomberg (stock exchange).

\subsubsection{Theoretical Considerations}

The relationship between a country's stock exchange and its FX markets has been studied with different aims, including to understand contagion during crisis, to inform portfolio investors, or to test exchange rate theories (as do Meese and Rogoff (1983)). Most papers focus on the direction and type of causality, but the long-run relationship between the two markets is also studied. Methodologies vary and different studies present divergent evidence. The next section briefly presents the literature centered on emerging countries, followed by the presentation and discussion of the results of a Vector Autoregressive (VAR) model.

This literature briefly explains the expected interactions between FX and equity markets. The usual mechanism tested is that exchange rates impacts stock prices through a country's exports, the financial health of its export companies, and thus, their stock prices: When a country's currency depreciates (appreciates), higher expected exports (or aggregate 
demand) improves (deteriorates) export companies future cash flows leading to a hike (decrease) of their stock prices. The causality is thus from exchange rates to stock prices and the impact is positive (if the exchange rate is given as the dollar price of a local currency unit). This is known as the 'traditional channel' ${ }^{34}$.

The opposite causality, that a currency depreciation leads to lower stock prices, has also been defended. Yang and Doong (2004) argue that in an economy with a significant import sector, currency depreciation could cause inflation, which, in turn, might exert a direct dampening effect on the stock market and an indirect one because foreign investors would be discouraged to invest in the country. However this causality might only take place in specific cases: in fact, if inflation is contemporaneous to economic growth, the stock exchange is more likely to present a positive rather than a negative performance.

The impact on the other direction, from stock prices to exchange rates, is said to take place through two channels, the 'wealth effects' and the 'portfolio channel' (as in Chkili and Nguyen (2014), Granger et al. (2000), Phylaktis and Ravazzolo (2005), Pan et al. (2007), and Yang and Doong (2004)). The first is based on the portfolio approach to exchange rate determination (seen in Chapter Three, Section 3.1.2.3) ${ }^{35}$, according to which, changes in investors demand for domestic and foreign financial assets determine the exchange rate. This is known as the 'portfolio channel'.

The impact from stock markets on exchange rates could also take place through 'wealth effects': According to the monetarist view of exchange rate determination (seen in Chapter Three, Section 3.1.2.1 ${ }^{36}$, a change in stock prices affect wealth and the demand for money, causing effects on the exchange rate. Given the restrictive hypothesis of the monetarist view and its empirical failure, this channel might not be deemed as relevant, so the portfolio channel is more realistic.

\footnotetext{
${ }^{34}$ Some further details on this literature. Chkili and Nguyen (2014) argue that the impact of an exchange rate change in a firm's performance, and thus, on the stock exchange could have been reduced with the advance of hedging strategies, as they reduce firms' sensitiveness to exchange rate fluctuations. As a result, this transmission channel would become less significant. Pan et al. (2007) refer to it as the 'goods market hypothesis', that they associate with Dornbusch and Fischer (1980). It is however slightly different from the dynamics just presented: instead of thinking about a change in the firms' expected revenues, it is focused on the actual increase of exports.

${ }^{35}$ Precisely, the usual references for portfolio models in this literature are Branson (1981), Dornbusch and Fischer (1980), and Frankel et al. (1987).

${ }^{36}$ Precisely, the usual references for monetary models in this literature is Gavin (1989), that argues that an important rise of stock markets can lead to a monetary expansion and exchange rate appreciation
} 
These two effects, from exchange rates to stock prices and the opposite, are not self excluding and cases where the two are in place are known as cases of bi-directional causality. When the transmission mechanisms in place are the 'traditional' and the 'portfolio' channels, one will attenuate the other, and the final result will depend on which one is stronger (Granger et al., 2000).

A few relevant points should be highlighted from these transmission mechanisms. First, the impact of stock prices on exchange rates is based on the assumption that markets are efficient and its prices perfectly reflect future economic conditions. In the words of Yang and Doong (2004, p. 1034) "stock prices incorporate present and expected economic activity as measured by industrial production, real economic growth, employment rate or corporate profits (see Fama, 1981; Geske and Roll, 1983)"37. It must be said that this hypothesis is controversial, at best.

Secondly, different transmission mechanisms might occur, but their timing might be different. It is important that the data frequency be chosen to reflect the hypothesis to be tested and that the two expected transmission mechanisms have the same timing. The impact from stock exchanges on exchange rates of the 'portfolio channel', for instance, is instantaneous. However, the impact of exchange rates on stock exchanges through inflation, takes a longer period to occur. This is also valid for the impact of exchange rate depreciation on actual net exports and thus, on stock prices (the 'traditional channel'): this would take a long time to take place and the first impact could even be of the opposite direction as in the $\mathrm{J}$-curve ${ }^{38}$.

Finally, a general remark. The pre-determination of transmission mechanisms supposed to work across different countries oversees the countries' specificities and the institutions in place. Take, for instance, the claimed negative impact of a currency depreciation on stock prices due to inflation. If an inflation targeting regime is in place, an inflationary depreciation might be followed by an interest rate rise, capital inflows and exchange rate appreciation,

\footnotetext{
${ }^{37}$ See Yang and Doong (2004) for references.

${ }^{38}$ The J-curve is famous in international-economics analyses for denoting the path of the current account that would follow a depreciation of the domestic currency: with the rising price of imported goods, the first effect will be a worsen, that will later give place to a hike as exports increase and imports decrease - suggesting a behavior in the format of the letter J. See McCombie (1993) for a more complex analysis on the expected impact of a depreciation.
} 
ruling out the first impact. The interest rate rise might also be expected to have a negative effect on aggregate demand, and thus, on the stock markets.

Which event will predominate depends on a country's institutions and on the "relative strength of the various competing events" (Phylaktis and Ravazzolo (2005)), which may also vary with time. Thus, the importance of understanding countries' transmission mechanisms ${ }^{39}$.

\subsubsection{Methodology}

These studies use different techniques to empirically analyze the relationship between stock and foreign-exchange markets. Meese and Rogoff (1983) and Pan et al. (2007) use VAR models and the latter add a test for Granger causality. Phylaktis and Ravazzolo (2005) ran the Granger causality test on a cointegration model. In this case, the cointegration model was chosen for enabling tests on the level of the variables, which is rarely done as they are not stationary ${ }^{40}$. Chkili and Nguyen (2014) apply a Markov-Switching EGARCH model that allows differentiating this relationship during normal and turbulent periods. Another interesting methodology is the Multivariate EGARCH model used by Yang and Doong (2004) that has the advantage of considering not only price, but also asymmetric volatility spillovers between the two markets.

An interesting methodological point is the one raised by Phylaktis and Ravazzolo (2005): the models that include stock and foreign exchange markets "could be incomplete systems because of the omission of an important variable", in their case, the influence of world markets. To handle this issue, the authors include the U.S. stock market in their model. The inclusion is justified by the hypothetical channels tested: a rise in U.S. stocks, occurring in tandem with higher economic growth, leads to higher imports that, in the four Asian countries studied, means more exports and, thus, enhances the financial condition of local

\footnotetext{
${ }^{39}$ This is also acknowledged by Pan et al. (2007) who states that "the linkages could vary across economies with respect to exchange rate regimes, the trade size, the degree of capital control, and the size of equity market" - even if authors only superficially do this type of analysis.

${ }^{40}$ Although this was a choice on the part of the authors, arguing that economic theory does not preclude the relationship in terms of levels, they recognize that the variations of these series seem to be imbibed of more economic sense.
} 
companies and rises local stock markets ${ }^{41}$. Such inclusion of a third element is however only justified by the importance of exports for the four economies under analysis. Given that this chapter deals with very different emerging economies, a similar procedure cannot be justified.

Still on the methodological front, two other ways of looking at the link between these two markets should be mentioned. The first specifically analyses the impact of stock market news on exchange rates, as done by Koulakiotis et al. (2015). The second analyses the transmission of the volatility from one market to the other. In so doing, Ho and Huang (2015) conclude that volatility could be transmitted between stock index and exchange rate even when there is no evidence of an impact on prices.

\subsubsection{The Model}

To model the short-run dynamic relationships between stock prices and exchange rates among EMEs the following VAR model is used:

$$
\begin{aligned}
& S E_{t}=c_{i}+\alpha_{i i, 1} S E_{t-1}+\ldots+\alpha_{i i, k} S E_{t-k}+\beta_{j i, 1} E R_{t-1}+\ldots+\beta_{j i, k} E R_{t-k}+e_{i, t} \\
& E R_{t}=c_{j}+\beta_{j j, 1} E R_{t-1}+\ldots+\beta_{j j, k} E R_{t-k}+\alpha_{i j, 1} S E_{t-1}+\ldots+\alpha_{i j, k} S E_{t-k}+e_{j, t}
\end{aligned}
$$

Where $S E_{t}$ is the stock exchange return in period $t, E R_{t}$ is the exchange rate change in period $t, \alpha_{i i}, \alpha_{i j}, \beta_{j j}$ and $\beta_{j i}$ are the coefficients of the impact from one market to the other or on itself ( $i$ for stock exchanges and $j$ for exchange rate), $c_{i, j}$ are the intercepts, and $e_{i, j}$ are the error terms. $k$ represent the number of lags, that vary from country to country.

\subsubsection{The hypothesis}

The main objective with the model is to test whether the exchange rate suffers impacts from the stock markets. An indication in this direction is given if we cannot reject the null hypothesis that the lagged $(\mathrm{k})$ coefficients $\alpha_{i j, 1}$ to $\alpha_{i j, k}$ in Equation 4.4 are different from zero, and if in the Granger causality test we cannot reject the hypothesis that stock returns

\footnotetext{
${ }^{41}$ The link between these events and the exchange rate is expected to be necessarily positive or negative, given the occurrence of impacts in two opposing directions.
} 
Granger cause exchange rates. This impact would be in accordance with the transmission channel proposed if the coefficients are negative.

Similarly, the impact from the exchange rate change on stocks is given by the impossibility of rejection that one of the (k) coefficients $\beta_{j i, 1}$ to $\beta_{j i, k}$ is different from zero, and by a result that does not allow us to reject that exchange rates Granger cause stock returns. We expect negative coefficients.

There are two hypothesis behind the case of bi-directional causality among EMEs. The first is that rising (decreasing) stock prices attract more (less) foreign investors, thus leading to exchange rate appreciation (depreciation). This channel has the same effect as the aforementioned "portfolio approach". The second interaction is that an exchange rate appreciation (depreciation), by increasing (decreasing) foreign investors' expected total returns, attracts (discourages) foreign investors. As they partially invest in stocks, there will be a rise (fall) of stock prices. Combined, these two mechanisms form a self-fulfilling spiral that can be either of a constantly appreciating exchange rate and booming stock exchange or the opposite, which is characteristic of country-runs. Kaltenbrunner and Painceira (2009) raises this point in the case of Brazil, and this mechanisms is further studied in Chapter Seven.

\subsubsection{The specifications and tests}

The two sets of series used - exchange rate change and stock exchange return were tested for non-stationarity, what was rejected at the $1 \%$ significance level for all 19 countries ${ }^{42}$. The Akaike (AIC) criteria was used to choose the number of lags. If the resulting model presented autocorrelated residuals ${ }^{43}$, the number of lags was chosen according to a different test (HQIC, SBIC, or FPE). If the problem persisted, another number of lags was chosen (up to four lags). Turkey is the only country for which the model's residuals presented autocorrelation with any number of lags between one and four. Running the model with more than four lags was not an option due to the number of observations needed.

In order to examine the dynamics of the system and better analyze the results, Granger causality tests were performed.

\footnotetext{
${ }^{42}$ The results are not included here, but can be requested to the author.

${ }^{43}$ Such a concern over residual tests was also present in the choice of Yang and Doong (2004) over its optimal lag length.
} 


\subsubsection{The results}

The estimated coefficients are presented in Tables 4.5 and 4.6. The first part of the table, "Stock Exchange", lists the statistics when lagged stock returns $\left(\alpha_{i i, k}\right)$ and lagged exchange rate changes $\left(\beta_{j i, k}\right)$ are regressed on stock price returns. The statistics of the reverse-order regressions are reported in the second part, "Exchange Rate", where $\beta_{j j, k}$ is the lagged exchange rate and $\alpha_{i j, k}$ the lagged stock exchange. The results from the Granger causality tests are presented in Table 4.7.

The results of the VAR model and of the Granger causality test suggest that there are important interactions between foreign exchange and stock markets among EMEs, specially from exchange rates to stock exchanges. A bi-directional causality between stock returns and exchange rates is found in half of the EMEs: Brazil, Hungary, India, Korea, Peru, South Africa, Russia, Taiwan, and Thailand. In seven other countries there is a causality from exchange rates to stock returns: Chile, Colombia, Malaysia, Mexico, the Philippines, Poland, and Turkey, but not an impact from stock prices to exchange rates. Finally, there are only three countries where there seems to be no cross-market impact: Argentina, China, and Czech Republic. Note that Argentina and China did not follow a floating regime in the $\operatorname{period}^{44}$.

In countries where foreign exchange market Granger causes stock markets, the impact was almost always (except Colombia) in the sense of a depreciation (appreciation) of the country's exchange rate leading to a drop (increase) of stock returns ${ }^{45}$. The result is coherent with the hypothesis that an exchange rate appreciation is seen by foreign investors as a rise of expected total returns, leading to higher purchases of the country's stocks and thus a rise of stock prices.

The impacts of stock returns on exchange rates are found to be negative in Brazil, India, Korea, Peru, Taiwan and Thailand, meaning that when the stock returns increase (decrease), the exchange rate appreciates (depreciates). This could support the portfolio determination

\footnotetext{
${ }^{44}$ However, Malaysia and Russia (to a lesser extent) have had non-floating regimes and for these countries impacts from at least one market to the other were found (see Table 6.12, on Exchange Rate Arrangements in Chapter Six).

${ }^{45}$ Recall that the exchange-rate series used in the Chapter are of the U.S. dollar price of one local currency unit, where a depreciation means an increase of value).
} 
TABLE 4.5 Results of the VAR Model (1/2)

\begin{tabular}{|c|c|c|c|c|c|c|c|}
\hline \multirow[b]{2}{*}{ Cnt } & \multirow[b]{2}{*}{$k=$} & \multicolumn{3}{|c|}{ Stock Exchange } & \multicolumn{3}{|c|}{ Exchange Rate } \\
\hline & & $c_{i}$ & $\alpha_{i i}$ & $\beta_{j i}$ & $c_{j}$ & $\beta_{j j}$ & $\alpha_{i j}$ \\
\hline \multirow[t]{5}{*}{ ARG } & 0 & $0.0015^{* *}$ & & & $0.0005^{*}$ & & \\
\hline & 1 & & & & & $0.0727^{* *}$ & \\
\hline & 2 & & $0.0835^{* *}$ & $0.3455^{* * *}$ & & $-0.2100 *$ & \\
\hline & 3 & & $0.0964^{*}$ & & & $-0.2708^{*}$ & $-0.0129^{* * *}$ \\
\hline & 4 & & & & & & \\
\hline \multirow[t]{4}{*}{ BRA } & 0 & $0.0010^{* *}$ & & & $-0.0005^{* * *}$ & & \\
\hline & 1 & & & & & $-0.1460^{*}$ & $-0.0422^{* *}$ \\
\hline & 2 & & & $-0.1701^{*}$ & & $-0.0634^{* * *}$ & \\
\hline & 3 & & $-0.1430^{*}$ & $-0.2476^{*}$ & & & \\
\hline \multirow[t]{5}{*}{ CHL } & 0 & $0.0012^{*}$ & & & & & \\
\hline & 1 & & $0.1618^{*}$ & & & & \\
\hline & 2 & & & $-0.1319 * *$ & & $0.0792^{* * *}$ & \\
\hline & 3 & & & $-0.0924^{* * *}$ & & $0.0790^{* * *}$ & \\
\hline & 4 & & & $-0.1325^{* *}$ & & & \\
\hline \multirow[t]{3}{*}{$\mathrm{CHN}$} & 0 & & & & $-0.0001^{*}$ & & \\
\hline & 1 & & $-0.0704^{*}$ & & & & \\
\hline & 2 & & & & & & \\
\hline \multirow[t]{5}{*}{$\mathrm{COL}$} & 0 & $0.0025^{*}$ & & & $-0.0006^{* *}$ & & \\
\hline & 1 & & $0.1388^{*}$ & $0.1721^{* *}$ & & $-0.1130^{*}$ & \\
\hline & 2 & & $-0.1481^{*}$ & & & & \\
\hline & 3 & & & & & & \\
\hline & 4 & & $-0.1388^{*}$ & & & & \\
\hline \multirow[t]{5}{*}{$\mathrm{CZE}$} & 0 & & & & & & \\
\hline & 1 & & & & & & $0.0518^{* *}$ \\
\hline & 2 & & & & & $0.1459 *$ & \\
\hline & 3 & & $-0.1364^{*}$ & $-0.1298^{* * *}$ & & $-0.0758^{* * *}$ & \\
\hline & 4 & & & & & $-0.0797 * * *$ & $0.0402 * * *$ \\
\hline \multirow[t]{5}{*}{ HUN } & 0 & & & & & & \\
\hline & 1 & & & $-0.1874^{*}$ & & & \\
\hline & 2 & & $-0.1135 *$ & $-0.1533^{* *}$ & & & \\
\hline & 3 & & & $-0.2024^{*}$ & & & \\
\hline & 4 & & & $-0.1367^{* *}$ & & & $0.0562^{* *}$ \\
\hline \multirow[t]{5}{*}{ IDN } & 0 & $0.0013^{* * *}$ & & & & & \\
\hline & 1 & & & $-0.3566^{* *}$ & & & \\
\hline & 2 & & & & & $-0.1598^{*}$ & \\
\hline & 3 & & & & & & \\
\hline & 4 & & & & & $-0.0867^{* *}$ & $-0.0250^{* *}$ \\
\hline \multirow[t]{5}{*}{ KOR } & 0 & & & & & & \\
\hline & 1 & & $0.1124^{* *}$ & & & $-0.1456^{*}$ & \\
\hline & 2 & & & $-0.2828^{*}$ & & $-0.1021^{* *}$ & \\
\hline & 3 & & & & & $-0.1385^{*}$ & $-0.0744^{*}$ \\
\hline & 4 & & $-0.1245^{*}$ & & & $-0.1400^{*}$ & \\
\hline
\end{tabular}


TABLE 4.6 Results of the VAR Model (2/2)

Stock Exchange

\begin{tabular}{|c|c|c|c|c|c|c|c|}
\hline Cnt & $k=$ & $\overline{c_{i}}$ & $\alpha_{i i}$ & $\beta_{j i}$ & $c_{j}$ & $\beta_{j j}$ & $\alpha_{i j}$ \\
\hline \multirow[t]{3}{*}{ MYS } & 0 & $0.0009^{*}$ & & & $-0.0001^{* * *}$ & & \\
\hline & 1 & & $-0.2029^{*}$ & $-0.4575^{*}$ & & $0.0540 * *$ & \\
\hline & 2 & & $-0.0372^{* * *}$ & $-0.1220^{* * *}$ & & & \\
\hline \multirow[t]{3}{*}{ MEX } & 0 & $0.0008 *$ & & & & & \\
\hline & 1 & & $0.1024 *$ & $-0.0884 * *$ & & $-0.1043^{*}$ & \\
\hline & 2 & & $-0.0387 * * *$ & $-0.1401 *$ & & & \\
\hline \multirow[t]{5}{*}{ PER } & 0 & $0.0023^{*}$ & & & & & \\
\hline & 1 & & $0.1259^{*}$ & & & $-0.1513^{*}$ & \\
\hline & 2 & & & & & & \\
\hline & 3 & & & $-0.8838 *$ & & & $-0.0179^{* *}$ \\
\hline & 4 & & & & & $0.0628^{* * *}$ & \\
\hline \multirow[t]{3}{*}{ PHL } & 0 & $0.0012^{*}$ & & & & $-0.0002^{* * *}$ & \\
\hline & 1 & & $0.0636^{*}$ & $-0.3716^{*}$ & & $-0.0812^{*}$ & \\
\hline & 2 & & & $-0.1524^{* * *}$ & & & \\
\hline \multirow{3}{*}{ POL } & 0 & & & & & & \\
\hline & 1 & & $-0.0506^{* *}$ & $-0.2316^{*}$ & & & \\
\hline & 2 & & $-0.0481^{* *}$ & $-0.1237^{*}$ & & & \\
\hline \multirow[t]{5}{*}{$\mathrm{ZAF}$} & 0 & & & & & & \\
\hline & 1 & & & $-0.0815^{* * *}$ & & $-0.1258^{*}$ & \\
\hline & 2 & & & & & & \\
\hline & 3 & & $-0.0781^{* * *}$ & $-0.1019 * *$ & & & $0.0923^{*}$ \\
\hline & 4 & & & & & $-0.0880^{* *}$ & \\
\hline \multirow[t]{5}{*}{ RUS } & 0 & & $0.0021^{* *}$ & & & & \\
\hline & 1 & & & $-0.5303^{* *}$ & & $0.3359^{*}$ & $-0.0493^{*}$ \\
\hline & 2 & & & $-0.7009^{*}$ & & & $-0.0193^{* *}$ \\
\hline & 3 & & $-0.2061^{*}$ & & & & $0.0173^{* * *}$ \\
\hline & 4 & & $-0.1067^{*}$ & & & & \\
\hline \multirow[t]{5}{*}{ TWN } & 0 & & & & & & \\
\hline & 1 & & & $-0.4593^{*}$ & & $-0.1269 *$ & $-0.0162^{* * *}$ \\
\hline & 2 & & & & & $-0.1480^{*}$ & $-0.0253^{* *}$ \\
\hline & 3 & & & & & & \\
\hline & 4 & & $-0.0772^{* *}$ & & & & \\
\hline \multirow[t]{3}{*}{ THA } & 0 & $0.0008^{* *}$ & & & & & \\
\hline & 1 & & $-0.0947^{*}$ & $-0.3336^{*}$ & & $-0.0771^{*}$ & \\
\hline & 2 & & $0.0684^{*}$ & & & & $-0.0228^{*}$ \\
\hline \multirow[t]{4}{*}{ TUR } & 0 & & $0.0016^{*}$ & & & & \\
\hline & 1 & & & $-0.5287^{*}$ & & $-0.0724^{* *}$ & \\
\hline & 2 & & $-0.0682^{* * *}$ & $-0.1875^{*}$ & & $0.0526^{* * *}$ & \\
\hline & 3 & & $-0.0774^{* *}$ & $-0.1370^{* *}$ & & & \\
\hline
\end{tabular}

Data source: Ecowin and Blooomberg. Author's estimations. ${ }^{*}=1 \%$ significance level; $* *$ $=5 \%$ significance level; $* * *=10 \%$ significance level. For ease of reading, only coefficients that are significant at least at the $10 \%$ level are reported. The complete list of results can be requested to the author. 
TABLE 4.7 Stock Exchange and Exchange Rates: Granger Causality Test

\begin{tabular}{|c|c|c|c|c|c|c|}
\hline \multirow[b]{2}{*}{ Cnt } & \multirow[b]{2}{*}{ Lags } & \multicolumn{2}{|c|}{ H0: Stock $\not \rightarrow$ ExchR } & \multicolumn{2}{|c|}{ H0: ExchR $\not \rightarrow$ Stock } & \multirow[b]{2}{*}{ Interpretation } \\
\hline & & Chi2 & $\mathrm{P}>\mathrm{Chi} 2$ & Chi2 & $\mathrm{P}>\mathrm{Chi} 2$ & \\
\hline$\overline{\mathrm{ARG}}$ & 4 & 6.3533 & 0.1740 & 3.5875 & 0.4650 & \\
\hline BRA & 3 & $7.2013^{* * *}$ & 0.0660 & $30.071^{*}$ & 0.0000 & Exc $>$ St, St $>$ Exc \\
\hline CHL & 4 & 0.5794 & 0.9650 & $16.071^{*}$ & 0.0030 & $\mathrm{Exc}>\mathrm{St}$ \\
\hline $\mathrm{CHN}$ & 2 & 3.0540 & 0.2170 & 2.0742 & 0.3540 & \\
\hline $\mathrm{COL}$ & 4 & 4.5264 & 0.3390 & $9.4403^{* * *}$ & 0.0510 & Exc $>$ St \\
\hline $\mathrm{CZE}$ & 4 & 7.2102 & 0.1250 & 7.3230 & 0.1200 & \\
\hline HUN & 4 & $8.0352^{* * *}$ & 0.0900 & $27.294^{*}$ & 0.0000 & Exc $>$ St, St $>$ Exc \\
\hline IDN & 4 & $8.0373^{* * *}$ & 0.0900 & $8.9834^{* * *}$ & 0.0620 & $\mathrm{Exc}>\mathrm{St}, \mathrm{St}>\mathrm{Exc}$ \\
\hline KOR & 4 & $17.246^{*}$ & 0.0020 & $10.734^{* *}$ & 0.0300 & Exc $>$ St, St $>$ Exc \\
\hline MYS & 2 & 2.7583 & 0.2520 & $52.068^{*}$ & 0.0000 & $\mathrm{Exc}>\mathrm{St}$ \\
\hline MEX & 2 & 1.1111 & 0.5740 & $13.956^{*}$ & 0.0010 & Exc $>$ St \\
\hline PER & 4 & $8.6269^{* * *}$ & 0.0710 & $34.062^{*}$ & 0.0000 & $\mathrm{Exc}>\mathrm{St}, \mathrm{St}>\mathrm{Exc}$ \\
\hline PHL & 2 & 1.1043 & 0.5760 & $23.16^{*}$ & 0.0000 & $\mathrm{Exc}>\mathrm{St}$ \\
\hline POL & 2 & 0.9255 & 0.6300 & $50.293^{*}$ & 0.0000 & $\mathrm{Exc}>\mathrm{St}$ \\
\hline $\mathrm{ZAF}$ & 4 & $9.3007 * * *$ & 0.0540 & $8.194^{* * *}$ & 0.0850 & Exc $>$ St, St $>$ Exc \\
\hline RUS & 4 & $47.94^{*}$ & 0.0000 & $26.345^{*}$ & 0.0000 & Exc $>$ St, St $>$ Exc \\
\hline TWN & 4 & $11.439^{* *}$ & 0.0220 & $10.733^{* *}$ & 0.0300 & $\mathrm{Exc}>\mathrm{St}, \mathrm{St}>\mathrm{Exc}$ \\
\hline THA & 2 & $8.383^{* *}$ & 0.0150 & $16.676^{*}$ & 0.0000 & $\mathrm{Exc}>\mathrm{St}, \mathrm{St}>\mathrm{Exc}$ \\
\hline TUR & 3 & 5.9679 & 0.1130 & $81.81^{*}$ & 0.0000 & $\mathrm{Exc}>\mathrm{St}$ \\
\hline
\end{tabular}

Data source: Ecowin and Blooomberg. Author's estimations. Note: $\not \rightarrow$ implies does not Granger cause. $^{*}=1 \%$ significance level; $* *=5 \%$ significance level; $* * *=10 \%$ significance level. "Interpretation" is based on the result of the Granger causality test, at $10 \%$

significance level. Exc $>$ St means that the test provides supportive evidence of causality between exchange rates and stock exchange prices. St $>$ Exc means existence of evidence of causality in the opposite direction.

of exchange rates. In Hungary and South Africa, however, the opposite mechanism seems to be at place: a rise in stock markets would lead to a depreciation of the exchange rate.

The bi-directional causality with the signs expected by the theoretical discussion is found to exist in Brazil, India, Korea, the Philippines, Taiwan and Thailand.

\subsubsection{Comparing the Results With the Empirical Literature}

The results found in the empirical literature focused on EMEs are diverse, but some studies also found bi-directional interactions in some EMEs. Diamandis and Drakos (2011) found it for four Latin American countries. Pan et al. (2007) find bi-directional causality for Hong 
Kong only. Granger et al. (2000) find bi-directional causality for nine countries ${ }^{46}$, but for a different period (1986 to 1997) and with a different type of impact of stock returns in foreign exchange markets: a currency depreciation leads to a hike in stocks. However, as the period analyzed by the authors vary from the one analyzed in this thesis, comparisons cannot be made given the significant difference in the importance of stocks markets.

Causality from stock exchange to foreign exchange was found by Chkili and Nguyen (2014) for Brazil, India and Russia and by Chkili et al. (2011) for Hong Kong, Singapore, Malaysia and Mexico. Chkili and Nguyen (2014) found it for China (using weekly data).

Pan et al. (2007) found that stock returns are significant predictors of exchange rate movements for Korea, Singapore, and Taiwan (as in our exercise) but not in Malaysia or Thailand (as do we). Moreover, their study concludes that exchange rates respond to stock price movements only in Japan, Malaysia, and Thailand (with the same sign as in our study). There is, however, an issue with comparability: their study uses data from 1988 to 1998, when equity markets in these countries were of a very different order ${ }^{47}$.

\subsubsection{The determination of impact from stock exchange to exchange rates}

This section has brought up a different potential source of vulnerability that arises from the shift towards equity-financing: an impact from stock markets to exchange rates. The model has shown that this impact occurs in half of EMEs, namely Brazil, Hungary, India, Korea, Peru, South Africa, Russia, Taiwan and Thailand. What could be the determinants of whether an impact from stock exchanges to exchange rates exist? Pan et al. (2007) indicate a few possibilities: exchange rate regimes, trade size, degree of capital control, and size of equity markets. In economies with less capital account restrictions the exchange rate would be more responsive to stock exchanges; high values of trade could make it respond more to trade than to financial flows (as the ones related to the stock markets); important equity markets are expected to generate more of such flows and thus increase its impact on

\footnotetext{
${ }^{46}$ Hong Kong, Indonesia, Japan, South Korea, Malaysia, the Philippines, Singapore, Thailand, and Taiwan.

${ }^{47}$ No comparison is made with studies that use monthly data, such as Phylaktis and Ravazzolo (2005), and Abdalla and Murinde (1997), due to the significant change in the hypothesis revealed by the different periodicity.
} 
the exchange rate; exchange rate regimes that provide no flexibility obviously decrease the potential response of exchange rates to stock prices.

To analyze the potential relationships, Figure 4.14 presents the capital account openness data (based on Chinn and Ito (2008)) and the trade levels of different EMEs. Figure 4.15 presents a country's stock market (presented in Section 4.1) and the share of equities on its total foreign liabilities (presented in Section 4.2). Countries where the stock exchange has an impact on the exchange rates are shown with round blue markers, the others with red triangles.

Figure 4.14: Stock-Prices-Exchange-Rate Interaction: Capital Account Openness and Trade

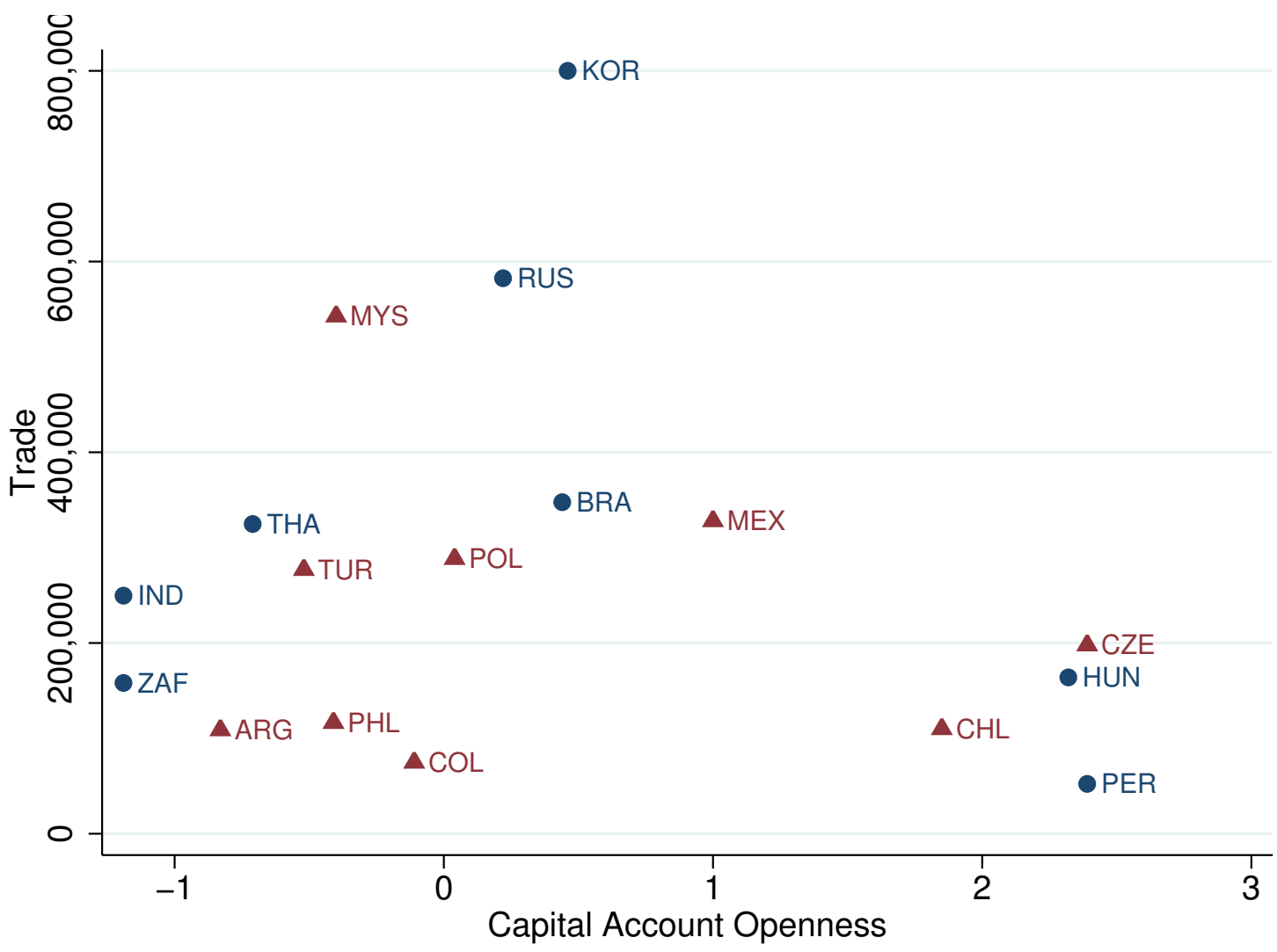

Foreign Trade: Exports plus Imports over GDP: US\$ Millions. Data source: WB WDI. 2003-2013 average. Capital Account Openness Data source: Chinn and Ito (2006). Data for China is not presented for ease of reading. Its trade level is about three times higher than the one of Korea; its capital account openness index is among the smallest.

In Figure 4.14, we observe that capital account openness and trade are not good predictors of the stock-price-exchange-rates interaction. Countries that have very little restrictions 
to capital account transactions, as as Chile and Czech Republic, do not present such interaction, while places with the most significant restrictions, as is the case of South Africa and Indonesia, do. Also the effect of trade is not as expected.

Figure 4.15, shows that the magnitude of a country's stock market (also presented in Section 4.1) and the share of equities on its total foreign liabilities (discussed in Section 4.2) seem to be better predictors of whether a change in stock prices will have an effect on exchange rates. In the countries with the most important stock markets the stocks-pricesexchange-rate-interaction was found - with the exception of China, that does not have a floating exchange rate. The share of the stock of equities on total foreign liabilities is also important: the interaction exists in half of the countries with the highest shares, with the sole exception of Mexico (Malaysia does not have a flexible exchange rate regime ${ }^{48}$ ); and among the countries with the lowest shares the interaction is only found in Hungary and Peru.

Regardless of their relatively small stock markets and share of equities in foreign liabilities, the presence of Hungary and Peru among the countries where the interaction is found, can be explained by the high presence of foreign investors in the two countries' stock markets (seen in Figure 4.12), their very low trade, or the smaller magnitudes of their economies (as shown in Figure 4.2).

In a nutshell, apart from the evident role of the exchange rate regime, the magnitude of the domestic equity market and of the importance of equities in the total stock hold by foreigners in the country seem to have determined whether an EME' exchange rate has responded to a change in stock prices in the last decade. The importance of trade plays a secondary role and capital account openness does not seem to have an effect on the presence or lack thereof of such interaction ${ }^{49}$.

\footnotetext{
${ }^{48}$ See more details on EMEs' exchange rate regimes in the Appendix of Chapter Six, Table 6.12.

${ }^{49}$ Analyses on the volatility of the different stock markets and its relationship with the country's characteristics were conducted, but the two do not seem to be closely related. The most volatile stock markets are the smallest ones: the Philippines, Argentina, Peru and Colombia.
} 
Figure 4.15: Stock-Prices-Exchange-Rate Interaction: Equities Share on Foreign Liabilities and Stock Market Capitalization

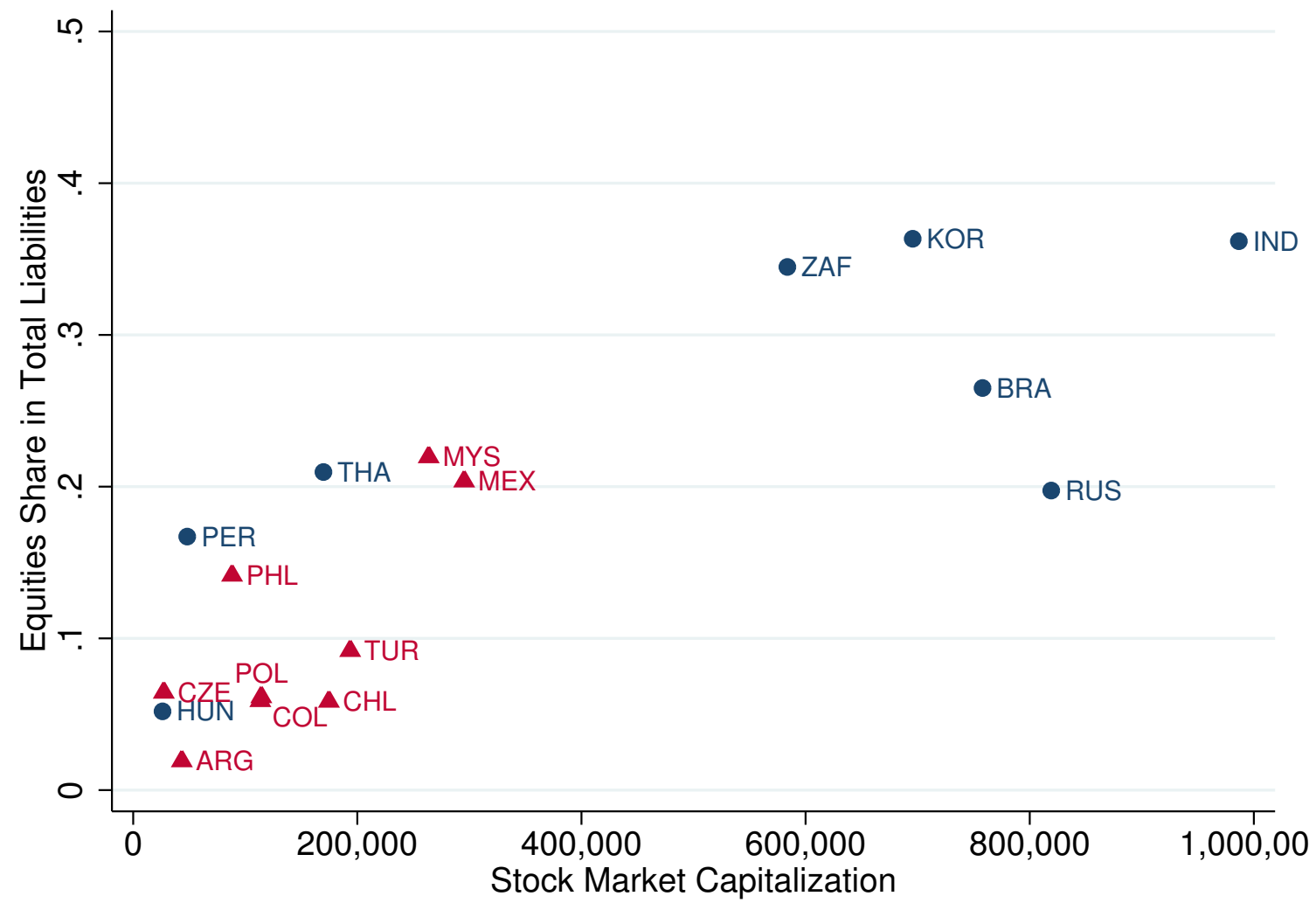

Equity Share on Total Foreign Liabilities: US\$ Millions. Data source: updated and extended database constructed by Lane and Milesi-Ferretti (2007). 2003-2011 average. Stock Market Capitalization: US\$ Millions. Data source: WB WDI. 2003-2013 average. Data for China is not presented for ease of reading. Its stock market value is 2,5 times the one of India; its share of equities is rather small, about the same as Peru's.

\subsection{Conclusions}

This chapter has debated the international insertion of EMEs in the last decade through an analysis of its stock of foreign liabilities, calling attention to the vulnerabilities built with new forms of integration. As shown, these countries have faced major increases of portfolio liabilities in the 2000s, specially from 2003 onward. In absolute terms the most important increases were seen in FDI liabilities, but the potential impacts of the major rise of equities as a portfolio liability were also highlighted. This change was especially important in Taiwan, Korea, India, Brazil and Malaysia. 
Regardless of different sizes of the economies, different fundamentals and different types of flows that are attracted, in almost all EMEs the stock of equities presented a N- or M-like path. Moreover, in addition to being strikingly similar across EMEs, their pattern seems to follow conditions of global financial markets. This common pattern indicates the high importance of international conditions (push factors) in the determination of this type of liability, which, in turn, adds an extra source of vulnerability: it is subject not only to domestic, but also to international shocks - in funding countries and in others that are also used in a portfolio diversification strategy. In other words, equities might be an important source of contagion of turbulence from other markets. The higher importance of equityfinancing also has the effect of significantly increasing the volumes traded in EMEs' stock exchanges, increasing the impact of these markets on the country's exchange rates ${ }^{50}$. An analysis based on the PCA was however unable to point to a higher comovement of equities than other types of foreign liabilities, which might result from the different pattern of the series.

The vulnerability related to equity financing also include the self-feeding interactions it can trigger: higher demand for equities increase its price, attracting more investors, pushing prices further. In addition of being negative per se, this spiral can also be transposed to an spiral of exchange rates. This will be analyzed in Chapter Seven.

The risk-sharing advantages of equity-financing must therefore be seen in light of the related risks: Equities are importantly influenced by push factors, being an important locus of transmission of contagion from other countries (as reflected in its higher volatility). A higher share of equity liabilities and a higher stock market might add exchange rate volatility for establishing an impact from stock markets to exchange rates - that is an impact from a volatile market. Equities self-feeding mechanisms can be transposed to exchange rates, creating an exchange rate spiral.

This chapter has looked at the overall changes in EMEs' integration. The next chapter will present a typology of financial integration among EMEs pointing to the differences in the integration of each country, especially focusing on financialization-related features. These three chapters have the objective of presenting a macro picture of EMEs' external insertion

\footnotetext{
${ }^{50}$ The preponderance of push factors in the determination of capital flows (this chapter is focused on stocks) to equity instruments has been broadly identified in the literature, as will be seen in Chapter Six.
} 
(Chapters Four and Five) and exchange rate patterns (Chapter Six), and how these two are associated (Chapter Six). After this macro and general picture, Chapter Seven makes use of Minsky's works on how financial fragility is built to provide insights on money managers' decision-making process. By so doing, it aims at explaining how this macro picture is built from a more micro perspective.

Avenues of future research This chapter explored different ways of analyzing the characteristics of different forms of liabilities other than focusing exclusively on its volatility. The analysis of comovement (graphical analysis and through the PCA) and the analysis of interaction between stock prices and exchange rates are first steps in this direction. It would also have been interesting to check for the higher comovement of EMEs' stock markets in the 2000s, but such an analysis is hindered by the fact that most EMEs' stock indices are available only for the 2000s (the only ones available for the complete period of the 1990s are the Philippine PSEI, the Chilean IPSA and the Taiwanese TWSE). Data availability also hampered testing the hypothesis of higher comovement between EMEs and USA Stock markets in the most recent period. Given the GFC in the middle of the period and the fact that correlation and comovement tend to be higher during crisis periods (as seen in the literature that will be analyzed in Chapter Six), an exercise of changes in comovement during the 2000s through individual analysis of its sub-periods could be misleading.

\subsection{Appendix}

TABLE 4.9 Percentage Change in the Stock of Foreign Liabilities: 2003 to 2011, by Country and Type of Capital.

\begin{tabular}{lcccc} 
Country & Year & Equities & Debt & FDI \\
\hline ARG & 2003 & 1.47 & 0.06 & 0.12 \\
& 2004 & 0.12 & 0.04 & 0.09 \\
& 2005 & 0.05 & -0.37 & 0.05 \\
& 2006 & 0.94 & 0.01 & 0.09 \\
& 2007 & 0.40 & 0.12 & 0.12
\end{tabular}




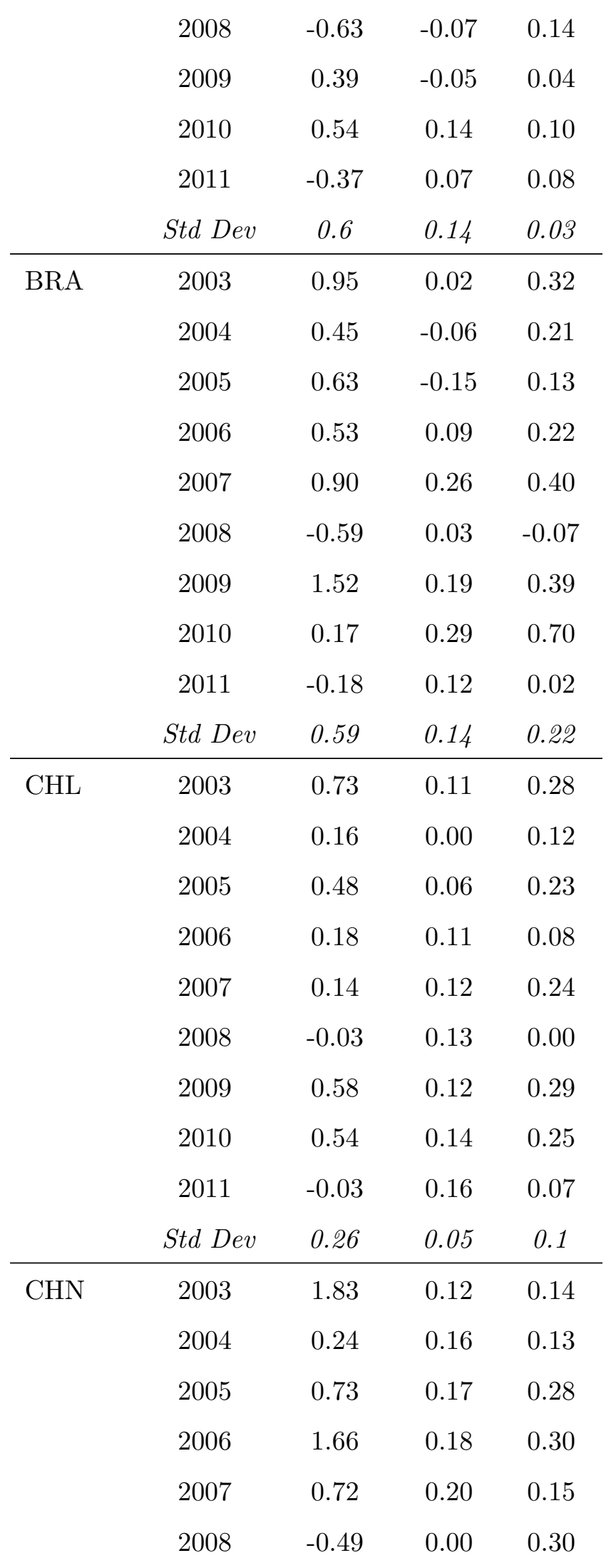




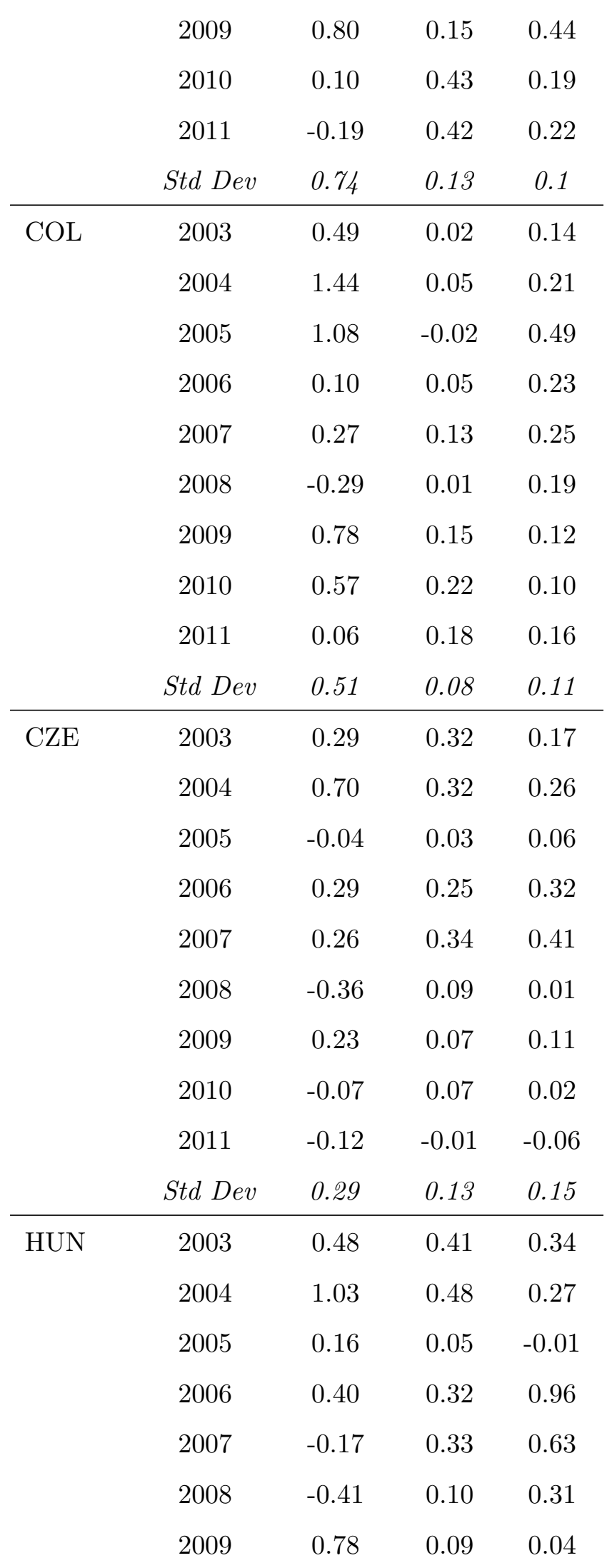




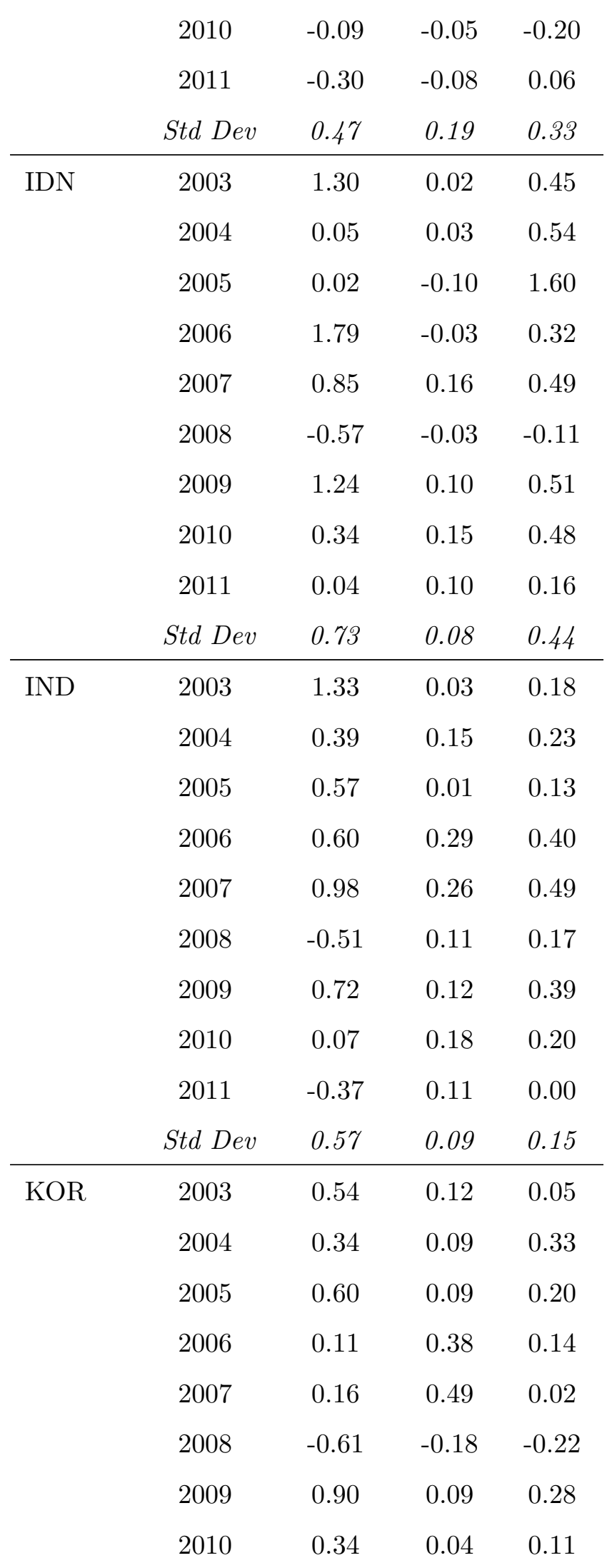




\begin{tabular}{|c|c|c|c|c|}
\hline & 2011 & -0.10 & 0.11 & 0.00 \\
\hline & Std Dev & 0.41 & 0.18 & 0.16 \\
\hline \multirow[t]{10}{*}{ MEX } & 2003 & 0.27 & 0.05 & 0.05 \\
\hline & 2004 & 0.31 & 0.06 & 0.20 \\
\hline & 2005 & 0.44 & 0.06 & 0.23 \\
\hline & 2006 & 0.45 & 0.02 & 0.15 \\
\hline & 2007 & 0.00 & 0.17 & 0.12 \\
\hline & 2008 & -0.04 & 0.05 & -0.19 \\
\hline & 2009 & -0.10 & -0.05 & 0.25 \\
\hline & 2010 & 0.20 & 0.32 & 0.25 \\
\hline & 2011 & -0.20 & 0.12 & -0.03 \\
\hline & Std Dev & 0.23 & 0.1 & 0.14 \\
\hline \multirow[t]{10}{*}{ MYS } & 2003 & 0.50 & 0.03 & 0.10 \\
\hline & 2004 & 0.50 & 0.23 & 0.05 \\
\hline & 2005 & -0.03 & -0.06 & 0.03 \\
\hline & 2006 & 0.51 & 0.04 & 0.21 \\
\hline & 2007 & 0.48 & 0.34 & 0.41 \\
\hline & 2008 & -0.59 & 0.00 & -0.03 \\
\hline & 2009 & 0.51 & 0.12 & 0.07 \\
\hline & 2010 & 0.58 & 0.26 & 0.29 \\
\hline & 2011 & 0.01 & 0.20 & 0.13 \\
\hline & Std Dev & 0.37 & 0.13 & 0.13 \\
\hline \multirow[t]{9}{*}{ PER } & 2003 & 0.29 & 0.06 & 0.03 \\
\hline & 2004 & 0.02 & 0.06 & 0.03 \\
\hline & 2005 & 0.71 & -0.08 & 0.19 \\
\hline & 2006 & 0.35 & 0.01 & 0.29 \\
\hline & 2007 & 1.11 & 0.14 & 0.31 \\
\hline & 2008 & -0.41 & 0.06 & 0.21 \\
\hline & 2009 & 0.74 & 0.04 & 0.07 \\
\hline & 2010 & 0.44 & 0.24 & 0.25 \\
\hline & 2011 & -0.08 & 0.09 & 0.19 \\
\hline
\end{tabular}




\begin{tabular}{|c|c|c|c|c|}
\hline & Std Dev & 0.44 & 0.08 & 0.1 \\
\hline \multirow[t]{10}{*}{ PHL } & 2003 & 0.62 & 0.05 & -0.01 \\
\hline & 2004 & 0.38 & -0.03 & 0.12 \\
\hline & 2005 & 0.48 & 0.01 & 0.18 \\
\hline & 2006 & 0.95 & -0.02 & 0.13 \\
\hline & 2007 & 0.60 & 0.09 & 0.21 \\
\hline & 2008 & -0.57 & -0.02 & 0.06 \\
\hline & 2009 & 0.48 & -0.01 & 0.06 \\
\hline & 2010 & 0.34 & 0.15 & 0.13 \\
\hline & 2011 & 0.02 & 0.03 & 0.09 \\
\hline & Std Dev & 0.41 & 0.06 & 0.06 \\
\hline \multirow[t]{10}{*}{ POL } & 2003 & 0.52 & 0.22 & 0.26 \\
\hline & 2004 & 1.05 & 0.22 & 0.50 \\
\hline & 2005 & 0.37 & 0.02 & 0.05 \\
\hline & 2006 & 0.21 & 0.23 & 0.39 \\
\hline & 2007 & 0.45 & 0.37 & 0.42 \\
\hline & 2008 & -0.51 & 0.05 & -0.08 \\
\hline & 2009 & 0.42 & 0.15 & 0.13 \\
\hline & 2010 & 0.39 & 0.10 & 0.18 \\
\hline & 2011 & -0.22 & 0.01 & -0.10 \\
\hline & Std Dev & 0.42 & 0.11 & 0.2 \\
\hline \multirow[t]{10}{*}{ RUS } & 2003 & 0.62 & 0.23 & 0.37 \\
\hline & 2004 & 0.54 & 0.15 & 0.26 \\
\hline & 2005 & 0.33 & 0.21 & 0.47 \\
\hline & 2006 & 0.76 & 0.19 & 0.48 \\
\hline & 2007 & 0.49 & 0.49 & 0.85 \\
\hline & 2008 & -0.73 & 0.01 & -0.56 \\
\hline & 2009 & 1.11 & -0.05 & 0.76 \\
\hline & 2010 & 0.31 & 0.01 & 0.30 \\
\hline & 2011 & -0.24 & 0.08 & -0.07 \\
\hline & Std Dev & 0.52 & 0.15 & 0.4 \\
\hline
\end{tabular}




\begin{tabular}{|c|c|c|c|c|}
\hline \multirow[t]{10}{*}{ THA } & 2003 & 0.98 & -0.14 & 0.28 \\
\hline & 2004 & 0.10 & 0.17 & 0.08 \\
\hline & 2005 & 0.24 & 0.00 & 0.12 \\
\hline & 2006 & 0.17 & 0.15 & 0.30 \\
\hline & 2007 & 0.48 & 0.07 & 0.20 \\
\hline & 2008 & -0.55 & 0.03 & 0.00 \\
\hline & 2009 & 0.75 & -0.02 & 0.14 \\
\hline & 2010 & 0.55 & 0.39 & 0.30 \\
\hline & 2011 & -0.01 & -0.04 & 0.06 \\
\hline & Std Dev & 0.43 & 0.15 & 0.1 \\
\hline \multirow[t]{10}{*}{ TUR } & 2003 & 1.60 & 0.09 & 0.77 \\
\hline & 2004 & 0.80 & 0.16 & 0.16 \\
\hline & 2005 & 1.07 & 0.11 & 0.85 \\
\hline & 2006 & 0.01 & 0.25 & 0.33 \\
\hline & 2007 & 0.90 & 0.20 & 0.63 \\
\hline & 2008 & -0.64 & 0.07 & -0.48 \\
\hline & 2009 & 1.04 & -0.06 & 0.79 \\
\hline & 2010 & 0.30 & 0.12 & 0.30 \\
\hline & 2011 & -0.36 & 0.07 & -0.25 \\
\hline & Std Dev & 0.7 & 0.08 & 0.45 \\
\hline \multirow[t]{10}{*}{ TWN } & 2003 & 1.22 & 0.32 & 0.24 \\
\hline & 2004 & 0.25 & 0.53 & 0.03 \\
\hline & 2005 & 0.50 & 0.13 & 0.13 \\
\hline & 2006 & 0.37 & 0.06 & 0.16 \\
\hline & 2007 & 0.14 & 0.07 & -0.03 \\
\hline & 2008 & -0.50 & -0.02 & -0.07 \\
\hline & 2009 & 0.89 & 0.02 & 0.23 \\
\hline & 2010 & 0.24 & 0.29 & 0.13 \\
\hline & 2011 & -0.23 & 0.18 & -0.13 \\
\hline & Std Dev & 0.49 & 0.17 & 0.12 \\
\hline ZAF & 2003 & 0.41 & 0.11 & 0.53 \\
\hline
\end{tabular}




$\begin{array}{cccc}2004 & 0.45 & 0.18 & 0.38 \\ 2005 & 0.42 & 0.06 & 0.23 \\ 2006 & 0.26 & 0.23 & 0.11 \\ 2007 & 0.30 & 0.23 & 0.26 \\ 2008 & -0.42 & -0.05 & -0.38 \\ 2009 & 0.56 & 0.12 & 0.73 \\ 2010 & 0.40 & 0.25 & 0.26 \\ 2011 & -0.25 & 0.09 & -0.09 \\ \text { Std Dev } & 0.32 & 0.09 & 0.31\end{array}$

Data souce: updated and extended version of Lane and Milesi-Ferretti (2007). Author's calculation.

TABLE 4.10 Average Yearly Variation of Stocks: Different Instruments

\begin{tabular}{l|cccc} 
Year & Equities & Debt & Port Inv & FDI \\
\hline 1991 & 1.09 & 0.07 & 0.08 & 0.35 \\
1992 & 0.74 & 0.07 & 0.08 & 0.28 \\
1993 & 3.41 & 0.13 & 0.23 & 0.37 \\
1994 & 0.63 & 0.13 & 0.14 & 0.30 \\
1995 & 0.10 & 0.13 & 0.12 & 0.37 \\
1996 & 0.90 & 0.07 & 0.09 & 0.22 \\
1997 & 0.26 & 0.06 & 0.05 & 0.14 \\
1998 & 0.00 & 0.08 & 0.06 & 0.27 \\
1999 & 0.86 & 0.02 & 0.10 & 0.30 \\
2000 & -0.25 & -0.02 & -0.06 & 0.05 \\
2001 & 0.10 & -0.01 & 0.01 & 0.18 \\
2002 & 0.02 & 0.05 & 0.05 & 0.05 \\
2003 & 0.82 & 0.11 & 0.20 & 0.24 \\
2004 & 0.47 & 0.15 & 0.19 & 0.21 \\
2005 & 0.44 & 0.01 & 0.10 & 0.28 \\
2006 & 0.53 & 0.14 & 0.22 & 0.28 \\
2007 & 0.47 & 0.23 & 0.31 & 0.33
\end{tabular}




\begin{tabular}{|c|c|c|c|c|}
\hline 2008 & -0.47 & 0.02 & -0.16 & -0.04 \\
\hline 2009 & 0.72 & 0.06 & 0.22 & 0.29 \\
\hline 2010 & 0.31 & 0.19 & 0.21 & 0.22 \\
\hline 2011 & -0.16 & 0.10 & 0.01 & 0.03 \\
\hline \multicolumn{5}{|c|}{ Standard Deviation } \\
\hline 2003-2011 & 0.12 & 0.03 & 0.03 & 0.07 \\
\hline 1991-2011 & 0.94 & 0.02 & 0.04 & 0.17 \\
\hline
\end{tabular}

Data souce: updated and extended version of Lane and Milesi-Ferretti (2007) 
Figure 4.16: The Weight of Reserves, Assets and Liabilities: 2003-2011 averages

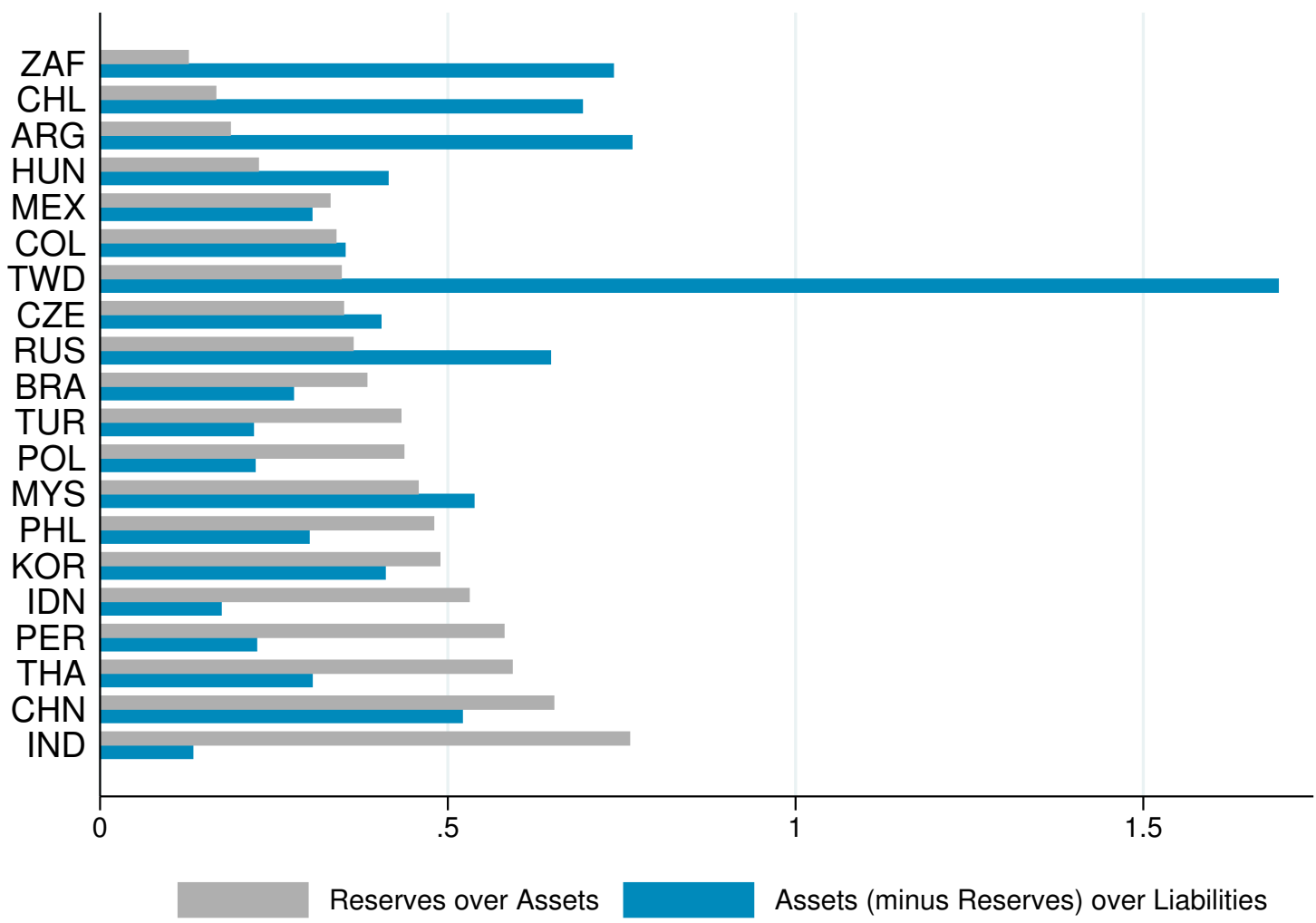

Data source: updated and extended version of Lane and Milesi-Ferretti (2007) 
TABLE 4.8 Weight of different types of liabilities in 2001

\begin{tabular}{lccc} 
& Equities & Debt & FDI \\
\hline ARG & 0.02 & $\mathbf{0 . 6 7}$ & 0.31 \\
BRA & 0.12 & $\mathbf{0 . 5 7}$ & 0.31 \\
CHL & 0.06 & 0.39 & $\mathbf{0 . 5 5}$ \\
CHN & 0.04 & 0.37 & $\mathbf{0 . 5 8}$ \\
COL & 0.01 & $\mathbf{0 . 7 5}$ & 0.23 \\
CZE & 0.07 & 0.43 & $\mathbf{0 . 5 0}$ \\
HUN & 0.06 & $\mathbf{0 . 5 0}$ & 0.43 \\
IDN & 0.03 & $\mathbf{0 . 8 6}$ & 0.10 \\
IND & 0.12 & $\mathbf{0 . 7 2}$ & 0.15 \\
KOR & 0.18 & $\mathbf{0 . 6 6}$ & 0.16 \\
MEX & 0.15 & $\mathbf{0 . 5 1}$ & 0.34 \\
MYS & 0.15 & $\mathbf{0 . 4 8}$ & 0.36 \\
PER & 0.06 & $\mathbf{0 . 6 7}$ & 0.27 \\
PHL & 0.04 & $\mathbf{0 . 8 1}$ & 0.14 \\
POL & 0.05 & $\mathbf{0 . 6 0}$ & 0.34 \\
RUS & 0.06 & $\mathbf{0 . 7 7}$ & 0.17 \\
THA & 0.07 & $\mathbf{0 . 6 5}$ & 0.27 \\
TUR & 0.05 & $\mathbf{0 . 8 2}$ & 0.13 \\
TWD & 0.32 & 0.45 & 0.24 \\
ZAF & 0.23 & 0.34 & 0.43
\end{tabular}

Data source: Ecowin. Author's estimations.

Values higher than 0.45 are presented in bold for ease of reading. 
Figure 4.17: Equity Shares on Total Liabilities and Stock Market Capitalization, 2000 to 2011
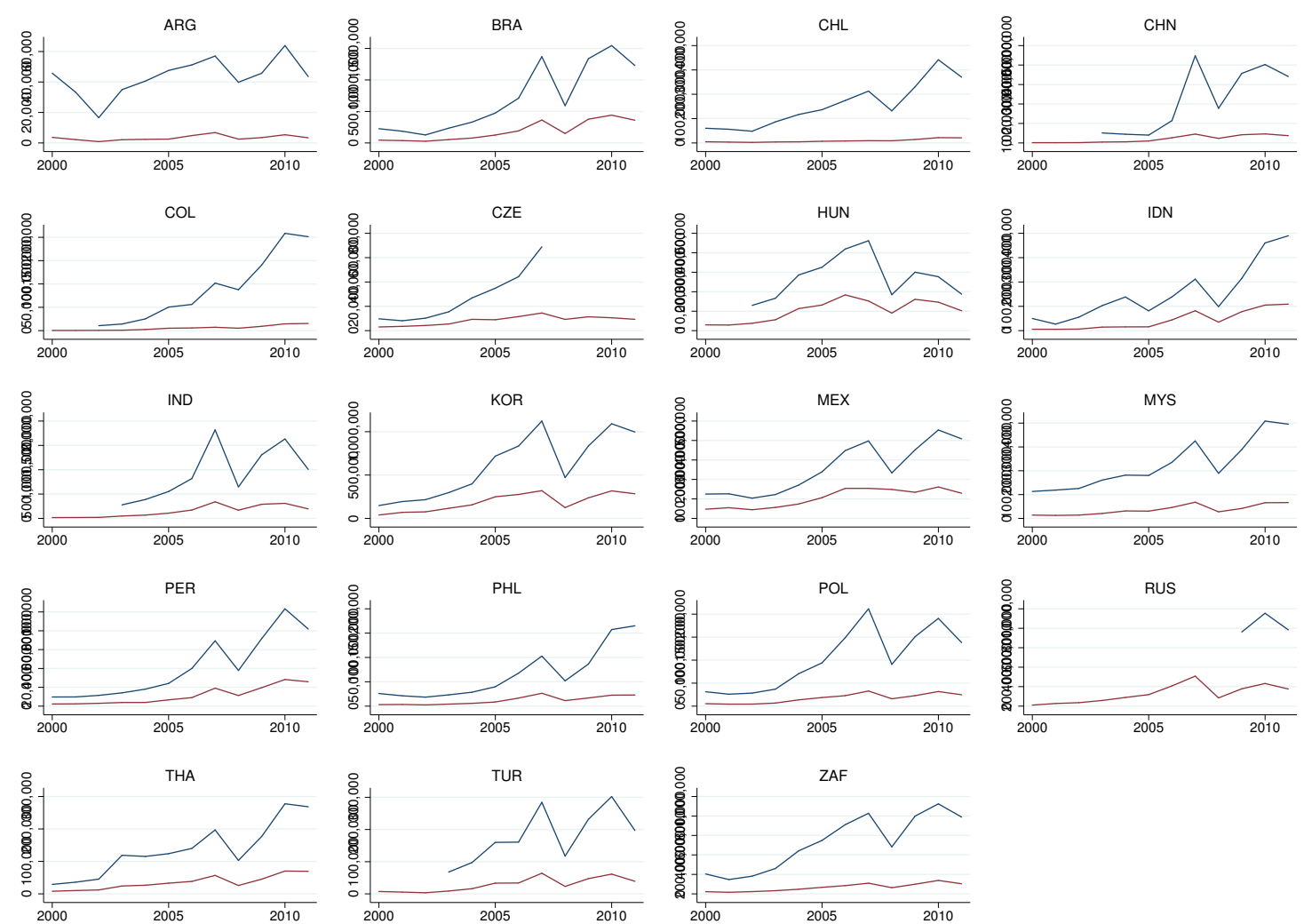

Data source: updated and extended database constructed by Lane and Milesi-Ferretti (2007). US \$ Millions. Equity Share on Total Foreign Liabilities. Stock Market Capitalization Data source: WB WDI. 


\section{Chapter 5}

\section{The Concept of Financialized}

\section{Integration and its Estimation for Emerging Market Economies}

Within the context of the rise of financialization in advanced economies, some developing countries opted for liberalizing their financial markets and capital accounts. This allowed their integration to the international financial system, characterized, in times of financialization, by the interconnectedness of markets from advanced countries and emerging market economies (EMEs) through money managers' balance-sheets and by the high level of sophistication of finance (as discussed in Chapter Two). With the rise of these features, financial integration could have implications on the determination of exchange-rates of EMEs. To test this hypothesis, this chapter suggests estimating how important financialization-related features are in characterizing these countries' integration. Or, how financialized their integration is.

Two financialization features are related to integration. The first is the higher importance of finance at the international level with its decoupling from earlier functions. Note that this differs from financial integration for focusing on the changing function of finance internationally, which now follows its own logic (see discussion in Chapter Two). It should therefore not be measured by the absolute magnitude of integration, but by how it diverges 
from the productive economy's factors. The second aspect is the sophistication of finance, through its products and innovations of usages, as the rise of carry trading and currency trading more broadly.

In this sense, a financialized integration is marked by large financial integration and sizable foreign exchange (FX) transactions relative to the underlying economic activity and trade. The relative weight of FX markets also points to the sophistication of finance, that can also be proxied by the weight of derivatives FX contracts.

This chapter discusses the presence of these characteristics in EMEs and advanced countries. It presents an account of the early 2000s and of current levels, indicating the velocity of the financialization process in these places. It is important to mention that the chapter aims at providing a macro picture of integration among EMEs. Analyses of the institutions behind this phenomenon, or the macro policies that could explain a country's higher financial integration are not within the scope of the chapter, and are only briefly mentioned throughout the text ${ }^{1}$.

The structure of the chapter Apart from this short introduction, the chapter is divided as follows. Section 5.1 presents the concept of financialized integration, building upon indicators used in the literature on financial integration and on that of financialization (as presented in Chapter Two). Sections 5.2 and 5.3 respectively look at the characteristics of financial integration and the FX markets, revealing the signs of financialized integration in both EMEs and advanced countries. Section 5.4 constructs an index of financialized integration. Section 5.5 further discusses the types of integration through a principal components analysis. Section 5.6 presents concluding remarks and avenues for future research.

\section{Data Used}

Two main sets of data are used to characterize financialized integration. The first, the updated and extended version of the dataset constructed by Lane and Milesi-Ferretti (2007), that regards financial integration and provides information on the stock of foreign assets and

\footnotetext{
${ }^{1}$ The focus on the resulting characteristics instead of on the institutional background is reflected on the choice for a de facto or an outcome measure of financial integration in this chapter (as will be discussed in Section 5.1).
} 
liabilities. In this dataset, capital is divided into equities, debt, foreign direct investment (FDI) and derivatives. Debt includes both "portfolio debt securities" and "other investment". Derivatives are not included in this chapter's analysis given their very low levels ${ }^{2}$. As the chapter aims at analyzing the behavior of foreign investors vis-a-vis of EMEs, focus is given to the liabilities' side (as discussed in Chapter Four). This dataset was updated until 2011, thus, that is the year used as estimate for the most recent period. The second set of data used relates to FX markets: the total size and weight of their derivatives contracts. It is based on the Bank of International Settlement's (BIS) Triennial Surveys of FX Markets. The change in the structure of FX markets is analyzed by comparing two years, 2001 (BIS, 2001) and 2013 (BIS, 2013) ${ }^{3}$. The 2001 survey was chosen to represent an early stage of the impacts of financialization on EMEs. The prior survey, conducted in 1998, contains potential biases from currency-crises and did not include the euro, that had not yet been implemented.

The analysis was done for the currencies for which data are available in both the 2001 and the 2013 surveys. There are 11 emerging currencies: the Brazilian real (BRL), the Chinese yuan (CNY), the Hungarian forint (HUF), the Indian rupee (INR), the Korean won (KRW), the Mexican peso (MXN), the Polish zloty (PLN), the Russian ruble (RUB), the Turkish lira (TRY), the New Taiwanese dollar (TWD), and the South African rand (ZAR). And 11 currencies from advanced countries: the Australian dollar (AUD), the Canadian dollar (CAD), the Swiss franc (CHF), the Danish krone (DKK), the euro (EUR), the Pound sterling (GBP), the Japanese yen (JPY), the Norwegian krone (NOK), the New Zealand dollar (NZD), the Swedish krona (SEK), and the U.S. dollar (USD, US\$) ${ }^{4}$. These currencies were defined as currencies of emerging or advanced countries according to the BIS' own characterization. Honk Kong and Singapore are not among the 20 EMEs considered in this thesis - as defined in Chapter Four. Their figures are also mentioned, but not considered in EMEs' averages.

Data on countries' GDP and foreign trade are taken from the World Bank's World Development Indicators (World Bank, 2015). To allow comparisons with EWN data, GDP,

\footnotetext{
${ }^{2}$ See Footnote 16 on Chapter Four.

${ }^{3}$ Precisely, the survey refers to the contracts that took place in the month of April of the respective year. The figures refer to average daily transactions.

${ }^{4}$ Figures mentioned in this chapter's analyses refer to these 24 currencies, not the complete market of the 2001 or 2013 surveys. Note that this is also not the same list of countries from last chapter's analyses. Also refer to the "List of Abbreviations" of countries and currencies in the Thesis' preamble.
} 
export and import data were taken in current U.S. dollars (Millions). For building indicators for the first period, data for 2001 is used. For the second period's indicators either 2011 or 2013 data is used, depending on whether it is used to build indicators with capital account data (EWN, where 2011 is the last period) or with FX market data (BIS, where 2013 data is used). To be clear, indicators of FX markets over GDP include WDI 2013 data, while data on the financial integration over trade, include WDI 2011 data.

\subsection{Measuring Financial Integration}

The empirical literature on financial integration uses two main types of indicators. Some analyses are based on the asset prices (returns) ruling in financial markets of two countries. Similar prices indicate integration. Other studies use indicators focused on the actual liberalization or integration. These two measures have been named price- and quantity-based (Garcia-Herrero and Wooldridge, 2007) - which, however, is not the most adequate, given that they are not only quantities (as will be presented in what follows ${ }^{5}$ ). A sounder understanding might be a separation between a strand that takes a more micro perspective of financial markets and look at the expected consequences of financial integration in financial markets, and another that takes a more macro perspective, and investigates the actual integration or liberalization.

The first strand of the literature assumes that every participant faces a single set of rules, has equal access and are treated equally (Baele et al., 2004). This would lead to a trend towards more similar returns of assets of identical risks in integrated markets (or the observation of the law of one price). A second expected effect of fully integrated markets is the diversification of country-specific risks that decreases the their significance in the pricing of assets (Garcia-Herrero and Wooldridge, 2007). Based on these two expected consequences of integration, two indicators of the degree of integration are used in his literature: the correlation among asset prices in different countries, ${ }^{6}$ and the importance of domestic factors in determining prices (or the arbitrage gap between onshore and offshore rates).

\footnotetext{
${ }^{5}$ Frankel (1992), as cited in Prasad et al. (2003), indicates other rather unusual measures of capital market integration: saving-investment correlations and interest parity conditions.

${ }^{6}$ An interesting example of this type of analysis is Phylaktis and Ravazzolo's (2002) where financial integration is measured by the covariance of excess returns of national stock markets.
} 
The strand of the literature that takes a more macro perspective examines what is now known as de jure or de facto measures. While the first analyzes the related legislation and regulation that could restrain capital mobility, the second focuses on estimations of the actual flow of capital between countries or the countries' stock of foreign assets and liabilities.

The most common in the de jure literature is to use indicators of the legal restrictions on cross-border capital flows based on information from the IMF's Annual Report on Exchange Arrangements and Exchange Restrictions. The ones constructed by Garcia-Herrero and Wooldridge (2007) and Chinn and Ito (2008) are based on a percentage of controls in place. Several other methodologies have also been proposed, as shown by (Da Silva and Da Fonseca, $2015)^{7}$.

Although widely used, such de jure measures of impediments to the free flow of capital have several shortcomings: restrictions may not be binding, respected or enforced; capital flows might not have existed in the first place; the measures cover a narrow aspect of all possible impediments; and they provide the picture of one day, so temporary and permanent measures are not differentiated (Garcia-Herrero and Wooldridge, 2007). In addition, de jure measures can be biased in the case of regulatory. Prasad et al. (2003) presents the possibility of capital flows despite controls in episodes of capital flight from some Latin American countries in the $1970 \mathrm{~s}$ and $1980 \mathrm{~s}^{8}$. Another way of understanding these shortcomings is the idea that liberalization does not mean integration, given that it only allows it to take place, not necessarily inducing it to actually happen (Bekaert and Harvey, 2000) and maybe also not hindering it from happening.

\footnotetext{
${ }^{7}$ Da Silva and Da Fonseca (2015) list other methodologies used in this literature that have different focus, such as: i) different dimensions of liberalization; ii) the accumulation of measures focusing on liberalizing or restricting capital flows through the time; iii) the proportion of restrictions according to different chosen dimensions; iv) the intensity of restrictions on capital account according to central bank reports; and v) binary variables related to liberalization of stock markets. See Da Silva and Da Fonseca (2015) for reference works of each type of methodology. There are also measures which are focused only in one type of capital, as Edison and Warnock's (2003) that propose a monthly measure of capital account openness based on the share of domestic equities available for foreign purchase.

${ }^{8}$ For a possibility to overcome some of these shortcomings, see Schindler (2009) who constructed a dataset that allows for dis-aggregation on asset categories according to inflows or outflows and resident or non-resident.
} 


\subsubsection{De Facto Measures of Integration}

De facto indicators of capital mobility could overcome most shortcomings of de jure measure by presenting the actual financial integration and its changing intensity over time. While de jure indicators demonstrate the extent of financial openness, or countries' "financial globalization strategies" (as put by Schindler (2009)), de facto measures investigate what happened - being an outcome or output indicator (as put by Calderón and Kubota (2009) and Kraay (1998), respectively). Although the terms 'financial openness' and 'capital account liberalization' are often used as synonyms of 'financial integration' (see the discussion in Chapter Two, page 27), the latter does not imply open or liberalized, but something that actually happened; while openness or liberalization are sounder to indicate developments that could have taken place. In this sense, de jure measures could only be used to indicate the former (being useful for instance in studying capital controls), but integration might be better proxied by de facto measures. Moreover, while capital account openness reflect governments' choices, actual integration reflects money managers' decisions - being in line with the view of financial integration as the result of money manager's decisions (Chesnais, 1997) - in line with the debate presented in Chapter Two ${ }^{9}$.

The literature on de facto measures gravitates around two main indicators: the sum of gross capital flows over GDP (following Kraay (1998)), and the sum of the gross stock of capital (assets plus liabilities) over GDP (following Lane and Milesi-Ferretti (2001)). The second is the most used indicator of financial integration (Jeanne et al., 2012), ${ }^{10}$ and is often calculated based on Lane and Milesi-Ferretti (2001) and its updated version, Lane and Milesi-Ferretti $(2007)^{11}$.

To illustrate this difference in the definitions when analyzing EMEs, Figure 5.1 presents Chinn and Ito's (2008) de jure index of capital account openness and the de facto level of financial integration in its absolute form and as a percentage of GDP - for averages for the 2003-2013 period. As observed, there is no strong relationship between the two, which

\footnotetext{
${ }^{9}$ For the debate on the dual responsibility of governments and money managers in respectively allowing and shaping the increasing weight of finance see Section 2.1 .

${ }^{10}$ Jeanne et al. (2012) argue that using capital flows instead of stocks is more coherent with the insights of Solow's growth model on foreign savings.

${ }^{11}$ Apart from the IMF's and Lane and Milesi-Ferretti's (2007) database, UNCTAD (United Nations Commission on Trade and Development) provides two quantity measures: FDI flow and stocks relative to GDP and to the world's FDI flows.
} 
supports the critique that a de jure openness is not enough for de facto integration. In fact, EMEs with the most open capital accounts present the lowest values of financial integration when looking at the absolute measure. Also, regarding relative integration, there seems to be no relationship between capital account openness and integration among EMEs (apart from Hungary, a very open and very integrated economy, and India, that is full of restrictions and presents the smallest integration).

Figure 5.1: Openness and Integration: De Jure and De Facto Measures for EMEs
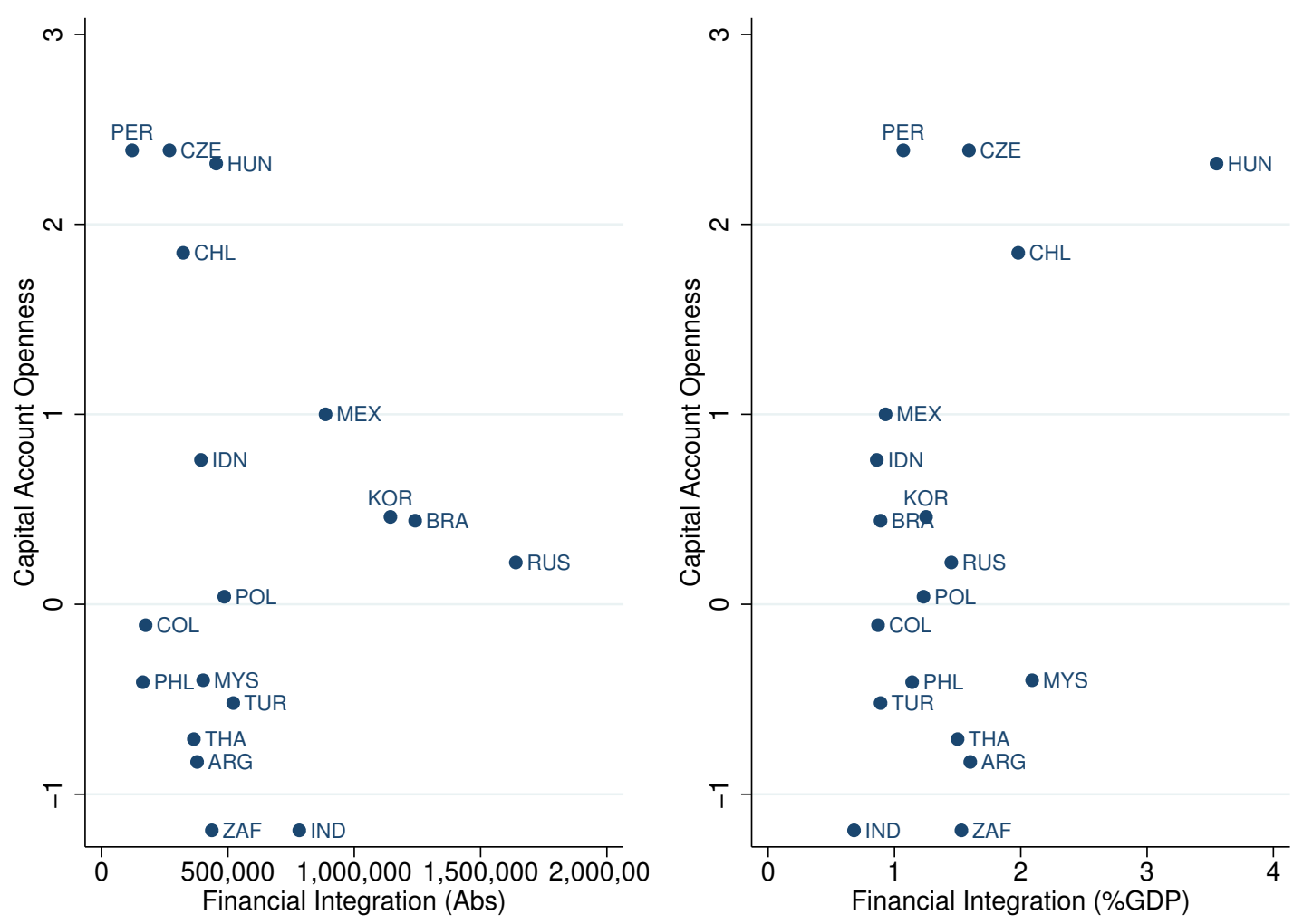

Data source: de jure measure, Chinn and Ito (2008); de facto measure, updated and extended version of Lane and Milesi-Ferretti (2007); GDP, World Bank (2015). Own calculations. Indicators are presented as averages for the 2003-2013 period. Data for China is not presented for ease of reading: its absolute financial integration is more than twice as big as the second biggest one. 


\subsubsection{Stock or flow measures?}

Stock measures have advantages over flow measures. Stock measures are used in the chapter due to the thesis' overall focus on the dynamics of the structure that emerges with financialization of interconnection of markets through money manager's balance sheets rather than capital flows, that are seen as (part of) the outcomes of these dynamics.

Second, stock measures are sounder than net-flows measures as most financial transactions yield zero-net flows (Borio and Disyatat, 2011) ${ }^{12}$. This might be more frequent in countries where there are restrictions on the use of foreign currencies in domestic territory, such as in Brazil. As put by Rossi (2014, p. 647), as a result, most of the FX onshore activities involve changes in foreign current accounts, resulting in changes in foreign assets and in residents' liabilities positions ${ }^{13}$, but very little in capital flows. Most importantly, FX derivatives traded in Brazil are non-deliverable, meaning that "gains or losses in these operations are settled in domestic (BRL) and not in the foreign currency (U.S. dollar)" (Fritz and Prates, 2014, p. 227).

Thirdly, stock measures are also preferred over flow measures for been less "noisier" (Quinn et al., 2011) thus depicting a more structural picture. Fourth, because they include capital gains, stock measures provide a better indication of the vulnerability faced by countries. However, taking capital gains into account is also restrictive because changes in the values of stocks cannot be attributed only to changes in the behavior of investors, as they can also reflect changes in asset prices.

Figure 5.2 compares absolute and relative measures of integration for EMEs in the 20032013 period. As it can be seen, there is no strong relationship between integration and an economy's size, yielding important differences between the two measures ${ }^{14}$.

\footnotetext{
${ }^{12}$ Also see Borio and Disyatat (2015).

${ }^{13}$ Another interesting particularity of the Brazilian market is that future contracts of FX are not liquidated in the respective currency (mostly the dollar), but in Brazilian reais (Rossi, 2014). This absence of obligation to be in possession of the foreign currency might allow a greater extent of people to participate in this market influencing its size (which is captured by the data) and also the type of investor that composes it (which is not captured). The market could therefore be more open to people whose main activity is not related to the foreign currency being traded.

${ }^{14} \mathrm{~A}$ comparison of results that use the two types of measures applied to industrial and to developing countries is shown by Prasad et al. (2003).
} 
Figure 5.2: Financial Integration: Absolute and Relative Measures Based on Stocks for EMEs

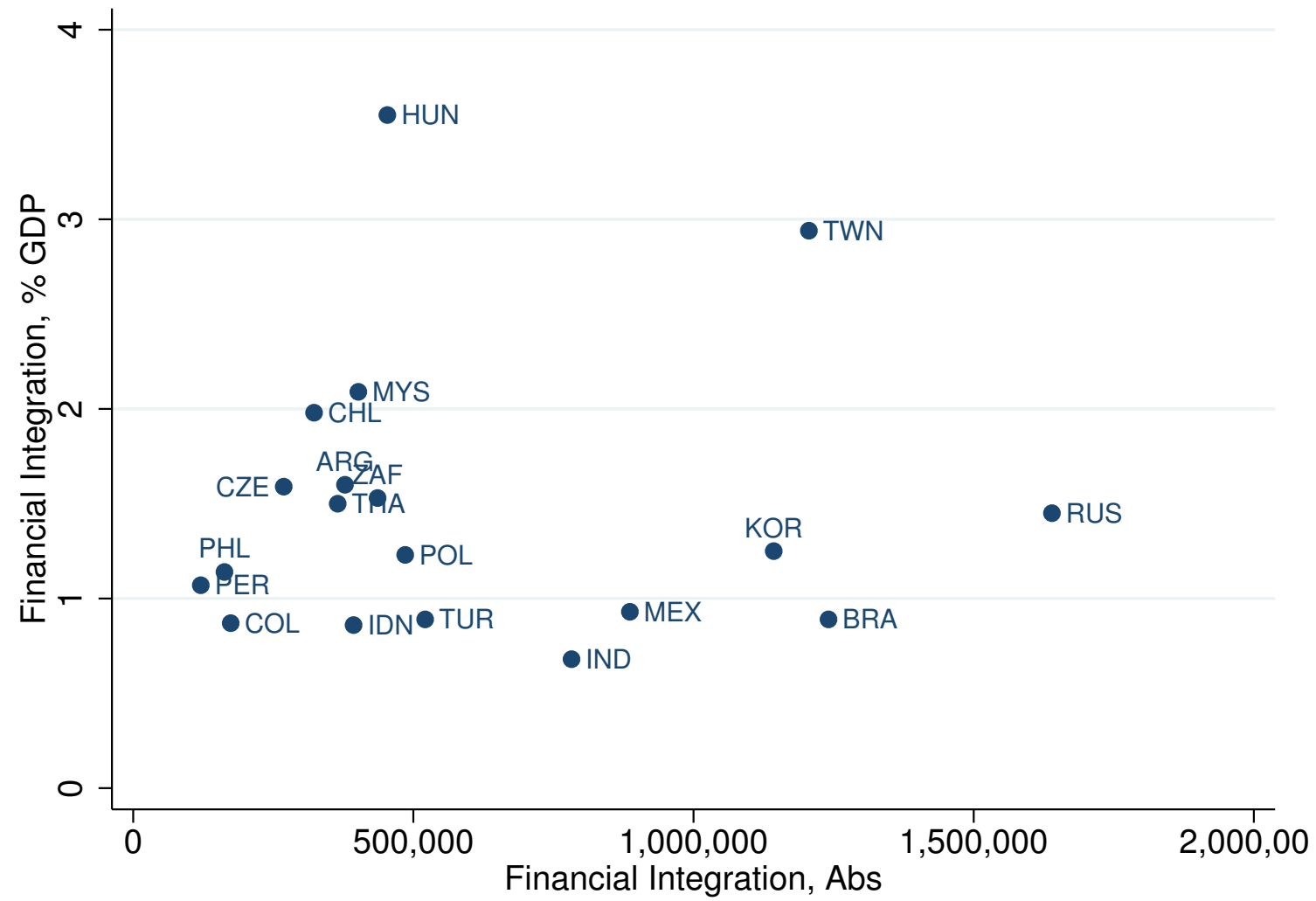

Financial Integration (Absolute value): US\$ Millions. Indicators are presented as averages for the 2003-2013 period. Data for China is not presented for ease of reading: its absolute financial integration is more than two times bigger than the second biggest one.

Which financial integration indicator better suits our purpose? Indicators that focus on the prices of financial assets are not compatible with an analysis including both EMEs and advanced countries, given that their assets are substantially different - also due to the greater exchange rate risk involved with EMEs' assets ${ }^{15}$. Secondly, measures based on capital flows could be biased estimations due to the outlined reasons and, in the specific case of this chapter's analyses, due to their recent high volatility in EMEs. Stock variables were thus chosen.

\footnotetext{
${ }^{15}$ As analyzed in Chapter Seven, an institutional investor that invests in its own country has no exchange rate risk. When investing in another advanced country, the risk exists, but is less important than the risk of investing in an EME. The specific risks related to emerging currencies are discussed in Chapter Three, Section 3.3.4.
} 


\subsection{From Financial to Financialized Integration}

Apart from being used by the literature on financial integration, indicators based on foreign assets and liabilities have also been used to proxy financialization. For instance, Chesnais (1997) mentions the ownership of foreign assets in portfolios of U.S. pension funds and Baker et al. (1998) cites the value of funds raised on international financial markets, i.e. foreign liabilities. The first is taken in absolute values, and the latter as a percentage of world exports, yielding in a comparison between financial and trade integration. Another direct form of comparing financial and commercial integration is to look at their weight in a country's balance of payment or GDP (as done by Plihon (2010); see Chapter Two, page $29)$.

The analyses in this section are based on both absolute and relative measures, with regards to GDP and trade. Relative measures will be used in the remainder of the chapter as indicators of financialization, to show, specifically, the part of integration that exceeds what would have been expected from an economic or trade activity, thus evincing the decoupling of finance from its prior functions (as discussed in Chapter Two, Section 2.1). By gradually analyzing relative measures, the section presents considerations on both countries' integration as well as financialized integration.

This section also analyzes assets-to-liabilities ratios to demonstrate the role of EMEs as suppliers of financial assets to international money managers and in the debate on the rise of carry trading (presented in Chapter Two, section 2.2.2.2). Before these analyses, the importance of reserves among EMEs' assets to avoid possible biases in the indicators from public decisions is discussed.

\subsubsection{The Weight of Reserves}

When analyzing assets and liabilities, a notable difference among EMEs and advanced countries is the magnitude of reserves (see Figure 5.3). 


\subsubsection{The reasons behind the build up of reserves}

In the aftermath of the late-1990s crises, EMEs started to significantly increase their holdings of reserves of international assets. Although sometimes called mercantilistic, in most countries this policy is seen as precautionary (Aizenman and Marion (2003); Aizenman and Lee (2007); Lee (2004)).

The reasons for being 'cautious' are numerous, and EMEs' increasing vulnerabilities (as analyzed throughout the thesis) asks for increasingly higher amounts of reserves. The choice for building up reserves must be understood against the background of the late-1990s currency crises faced by most of the countries. Indeed, the after-crisis literature pointed out that one of its reasons was the high short-term debt to reserves ratio (Rodrik and Velasco, 1999) and that holding reserves could decrease the probability of crisis in general (Garcia and Soto, 2004). As Feldstein (1999) described, in the absence of a lender of last resort ${ }^{16}$, reserves are a self insurance which mitigates and prevents crisis: by enabling countries to restrain currency depreciation, it decreases the expectation of such an incident and speculation on this direction. With reserves EMEs would also be able to counter act sudden outflows independently from the IMF; whose reaction at that time came late and attached with procyclical conditionalities (UNCTAD, 2009) ${ }^{17}$. The subsequent volatility of floating regimes is also relevant. To avert crises and decrease volatility, many EMEs decided to accumulate reserves. The association of a floating regime with FX intervention is known as a 'dirtyfloating' regime and the practice of limiting exchange rate fluctuation was labeled 'fear of floating'. Intervention would also have resulted from the need to contain inflation pressures coming from exchange rate changes given that these countries have more relevant passthrough (Calvo and Reinhart, 2002).

\footnotetext{
${ }^{16}$ A lender of last resort, for Bagehot (1873), lends freely, at penalty interest rates, on appropriate collateral. The IMF, on the other hand, "disburses its funds gradually as the stricken countries meet a series of detailed conditions" (Feldstein, 1999).

${ }^{17}$ Calvo et al. (2012, p. 4) also mentions the role of IMF's mishandling of the Asian crisis, "which erroneously treated those economies as if they were fiscal pro-fligates".
} 


\subsubsection{The optimal level of reserves}

Recommendations concerning reserves' appropriate level changed after the late 1990s crises. Until then, the IMF recommended levels equivalent to three or four months of the country's imports; such focus on trade flows might reflect a different type of integration than the current one, where financial integration was smaller. This was next substituted for the country's short-term debt (known as the Guidotti-Greenspan rule) and by 2001 IMF's guidance was to hold reserves well in excess of this level and according to the country's "macro-economic fundamentals; the exchange rate regime; the quality of private risk management and financial sector supervision; and the size and currency composition of the external debt" (Fischer, 2001). Moreover, if the country suffers not only a sudden capital flight from foreign investors, but also an internal drain, the amount of reserves needed might be even greater as the size of the internal financial markets should be considered (Obstfeld et al., 2009).

The FX intervention needed for buying reserves must be sterilized, what can be costly depending on the countries' interest rates (as it will be seen in Chapter Seven, Section 7.2.5.2). Based on these costs, and on the estimation of the value of the insurance provided by reserves, some studies estimate the optimal amount of reserves, following Aizenman and Marion (2003) and Ranciere and Jeanne (2006). The possibility of accurately estimating this level is however debatable. They involve estimating probabilities of crisis (as in Garcia and Soto (2004)), or of a sudden stop and the GDP costs associated with it (as in Calvo et al. (2012)), which are very sensitive to the data utilized and the specification of the model (Garcia and Soto, 2004). In addition, with the increasing focus on very short-term strategies (as showed in Chapter Two), and the manifest volatility of FDI and flight of capital in the form of FDI (as seen in Chapter Three ${ }^{18}$ ), the exact estimation of what part of foreign liabilities is subject to leave the country in moments of turbulence becomes however very imprecise.

\footnotetext{
${ }^{18}$ Evidence in this sense for the case of Brazil is found by Corrêa et al. (2012), and the turbulence of FDI in EMEs with the GFC can be seen in Figure 4.10 in Chapter Four especially for Russia and Turkey.
} 


\subsubsection{The magnitude of reserves in EMEs}

Among EMEs, reserves increased 518\% from 2001 to 2011 - which corresponds to an average rise from $23 \%$ to $35 \%$ of the countries' GDP. The highest increases happened in Hong Kong (50 percentage points of GDP), in China (28 p.p.), and in Hungary (15 p.p. $)^{19}$. Because these sizable amounts fall within the realm of public policies, they are subtracted from the total amount of a country's assets in order to better compare EMEs and advanced countries (as discussed in Chapter Four).

Figure 5.3: Assets and Liabilities: 2001 \& 2011, by Economic Group and Country
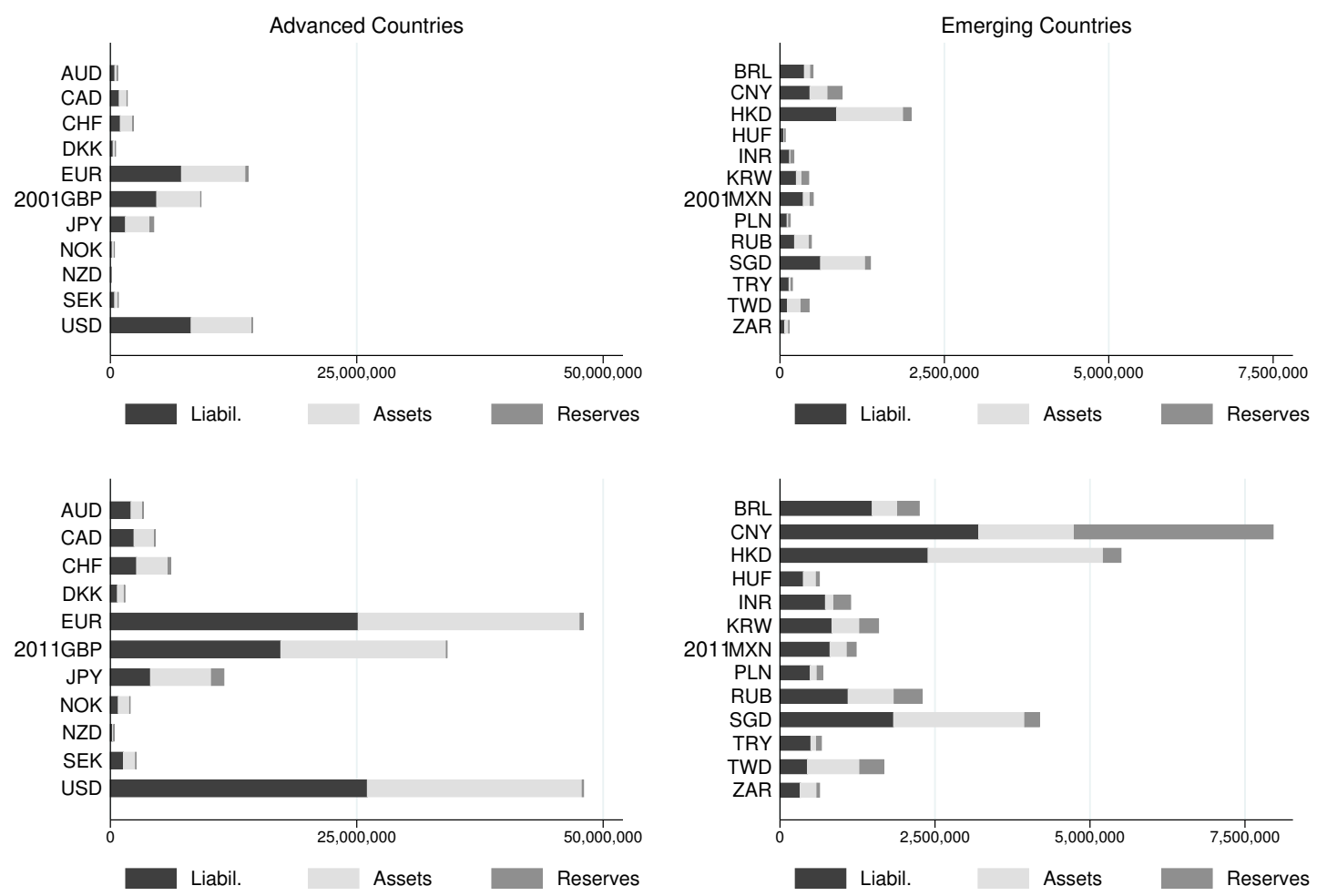

Data source: updated and extended version of Lane and Milesi-Ferretti (2007).

\footnotetext{
${ }^{19}$ Note that in some EMEs the reason for high reserves relies on the fact that they do not follow floating exchange rate regimes.
} 


\subsubsection{Liabilities}

The magnitude of the stocks of liabilities could indicate the countries preferred by money managers. The highest values among EMEs in 2011 are found in China, Brazil, Russia, Korea, Mexico and India (see Figure 5.3) (apart from Hong Kong and Singapore, that are classified by the BIS Triennial Surveys as EMEs, but might be better analyzed as financial centers). When looking at the changes in stocks from 2001 to 2011 the list of countries that experienced the most notable increases in the stock of liabilities is similar - China, Brazil, and Russia (apart from Hong Kong and Singapore).

Among advanced countries, the United States (US), the Euro Area, the United Kingdom and Japan exhibit the highest demand for financial assets (with high amounts of assets).

\subsubsection{The Assets-to-Liabilities Ratio}

When excluding the value of reserves from total assets, in most EMEs, the accumulated stock of assets is smaller than that of liabilities ${ }^{20}$. The ratio of assets over liabilities provides a clear depiction, as presented in Figure 5.4. From this figure a second difference among the two groups of countries emerges: the average assets-to-liabilities ratio is $30 \%$ higher among advanced countries (0.97) than in EMEs $(0.66)^{21}$. So, EMEs would typically sell more assets to foreign investors (resulting in a ratio lower than one) than invest more abroad. This result illustrates the theoretical discussion of Chapter Two that EMEs play a role in supplying financial assets to advanced countries' investors, which cannot be dissociated from EMEs higher interest rates (as it will be seen in Chapter Six) ${ }^{22}$.

Accordingly, the different levels of the assets-to-liabilities ratios are, in some cases, evidence of the use of a currency in carry trade operations, either as funding or as investment

\footnotetext{
${ }^{20}$ Remember that both assets and liabilities include FDI, equity, and debt while assets also include central bank reserves, except for gold.

${ }^{21}$ Among EMEs, the only countries where assets are higher than liabilities are Hong Kong, Singapore and Taiwan, which are better seen as financial centers (see Figure 5.4).

${ }^{22}$ Although this relationship does not look exactly at the Net Foreign Assets, it is in line with the 'stages hypothesis' of Eichengreen (1990) according to which a country would move from net debtor to net creditor with an increasing development level.
} 
Figure 5.4: Assets-to-Liabilities Ratio: 2001 \& 2011, by Economic Group and Country
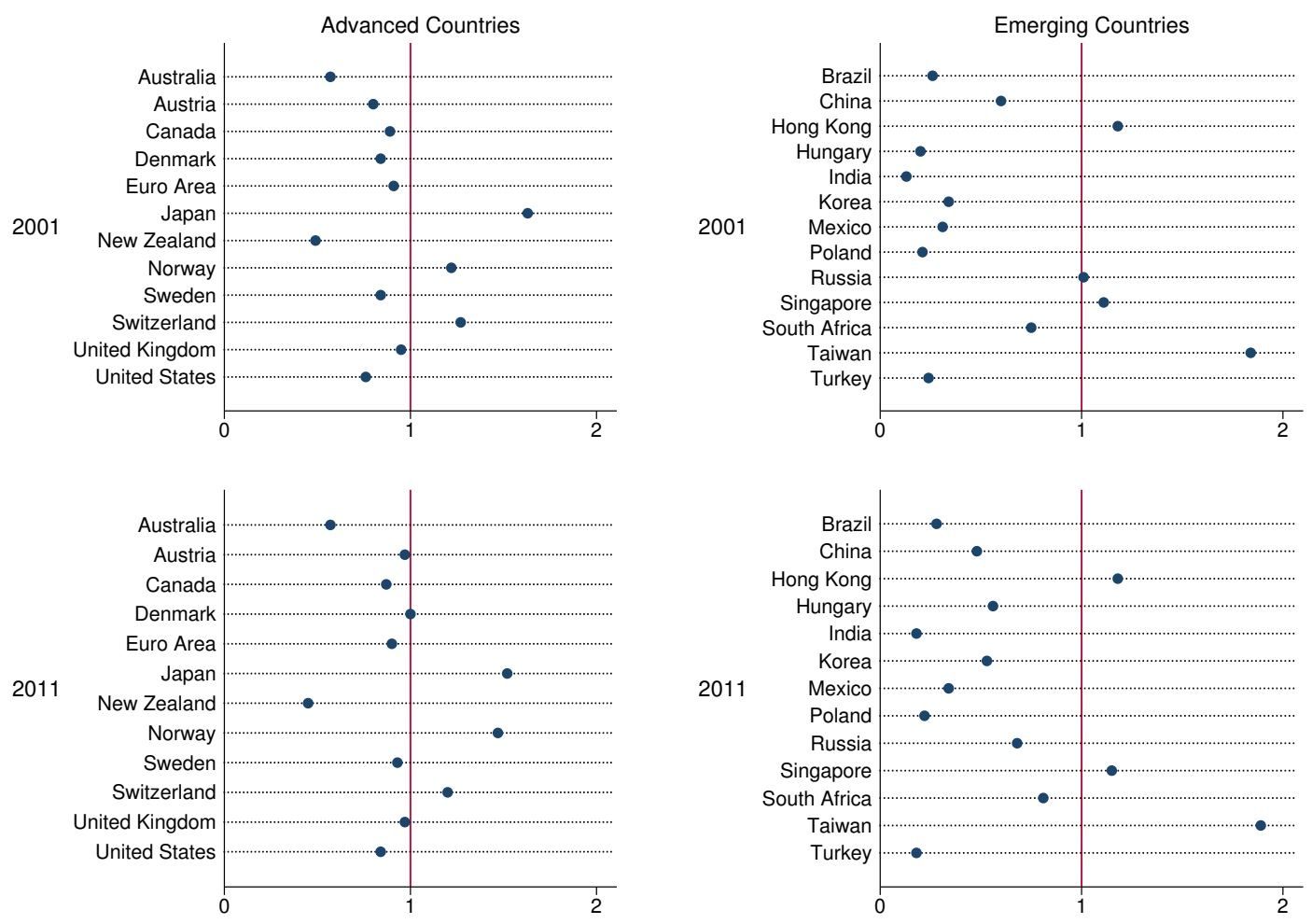

Data source: updated and extended version of Lane and Milesi-Ferretti (2007). The vertical lines represent the unity - countries to the right of this line have higher assets than liabilities.

currencies $^{23}$. The U.S. dollar, the Japanese yen, and the Swiss franc ${ }^{24}$ are often cited as funding currencies. The Australian dollar, the New Zealand dollar, the Brazilian real, the Hungarian forint, the Mexican peso, the South African rand, and, to a lesser extend, the Indonesian rupiah, the Indian rupee, and the Philippine peso are often cited as investment or target currencies (Galati and Melvin (2004); UNCTAD (2007); Gyntelberg and Remolona (2007); Heath et al. (2007)).

While most advanced countries present a balanced (around 1) ratio, Japan, Norway and Switzerland exhibit more assets than liabilities, coherent with the idea that Japan and Switzerland are places of origin or funding of carry trade operations. On the other end, New

\footnotetext{
${ }^{23}$ See the theoretical discussion on carry trade in Chapter Two, page 40.

${ }^{24}$ The role of the U.S. dollar might have shifted from funding to target with the end of the early 2000 s low interest rate policies (Heath et al., 2007), but since the GFC it is surely a funding currency. See Burnside et al. (2006) for an empirical analysis of the Japanese yen and the consequences of being a funding currency.
} 
Zealand and Australia have the lowest ratios - confirming the use of these countries' assets or currencies in carry trade operations (as target currencies).

Among the countries that have a more balanced position, the United States and the Euro Area (to a lower extent) are special cases, because their higher amount of liabilities are, in part, due to central bankers around the globe building international reserves of advanced countries government bonds. This is different from EMEs, where liabilities reflect private agents actions' - either foreign investors buying financial assets (equities, debt instruments) or domestic entities borrowing from abroad.

Figure 5.5: Assets-to-Liabilities Ratio: Equities, Debt and FDI. 2011, by Economic Group and Country
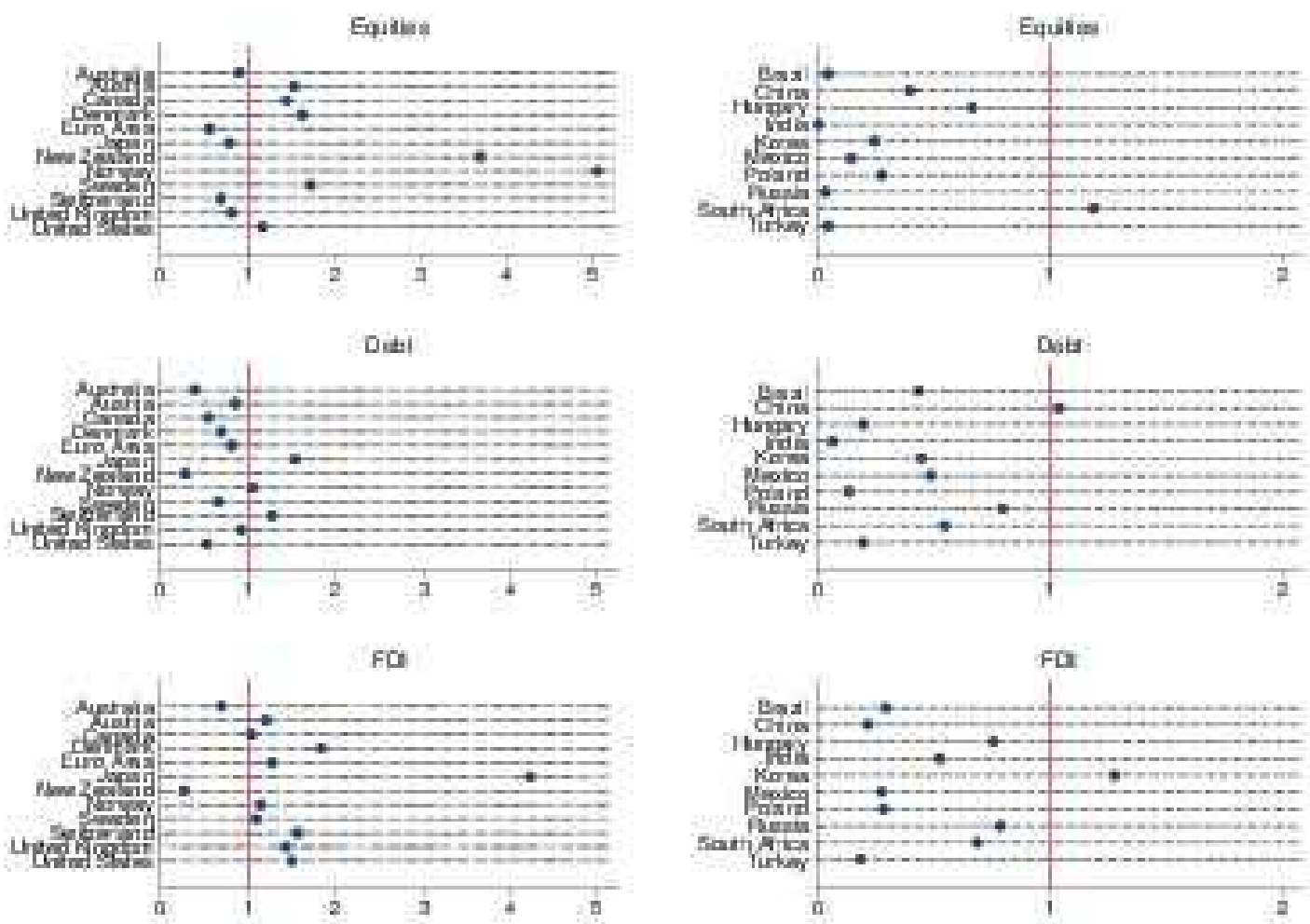

Data source: updated and extended version of Lane and Milesi-Ferretti (2007). Assets do not include reserves. The vertical lines represent the unity - countries to the right of this line have higher assets than liabilities.

The lower assets-to-liabilities ratio of the United States (0.52) being due to foreign liabilities related to other countries' Central Banks policies is confirmed by its low ratio in regards to debt instruments (see Figure 5.5). In fact, the average assets-to-liabilities ratios of 
advanced countries are higher for equities (1.71) and FDI (1.43), and lower for debt (0.82). For EMEs, on the other hand, the ratios are low for all three categories, equities (0.31), debt (0.44), and FDI (0.53) (when Taiwan, Singapore and Hong Kong are not considered). Among advanced countries, Japan (1.54) and Switzerland (1.27) present the highest ratios regarding debt instruments, while New Zealand (0.28) and Australia (0.38) present the lowest ones, confirming the association of these two groups of countries on opposing ends of carry trade operations.

Among EMEs, the lowest assets-to-liabilities ratio in the form of debt are India, Poland, Turkey, Hungary and Brazil. Of these five countries, Turkey, Brazil and India are cited in the literature as target currencies for carry trade operations and are among the five countries to present the highest interest rate differential with regards to the US Fed Fund rate.

\subsubsection{Absolute Financial Integration}

Knowing the characteristics of assets and liabilities in the two country groups, the analysis continues with indicators of financial integration. The first, the sum of assets and liabilities, is an indicator of absolute integration.

Analyzed through the value of assets plus liabilities of EMEs in 2011, China, Brazil, Russia and Korea ${ }^{25}$ are the most financially integrated (see Figure 5.6). Hungary had the lowest integration level in 2001 (seven times lower than EMEs' average) and grew 730\% between the two periods. China and India also presented high growth rates. Among advanced countries, the US, the Euro Area and the United Kingdom are the most integrated. Japan is next, but with a value three times lower.

\subsubsection{Financial Integration Relative to GDP}

The evolution of the ratio of assets and liabilities over GDP supports the idea that advanced countries have undergone a greater process of integration than emerging (or other developing countries), with a higher than six average ratio in 2011 (see Figure 5.7). The result reflects

\footnotetext{
${ }^{25}$ Apart from Hong Kong, Singapore and Taiwan
} 
Figure 5.6: Assets (Minus Reserves) Plus Liabilities: 2001 \& 2011, by Economic Group and Country
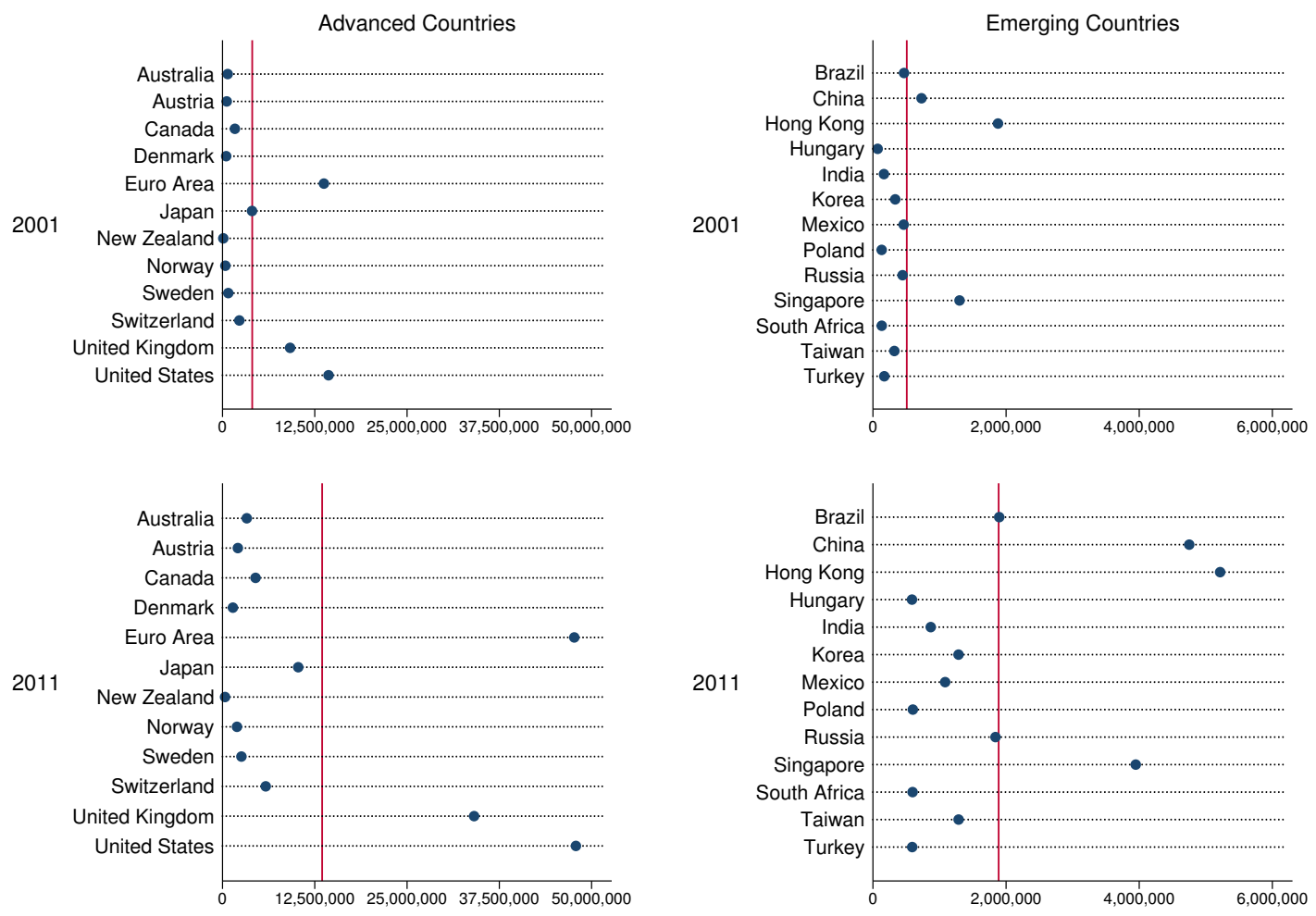

Data source: updated and extended version of Lane and Milesi-Ferretti (2007). The vertical lines represent the group's average.

the asymmetry of the international financial system (see Andrade and Prates (2013)) that, as discussed in Chapter Three, is composed in its vast majority by advanced countries' assets.

The comparison of the EMEs that have FX data available to the other EMEs (Argentina, Chile, Colombia, Czech Republic, Indonesia, Malaysia, Peru, the Philippines, Taiwan and Thailand) indicates that the first group presented a marked hike in integration from 2005 onward, achieving the average ratio of assets and liabilities over GDP of 4 in 2011. The latter group displayed lower average integration - an average ratio lower than 2 in 2011 . The integration of developing countries is higher than that of the second group of EMEs, and lower than the integration of the EMEs analyzed in this chapter (see Figure $5.7^{26}$ ).

\footnotetext{
${ }^{26}$ The list of countries included in Figure 5.7 is provided in the Appendix 5.7. It is partially based on the country groups used by Lane and Milesi-Ferretti (2007), but EMEs are differentiated to fit this thesis' analyses. Luxembourg is excluded from the graph for avoiding biases: its series starts in 1990 with an assets-plus-liabilities-over-GDP ratio of 136, while the average of the other industrial countries is under two.
} 
Figure 5.7: Assets Plus Liabilities Over GDP: 1970 to 2011, Different Groups

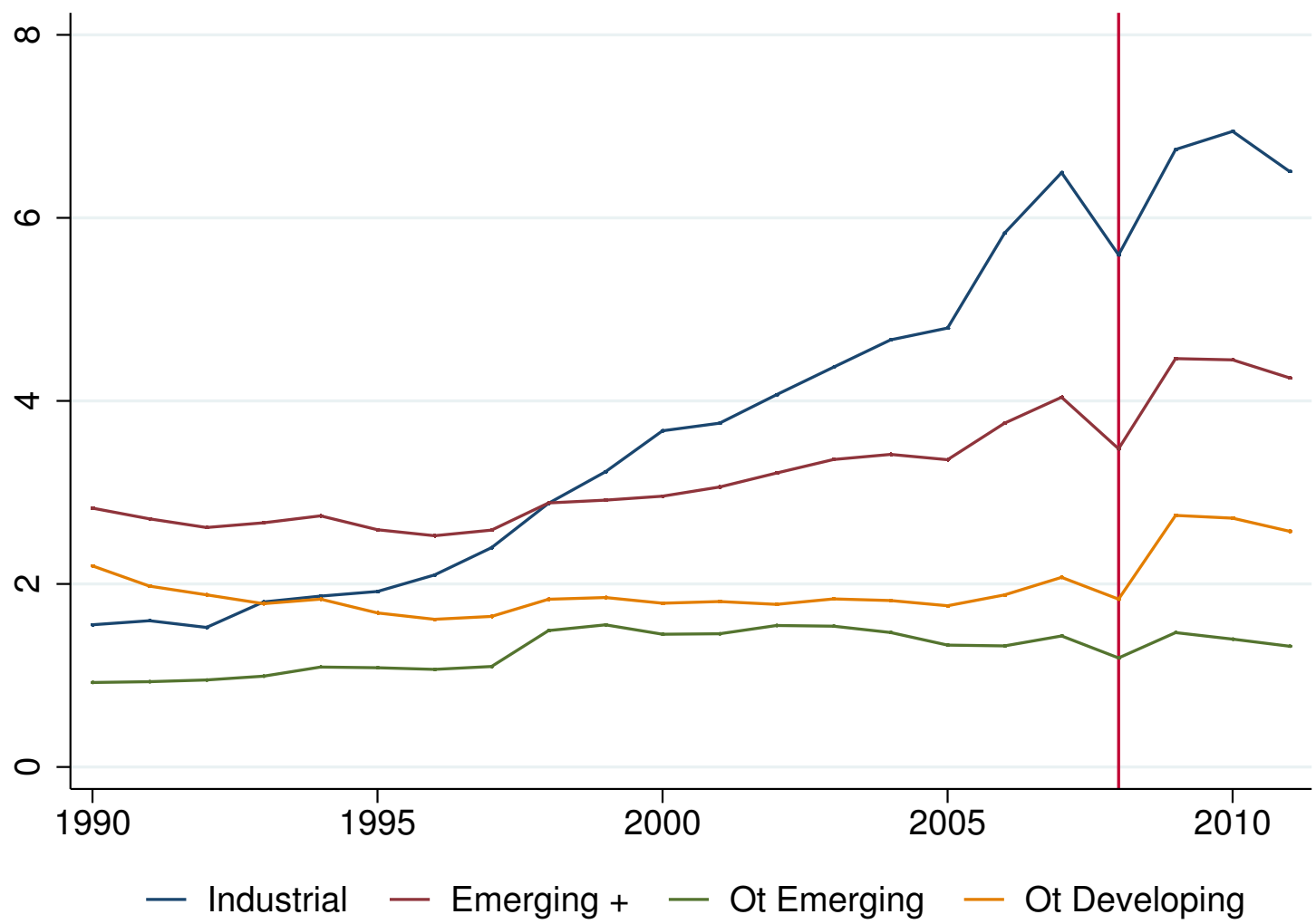

Data source: updated and extended version of Lane and Milesi-Ferretti (2007). The vertical line marks the year 2008 .

Looking specifically at the relative values of asset plus liabilities in 2011 (in Figure 5.8) reveals that Hungary has the highest integration, followed by South Africa, Poland and Korea. Among advanced countries, the relevance of the US' integration decreased considerably from 2001 to 2011, going from having 3.5 times the group's average to less than $70 \%$ of it. Switzerland and smaller countries, such as Austria, Sweden, Denmark and Norway, present a relatively large integration and the United Kingdom presents the highest integration.

\subsubsection{Financial-to-Trade Integration}

While the analysis of the magnitude of assets and liabilities reveals different levels of integration to international financial markets, the inclusion of considerations on the country's trade integration provides an idea of finance relative to trade integration. This is especially interesting for an exchange rate analysis for indicating the two sources of FX transactions. In this 
Figure 5.8: Assets (Minus Reserves) Plus Liabilities Over GDP: 2001 \& 2011, by Economic Group and Country
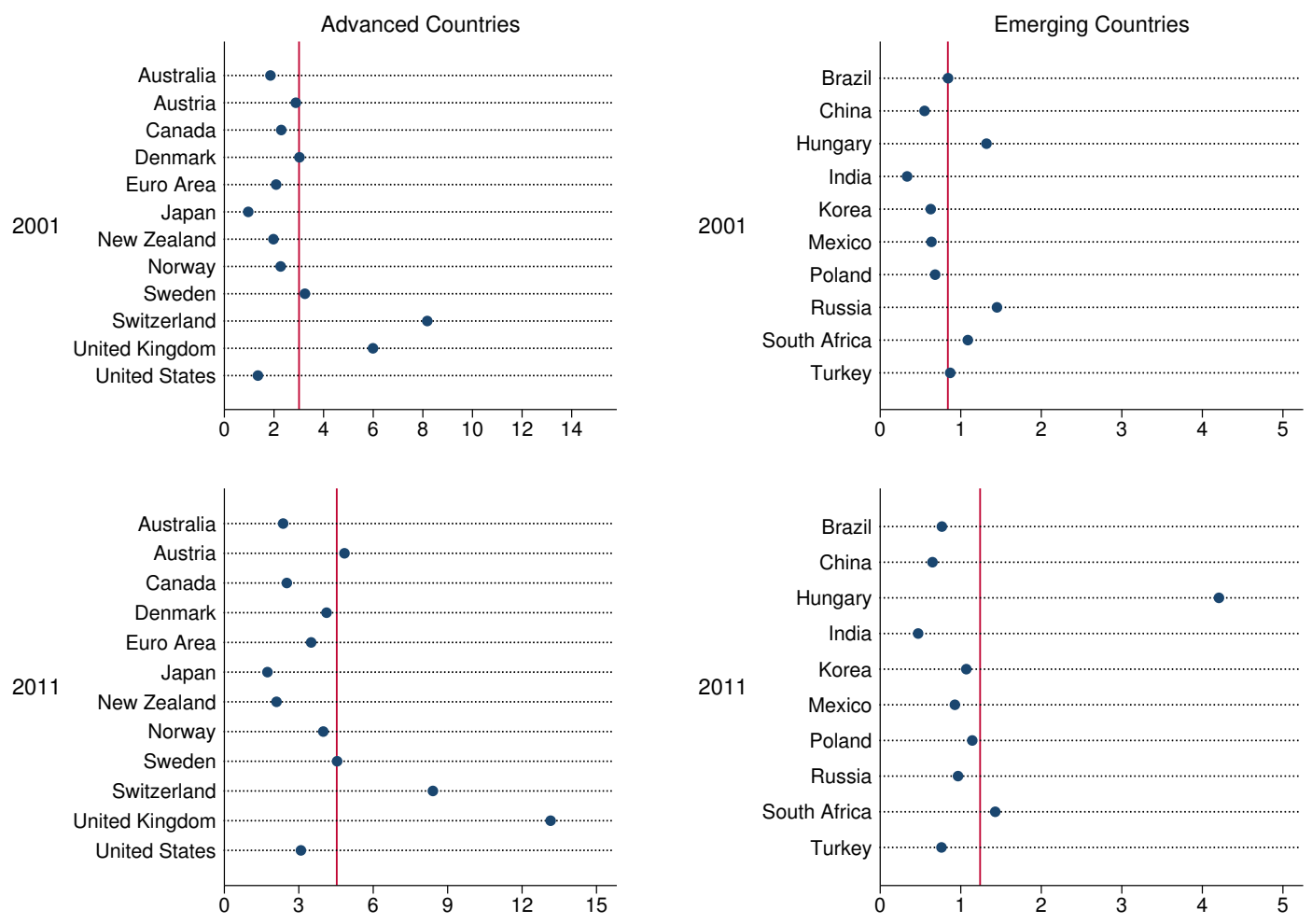

Data source: updated and extended version of Lane and Milesi-Ferretti (2007). The vertical lines represent the group's average.

analysis, the sum of assets and liabilities in relation to GDP, over the sum of exports and imports (their absolute values) in relation to GDP (following Lane and Milesi-Ferretti (2007)), or, put simply, the financial-to-trade integration, is used ${ }^{27}$. According to this measure, financial integration is larger than trade integration in both EMEs and advanced countries, but among advanced countries the difference between the two is much greater. Among advanced countries the financial-to-trade integration in 2011 was, on average, almost four-times greater than among EMEs: 6.38 against 1.7 (when Hong Kong, Singapore and Taiwan are not considered). The change in the ratios from 2001 to 2011 is also stronger among advanced countries (see Figure 5.9).

\footnotetext{
${ }^{27}$ World Bank data (relative to foreign trade) is converted from local currency units to USD with the end-ofthe-period exchange rate, while EWN data uses the year's average exchange rate. To allow for comparability of the two, trade data was re-estimated with the year's average exchange rate.
} 
Figure 5.9: Assets (Minus Reserves) Plus Liabilities Over Exports Plus Imports: 2001 \& 2011, by Economic Group and Country
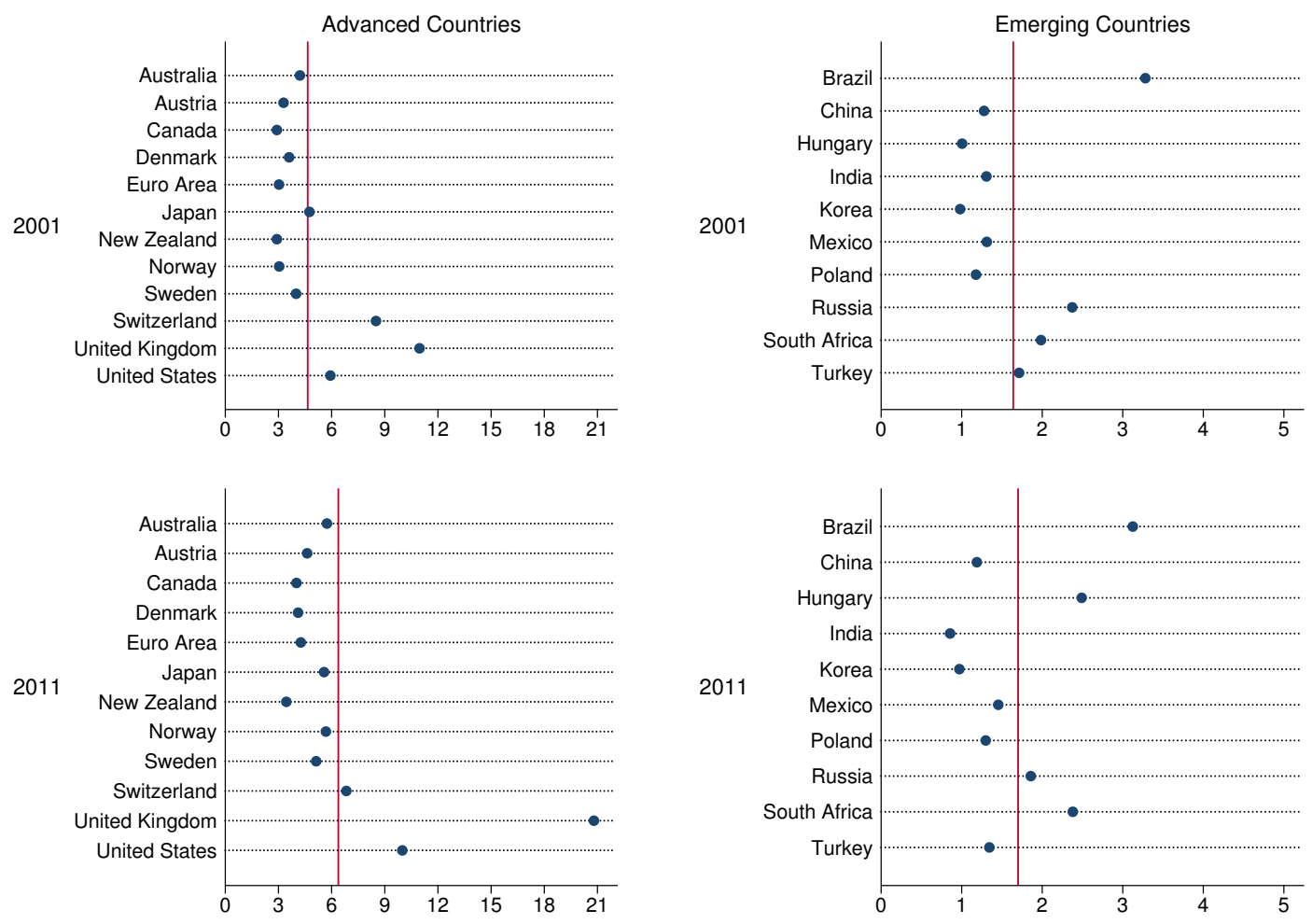

Data source: World Bank (2015) and updated and extended version of Lane and Milesi-Ferretti (2007). The 2001 and 2011 indicators for Hong Kong (4.11 e 4.69, respectively), and Singapore (4.13 e 3.85) are not presented. The WDI does not specify trade data for Taiwan. The vertical lines represent the group's average.

The substantially different magnitude of the financial vis-a-vis the trade integration reflects the aspects, studied in Chapter Two, of international finance decoupling from its prior role of financing trade and production (or the autonomy of financial globalization from production (Chesnais, 1997)), and it is evidence that at an international level, finance follows its own logic (Plihon and Ponssard, 2002).

Among EMEs, Brazil (3.12), Hungary (2.49), South Africa (2.38), and Russia (1.86) present above average financial-to-trade integration. The average EMEs indicator is stable because in some countries there were major decreases: Russia (-0.51), India (-0.45), Turkey $(-0.37)$. On the other hand, among advanced economies, the average indicator increased from 4.65 to 6.38 , boosted by considerable increases in the United Kingdom and in the US. 
This different path reflects that, among advanced countries, the growth of assets' trade was huge while of goods' trade, only modest. Among developing countries the opposite happened: the growth in asset trade was rather weak, and trade in goods increased rapidly (Lane and Milesi-Ferretti, 2007), reflecting the commodities' boom.

\subsubsection{Concluding Remarks}

The analyses of financial integration have shown that advanced countries are significantly more integrated than EMEs. When trade or GDP levels are considered, this difference decreases, but advanced countries remain more financialized.

The analyses of the assets-to-liabilities ratios support the argument of an increasing use of canonical carry trade operations. The low assets-to-liabilities ratio of the Brazilian real, the Turkish lira, and the Indian rupee confirm their use as target currencies. These are also among the EMEs to present the five highest interest rate differentials with the US Fed Fund rate ${ }^{28}$. Among advanced currencies, Japan and Switzerland's great assets-to-liabilities ratios support the idea of the high use of the Japanese yen and the Swiss franc as funding currencies. Other often mentioned funding currencies, the U.S. dollar and the euro, which hold important foreign liabilities related to developing countries' reserves policies, and thus, present lower assets-to-liabilities ratios. The Australian and the New Zealand dollar, notable target currencies, have the lowest assets-to-liabilities ratio among advanced countries.

The overall lower assets-to-liabilities ratios of EMEs confirms the argument that EMEs play a role in the international financial system (IFS) of suppliers of financial assets of a specific class of risk $^{29}$. As reserves are withdrawn, the asset-to-liability indicators are focused on the private sphere. When expanded to include the public sphere, the role of EMEs in international financial markets also includes the purchases of advanced countries governments' liabilities: reserves of international assets reached 37\% of EMEs' foreign assets in $2011^{30}$. Reserves' dynamics are however markedly different from that of money managers'

\footnotetext{
${ }^{28}$ Fore EMEs' interest rates see Figures 6.25 and 6.26 in the Appendix of Chapter Six.

${ }^{29}$ The insertion of EMEs in the IFS as suppliers of financial assets is discussed in Chapter Two. The debate on the specificities of emerging currencies is presented in Chapter Three. In the analysis presented in Chapter Seven, money managers incur an exchange rate risk when investing in assets from both EMEs or advanced countries other than the one where their liabilities are issued. However, investments in EMEs' assets are associated with a safety smaller margin, given that the range of possible exchange rate returns is larger.

${ }^{30}$ This refers to the 13 EMEs with the largest FX markets studied in this chapter.
} 
(that will be further discussed in Chapter Seven). It is a stable form of holding capital, with no intention of gaining with total returns. In some cases this policy is even associated with sterilization costs that are greater than foreign assets' returns (Jeanne (2007); Ramos (2010), Ranciere and Jeanne (2006)).

These policies' focus on maintaining a high and stable level of assets is also confirmed by the very marginal use of reserves in the wake of the GFC (Aizenman and Hutchison, 2012). In addition, being focused on decreasing exchange rate volatility the policy of reserves acts in the opposite direction of private investors, having (if any) a counter cyclical influence not only in the emerging currency, but also in the advanced country's currency. Money managers' behavior, on the other hand, is marked by speculation with world-wide assets, and might result in domestic asset prices and exchange rates that are volatile and associated to the international sphere (as it will be seen in the next chapter).

This difference in the dynamics of (part of) the demand for EMEs' and advanced countries' assets can be seen as an additional form of asymmetry of the IFS; i.e. an asymmetry of the behavior of demand. The demand of EMEs' assets is marked by speculation while part of the demand of advanced countries is marked by stability and counter-cyclical behavior. This asymmetry derives from the fact that emerging currencies are not used internationally as reserve of value (as discussed in Chapter Three) ${ }^{31}$.

\subsection{Increasing Importance of FX Transactions}

This section discusses FX markets in order to further characterize financial integration, demonstrating the sophistication of finance and its potential consequences. It analyzes the changes that took place over time and the differences between EMEs and advanced economies. It examines the total (absolute or relative) size of FX markets and the relative weight of derivatives and spot markets. Both measures are used as proxies of financialization in the literature. The first, the size of FX markets, indicates both the aspect of increasing importance of finance internationally (as did Chesnais (1997) and Epstein (2005)) and the

\footnotetext{
${ }^{31}$ As discussed in Chapter Three, the IFS is also characterized by an asymmetric weight of advanced and EMEs' assets. In the specific discussed here, the fact that emerging currencies do not exercise a function of reserve of value internationally is represented by the fact that EMEs' assets are not used as international reserves of public entities of advanced countries.
} 
sophistication of finance, as it is evidence of the rise of carry trade operations (as argued by Galati and Melvin (2004)). The second measure, the size of derivatives markets, proxies the sophistication of FX markets and the importance of operations as derivatives carry trading.

\subsubsection{Total FX Market}

Between 2001 and 2013 FX markets underwent major changes in different aspects. Its total size exceeded US\$ 4 trillion (daily), four-folding from 2001's level ${ }^{32}$. The participation of emerging currencies in total contracts doubled, achieving $8.4 \%$ (see Table 5.6 for details on the market size of emerging currencies in 2001 and 2013, and Table 5.5 for data on advanced countries). Although the importance of emerging currencies internationally has significantly changed, they still count for a small part of total transactions (see Figure 5.14). It is further evidence of the hypotheses of asymmetries of the international financial and monetary systems (discussed in Chapter Three).

In 2001, the transactions in the Chinese yuan accounted for only $0.1 \%$ of the EMEs' market, but presented the highest growth rate, 108,385\%. The amount of contracts denominated in the Turkish lira and the Hungarian forint also grew significantly $(14,746 \%$ and $10,678 \%$ respectively). The remaining currencies grew less, but still at a high pace: an average of $806 \%$, almost double of advanced countries' average (422\%).

In 2013, the Mexican peso was the emerging currency to be traded the most, representing $15.7 \%$ of total EMEs' markets (see Figure 5.10). It was followed by the Chinese yuan (that accounted for $12.5 \%)$, the Russian ruble (10.1\%), the Turkish lira (7.9\%), the Korean won (7.3\%) and the South African rand (7.1\%) (apart from the Honk Kong dollar (9.3\%), and the Singaporean dollar (8.7\%)). Among advanced economies, the U.S. dollar is by far the most traded currency, its FX market being more than twice that of the euro, the second biggest market. The Japanese yen and the Great Britain pound come next.

Among currencies from advanced countries, the order of magnitude of the different markets has not changed from the 2001 survey. Among emerging currencies the relative importance of FX markets varied: the Mexican peso and the Korean won remained among the five most important currencies, but the South African rand, the Polish zloty, and the

\footnotetext{
${ }^{32}$ For an overall presentation of the 2013 results, see Rime and Schrimpf (2013).
} 
Figure 5.10: FX Market: 2001 \& 2013, by Economic Group and Currency
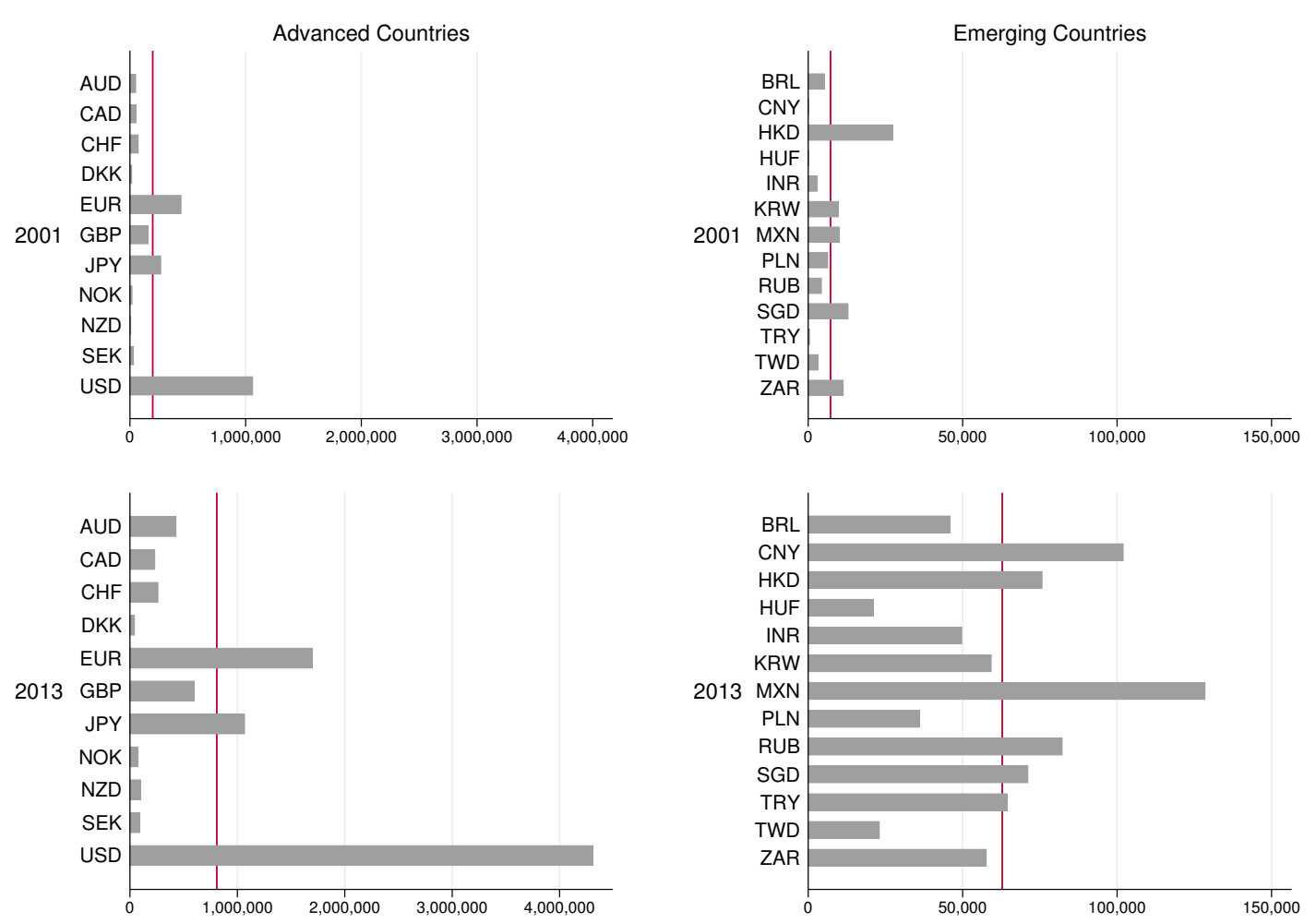

Data source: BIS (2013) and BIS (2001). The vertical lines represent the group's average.

Brazilian real lost their positions to the Chinese yuan, the Russian ruble and the Turkish lira.

This difference reveals a structural character of the motives for using advanced currencies in contrast to a demand that pertains to conjuncture among emerging currencies (as discussed in Chapter Three, Section 3.3.4). Among emerging currencies the important magnitude of the markets of the Chinese yuan, the Korean won, the Mexican peso, and the Russian ruble can be explained by trade ${ }^{33}$, while the changing positions of the South African rand, the Polish zloty, the Brazilian real, and the Turkish lira might be related to financial motives. Indeed, the four have high interest rates and Brazil and Turkey present low assets-to-liabilities ratios. These currencies demands might also have been associated with currency financialization during the 2000s, given that these are among the five most volatile

\footnotetext{
${ }^{33}$ Trade data is presented in Figure 4.2, on Chapter Four, page 144.
} 
emerging currencies, and are among the five with the most frequent depreciations of extreme magnitude (as it will be seen in Chapter Six).

The trading of these four currencies - the Brazilian real, the Polish zloty, the South Africa rand, and the Turkish lira - could therefore vary more depending on their interest rates, turbulence in their exchange rate, and the general sentiment of financial markets internationally.

\subsubsection{FX Markets Relative to the Productive Economy}

In order to further analyze the degree of financialization of the different countries, this subsection compares the importance of a currency's FX market with its underlying economic activity - GDP and foreign trade.

\subsubsection{FX turnover over GDP}

When compared with GDP, FX markets ${ }^{34}$ have grown faster among emerging currencies than in advanced ones. While the ratio increased $108 \%$ among advanced currencies (from 0.11 in 2001 to 0.23 in 2013), it increased $158 \%$ among emerging currencies (from 0.04 to 0.10 ; see Figure 5.11), indicating a more intense process of financialization in EMEs. Moreover, the important difference in magnitude between the two groups of countries confirms that, as expected, advanced countries present a higher financialization level.

In 2013, the highest FX-to-GDP ratios among EMEs were observed in Hungary (0.16), South Africa (0.16), Mexico (0.1) and Turkey (0.08) ${ }^{35}$. In regards to the financialization process, Mexico reveals a remarkable increase of the FX-to-GDP ratio of $900 \%$, followed by Russia (300\%), India (200\%), and Korea (150\%). Among advanced economies, the highest ratios were New Zealand's (0.54), Switzerland's (0.38), Australia's (0.27), the United States' (0.26), Japan's (0.22) and the United Kingdom's (0.22) - again indicating the weight of carry trading operations with these currencies (the New Zealand and the Australian dollars being target currencies and the others, funding currencies).

\footnotetext{
${ }^{34}$ Note that the FX value used in building the FX-to-GDP ratio has not been annualized - it is a daily value of FX turnover compared to the annual GDP.

${ }^{35}$ Apart from Hong Kong (0.28) and Singapore (0.24).
} 
Figure 5.11: FX Market Over GDP: 2001 \& 2013, by Economic Group and Country
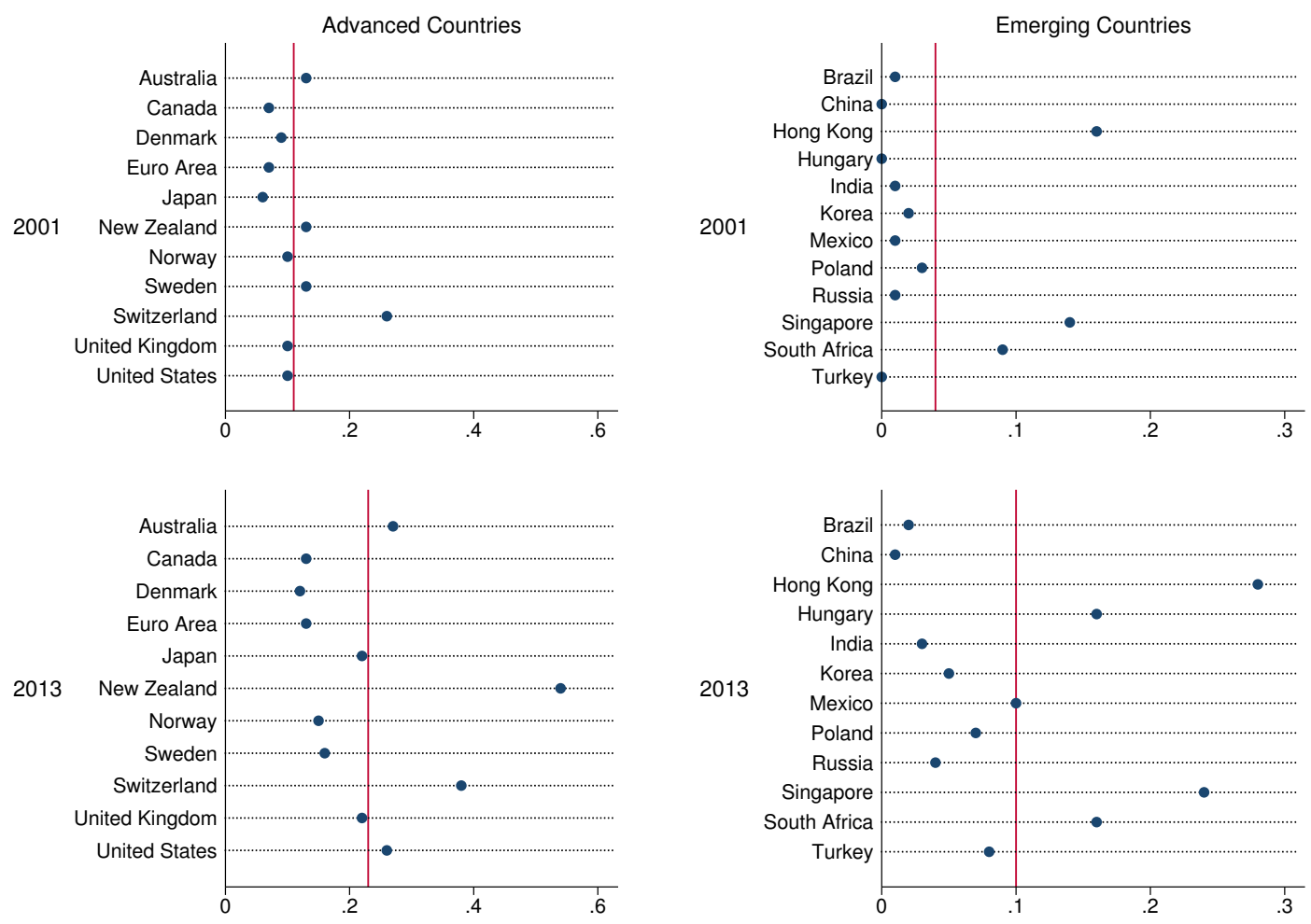

Data source: BIS (2013), BIS (2001), World Bank (2015). The vertical lines represent the group's average.

\subsubsection{FX turnover over trade}

A second indicator of the relative relevance of an FX market is the FX-to-trade indicator, that hints at whether "trading has become more financial" (McCauley and Scatigna, 2011, p. 68$)^{36}$. The indicator demonstrates the degree of financialization, underscoring which part of the transaction relates to trade, and which are related to 'finance'.

The average FX-to-trade ratio across EMEs was 0.04 in 2001, a low average despite the high ratio of South Africa: 0.17. In 2013, the average ratio increased to 0.09. The EMEs that presented the most financialized structure was South Africa, with a ratio of 0.25 , followed by Mexico (0.16) and Turkey (0.14) (see Figure 5.12).

\footnotetext{
${ }^{36}$ Foreign trade is estimated as the sum of the absolute value of exports and imports.
} 
Figure 5.12: FX Markets Over Exports Plus Imports: 2001 \& 2013, by Economic Group and Country
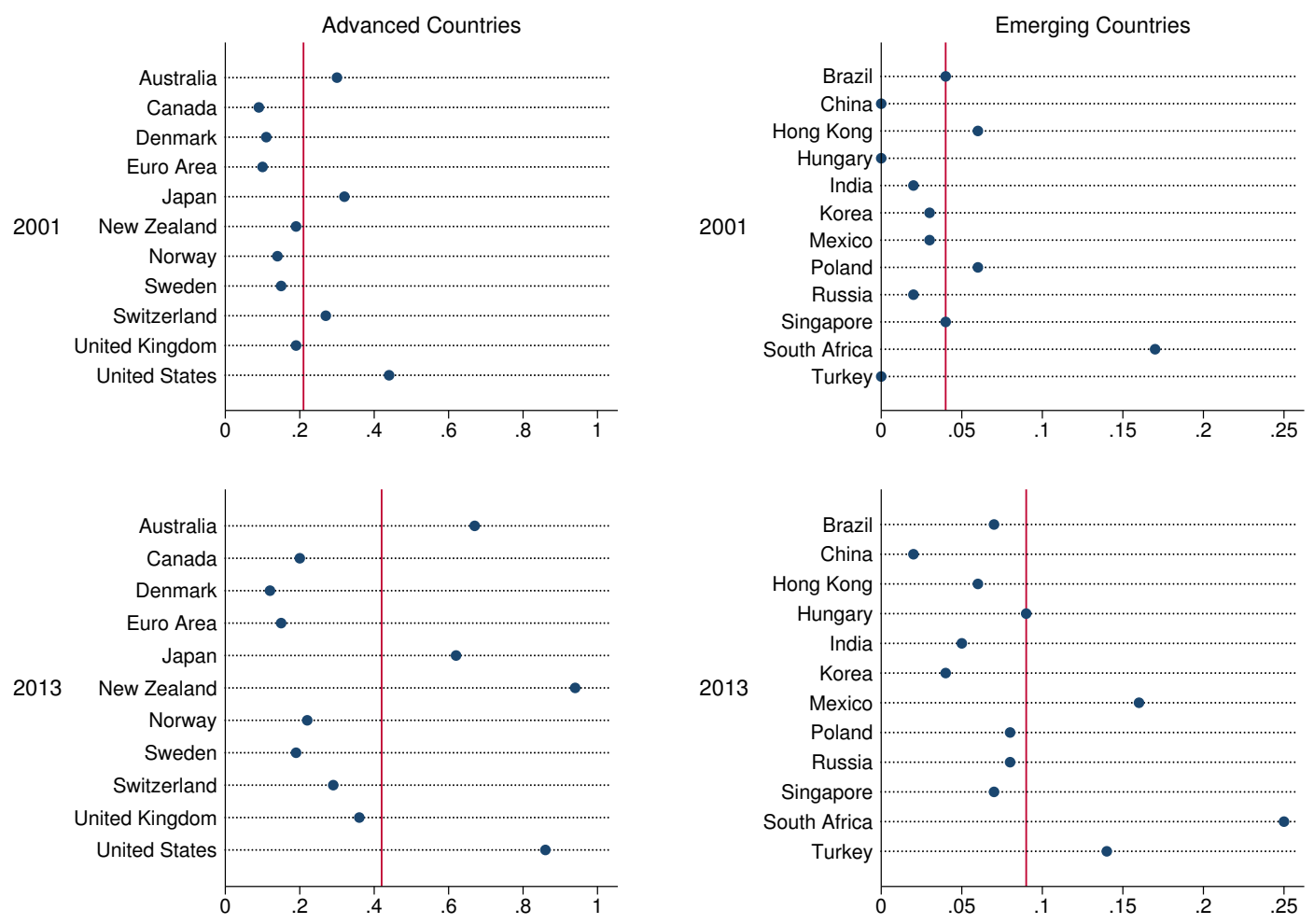

Data source: BIS (2013), BIS (2001), World Bank (2015). The 2001 and 2011 indicators for Hong Kong (0.06 and 0.06, respectively), and Singapore (0.04 and 0.07) are not presented for facilitating the reading of the graph. The vertical lines represent the group's average.

Regarding the financialization process, the FX-to-trade ratio increased an average of $136 \%$ - a higher rate than among advanced economies, that grew 101\%. This increasing financialization process occurred in almost every EMEs, but with different intensities: it reached $433 \%$ in Mexico, but only $33 \%$ in Korea.

Among advanced countries the average FX-to-trade ratio doubled from 0.21 to 0.42 . The highest FX-to-trade ratio in 2013 was New Zealand's (0.94), followed by the United States' (0.86), Australia's (0.67) and Japan's (0.62). Indeed, these advanced countries are the most associated with carry trading operations (together with Switzerland) and are a different group than the group with the largest FX markets: the US, the Euro Area, the UK and Japan. 
The FX-to-trade ratios of EMEs are four-times lower than that of advanced countries, indicating a lower degree of financialization among them. However, the process has been more intense in EMEs.

\subsubsection{Spot and Derivatives Markets}

As argued in Chapter Two, derivatives contracts are essential to understand the possible consequences of financial integration on emerging currencies, because their leverage possibilities make them excellent tools for speculation and because they can also increase exchange rate volatility for being an extra conduit of determination of spot rates. Derivatives FX markets also proxy the overall level of sophistication of a country's markets, evincing the extent of the investment possibilities offered to money managers.

When analyzing BIS data on derivatives, it must be noted that the dataset only includes data on over-the-counter (OTC) markets. Indeed, OTC are the predominant places of derivatives trade in most countries, but in Brazil, Korea and India, the derivatives transactions in organized markets would be most significant (McCauley and Scatigna, 2011) ${ }^{37}$. However, according to Fritz and Prates (2014), in Korea, considering only onshore transactions, FX turnover in the $O T C$ market is higher than exchange-traded turnover.

When looking at emerging and advanced currencies combined, spot contracts increased more $(444 \%)$ than derivatives contracts $(274 \%)$. With the slower growth, derivatives contracts lost weight in total market (from $67 \%$ to $59 \%$ ), but remain larger than spot contracts (see Figure 5.13 for the absolute size of each type of contract). This is due to the highest increase of spot contracts among advanced currencies ( $532 \%$ versus $352 \%$ of derivatives). The opposite happened among emerging currencies: derivatives contracts grew faster than

\footnotetext{
${ }^{37}$ As put by McCauley and Scatigna (2011, p. 68): "Foreign exchange turnover includes not only overthe-counter but also exchange-traded turnover, which is most significant for the Brazilian real, the Indian rupee and the Korean won." McCauley and Scatigna (2011) estimate the total size of derivatives markets, adding contracts traded in OTC and organized markets. The data source for the organized markets is however proprietary and there are no details on how it is calculated to overcome the incompatibility of the two, given how differently operations are closed. That is because in organized markets, when a participant wants to close an operation it makes an opposite operation. In OTC markets, on the other hand, participants take a position identical to the old one, but with opposite signs, which leads to double counting of operations that are 'closed' (Farhi, 1998). On the high liquidity of the derivatives market of the Brazilian real, see Farhi (2006), Farhi (2010), Fritz and Prates (2014), Garcia and Urban (2004), Kaltenbrunner (2010), Prates (2015), Ventura and Garcia (2012), and Rossi (2016).
} 
Figure 5.13: Daily Exchange Rate Transactions: Spot and Derivatives Contracts. 2001 \& 2013, by Currency and Economic Group

Advanced Countries
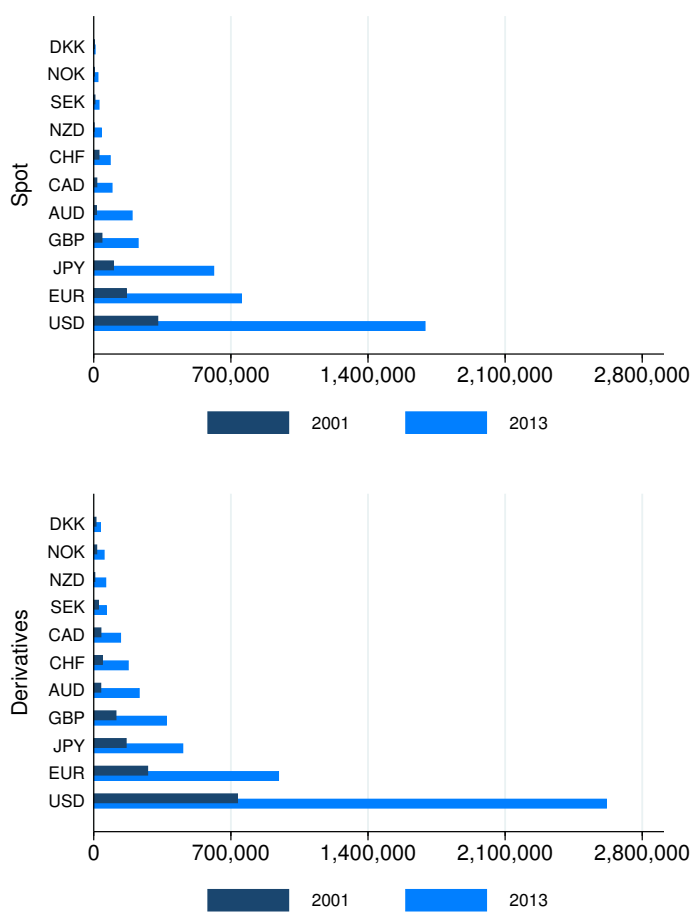

Emerging Countries
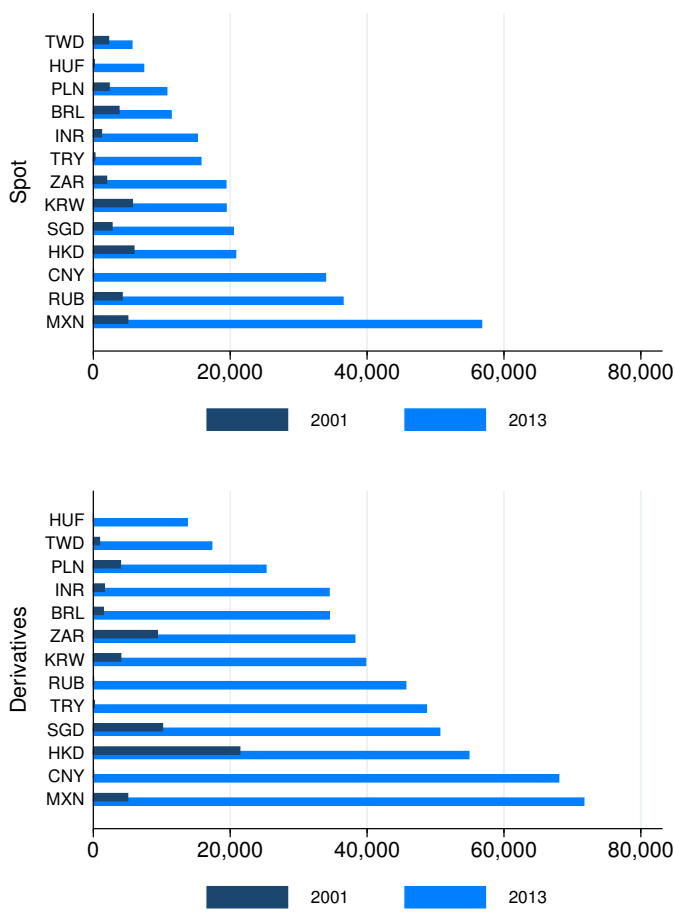

US\$ Million. Data source: BIS (2013) and BIS (2001).

spot contracts (931\% and $766 \%$, respectively). This indicates a more intense process of financialization among emerging currencies than in advanced ones in this period.

In 2013, the most important derivatives markets among emerging currencies were those of the Mexican peso (13.2\% of total contracts in emerging currencies), of the Chinese yuan (12.5\%), of the Turkish lira (9\%) and of the Russian ruble $(8.4 \%)^{38}$ (see Figure 5.14). Considering Rossi's (2016) estimation of the amount of derivatives contracts in Brazilian reais traded in organized markets, the derivatives markets of the Brazilian real would be among the three most important in EMEs.

Emerging currencies' derivatives contracts varied significantly in magnitude: the Mexican peso is four times larger than the Hungarian forint. This discrepancy and the low

\footnotetext{
${ }^{38}$ Currencies of financial centers also had important derivatives markets: the Hong Kong dollar, $10.1 \%$ and the Singapore dollar, $9.3 \%$.
} 
Figure 5.14: FX Contracts, Total market: $2001 \&$ 2013, by Economic Group and Type of Contract

2001

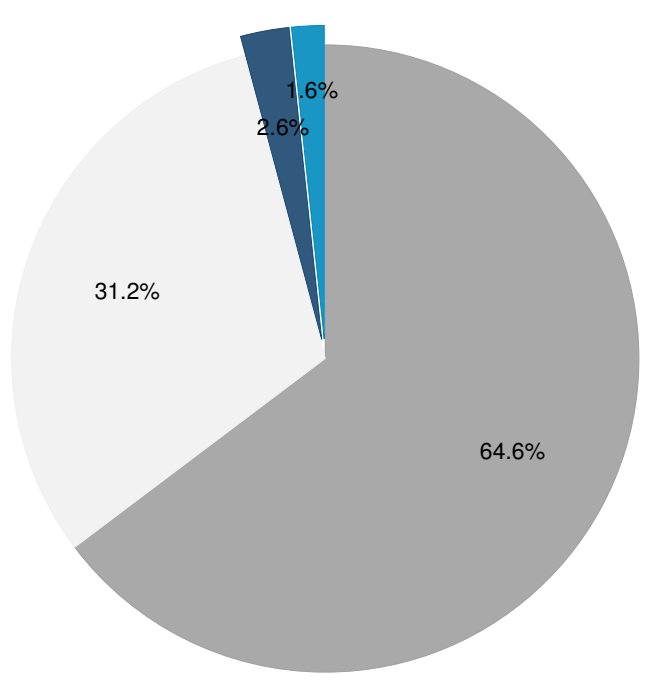

Emerging, Spot Advanced, Spot
Emerging, Derivatives

Advanced, Derivatives

US\$ Million. Data source: BIS (2013) and BIS (2001).

liquidity of some emerging currencies' markets explains why some currencies are used by foreign investors as proxy for other emerging currencies - as Prates' (2009) argument about the use of the Brazilian real.

The relative size of derivatives vis-a-vis of spot markets indicates financialization, underscoring the speculation aspect that arises when derivatives are detached from spot transactions, that is partially related to 'productive operations'.

With the high growth of derivatives markets in EMEs, the average derivatives-to-spot ratio increased from 1.53 to 2.25 - while in advanced economies it decreased from 2.99 to 1.91. While the increase of the derivatives-to-spot ratios is spread-out across EMEs, ${ }^{39}$ among advanced countries the ratio decreased in every country except for Denmark and Switzerland. This suggests a rather financialized structure in EMEs in general (see Figure 5.15).

\footnotetext{
${ }^{39}$ The ratio of the South African rand decreased, but it was an outlier in 2001.
} 
Figure 5.15: Derivatives-to-Spot Ratios, Advanced \& EMEs, 2001 \& 2013
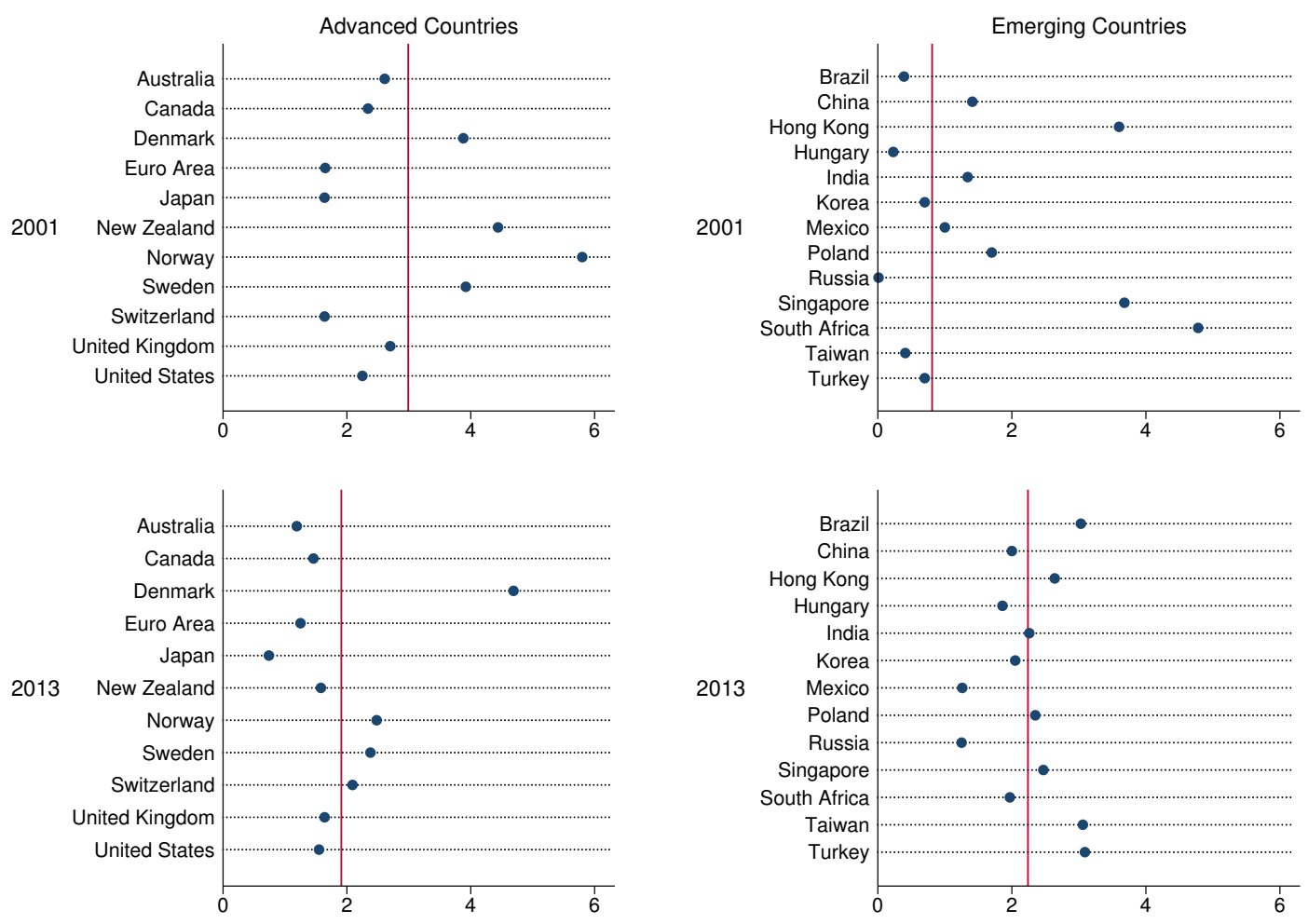

Data source: BIS (2013) and BIS (2001). The vertical lines represent the group's average.

In 2013, the highest derivatives-to-spot ratios among emerging currencies were the Turkish lira, the Taiwanese dollar and the Brazilian real, with around three times more derivatives than spot contracts. Compared to advanced countries, these ratios are considerably higher - only lower than that of the Danish koruna (4.7). Ratios higher than two were seen in the Chinese yuan, the Indian rupee, the Korean won, and the Polish zloty - except for the Hong Kong and the Singaporean dollars. On the other end, oil exporters Mexico and Russia (among the three largest EMEs spot markets) presented relatively low derivatives-to-spot ratios. The derivatives-to-spot ratios thus suggest more financialized FX markets in Turkey, Taiwan and Brazil. 


\subsubsection{Concluding Remarks}

The analyses of the FX markets of advanced and emerging currencies resulted in very different characteristics in the two country groups. FX markets of emerging currencies have grown at a faster pace. This development was not due to potentially different growth of GDP or trade. With regards to the debate on financialization, the evidence demonstrates a decoupling of $F X$ contracts from the globalization of production or trade, and a more intense process of financialization among emerging currencies and EMEs. Emerging FX markets are also marked by a higher weight of derivatives contracts, showing the high sophistication of these markets. As expected, advanced countries' currencies continued to present a more financialized integration.

The comparison of the financialization process observed by the relative magnitudes of integration and FX markets is an interesting evidence of financialization. For instance, among EMEs, while integration grew $48 \%$ more than GDP, FX contracts grew $158 \%$ more than GDP (see Table 5.1 for a summary of these findings). Being a flow, not a stock measure, FX markets are a smaller part of GDP than financial integration. Its growth, however, was higher than the growth of integration. This indicates the dissociation of FX transactions not only from the productive economy (as proxied by GDP or trade), but also from financial integration itself. These developments demonstrate financialization, underscoring not only a decoupling from production, but also the new logic of finance at the international level.

As the rise of FX transactions among emerging currencies was concentrated in derivatives contracts, its decoupling from financial integration highlights the innovations of products, and among the innovations of usages, the use of derivatives carry trading.

\subsection{Measuring Financialized Integration}

As argued in Sections 5.2 and 5.3, some of the discussed indicators are representative of the aspects of financialization related to integration. These are: the stock of foreign assets and liabilities relative to i) GDP and to ii) foreign trade, the weight of FX markets relative to iii) GDP and to iv) foreign trade, and the v) importance of derivatives relative to spot contracts. 
Their level in the recent period indicate how financialized these countries' integration are and the changes observed between the two periods indicate the intensity of the financialization process.

There are different associations of these five indicators with the two aspects of financialization that have the highest potential impact on exchange rates (the two first among the three aspects studied in Chapter Two). The first four indicators point to aspects of the financialization of growth of finance at the international level, and its decoupling from earlier functions related to the globalization of trade and production. They can therefore be seen as proxies of the first aspect of financialization: the increasing importance of finance at the international level (studied in Section 2.2.1).

The characteristic of a country's FX market (the fifth indicator) and its size (the third and the fourth) point to the use of derivatives, indicating the level of sophistication of financial markets and the possibilities of speculation offered. These three series are thus used as indicators of (part of) the second aspect of financialization: the innovations of products (studied in Section 2.2.2).

The innovations of usages, such as carry trading and currency trading more broadly, are also significant among the innovations of finance. Carry trading and currency trading result in higher FX markets (the third and fourth indicators). Canonical carry trading results in high integration (first and second indicators), derivatives carry trading in higher derivatives markets and FX contracts (third, fourth and fifth indicators).

The average values of the five indicators are presented in Table 5.1 for the two groups of countries. They are presented for the most recent period (either 2011 or 2013, indicating the financialization level) and the change seen in a comparison with 2001 (indicating the financialization process).

As discussed in Section 5.2, EMEs present a lower level of financial integration than advanced countries, even when lower GDP is considered and when trade is taken into account (in the first case, advanced countries are 14\% more integrated; in the latter case, advanced countries are three times more integrated). Section 5.3 has shown that FX markets of advanced countries' currencies are much larger than those of emerging currencies. 
TABLE 5.1 Sum of Indicators of Financialization

\begin{tabular}{lccccc} 
& \multicolumn{3}{c}{ State $(2011 / 13$ level $)$} & \multicolumn{2}{c}{ Process $(2001$ to $2011 / 13)$} \\
& Adv. & EME & Adv./EME & Adv. & EME \\
\hline Assets+Liab/GDP & 4.53 & 3.98 & 1.14 & $50 \%$ & $40 \%$ \\
Assets+Liab/Trade & 6.68 & 2.13 & 3.14 & $40 \%$ & $3 \%$ \\
FX Mkt/GDP & 0.23 & 0.10 & 2.27 & $108 \%$ & $158 \%$ \\
FX Mkt/Trade & 0.42 & 0.09 & 4.54 & $101 \%$ & $136 \%$ \\
Derv-to-Spot Ratio & 1.91 & 2.25 & 0.85 & $-36 \%$ & $47 \%$
\end{tabular}

When factoring in relation to GDP or trade, the difference decreases, but they remain, respectively, twice or four times bigger than emerging currencies' markets. The evidence of the smaller financial integration and of the smaller FX markets of EMEs supports the idea of the asymmetries of the international financial and monetary systems (discussed in Chapter Three). Despite their lower financial integration and FX markets, regarding the weight of derivatives contracts, emerging currencies are more financialized.

With the aim of building a financialization indicator with respect to the type of integration, these five indicators are combined in an index that proxies the level of financialization of the countries' integration, or, in other words, of how financialized their integration are. It is presented in Figure $5.16^{40}$.

South Africa, Turkey, Brazil, Hungary and Poland are the five countries to present the most financialized integration (apart from Hong Kong and Singapore). The relative size of FX market to trade in South Africa is much higher than in other EMEs. In Turkey and Brazil the derivatives-to-spot ratio is the variable responsible for the highly financialized characterization. Poland appears with its important FX market relative to GDP and an above average financial-to-trade integration. This indicator will be used in the next chapter to analyze if financialized integration has an impact on exchange rate dynamics.

\footnotetext{
${ }^{40}$ It is a min-max composite index relative to EMEs' 2013 values.
} 
Figure 5.16: Levels of Financialization of EMEs According to Five Indicators

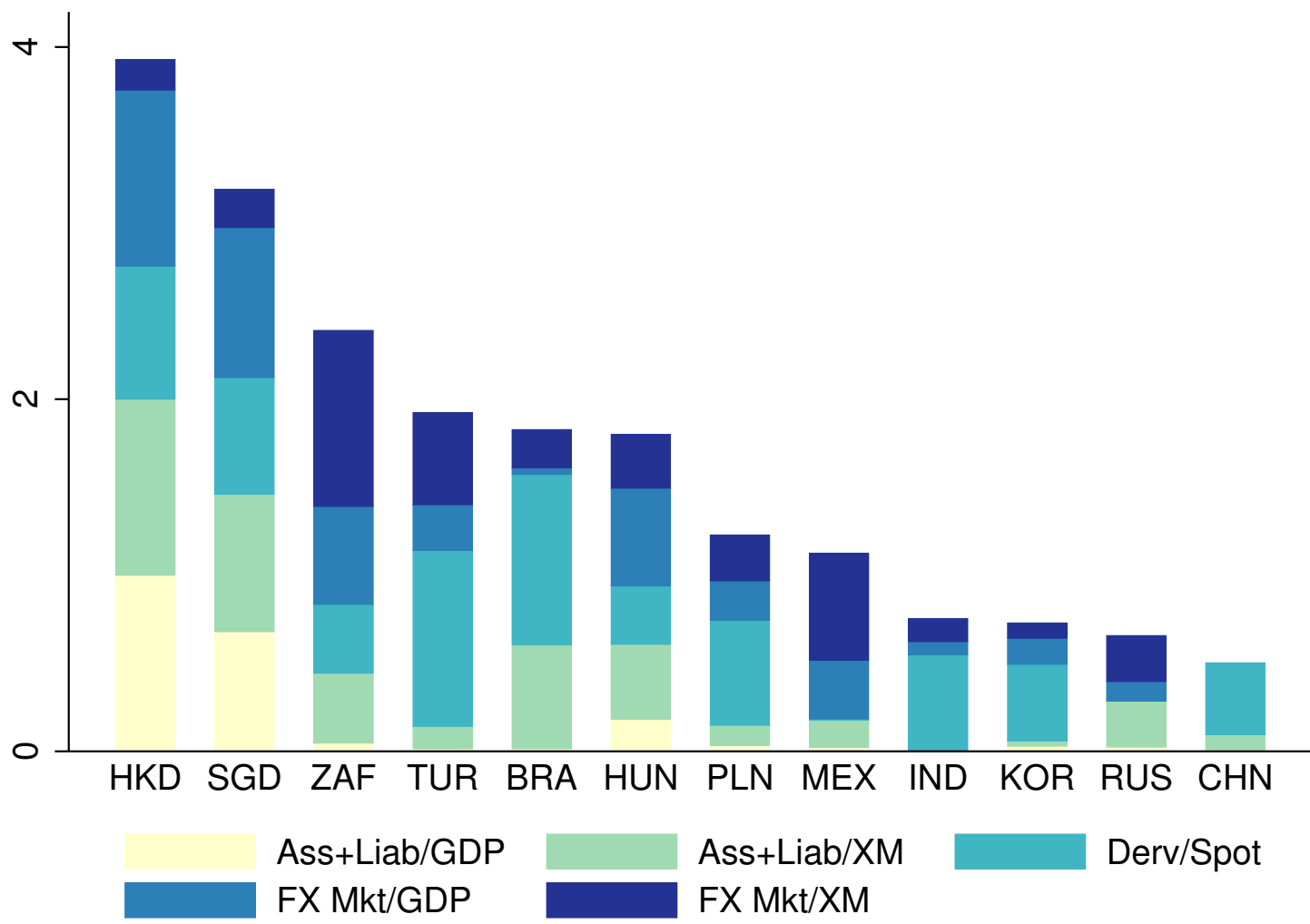

Source: Author's estimation. Data source: financial integration from the updated and extended database of Lane and Milesi-Ferretti (2007); FX turnover statistics from BIS (2013); GDP and foreign trade from World Bank (2015).

\subsection{Characterizing Financial Integration: a Principal Com- ponents Analysis}

This section makes use of a principal components analysis (PCA) to further study the different characteristics of financial integration across advanced countries and EMEs without dividing them into two country groups. It is based on different indicators analyzed throughout the chapter (they are presented in Table $5.2^{41}$ ). PCA is a mathematical technique that reduces the dimensions of a dataset into a series of principal components that explain as much of the variance of the original series as possible. See Chapter Four for more on this methodology.

\footnotetext{
${ }^{41}$ Data on reserves were not included. Otherwise they would account for too high a proportion of the difference among EMEs and advanced countries, leaving little to be explained by 'more interesting' variables.
} 
TABle 5.2 Variables Used in the PCA

$\begin{array}{ll}\text { ttasset } & \text { Total assets minus reserves } \\ \text { ttliab } & \text { Total liabilities } \\ \text { assliab/gdp } & \text { Assets (minus reserves) plus liabilities over GDP } \\ \text { assliab/xm } & \text { Assets (minus reserves) plus liabilities over exports plus imports } \\ \text { ttass/ttliab } & \text { Total assets over total liabilities } \\ \text { eqass/liab } & \text { Assets-to-liabilities ratio: equities } \\ \text { debtass/liab } & \text { Assets-to-liabilities ratio: debt } \\ \text { fdiass/liab } & \text { Assets-to-liabilities ratio: FDI } \\ \text { ttfxmkt } & \text { Total foreign exchange market } \\ \text { ttfxmkt/gdp } & \text { Total foreign exchange market over GDP } \\ \text { ttfxmkt/xm } & \text { Total foreign exchange market over exports plus imports } \\ \text { derv } & \text { Total derivatives market } \\ \text { derv/spot } & \text { Derivatives over spot contracts }\end{array}$

The components estimated are presented in Table 5.3. As in Chapter Four, following the Kaiser rule, only the components whose eigenvalues are greater than one are considered - in this case, the first four components. With these four series, $83 \%$ of the variance of the original dataset is explained. To understand what the four layers represent, the loadings of the original variables into each of them is analyzed (see Table 5.4). Values higher than 0.4 were considered a relevant loading. Values lower than that are not printed for ease of reading.

TABle 5.3 Principal Components and Eigenvalues

\begin{tabular}{lcccc} 
Component & Eigenvalue & Difference & Proportion & Cumulative \\
\hline Comp1 & 5.11106 & 2.2613 & 0.3932 & 0.3932 \\
Comp2 & 2.84976 & 1.23588 & 0.2192 & 0.6124 \\
Comp3 & 1.61388 & 0.430758 & 0.1241 & 0.7365 \\
Comp4 & 1.18312 & 0.355183 & 0.091 & 0.8275 \\
Comp5 & 0.827941 & 0.238479 & 0.0637 & 0.8912
\end{tabular}

The first component (PC 1) is related to the absolute size of FX markets (the total size and the size of derivatives markets) and to the importance of financial integration (the size of the stock of assets and of liabilities).

The second component (PC 2) is a series that represents the type of financial integration. Countries that have high scores in this component tend to have a high asset-to-liability ratio 
TABLE 5.4 Component Loadings

\begin{tabular}{lccccc} 
Variable & PC 1 & PC 2 & PC 3 & PC 4 & Unexplained \\
\hline ttfxmkt & 0.4381 & & & & 0.1042 \\
fxmkt/gdp & & & 0.6196 & & 0.1294 \\
fxmkt/xm & & & 0.5737 & & 0.0629 \\
derv & 0.4467 & & & & 0.1161 \\
derv/spot & & & & 0.4702 & 0.4630 \\
ttass/ttliab & 0.5204 & & & 0.0737 \\
eqass/liab & & & 0.4573 & & 0.3293 \\
debtass/liab & & 0.5402 & & & 0.1333 \\
fdiass/liab & 0.6125 & & & 0.1734 \\
ttasset & 0.481 & & & & 0.0571 \\
ttliab & 0.5041 & & & \multirow{2}{*}{0.6171} & 0.1845 \\
assliab/gdp & & & & & 0.3701
\end{tabular}

with regards to FDI, debt and to the sum of the three types of investments (FDI, debt and equity). In other words, they tend to have more assets abroad than foreign liabilities.

The third component (PC 3) informs the relative size of FX markets, but it also contains information on the importance of the assets-to-liabilities ratio of equities. Countries with a high relative FX market tend to have a high stock of equity investments abroad vis-a-vis of the stock of foreign capital invested on equities.

The fourth component (PC 4) includes information about the importance of derivatives vis-a-vis spot contracts and of the importance of their financial integration relative to GDP. It can therefore be seen as the series that is closest to financialization for including two of the five indicators used to proxy financialization. The very combination of these two indicators in the same component indicate that more sophisticated FX markets exist in currencies of highly financially integrated countries.

In summary, there are two size components, absolute and relative (PC 1 and PC 3), one on whether the country invests abroad or receives flows (PC 2) and another that partially indicates how financialized a country's FX market or its integration are. It is important to keep in mind that the last component is not the only one to proxy financialization. Indeed, a relatively high FX market and an important derivatives market are also proxies of financialization and these variables have high weights on PC 3 and PC 1, respectively. 
For not yielding in a set of components where financialization-related features are gathered in the same component, the PCA cannot be used to provide a typology of countries according to financialization. Its analysis however results in interesting points. PC 1 is associated with variables of the absolute size of FX markets and with the level of financial integration, while the variables that load the most on PC 3 are related to the relative size of FX markets (relative to GDP and to foreign trade). The fact that the two sets of variables related to the absolute and the relative sizes of FX markets load in different components (not being correlated enough to load in the same component) indicates a high level of financialization of some FX markets. The countries that present the largest FX markets are not the same that present the largest FX markets relative to their economy. In other words, this result indicates that FX markets' size are independent from the economy's size or the magnitude of its foreign trade. Indeed, the correlation between the country scores on these two components is 0.25 , one of the lowest among different components.

Also interesting in a PCA analysis is to see how each country performs in each component. This is shown in Figure 5.17; Figure 5.18 only shows EMEs for better visualization. The different combinations presented in the four plots of Figure 5.17 shows that advanced countries (with blue circular markers) and EMEs (with red triangles as markers) most often form two clearly different sets of countries, with the exception of Hong Kong and Singapore, whose characteristics are more similar to advanced countries (which is in line with their role as financial centers and their different structures, as seen in Sections 5.2 and 5.3).

Plot (d) is the most revealing to analyze financialization, because it groups most of the financialization-related variables: the relative size of FX markets (on PC 3), and the derivatives-to-spot ratios and the international financial integration (on PC 4). When considering these variables, the most financialized structures are those that have high scores on both components. Among EMEs, Brazil stands out with relatively high PC 3 and high PC 4, which indicates the high financialization level of its integration. Turkey has a high score on PC 4 and China on PC 3. But the highest scores are, as expected, those of advanced countries, as the United Kingdom, Switzerland, Norway, and, to a lesser extent, Sweden. The combination of the United States, Japan, New Zealand and Australia in a same group is revealing of their large FX markets (in relative terms), but low derivatives-to-spot ratios 
Figure 5.17: Country Scores on the Four Principal Components: 2011/2013

(a)

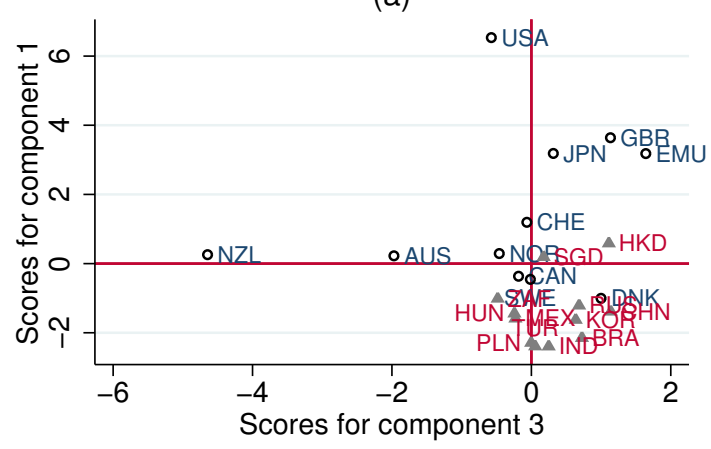

(c)

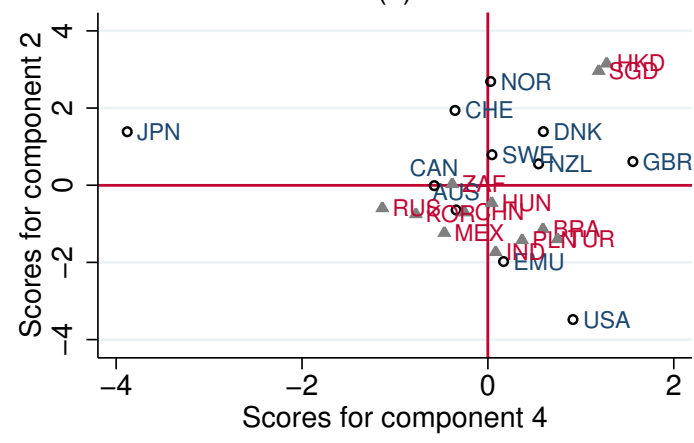

(b)

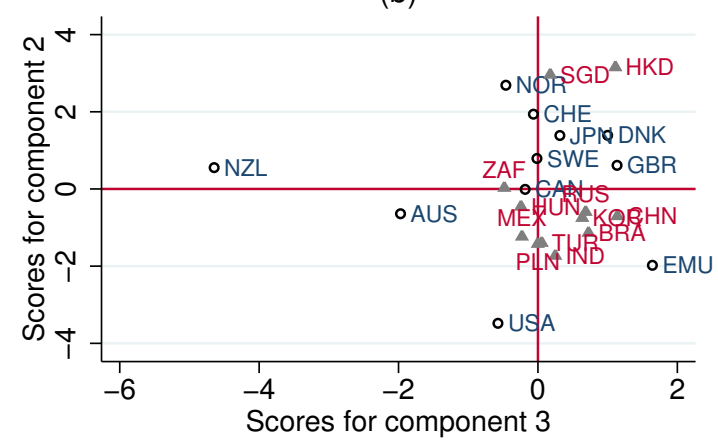

(d)

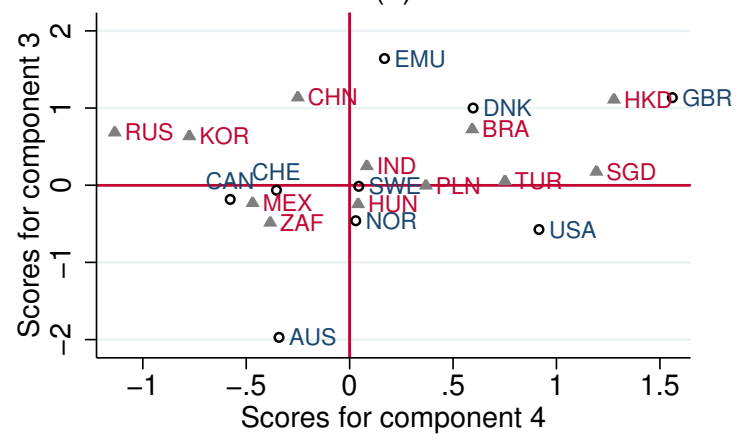

Rotation: orthogonal varimax. For ease of reading, the four plots are presented individually in the Appendix (Figures 5.19 to 5.22). For ease of reading, Japan and New Zealand are not presented in plot (d); their respective values for PC 3 and PC 4 are $0.31,-3.88$ and $-4.65,0.55$.

- what hints to a higher weight of canonical, rather than derivatives carry trade in these funding and target currencies.

Plot (a) presents the relationship between the country scores on PC 1 and PC 3. In this plot the most financialized type of country is one that has a large FX market relative to the underlying economy (PC 3), a large FX market and a significant integration (PC 1). This set of countries includes the United States, the United Kingdom, and Japan. New Zealand, Norway, Singapore, Hong Kong, Switzerland, Australia, and Sweden are also very financialized, and their FX markets and integration are big relative to their GDP or trade, but with a small FX market. The European Area presents a less financialized structure: although it is highly integrated and its FX market is important, it is not so when it's GDP or trade are taken into account. EMEs, Canada and Denmark compose a fourth set of 
Figure 5.18: Country Scores on the Four Principal Components: EMEs, 2011/2013

(a)

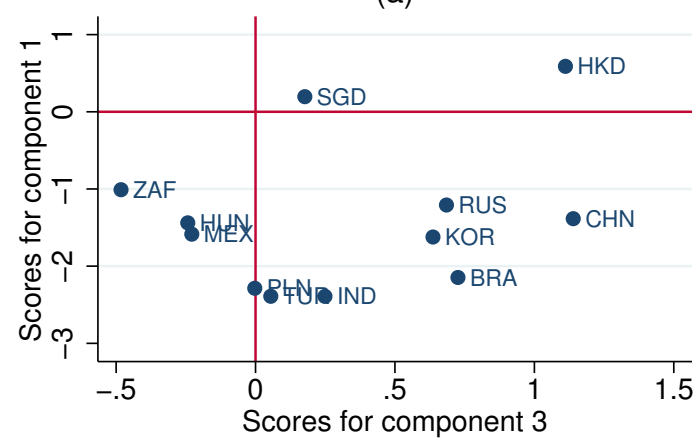

(c)

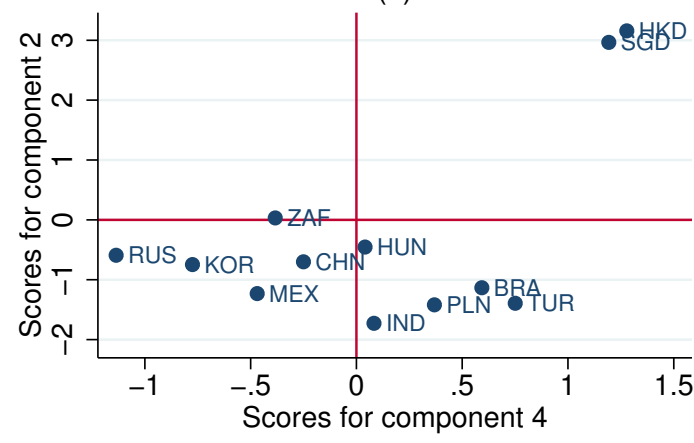

(b)

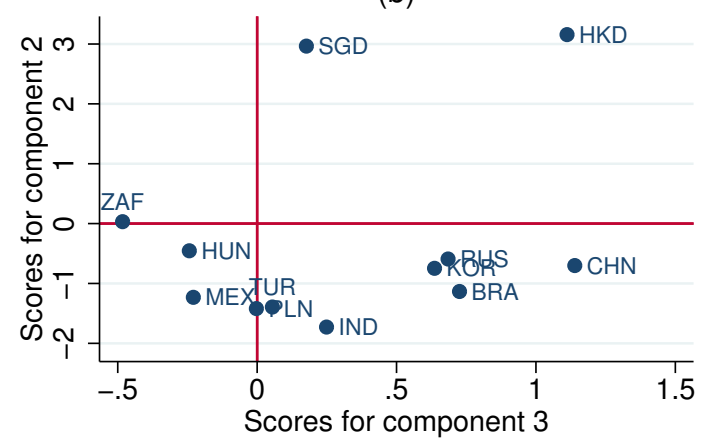

(d)

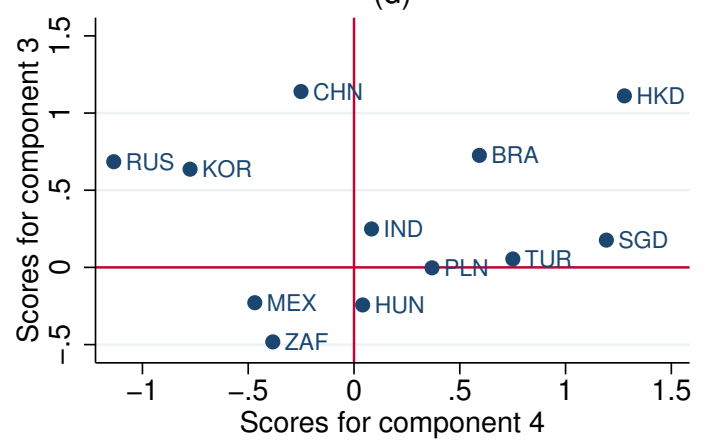

Rotation: orthogonal varimax. For ease of reading, the four plots are presented individually in the Appendix (Figures 5.23 to 5.26).

countries, which are less integrated and have smaller FX markets in absolute and relative measures. Among EMEs, South Africa and Hungary appear with the most important FX markets in relation to GDP or trade. China and Brazil, perhaps due to their large GDP, are, on the other end,reveal smaller relative FX markets.

Plot (b) displays countries according to their type of integration (PC 2, whether they invest more abroad, or receive funds) and the relative size of their FX markets and of their integration. EMEs form a relatively homogeneous group, with a higher probability of receiving more than sending funds abroad and with small relative financial integration and FX markets - here, once more, Singapore and Honk Kong are exceptions. Among EMEs, as mentioned above, South Africa and Hungary present the most important financial integration (have high scores on PC 3) and Russia is the one that is least associated with the 'receiving capital' type. 
Australia and New Zealand are similar to EMEs for being more on the 'receiving capital' type, but are more integrated. Among the advanced countries, Japan, Switzerland, the United Kingdom, and the United States are a rather uniform group, highly integrated and that tend to invest more abroad - the United States being the one that least fits in this last category, given high amounts of foreign liabilities.

Plot (c) presents the integration type (PC 2) against the financialization level (PC 4). EMEs are again a rather uniform group: the 'receivers' type and not so financialized, along with New Zealand and Australia. Japan, the Euro Area, the United States and Canada present a type of integration of investing abroad and are not so financialized - in the United States' case, probably due to their important trade, and thus spot markets.

The analysis of the principal components show that EMEs and advanced countries are clearly different groups even if the differentiation of countries is not done ex-ante, as in the last section where each of the groups' average were compared. Financial centers, Hong Kong and Singapore, have structures that are very close to those of advanced countries. Australia and New Zealand are similar to EMEs in some aspects. Hong Kong and Brazil stand out as the most financialized for presenting the highest values in the two components that include financialization-related aspects (PC 3 and PC 4). Singapore and Turkey come next, followed by Poland, India, and Hungary (for their relatively high values for PC 4). The United Kingdom is the most financialized economy, having a significant FX market, derivatives contracts, and important financial integration, in both absolute and relative measures. The United States, Japan, Switzerland and Norway also present more financialized structures. The Euro Area does not present a high financialization level.

In comparison with the analysis of the level of financialized integration discussed in Section 5.4, the PCA results in a slightly different ordering of countries according to the level of their financialized integration. According to the PCA, the EMEs that present the most financialized structures are Brazil and, to a smaller extent, Turkey, Poland, and India. From the min-max index based on the five indicators, the most financialized are South Africa, Turkey, Brazil, Hungary and Poland. The different results stem from the fact that the five indicators of financialization are not grouped in a single component and the two components that are 
related to financialization are not necessarily composed only by financialization-related indicators, which hinders the strict use of these components as proxies of financialization. The analysis done in Chapter Six is thus based on the composite index as a proxy for the type of integration.

\subsection{Conclusions}

The international financial system might be the place where the consequences of financialization were first seen - one of its main changes, the emergence of the eurodollar market, is even considered by Bourguinat (1992) to be the first stage of the current phase of capitalism. With financialization, finance has not only grown in magnitude at the international level, but this growth has been considered a dissociation from its earlier functions and evidence that it now follows its own logic (Chesnais (1997); Plihon and Ponssard (2002)). If international finance follows a different dynamic, the impacts of financial integration on a country are not the same, which requires an understanding of the characteristics of finance and integration: as EMEs' levels of integration vary, so do their types of integration. This chapter's analyses of EMEs' integration has four main contributions.

First, the chapter presents evidence that supports the idea of a decoupling of finance from productive economy's factors and from financial integration, not only among advanced countries, but also among EMEs. This decoupling of finance from its earlier logic is the first of the three phenomena related to financialization presented in Chapter Two. Part of the changes of finance (the second phenomena) are evidence of the decoupling.

The dissociation of finance at the international level from the productive economy is observed in the faster growth of financial integration and FX transactions than that of trade or GDP. Its dissociation from financial integration is observed in the faster growth of FX transactions than that of financial integration. In other words, there have been more FX transactions per patrimonial changes than before. As the transactions are daily and the patrimonial value is taken by the end of the year, a higher number of transactions might be associated with more frequent changes inside the year. 
Seen from Kaldor's (1939) definition of speculation ${ }^{42}$, this more rapid change might be understood as a rise of speculation: investors would hold assets more for their changes in prices (or expected changes) then for the returns paid by the assets, what demands frequently purchasing and selling the asset. As an important part of the return comes from the exchange rate variation, this behavior also involves FX transactions and transactions due to expected changes in the exchange rate. Apart from the exchange rate change, common to each type of instrument, such behavior is expected to be common with equity investment, given its larger price variations.

Most of the growth of FX transactions among emerging currencies is related to derivatives, not spot, contracts. In this case, in addition to evincing higher speculation, the disconnection of FX transactions from financial integration underscores the rise of derivatives carry trading - a phenomenon that was identified in a few emerging currencies in the chapter.

The second main contribution of the chapter is related to the different type of integration of EMEs vis-a-vis of advanced countries. The overall low level of the asset-to-liability ratios of EMEs when reserves are not considered support the view that EMEs have a function in the IFS of suppliers of financial assets. The chapter has also argued that the IFS is marked by an additional asymmetry with regards to emerging and advanced currencies. The demand for advanced countries' assets include purchases from developing countries' public institutions whose behavior is strongly marked by stability and is counter cyclical. The demand of EMEs' assets, on the other hand, stems from international money managers whose behavior (as analyzed throughout the thesis), is marked by speculation of assets around the globe, yielding high volatility and high influence of international conditions in the determination of domestic prices and exchange rates. To further describe this asymmetry, comparing total reserves from developing countries to US and European foreign liabilities and their impact on the respective currencies, would be a compelling avenue for future research.

The third contribution of this chapter is the suggestion of the concept of financialized integration to characterize integration with regards to the presence of financialization features. The index proposed is focused on indicators that measure the extent of the decoupling of integration from the economy's features, from financial integration, and the sophistication

\footnotetext{
${ }^{42}$ Kaldor's (1939) definition of speculation is presented in Chapter Two, page 35.
} 
level of its FX market. This composite index suggests that South Africa, Turkey, Brazil, Hungary and Poland are the EMEs to present the most financialized integration to international markets (Figure 5.16). Adding financialization-related features to the relative magnitude of financial integration, the index presents different results than measures of financial integration - for instance, the latter do not result in a significant level of financial integration for Turkey and Brazil ${ }^{43}$.

The different types of integration were also analyzed through a principal components analysis, that allowed looking at countries' characteristics without first grouping them as emerging or advanced countries. The analyses confirmed that New Zealand and Australia present some 'EMEs' features' while Hong Kong and Singapore are, in some respects, more similar to advanced countries than to EMEs. Although it is interesting to further describe different types of integration, the methodology could not be used for building an index of financialized integration because the five main indicators of interest are not correlated enough to be grouped into a single component, and the components where these indicators loaded the most also group other indicators. However, with these shortcomings in mind, the analysis still reveals the high level of financialization of Brazil, Turkey and Poland - as done by the composite index.

Fourth, the chapter contributes to the carry-trading literature by suggesting ways of identifying currencies used in carry trading operations through the countries' assets-to-liabilities ratio (its overall value or only with regards to debt instruments), its FX-to-trade ratios (combined with the absolute size of FX markets). The first measure is closer to canonical carry trading currencies and the second one underscores currencies used in derivatives carry trading. In the literature this identification is generally based on which currencies are expected to be important given their interest rate levels, or based on their total FX size. An interesting avenue for future research in this area is the comparison of the evolution of assets-to-liabilities ratios with FX market sizes and interest rate differentials.

The analyses indicated the presence of canonical carry trading operations with the currencies of: South Africa and Mexico (according to their FX size relative to GDP or trade), Hungary (according to its FX magnitude relative to GDP), Brazil and India (according to

\footnotetext{
${ }^{43}$ This refers to the size of integration relatively to GDP, presented in Figure 5.8.
} 
the assets-to-liabilities ratio), and Turkey (for the three mentioned measures). This result is similar to what is argued in the literature, that indicate these currencies (all except Mexico) as the most important carry trading currencies among EMEs.

Among advanced countries, the currencies that stand out as important carry trading currencies are those from: Switzerland (for assets-to-liabilities and FX size relatively to GDP), the United Kingdom (for its FX size relative to GDP), the US (for its important FX markets relative to GDP and trade), and New Zealand, Australia, and Japan (for the three measures). These are the six currencies from advanced countries most cited as carry trading currencies. 


\subsection{Appendix I: List of Countries for Figure 5.7}

The list of countries included in the statistics presented in Figure 5.7 is partially based on Lane and Milesi-Ferretti (2007), but adapted to differentiate EMEs according to this thesis analysis.

Industrial countries are: Australia, Austria, Belgium, Canada, Denmark, Finland, France, Germany, Greece, Iceland, Ireland, Italy, Japan, Luxembourg, Netherlands, New Zealand, Norway, Portugal, Spain, Sweden, Switzerland, the United Kingdom, and the United States.

Emerging + are countries for which FX market data is available: Brazil, China, Hungary, India, Korea, Mexico, Poland, South Africa, Turkey, Russia, Honk Kong and Singapore.

Other EMEs are: Argentina, Chile, Colombia, Czech Republic, Indonesia, Malaysia, Peru, the Philippines, Taiwan and Thailand.

Other developing countries are: Albania, Algeria, Angola, Armenia, Azerbaijan, Bahrain, Bangladesh, Belarus, Benin, Bolivia, Bosnia and Herzegovina, Botswana, Brunei Darussalam, Bulgaria, Burkina Faso, Cambodia, Cameroon, Chad, Congo, Dem. Rep. of, Congo, Republic of, Costa Rica, Croatia, Cyprus, Cte d'Ivoire, Dominican Republic, Ecuador, Egypt, El Salvador, Equatorial Guinea, Estonia, Ethiopia, Fiji, Gabon, Georgia, Ghana, Guatemala, Guinea, Haiti, Honduras, Iran, Islamic Republic of, Israel, Jamaica, Jordan, Kazakhstan, Kenya, Korea, Kuwait, Kyrgyz Republic, Lao People's Dem.Rep, Latvia, Lebanon, Libya, Lithuania, Macedonia, Madagascar, Malawi, Malaysia, Mali, Malta, Mauritius, Moldova, Morocco, Mozambique, Myanmar, Namibia, Nepal, Nicaragua, Niger, Nigeria, Oman, Pakistan, Panama, Papua New Guinea, Paraguay, Qatar, Romania, Rwanda, Saudi Arabia, Senegal, Serbia, Slovak Republic, Slovenia, Sri Lanka, Sudan, Swaziland, Syrian Arab Republic, Taiwan, Tajikistan, Tanzania, Thailand, Togo, Trinidad and Tobago, Tunisia, Turkmenistan, Uganda, Ukraine, United Arab Emirates, Uruguay, Uzbekistan, Venezuela, Rep. Bol., Vietnam, Yemen, Republic of, Zambia, and Zimbabwe. 


\subsection{Appendix II: Additional Statistics and Figures}

TABle 5.5 Total FX Markets, Advanced Economies. US\$ Millions.

\begin{tabular}{lccccc} 
& \multicolumn{4}{c}{2001} & \multicolumn{2}{c}{2013} \\
Currency & Absolute & Share & Absolute & Share & Growth \\
\hline Total & $2,165,490$ & $100.0 \%$ & $8,897,019$ & $100.0 \%$ & $422.1 \%$ \\
\hline AUD & 49,654 & $2.3 \%$ & 428,218 & $4.8 \%$ & $762.4 \%$ \\
CAD & 52,275 & $2.4 \%$ & 230,296 & $2.6 \%$ & $340.5 \%$ \\
CHF & 71,053 & $3.3 \%$ & 260,459 & $2.9 \%$ & $266.6 \%$ \\
DKK & 14,589 & $0.7 \%$ & 41,574 & $0.5 \%$ & $185.0 \%$ \\
EUR & 441,545 & $20.4 \%$ & $1,697,554$ & $19.1 \%$ & $284.5 \%$ \\
GBP & 155,310 & $7.2 \%$ & 597,506 & $6.7 \%$ & $284.7 \%$ \\
JPY & 266,050 & $12.3 \%$ & $1,066,903$ & $12.0 \%$ & $301.0 \%$ \\
NOK & 17,701 & $0.8 \%$ & 74,404 & $0.8 \%$ & $320.3 \%$ \\
NZD & 6,725 & $0.3 \%$ & 100,052 & $1.1 \%$ & $1,387.8 \%$ \\
SEK & 30,147 & $1.4 \%$ & 91,550 & $1.0 \%$ & $203.7 \%$ \\
USD & $1,060,441$ & $49.0 \%$ & $4,308,503$ & $48.4 \%$ & $306.3 \%$
\end{tabular}

TABLE 5.6 Total FX Markets, EMEs. US\$ Millions.

\begin{tabular}{lccccc} 
& \multicolumn{4}{c}{2001} & \multicolumn{2}{c}{2013} \\
Currency & Absolute & Share & Absolute & Share & Growth \\
\hline Total & 94,012 & $100.0 \%$ & 816,456 & $100.0 \%$ & $10,912.9 \%$ \\
\hline BRL & 5,238 & $5.6 \%$ & 45,893 & $5.6 \%$ & $776.1 \%$ \\
CNY & 94 & $0.1 \%$ & 101,976 & $12.5 \%$ & $108,385.1 \%$ \\
HKD & 27,381 & $29.1 \%$ & 75,723 & $9.3 \%$ & $176.6 \%$ \\
HUF & 196 & $0.2 \%$ & 21,125 & $2.6 \%$ & $10,678.3 \%$ \\
INR & 2,841 & $3.0 \%$ & 49,702 & $6.1 \%$ & $1,649.5 \%$ \\
KRW & 9,756 & $10.4 \%$ & 59,245 & $7.3 \%$ & $507.3 \%$ \\
MXN & 10,086 & $10.7 \%$ & 128,444 & $15.7 \%$ & $1,173.5 \%$ \\
PLN & 6,324 & $6.7 \%$ & 36,004 & $4.4 \%$ & $469.3 \%$ \\
RUB & 4,282 & $4.6 \%$ & 82,187 & $10.1 \%$ & $1,819.4 \%$ \\
SGD & 12,886 & $13.7 \%$ & 71,107 & $8.7 \%$ & $451.8 \%$ \\
TRY & 434 & $0.5 \%$ & 64,435 & $7.9 \%$ & $14,746.8 \%$ \\
TWD & 3,168 & $3.4 \%$ & 22,990 & $2.8 \%$ & $625.7 \%$ \\
ZAR & 11,326 & $12.0 \%$ & 57,624 & $7.1 \%$ & $408.8 \%$
\end{tabular}


TABle 5.7 Country Scores on the Four Principal Components

\begin{tabular}{lcccc} 
& PC 1 & PC 2 & PC 3 & PC 4 \\
\hline Brazil & -2.15 & -1.13 & 0.73 & 0.59 \\
China & -1.38 & -0.70 & 1.14 & -0.25 \\
Hungary & -1.44 & -0.45 & -0.24 & 0.04 \\
India & -2.39 & -1.73 & 0.25 & 0.08 \\
Korea & -1.62 & -0.75 & 0.64 & -0.77 \\
Mexico & -1.59 & -1.23 & -0.23 & -0.47 \\
Russia & -1.21 & -0.59 & 0.68 & -1.14 \\
South Africa & -1.01 & 0.03 & -0.48 & -0.38 \\
Turkey & -2.39 & -1.39 & 0.05 & 0.75 \\
Poland & -2.29 & -1.42 & 0.00 & 0.37 \\
Hong Kong & 0.59 & 3.16 & 1.11 & 1.28 \\
Singapore & 0.20 & 2.96 & 0.18 & 1.19 \\
\hline Australia & 0.22 & -0.64 & -1.97 & -0.34 \\
Canada & -0.37 & -0.01 & -0.18 & -0.58 \\
Denmark & -1.00 & 1.39 & 1.00 & 0.60 \\
Euro Area & 3.18 & -1.98 & 1.64 & 0.17 \\
Japan & 3.19 & 1.39 & 0.31 & -3.88 \\
New Zealand & 0.26 & 0.55 & -4.65 & 0.55 \\
Norway & 0.29 & 2.69 & -0.46 & 0.03 \\
Sweden & -0.46 & 0.79 & -0.01 & 0.04 \\
Switzerland & 1.19 & 1.94 & -0.06 & -0.35 \\
United Kingdom & 3.64 & 0.61 & 1.13 & 1.56 \\
United States & 6.53 & -3.48 & -0.57 & 0.92 \\
\hline Avg EM & -1.39 & -0.27 & 0.32 & 0.11 \\
Avg Adv & 1.52 & 0.30 & -0.35 & -0.12 \\
& & & &
\end{tabular}


Figure 5.19: Loadings on PC1 and PC3: Advanced and EMEs

(a)

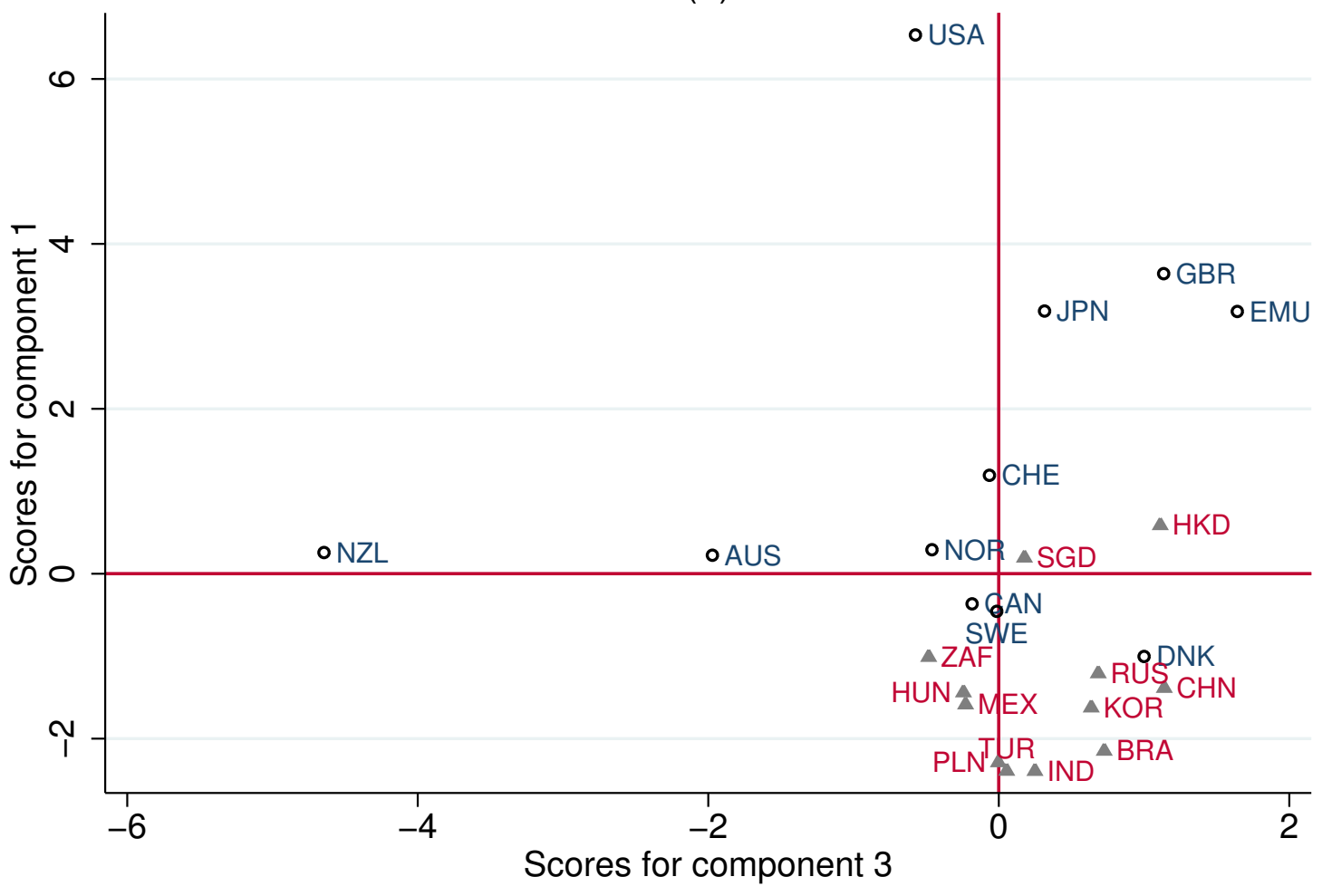


Figure 5.20: Loadings on PC2 and PC3: Advanced and EMEs

(b)

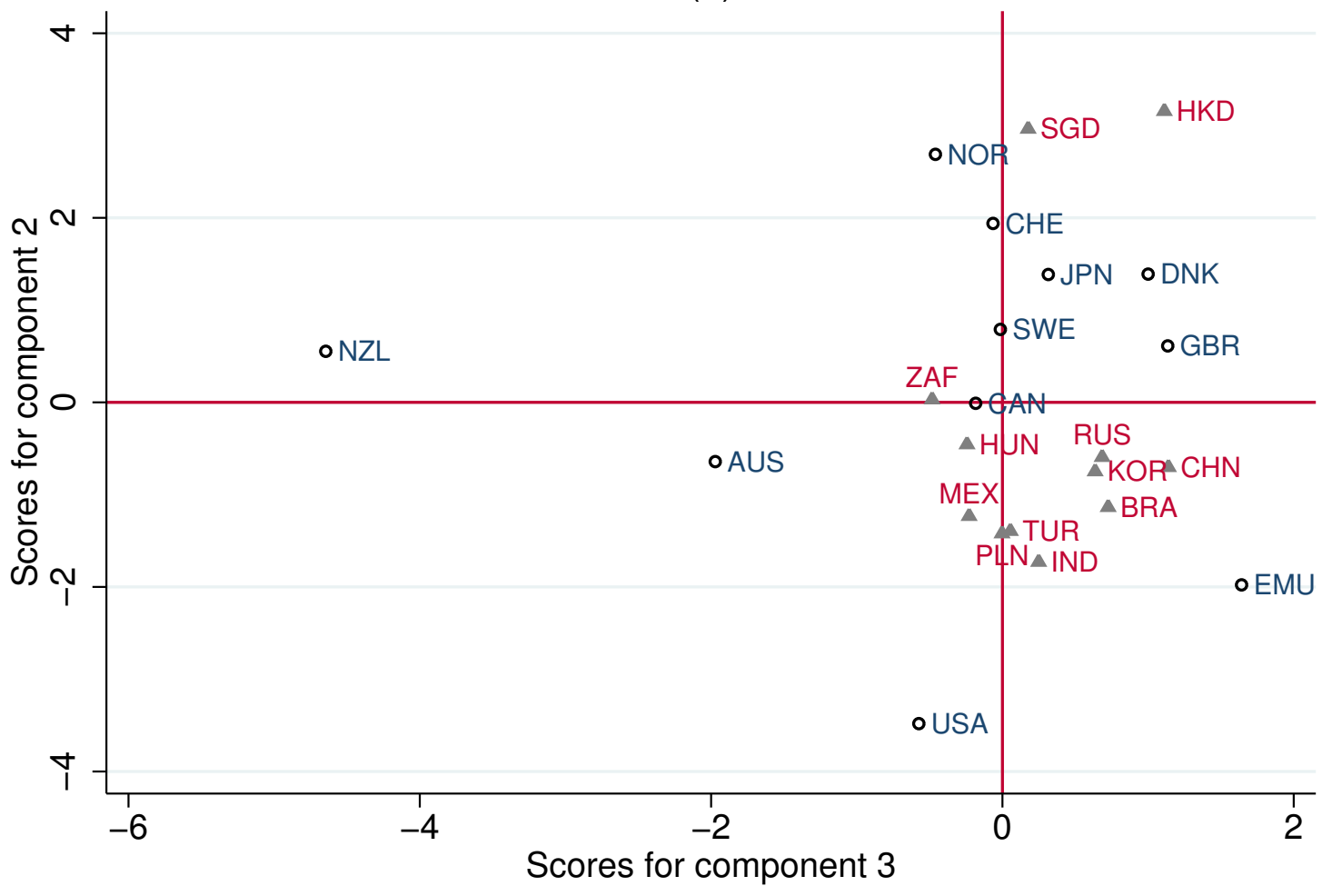


Figure 5.21: Loadings on PC2 and PC4: Advanced and EMEs

(c)

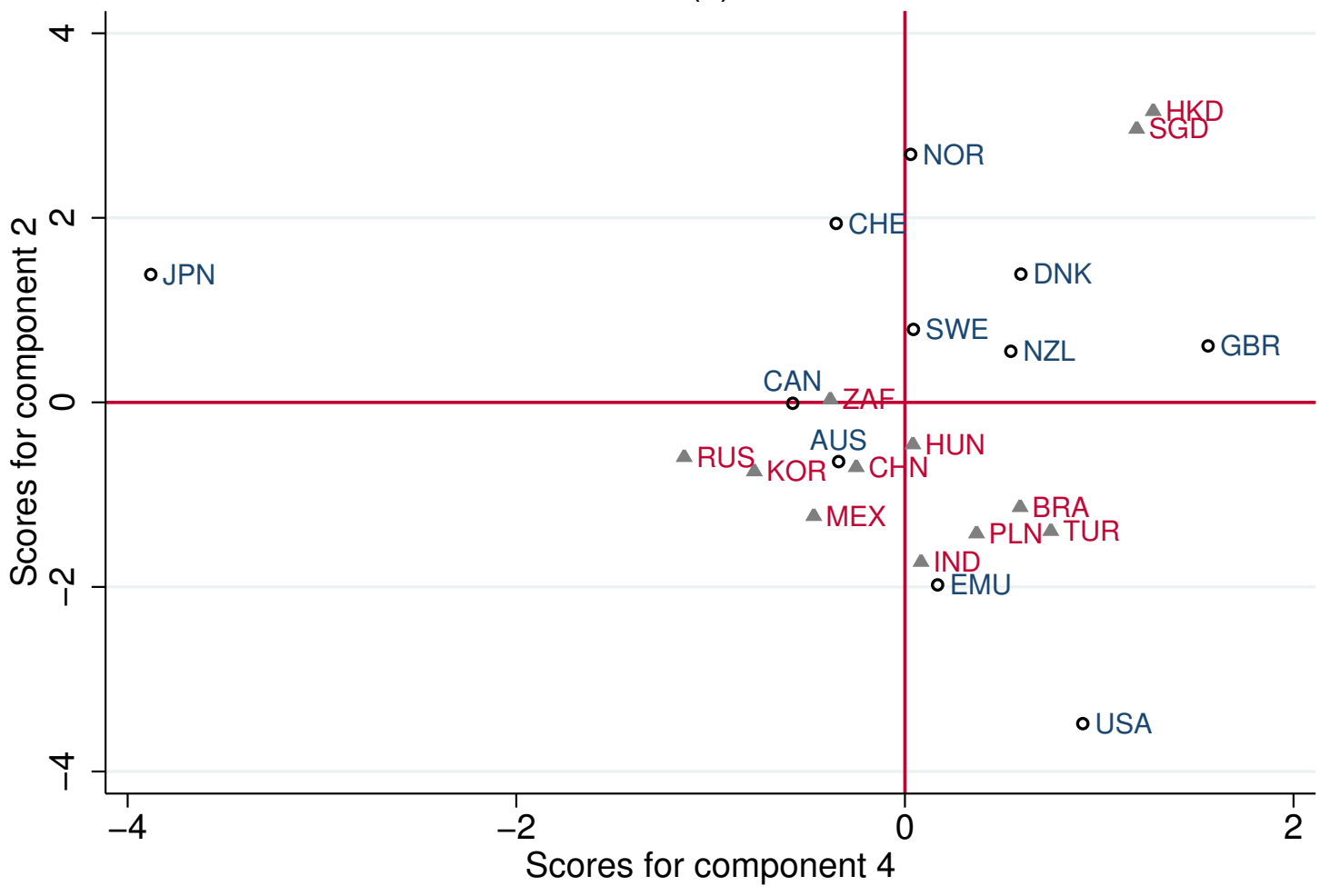


Figure 5.22: Loadings on PC3 and PC4: Advanced and EMEs

(d)

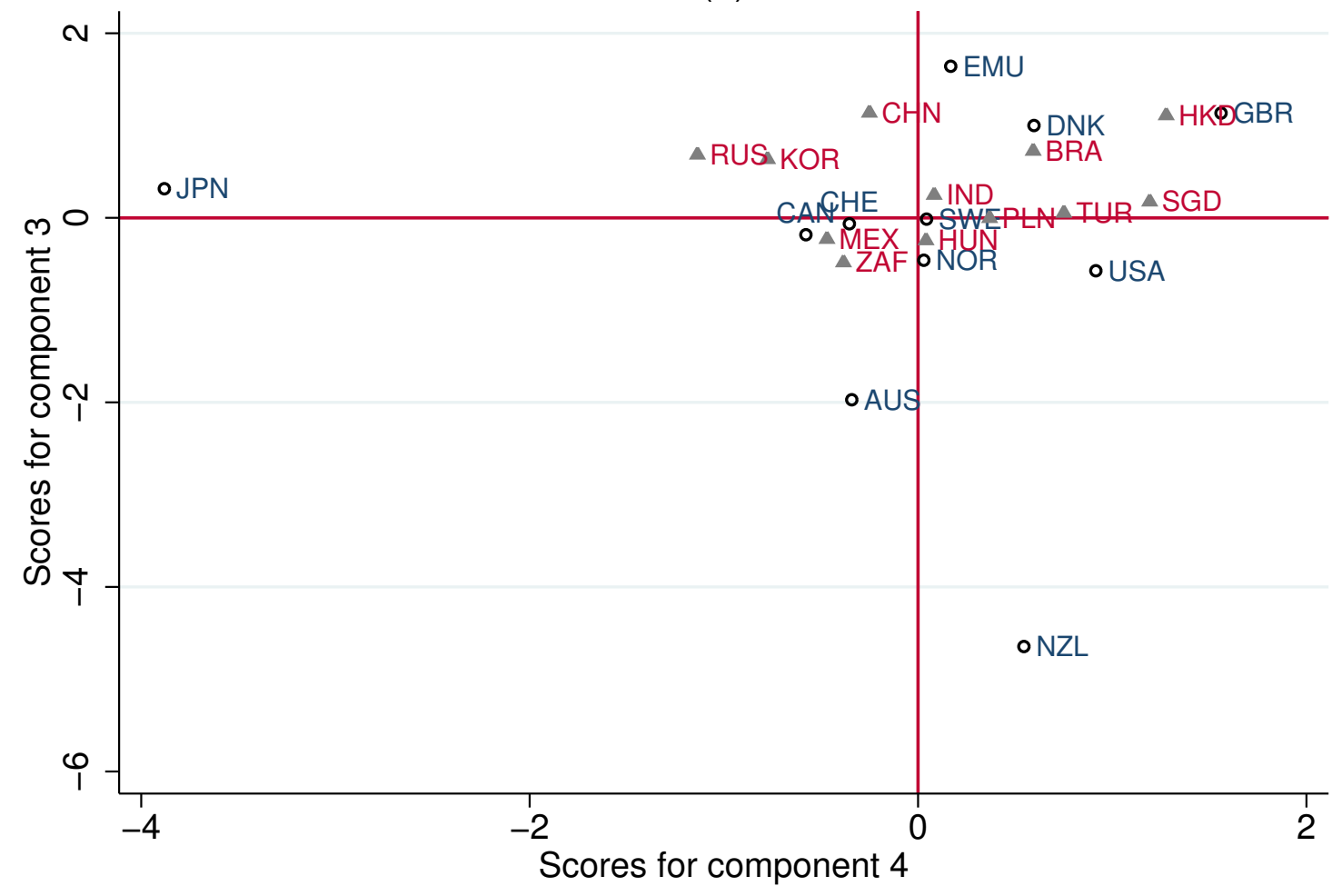


Figure 5.23: Loadings on PC1 and PC3: EMEs

(a)

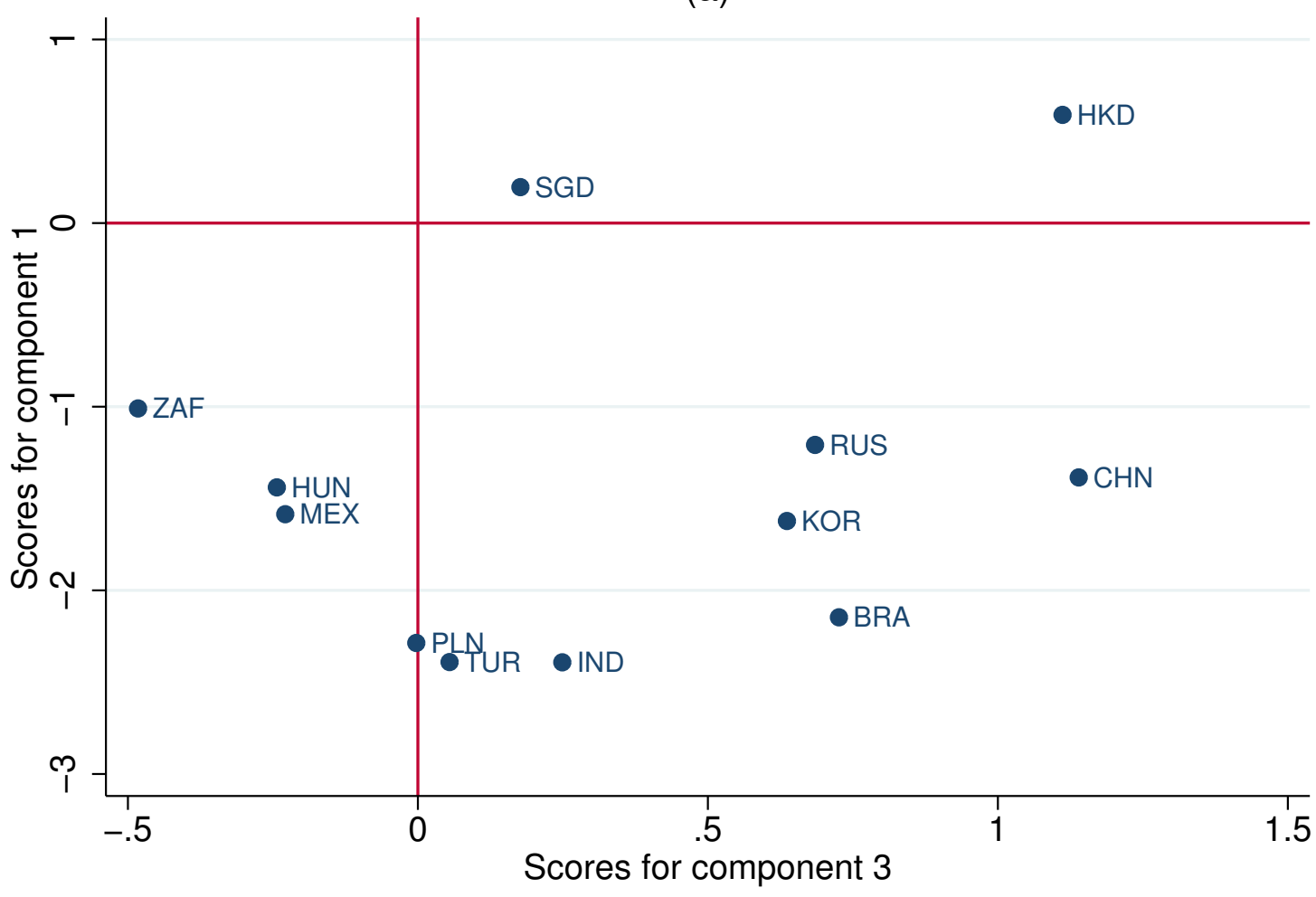


Figure 5.24: Loadings on PC2 and PC3: EMEs

(b)

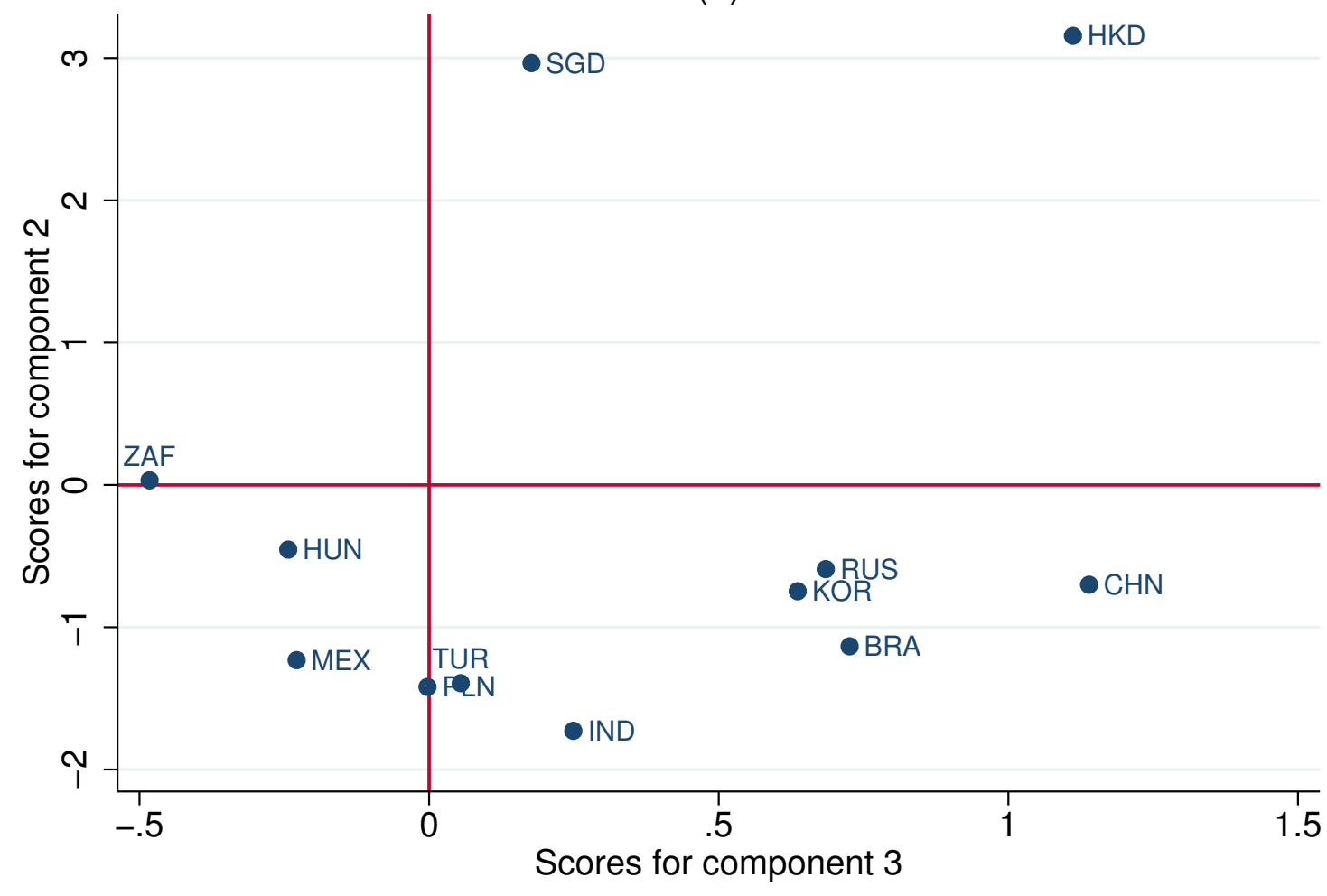


Figure 5.25: Loadings on PC2 and PC4: EMEs

(c)

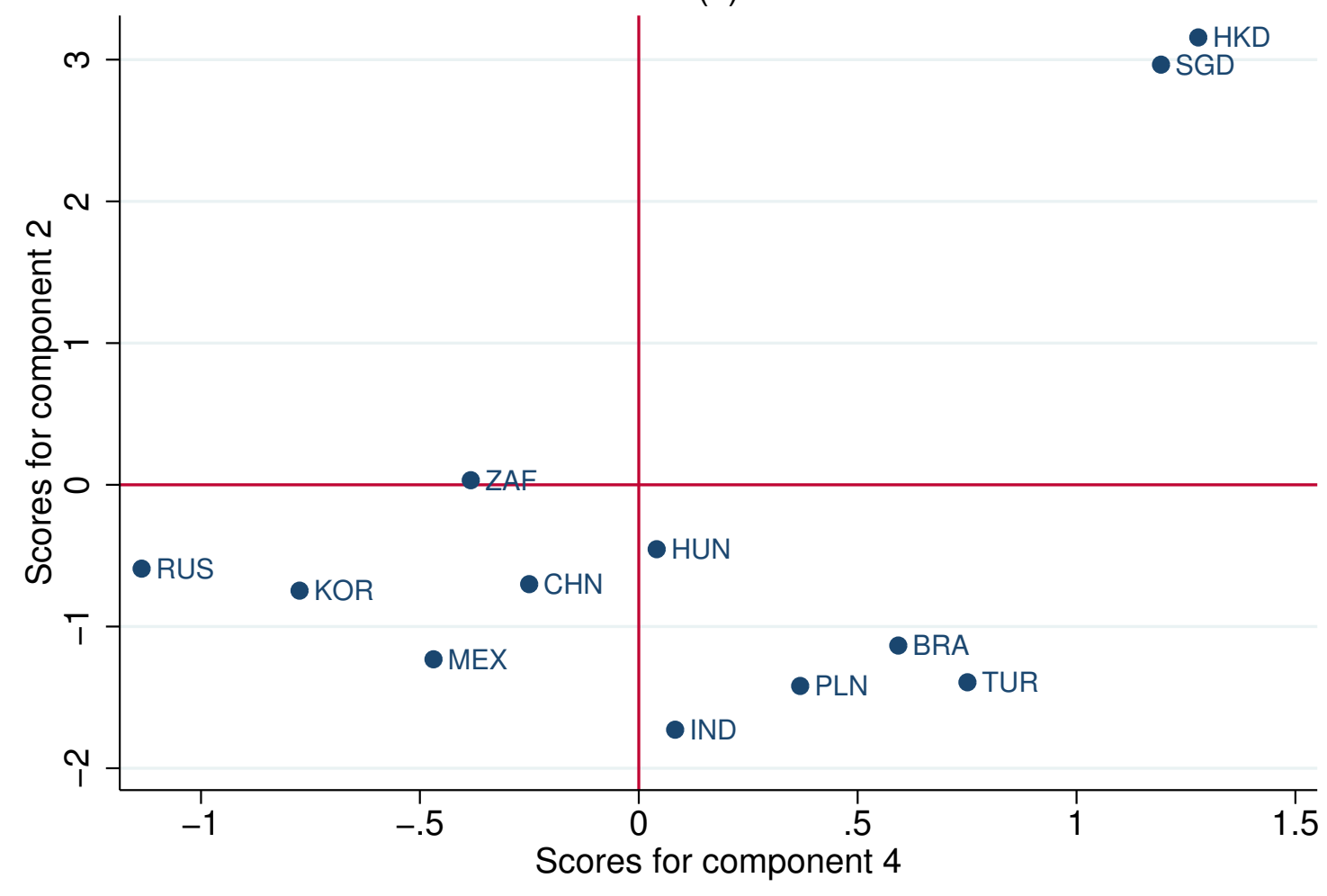


Figure 5.26: Loadings on PC3 and PC4: EMEs

(d)

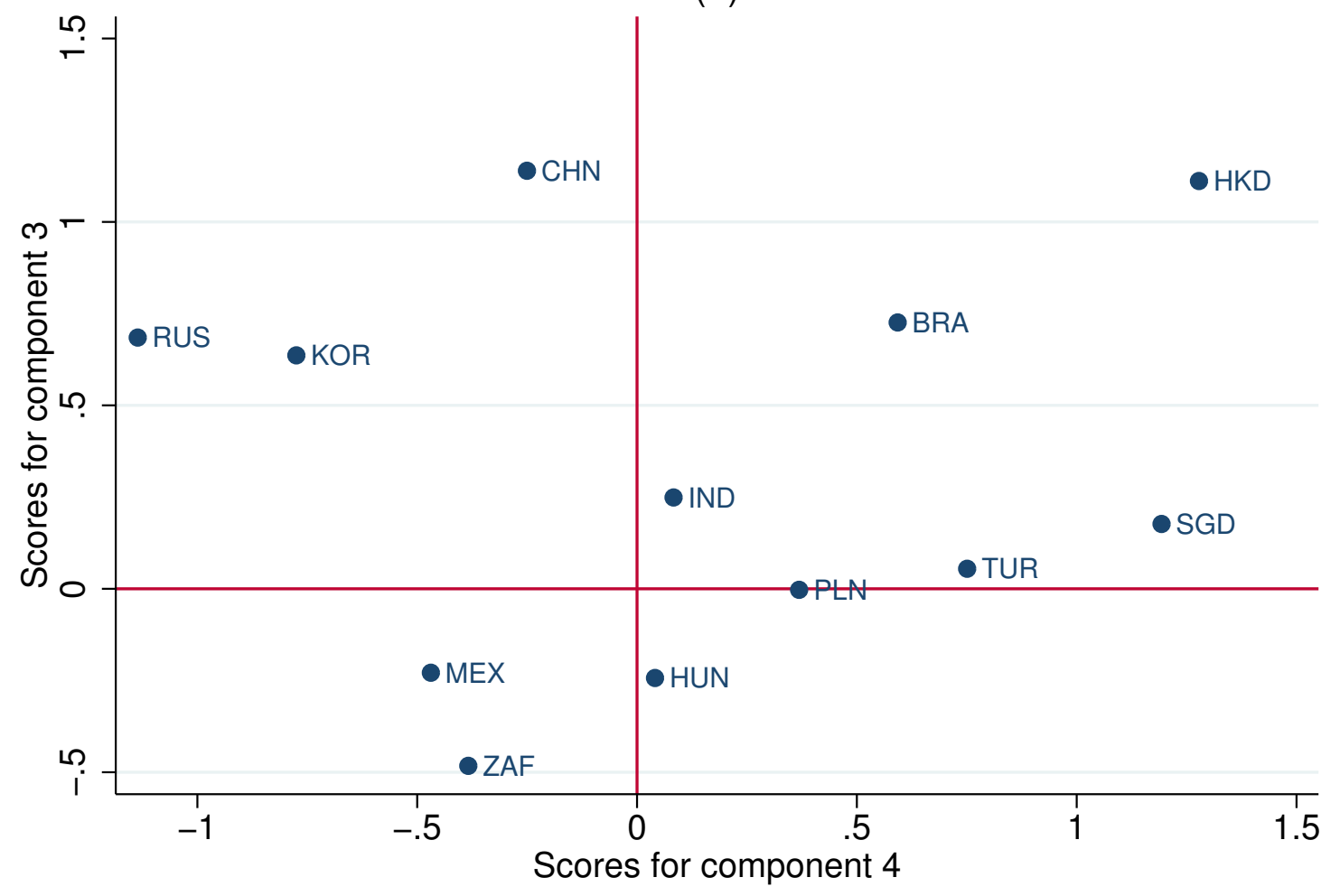




\section{Chapter 6}

\section{Emerging Countries' Exchange}

\section{Rate Dynamics in Times of}

\section{Financialization}

As mentioned in the Introduction Chapter, after having opted for floating exchange rate regimes in the aftermath of the late-1990s currency crises, some emerging market economies (EMEs) have been intervening in their foreign exchange (FX) markets with the aim of reducing the exchange rate volatility. The pattern of EMEs' exchange rates (emerging currencies) and their association with the international financial scenarios are discussed in the Introduction Chapter. The path of the 20 emerging currencies since the year 2000 is replicated in Figure 6.1 for simplicity.

In light of the discussions in Chapters Two and Three, exchange rate volatility is a potential consequence of a specific type of integration, alongside the higher vulnerability to the international sphere and correlation with other emerging currencies - these features that characterize fragility would emerge from a type of integration to international financial markets that is more marked by characteristics such as the high importance of financial flows and sophisticated FX markets ${ }^{1}$ - two features that are increasingly present in times

\footnotetext{
${ }^{1}$ Sophisticated FX markets are proxied, in the empirical chapters of this thesis, by the amount of derivatives markets and their relative weight.
} 

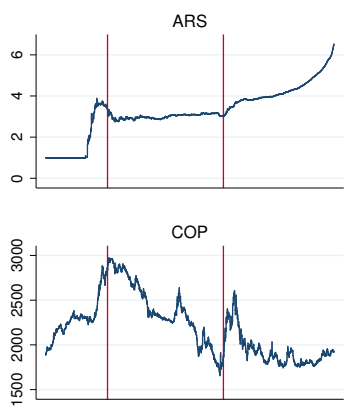

INR
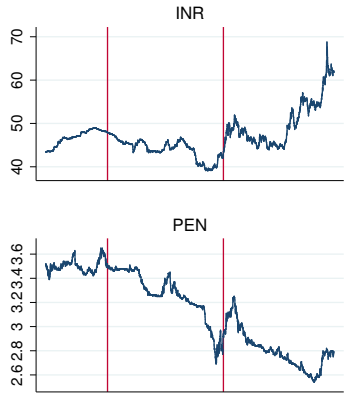

THB

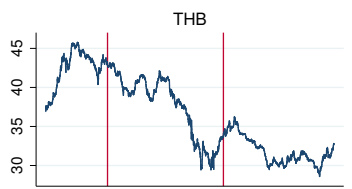

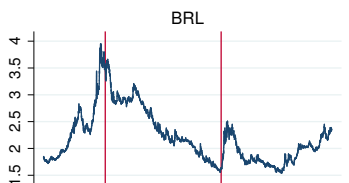

CZK

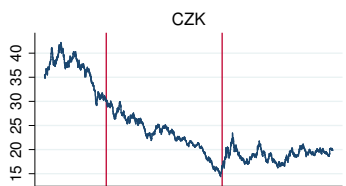

KRW
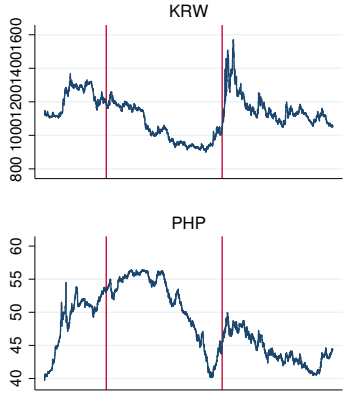

TRY

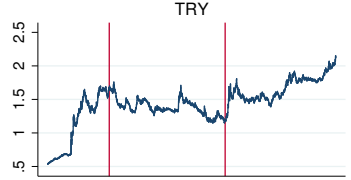

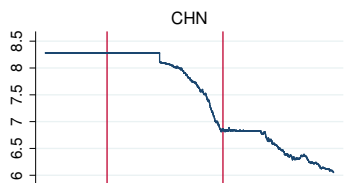

HUF

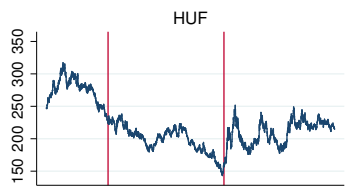

MYR

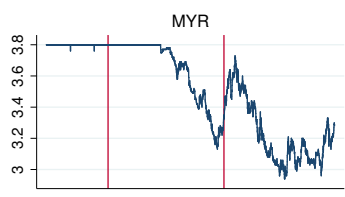

PLN

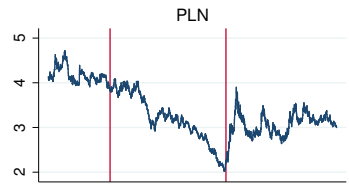

TWD

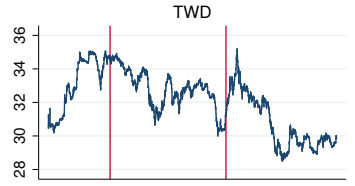

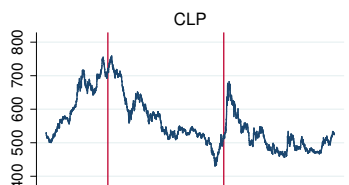

IDR

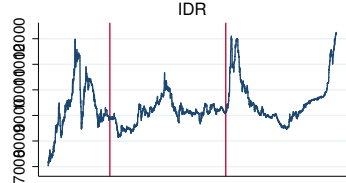

MXP
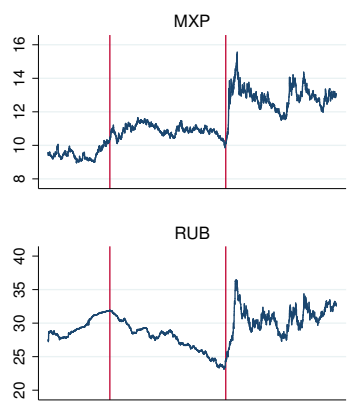

ZAR

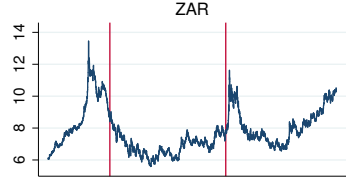

Data source: Ecowin, daily values. The vertical lines are references to two important dates: the new phase of the cycle of capital towards developing countries, January 1st, 2003, and the collapse of the Lehman Brothers, in September 15th, 2008.

of financialization and that indicate a country's integration to money managers' balancesheets and the weight of speculation (as discussed in Chapter Two). This type of integration was defined in Chapter Five as "financialized integration", and proxied by the following five indicators: the total stock of assets and liabilities in relation i) to GDP and ii) to trade (sum of exports and imports), the total exchange rate markets relative iii) to GDP and iv) to trade, and v) the weigh of derivatives FX contracts on total contracts.

This chapter discusses currency features that characterize fragility and whether they can be associated with a different type of financial integration. In other words, it suggests a possible exchange rate determination in times of financialization that leads to specific exchange rate determination in EMEs. In addition to the financialization and the exchangerate literatures presented in Chapters Two and Three, this hypothesis also dialogues with 
two important literatures: the one on the consequences of capital account liberalization or financial integration, and the push vs. pull debate on the determinants of capital flows.

The analysis in this chapter suggests an impact from exchange rates to growth prospects, through transmission channels that are not considered in the financial integration literature. While this chapter's analysis is based on a type of financial integration, in the literature the impacts of integration are based on its size or magnitude. The different de facto measures of integration used in the literature include the absolute or relative importance of either capital flows or of the stock of foreign assets and liabilities - the latter being sounder for this thesis' purposes, as discussed in Chapter Five. Among relative measures, the indicator of financial integration relative to trade might be the most interesting for emphasizing the two sources of FX transactions. Throughout the chapter exchange rate features are analyzed not only against the indicator of financialized integration (focused on the characteristics of the integration), but also against the indicator of financial-to-trade integration (that focus on the magnitude). The relationship between the two can be seen in see Figure 6.27 in the Appendix.

With regards to the push vs. pull literature, by analyzing exchange rate features the chapter suggests the relevance of the international condition, a push factor. The impact is analyzed directly on exchange rates, while the literature focuses on consequences on capital flows and do not necessarily link it to exchange rate dynamics. Sections 6.1 and 6.3 will present the parallel literature on the consequences of financial integration and the role of push and pull factors, respectively, to further explain this chapter's findings.

The structure of the chapter The remainder of the chapter is divided as follows. Section 6.1 presents the literature on the impacts of integration to international financial markets. The three following sections are dedicated to the potential features of emerging currencies and their relationships with the type of integration. Section 6.2 examines exchange rate volatility (from the aspects of deviation and of extreme change). Section 6.3 is focused on the association between emerging currencies and international liquidity conditions. Section 6.4 discusses the comovement of emerging currencies. Section 6.5 discusses other elements that could potentially explain emerging currencies' patterns. Section 6.6 presents concluding remarks and avenues for future research. 


\section{Methodological Note}

Most of the empirical analyses done in this chapter involve the indicator of the level of financialization of country's integration, as presented in Chapter Five. The type of integration is estimated using 2013 data. It is one point that is expected to be representative given the structural character of the variable - specially for its dependency on stock variables. A more frequent estimation of this variable is not possible, because it is dependent on data released every three years (the triennial surveys of the Bank for International Settlements, BIS). Earlier points could be biased by the GFC: financial integration relative to GDP increased substantially before the crisis, dropped in 2008, and increased again in what followed; but apart from that, it has grown in stable fashion - see Figure 5.7. Using data from previous years would also lead to a different stage of EMEs' financial insertion, because, as seen in Chapter Four, EMEs' integration in 2001 was very different than the current one.

The limited amount of observations surely restricts the possible methodological approaches. The use of graphical analyses to suggest the potential correlation between two variables is deemed the most appropriate method. To enrich the analyses, the Pearson correlation coefficient - and coefficients of determination ${ }^{2}$. were used to quantify the potential correlation. The Pearson correlation coefficient is a measure of linear correlation between two variables developed in the late 19th century. It is estimated (for samples) by the formula in Equation 6.1 (STATA, 2016) $)^{3}$.

$$
r=\frac{\sum_{i=1}^{n}\left(x_{i}-\bar{x}\right)\left(y_{i}-\bar{y}\right)}{\sqrt{\sum_{i=1}^{n}\left(x_{i}-\bar{x}\right)^{2}} \sqrt{\sum_{i=1}^{n}\left(y_{i}-\bar{y}\right)^{2}}}
$$

The Pearson correlation coefficient is therefore based on the relationship between two series' observations distance to their mean, pointing to the relationship between the two series. A coefficient of -1 indicates a perfectly negative linear relationship, 1 indicates a positive relationship, and 0 indicates no correlation between variables.

\footnotetext{
${ }^{2}$ Coefficients of determination are the square of the correlation coefficient between two variables. It gives the proportion of the variation in one variable that is accounted for by the other (Everitt and Skrondal, 1998, p. 89). See Everitt and Skrondal (1998) for references and details.

${ }^{3}$ Stata allows the option of adding weights to variables, which was not done in this chapter.
} 
The resulting correlation coefficients are analyzed together with the respective scatter plots given the potential weight of outliers in the coefficients. Another concern with potential bias emerges from the small number of observations. Aiming to avoid them, the respective significance of the coefficients' level were added.

It might be worth recalling the similarities between the correlation coefficient and a regression. In the case of a simple linear regression analysis, its coefficient of determination $\left(r^{2}\right)$ is the same as the square of the correlation coefficient (Everitt and Skrondal, 1998, p. $89)^{4}$. Another similarity between these two methods is that they do not imply causality. In regressions, tests for causalities as the Granger causality test might be run $^{5}$ (Granger, 1969). The direction of causality of the analyses conducted in this chapter are however clear from the theoretical discussion, dismissing causality tests.

All the estimations were done in Stata (11).

On the analyzed countries This chapter follows the "financial-markets-oriented" operational definition of EMEs discussed in Chapter Four (Section 4.1.1). EMEs are: Argentina, Brazil, Chile, China, Colombia, Czech Republic, Hungary, India, Indonesia, Korea, Malaysia, Mexico, Peru, Philippines, Poland, Russia, South Africa, Taiwan, Thailand, and Turkey. Please refer to the "List of Abbreviations" of countries and currencies in the Thesis' preamble.

Whether a country has a floating or a non-floating regime was defined based on IMF's de facto characterization of these countries' exchange rate arrangements from 2003 to 2013 , presented in table 6.12 in the Appendix. Also note the discussion immediately preceding the table, that served as a basis to consider the following countries as having a floating exchange rate regime: Brazil, Chile, Colombia, Czech Republic, India, Indonesia, Korea, Mexico, Peru, Philippines, Poland, South Africa, Russia, Taiwan, Thailand, and Turkey. The ones with non-floating regimes are: Argentina, China, and Malaysia.

\footnotetext{
${ }^{4}$ In the analyses done in this chapter the best fit for two variables was most often of a linear regression with no intercepts. Simple linear regressions and regressions with a dummy variable for the exchange rate regime were run and in most cases the adjusted $r^{2}$ were better for regressions without the intercept and the intercepts were not significative at the $10 \%$ level.

${ }^{5}$ Such analyses would however probably be hindered in the analyses given the low amount of observations in this chapter's study (and thus of degrees of freedom).
} 
Therefore, from the analyzed 20 emerging currencies, 17 have floating exchange-rate regimes and three have non-floating regimes. The index of financialized integration is estimated for the nine emerging currencies analyzed in BIS Triennial Surveys (in 2001 and 2013): Brazil, China, Hungary, India, Korea, Mexico, Poland, Russia, Taiwan, Turkey and South Africa. Given that no trade data is available for Taiwan, the financial-to-trade integration index is estimated for 19 EMEs. Other indicators are estimated for all 20 emerging currencies. To facilitate the differentiation of the currencies under study, the number of countries involved in each case is presented in the tables that compare correlation coefficients of different country groups.

\subsection{The Expected Impacts of Integration}

Whether or not a country should open its capital account is an important question in economic literature. As liberalization becomes the rule across developing countries, the question has moved from the impacts of liberalization to the impact of a de facto integration - in empirical studies, the substitution from the de jure liberalization proxy to the de facto proxy of integration is an indication of this shift, as discussed in Chapter Five. The literature is briefly reviewed in this section, to shed light on how it relates to the debate presented in the chapter.

The main arguments for capital account liberalization and integration focus on the possible economic growth from the flow of capital, from abundance to scarcity. Liberalization would boost investments by making cheaper loans available to residents and reducing risks for investors by diversifying assets in different countries and markets. According to this argument, it is noteworthy to mention that opening the capital account would benefit not only the specific country, but the global economy in general ${ }^{6}$. The efficiency of domestic financial markets would be enhanced due to exposure to competing foreign firms; and technologies, institutions, and property rights would improve with a country's exposure to global financial markets and by the 'macroeconomic discipline' it imposes (which from another perspective,

\footnotetext{
${ }^{6}$ Although this review is only a short overview, it is interesting to highlight that the theoretical background behind arguing for capital account liberalization are in line with Solow's (1956) growth model, where capital is one of the main factors leading to growth (together with labor and productivity) and the loanable funds theory, which states that savings determine investments (Da Silva and Da Fonseca, 2015).
} 
might be seen as a loss of policy autonomy). Furthermore, liberalization of the capital account would allow for consumption smoothing over time, which would be particularly valuable if borrowed capital were used to improve a country's ability to produce goods and services (see Fischer (1997), Kose et al. (2006), Levine and Zervos (1996), Mishkin (2006), and Neely $(1999))^{7}$.

The arguments against financial integration are mainly focused on the instability brought by capital flows, which are a consequence of the procyclicality of financial markets in general (Borio, 2014) and of portfolio flows specifically, that results in an intensification of boom and bust cycles (Edwards, 2001) - a reason being that inflows lead to credit booms (Blanchard et al., 2015) and to financial crisis as illustrated by developing countries across the globe since the late 1990s. Due to their cyclicality and volatility, capital flows could also be detrimental to investment (Moguillansky, 2002) $)^{8}$.

Mishkin (2006) and Kose et al. (2006) would respond to counter-arguments based on the manifest crises, stating that crises emphasize the costs of liberalization, but, in reality, are just a reflection of the fact that costs are concentrated and immediate, while gains are dispersed and gradually presented.

But the prevalent argument is that such crises occur in developing countries due to problems in their financial systems. Several authors point to the early stage of development of financial markets (see Bekaert et al. (2005), Edwards (2001), and Eichengreen (2001)). The IMF (2001) posits that the net results of liberalization depend on the strength of domestic macroeconomic policies and financial structures. Also Eichengreen and Leblang (2003, p. 23-24) argue that the result from capital account liberalization depends on the robustness of the domestic financial system - and on whether the international financial system is "prone to costly and disruptive crises".

Obstfeld (2009, italics added) also argues that the stage of development of countries' financial markets matters, specifically in increasing exchange rate volatility:

\footnotetext{
${ }^{7}$ See Kregel (1996) for criticism on an "utopian" view of the benefits of globalization, including financial globalization.

${ }^{8}$ Moguillansky (2002, p. 57) argues that this would take place due to "the microeconomic effect transmitted by the reduced external borrowing capacity of large companies, the flight to quality in the domestic financial system (which results in a credit crunch for small and medium-sized enterprises), and the increase in uncertainty for economic agents".
} 
In addition, whereas fixed exchange rates have proved dangerous in a context of open capital markets, a regime of freely floating rates raises problems of exchangerate volatility that are particularly severe for emerging economies pending further evolution in their financial markets. (p. 2)

In a way, these arguments persist since the debate on the sequencing of liberalization (domestic financial liberalization first, followed by opening the current account, and only later the capital account ${ }^{9}$ ). The debate occurred when the reality of financial markets in developing countries was completely different. The current evidence of high exchange rate volatility in countries that have developed financial systems and FX markets make it more difficult to defend such positions ${ }^{10}$.

However, it is important to note that the mainstream position on the subject might be evolving since the GFC, as marked by IMF's new position on capital controls presented in Chapter Seven (see Blanchard et al. (2012); Claessens et al. (2010); Ostry et al. (2010); and Ostry et al. $\left.(2011)^{11}\right)$.

Empirical findings The empirical results on the overall impact of capital account liberalization portray mixed findings ${ }^{12}$. Some authors found a positive relationship between capital account liberalization and growth (Quinn (1997); IMF (2001)), and others found no robust correlation (Grilli and Milesi-Ferretti (1995); Rodrik (1998)) $)^{13}$.

After a great amount of empirical tests, meta-analyses emerged based on those findings. The elusiveness of the debated is confirmed by Jeanne et al.'s (2012) meta-analysis. Based

\footnotetext{
${ }^{9}$ According to the debate on the importance of the gradual liberalization intensified with the Mexican and Asian crises of the 1990s, after having been left aside by the optimistic views of the late 1980s and early 1990s.

${ }^{10}$ Note that there is also a debate on the different impacts of the different types of flows, consistent with the idea that not every type of capital has the same implications, nor the same patterns (discussed in Chapter Four, Section 4.3). See Reisen and Soto (2001), who depicts a rather benign picture of capital flows. In general, FDI is seen as the type of inflow that would be the most beneficial for growth. For instance, OECD (2002) argues that given appropriate host-country policies and a basic level of development, FDI facilitates the transfer of technological advances and know-how; it increases competition; human capital improves; it integrates the economy towards the world economy; and it pushes for more positive development of firms. See Margeirsson (2015) for references.

${ }^{11}$ See Fritz and Prates (2014) for a critique on IMF's new approach to capital account openness and Roy and Ramos (2012) that demonstrates the lack of consideration of this new position in the policy recommended to developing countries.

${ }^{12}$ For the debate on the Brazilian case see Arida (2003a), Arida (2003b), Arida (2004), Ferrari Filho et al. (2005) and Oreiro (2004).

${ }^{13}$ In addition to the studies that analyze different countries, also note Henry (2006) analysis based on event studies.
} 
on 2,340 regressions, their results suggest positive findings regarding FDI and equity flows vis-a-vis banking or debt flows, and among advanced countries, but due to the sensitivity of the samples used, the evidence is not conclusive. However, the authors' overall conclusion is clear:

the international community should not seek to promote totally free trade in assets even over the long run because free capital mobility seems to have little benefit in terms of long run growth and because there is a good case to be made for prudential and non-distortive capital controls. (p. 5)

In fact, it is hard to find positive outcomes from capital account openness. As put by Rey (2015): "As attested by the most recent surveys reviewing a long list of empirical papers, it is hard to find robust evidence of an impact of financial openness on growth or on improved risk sharing" (also see Eichengreen (2001); Kose et al. (2006); and Obstfeld (2009)). Nevertheless, most conclusions are not as direct as Jeanne et al.'s (2012). Eichengreen and Leblang (2003) affirm that "results suggest that capital account liberalization is neither plague nor panacea". Rey (2015, p. 20) states that "One thing is clear at this stage: we cannot take them [the gains to international capital flows] for granted". While Obstfeld (2009, p. 1, italics added) puts that: "Despite an abundance of cross-section, panel, and event studies, there is strikingly little convincing documentation of direct positive impacts of financial opening on the economic welfare levels or growth rates of developing countries" ${ }^{14}$.

Rey (2015) reminds her reader that the benefits of capital account liberalization should not be taken for granted and Obstfeld $(2009$, p. 1) finds the absence of positive results striking. These positions seem to reflect the fact that mainstream scholars expect, beforehand, that capital account liberalization could only be positive, given that it is a direct application of Solow's and the loanable funds' theory.

\footnotetext{
${ }^{14}$ An important exception among this large skepticism found in the literature is Kose et al. (2006, p. 2), who argues that: "A central conclusion of this paper is that while the rapidly-growing empirical literature is gradually tilting towards supporting a significant positive role for financial globalization, there are many unanswered questions about how a country should organize and pace its move. At the same time, we find there is very little meaningful empirical support to underpin the more polemic claims of those who argue that capital account liberalizations (as opposed to, say, inappropriately rigid exchange rate regimes) are the root problem behind most developing country financial crises of the past fifteen years."
} 
Integration and Exchange Rate Volatility Though abundant, this literature is mostly focused on the expected final results from liberalization/integration, neglecting the transmission channels through which these results would be achieved. In regards to exchange rates, their only potential impact are with respect to crises of pegged regimes. However the issue of instability brought by financial integration do not only come from financial crisis, or from crisis related to fixed-exchange rate pegs, but also from its impacts on floating exchange rates, that might be deleterious for growth.

As mentioned in the Introduction Chapter, "excessive" exchange rate appreciation is negative for growth and so is exchange rate volatility. And as discussed in Chapter Three (Section 3.3.4), the integration to international financial markets, and the exposure to money managers' behavior might be resulting in exchange rates that follow the cycles of international financial markets, with major volatility in moments of turbulence and appreciation in periods of tranquility. Financial integration can therefore be negative for growth through its effect on the level and the on volatility of the exchange rate.

The debate presented in this chapter could contribute to the literature by analyzing if the specific exchange rate pattern is related to the type of integration. The chapter might also contribute to the literature by shifting the focus from the size to the type of integration, calling attention to the importance of the characteristics of FX markets on creating these specific exchange rate features. Given that financial integration can bring instability, whether it allows for more or less speculation is a relevant matter.

\subsection{Exchange Rate Volatility}

This section examines the first of the three exchange rate features associated with financialized integration: volatility. Its discussion is based on exchange rate deviation from its trend (the standard deviation), on the features of the distribution of exchange rate changes, and on the frequency of important exchange rate changes. These features are associated with the level of financialization of EMEs' integration. 


\subsubsection{Measuring Volatility: the Standard Deviation}

The standard deviation of the exchange rate change is the most broadly used indicator of exchange rate volatility in economic literature (Clark et al., 2004). Equation 6.2 shows the standard deviation $(\sigma)$, the average of the absolute deviation of each observation $\left(x_{i}\right)$ to this series' mean $(\bar{x})$ :

$$
\sigma=\sqrt{\frac{1}{N} \sum_{i=1}^{N}\left(x_{i}-\bar{x}\right)^{2}}
$$

Given that the mean $(\bar{x})$ exchange rate change is the period's trend (positive in the case of depreciation and negative in the case of an appreciation), a standard deviation close to zero does not indicate exchange rate stability, but low variability around the trend; a high standard deviation indicates that changes varied over a wider range of values. Therefore, a volatility indicator based on the standard deviation informs the variability of the exchange rate change vis-a-vis its trend and not the absolute variability of changes in absolute terms ${ }^{15}$.

An estimation of exchange rate volatility based on the absolute change can be done by substituting the series average ( $\bar{x}$ in Equation 6.2$)$ by a zero - which could be referred to as an estimator of non-stability. Applied to EMEs during the 2003-2013 period, the indicator changes the ordering of countries when compared to the standard-deviation measure (see Figure 6.29 in the Appendix for a comparison between the two). In fact, the higher a currency's appreciation trend in the period, the lower $\bar{x}$ and the higher the difference between the two estimators. In this sense, it can be stated that the standard deviation overestimates the volatility of a currency that faced an important appreciation in the period.

\subsubsection{The standard deviation: emerging currencies' levels}

Figure 6.2 presents the estimation of emerging currencies' volatility with the standard deviation measure for the 2003-2013 period (see Figure 6.28 in the Appendix for the daily

\footnotetext{
${ }^{15}$ The above formula is used for estimating the volatility in a specific period. For analyzing the evolution of the exchange rate volatility, two main methods are used: the estimation of the standard deviation of sub-periods (as months), or the moving average of the standard deviation. The latter has the advantage of providing a smother series that is not calendar constrained.
} 
exchange rate changes). The choice of period reflects the current cycle of capital flows to EMEs that began in 2003, according to Prates (2015) (discussed in Section 6.3.1) and data availability (BIS data used in the estimation of financialized integration in Chapter Five is available for 2013 and EWN data available up to 2011). Note that, by not considering 2001 and 2002 data avoids biases from exchange-rate crises $^{16}$.

Figure 6.2: Volatility of Emerging Currencies: from 2003 to 2013

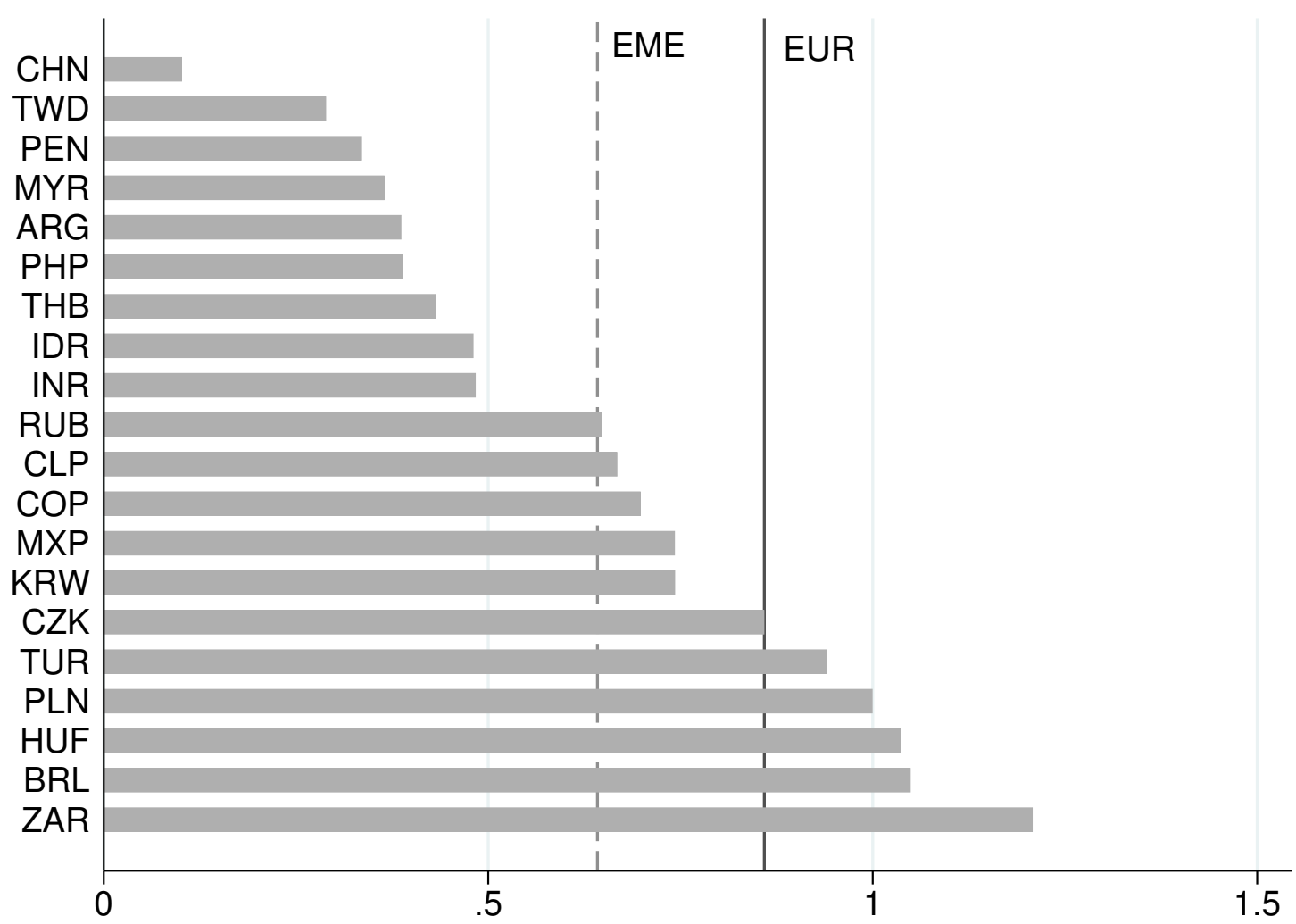

Volatility is estimated here as the standard deviation of the percentage change of exchange rate daily rates. EME indicates the average of the 20 emerging market economies. EUR refers to the euro/US\$ rate.

As observed, the volatility of emerging currencies varied significantly across emerging currencies, ranging from 0.1 in China to 1.21 in South Africa (see Figure 6.2). When using EMEs' average and the euro/U.S. dollar pair as reference points, three levels of volatility

\footnotetext{
${ }^{16}$ When the volatility is calculated for the 2000 to 2014 period the countries to present the highest exchange rate volatility are almost the same as when it is calculated from 2003 to 2013: Brazil, South Africa, and Turkey.
} 
can be identified ${ }^{17}$. The first, composed of countries with low exchange rate volatility (lower than emerging currencies' average), counts for about half of the sample: the Chinese yuan (volatility index of 0.1), the Taiwanese dollar (0.29), the Peruvian nuevo sol (0.34), the Malaysian ringgit (0.36), the Philippine peso (0.39), the Argentinean peso (0.39), the Indian rupee (0.48), the Indonesian rupiah (0.48), and the Thai bath (0.43). A second group includes countries with middle-high volatility (between the EMEs' average and the euro): the Russian ruble (0.65), the Chilean peso (0.67), the Colombian peso (0.7), the Mexican peso (0.74), the Korean won (0.74), and Czech Republic (0.86). A group of five countries is on the highvolatility end (higher than the euro): the South African rand (1.21), the Brazilian real (1.05), the Hungarian forint (1.04), the Polish zloty (1), and the Turkish lira (0.94).

Volatility: EMEs and the euro's level As seen in Figure 6.2, when measured by the standard deviation, emerging currencies average volatility is lower than the level of the EUR/USD, with only five of the 20 EMEs presenting higher volatility than the euro. When only EMEs with floating regimes are considered, the average volatility is still lower than the one of the euro (0.71, against 0.86). De Conti (2011) compared the volatility of emerging currencies with currencies from advanced countries and reached similar results: the volatility of emerging countries' currencies is not necessarily higher than that of advanced countries.

The result contradicts claims that emerging currencies are more volatile due to their peripheral insertion in the international monetary and financial systems, found in centerperiphery literature on exchange rates, discussed in Chapter Three (Section 3.3.4). De Conti (2011, p. 101) argues that the low volatility of some emerging currencies lies on different macroeconomic domestic policies adopted by (mostly Asian) countries to counter act volatility. Were these policies not in place, these countries would have a higher "potential volatility" than the (actual) "observed volatility". However, as Chapter Three's review of the center-periphery analyses of emerging currencies argued, a different insertion would not necessarily lead to exchange rate volatility in general, but to major depreciation in moments of crisis (see Section 3.3.4.1).

\footnotetext{
${ }^{17}$ The euro/U.S. dollar rate was chosen for representing advanced countries as they are the two most important currencies in the current configuration of the international monetary system. As discussed in Chapter Three, the U.S. dollar is the system's key currency and the euro, used in several countries, is in the second-highest position (De Conti, 2011, p. 46).
} 


\subsubsection{Explaining different levels: exchange rate regimes}

Part of the heterogeneity of volatility estimates is obviously due to the exchange rate regime adopted. Although most countries had floating regimes in the analyzed period, "craw-like" regimes prevailed in Argentina and in China and "other managed regime" in Malaysia (IMF, 2014 , p. 6-7 ${ }^{18}$. These three countries are in the low-volatility group. As expected, the average volatility of currencies with floating regimes is significantly higher than the volatility of this group of non-floating regimes: 0.71 against 0.28 .

The combined choice of exchange rate regime and monetary policy framework - though not the focus of this thesis - is a noteworthy perspective to understand the volatility of emerging currencies. From this viewpoint, it is interesting to note that the average volatility of the 14 countries following an inflation targeting regime with floating exchange rates ${ }^{19}$ is higher (0.75) than the average of the broader group of countries with floating exchange rate regimes (0.71).

\subsubsection{Explaining different volatility levels: the magnitude and type of financial integration}

The magnitude of financial integration Financial-to-trade integration is the ratio of financial integration (proxied by the sum of the stock of foreign assets and liabilities) to trade (proxied by the sum of exports and imports ${ }^{20}$.

Figure 6.3 shows the relationship between financial-to-trade integration and exchange rate volatility for EMEs. A positive relationship between the two is observed - countries with high or mid-high integration tend to have higher-than-average volatility. This relationship, however, does not seem to be strong. To further analyze whether a relationship exists, a

\footnotetext{
${ }^{18}$ See Table 6.12 in the Appendix 6.8 for the definition of the exchange rate arrangements used in this chapter.

${ }^{19}$ Not including India, that implemented the inflation targeting regime after the period considered in this analysis.

${ }^{20}$ The financial-to-trade indicator can also be thought of as the relative weight of financial integration with regards to GDP compared to the weight of trade integration in relation to GDP. This indicator is used by Lane and Milesi-Ferretti (2007) when analyzing the expansion of asset trade in comparison to the expansion of product trade among advanced and developing countries.
} 
Pearson's correlation was run, resulting in a weak correlation coefficient of 0.46 , significant only at the $10 \%$ level.

Argentina and China are notable outliers: Argentina has a high level of financial integration and low exchange rate volatility and China has very low exchange rate volatility, even when its small integration level is considered ${ }^{21}$. The outliers are clearly due to the countries' different (non-floating) exchange rate regimes ${ }^{22}$.

Figure 6.3: Exchange Rate Volatility and Financial-to-Trade Integration: 19 EMEs, 2003

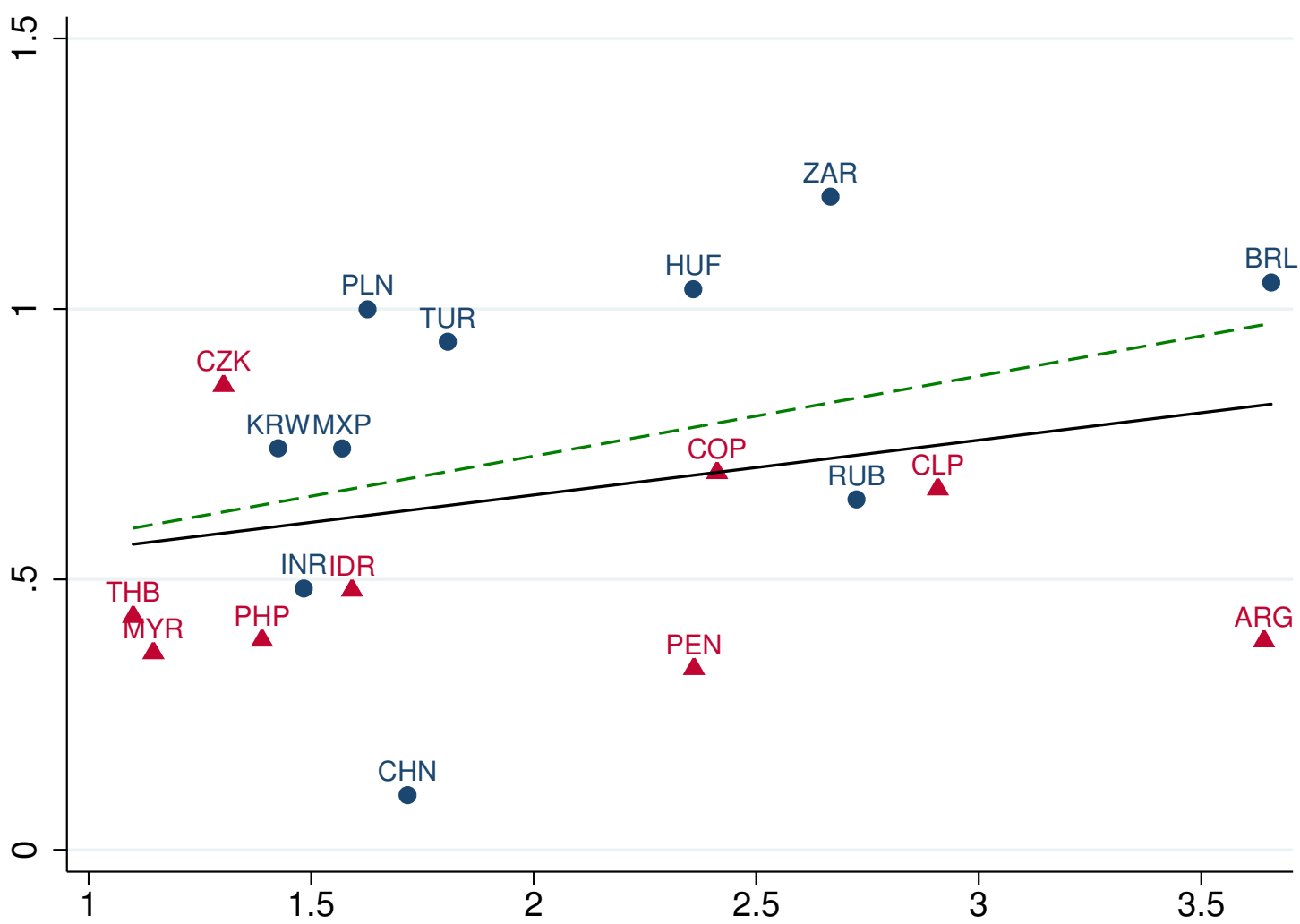

Exchange rate volatility is presented in the vertical axis, and Financial-to-trade integration is presented on the horizontal one. The different label markers indicate whether statistics of the country's currency are identified by the BIS or not: blue and circles are used for the EMEs for which the BIS presents the FX statistics and red triangles for the others. The solid line present the fitted values for all countries and the dashed one for the countries with floating exchange rates (all except Argentina, China and Malaysia). Pearson correlation coefficient: 0.46 , significative at the $10 \%$ level.

\footnotetext{
${ }^{21}$ On the other hand, South Africa has very high volatility,even when financial integration is taken into account.

${ }^{22}$ The fixed exchange rate regime could be concomitant with high volatility if there were an exchange rate crisis, which was not the case in the period analyzed.
} 
Indeed, in countries with floating exchange rate regimes the same financial-to-trade integration level seems to be associated with higher exchange rate volatility. This can be observed in the difference between the two lines in Figure 6.3: the higher, dashed line represents the relationship for countries with floating exchange rates, and the solid, lower line, represents countries with non-floating regimes.

Before analyzing volatility based on the type of financial integration, the role of the magnitude of the FX markets in explaining volatility together with the financial-to-trade integration was estimated. The estimation was based on a currency international importance, enabled by the fact that BIS' FX surveys are conducted for the most important currencies, grouping currencies of other EMEs into a "other" or "residual" group. To facilitate this analysis, the markers of countries in Figure 6.3 are differentiated for these two groups: blue circles represent EMEs on BIS' FX statistics and red triangles represent the others. As observed, these two groups of countries are rather distinct: those with more important FX markets show higher exchange rate volatility for all levels of financial-to-trade integration. For instance, the Brazilian real and the Argentinean peso show high levels of financial-totrade integration, but the Brazilian real that has important FX market, has much higher exchange rate volatility. The Hungarian forint and the Colombian (or the Peruvian) pesos are in the same situation, but with middle levels of financial-to-trade integration. There are also examples among the currencies of low financial-to-trade integration, such as the Mexican peso compared with the Indonesia rupiah. In other words, the probability of a currency with large FX markets to have above-average exchange rate volatility is higher than that of currencies that have smaller FX markets. China has an important FX market but low exchange rate volatility but is an exception due to its exchange rate regime. Although not an exact proxy, the differences between the two groups of countries (with important FX market or not) is a first evidence of the importance of the amount of FX contracts in explaining exchange rate volatility.

The type of financial integration Figure 6.4 analyzes exchange rate volatility against the index of financialized integration. Exchange rate volatility and a more financialized integration have a clearly positive relationship for floating currencies: the countries with the most financialized integration - South Africa, Turkey, Brazil, and Hungary - also present the 
highest exchange rate volatility. On the other end, Mexico, Korea, Russia and India, have low levels of financialized integration and of volatility. The correlation coefficient between a country's exchange rate volatility and the level of financialization of its integration confirms the graphical analysis: 0.89 , significant at the $1 \%$ level with the level of financialized integration explaining $79 \%$ of the exchange rate volatility ${ }^{23}$.

Figure 6.4: Exchange Rate Volatility and Financialized Integration

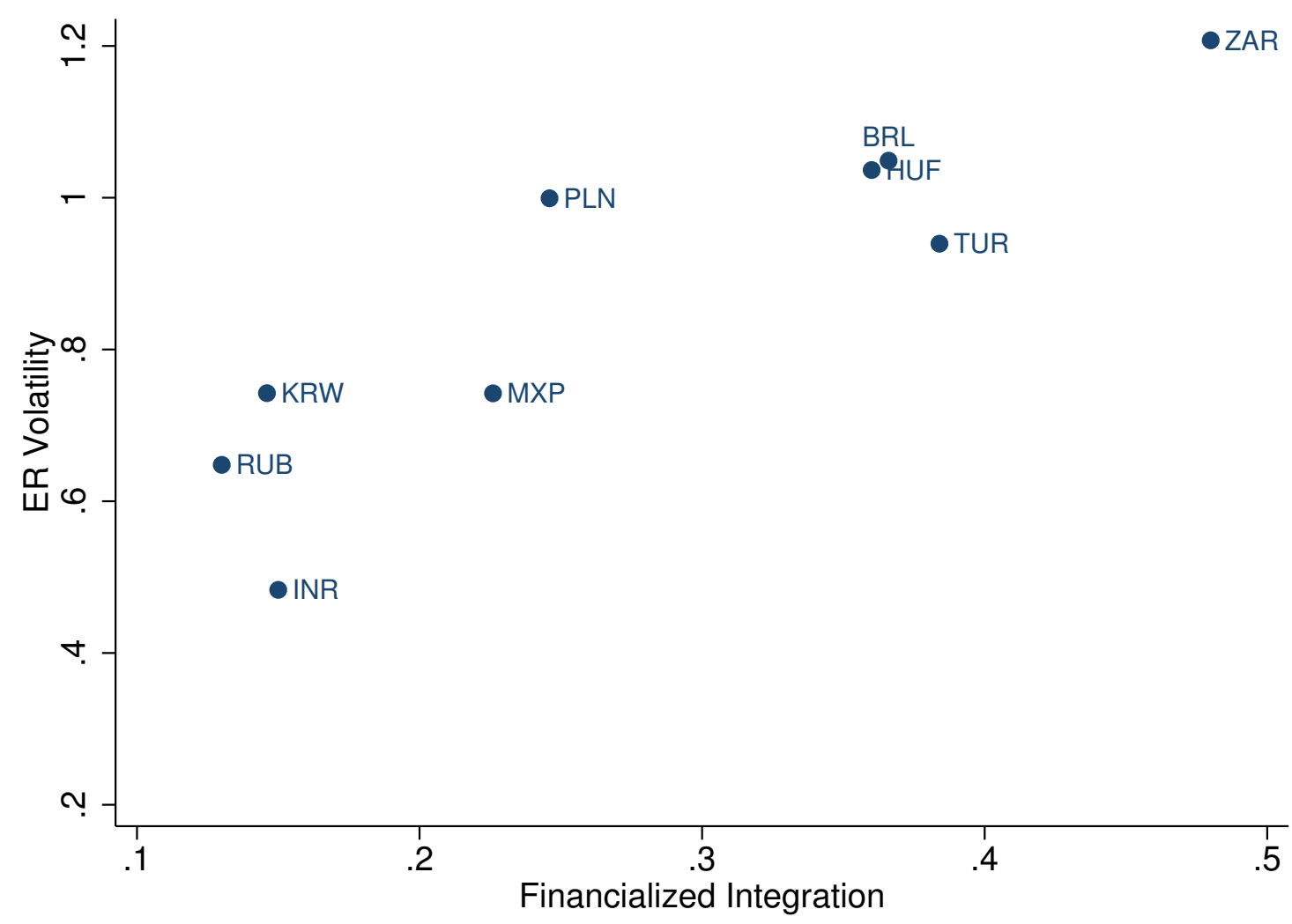

The index of Financialized Integration is presented in Chapter Five. It is based on five indicators concerning the financial integration relative to GDP and to trade, and on characteristics of the country's FX market, as its size relative to GDP and to trade, and its derivatives-to-spot ratio.

This is a much higher coefficient than that of the volatility and financial-to-trade integration (0.46). Given that the financialization index includes the financial-to-trade indicator, this difference indicates the importance of other indicators used in the composite index, notably the magnitude of its FX market and the weight of its derivatives contracts (in addition

\footnotetext{
${ }^{23}$ As throughout the chapter, this assumes that the causality runs from the type of integration to the exchange rate volatility. We could also argue that the volatility has an influence on the amounts of speculative flows, therefore partially impacting the integration indicator, but this is not expected to be an important driver for integration.
} 
to the relative magnitude of financial integration relative to GDP) in explaining exchange rate volatility.

\subsubsection{On the use of the standard deviation to estimate volatility}

As mentioned, the theoretical debate on emerging currencies presented in Chapter Three discusses specific type of volatility more closely related to major changes in certain moments than to volatility in general. While the latter aspect is captured by the use of the standard deviation, the former is not. In addition, the standard deviation estimator is flawed and too narrow when compared to definitions of volatility.

Dictionary definitions facilitate a discussion on the limitations of the standard deviation in this specific use. According to the Oxford dictionary, volatility denotes something that is "liable to change rapidly and unpredictably, especially for the worse". Deviation is a narrower concept: "the action of departing from an established course or accepted standard: deviation from a norm" ("Volatile", 2015). In these definitions, deviation only partially captures the three aspects of volatility: velocity, predictability and direction. The first refers to how rapidly the deviation takes place. In regards to time series of daily changes, velocity refers to the magnitude of the deviation. This aspect is captured by the standard deviation, which is formed by the average of every deviation. However, because the standard deviation is based on averages it would be the same for two very distinct groups: one in which the deviations are regular and limited to a given value, and another composed mostly by relatively smaller deviations, but that includes large ones. In other words, the standard deviation is not telling for being based on averages: relevant changes in value can easily be hidden behind small variations if the sample period is long enough.

Because it presents the same average without reflecting distribution, the standard deviation does not capture the second aspect of volatility, the predictability of a series. In the two mentioned groups, the first, with deviations of similar magnitude, is more predictable than the second, that presents large outliers. However, predictability is very relevant given its weight on decision-making, especially relating to decisions concerning exchange rates in open economies. Specifically thinking of the decisions of foreign investors, predictability affects expectations concerning possible loss of investments. 
This concern calls attention to the third aspect of volatility present in the definition: the direction of the deviation, an aspect that cannot be captured by the standard deviation, that is based on absolute deviations ${ }^{24}$. Predictability seems to be specially relevant for analyzing exchange rates given the presence of "jumps" (or discontinuities in prices) that characterize their series. The presence of "jumps" is in fact one of the three "most prominent features of foreign exchange volatility" for Erdemlioglu et al. (2012, p. 1) and the acknowledgment of the importance of this and other exchange rate features triggered a new generation of models that would yield in exchange rates featuring these specific characteristics (see the exchange rate puzzles in Table 3.1 in Chapter Three).

In other words, the distribution of exchange rate changes are fat-tailed and are in the realm of what Taleb (2007) called Extremistan. As opposed to Mediocristan, where a particular unexpected event cannot have a significant consequence on the outcome of total events, in thick tailed Extremistan the one event can dominate the outcome of all other ${ }^{25}$. This feature affects how money managers see a currency, exactly because of their potential of changing the overall groups average being most important given the representativeness principle.

On top of these limitations of measures of deviation to characterize volatility, there are also problems related to the specific application of the standard deviation to time series. By definition, deviation is a relative concept and the reference point has an important role. When thinking about a group of individuals in a specific point in time, their deviation to

\footnotetext{
${ }^{24}$ It is interesting to note that the shortfall of the standard deviation and the importance of the exchange rate peaks and other characteristics of what we understand as risk have driven to interesting developments in the estimation of volatility, specially inside finance given the importance of volatility in risk management and portfolio allocation. Reviewing the advances in volatility modeling since the use of the ARCH/GARCH family to sophisticated models that estimate jumps and combine autoregressive volatility and jumps, Erdemlioglu et al. (2012, p. 1) enumerates the features of exchange rate volatility that call for these modeler's work: "(i) it tends to be autocorrelated; (ii) it is periodic, displaying intraday and intraweek patterns; and (iii) it includes discontinuities (jumps) in prices." While autocorrelation might be more interesting for economic modeling, and intraday volatility is most of the time too short of a periodicity to have economic impact, the discontinuities and exchange rate peaks are very important for foreign investment decisions. "The importance of Fat Tails for finance is broadly known and has lead to the development of Value at Risk (VaR) from parametrical calculations that utilizes the Normal distribution to the "Fat-tailed VaR" that utilizes the Skewed Student's distribution which accounts not only for the two moments of the Normal (mean and standard Deviation), but also the skewness and the degrees of freedom (tail fatness)".

${ }^{25}$ Mediocristan and Extremistan are Taleb's (2007) types of environment, or "classes of probability domain". The author gives an interesting example to differentiate the two terms: the weight of a group of 1000 people (to characterize Mediocristan) and the wealth of this group (to characterize Extremistan). When Bill Gates enters the group, total weight will not change much, but total wealth will significantly change. With regards to exchange rates, an interesting example is the total exchange rate variation of an European currency against the U.S. dollar that, in few years, drastically changed when the European Monetary System collapsed.
} 
the group's average seems to be a sound indicator for characterizing an individual. But when applied to time series, the definition of normality is not trivial: Should we choose a specific point in time to be considered the norm? Or a point which would be preferred for representing some sort of "equilibrium" value? When thinking about a series of percentage changes, the ideal is a change that deviates from the period's trend, from a chosen value, or from zero?

The standard deviation of exchange rate changes to the period's average - the most used methodology - also has specific problems: it is based on the deviation from the period's average change, or its trends, which might result in biased indicators when the volatility in different countries is compared, given that their deviations would not be compared to the same norm. For instance, in the cases just analyzed, for the 2003 to 2008 period, Brazil's exchange rate appreciated $49 \%$ while India's depreciated $6 \%$. There is therefore an underestimation (overestimation) in the case of India where the trend was of depreciation (appreciated), given that its "norm" was a positive value.

In summary, when characterizing volatility through the use of the standard deviation only velocity (or the aspect of the magnitude of the deviation) is taken into account and cross-countries comparisons present comparability issues. In an attempt to overcome these limitations and better characterize exchange rate volatility including in regards to predictability and direction, the next subsections suggest an analyses based on other indicators.

\subsubsection{Measuring Volatility: Frequency of Extreme Exchange Rate Changes}

\subsubsection{The role of extreme changes}

Exchange rate features as 'jumps' call for estimators of volatility that take them into account not only for methodological reasons, but also because we cannot expect the economic impact of small exchange rate changes to be the same as the one of a major shock. For instance, based on French economy data, Berman et al. (2012) argued that exporters can absorb exchange rate changes in their profit margins; but could exporters also absorb changes of an exceptional magnitude? Thinking about foreign portfolio investors investing in EMEs, the impact of exchange rate changes might even be more relevant, given its role in determining 
total returns (a subject that will be discussed in the next chapter). More than change, direction is also of great importance given the obviously different impact of appreciation and depreciation of the currency in which assets are labeled.

Apart from the immediate impact of creating uncertainty, extreme exchange rate changes also impact the memory of agents: given the workings of associative memory in our intuitive thinking (or 'System 1', as labeled by Kahneman (2011)), the process of constructing a coherent interpretation of such event will create an association of the currency in question with risk. And once such association is created it is considered by investors in their decisions, even if unconsciously. These are expected to be of even greater importance in highly turbulent moments. Indeed, there is evidence that a more unstable currency is seen as riskier and investors demand a higher risk premium for holding them (Plihon, 2010) ${ }^{26}$. This is in line with the representativeness principle, according to which the more available something is in our memory, the more frequent or likely that event is deemed to be, resulting in agents overrating the importance of dramatic events (as discussed in Chapter Three, page 97).

To account for these features, this subsection proposes the characterization of exchange rate volatility based on the probability distribution of the daily exchange rate changes. It starts by analyzing the basic descriptive statistics of the histograms and then suggests specific indicators. In doing so, it continues De Conti's (2011) analysis, who compares exchange rate volatility in developing and advanced countries with the use of histograms of the daily changes between July 1994 and December $2009^{27}$.

\subsubsection{The range of exchange rate changes}

The range of exchange rate changes is a good indicator of volatility of exchange rates because it highlights the maximum change seen in the country's currency - which could point to financial practitioners' assessments of the potential extent of exchange rate changes.

South Africa's rand is the currency that presents the highest range of changes between 2003 and 2013, varying 24 p.p. and with the highest daily depreciation. High ranges are

\footnotetext{
${ }^{26}$ Evidence in this sense was found by Giovannini and Jorion (1989) who compared the currencies that were part of the European Monetary System with floating ones (the Japanese yen or the American dollar) and found that the risk premium asked for the latter ones were greater.

${ }^{27}$ De Conti's (2011) analysis of the euro is done from January 2002 to December 2009 (p. 109).
} 
also seen in Korea (21 p.p.), Brazil (15 p.p.), Mexico (14 p.p.), India (13 p.p.), Hungary (13 p.p.), and Turkey (12 p.p.) - see Table 6.1 for the main statistics of the series of exchange rate changes. The changes of the euro, on the other hand, have been contained among an appreciation of $3.9 \%$ and depreciation of $3.08 \%$, resulting in a range of 6.97 p.p. in this period. Seen by the range, the euro is therefore much less volatile than the most volatile emerging currencies and is only more volatile than the Philippines peso and the Taiwanese Dollar - with the exception of the Malaysian ringgit and the Chinese yuan that do not follow a floating regime. The higher range of emerging currencies can also be easily seen in the larger ranges of the horizontal axis of the histograms presented in Figure 6.5.

\subsubsection{The tails of the distribution}

When analyzed alone, range is a misleading indicator of extreme exchange rate changes if they are the result of infrequent events - as might be the case for Argentina, for instance. A deeper analysis of the histograms, looking at the different percentiles of the distribution provides a more detailed picture - see Figure 6.5 for the individual histograms of emerging currencies' daily changes and Table 6.1 for its details.

An analysis of the histograms provides further insights. First, no series seem to follow a normal distribution: emerging currencies show important peaks (higher probabilities of cases of very small exchange rate changes) than the Normal curve and have heavy tails. The distribution of the euro, is different: the core of its deviations occurs among changes that are of greater magnitude than most of emerging currencies. This is clear in a comparison of the values corresponding the 10th and 90th percentiles (or the P10 and P90 of Table 6.1, or the core $80 \%$ of the daily changes). As mentioned, considering all daily changes of the euro, there was a maximum high of $3.08 \%$ and a minimum low of $-3.90 \%$, but when considering only the core $80 \%$, the daily changes varied between $-1.3 \%$ and $1.3 \%$. The Brazilian real, on the other hand, presented a much larger range in total (from $-7.79 \%$ to $7.44 \%$ ), but its core $80 \%$ presented a lower range than the euro (from $-1.12 \%$ to $1.13 \%$ ). In fact, it was only the South African rand whose $80 \%$ core variations $(-1.32 \%$ to $1.39 \%)$ were more important than the ones of the euro. 
Figure 6.5: Histogram of Emerging Currencies' Changes from 2003 to 2013
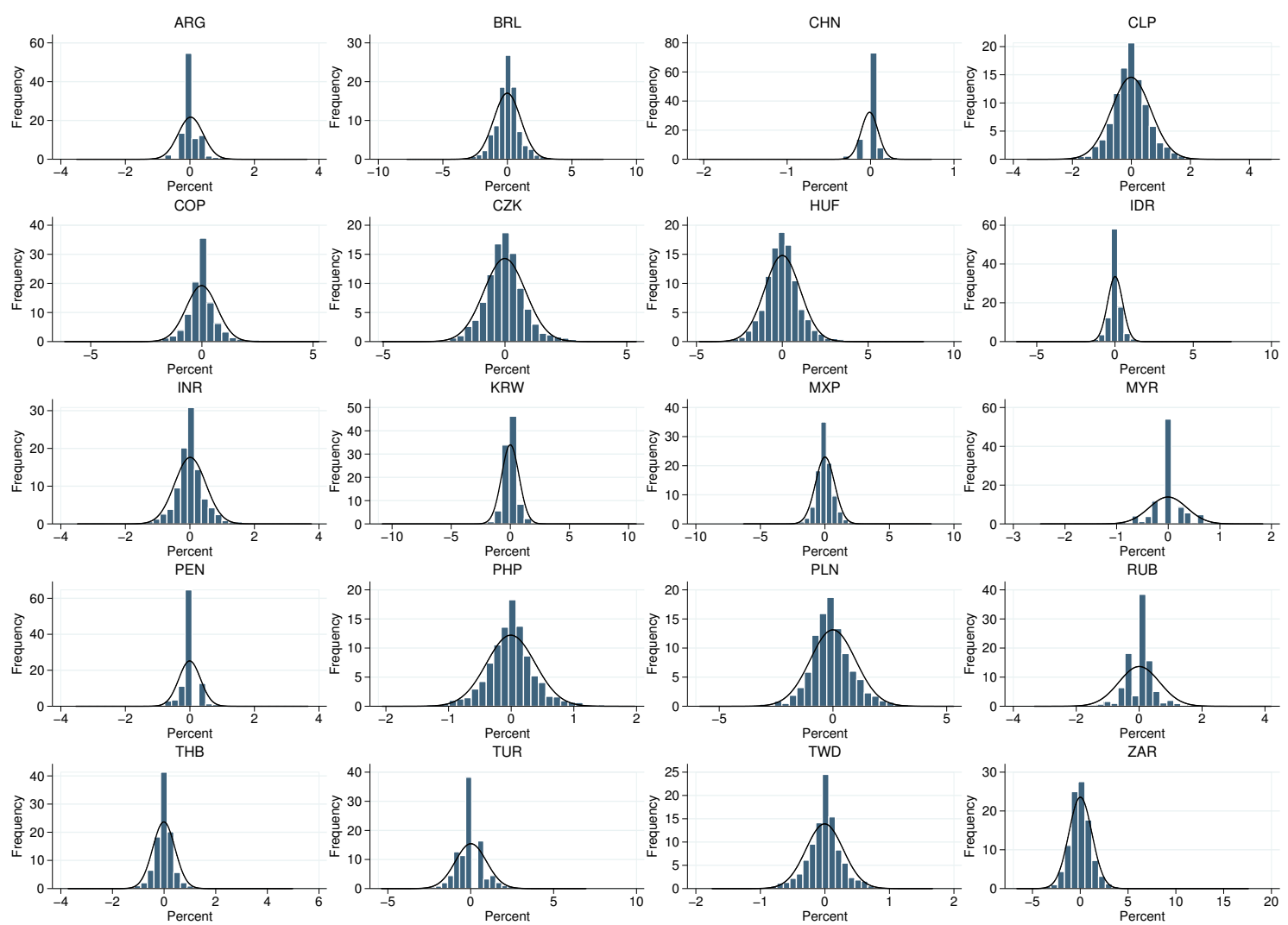

Own estimations based on daily closing values. Done in Stata 11. Data source: Ecowin.

Based on an analysis of the core $80 \%$ of the daily changes, we could thus conclude that the euro presents more important deviations than emerging currencies (except for South Africa), but when the analysis moves to the extremities of the distributions the picture is very different. Looking at the $10 \%$ most extreme values (P5 and P95), the Hungarian forint, the Brazilian real, and the Polish zloty also present more important extreme changes than the euro. Looking at the $2 \%$ most extreme values (P1 and P99), ten emerging currencies presented more extreme changes than the euro: the Brazilian real, the South African rand, the Hungarian forint, the Polish zloty, the Turkish lira, the Russian ruble, the Czech koruna, the Korean won, the Colombian peso, and the Chilean peso.

The analysis of the tails of the histograms indicates that, compared to the euro/U.S. dollar pair, in half of the emerging currencies the changes are mostly (90\% of the time) rather small, but their tails are composed of absolute values of greater magnitude. Indeed, compared to a Normal distribution, every emerging currency analyzed is leptokurtic (as seen 
TABLE 6.1 Distribution of Daily Exchange Rate Percent Changes

\begin{tabular}{lccccccccccc} 
& Min & P1 & P5 & P10 & P90 & P95 & P99 & Max & Rng & Skew & Kurt \\
\hline ARG & -3.51 & -1.05 & -0.35 & -0.33 & 0.33 & 0.35 & 1.08 & 3.64 & 7.15 & 0.42 & 23.08 \\
BRL & -7.79 & -2.81 & -1.52 & -1.12 & 1.13 & 1.69 & 3.07 & 7.44 & 15.23 & 0.42 & 9.63 \\
CHN & -2.05 & -0.30 & -0.16 & -0.15 & 0.12 & 0.15 & 0.28 & 0.73 & 2.79 & -3.08 & 64.31 \\
CLP & -3.53 & -1.77 & -1.03 & -0.76 & 0.76 & 1.08 & 1.81 & 4.75 & 8.28 & 0.42 & 7.18 \\
COP & -6.18 & -1.82 & -1.04 & -0.69 & 0.67 & 1.04 & 2.16 & 5.26 & 11.44 & 0.37 & 13.41 \\
CZK & -5.05 & -2.07 & -1.35 & -0.97 & 0.96 & 1.37 & 2.40 & 5.40 & 10.45 & 0.23 & 6.24 \\
HUF & -4.84 & -2.59 & -1.61 & -1.19 & 1.21 & 1.70 & 3.05 & 8.23 & 13.08 & 0.49 & 6.69 \\
IDR & -6.29 & -1.36 & -0.67 & -0.43 & 0.43 & 0.66 & 1.30 & 7.44 & 13.73 & 1.03 & 41.36 \\
INR & -3.49 & -1.26 & -0.74 & -0.47 & 0.54 & 0.78 & 1.47 & 3.77 & 7.26 & 0.20 & 10.02 \\
KRW & -10.85 & -2.06 & -0.91 & -0.61 & 0.61 & 1.01 & 2.46 & 10.67 & 21.51 & 0.24 & 41.30 \\
MXP & -6.31 & -1.89 & -0.99 & -0.72 & 0.79 & 1.17 & 2.09 & 8.25 & 14.55 & 1.08 & 17.72 \\
MYR & -2.48 & -1.11 & -0.62 & -0.33 & 0.33 & 0.63 & 0.99 & 1.83 & 4.31 & -0.13 & 7.23 \\
PEN & -3.54 & -0.98 & -0.38 & -0.35 & 0.34 & 0.37 & 1.06 & 3.67 & 7.20 & 0.32 & 21.01 \\
PHP & -2.06 & -1.05 & -0.63 & -0.45 & 0.44 & 0.62 & 1.06 & 1.98 & 4.04 & 0.09 & 5.21 \\
PLN & -5.86 & -2.53 & -1.49 & -1.04 & 1.17 & 1.61 & 2.89 & 5.32 & 11.18 & 0.32 & 6.56 \\
RUB & -3.33 & -2.27 & -0.87 & -0.56 & 0.58 & 0.93 & 2.53 & 4.21 & 7.54 & 0.62 & 11.63 \\
THB & -3.72 & -1.16 & -0.58 & -0.40 & 0.36 & 0.55 & 1.07 & 4.99 & 8.71 & 1.02 & 26.22 \\
TUR & -5.39 & -2.40 & -1.33 & -0.82 & 1.12 & 1.50 & 2.84 & 6.96 & 12.35 & 0.70 & 8.29 \\
TWD & -1.75 & -0.78 & -0.47 & -0.31 & 0.31 & 0.47 & 0.78 & 1.67 & 3.42 & -0.11 & 6.83 \\
ZAR & -6.64 & -2.71 & -1.76 & -1.32 & 1.39 & 1.98 & 3.21 & 17.60 & 24.24 & 1.37 & 21.25 \\
\hline EUR & -3.90 & -1.56 & -1.39 & -1.30 & 1.30 & 1.39 & 1.59 & 3.08 & 6.97 & 0.02 & 3.68
\end{tabular}

Own estimations based on daily closing values between 2003 and 2013. Done in Stata 11.

Data source: Ecowin.

by the kurtosis coefficient greater than 3), while the euro (with a coefficient close to 3 ) shows "smaller kurtosis" (see Table 6.1) ${ }^{28}$.

Although the kurtosis indicator is interesting for characterizing a distribution, it is not the soundest for proxing volatility and can be biased in cross-country comparisons because it is a relative measure, defined in relation to the distribution's own peak. If a distribution has a high peak and one outlier, it will have a high kurtosis coefficient. This is similar to the case of the Chinese yuan: as most of its daily changes are close to zero ( $80 \%$ are between -0.15 and 0.12 , the smallest values among emerging currencies), it has a high peak and, relative to this peak, "heavy tails". As a result, the Chinese yuan presents the highest kurtosis coefficient among emerging currencies (64), although the absolute value of its tails are the smallest (a

\footnotetext{
${ }^{28}$ Kurtosis is a feature defining the shape of a distribution, more specifically, its fourth moment. The normal distribution has a kurtosis coefficient of 3 , making the usual kurtosis indicator be analyzed relative to this value. A distribution that has a coefficient higher than 3 is said to have positive kurtosis, or to be leptokurtic. A negative kurtosis is called platykurtic. Compared to the Normal distribution, the former has heavier tails and a higher peak, while the latter has lighter tails and is flatter (it can be represented by a curve that suggests an inverted U shape) (De Carlo, 1997).
} 
range of 2.8). But if most of its changes were small, should we label the Chinese yuan as volatile? From the three mentioned aspects of volatility, the use of the kurtosis coefficient accounts for predictability, but the direction of the deviation is not considered and its velocity (or magnitude) is accounted for in analyses of an individual country, but not in cross-country comparisons $^{29}$.

However, the histograms are useful to indicate the skew of the distributions. Indeed, as seen in Table 6.1, most emerging currencies are skewed to the right (indicated by positive coefficients), indicating a higher weight of depreciations than of appreciations ${ }^{30}$. This skewness can be considered a 'direction bias', that better reflects the different type of behavior of foreign investors in moments of crisis. Such behavior is stronger in the following countries: South Africa, Indonesia, Mexico, and Thailand.

It is interesting to note that the euro presents a light skew, smaller than in any emerging currency, which can be evidence of a higher impact of speculation (with its resulting important exchange-rate depreciation) on emerging currencies.

\subsubsection{The frequency of extreme changes and depreciations}

The values of the percentiles (analyzed in Section 6.2.2.3) showed that the tails of some emerging currencies' distributions are generally longer than the euro's. This was done based on analysis of the length of a currency's distribution tails. The analysis in this section differs from the previous one, because it observes the thickness of these tails at a given point, simplifying cross-country comparisons. The given point is intentionally a very high change, an 'extreme' value, in line with the aim of analyzing the frequency of events of major impact on foreign investors' decisions. The definition of 'extreme' is arbitrary. To partially avoid this problem, analyses are done based on the frequency of exchange rate change higher than five different thresholds: $2 \%, 3 \%, 4 \%, 5 \%$ and $6 \%$. Note that these values refer to very extreme changes when compared to the values related to the $1 \%$ highest changes seen above (1st and 99th percentiles). It will be observed that in a few countries there has not been any

\footnotetext{
${ }^{29}$ See Koedijk et al. (1990) for more on tails of distributions of exchange rate returns.

${ }^{30}$ Note that left-skewed here is the same as what is referred to as right-skewed when the exchange rate is the value of the LCU in a foreign currency.
} 
change greater than $2 \%$ (its frequency, presented in the Figure 6.6, being therefore equal to zero).

This measure perfectly captures the volatility aspect of velocity (or magnitude). The aspect of predictability is partially captured given that it also derives from velocity. However, as the indicator does not inform 'how extreme' these extreme changes are vis-a-vis of the series 'normality', predictability is not completely captured. Still, as all the series under analysis are series of exchange rate change, it can be argued that the definition of extreme is not very different among them - especially among the ones that follow the same exchange rate regime. In other words, a $5 \%$ change in a day is significant for the Polish zloty and for the South African rand. Moreover, the analysis focuses on measuring the impact of these changes in the minds of investors that deal with the series simultaneously, and presumably, compare them as a group, and not relatively to its own past values.

The volatility aspect of direction is not captured by the frequency of extreme changes. To overcome this issue, and given the major importance of depreciation for the subject of analysis in this thesis, the frequency of exchange rate depreciation is also estimated - with the same thresholds.

\subsubsection{The frequency of extreme changes: emerging currencies' values}

The South African rand is the currency that presents the highest proportion of changes higher than 2\%: $7 \%$ of the daily changes, or 201 days. It is followed by the Brazilian real (6\%), the Turkish lira (5\%), the Hungarian forint (5\%), and the Polish zloty (4\%) (see Figure $6.6^{31}$ ). These five countries also present the highest volatility as measured by the standard deviation.

In addition to this country group, eight countries also presented a higher frequency of extreme changes (higher than $2 \%$ change) than the euro: Czech Republic, Russia, Argentina, Korea, Colombia, Indonesia, Mexico and Chile.

When we analyze changes higher than $3 \%$ or $6 \%$, the list of countries with middle or high volatility is similar (except for the Turkish lira, that stands out with high proportion

\footnotetext{
${ }^{31}$ The frequencies are also presented in Table 6.1 in the Appendix.
} 
Figure 6.6: Frequency of Exchange Rate Change: Different Levels, Percentage Change, From 2003 to 2013

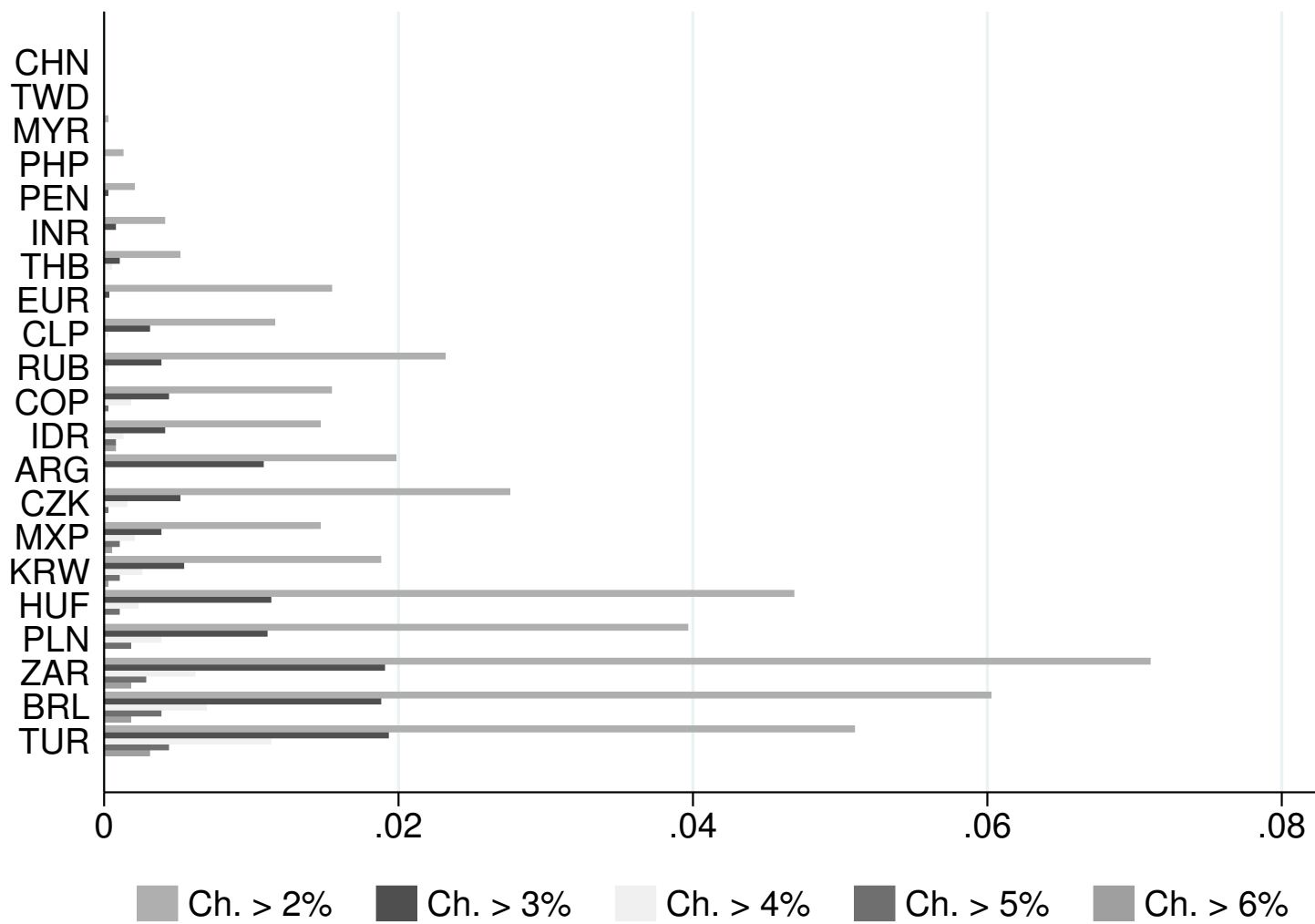

Countries are ordered according to the index of frequency of extreme changes. Own estimations based on daily closing values. Data source: Ecowin.

of changes higher than $6 \%$ : almost $0.5 \%$, or about 14 days). The comparison of the euro to some emerging currencies shows relevant differences. While deviations higher than $3 \%$ happened only $0.03 \%$ of the time in the euro, it happened around $2 \%$ of the time in Turkey, South Africa and Brazil.

Compared to the standard deviation, the use of indicators of frequency of extreme change led to a few important changes in the countries ranking. The most striking being Argentina: the peso had relatively low volatility when measured by the standard deviation (0.39, or the 5th lowest among the 20 countries), but had a high proportion of changes higher than $2 \%$ ( $2 \%$ of the observations, or the 6 th highest). This will be analyzed in the following (Figure 6.9). 


\subsubsection{The frequency of extreme depreciation: emerging currencies' values}

As discussed, the aspect of direction of the deviations is analyzed through the frequency of exchange rate depreciations higher than given thresholds, as presented in Figure 6.7. The list of countries with the highest frequency of depreciations is similar to that of the countries with extreme changes, except for South Africa, Argentina, and Russia, that showed high proportions of depreciation higher than $2 \%$ relative to their proportion of changes. In the case of South Africa, the bias towards depreciation had already been observed in its distribution's most relevant left-skew. In the case of Russia and Argentina, this high skew is only present among extreme changes, which indicates the existence of currency crisis in these countries.

Figure 6.7: Frequency of Exchange Rate Depreciation: Different Levels, Percentage Change, from 2003 to 2013

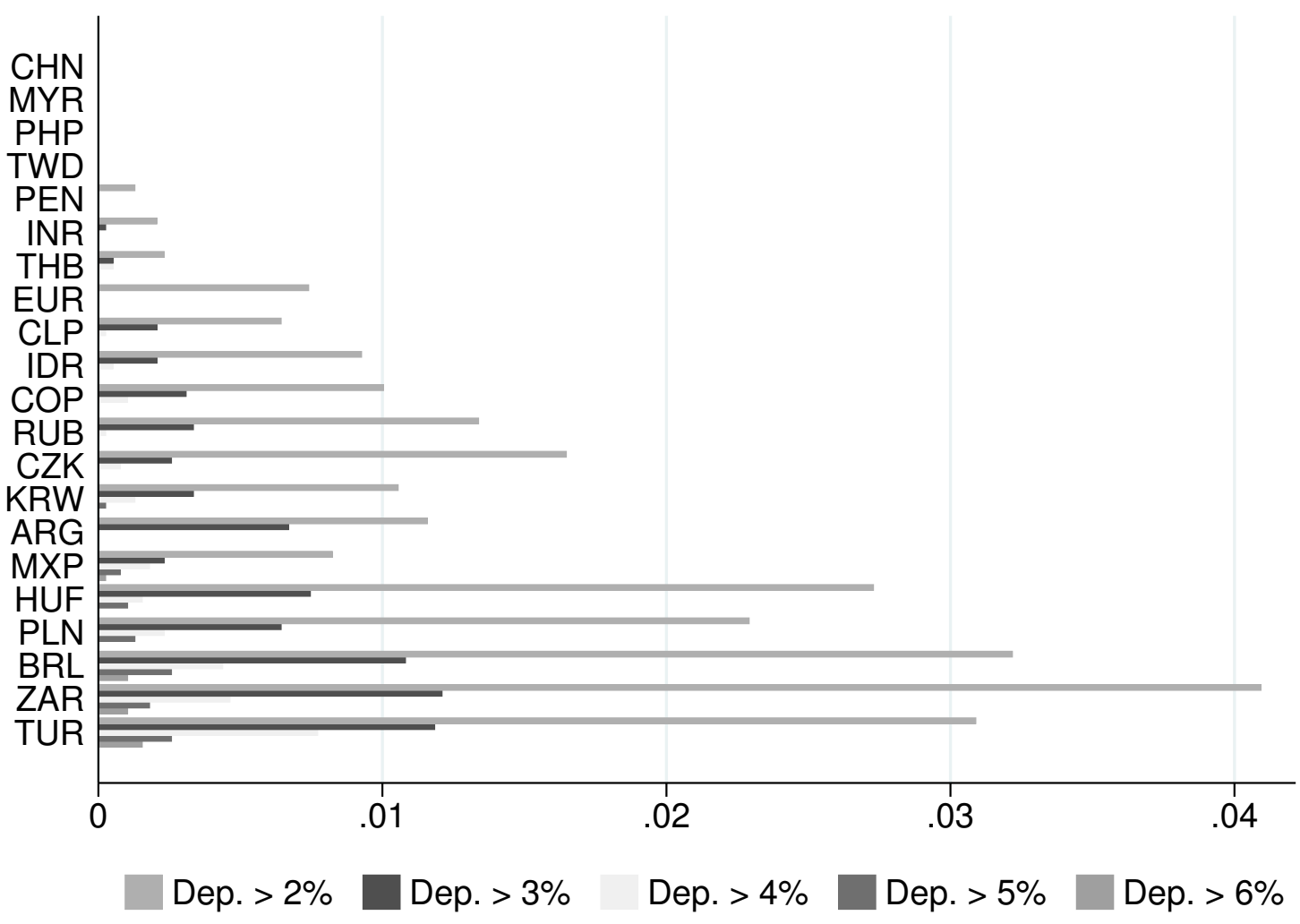

Countries are ordered according to the index of frequency of extreme depreciation. Own estimations based on daily closing values. Data source: Ecowin.

To summarize the information shown in Figures 6.6 and 6.7, Figure 6.8 presents composite indicators based on the different frequencies: the index of frequency of extreme changes 
built from the frequencies of exchange rate change higher than $2 \%, 3 \%, 4 \%, 5 \%$ and $6 \%$ and the index of frequency of extreme depreciation constructed with the frequencies of extreme depreciations, based on the same thresholds. It is a simple way of analyzing the frequency of extreme values, taking into account different levels, and thus, attenuating the problem of defining 'extreme'. These are max-min indices, where one denotes the currency where these frequencies were the highest and zero indicates no extreme change during the analyzed $\operatorname{period}^{32}$.

Figure 6.8: Index of Frequency of Extreme Change and Depreciation

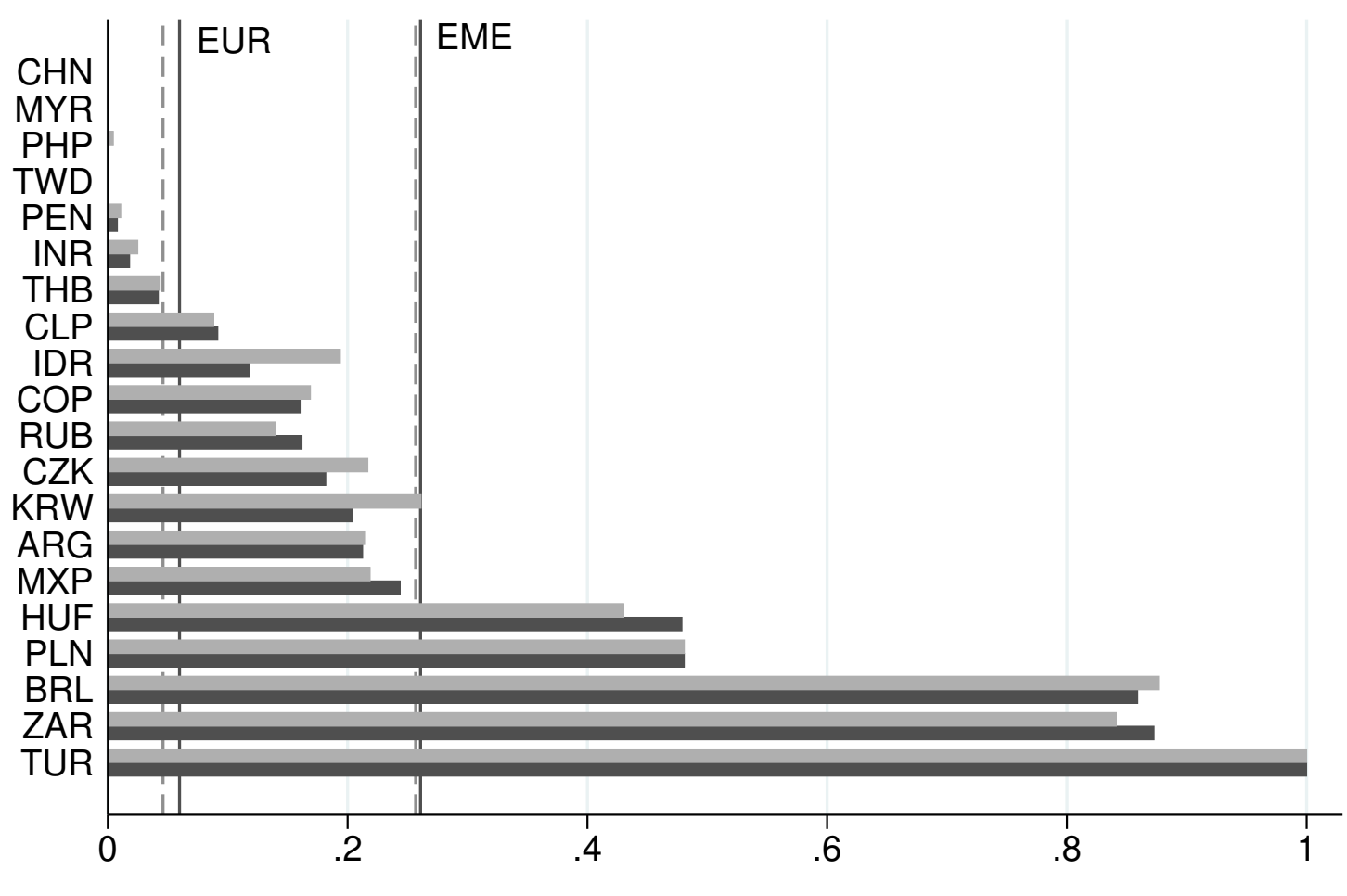

Id. Freq. of Ext. Change Id. Freq. of Ext. Depreciation

Countries are ordered according to the index of frequency of extreme depreciation. Indeces for the euro and for the average of the 20 EMEs' currencies (EME) are presented as reference. The dashed lines refer to the index of frequency of extreme change and the solid one to the index of frequency of extreme depreciation. Own estimations based on daily closing values. Data source: Ecowin.

\footnotetext{
${ }^{32}$ The max-min index is calculated for each of the five thresholds and the resulting index is the average of the five. Max-min is calculated as the ratio of: the difference between the observation and the lowest value of the series and the difference between the highest and the lowest values.
} 
Figure 6.8 confirms that emerging currencies tend to have more extreme exchange rate changes and depreciations than the euro. According to this index, we could say that the volatility of 13 emerging currencies is higher than the volatility of the euro. Only the volatility of the Philippine peso, the Taiwanese dollar, the Peruvian nuevo sol, the Indian rupee, and the Thai baht is lower than that of the euro - apart from non-floating currencies: the Chinese yuan, and the Malaysian ringgit.

\subsubsection{The frequency of extreme depreciation versus the standard deviation}

With the index of frequency of extreme depreciations, the exchange rate volatility as measured by the standard deviation - which focuses on the aspect of deviation - can be compared to that measured by the frequency of extreme depreciations - which better accounts for aspects of velocity (or magnitude) and direction.

FiguRe 6.9: Frequency of Exchange Rate Depreciation and Standard Deviation

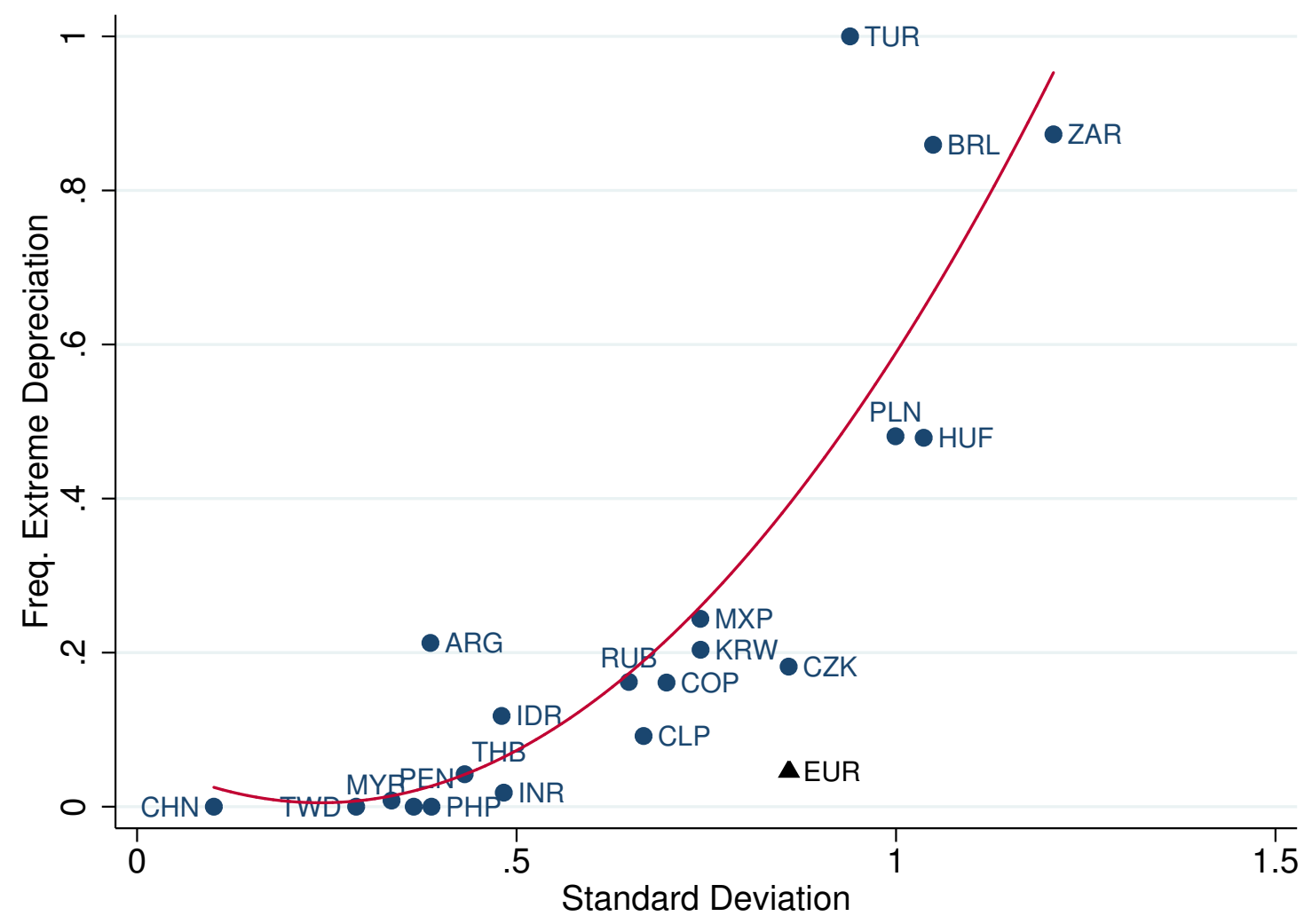

Own estimations based on daily closing values between 2003 and 2013. Data source: Ecowin. 
Figure 6.9 shows a positive relationship between the two estimators of volatility. This relationship is better described by a quadratic fit than by a linear one: countries with a higher frequency of extreme depreciations only have slightly higher exchange rate volatility as measured by the standard deviation. This relationship supports the argument that the use of the standard deviation as a measure of volatility can veil extreme values and thus hide the existence of 'micro-crisis' (which can create uncertainty and define how foreign investors view emerging currencies).

The figure also confirms the idea that the euro has behaved differently than emerging currencies in the analyzed period ${ }^{33}$ with a volatility level, measured by the standard deviation, that is much higher than what would have been predicted by its frequency of extreme depreciations. This derives from the fact that while most of the deviations of the euro are higher than the ones of emerging currencies, it has less extreme deviations ${ }^{34}$.

Turkey and, to a lower extent, Argentina, are on opposing ends. They have low standard deviations given their frequency of extreme exchange rate depreciations. In these countries, the exchange rate depreciations are mostly low, but, nevertheless, relevant.

\subsubsection{Explaining different volatility levels: type and magnitude of financial integration}

The type of financial integration Returning to the importance of the type of financialization in explaining exchange rate volatility, it is interesting to note that the countries with the highest frequencies of extreme depreciations also present the most financialized levels of integration: South Africa, Brazil, Turkey, and Hungary (see Figure 6.10). Indeed, the relationship between these two variables is positive and strong: the Person correlation coefficient is very high, 0.9 and significant at the $1 \%$ level.

Looking at Table 6.2 a summary of the correlation coefficients found on the relationship of the different measures of financial integration and exchange rate volatility can be observed.

\footnotetext{
${ }^{33}$ The fitted line in the graph was drawn based only on the values of the emerging currencies, having no impact from the euro. A fitted line that takes the euro into account is however not much different.

${ }^{34}$ As discussed in the analysis of the histograms in Section 6.2 .2 .3 , when the $2 \%$ most extreme values are analyzed, the values of 10 emerging currencies are of greater magnitude than the one of the euro. These are: the Brazilian real, the South African rand, the Hungarian forint, the Polish zloty, the Turkish lira, the Russian ruble, the Czech koruna, the Korean won, the Colombian peso, and the Chilean peso.
} 
Figure 6.10: Frequency of Extreme Exchange Rate Depreciation and Financialized Integration

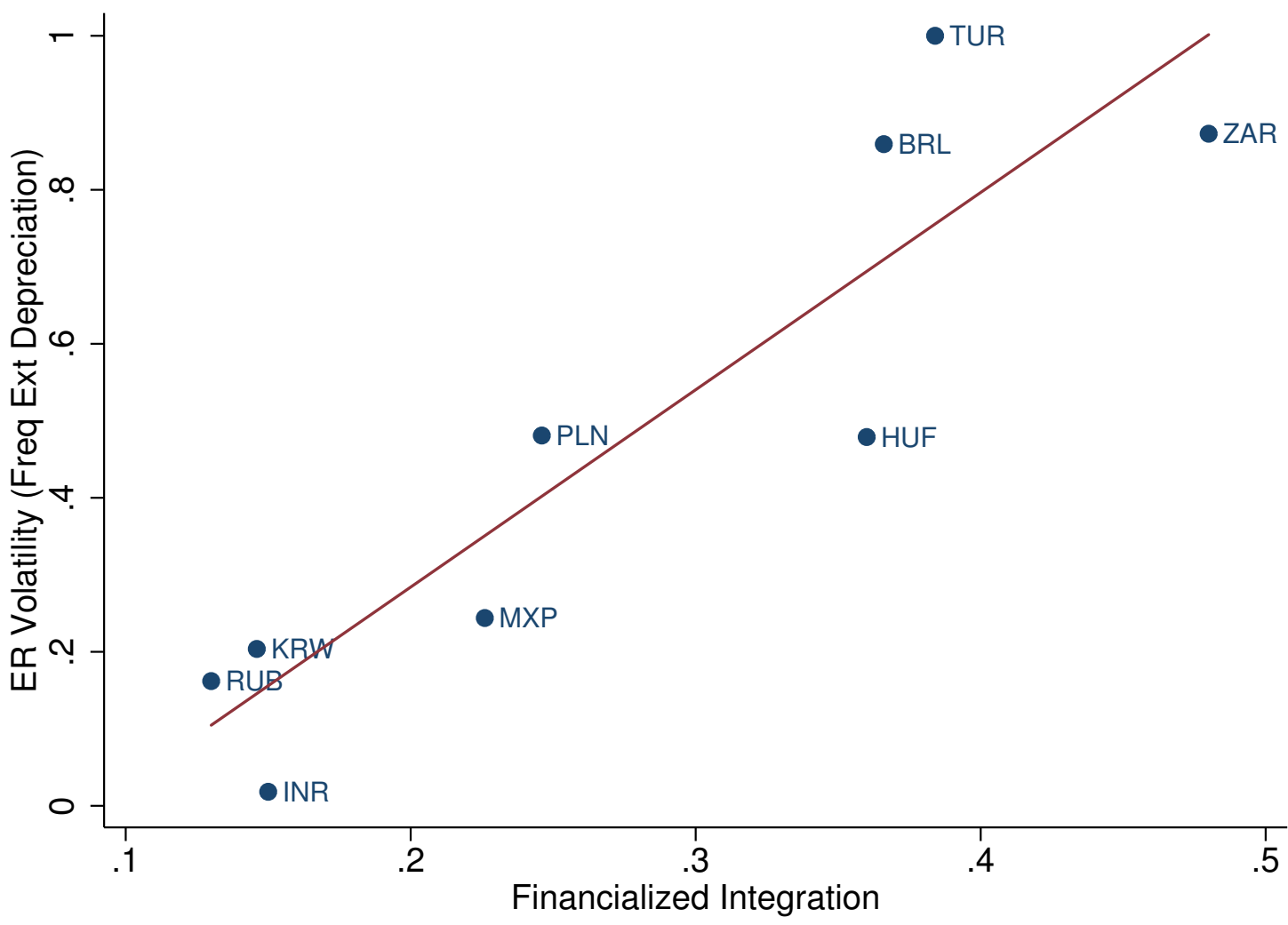

China is not shown in the Figure for not having a floating exchange rate regime. The Person correlation coefficient is very high, 0.9 and significant at the $1 \%$ level when only countries with floating regimes are considered. When China is added to the analysis the correlation coefficient is slightly greater: 0.92 , and is also significant at the $1 \%$ level (see Table 6.2). Own estimations based on daily closing values between 2003 and 2013. Data source: Ecowin.

At first sight, financialized integration seems to better explain volatility as measured by the frequency of extreme depreciations than as measured by the standard deviation (the first yields a coefficient of 0.92 and the latter 0.86 , both being significant at the $1 \%$ level). The difference however comes from the inclusion of China. With the lowest level of financialized integration (0.1) and zero extreme depreciations, China perfectly fits the line presented in Figure 6.10 and increases the correlation coefficient. Given the importance of the exchange rate regime in determining exchange rate volatility, comparing countries with similar regimes seems sounder than having China in the sample. By looking only at countries with floating exchange rates, the level of financialization of the integration explains the average exchange 
TABLE 6.2 Integration and Volatility: Pearson Correlation Coefficients

Std Dev. Freq. Extreme Dep. Obs.

All obs.

Financialized Int.

$0.86^{*}$

$0.90^{*}$

10

Fin.-to-Trade Int.

0.27

0.37

19

Only floating regimes

Financialized Int.

$0.9^{*}$

$0.87^{*}$

0.41

0.42

9

Fin.-to-Trade Int.

$\begin{array}{lll}0.9^{*} & 0.9^{*} & 9 \\ 0.49 & 0.47 & 9\end{array}$

Floating regime $E_{3}$ BIS data available

Financialized Int.

0.49

0.47

9

Fin.-to-Trade Int.

$*=1 \%$ significance level; $* *=5 \%$ significance level; $* * *=10 \%$ significance level. Countries
with non-floating regimes in the analyzed period are China, Malaysia and Argentina, as discussed from the analysis of Table 6.12 presented in the Appendix. Source: own estimations, done in Stata 11. Data source: exchange rates, Ecowin; financial integration, updated and extended version of Lane and Milesi-Ferretti (2007); GDP and trade, World Bank (2015); FX statistics, BIS (2013).

rate deviations as well as the frequency of extreme depreciations: the correlation coefficient is the same, 0.9 , in both cases.

The size of financial integration When financial integration is not analyzed through its type, but rather by its size (as proxied by the financial-to-trade indicator), there is no relationship between integration and exchange rate volatility (see Figure 6.11). The correlation coefficient between the two is not significant at the $10 \%$ level and is rather small, 0.42 , when considering only floating currencies (see Table 6.2$)^{35}$. The absence of correlation between exchange rate volatility and financial integration is also seen when other indicators are used as proxy for financial integration, as the index of the capital account opening or the size of the integration relatively to the GDP (as it will be discussed in Section 6.5).

The important difference between the correlation of the type (financialized) and the size (relative to trade) of integration in explaining exchange rate volatility measured as the average deviation or as extreme cases highlights the importance of taking the characteristics of the countries' FX markets into account when explaining exchange rate features. This can

\footnotetext{
${ }^{35}$ To test whether this would be a bias from the size of the FX markets, the correlation for currencies available on the BIS data was also estimated. As seen in Table 6.2 this relationship also yielded a coefficient that is not significant at the $10 \%$ level.
} 
Figure 6.11: Frequency of Extreme Exchange Rate Depreciation and Financial-to-Trade Integration

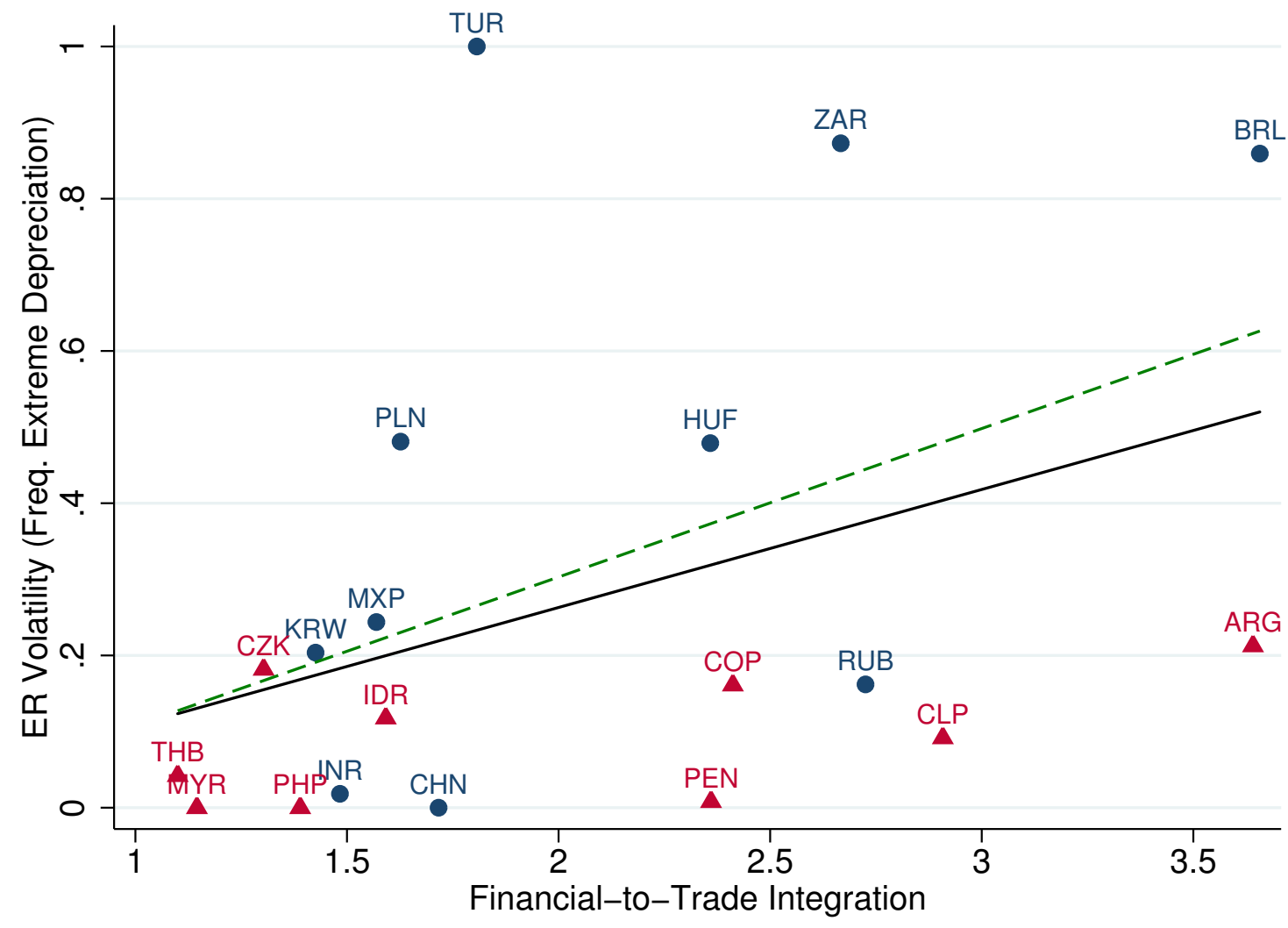

The different label markers indicate whether the country's currency features in BIS Triennial Surveys (blue circles) or not (red triangles), indicating the importance of their FX markets. The solid line present the fitted values for all countries and the dashed one for the countries with floating exchange rates (all except Argentina, China and Malaysia). Pearson Correlation Coefficient: 0.42 for floating currencies, 0.5 for countries for which BIS data is available, and 0.39 for all 19 EMEs, none being significative at the $10 \%$ level (see Table 6.2). Source: own estimations. Data source: exchange rates, Ecowin; financial integration, updated and extended version of Lane and Milesi-Ferretti (2007); GDP and trade, World Bank (2015).

also be observed in Figure 6.11, where currencies with larger FX markets (for which BIS data are available, with blue circles as markers) tend to have more extreme depreciations for all levels of financial-to-trade integration. 


\subsubsection{Concluding Remarks}

This section i) presented a discussion on the different measures of exchange rate volatility; ii) argued for the importance of taking extreme events into account; iii) presented the different levels of exchange rate volatility among emerging currencies and how they diverge from the euro/U.S. dollar pair; and iv) analyzed possible causes of volatility.

Regarding different measures of exchange rate volatility, it was argued that the standard deviation, as it is based on averages, veils the presence of extreme exchange rate changes, that are crucial in characterizing emerging currencies. Moreover, these extreme changes, especially the depreciations, can play a major role in how foreign investors view emerging currencies and thus, how they trade assets labeled in these currencies. A measure of volatility based on the frequency of extreme exchange-rate depreciations was suggested to deal with this drawback.

Measuring volatility by the frequency of extreme changes and through the standard deviation led to different results, and the comparison to the euro created a clearer picture of the state of volatility among emerging currencies. By analyzing only the standard deviation, five out of the 17 emerging currencies with a floating regime were more volatile than the euro. However, when the magnitude of the daily change is the focus of the measure, many emerging currencies are more volatile (as shown in Table 6.15): through an analysis of the range, most emerging currencies are more volatile than the euro; when the analysis considers the frequency of extreme changes, 13 emerging currencies are more volatile than the euro.

In analyzing possible causes of exchange rate volatility, this section presented evidence that a more financialized integration is associated with higher exchange rate volatility in emerging currencies - as measured by the two estimators, while estimators of the relative size of integration do not present any significant relation with exchange rate volatility. The type of integration has no greater impact on extreme exchange-rate depreciations than on average deviation.

The next two sections cover two other possible consequences of a financialized integration to international financial markets: the comovement of different emerging currencies and the higher importance of international factors in determining these currencies' path. 


\subsection{Influence From International Liquidity Cycles}

Attempting to advance on the hypothesis that the type of integration - more or less financialized - can determine emerging currencies' features, this section analyzes the impacts of international financial conditions on emerging currencies. The importance of international conditions is also studied by the push vs. pull literature, but while the latter focuses on the impacts on capital flows, the thesis focuses on exchange rates.

\subsubsection{International Liquidity Cycles and Capital Flows to EMEs}

The literature on the determinants of capital flows has flourished since the 1990s, following the seminal works of Calvo et al. (1993) and Fernandez-Arias (1996) who differentiated "push" (external) and "pull" (domestic) determinants of capital flows ${ }^{36}$.

Several authors have conducted empirical analyses on the relative weight of push and pull factors on capital flows, without achieving a consensus (see Weiss and Prates (2015)). When looking specifically at portfolio flows, however, the empirical evidence suggests a predominance of finance-related push factors (see Rey (2015)). Indeed, that is the finding of Koepke (2015) based on a qualitative meta-analysis of 40 empirical works. Specifically, the study concludes that there is strong evidence that portfolio flows suffer negative impacts from interest rate in mature economies and from global risk aversion; and that there is no strong evidence of impact from GDP growth in mature economies (for which there is only some evidence of impact on portfolio flows). The evidence for pull factors, on the other hand, is weak: there is only some evidence of impact from domestic output growth, asset return indicators, and country risk indicators.

From another perspective, Koepke's (2015) results on the different types of flows indicate that, for portfolio flows (equity and debt), the importance of push factors is more evident,

\footnotetext{
${ }^{36}$ Push and pull factors are sometimes seen as the respective correspondents of supply and demand of capital, as stated by Ghosh et al. (2014, p. 268): "The literature on this subject has a long tradition of trying to identify global "push" and domestic "pull" factors in determining flows to recipient economies. Yet, in equilibrium, capital flows must reflect the confluence of supply and demand, so there must be both push (supply-side) and pull (demand-side) factors, and it is hard to attribute the observed flows to one side or the other." This comparison should however be avoided as demand is determined by both pull and push, and global and domestic factors.
} 
while there are mixed findings for pull factors. Banking flows are the only type that have clear, strong evidence to the importance of pull factors (but evidence to the role of global risk aversion, a push factor, is also important). FDI is also subject to mixed evidence. Domestic output growth (a pull factor) is the only factor for which there is strong evidence.

The major relevance of push factors is also clear in a less formalized literature that studies the development behind episodes of surges of capital flows to developing countries in different moments in history. Akyüz (2012) identify four cycles of capital flows to developing countries in the post-war period: and argue that every cycle was preceded by a hike of liquidity and low interest rates in reserve-issuing currencies (notably the United States) and ended with an external shock.

Helleiner (1997) also studies capital flows to developing countries and argues that apart from internal drivers, the decrease of interest rates in the United States in 1990-91 was highly important in determining these flows. More recently, Obstfeld (2009) agreed that in both the current cycle of capital flows to developing countries and in the 1990s one, low global interest rates were an initial driving force. Ghosh et al. (2014) agree with the importance of push factors, concluding that:

The picture that emerges from our regression analysis is one in which global push factors, notably, the real US interest rate and global market uncertainty, determine whether there will be a surge of capital flows towards EMEs generally, which helps to explain why surges are synchronized internationally, and why they recur. (p. 23)

For Brazil, Kaltenbrunner and Painceira (2015) argue that the sudden changes in capital flows to the country have taken place irrespective of Brazil's fundamentals, but rather according to the conditions of international financial markets.

Specifically contemplating emerging countries, the reason behind the predominance of push factors might be found in the structural characteristics of their currencies. Biancareli (2011) argues that:

[due to] monetary, financial, and macroeconomic asymmetries, the movement of private capital flows to developing countries, issuers of currencies that are 
not internationally liquid, is always a consequence of a reduction in liquidity preference in the international level (or a decrease in risk aversion). (p. 9)

In this sense, pull factors could only reinforce a trend of flows which is determined in the international sphere. The changing liquidity internationally, from scarcity to abundance, called "liquidity cycle" ${ }^{37}$, is therefore the determinant of flows to developing countries. This would be in line with Hoti's (2004) findings that capital flows are directed to emerging markets according to the ruling international financial condition (a push factor), but its geographic distribution is explained by pull factors.

\subsubsection{Liquidity Preference and the VIX Index}

As seen, liquidity conditions are a major push factor among the different ones analyzed: both liquidity itself and liquidity preference (two inverse correlated concepts when dealing with capital flows to emerging countries). While liquidity preference and risk aversion seem to be similar concepts, it is important to note that liquidity preference does not assume risk to be measurable, and is more coherent with a definition of uncertainty as (Knightian) fundamental uncertainty (as discussed in Chapter Two, page 34). Although available liquidity might be an important determinant of flows to emerging countries, liquidity preference is more dynamic and thus more coherent with the rapidly changing "market mood" (in the words of Hesse et al. (2008)), or the financial markets' conditions - which, in turn, are much more relevant for financial (and speculative) flows ${ }^{38}$. Given that both exchange rates and liquidity preference are high-frequency data their analysis has the advantage of profiting the most from the liquidity preference information. In other words, although analyses of capital flows gain from using liquidity preference as a determinant, studies focused on exchange rates can (potentially) better grasp its effects.

Proxies of liquidity are not problem-free. Coudert and Gex (2008) proxy liquidity by "the inverse of average short-term rates of the four largest economies (United States, the Euro area, United Kingdom and Japan), weighted by GDP". However, this can be problematic given that it simultaneously indicates liquidity and return.

\footnotetext{
${ }^{37}$ See Biancareli (2007) for an analysis of recent liquidity cycles.

${ }^{38}$ See Chapter Three, Sections 3.3.4 and 3.3.6 for more on liquidity and liquidity preference.
} 
Analyses focused on measuring risk aversion or liquidity preference mostly use the VIX index: in 2008, Hesse et al. (2008) argued that there was a consensus on its use and since then it has been growing in both heterodox ${ }^{39}$ and mainstream circles: Bekaert et al. (2013) decompose the VIX as a measure of 'stock market volatility' and a residual, "perhaps even Knightian uncertainty"; Rey (2015) use it as "a measure of uncertainty and risk aversion of the markets"; Basu and Bundick (2012) states that the VIX measures "aggregate uncertainty"; Forbes and Warnock $(2012)^{40}$, use the VIX to proxy "overall economic uncertainty or risk" 41 .

Alternatives to the VIX exist. Bonizzi (2013) compares the VIX with its FTSE pair, the FTSE Volatility Index. Ahmed and Zlate (2014) also use the Credit Suisse's Global Risk Appetite Index for robustness reasons. Baker et al. (2015) create an indicator based on counting how many times the word "uncertain*" appears in the Beige Book, released before each regularly scheduled meeting of the Federal Open Market Committee ${ }^{42}$. Forbes and Warnock (2012) also use its older version, VXO, to cover a longer period (before 1990).

Brunnermeier (2008) use the TED spread, the spread between the risky LIBOR and the risk-free U.S. Treasury bill rate. It is used to proxy "times of crises" or "uncertainty" and explains how the TED spread widens in times of uncertainty:

In times of uncertainty, banks charge higher interest for unsecured loans, which increases the LIBOR rate. Further, banks want to get first-rate collateral, which makes holding Treasury bonds more attractive and pushes down the Treasury bond rate. For both reasons, the TED spread widens in times of crises. (p. 12)

As with liquidity measures, this risk aversion proxy also suffer from ambiguity for having two meanings: risk aversion and international funding conditions, which can compromise the analysis.

\footnotetext{
${ }^{39}$ Examples of recent use of the VIX in heterodox literature are varied and include Baumann and Gallagher (2013), Bonizzi (2013), Hoffmann (2013), Kaltenbrunner and Painceira (2009), Kaltenbrunner (2011), Da Silva and Da Fonseca (2015), Prates and Biancareli (2009), and Weiss and Prates (2015).

${ }^{40}$ Forbes and Warnock (2012) also consider the use of "the Quality Spread (the difference between Moodys Baa and Aaa corporate bond yields)" to measure "both economic uncertainty as well as risk aversion".

${ }^{41}$ Note that the concept of uncertainty in these mainstream authors is not of knightian or fundamental uncertainty, as used in this thesis. Differently from these mainstream authors, Bruno and Shin (2015), use the VIX as a proxy of "banks' Value-at-Risk" and the "balance sheet capacity of international banks" which would, in turn, drive capital flows.

${ }^{42}$ Given the different available indicators, an interesting methodology might be to use the principal component of different proxies, as done by Barbosa and Costa (2010), who focus on risk premium.
} 
Baker et al. (2015) compares the VIX with the EPU, an index of Economic policy uncertainty. They argue that the VIX better reflects events closely related to stock markets (as Asian Financial Crisis, the WorldCom Fraud and the Lehman Brothers' collapse) but it would have the disadvantage of being based on publicly traded firms, which only account for about a third of private employment in the US. However, the meaning of the VIX should not be limited to to the companies listed in the S\&P 500 Index, being it is broader than its calculation methods imply. Its similarity to its European pair, the $\operatorname{VSTOXX}^{43}$ (shown in Figure 6.12) is evidence to this sense.

Figure 6.12: Liquidity Preference From 2000 to 2014: VIX and VSTOXX Daily Data

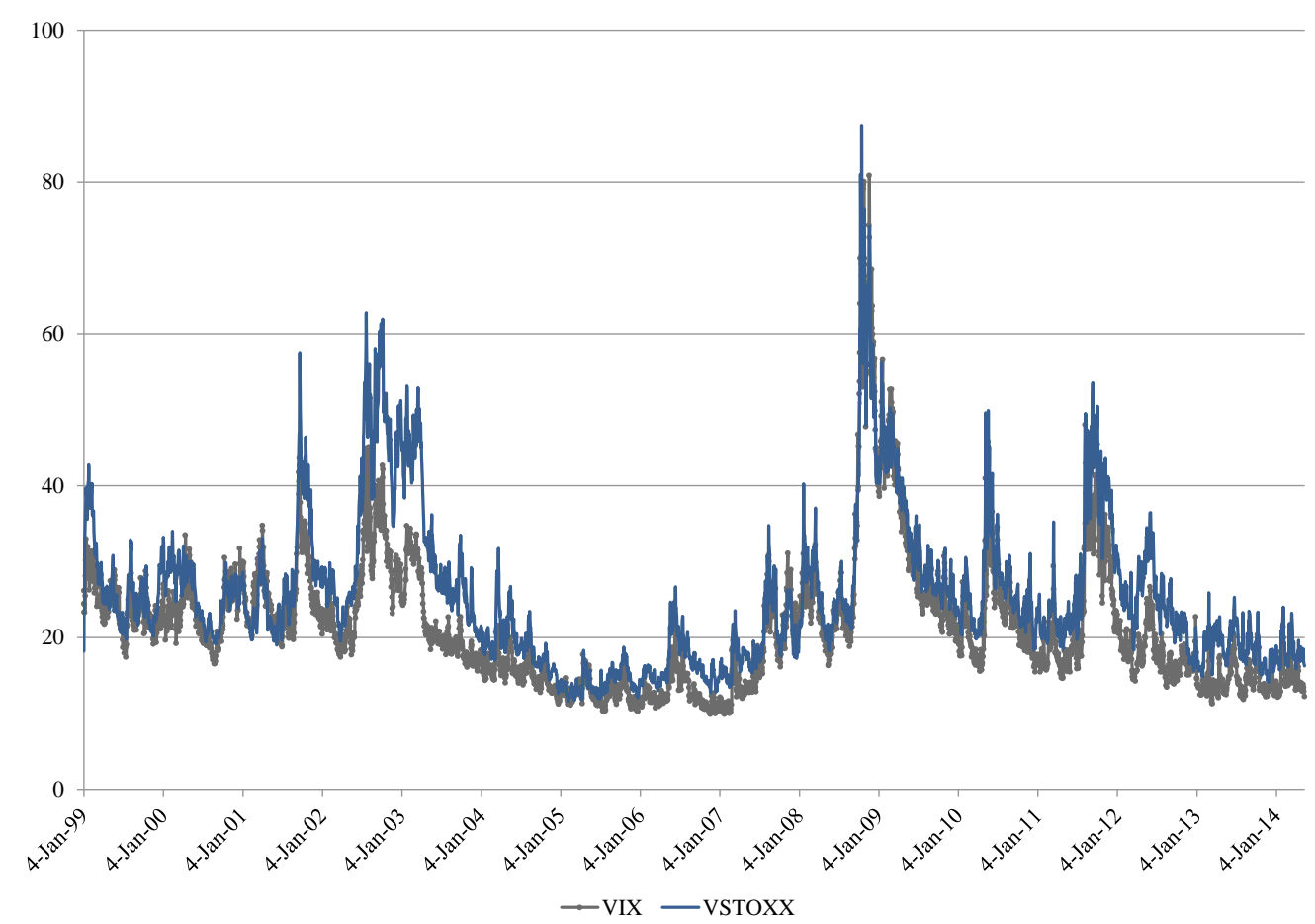

Data source: "VIX Index" (2013) and "VSTOXX Index" (2013). As the series are not available for the same workdays, data presented here corresponds to the availability of the VIX index.

\footnotetext{
${ }^{43}$ The VSTOXX is an estimation of the volatility implied in the EURO STOXX 50 option prices, being based on the EURO STOXX 50 real time options prices. It is measured by the square root of the implied variance across all options of a given time to expiration ("VSTOXX Index", 2013) - the EURO STOXX 50 being made up of fifty of the largest and most liquid stocks.
} 
Indeed, although the VIX index is estimated with regards to the S\&P500 index ${ }^{44}$, it reflects the conditions of financial markets in all major centers, due to the interconnectedness of global financial markets and, as put by Pusch (2012, p. 5), the particular depth and therefore central role of US markets in international financial markets.

The Recent Path of the VIX Liquidity preference varied significantly since the 2000s (shown in Figure 6.12): an long period of low risk aversion occurred from 2003 until the collapse of the Lehman Brothers; the peak was followed by an notable but temporary decrease of risk aversion that lasted until fears concerning the stability of the euro arose in 2011. These ups and downs of the VIX correspond to the cycles of capital flows to emerging countries, that increased considerably in the beginning of the 2000s, until the Global Financial Crisis (GFC), decreased with the crisis, and then increased again (see Figure 6.13).

\subsubsection{The VIX and Capital Flows}

Indeed, several empirical studies use the VIX as a proxy for risk aversion or liquidity preference internationally and conclude for the importance of these factors in explaining capital flows ${ }^{45}$. Ahmed and Zlate (2014), using the VIX on levels, find that the index influences net capital flows to EMEs. Weiss and Prates (2015) use an annual VIX (created from the average of monthly data) and find it is significant in determining financial flows to developing and emerging countries (across different econometric techniques and combination of determinants). Also using the VIX, Obstfeld (2015) finds evidence "consistent with the view that reductions in global-risk aversion are associated with portfolio shifts toward EMEs." Bruno and Shin (2015) use the log of the VIX and find support for the predominance of external factors and for the relevance of the Fed fund rates in the VIX ${ }^{46}$. Rey (2015) concludes that the VIX is important and that it is highly influenced by the Fed fund rate.

\footnotetext{
${ }^{44}$ According to the Chicago Board Options Exchange (CBOE), The VIX index is: "The CBOE Volatility Index (VIX) is based on the S\&P 500 Index (SPX), the core index for U.S. equities, and estimates expected volatility by averaging the weighted prices of SPX puts and calls over a wide range of strike prices" (Chicago Board Options Exchange, 2015).

${ }^{45}$ It is interesting to note that the use of the VIX index as a proxy for the 'mood of international financial markets' had long been used among heterodox circles, and has recently spread o other schools of thought.

${ }^{46}$ To be precise, the authors find a dual causality: "a cut in the Fed Funds rate is followed by a dampening of the VIX index, while an increase in the VIX index elicits a response from the Federal Reserve who react by cutting the target Fed Funds rate" (pg. 4).
} 
Figure 6.13: Capital Flows to Emerging Countries: 1999 - 2012

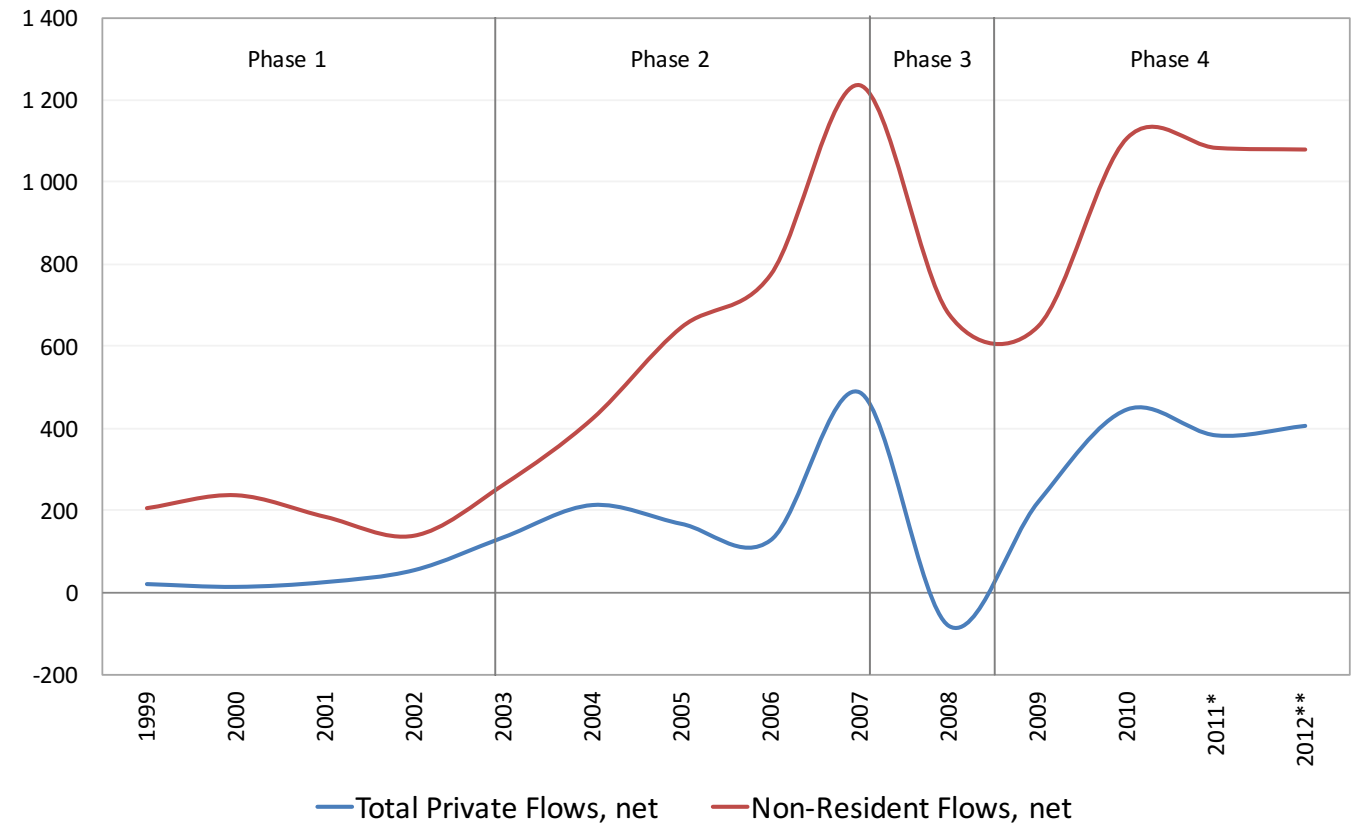

Source: Prates (2015). Orange line: total private flows, liquid. Red line: non-residents flows, liquid. Data source: Institute of International Finance (IIF).

It is interesting to note that the explanation of the causality from the VIX to higher capital flows is not the same across these studies. In fact, most of them do not present much debate on causality, though two exceptions should be mentioned. First, the 'risktaking channel' ${ }^{47}$ : a lower VIX enables Value-at-Risk constrained banks to take on a greater leverage and then invest in EMEs, leading to an appreciation of their currencies and a "decline in measured risks" that allows a second round of capital flows (Bruno and Shin, 2015).

\footnotetext{
${ }^{47}$ As the authors explain: "One channel that is often neglected in conventional monetary economics is the role of the banking sector in driving financial conditions and risk premiums over the cycle. Banks are intermediaries who borrow short and lend long, so that the size of the term spread (i.e. slope of the yield curve) influences the profitability of new lending. Since long rates are less sensitive than short rates to shifts in the central bank's policy rate, monetary policy exerts considerable influence on the size of the term spread, at least for short periods of time. Through this channel, the central bank's policy rate may act directly on the economy through greater risk-taking by the banking sector. Borio and Zhu (2008) coined the term "risk-taking channel of monetary policy", and Adrian and Shin $(2008,2011)$ and Adrian, Estrella and Shin (2009) have explored the workings of the risk-taking channel empirically, finding empirical support for the risk-taking channel for the United States. In this chapter, we will explore the workings of the risk-taking channel in an international setting through the cross-border activity of global banks." (Bruno and Shin, 2015, p. 2-3). See the article for mentioned references.
} 
A different approach sees the VIX as an indicator of liquidity preference. High levels of liquidity preference - and of the VIX - would lead to flight to assets denominated in highlyliquid currencies ${ }^{48}$ capital flowing to EMEs only if liquidity preference is low (Weiss and Prates, 2015). This approach and this causality are adopted in the thesis. According to this view, it is expected that a moment of low liquidity preference, marked by a low and stable VIX would allow appreciation of the emerging currency, while a hike in liquidity preference would lead to depreciation (as shown in Chapter Three).

\subsubsection{The VIX Index and Emerging Currencies}

Given the association between liquidity preference in international financial markets and capital flows to emerging countries, and the impact of capital flows on a country's currency, emerging currencies are expected to respond to liquidity preference. As shown by Kaltenbrunner and Painceira (2009) for the Brazilian real:

one can observe a strong comovement of this indicator of international market conditions and the Brazilian real. As global risk or risk aversion increases, so does the Brazilian real as international investors quickly adjust their portfolios to alternative investments. (p. 27) (also see Kaltenbrunner and Painceira (2015)).

The analysis in this chapter focuses on exchange rates because they are the object of the thesis, however, it is worth highlighting that an examination of the international liquidity preference measured by the VIX on exchange rates directly, instead of on capital flows, also has advantages. As both are high-frequency variables, the rapidly changing mood of financial markets can be more precisely captured; and as periodicity (daily) is the same for both, the analysis also gains accuracy because there is no demand for transformations, such as averaging the VIX (a procedure that could reduce much of the information contained on it).

Figure 6.14 compares the VIX with the emerging currencies from 2003 to 2013. As observed, in a number of countries the exchange rate i) appreciated until the GFC, a period where the VIX was at very low levels; ii) depreciated strongly with the GFC, a moment of historic hike of the VIX; iii) appreciated rapidly next, in tandem with the decrease of

\footnotetext{
${ }^{48}$ See this discussion in Chapter Three, Section 3.3.4.
} 
Figure 6.14: The VIX Index and Emerging Currencies: 2003 - 2013
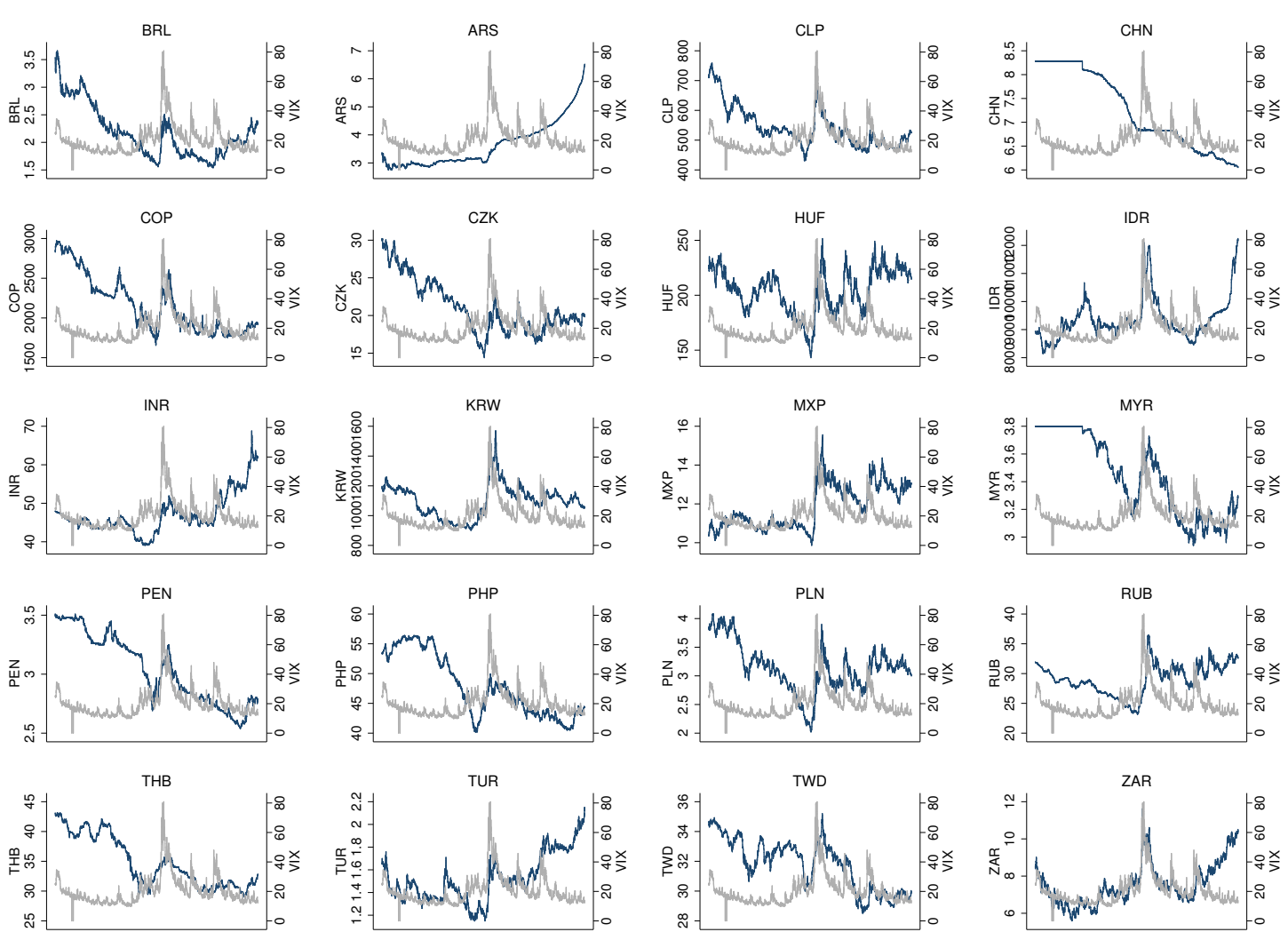

Data source for exchange rates: Ecowin; VIX: "VIX Index" (2013). For reference: the most important peak of the VIX index, on the beginning of the second half of the plots, took place on mid 2008.

the VIX; and iv) has been unstable and presented a depreciation trend since then (whose strength varies across EMEs), showing hikes in moments related to the euro-crisis and to the fear of tapering, alongside VIX hikes (as shown in the Introduction Chapter).

A graphical analysis reveals the countries where this pattern seems more important: Brazil, Chile, Colombia, Czech Republic, Hungary, Peru, Poland, Turkey and South Africa although the South African rand started depreciating before the GFC. In Mexico and South Korea there was no appreciation of the currencies before the crisis $^{49}$.

\footnotetext{
${ }^{49}$ It is interesting to highlight that the comovement of the exchange rates and the VIX seems even stronger in moments of turbulence and higher liquidity preference - the mentioned peaks of the VIX. This is in line with the arguments that comovement in financial markets is higher in moments of turbulence. Campbell et al. (2002) studies conditional correlation among different markets, concluding that their comovement is higher at bear times. Longin and Solnik (1995, p. 4) argues that correlation of financial returns internationally increases "when global factors dominate domestic ones".
} 
TABle 6.3 Correlation Between EMEs' Currencies and the VIX (2003-2013)

$\begin{array}{lc}\text { ARS } & 0 \\ \text { BRL } & 0.3818 \\ \text { CLP } & 0.2352 \\ \text { CHN } & 0.0111 \\ \text { COP } & 0.2452 \\ \text { CZK } & 0.2469 \\ \text { HUF } & 0.3147 \\ \text { IDR } & 0.0370 \\ \text { INR } & 0.1653 \\ \text { KRW } & 0.1196 \\ \text { MXP } & 0.4618 \\ \text { MYR } & 0.0915 \\ \text { PEN } & 0.1241 \\ \text { PHP } & 0.0808 \\ \text { PLN } & 0.3256 \\ \text { RUB } & 0.0059 \\ \text { THB } & 0.0714 \\ \text { TUR } & 0.3618 \\ \text { TWD } & 0.0862 \\ \text { ZAR } & 0.3520\end{array}$

The correlations are calculated based on the daily percentage changes of the variables. Almost all of these correlation coefficients are significant at the $1 \%$ level, except the Argentinean peso, the Chinese yuan, the Indonesian peso, and the Russian ruble.

To further examine the association between the VIX and emerging currencies, the correlation between the two was calculated for the 2003-2013 period (see Table 6.3). The Pearson correlation coefficients vary significantly across the countries, from 0.46 in Mexico to 0.005 in Russia. With a positive correlation coefficient, the daily exchange rates and the VIX indeces tend to lie on the same side of their respective means: when one is higher than the mean, the other is too. It is always arbitrary to denote if a correlation is strong or not. However, we can highlight the countries where the correlations of their exchange rates with the VIX index are the highest. They are: Mexico (0.46), Brazil (0.38), Hungary (0.32), Poland (0.33), Turkey (0.36) and South Africa (0.35). These are the countries where most of the variance of the exchange rate could be explained by the variance of the VIX (varying from $21 \%$ in the case of the Mexican peso to $12 \%$ in the case of the variance of the South African rand). 


\subsubsection{Explaining different levels of influence from international conditions}

The importance of the type of integration Could the different level of correlation with the VIX be explained by the type of integration these countries have? Examining the list of countries with the highest correlation with the VIX, it is found that five out of the six countries present the most financialized type of integration: Brazil, Hungary, Poland, Turkey and South Africa. Mexico presented a higher correlation with the VIX than the expected from its type of integration, but as an outlier, this does not lean against the chapter's conclusions.

In fact, the presence of Mexico in this list indicates a limitation to using correlation to measure the relationship between the two variables: the theoretically expected relationship is that a low and stable VIX leads to exchange rate appreciation (decrease of the LCU value), while a high level VIX would lead to depreciation (increase of value). However, the correlation captures only part of this relationship: when a hike of the VIX leads to an exchange rate depreciation or when a decrease leads to appreciation. The expected impact of a stable VIX on appreciating exchange rates is not captured.

That is exactly why the Mexican peso presented a higher correlation: it did not appreciate in the pre-GFC period as much as most of the other emerging currencies; it was stable, as the VIX. The high correlation coefficient of the Mexican peso reflects the high correlation in this period. The correlation of the other five countries is lessened by the fact that the behavior between the two variables, though perfect in the sense of performing in the exact way the theory had predicted, cannot be captured by the correlation coefficient.

Having taken the limitations of the use of the correlation coefficient into account, the relationship between the correlation of the emerging currencies with the VIX and their level of financialization are plotted in Figure 6.15 for the floating currencies (all except for China, who has a low level of financialization of its integration and a low level of correlation of its exchange rate and the VIX).

The figure makes it clear that the currencies of the countries with more financialized integration are those with higher correlation with the VIX, while the less financialized have 
FIGURE 6.15: Changes in the VIX Index and the Level of Financialization of Integration

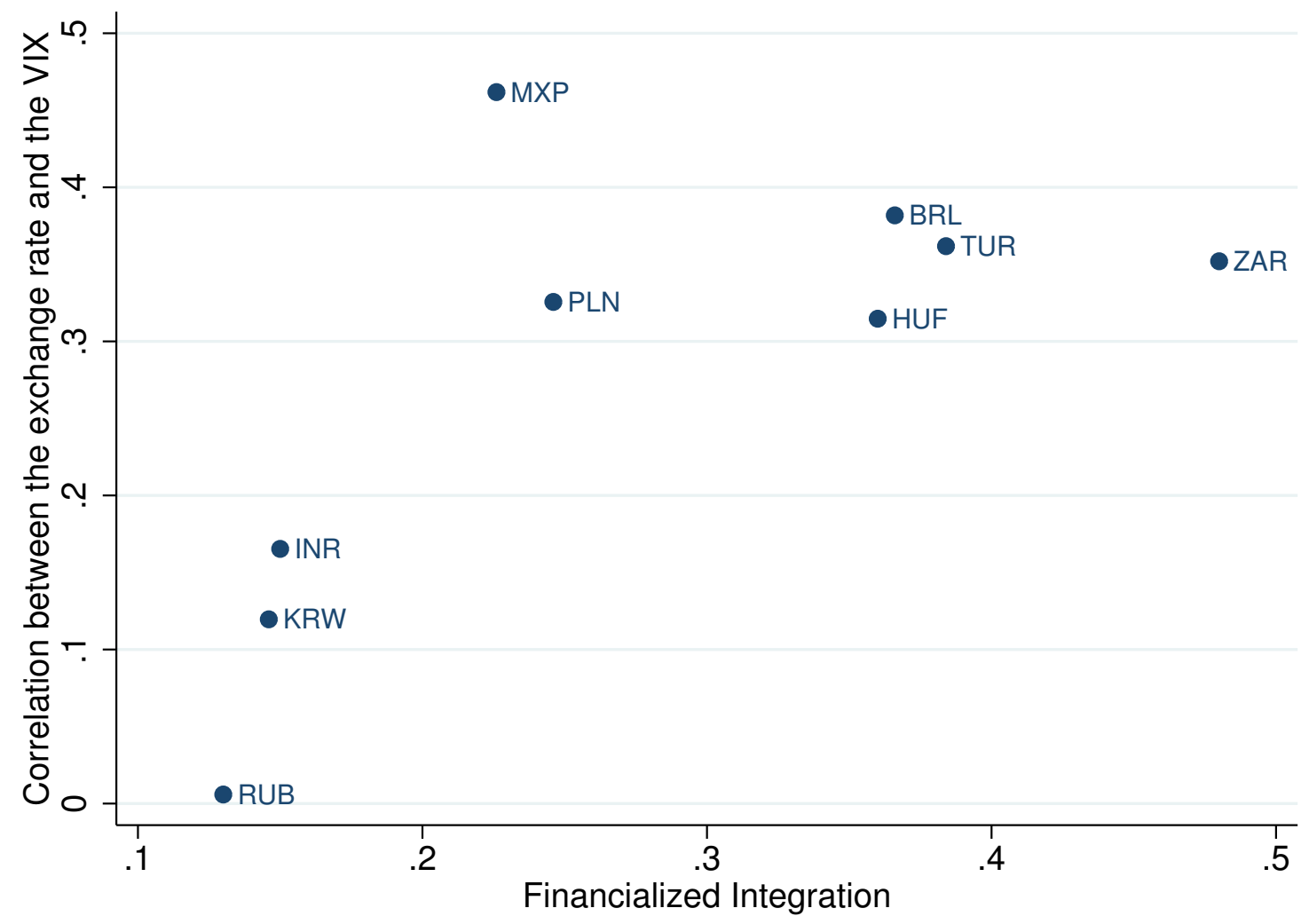

The Pearson correlation coefficient for the nine countries is 0.68 and is significant at the $5 \%$ level. When China, that does not have a floating currency, is included, the coefficient is slightly smaller, 0.65 and is also significant at the $5 \%$ level. Source: own estimations. Data source: exchange rates, Ecowin; financial integration, updated and extended version of Lane and Milesi-Ferretti (2007); GDP and trade, World Bank (2015); FX statistics, BIS (2013); VIX, Chicago Board Options Exchange (2015).

the lowest correlation. A notable outlier is the Mexican peso, for the reasons outlined above ${ }^{50}$.

The relationship yielded a very high correlation coefficient, 0.86 , and is significative at the $1 \%$ level $^{51}$, when Mexico is not considered (due to the estimation bias discussed above). The overall coefficient is also relatively high, 0.68, significative at the $5 \%$ level (for EMEs with floating currencies), see Table 6.4.

\footnotetext{
${ }^{50}$ Note that, from the graphical analysis of Figure 6.1 , the exchange rates of Chile, Colombia, Czech Republic, and Peru depreciated when the VIX increased and appreciated in periods of low VIX. We cannot, however, talk about the financialization level of their integration, due to lack of data.

${ }^{51}$ Note that causality tests are not needed here as it is not expected that the causality would run from the influence from international conditions to the type of integration.
} 
TABLE 6.4 Integration and International Influence: Pearson Correlation Coefficients

All obs.

Currency corr with the VIX Obs.

Financialized Int.

$0.5^{* *} \quad 10$

Fin.-to-Trade Int.

$-0.01$

19

Only floating regimes

Financialized Int.

$0.68^{* *} \quad 9$

Fin.-to-Trade Int.

0.13

16

Floating regime \& $B I S$ data available

Financialized Int.

$0.68^{* *} \quad 9$

Fin.-to-Trade Int.

0.08

9

$*=1 \%$ significance level ${ }^{* *}=5 \%$ significance level ${ }^{* * *}=10 \%$ significance level. Countries with non-floating regimes in the analyzed period are China, Malaysia and Argentina, as discussed from the analysis of Table 6.12 presented in the Appendix. Source: own estimations, done in Stata 11. Data source: exchange rates, Ecowin; financial integration, updated and extended version of Lane and Milesi-Ferretti (2007); GDP and trade, World Bank (2015); FX statistics, BIS (2013).

Therefore, the result supports the hypothesis that a more financialized integration leads to a higher influence of the conditions of the international financial markets on emerging currencies. This is a second characteristic of these countries' currencies, in addition to the higher volatility seen in the last section.

The importance of the size of integration Analyzed through its size, instead of type, financial integration cannot explain the different levels of importance of international conditions. Indeed, the correlation coefficient between the financial-to-trade integration and a currency correlation with the VIX is 0.08 and not significative at the $10 \%$ level. Table 6.4 presents the different coefficients estimated for the different country groups. There is not a significant relationship between this indicator and the influence of international liquidity conditions. The absence of correlation between financial integration and a currency's correlation with the VIX is also observed when other indicators are used as proxy for financial integration, as financial integration to GDP or financial openness (which will be discussed in Section 6.5). 


\subsubsection{The VIX Index, Stock Exchange, and Exchange Rates}

Because it affects foreign investors decisions, a change in the VIX index could also affect markets where these investors keep their assets, which could be observed as a relationship between the VIX index and EMEs' stock indices. The subsection analyzes whether such a relationship has occurred among EMEs in the recent period.

First, the evolution of the EMEs' major stock exchange indices for the period of 2000 to 2013, presented in Figure 6.16, is examined. As observed, most countries saw an important hike of their stock markets until the GFC (which is presented as a reference line in the plots), when they suffered important, but (in most cases) short-lived, losses. The GFC shock was followed by an important hike in most EMEs and from 2011 onward, due to the Euro crisis, the most common pattern is a side movement. After the crisis, some markets continued to gain value (Argentina, the Philippines, Thailand, Turkey and South Africa), but in most of them the stock index had, in 2013, a similar value as in 2010.

Stock markets in some of the Asian countries and in South Africa ${ }^{52}$ continued to boom in the aftermath of the GFC.

The stock indices and the VIX index are plotted against each other in Figure 6.17 for a better look into the two series ${ }^{53}$. The plots suggest a stronger relationship between the two in some countries and also vary for different periods. But generally the two series tend to move in opposite directions: periods of fall of the VIX index go in tandem with the rise of the countries' stock indices. As expected, this relationship is the clearest for the U.S. S\&P 500 index, as the VIX is based on the U.S. market - although not being estimated based on the S\&P 500 index.

In order to further analyze this relationship, a correlation between the two was estimated. Given that the relationship seems to evolve through time, different coefficients were estimated based on 80-day periods (or approximately four months). They are presented in the form of a moving average (20 days) for ease of reading the graphs (see Figure 6.18).

\footnotetext{
${ }^{52}$ Argentina is a third case, where there was no rise and side movement nor only rise. There was a rise, interrupted by a side-movement and a rise.

${ }^{53}$ The S\&P index is also plotted for enabling a comparison between the U.S. and the EMEs' equity-cycles and the equity-VIX relationship.
} 
Figure 6.16: EMEs' Stock Exchange indices: 2000 to 2013
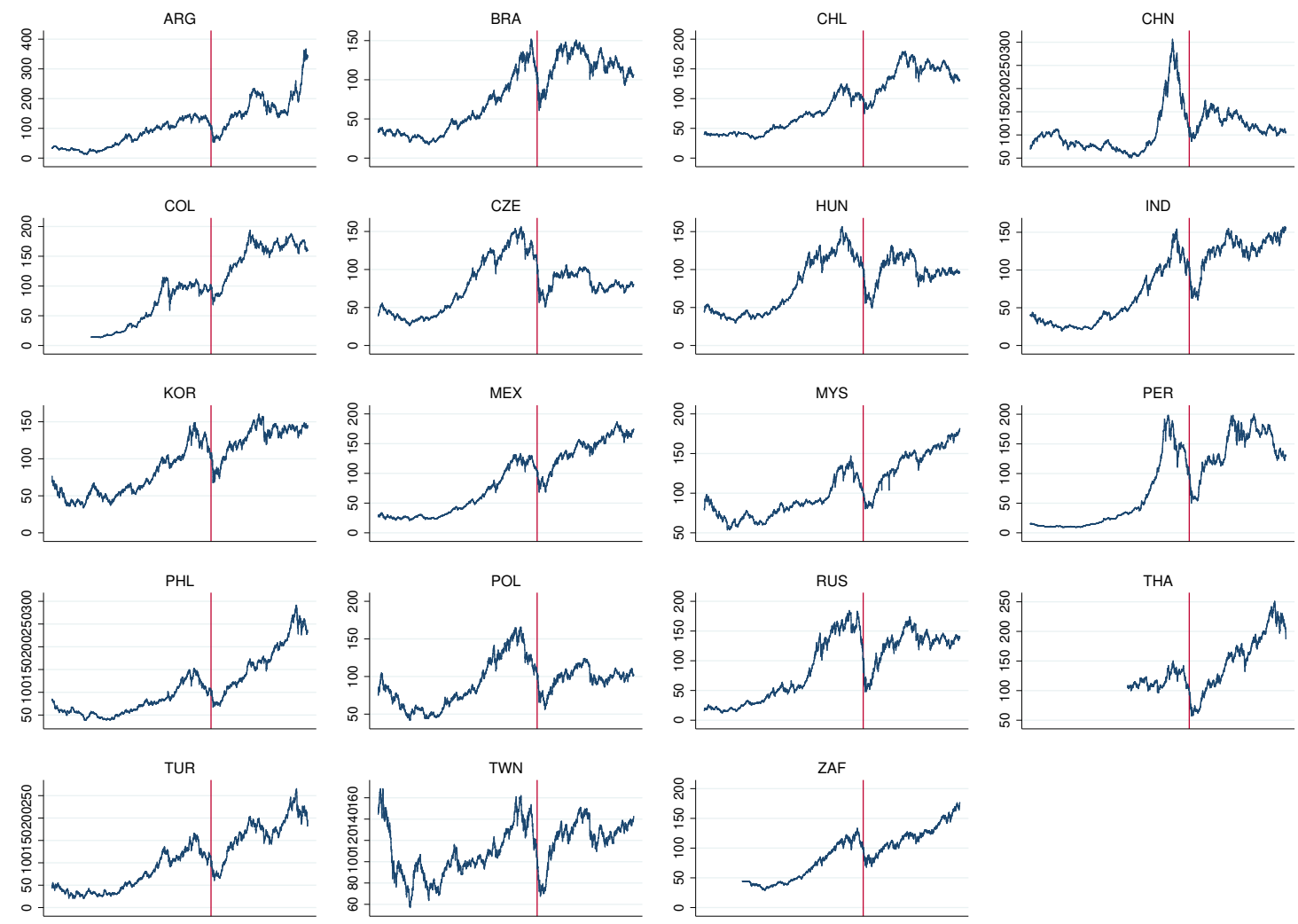

For the details on the indices used and their data sources, see Table 6.13 in the Appendix. The series are constructed having September 15th, 2008 as the 100-points basis. This date is presented as a vertical line for reference.

The plots indicate that the correlation between the VIX and the local stock-exchange prices tend to be negative and is confirmed by the fact that the median of the correlation coefficients are all negative - meaning that in at least $50 \%$ of the time the (sub-periods') correlation is negative - see Table 6.5. Taken by the mean of the coefficients, Mexico (-0.51), Brazil (-0.45) and South Korea (-0.45) have the stock markets that presented the highest correlation with the VIX index. On the opposite end are China (-0.04), Malaysia (-0.12) and the Philippines (-0.14).

Although it is difficult to observe a common pattern of the correlation coefficients through time, they tend to be stronger (and more frequently negative) during the GFC period. This is remarkable for the cases of South Africa, Brazil, Poland, Hungary, India, and Korea - see Figure 6.18. An exception is the case of Mexico, where the coefficients seem to 
FIGURE 6.17: EMEs' Stock Exchange indices and the VIX Index
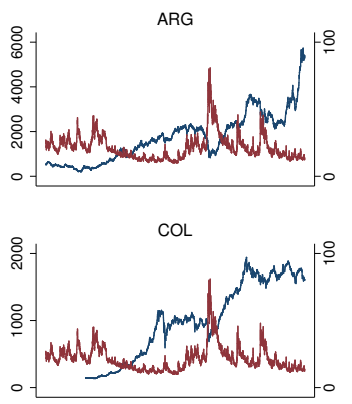

KOR
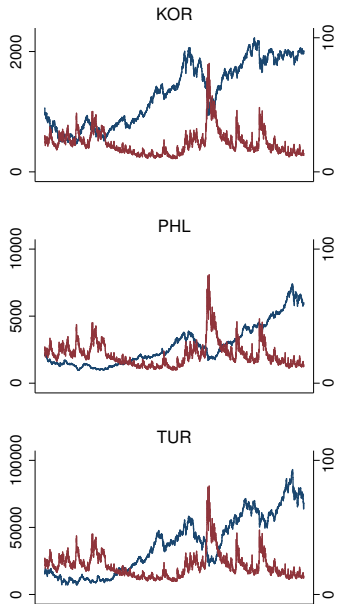

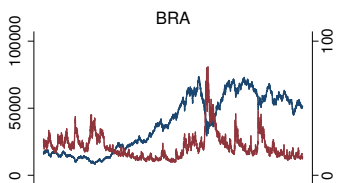

ZE

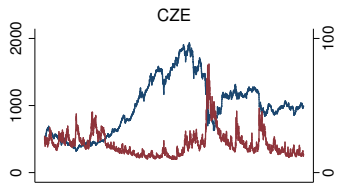

MEX
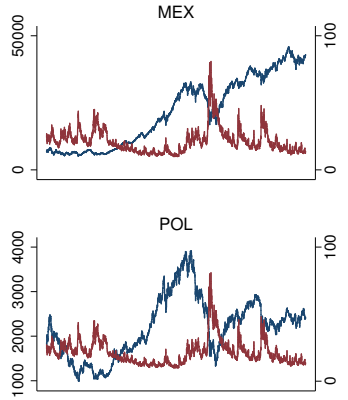

TWN

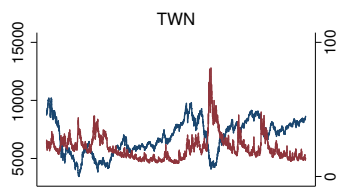

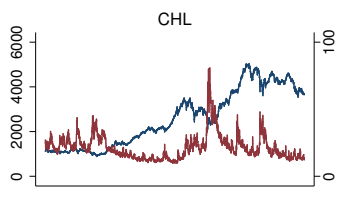
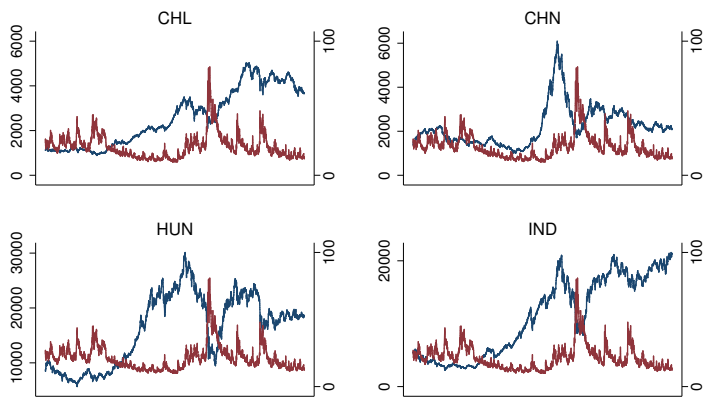

MYS
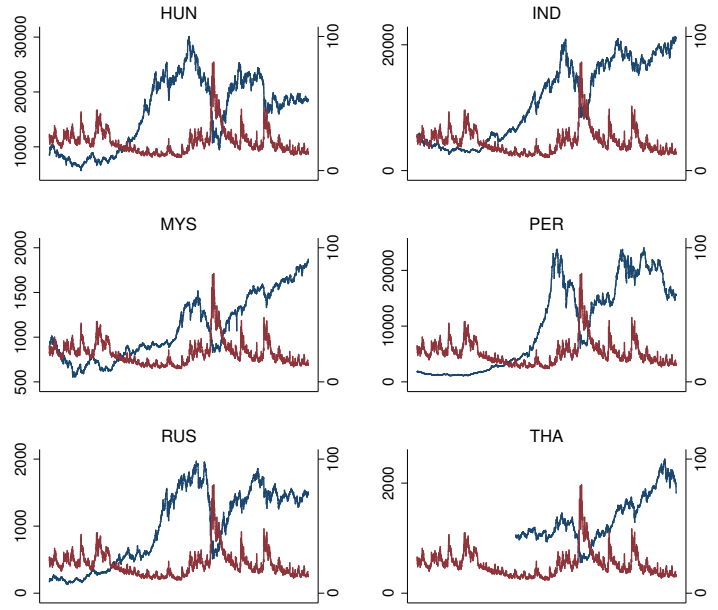

ZAF

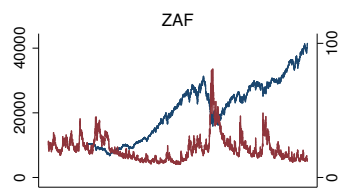

THA

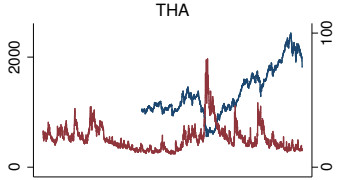

USA

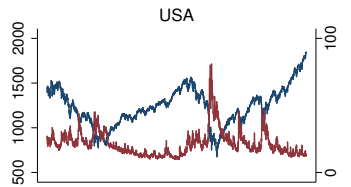

Source: own estimations. Data source of the VIX, Chicago Board Options Exchange (2015). For the details on the indices used and their data sources, see Table 6.13 in the Appendix.

vary less and are low throughout the period.

\subsubsection{Explaining different correlation levels: the type of financial integration}

Would the VIX-stock-exchange correlation depend on the type of a country's integration to international financial markets? Brazil and South Africa are among the countries with the strongest correlations and that present very financialized integration. China and India are on the other end, having weak correlation and no financialized integration. This relationship is presented in Figure 6.19. As expected, it is negative (a more financialized type of integration is associated with a stronger negative correlation between the country's stock market and the VIX index), but it is weak, with a low correlation coefficient (-0.11) that is not significant at the $10 \%$ level. 
Figure 6.18: Moving Average of the Correlation Between EMEs' Stock Exchange and the VIX indices

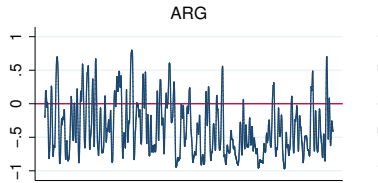

$\mathrm{COL}$

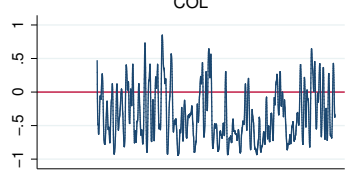

KOR

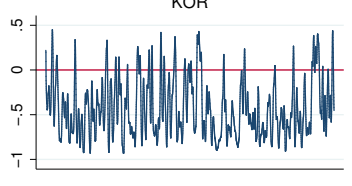

PHL

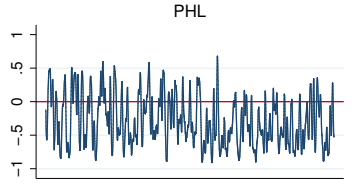

TUR

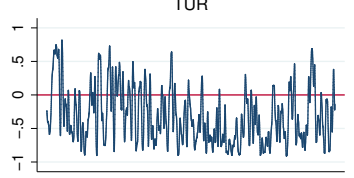

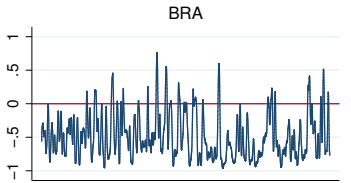

CZE

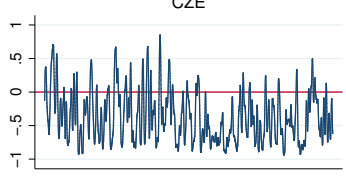

MEX

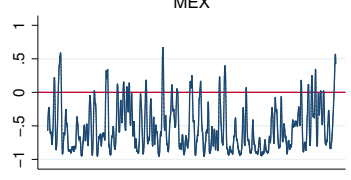

POL

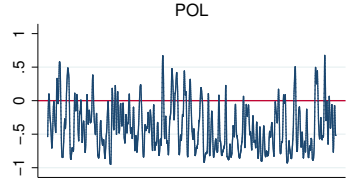

TWN

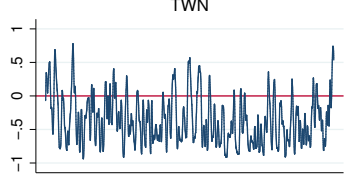

$\mathrm{CHL}$

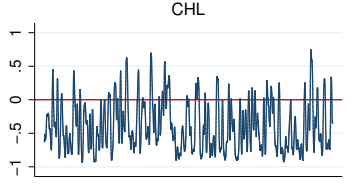

HUN

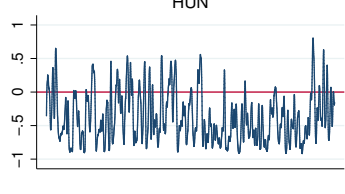

MYS

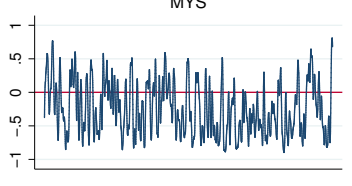

RUS

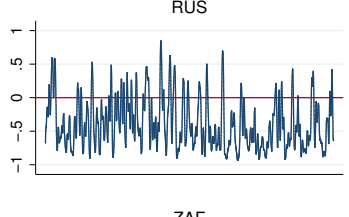

ZAF

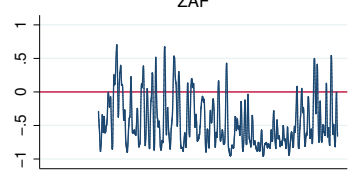

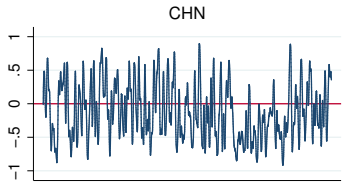

IND

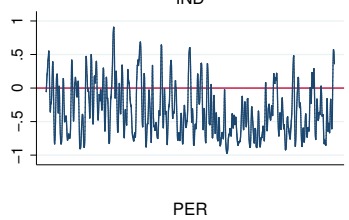

PER

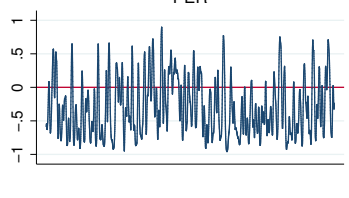

THA

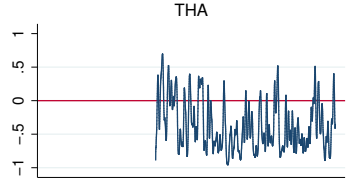

USA

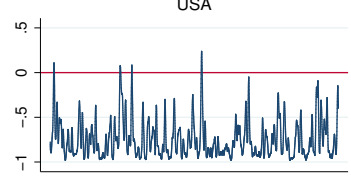

Source: own estimations, done in Stata 11. Data source: exchange rates, Ecowin; VIX, Chicago Board Options Exchange (2015). For the details on the stock market indices used and their data sources, see Table 6.13 in the Appendix.

The VIX seems to be more closely related to the changes on exchange rates than to the countries' equity markets. There are two possible explanations: i) the impact of the VIX is divided among different markets - not only on stock exchanges, but also in the securities market, for instance; and ii) the spot exchange rate is also impacted by the pressure from derivatives markets ${ }^{54}$.

\footnotetext{
${ }^{54}$ As discussed in Chapter Two, the spot and the future markets are connected through arbitrage, one having an impact on the other. The direction of the impact will depend on the size of each market (Farhi, 1999).
} 
TABLE 6.5 EMEs' Stock indices and VIX: Correlation Coefficients

\begin{tabular}{lccc} 
Country & $\mathrm{N}$ & mean & $\mathrm{p} 50$ \\
\hline ARG & 1056 & -0.25 & -0.34 \\
BRA & 1056 & -0.45 & -0.49 \\
CHL & 1056 & -0.42 & -0.48 \\
CHN & 1056 & -0.04 & -0.05 \\
COL & 170 & -0.30 & -0.34 \\
CZE & 1056 & -0.28 & -0.33 \\
HUN & 1056 & -0.37 & -0.47 \\
IND & 1056 & -0.20 & -0.20 \\
KOR & 1056 & -0.45 & -0.48 \\
MEX & 1056 & -0.51 & -0.64 \\
MYS & 1056 & -0.12 & -0.18 \\
PER & 1056 & -0.38 & -0.52 \\
PHL & 1056 & -0.14 & -0.11 \\
POL & 1056 & -0.31 & -0.36 \\
RUS & 1056 & -0.35 & -0.42 \\
TUR & 1056 & -0.18 & -0.29 \\
TWN & 1056 & -0.25 & -0.28 \\
ZAF & 192 & -0.46 & -0.49 \\
USA & 1056 & -0.74 & -0.81
\end{tabular}

Source: own estimations, done in Stata 11. Data source: exchange rates, Ecowin; VIX, Chicago Board Options Exchange (2015). For the details on the stock market indices used and their data sources, see Table 6.13 in the Appendix.

\subsubsection{Concluding Remarks}

The evidence presented in this section supports the idea that currencies of EMEs with a more financialized integration are subject to a higher influence from the international financial conditions. This evidence might favor arguments on the importance of push factors and, specifically, on the importance of liquidity preference, in determining emerging currencies dynamics - as argued by the literature on emerging currencies specificities (mentioned in this section and deeply discussed in Chapter Three (Section 3.3.4)).

The importance of push factors on exchange rates, however, do not necessarily involve a change in the amount of capital flows (as studied by the push-vs-pull literature), especially if measured as net-flows, because most financial transactions yield zero-net flows (Borio and Disyatat, 2011). This might be worst in the case of the Brazilian real. First, in Brazil, where FX derivatives are non-deliverable, operations are settled in domestic (BRL) and not in the foreign currency (U.S. dollar) (Fritz and Prates, 2014). Secondly, most of the onshore 
Figure 6.19: Correlation Between Stock Exchange and the VIX indices and Financialized Integration

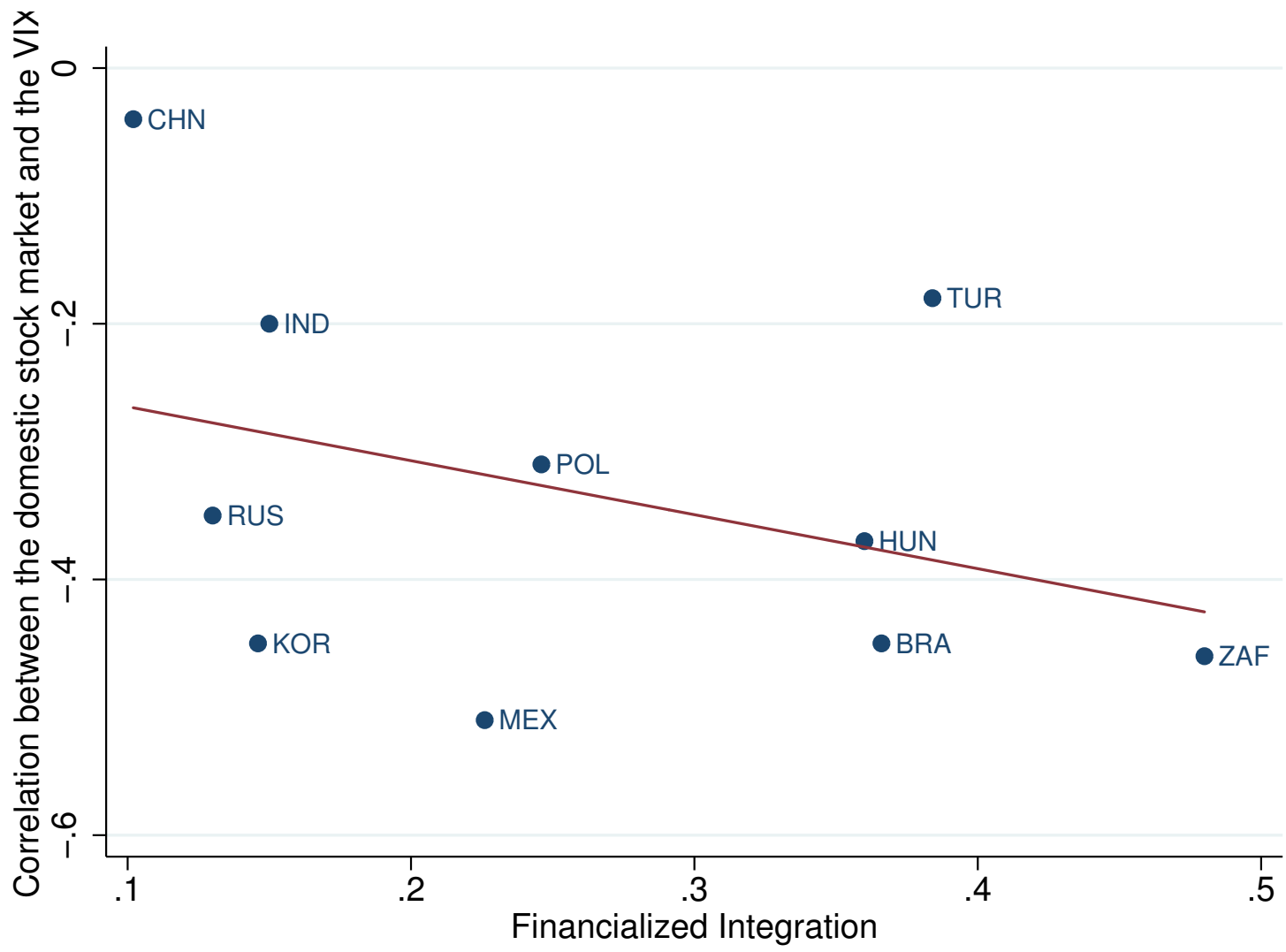

The correlation of these 10 EMEs' yields a coefficient of -0.42 and only for floating currencies, -0.11 . None of these two is significant at the $10 \%$ level. Source: own estimations, done in Stata 11. Data source: exchange rates, Ecowin; financial integration, updated and extended version of Lane and Milesi-Ferretti (2007); GDP and trade, World Bank (2015); FX statistics, BIS (2013). For the details on the stock market indices used and their data sources, see Table 6.13 in the Appendix.

activities involve changes that take place in foreign current accounts, resulting in changes in foreign asset and liabilities positions of residents (Rossi, 2014, p. 647), but in less capital flows (see the discussion in Chapter Five (Section 5.1.1).

The fact that the VIX index has an impact on exchange rates but not on the countries' equity markets is evidence that supports this view. It also might be seen as evidence of increasing currency financialization (investors trading the currency per se, not necessarily its assets) and carry trade specifically. However, to further argue that the VIX directly impacts emerging currencies without impacting the countries' markets would demand an analysis of the impact of the VIX index on other asset markets: The part of capital flows directed to 
stock markets in EMEs is small (as discussed in Chapter Four) and the impact on flows and then on the exchange rate could take place through other markets.

To be subject to changes in international financial conditions, this second currency feature, as the first (high volatility), is explained by the type of integration, but not by its relative magnitude. This suggests the importance of considering the characteristics of FX markets in explaining emerging currencies patterns.

\subsection{Comovement and Correlation of Different Currencies}

The main prices in integrated financial markets have a tendency of comovement, as different markets become options for portfolio diversification strategies for groups of investors. Chapter Two discussed that this happens with financialization: as money managers' portfolios include both advanced and emerging countries' markets, asset prices in these markets are tied together ${ }^{55}$. Given this effect on asset prices, a strand of the literature on financial integration uses price-related indicators to characterize integration, as discussed in Chapter Five.

If international investors have EMEs' assets in their portfolios, and considering that demand for their assets impacts not only asset prices but also the exchange rate, EMEs' exchange rates are also expected to comove. Note that this hypothesis seems to hold at least for some emerging currencies, as seen by the correlation of their exchange rate paths with the VIX index.

In order to study the hypothesis of increasing exchange rate comovement, two exercises are done. First, a Principal Component Analysis (PCA) of the changes in emerging currencies is done for three different periods in order to analyze whether comovement has increased. The second is a study of the correlation of different emerging currencies.

\footnotetext{
${ }^{55}$ The idea that foreign investors tie financial markets together made Hofmann and Takáts (2015), analyze comovement of interest rates only of countries that are "well integrated in the global financial system", arguing that it would be an advancement vis-a-vis of other studies given that "global financial and economic integration (...) determines the strength of investor arbitrage by tying bond market rates to those prevailing in the core economies."
} 


\subsubsection{Comovement of Currencies}

Chapter Four provides an explanation of the PCA methodology and a review of the literature that uses it. For this analysis, it is important to understand that with PCA a series of components is estimated to explain the variability of a dataset. If the data is perfectly correlated, only one component would explain $100 \%$ of the variability. If the number of components needed to explain the variability approaches the number of series in the original dataset, we can say that the variability in the original series was high. In this sense, Reinhart and Reinhart (2008), for instance, use a PCA analysis to study whether the comovement of exchange rates of selected countries decreased following the imposition of capital account controls. This is done by comparing the number of components needed to explain the variability of the exchange rate series in different periods. The same type of analysis is presented here.

The study is done with data on daily percent change of emerging currencies, or 20 data series. The periods were chosen to reflect the different characteristics of exchange rates and the cycle of capital flows: 2000 to 2003 is a period before the hike in inflows of capital to EMEs; 2003 to August, 2008 was marked by tranquility in exchange rate markets; and from then to 2013 there were significant depreciations with the GFC, the two-speed recovery and its inflows and major appreciation and turbulence related to the Euro crisis and the fear of tapering (see the discussion in the Introduction Chapter). The summary of the results are presented in Table 6.6 and the details for the respective periods are presented in Tables 6.16, 6.17, and 6.18, in the Appendix.

TABLE 6.6 PCA: Exchange Rate Changes. Summary of Results

\begin{tabular}{lcc} 
Period & Number of Components & Rho \\
\hline 2000 to 2003 & 6 & 0.4624 \\
2004 to 2008, Aug & 5 & 0.4853 \\
2008, Aug to 2013 & 4 & 0.5597
\end{tabular}

Source: own estimations, done in Stata 11. Data source of exchange rates, Ecowin.

To explain the variability in the dataset ${ }^{56}$ for the period of 2000 to 2003 , before the beginning of the boom of financial flows to EMEs, six components are needed. With these

\footnotetext{
${ }^{56}$ In line with the literature, we follow the Kaiser rule: only components whose Eigenvalues are greater than one are considered.
} 
six components, $46.24 \%$ of the variability is explained ${ }^{57}$.

In the following period, from 2003 to August of 2008, when capital flows to EMEs were abundant and exchange rates slowly appreciated throughout the period in most EMEs, a set composed by a smaller number of components, five, is able to explain more of the variability of the exchange rate series: $48 \%$; meaning that the path followed by these currencies presented more similarities in this period than in the prior one. The higher comovement in this period is expected given that the previous one saw some exchange rate crises and because countries' integration was higher with the new inflow of capital.

In the third and last period, from August 2008 to 2013, the comovement of the emerging currencies increased even more: with only four components, $56 \%$ of the variability is explained. The decreasing number of components needed to explain an increasing variance of the exchange rate series indicate that the emerging currencies have, since the 2000s, followed an increasingly similar path. This comovement was estimated including all 20 currencies studied in this chapter. As expected, when only currencies that follow floating regimes are studied, the similarity of the relationship is even greater.

This increasingly similar path of emerging currencies indicate that these countries have become increasingly tied to the global network of portfolio diversification, and thus, have been more influenced by them. In this sense, this is another evidence of the influence of the international financial scenario in the determination of emerging currencies - along with the correlation of emerging currencies with the VIX for the countries with the highest levels of financialized integration.

\subsubsection{Explaining different correlation levels: the type and the size of financial integration}

The influence of international financial conditions is not expected to be the same across emerging currencies - in the same way that some currencies presented a stronger relationship with external financial conditions (proxied by the VIX), it would be expected that these currencies would present a more similar pattern. In the PCA, this would result in these

\footnotetext{
${ }^{57}$ In the Table 6.6 this percentage can be found under the label "Rho", and in the Tables 6.16, 6.17, and 6.18 , it is presented as the "Cumulative" explanatory value of the last "Component" used.
} 
currencies composing a unique component ${ }^{58}$, given that a component indicates observations that are more correlated to each other.

When analyzing the components that resulted from the PCA, we see that in the 20032008 period, marked by lower uncertainty (or tranquility, in Minsky's terms) and low VIX levels, the set of countries that are grouped in the first component - which, by definition, is the one that gathers the most similar countries thus explaining the highest part of the variability of the whole dataset - is the one of low-volatility currencies: the Indian rupee, the Indonesian rupiah, the Korean won, the Malaysian ringgit and the Philippine peso. That these currencies presented the most similar paths is a reflection that they presented only small variations, while others varied significantly, mostly following an appreciation trend, but not necessarily of the same magnitude. The fact that they are all Asian currencies also make them subject to the same set of factors.

What is impressive, however, is that the group of currencies that compose the first component of the PCA conducted for the turbulent 2008-2013 period includes the Brazilian real ${ }^{59}$, the Czech koruna, the Hungarian forint, the Mexican peso, the Polish zloty, the Turkish lira, and the South African rand, which are the currencies that present the highest volatility. In other words, even with significant deviations in this period, these currencies presented a more similar path than the low-volatility (small deviations) ones, pointing to the significance of their comovement. Currencies of small deviations are also highly correlated among themselves: the Indian rupee, the Korean won, the Russian ruble, and the Chinese yuan. Figure 6.20 presents these two sets of inter-correlated currencies in the mid-2008 to 2013 period against their respective level of financialized integration.

As shown by Figure 6.20, the group of highly correlated currencies is also similar to the group of currencies with the most important FX markets and presents the most financialized type of integration. Indeed, the correlation between the loading on this first component and the level of financialized integration yields a very high correlation coefficient, 0.77 , significant at the $5 \%$ level. The relationship between comovement and the financial-to-trade integration, the level of financial integration or the financial integration over GDP are not significant.

\footnotetext{
${ }^{58}$ The currencies that compose the different components are the ones who have the highest loadings on each. In Tables 6.16, 6.17, and 6.18, only loading higher than 0.3 (in absolute values) are presented for ease of reading.

${ }^{59}$ Brazil's loading, 0.29 , is not shown as only values higher than 0.3 are printed.
} 
Figure 6.20: Exchange Rate Comovement from August 2008 to 2013 and Financialized Integration

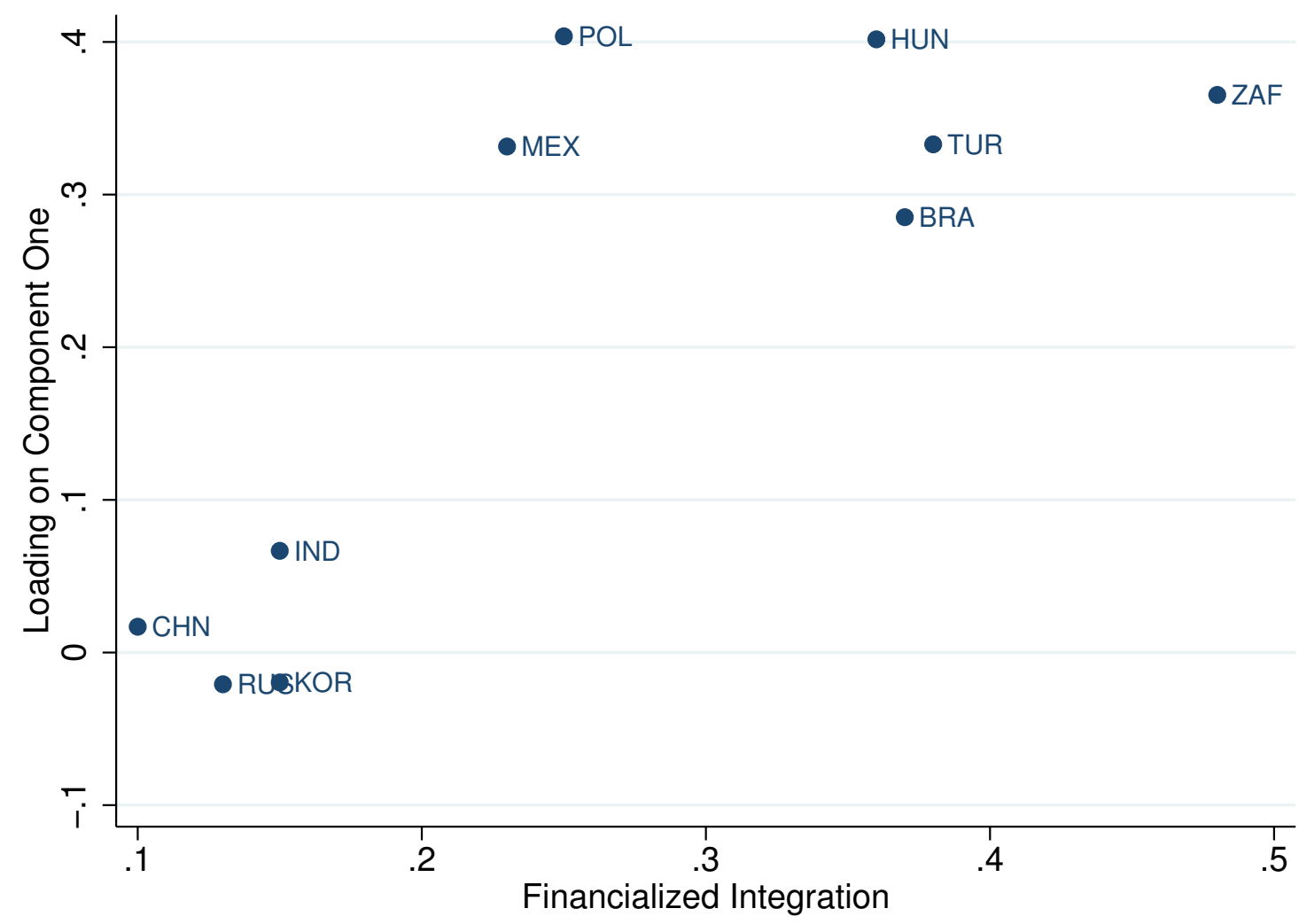

The correlation of these 10 emerging currencies yields a coefficient of 0.81 significant at the $1 \%$ level. When only for floating currencies are considered, the coefficient is 0.77 , significant at the 5\% level. Source: own estimations. Data source: exchange rates, Ecowin; financial integration, updated and extended version of Lane and Milesi-Ferretti (2007); GDP and trade, World Bank (2015); FX statistics, BIS (2013).

This result could suggest that a more financialized integration increases the comovement of floating emerging currencies.

\subsubsection{Correlation of Currencies}

It is also interesting to note the correlation among the different emerging currencies. They are presented in Table 6.19 and 6.20 in the Appendix. As expected, some emerging currencies are correlated with others, while others are more independent. The Argentinean peso and the Chinese yuan, which presented long periods of fixed rates, have low average correlation coefficients. On the other end are the Polish zloty, the Hungarian forint, the Czech 
koruna, the Turkish lira, the South African rand and the Mexican peso present high average correlation.

It is expected that the currencies of neighboring countries are more correlated among themselves, given that they have similar ties and that foreign investors build their expectations upon the same set of variables. For instance, this is observed in the high correlation among the European emerging currencies. However, relevant correlations are also found among currencies of different regions. They are listed in Table 6.7.

TABle 6.7 Emerging Currencies With Relevant "out of the Region" correlation (2003-2013)

Brazil with Hungary, Poland, Turkey and South Africa

Czech Rep. with Mexico and South Africa

Hungary with Brazil, Mexico and South Africa

Mexico with Czech Rep., Hungary, Poland, South Africa and Turkey

Poland with Brazil, Mexico and South Africa

South Africa with Brazil, Czech Rep., Hungary, Mexico, Poland, Russia and Turkey

Turkey with Brazil, Mexico and South Africa

Correlation coefficients considered as "relevant" are the ones above 0.4 (presented in Tables 6.19 and 6.20).

From these currencies, six are highly correlated with at least three currencies of other continents: the Brazilian real, the Hungarian forint, the Mexican peso, the Polish zloty, the South African rand, and the Turkish lira. This suggests that these currencies have a higher influence on international financial conditions. Also note that these currencies have been highly correlated among themselves since the GFC and present the highest levels of financialized integration.

\subsubsection{Concluding Remarks}

Several conclusions can be drawn from the evidence presented. First, the higher comovement of emerging currencies through time as a group results from the increasing integration of EMEs to the international financial markets (as shown in Chapter Four).

Secondly, the high comovement of currencies of EMEs which have a more financialized type of integration suggests that the impact of external financial conditions on these currencies is even greater - which was also suggested by the higher correlation of these countries' 
currencies with the VIX. It is worth mentioning that this conclusion excludes the possibility that higher comovement results from a more similar path of the (mainstream notion of) 'fundamentals ${ }^{\prime 60}$. Such hypothesis is excluded given the difference of these countries' fundamentals (Kaltenbrunner and Painceira, 2014) and because the fundamentals could not be going through such significant changes ${ }^{61}$.

From a mainstream point of view, and having accepted that these countries fundamentals would not have been evolving in a synchronized fashion, the fact that emerging currencies follow similar paths explains why their estimations of misalignment tend to evolve in a similar way. As shown by Ramos (2012), Cline and Willamson's estimations of exchange rate overvaluation for countries such as Brazil, Turkey and South Africa have evolved in a similar way: they increased from 2009 to 2011, when nominal currencies appreciated, and decreased from 2011 to 2012, when they depreciated.

Therefore, it can be concluded that a third feature of the currencies of EMEs that have a more financialized type of integration to international markets exists: they all follow a similar path - in addition to being more volatile and to suffering higher influence from the conditions of international financial markets, as discussed in Sections 6.2 and 6.3, respectively.

On the relationship between these results and the debate on the importance of international liquidity cycles (discussed in section 6.3), it is interesting to highlight that the comovement of emerging currencies has increased with higher portfolio inflows (of the 20032008 period) and is at its highest level when external conditions became more volatile (in the 2008-2013 period). The higher importance of external factors in turbulent periods is in line with Hoti's (2004) argument that the international condition determines capital flows to EMEs, but domestic factors define its geographic location. In the first period, international conditions pushed capital flows to emerging countries, but these flows were not the same across countries as they are also dependent on pull factors, resulting in different exchange rate paths. In the second, turbulent period, push factors would have overcome pull

\footnotetext{
${ }^{60}$ See Chapter Three for the concept of fundamental as the variable that makes exchange rate a market clearing price as used among mainstream economists and its use by heterodox authors as a subjective variable defined by the financial convention ruling among traders.

${ }^{61}$ This impossibility is known as the third exchange rate puzzle, discussed in Chapter Three, that emerges from the observation that the exchange rates are normally much more volatile than the economic variables they are supposed to explain.
} 
ones, leading to the same movement - capital outflows - in every country and thus higher comovement.

\subsection{Other Important Elements in Explaining Emerging Cur- rency Patterns}

This chapter is focused on the relationship between a more financialized type of integration and some emerging currencies' features, notably high volatility, high frequency of extreme exchange rate depreciation, the connection of a country's exchange rate with international financial markets' sentiments and the similarity of patterns.

However, these features can also be influenced by other types of country characteristics. The exchange rate regime is an obvious first, and its role has been highlighted throughout the chapter. Other potentially important features are interest rate differential, the monetary regimes in place, the position of a country's currency in the hierarchy of currencies, whether capital account restrictions are in place, and the absolute magnitude of financial integration. This section examines how these other characteristics relate to the exchange rate features analyzed. Some have already been described when EMEs were presented in Chapter Four, and an overview can be found in Table 6.8.

It is important to keep in mind that some of these country characteristics are interdependent: the choice of the monetary and exchange rate regimes can impact the interest rate, and the size of stock markets and the financial integration level are inseparable. For EMEs, specifically, Chapter Four showed that in the 2003-2013 period a country had a higher probability of having a high interest rate differential to the Fed Fund rate when it had a "Floating" or "Free Floating" exchange rate regime associated with an inflation targeting regime. 
TABLE 6.8 An Overview on EMEs' Exchange Rate and Other Characteristics

\begin{tabular}{|c|c|c|c|c|c|c|c|c|c|c|c|c|c|c|c|c|c|}
\hline & \multicolumn{5}{|c|}{ Exchange Rate Characteristics } & \multicolumn{3}{|c|}{ Integration } & \multicolumn{3}{|c|}{ ER and Monetary Reg. } & \multicolumn{6}{|c|}{ Other Characteristics } \\
\hline & $\begin{array}{l}\text { Std. } \\
\text { Dev. }\end{array}$ & $\begin{array}{l}\text { Freq. } \\
\text { Extr. } \\
\text { Dep. }\end{array}$ & $\begin{array}{c}\text { Corr. } \\
\text { w/ } \\
\text { VIX }\end{array}$ & $\begin{array}{c}\text { Corr. } \\
\text { w/ ot. } \\
\text { reg. }\end{array}$ & $\begin{array}{l}\text { Biv. } \\
\text { Caus. }\end{array}$ & $\begin{array}{l}\text { Cap. } \\
\text { Acc. } \\
\text { Open. }\end{array}$ & $\begin{array}{l}\text { Fin. } \\
\text { Int. }\end{array}$ & FI & $\begin{array}{l}\text { Exch. } \\
\text { Rate } \\
\text { Reg. }\end{array}$ & $\begin{array}{l}\text { Mon. } \\
\text { Reg. }\end{array}$ & $\begin{array}{l}\text { Int.R. } \\
\text { Diff. }\end{array}$ & $\begin{array}{l}\text { Curr. } \\
\text { Hier. }\end{array}$ & $\begin{array}{c}\text { Derv. } \\
\text { Mkt }\end{array}$ & $\begin{array}{c}\text { Derv. } \\
\text { over } \\
\text { Spot }\end{array}$ & $\begin{array}{l}\text { St. } \\
\text { Mkt } \\
\text { Cap. }\end{array}$ & $\begin{array}{c}\text { St. } \\
\text { Corr. } \\
\text { VIX }\end{array}$ & $\begin{array}{l}\text { For. } \\
\text { Trade }\end{array}$ \\
\hline Argentina & Low & Mid & Low & Low & & Low & $\mathbf{H i}$ & 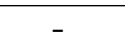 & Craw & & & Bott. & 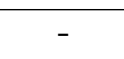 & 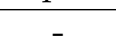 & Low & Mid & Low \\
\hline Bra & High & High & High & High & Yes & Mid & Lo & High & Float. & IT & High & Mid & Mid & High & High & High & High \\
\hline Chile & Mid & Mid & Low & Low & & High & High & - & F.Float. & IT & & Bott. & - & - & & High & Low \\
\hline Chil & Low & Low & Mid & Low & & Low & Low & Low & & Othe & Low & Top & High & Mid & $\mathrm{Hi}$ & Low & High \\
\hline 1) & Mid & $\mathrm{M}$ & Mid & Low & & Mid & Lo & - & & ITT & & & - & - & $\mathrm{Lc}$ & & Low \\
\hline ( & High & M & High & $\mathbf{H i}$ & & $\mathrm{Hi}$ & $\mathrm{Hi}$ & - & & & $\mathrm{L}$ & & - & - & & Mid & Mid \\
\hline & High & $\mathbf{H i}$ & High & $\mathbf{H i}$ & Ye & & & Hi & & $I^{\prime}$ & & $\mathrm{M}$ & Lor & Low & & Mid & Mid \\
\hline & & & & & & & & . & & & & & - & - & & Low & High \\
\hline & & & & & & & & & & & & & Lor & & & & Mid \\
\hline & h & & & & & & & & & & & & & & & & ligh \\
\hline & & & & & & & & & & & & & Iigh & & & & \\
\hline & & & & & & & & 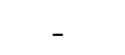 & & & & & - & - & & & \\
\hline & & & & & Yes & & & - & & & & & - & - & & & Low \\
\hline & & & & & & & & - & & & & & - & - & & w & Low \\
\hline & High & $\mathrm{Hi}$ & igh & $\mathbf{H i}$ & & & & & & & & & 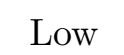 & & & & Mid \\
\hline & & & & Lo & Yes & & & Lov & & & & & High & Low & & & High \\
\hline & & & & & & Low & & - & & & & $\mathrm{Bc}$ & - & - & & & Mid \\
\hline & High & $2 x$ & $\mathbf{H}$ & $\mathrm{Hi}$ & 1 & Low & & Iig & & & & $\mathbf{T}$ & & & $\mathrm{Mic}$ & Low & Mid \\
\hline & Low & Low & & & Yes & 年 & High & - & & Other & Low & Mid & Low & High & - & Mid & - \\
\hline S. Africa & High & High & High & High & Yes & Low & High & High & Float. & IT & High & Mid & Mid & Low & High & High & Low \\
\hline
\end{tabular}

FI stands for Financialized Integration. IT, for inflation targeting. The divisions between Low (Bottom), Mid, and High (Top)

categories was done to divide the countries into groups of similar amounts of countries. High and Top are presented in bolded faces for facilitating understanding. Currency hierarchy is based on the absolute size of FX markets. Also see Figure 6.21. Data source:

exchange rates, Ecowin; financial integration, updated and extended version of Lane and Milesi-Ferretti (2007); GDP and trade, World Bank (2015); FX statistics, BIS (2013); VIX, Chicago Board Options Exchange (2015); capital account openness, Chinn and Ito

(2008). For the details on the stock market indices used and their data sources, see Table 6.13 in the Appendix. The data sources on the definition of the exchange rate and monetary regimes are presented in the Appendix II, page 335. For details on the bivariate causality among exchange rates and stock exchange indeces, see Section 4.6.2. 


\subsubsection{Exchange Rate Regimes and Monetary Policy Frameworks}

As seen in Chapter Four, most EMEs now opt for floating exchange rates and inflation targeting regimes. Are these choices associated with the currency features analyzed in this chapter? The four main currency features are highly correlated (see Table 6.8): emerging currencies with high exchange rate volatility as measured by deviation, tend to have more frequent extreme exchange rate depreciation, are more correlated with the VIX, and with other emerging currencies. There are five countries with "high" values in all four currency characteristics: Brazil, Hungary, Poland, Turkey, and South Africa. All of these countries have a floating (or free floating) exchange rate and follow an inflation targeting regime - see Table 6.8 and Figure 6.21.

Conversely, Argentina, China, Malaysia, Peru, the Philippines, Thailand, and Taiwan are the six countries with "low" values for at least three of the characteristics, and thus, have the least fragile exchange rates. Among them, three have exchange rates that follow a craw-like or a managed arrangement and a monetary regime that is not inflation targeting, and three have floating currency and inflation targeting simultaneously. The combination of floating and inflation targeting partially explains the presence or not of financialized integration: more than half of those that have opted for an IT regime with a floating currency present fragile exchange rates $^{62}$.

\subsubsection{Interest Rate Differential, Currency Hierarchy, Capital Account Open- ness, Financial Integration}

Unlike the exchange rate and monetary regimes, other 'additional' elements are quantifiable, so it is easier to grasp their relationship with currency patterns. This section analyzes how these elements are related to exchange rate volatility (standard deviation and frequency of extreme depreciation) and their correlation with the VIX.

Currency Hierarchy As extensively discussed in Chapter Three, the international monetary and financial systems are hierarchic, resulting in an asymmetry of currencies that would

\footnotetext{
${ }^{62}$ None of the three that have not opted for these two policies present financialized features. However, this is influenced from the fact that without a floating exchange rate regime volatility cannot be high.
} 
Figure 6.21: Exchange-Rate Features and Monetary and Exchange-Rate Regimes

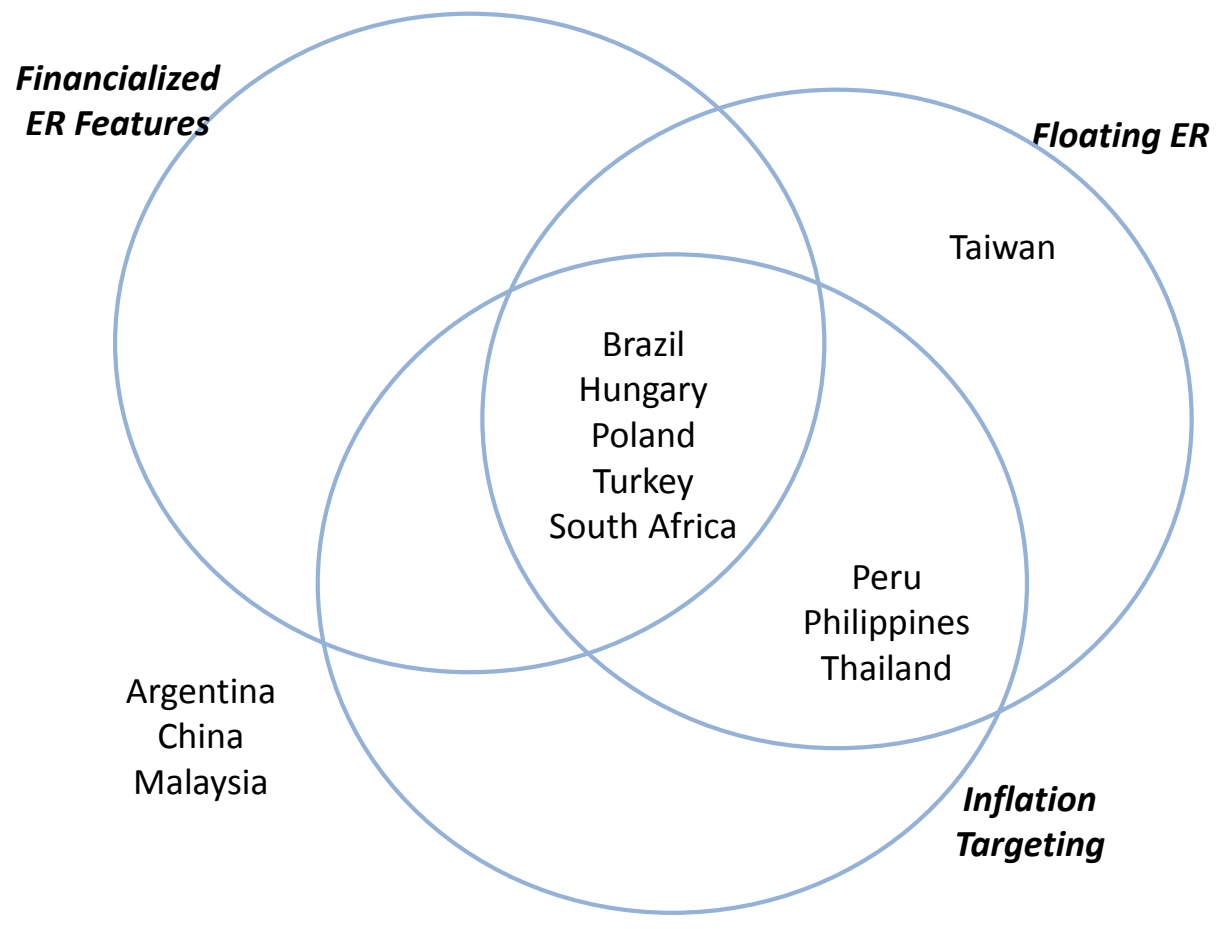

Own estimations. Data source: exchange rates, Ecowin; financial integration, updated and extended version of Lane and Milesi-Ferretti (2007); GDP and trade, World Bank (2015); FX statistics, BIS (2013). The data sources on the definition of the exchange rate and monetary regimes are presented in the Appendix II, page 335.

determine a specific pattern of demand for emerging countries' assets (denominated in currencies which do not occupy a central place in this system). Demand would be higher if there were an expectation of appreciation of these currencies, or if liquidity preference was lower, and demand would vanish if there were a hike in liquidity preference or a need for currencies that are used to denominate financial obligations. As argued in Chapter Three, the result of these considerations is that these currencies would suffer important impacts from international conditions and would more often face extreme depreciations. A proxy of the importance of a currency in the international monetary market could be the FX market turnover, in absolute values, as in De Conti and Prates (2014, p. 6). 
Interest Rate Differential As discussed in Chapter Three, interest rates, more specifically, interest rate differential with regards to that of the US (a major funding country), are a major variable in exchange rate analyses for its obvious impacts on attracting capital flows to a country.

Interest rates varied significantly among EMEs, with the 2003-2013 average ranging from about $1 \%$ in Czech Republic to more than $20 \%$ in Turkey (see Figure 6.26). Given the prevailing very low rate in the US since the GFC, the average 2000-2013 EMEs' interest rate differential is positive for every country except Czech Republic. EMEs with low interest rate differential are Taiwan, Thailand, Mexico, Peru, China and Malaysia. On the other end, Turkey, Brazil and South Africa presented much higher levels compared to other EMEs.

The recent development of EMEs' interest rate differential is rather similar, when compared to the diversity of pre-GFC levels (see Figure 6.25). Before the crisis, some countries presented (mostly) negative interest rate differentials, such as China, Czech Republic, Malaysia, Thailand and Taiwan. These disappeared with the GFC and the significant drop of US rates. At that moment, there was a marked hike of interest differential across EMEs.

Capital Account Openness and Financial Integration As seen in Section 6.1 capital account openness is sometimes used as proxy of financial integration, and can therefore be a determinant of exchange rate instability. As presented in Chapter Four (based on the index developed by Chinn and Ito (2008)), capital account openness in EMEs vary from more open, such as Peru, Chile, Czech Republic and Hungary, to countries with more restrictions, such as China, India and South Africa.

\subsubsection{Explaining exchange rate volatility: the standard deviation}

The four plots presented in Figure 6.22 show the relationship between emerging currency volatility (as estimated by the standard deviation) and the four aforementioned features. The first two plots show that the de jure indicator of financial openness and the de facto indicator of financial integration do not explain the country's exchange rate volatility: several countries have the same level of volatility with very diverse levels of liberalization, and, there 
are several cases of similar levels of integration with very diverse levels of volatility in relation to GDP.

Figure 6.22: Exchange Rate Volatility and: Capital Account Openness, Financial Integration, Interest Rate Differential and Financialized Integration
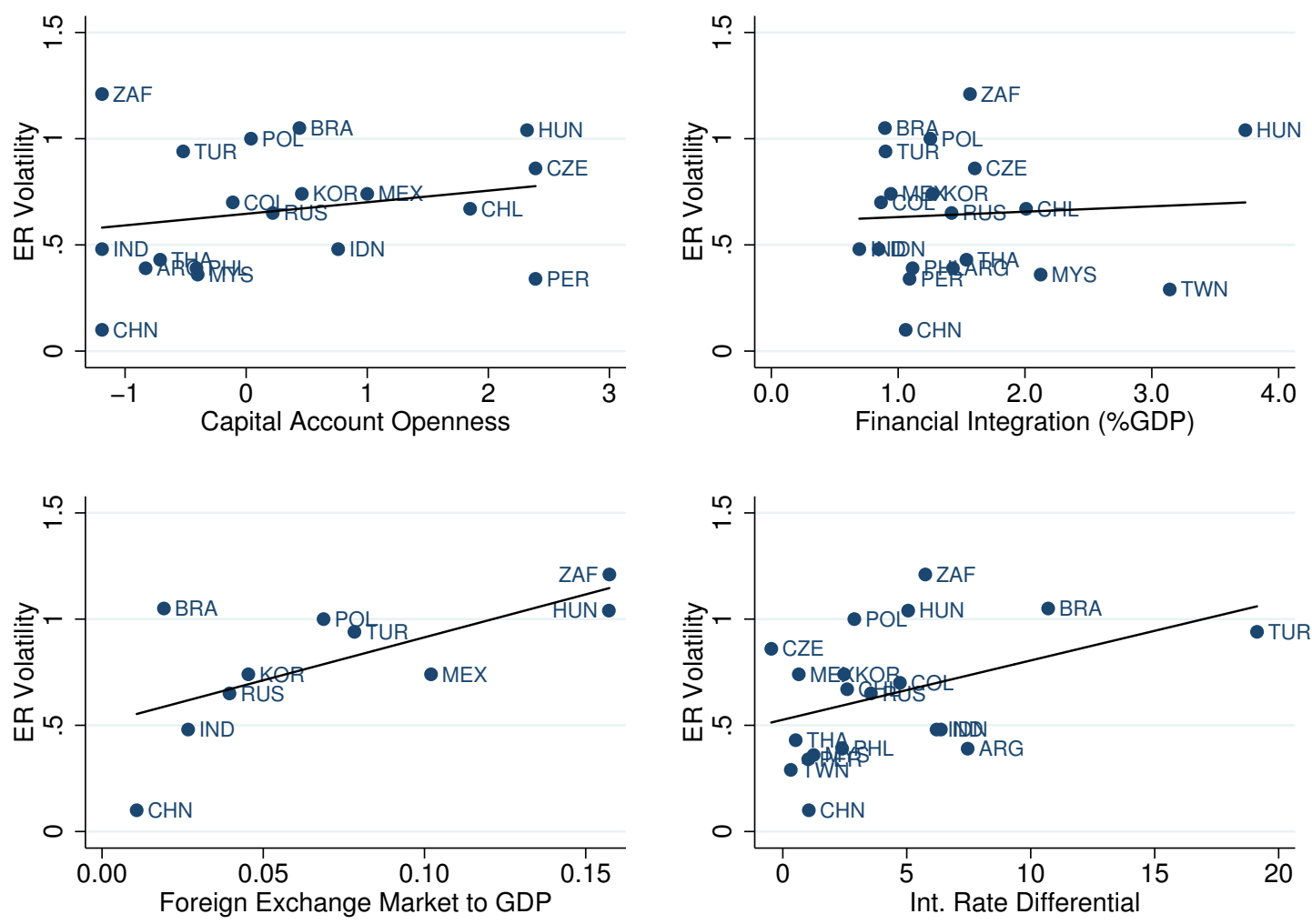

See Table 6.9 for the correlation coefficients. Source: onw estimations. Data source: exchange rates, Ecowin; financial integration, updated and extended version of Lane and Milesi-Ferretti (2007); GDP and trade, World Bank (2015); FX statistics, BIS (2013); capital account openness, Chinn and Ito (2008). For information and data sources on interest rate differential, see Appendix I, on page 334 .

The correlation coefficients complement the graphical analysis (see Table 6.9). Financial integration is not significantly associated with the standard exchange rate deviation neither through its de jure nor through de facto indicators in any of the analyzed sample (of all emerging currencies, of only those with floating regimes, and of those for whom BIS data is available, of a proxy of the size of FX markets) or in any of its different forms (absolute values, relative to GDP, relative to trade).

The association of volatility and the size of the country's FX market is relevant only 
TABle 6.9 Volatility, Standard Deviation, and Explanatory Factors: Pearson Correlation Coefficients

All obs.

Capital Account Openness

ER Volatility (St. Deviation) Obs.

Fin. Integration

$0.22 \quad 19$

Fin. Integration (\%GDP)

$-0.33$

20

Fin.-to-Trade Int.

$0.06 \quad 20$

For. Exch. Market

$\begin{array}{ll}0.27 & 19\end{array}$

For. Exch. Market (\%GDP)

$-0.28 \quad 11$

Int. Rate Differential

$0.66^{* *}$

10

Financialized Int.

$0.42^{* * *}$

20

$0.86^{*}$

10

Only floating regimes

Capital Account Openness $\quad-0.02 \quad 16$

$\begin{array}{lll}\text { Fin. Integration } & 0.05 & 17\end{array}$

$\begin{array}{lll}\text { Fin. Integration (\%GDP) } & 0.07 & 17\end{array}$

Fin.-to-Trade Int. $\quad 0.41 \quad 16$

$\begin{array}{lll}\text { For. Exch. Market } & -0.03 & 10\end{array}$

For. Exch. Market (\%GDP) $0.6^{* * *} \quad 9$

$\begin{array}{lll}\text { Int. Rate Differential } & 0.43^{* * *} & 17\end{array}$

$\begin{array}{lll}\text { Financialized Int. } & 0.9^{*} & 9\end{array}$

Floating regime $\&$ BIS data available

$\begin{array}{lll}\text { Capital Account Openness } & 0.13 & 9\end{array}$

Fin. Integration $\quad-0.51 \quad 9$

Fin. Integration (\%GDP) $\quad 0.39 \quad 9$

Fin.-to-Trade Int. $\quad 0.49 \quad 9$

For. Exch. Market $\quad-0.39 \quad 9$

For. Exch. Market (\%GDP) $\quad 0.6^{* * *} \quad 9$

Int. Rate Differential $\quad 0.26 \quad 9$

Financialized Int. $\quad 0.9^{*} \quad 9$

$*=1 \%$ significance level ${ }^{* *}=5 \%$ significance level; ${ }^{* * *}=10 \%$ significance level. Countries with non-floating regimes in the analyzed period are China, Malaysia and Argentina, as discussed from the analysis of Table 6.12 presented in the Appendix. Source: own estimations, done in Stata 11. Data source: exchange rates, Ecowin; financial integration, updated and extended version of Lane and Milesi-Ferretti (2007); GDP and trade, World Bank (2015); FX statistics, BIS (2013); capital account opennesses, Chinn and Ito (2008). For information and data sources on interest rate differential, see Appendix I, on page 334 . 
when seen in relation to GDP. The relationship is positive and only Brazil and China seem to be slightly out of the (linear) fitted line - Brazil for having higher than predicted volatility, and China, lower than predicted. There is a strong association between the size of FX market not only among emerging currencies with floating exchange rate regimes (0.6) but also when the sample includes countries with non-floating regimes (0.66). It is however important to highlight that it is not clear if the debate on the nature of the international financial system considers the size of the FX market in relation to GDP. When taken in absolute values, the size of the FX market is not correlated with exchange rate volatility, as seen in Table 6.9.

Interest rate differential is positively related to exchange rate volatility, though there are outliers: the South African rand, and the non-floating Chinese yuan and Argentinean peso. As shown by the correlation coefficient, its association with volatility is less important than that of the relative importance of the FX markets to GDP and of the level of financialized integration. When analyzing the countries with the most important FX markets, interest rate is not a significant factor - with a correlation coefficient that is not significant at the $10 \%$ level.

In conclusion, the correlation coefficients suggest a better explanatory power of the type of integration with regards to financialization - a factor that presents a much higher correlation coefficient. Considering only the nine floating currencies for which we have the level of financialized integration, the association of this indicator with exchange rate volatility yields a coefficient of 0.9 , while the correlation coefficient for the association between the size of FX markets is of 0.6 and that of interest rate differential is not significant.

Compared to the (non) significance of the size of the integration (in absolute forms or relative to trade or GDP) to explain exchange rate volatility, results suggest the importance of adding considerations on the type of the FX market analyzed (the weight of derivatives markets) and on its size to understand emerging currency volatility. The relative size of the integration is however still important in explaining volatility as seen by the significant difference between the correlation coefficients of the relative size of the FX market (0.6 to 0.66 ) and the one of financialized integration (where these factors are taken into account, 0.86 to 0.9$)$. 


\subsubsection{Explaining exchange rate volatility: frequency of extreme depreciation}

The plots on Figure 6.23 show the relationship between the frequency of extreme depreciation of emerging currencies against the four additional elements from above. Capital account liberalization and financial integration do not relate to extreme depreciations: the relationship (if any) is weak and there are many outliers. The correlation coefficients (shown in Table 6.10) confirm that no significant relationship between the level of financial integration (in its de jure or de facto, absolute or relative forms) and the frequency of extreme exchange rate depreciation is found.

Figure 6.23: Frequency of Extreme Depreciation, Capital Account Openness, Financial Integration, Interest Rate Differential and Financialized Integration
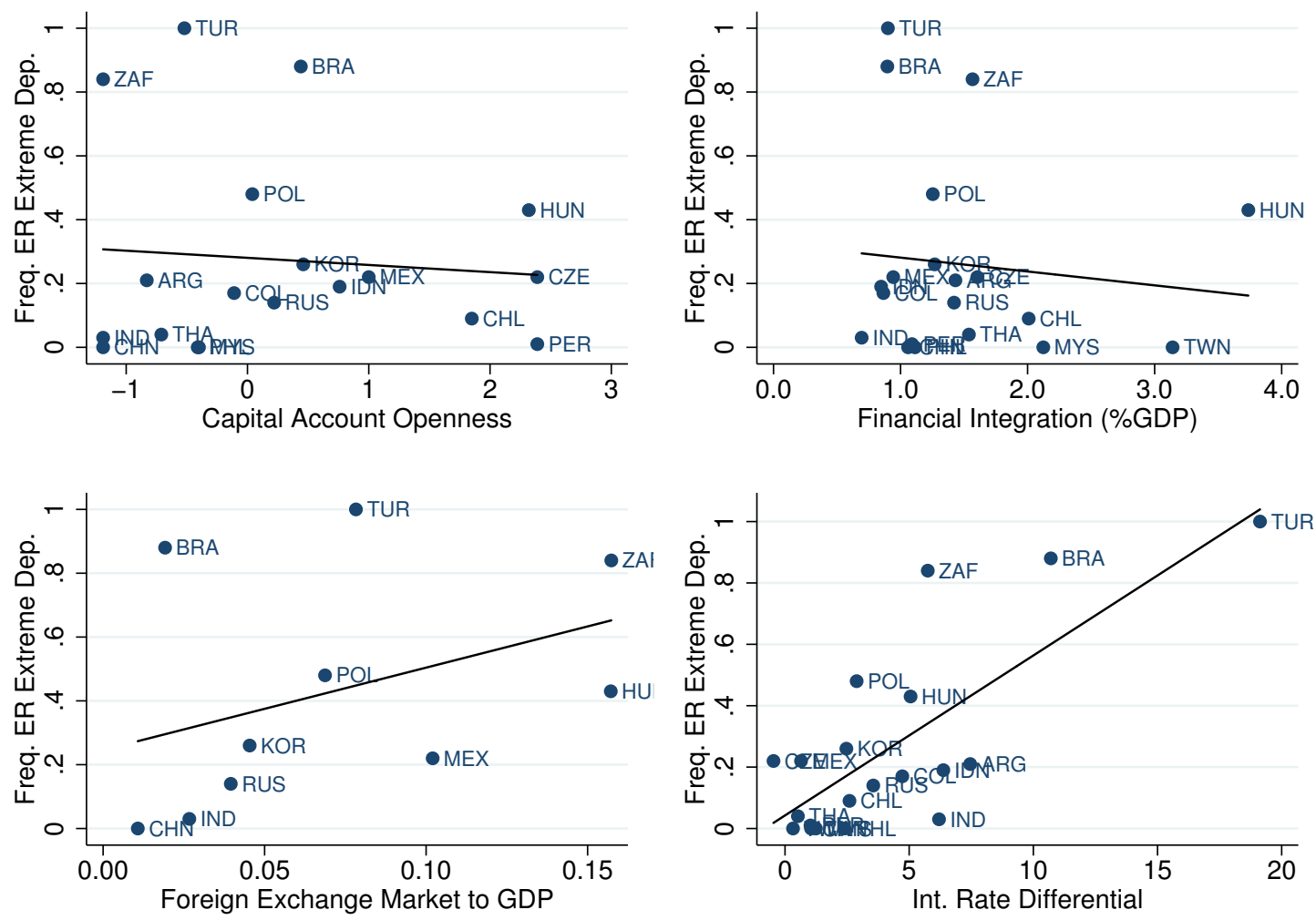

See Table 6.10 for the correlation coefficients. Source: onw estimations. Data source: exchange rates, Ecowin; financial integration, updated and extended version of Lane and Milesi-Ferretti (2007); GDP and trade, World Bank (2015); FX statistics, BIS (2013); capital account openness, Chinn and Ito (2008). For information and data sources for information on interest rate differential, see Appendix I, on page 334. 
The relative weight of the FX market is loosely related to extreme depreciations and there are well marked outliers. Observed from the non-significance of the correlation coefficient, the relative size of FX markets is found to not be an important element - differently from the analysis of standard deviation.

The interest rate differential impacts extreme depreciations, confirmed by a high correlation coefficient (around 0.7) significant at the 1\% level. South Africa is a notable outlier, with higher depreciations than predicted by other countries' relationships. India is also an outlier, because it has lower than predicted depreciations.

The level of financialized integration is the variable capable of explaining the highest part of the variability of the frequency of extreme depreciations.

\subsubsection{Explaining exchange rate correlation with the VIX}

The explanation power of the additional elements regarding currency correlation with the VIX (see Figure 6.24) are similar to their power in explaining extreme depreciations: there is no marked relationship between this exchange rate feature and capital account openness or financial integration. The latter actually actually presents a negative correlation between the two, significant at the $10 \%$ level (see Table 6.11).

The relationship of the correlation with the VIX and the weight of FX markets is positive, but not very relevant or with well marked outliers. The correlation coefficients are not significant. There are several outliers with regards to the interest rate differential, as currencies with very different levels of correlation have rather similar interest rate differentials.

A currency's correlation with the VIX might be the currency feature that presents the lowest correlation with the studied explanatory variables. The type of integration is the only variable with a significative explanation power. However, its power to explain the international influence on emerging currencies is lower than its power to explain the other currency features, suggesting that the type of integration explains volatility better than it explains the weight of the international sphere. 
TABLE 6.10 Volatility, Frequency of Extreme Depreciations, and Explanatory Factors: Pearson Correlation Coefficients

All obs.

Capital Account Openness $\quad-0.09 \quad 19$

Fin. Integration $\quad-0.12 \quad 20$

Fin. Integration (\%GDP) $\quad-0.11 \quad 20$

Fin.-to-Trade Int. $\quad 0.37 \quad 19$

For. Exch. Market $\quad-0.21 \quad 11$

For. Exch. Market (\%GDP) $\quad 0.38 \quad 10$

Int. Rate Differential $\quad 0.76^{*} \quad 20$

Financialized Int. $\quad 0.9^{*} \quad 10$

Only floating regimes

Capital Account Openness $\quad-0.23 \quad 16$

$\begin{array}{lll}\text { Fin. Integration } & 0.11 & 17\end{array}$

Fin. Integration (\%GDP) $\quad-0.11 \quad 17$

Fin.-to-Trade Int. $\quad 0.40 \quad 16$

$\begin{array}{lll}\text { For. Exch. Market } & -0.07 & 10\end{array}$

For. Exch. Market (\%GDP) $\quad 0.26 \quad 9$

$\begin{array}{lll}\text { Int. Rate Differential } & 0.77^{*} & 17\end{array}$

$\begin{array}{lll}\text { Financialized Int. } & 0.87^{*} & 9\end{array}$

Floating regime $\& 3$ BIS data available

Capital Account Openness $\quad-0.17 \quad 9$

Fin. Integration $\quad-0.38 \quad 9$

Fin. Integration (\%GDP) $\quad-0.02 \quad 9$

Fin.-to-Trade Int. $\quad 0.47 \quad 9$

For. Exch. Market $\quad-0.26 \quad 9$

$\begin{array}{lll}\text { For. Exch. Market (\%GDP) } & 0.26 & 9\end{array}$

$\begin{array}{lll}\text { Int. Rate Differential } & 0.73^{*} & 9\end{array}$

Financialized Int. $\quad 0.8^{*} \quad 9$

$*=1 \%$ significance level ${ }^{* *}=5 \%$ significance level ${ }^{* * *}=10 \%$ significance level. Countries with non-floating regimes in the analyzed period are China, Malaysia and Argentina, as discussed from the analysis of Table 6.12 presented in the Appendix. Source: own estimations, done in Stata 11. Data source: exchange rates, Ecowin; financial integration, updated and extended version of Lane and Milesi-Ferretti (2007); GDP and trade, World Bank (2015); FX statistics, BIS (2013); capital account openness, Chinn and Ito (2008). For information and data sources for information on interest rate differential, see Appendix I, on page 334 .

\subsection{Conclusions}

This chapter analyzed emerging currencies' features and whether they are associated to the country's type of integration to international financial markets. It presents intriguing evidence that support the following ideas. First, a high level of financialization of a country's 
TABle 6.11 Currency Correlation with the VIX and Explanatory Factors: Pearson Correlation Coefficients

All obs.

Currency corr. w/ the VIX Obs.

Capital Account Openness

$\begin{array}{cc}0.03 & 19 \\ 0.10 & 20 \\ -0.13 & 20 \\ -0.01 & 19 \\ 0.21 & 11 \\ 0.45 & 10 \\ 0.3 & 20 \\ 0.65^{* *} & 10\end{array}$

Fin. Integration

Fin. Integration (\%GDP)

Fin.-to-Trade Int.

For. Exch. Market

For. Exch. Market (\%GDP)

Int. Rate Differential

$0.65^{* *}$

10

Only floating regimes

Capital Account Openness

$\begin{array}{ll}-0.06 & 16\end{array}$

Fin. Integration

$-0.02 \quad 17$

Fin. Integration (\%GDP)

$-0.10 \quad 17$

Fin.-to-Trade Int.

$0.13 \quad 16$

For. Exch. Market

$0.25 \quad 10$

For. Exch. Market (\%GDP)

$0.45 \quad 9$

Int. Rate Differential

0.37

9
17

Financialized Int.

$0.68^{* *}$

9

Floating regime $\& 3$ BIS data available

Capital Account Openness

$\begin{array}{cc}0.14 & 9 \\ -0.6^{* * *} & 9 \\ -0.00 & 9 \\ 0.07 & 9 \\ 0.11 & 9 \\ 0.45 & 9 \\ 0.24 & 9 \\ 0.68^{*} & 9\end{array}$

Fin. Integration

Fin. Integration (\%GDP)

Fin.-to-Trade Int.

9

9

9

For. Exch. Market

9

For. Exch. Market (\%GDP)

9

Int. Rate Differential

9

Financialized Int.

$*=1 \%$ significance level ${ }^{* *}=5 \%$ significance level ${ }^{* * *}=10 \%$ significance level. Countries with non-floating regimes in the analyzed period are China, Malaysia and Argentina, as discussed from the analysis of Table 6.12 presented in the Appendix. Source: own estimations, done in Stata 11. Data source: exchange rates, Ecowin; financial integration, updated and extended version of Lane and Milesi-Ferretti (2007); GDP and trade, World Bank (2015); FX statistics, BIS (2013); capital account openness, Chinn and Ito (2008). For information and data sources for information on interest rate differential, see Appendix I, on page 334 . 
Figure 6.24: Correlation With the VIX, Capital Account Openness, Financial Integration, Interest Rate Differential and Financialized Integration
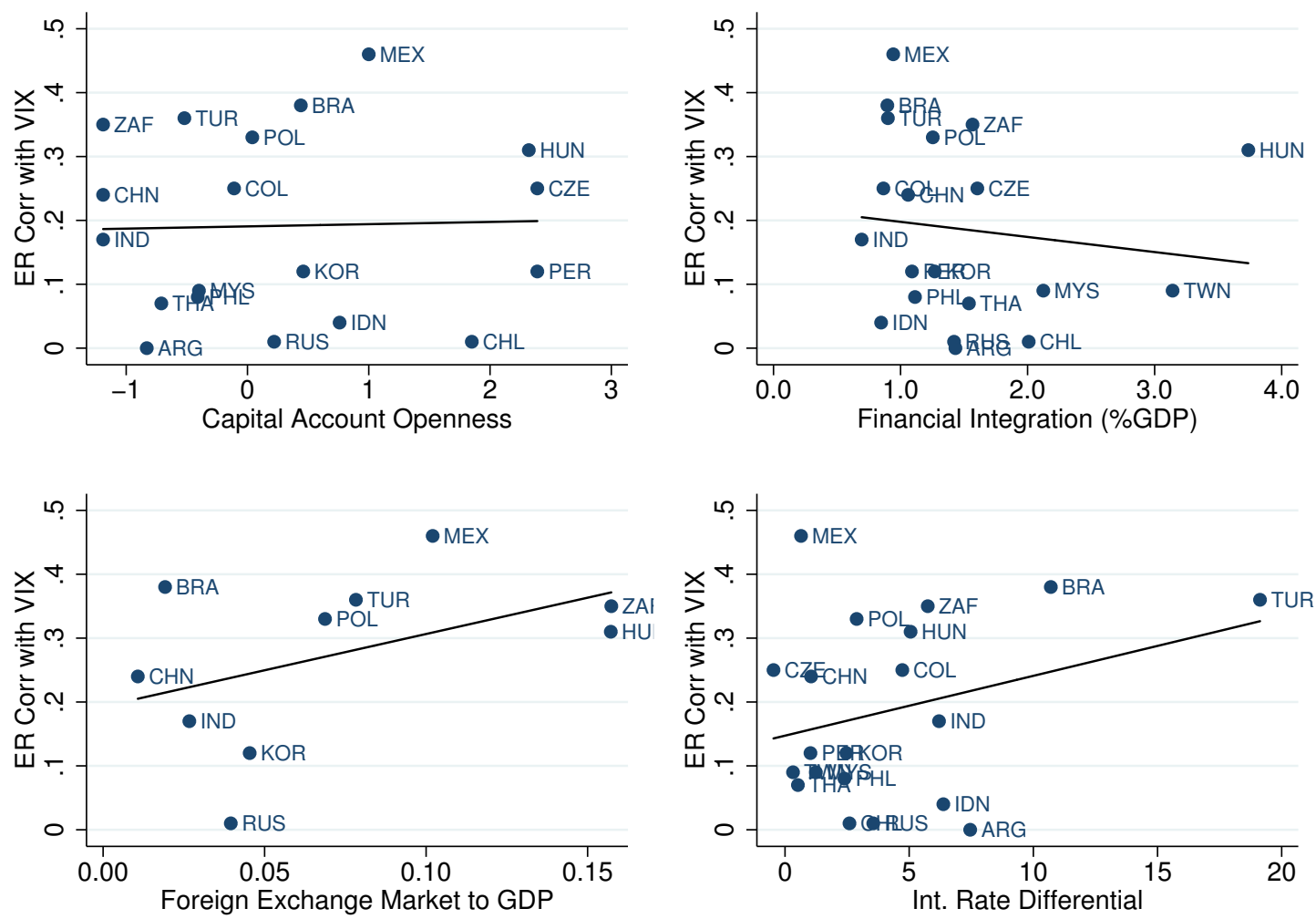

See Table 6.11 for the correlation coefficients. Source: onw estimations. Data source: exchange rates, Ecowin; financial integration, updated and extended version of Lane and Milesi-Ferretti (2007); GDP and trade, World Bank (2015); FX statistics, BIS (2013); capital account openness, Chinn and Ito (2008). For information and data sources for information on interest rate differential, see Appendix I, on page 334.

integration (developed in Chapter Five) is strongly associated with significant deviations of the currency from its trend and with frequent extreme depreciations. The relationship between this indicator and exchange rate volatility is stronger than variables as the interest rate differential, de jure indicators of openness, several de facto indicators of integration, and indicators of the size of FX markets. Among these other variables, the country's interest rate differential is the only meaningful explanatory variable. The strong association between financialized integration and exchange rate volatility is also robust to different country groupings: all of the EMEs, only those with floating exchange rates, or only those with important FX markets. 
The most volatile currencies (as proxied by the standard deviation) are the Brazilian real, the Hungarian forint, the Polish zloty, the South African rand, and the Turkish lira. These five, plus the Mexican peso, present the highest frequency of extreme depreciations. The countries of these six currencies present the most financialized integration (especially Brazil, Hungary, South Africa, and Turkey).

Secondly, EMEs with a more financialized integration have currencies which are more correlated with international liquidity conditions - the six more financialized currencies also present the highest correlation with the VIX. The interest rate differential is also a relevant variable in explaining the correlation with the VIX, but the level of financialization of its integration has a higher explanatory power.

Thirdly, floating emerging currencies have been presenting an increasingly similar path; the aforementioned six countries with more financialized integration have presented a strikingly similar path in the turbulent (most recent) period. These six currencies also present the highest number of relevant out-of-the-region correlation (correlation with currencies of other continents).

The comparison of the correlation coefficients of the indicators of the level of financialization of integration with other indicators demonstrate that the type of integration has a better explanatory power than the size of integration. This is partially opposed to Eichengreen and Gupta's (2015) argument on the importance of the magnitude of integration (the countries' financial markets size and openness) in determining the impact of 'tapering talks' on emerging currencies. On the other hand, it would be in line with Kaltenbrunner and Painceira's (2014) hypothesis that the vulnerability of the Brazilian real to international sphere is due to the country's "particularly liquid domestic financial markets and advanced stage of financial integration, which resulted in one of the highest stocks of short-term external obligations" (p. 18) - where "advanced" seems to refer not only to the magnitude, but also to the type of integration, as it is related to extent of use of the country's "complex set of very short-term domestic currency assets" (p. 1).

These findings raise important theoretical- and policy-related concerns, and point to interesting avenues of future research. Regarding the theoretical debate, the evidence of comovement of currencies indicate a high influence of external factors in determining these 
currencies. Their high correlation with the VIX indicates one possible external factor: the condition of international financial markets. Such an exchange rate determination seems at odds with the mainstream theories (see Chapter Three). In mainstream models, the impact of the international scenario is limited to interest rate differentials, which is a measure of return, not of uncertainty. Rey (2015) could be said to be an exception, as she argues that global financial cycles are crucial in determining the exchange rate of countries receiving credit inflows. However, she uses a different transmission channel, focused on bank constraints that would vary with changes in risk aversion due to monetary policy changes in a given country ${ }^{63}$. However, major exchange rate changes, as those related to the Lehman Brothers' collapse or the Euro crisis, are not associated with changes in monetary policies; they are purely a change of uncertainty levels, intrinsic to financial markets dynamics. In this sense, the chapter indicates the role of external conditions, rather than country fundamentals, what, for the case of the GFC, is in line with Kaltenbrunner and Painceira (2014).

The importance of liquidity preference in determining investments in low-liquid currencies (as seen in Chapter Three, Section 3.3.4 and the theory of liquidity cycles) are the most appropriate theoretical background for these findings. They explain both the comovement of currencies (as they all have the same characteristic), the correlation with the VIX (that proxies liquidity preference) and the high frequency of depreciations (due to turbulence of international financial markets and liquidity preference).

With regards to the pull-vs-push literature, evidence on the high importance of external factors in determining exchange rates (comovement among currencies and with the VIX) supports the idea that pull factors are important in tranquil periods but push factors predominate in turbulent ones. In addition, the correlation of some emerging currencies with the VIX supports the view that the importance of push factors is related to the conditions of international financial markets.

With regards to the literature on the implications of financial integration, the comparison of the importance of the explanation power of level of financialized integration to the indicators of financial openness and integration, and the size of FX markets revealed the

\footnotetext{
${ }^{63}$ Rey (2015, p. 25) states that "one important determinant of the global financial cycle is monetary policy in the centre country, which affects leverage of global banks, credit flows and credit growth in the international financial system."
} 
higher relevance of the first indicator in explaining exchange rate features. It underscores the relevance of the characteristics or type of a country's integration instead of its magnitude in determining emerging currency patterns, especially the ones related to the FX markets.

Given the continuous rise of financialization, these results indicate the need to study the economic impacts of more volatile exchange rates that frequently undergo sudden changes, and that reflect the international rather than the domestic context. The emergence and the consequences of a new pattern of emerging currencies is disregarded by the literature on the potential impacts of financial integration, because it focuses on the magnitude of the integration, which is not associated with a given exchange rate pattern (as shown in Section 6.5). This chapter's findings indicate valuable considerations for future research, such as considerations on the type of integration in the literature on the effect of financial integration through the potential impacts of a new type of exchange rate determination on growth.

The expected impacts from financial integration in terms of gains from diversification and risk reduction must also be questioned: if, as portfolio diversification achieves several countries, their exchange rates start moving in tandem, potential diversification-related gains vanish. Indeed, international diversification of equity portfolios was first advocated on the basis of low correlation between markets (Longin and Solnik, 1995), but as integration growths, correlation increases, and the possible gains from diversification are lost ${ }^{64}$.

Regarding the literature on exchange rates, the findings on the characteristics of the emerging currencies with a highly financialized integration support the argument that exchange rates no longer serve as an adjustment variable, but rather as an asset price determined by portfolio diversification (as discussed in Chapter Three). How the decisions on portfolio diversification take place, especially regarding EMEs' assets and the role played by the external environment, is the subject of the next chapter.

The confirmation that emerging currencies are asset prices opens a large spectrum of exchange rate analyses with techniques that are currently mostly used in financial market studies. The analyses of comovement of currencies and their comovement with the VIX are a

\footnotetext{
${ }^{64}$ There is sizable literature on the financial area that looks at the stability of the correlation matrix of returns in different markets and finds that it has not been stable over time. See Longin and Solnik (1995).
} 
step in this direction. Other analyses include spill over and contagion effects, and asymmetric or regime-based effects, and advanced techniques for estimating risk and volatility.

Comparing volatility of different time-frames, such as intra-day or monthly changes, on the characterization of volatility of exchange rates of EMEs' and advanced countries is an intriguing possibility for future research. Intra-day volatility might be more important in places with higher speculation possibilities ${ }^{65}$. Monthly changes, on the other hand, are interesting for analyses investigating the impact of changes in the exchange rate on uncertainty and on domestic economy.

Still on avenues for future research, the findings on the consequences of a more financialized integration on exchange rates invites analysis to uncover explanations for this type of integration. The relevance of derivatives markets is observed from the different explanatory power of the index of financialized integration and the indices of relative integration. But what determines the size of FX markets and its characteristics? Interest rate levels are surely an option. As Table 6.15 demonstrates, out of the five currencies that present specific features in the strongest of forms, four presented high interest rate differentials with the U.S. rate (Poland presented a medium level).

As discussed in Chapter Two, financial innovations explain the association of high interest rates and large FX markets (of derivatives, in particular). The broad use of carry trade operations has a clear role in increasing flows to countries with the highest interest rate levels. This results in appreciation of the target currencies, an incentive for currency trading - trading the currency itself and gaining from its appreciation. Derivatives markets, in turn, grow by allowing such operations (carry trading and currency trading) to be realized with considerably lower amounts, for its leveraging possibilities.

The fact that all five countries with the most financialized integration follow an inflation targeting regime with a floating exchange rate arrangement raises concern over these countries' independence in pursuit of monetary policies. The findings also suggest consequences to the very use of inflation targeting regimes in EMEs, that must be further studied. If this

\footnotetext{
${ }^{65}$ An example where the daily change does not capture the volatility: On May 9th, with the possibility of canceling the impeachment process of Brazil's President, Mrs Rouseff, the Brazilian real depreciated 0.56\%, but during the day it achieved a depreciation higher than 5\% (Castro, 2016).
} 
regime is associated with exchange rates that often face extreme depreciations, the impacts of such depreciations reduce the efficiency of the policy in these countries.

After having presented the macro picture of financialized integration and how it is related to specific exchange rate features, the next chapter will provide a micro view of how these features might emerge from money managers' decisions. Based on this chapter's findings on the role of the conditions ruling in international financial markets in determining exchange rates, the units whose decisions will be analyzed are the money managers. This is also in line with the idea of interconnection of markets through money managers' balancesheets. 


\subsection{Appendix I: Information on Interest Rate Differential}

FiguRE 6.25: Interest Rate Differential: 2000 to 2013
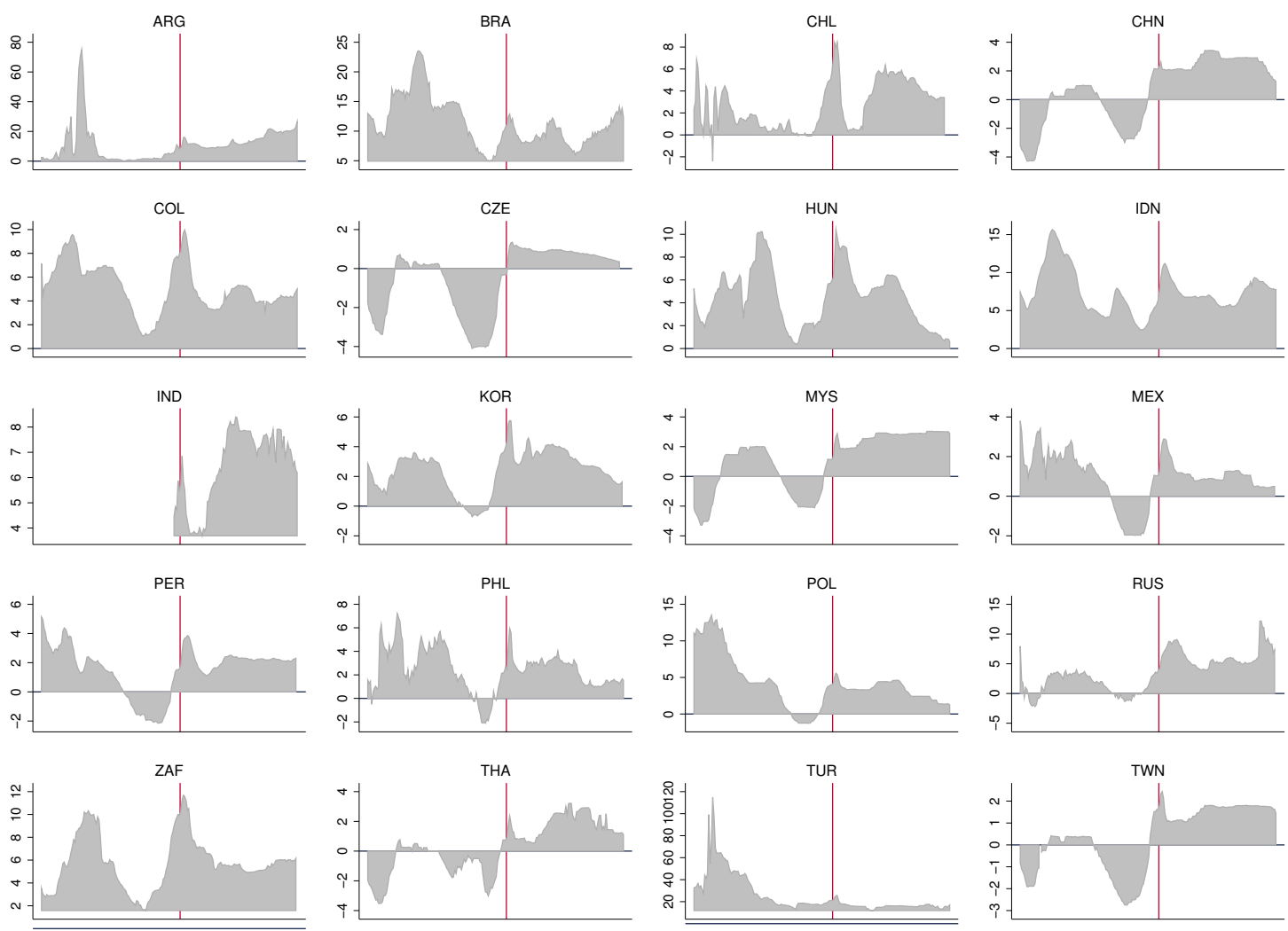

September 15th is presented as a vertical line for reference. Data is presented as monthly averages.

\subsubsection{Interest rate data details}

United States: Source: Board of Governors of the Federal Reserve System (US) Series Name: Effective Federal Funds Rate. Monthly (Averages of daily figures). H.15 Selected Interest Rates Release. Website: http://www.federalreserve.gov/releases/h15/data.htm

India: Reserve Bank of India. Database on the Indian Economy. Table: Daily Money Market Operations, Liquidity Adjustment Facility, Repo (Fixed Rate), Rate. Website: http://dbie.rbi.org.in/DBIE/dbie.rbi?site=home Monthly average of daily data. 
Taiwan: Central Bank of China (Taiwan). Series name: Discount Rate. Website: http://www.cbc.gov.tw/lp.asp?CtNode=695\&CtUnit=303\&BaseDSD=32\&mp=2 Monthly average of daily data.

All other countries: IMF International Financial Statistics. Monthly. Series Name: Interest Rates, Deposits, Percent per annum. Website: http://data.imf.org

\subsection{Appendix II: Information on Exchange Rate Regimes}

In accordance with IMF's article IV of IMF's Articles of Agreement, the authorities of different countries notifies the Fund during the annual visit of its Staff to the country of its

FiguRE 6.26: Interest Rates and Interest Rate Differential. Average from 2000 to 2013
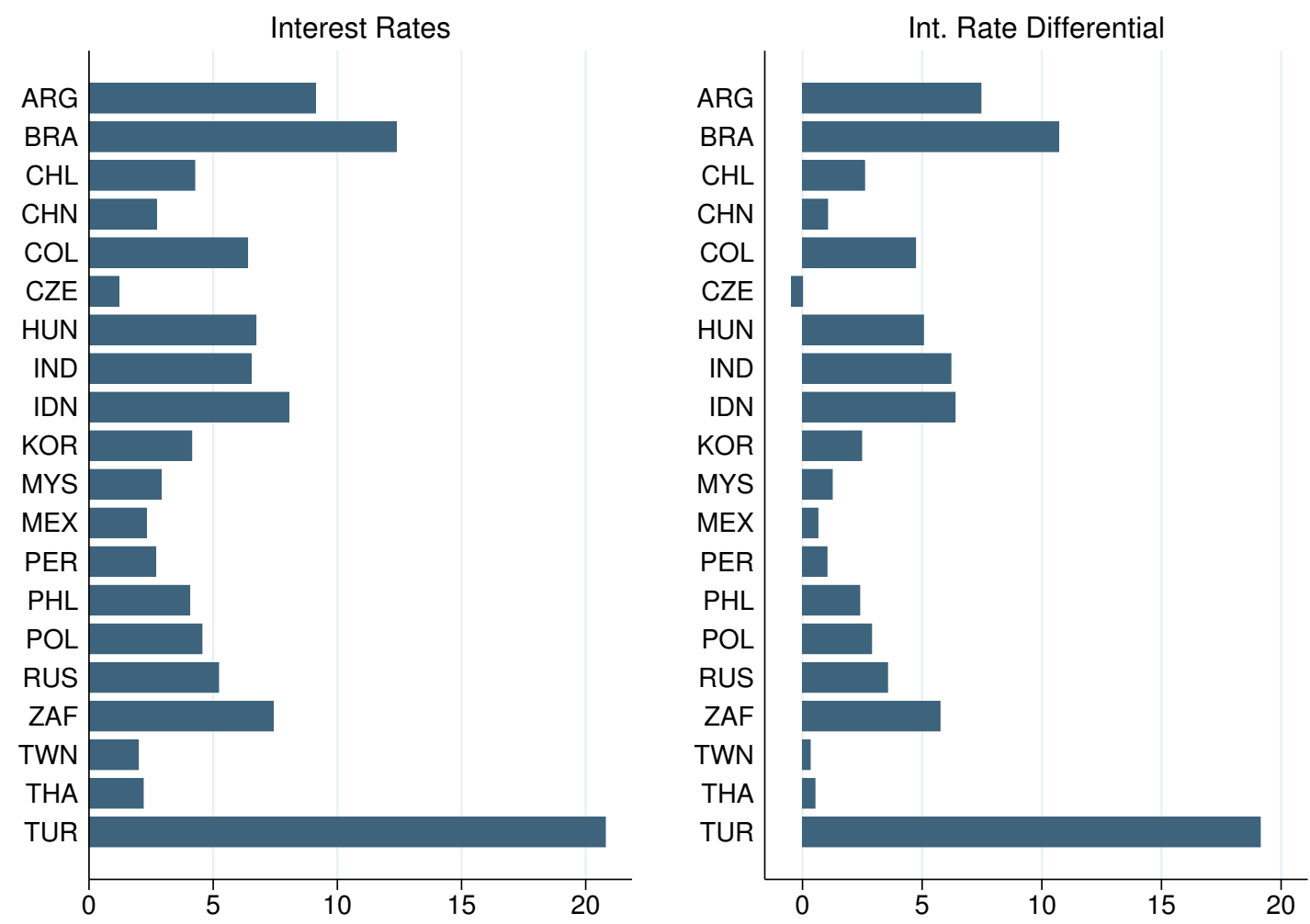

Data sources are varied. See Section "Interest rate details" above. Author's calculation. Interest rate differentials are estimated in nominal terms as the difference from the emerging countries' to the US Fed Fund rate. Source: own estimations, based on the data detailed below. 
exchange rate arrangement. This is known as the de jure arrangement. However, since 1998, the IMF staff assess a country's de facto (or observed) exchange rate arrangement, mostly based on "the existence of formal or informal commitments to exchange rate paths" (IMF, 2004).

According to the methodology adopted in 1998, the de facto classification "broadly distinguishes three groups of arrangements: hard pegs (arrangements with fixed exchange rates that are difficult to modify, such as currency boards), soft pegs (arrangements with exchange rates based around a central rate or bandwidth that may be adjusted, such as conventional fixed pegs and crawling pegs), and floating arrangements (arrangements without exchange rate anchors, such as managed floating and independently floating)."

This classification was changed in 2008 from the 1997-established taxonomy given the more complex intervention practices of countries and the overly heterogeneous nature of the residual category of managed floating (Kokenyne et al., 2009, p. 6).

In order to compare the two, it is important to know that since 2008, non-floating de facto arrangements were subdivided into stabilized and crawl-like and floating regimes, that before were subdivided into managed floating and independently floating became floating or free floating. Other managed arrangement is the new residual category. In other words, what is broadly known as a dirty floating regime used to be labeled "Managed floating with no predetermined path for the exchange rate" and became just "floating"; and "free floating" used to be "independently floating" 66 .

Table 6.12 presents the de facto exchange rate arrangements that prevailed in emerging market countries in the period analyzed in this chapter, as well as the associated monetary policy framework. We can sum up and simplify the information provided there in floating or non-floating exchange rate regimes in this period in the following form.

Countries with rather non-floating regimes: China, Malaysia.

Countries with rather floating regimes: Brazil, Chile, Colombia, India, Indonesia, Korea, Mexico, Peru, Philippines, Poland, South Africa, Taiwan, Thailand, and Turkey.

\footnotetext{
${ }^{66} \mathrm{It}$ is interesting to highlight that given the substantial increase - three-fold from 1999 to 2006 in absolute terms (Kokenyne et al., 2009) - of the reserves of foreign assets hold by countries whose exchange rate arrangement is labeled as "free floating" we should not consider that this category means absolutely free floating.
} 
Hungary changed from non-floating to floating in February 2008, but given that before the change it had a band that allowed an important fluctuation (+- 15\%) and that this fluctuation was with regards to the euro, we will consider that it had, in the period, a floating regime with regards to the U.S. dollar.

According to the IMF characterization, Argentina changed from floating to non-floating between 2006 and 2008, but observing it's exchange rate path we can argue that during its "floating" period it used to have a very stable path - changing less than 10 percentage points from mid-2003 (when there was a devaluation) to 2006.

Czech Republic and Russia changed from a dirty floating to the residual category. According to the way the IMF analyzes the changes in the countries' choices ${ }^{67}$, the residual category can be seen as a floating one. For Czech Republic the characterization as floating regime seems appropriated fr this thesis analysis: given the currency's peg to the euro, it presents considerable variance with regards to the dollar. The characterization as floating might however be controversial for Russia given the observed change in the exchange rate pattern in the middle of the $2000 \mathrm{~s}$ - as seen in 6.1. Important to pinpoint: the crisis in the late 2014 is out of the period analyzed in the chapter.

Details of Table 6.12: The data in parenthesis indicate when a regime was established. †indicates the regime prevailing in June 2004 (IMF, 2004) and ‡indicates the regime prevailing in 2013/2014 (IMF, 2014) Other sources than the ones indicated: Roger (2010) for dates concerning the beginning of the inflation targeting regimes; IMF (2004) for the 2004 arrangements. For Taiwan: "Foreign Exchange Regime" $(2015)^{68}$. For India, Nam and Kumar (2015). Hungary lifted the band (established in 2001) in which the country's currency floated against the euro in a +- 15\% in February 2008 (Perry, 2008) ** indicates "IMF-supported or other monetary program". ***, "the country adopts more than one nominal anchor in conducting monetary policy" (IMF, 2014).

\footnotetext{
67 "The number of countries that used a soft peg bounced back almost to its previous (April 2011) level while the number that fell into the residual category other managed arrangements experienced the greatest decline. In short, countries returned to more stable exchange rate arrangements they had previously abandoned because of weakening external balance positions or strong appreciation pressure." (Kokenyne et al., 2009, p. 2)

68 "Foreign Exchange Regime" (2015) reads: "Following the establishment of the Taipei Foreign Exchange Market in February 1979, a flexible exchange rate system was formally implemented. Since then, the NT dollar exchange rate has been determined by the market. However, when the market is disrupted by seasonal or irregular factors, the Bank will step in."
} 
TABLE 6.12 EMEs' Exchange Rate Arrangements and Monetary Policy Framework

Exchange rate arrangement

Managed Float., no pre-det. path( $\nmid-2006)$

Argentina

Brazil

Chile

China

Colombia

Czech Republic

Hungary

India

Indonesia

Korea

Malaysia

Mexico

Peru

Philippines

Poland

Russia

South Africa

Taiwan

Thailand

Turkey

Data sources are varied. See Section "Details of Table 6.12" above.

Independently Floating $\dagger$

Floating

Independently Floating $\dagger$

Free floating $\ddagger$

Conventional fixed peg arrangement $\dagger$

Crawl-likeł

Independently Floating $\ddagger$

Floating $\ddagger$

Managed Float., no pre-det. path $\dagger$

Other managed $\ddagger$

Pegged within horizontal bands $\dagger^{* * *}$

Floating $\ddagger(2008)$

Managed Float., no pre-det. path $\dagger$ Floating $f$

Managed Float., no pre-det. path $\dagger$

Floating

Independently Floating $\dagger$

Floating

Conventional fixed peg arrangement $\dagger$

Other managed $\ddagger$

Independently Floating $\dagger$

Free floating $\ddagger$

Managed Float., no pre-det. path $\dagger$

Floating (2011)

Independently Floating $\dagger$

Floatingf

Independently Floating $\dagger$

Free floating $\ddagger$

Managed Float., no pre-det. path $\dagger$

Other managed $\ddagger$

Independently Floating $\dagger$

Floating

Floating

Managed Float., no pre-det. path $\dagger$

Floating

Independently Floating $\dagger$

Floating $\ddagger$
Monetary Policy Framework $\mathrm{IMF}^{* * \dagger}$

Monetary aggregate target $\ddagger$

Inflation targeting (1999)
Inflation targeting (1999)

Exc. rate anchor \& Mon. Agg. Target $\dagger$

Monetary aggregate target $\ddagger$

Inflation targeting (1999)

Inflation targeting (1997)

Inflation targeting (2001)

Other†

Inflation targeting (2015)

Monetary aggregate target $\dagger$

Inflation targeting (2005)

Inflation targeting (2001)

Exchange rate anchor $\dagger$

Other $\ddagger$

Inflation targeting (2001)

Inflation targeting (2002)

Inflation targeting (2002)

Inflation targeting (1998)

Other $\dagger$

Other

Inflation targeting (2000)

Inflation targeting (2000)

Inflation targeting (2006) 


\subsection{Appendix III: Other Data}

FiguRE 6.27: Financial-to-Trade and Financialized Integration

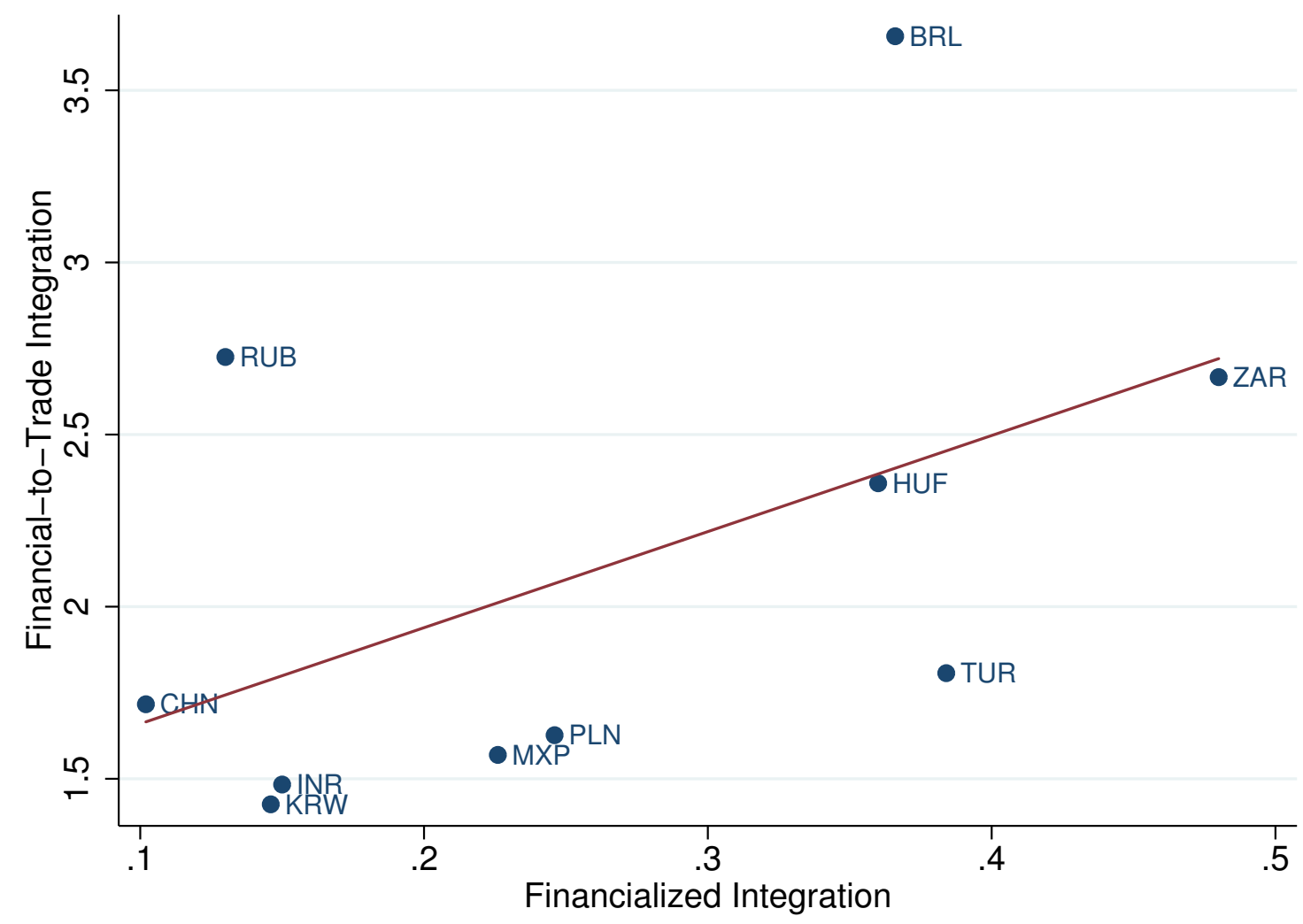

Data source: WDI, BIS, updated and extended version of Lane and Milesi-Ferretti (2007). Authors' calculation.

The correlation coefficient between the two measures of integration are: 0.5 , not significant at the $10 \%$ level, for the 10 EMEs; and 0.48, not significant at the $10 \%$ level, for the 9 floating emerging currencies. 
TABle 6.13 Details on Countries Currencies and Stock Exchange indices

\begin{tabular}{lcccc} 
Country & $\begin{array}{c}\text { Country } \\
\text { Code }\end{array}$ & Currency & $\begin{array}{c}\text { ISO currency } \\
\text { Code }\end{array}$ & $\begin{array}{c}\text { Stock Exc. } \\
\text { Index }\end{array}$ \\
\hline Argentina & ARG & Argentine peso & ARS & MERV \\
Brazil & BRA & Brazilian real & BRL & BVSP \\
Chile & CHL & Chilean peso & CLP & IPSA \\
China & CHN & Yuan renminbi & CNY & SSE \\
Colombia & COL & Colombian peso & COP & COLCAP \\
Czech Rep. & CZE & Czech koruna & CZK & PX \\
India & IDN & Indian rupee & INR & BSES \\
Malaysia & MYS & Malaysian ringgit & MYR & KLSE \\
Mexico & MEX & Mexican peso & MXN & MMX \\
Peru & PER & Nuevo sol & PEN & IGBVL \\
Philippines & PHL & Philippine peso & PHP & PSEI \\
Poland & POL & zloty & PLN & WIG20 \\
Korea & KOR & South Korean won & KRW & KOSPI \\
Hungary & HUN & Forint & HUF & BUX \\
Hong Kong & HKG & Hong Kong dollar & HKD & HSEI \\
Russia & RUS & Russian ruble & RUB & MICEX \\
Singapore & SGP & Singapore dollar & SGD & STI \\
South Africa & ZAF & South African rand & ZAR & JSE 40 \\
Taiwan & TWN & New Taiwan dollar & TWD & TWSE \\
Thailand & THA & Baht & THB & SET 100 \\
Turkey & TUR & New Turkish lira & TRY & BIST \\
United States & USA & U.S. dollar & USD & S\&P 500
\end{tabular}

Data sources: Colombia's COLCAP, Chile's IPSA, South Africa's JSE Top 40, Russia's MICEX, Taiwan's TWSE, and Philippine's PSEI are from Bloomberg. The remaining are from Yahoo! Finance.

Some series are not available for the whole period. Thailand's SET 100 begins at May 2nd, 2005. South Africa's JSE Top 40 begins in June 6th, 2002. Colombia's COLCAP begins in July 7 th, 2002. Data for Indonesia were not available. 
Figure 6.28: Emerging Currencies' Daily Changes: 2003 to 2013

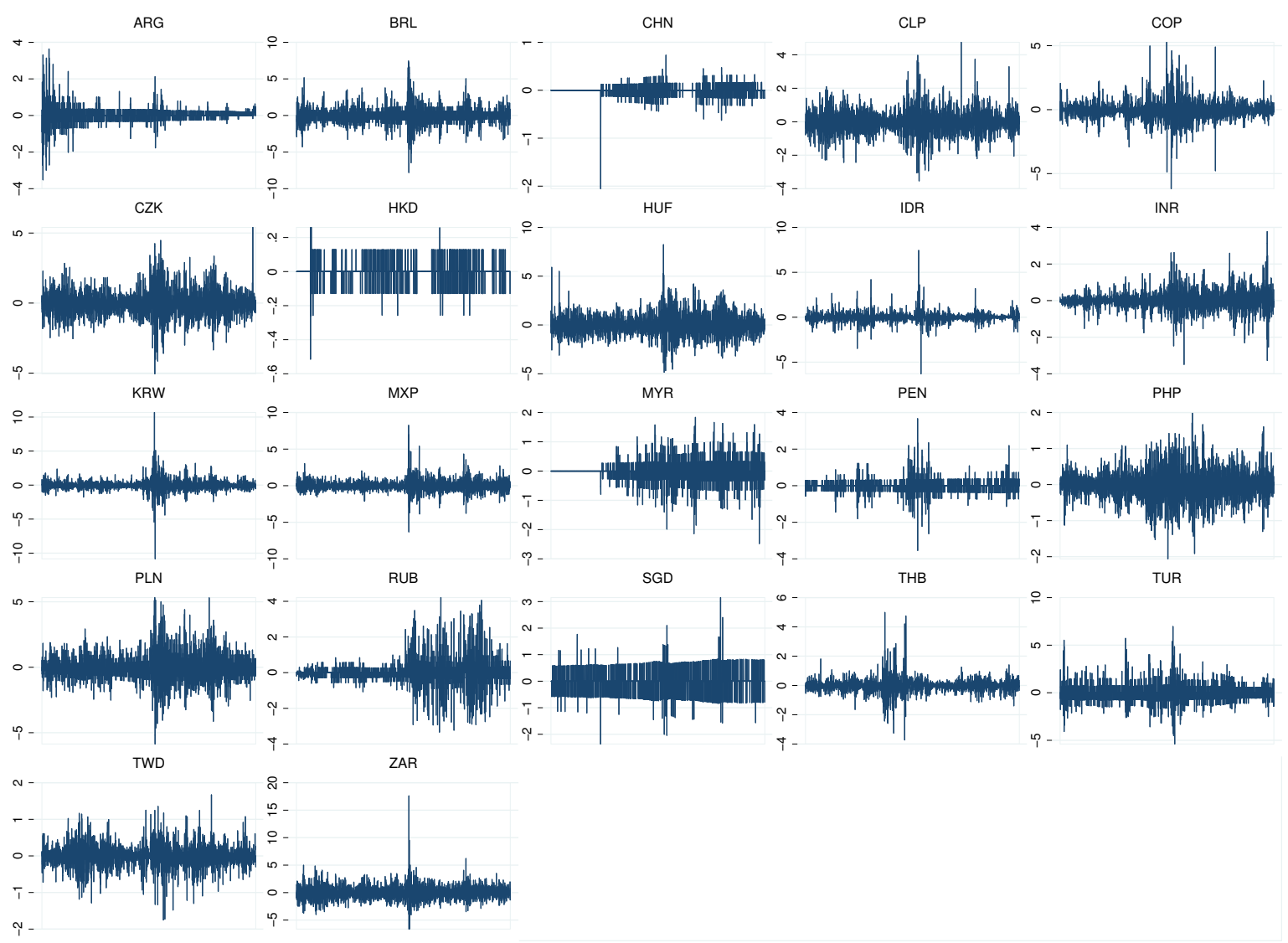

Data source: Ecowin. Authors' calculation. 
Figure 6.29: Volatility: Standard Deviation and Index of Non-Stability, 2003 to 2013 average

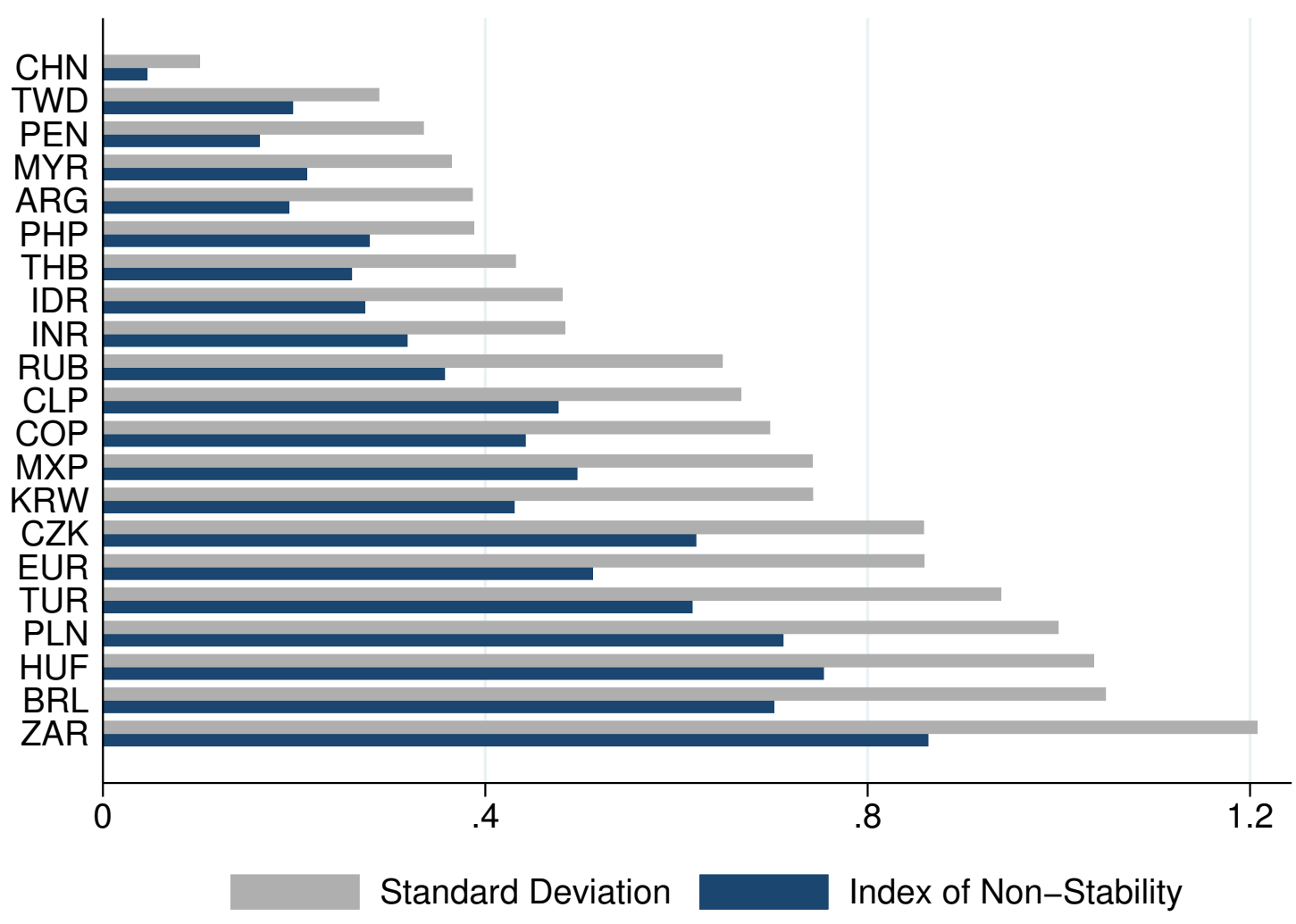

Data source: Ecowin. Authors' calculation.

The concept of Index of Non-Stability is presented in Section 6.2 in the debate over the meaning and use of the Standard Deviation in estimating volatility. 
TABLE 6.14 Vulnerability and Fragility

\begin{tabular}{|c|c|c|c|c|c|c|c|c|c|}
\hline & \multicolumn{2}{|c|}{ Vulnerability } & \multicolumn{2}{|c|}{ Fragility } & \multicolumn{2}{|c|}{ Vulnerability } & \multicolumn{2}{|c|}{ Fragility } & \multirow[b]{2}{*}{ Freq. } \\
\hline & Ch.i & Freq. & Dep. i & Freq. & & Ch.i & Freq. & Dep.i & \\
\hline \multirow{3}{*}{ ARG } & 2 & 0.020 & 2 & 0.01 & MXP & 2 & 0.015 & 2 & 0.01 \\
\hline & 3 & 0.011 & 3 & 0.01 & & 3 & 0.004 & 3 & 0.00 \\
\hline & 4 & - & 4 & - & & 4 & 0.002 & 4 & 0.00 \\
\hline \multirow[t]{5}{*}{ BRL } & 2 & 0.060 & 2 & 0.03 & & 5 & 0.001 & 5 & 0.00 \\
\hline & 3 & 0.019 & 3 & 0.01 & & 6 & 0.001 & 6 & 0.00 \\
\hline & 4 & 0.007 & 4 & 0.00 & MYR & 2 & 0.00 & 2 & - \\
\hline & 5 & 0.004 & 5 & 0.00 & & 3 & - & 3 & - \\
\hline & 6 & 0.002 & 6 & 0.00 & PEN & 2 & 0.00 & 2 & 0.00 \\
\hline $\mathrm{CHN}$ & 2 & - & 2 & - & & 3 & 0.00 & 3 & 0.00 \\
\hline \multirow[t]{4}{*}{ CLP } & 2 & 0.012 & 2 & 0.01 & & 4 & - & 4 & - \\
\hline & 3 & 0.003 & 3 & 0.00 & PHP & 2 & 0.00 & 2 & - \\
\hline & 4 & 0.000 & 4 & 0.00 & & 3 & - & 3 & - \\
\hline & 5 & - & 5 & - & PLN & 2 & 0.04 & 2 & 0.02 \\
\hline \multirow[t]{5}{*}{$\mathrm{COP}$} & 2 & 0.015 & 2 & 0.01 & & 3 & 0.01 & 3 & 0.01 \\
\hline & 3 & 0.004 & 3 & 0.00 & & 4 & 0.00 & 4 & 0.00 \\
\hline & 4 & 0.002 & 4 & 0.00 & & 5 & 0.00 & 5 & 0.00 \\
\hline & 5 & 0.000 & 5 & 0.00 & & 6 & - & 6 & - \\
\hline & 6 & - & 6 & - & RUB & 2 & 0.02 & 2 & 0.01 \\
\hline \multirow[t]{5}{*}{ CZK } & 2 & 0.028 & 2 & 0.02 & & 3 & 0.00 & 3 & 0.00 \\
\hline & 3 & 0.005 & 3 & 0.00 & & 4 & 0.00 & 4 & 0.00 \\
\hline & 4 & 0.002 & 4 & 0.00 & & 5 & - & 5 & - \\
\hline & 5 & 0.000 & 5 & 0.00 & THB & 2 & 0.01 & 2 & 0.00 \\
\hline & 6 & - & 6 & - & & 3 & 0.00 & 3 & 0.00 \\
\hline \multirow[t]{5}{*}{ HUF } & 2 & 0.047 & 2 & 0.03 & & 4 & 0.00 & 4 & 0.00 \\
\hline & 3 & 0.011 & 3 & 0.01 & & 5 & - & 5 & - \\
\hline & 4 & 0.002 & 4 & 0.00 & TUR & 2 & 0.05 & 2 & 0.03 \\
\hline & 5 & 0.001 & 5 & 0.00 & & 3 & 0.02 & 3 & 0.01 \\
\hline & 6 & - & 6 & 0.00 & & 4 & 0.01 & 4 & 0.01 \\
\hline \multirow[t]{5}{*}{ IDR } & 2 & 0.015 & 2 & 0.01 & & 5 & 0.00 & 5 & 0.00 \\
\hline & 3 & 0.004 & 3 & 0.00 & & 6 & 0.00 & 6 & 0.00 \\
\hline & 4 & 0.001 & 4 & 0.00 & TWD & 2 & - & 2 & - \\
\hline & 5 & 0.001 & 5 & 0.00 & ZAR & 2 & 0.07 & 2 & 0.04 \\
\hline & 6 & 0.001 & 6 & 0.00 & & 3 & 0.02 & 3 & 0.01 \\
\hline \multirow[t]{3}{*}{ INR } & 2 & 0.004 & 2 & 0.00 & & 4 & 0.01 & 4 & 0.00 \\
\hline & 3 & 0.001 & 3 & 0.00 & & 5 & 0.00 & 5 & 0.00 \\
\hline & 4 & - & 4 & - & & 6 & 0.00 & 6 & 0.00 \\
\hline \multirow[t]{5}{*}{ KRW } & 2 & 0.019 & 2 & 0.01 & EME & 2 & 0.00 & 2 & 0.00 \\
\hline & 3 & 0.005 & 3 & 0.00 & & 3 & - & 3 & 0.00 \\
\hline & 4 & 0.003 & 4 & 0.00 & EUR & 2 & 0.02 & 2 & 0.01 \\
\hline & 5 & 0.001 & 5 & 0.00 & & 3 & 0.00 & 3 & 0.00 \\
\hline & 6 & 0.000 & 6 & 0.00 & & 4 & - & 4 & - \\
\hline
\end{tabular}

Data source: Ecowin. Authors' calculation. 
TABLE 6.15 Exchange Rate Volatility: Summary

\begin{tabular}{|c|c|c|c|c|c|c|}
\hline & Std Deviation & Range & $2 \%$ Change & $3 \%$ Change & Id. Ext. Ch. & Id. Ext. Dep \\
\hline High & $\begin{array}{l}\text { ZAR BRL } \\
\text { HUF PLN } \\
\text { TUR CZK } \\
\text { EUR }\end{array}$ & $\begin{array}{c}\text { ZAR KRW } \\
\text { BRL MXP } \\
\text { IND HUF } \\
\text { TUR }\end{array}$ & $\begin{array}{l}\text { ZAR BRL } \\
\text { TUR HUF } \\
\text { PLN CZK }\end{array}$ & $\begin{array}{l}\text { TUR ZAR } \\
\text { BRL HUF } \\
\text { PLN ARS }\end{array}$ & $\begin{array}{l}\text { TUR BRL } \\
\text { ZAR PLN } \\
\text { HUF KRW }\end{array}$ & $\begin{array}{l}\text { TUR ZAR } \\
\text { BRL PLN } \\
\text { HUF }\end{array}$ \\
\hline Mid-high & $\begin{array}{l}\text { KRW MXP } \\
\text { COP CLP } \\
\text { RUB }\end{array}$ & $\begin{array}{l}\text { COP CZK } \\
\text { THB CLP } \\
\text { RUB ARS } \\
\text { INR }\end{array}$ & $\begin{array}{c}\text { RUB ARS } \\
\text { KRW EUR } \\
\text { COP IDR } \\
\text { MXP }\end{array}$ & $\begin{array}{c}\text { KRW CZK } \\
\text { COP IDR } \\
\text { RUB MXP } \\
\text { CLP }\end{array}$ & $\begin{array}{c}\text { MXP ARS } \\
\text { CZK RUB } \\
\text { COP IDR } \\
\text { CLP EUR }\end{array}$ & $\begin{array}{l}\text { MXP ARS } \\
\text { KRW CZK } \\
\text { RUB COP } \\
\text { IDR CLP }\end{array}$ \\
\hline Low & $\begin{array}{c}\text { INR IDR } \\
\text { THB PHP } \\
\text { ARS MYR } \\
\text { PEN TWD } \\
\text { CHN }\end{array}$ & $\begin{array}{c}\text { EUR MYR } \\
\text { PHP TWD } \\
\text { CHN }\end{array}$ & $\begin{array}{c}\text { CLP THB } \\
\text { INR PEN } \\
\text { PHP MYR }\end{array}$ & $\begin{array}{l}\text { THB INR } \\
\text { EUR PEN }\end{array}$ & $\begin{array}{l}\text { THB INR } \\
\text { PEN }\end{array}$ & $\begin{array}{l}\text { EUR THB } \\
\text { INR PEN }\end{array}$ \\
\hline Zero & & & CHN TWD & $\begin{array}{l}\text { CHN MYR } \\
\text { PHP TWD }\end{array}$ & $\begin{array}{c}\text { CHN MYR } \\
\text { TWD }\end{array}$ & $\begin{array}{l}\text { CHN MYR } \\
\text { PHP TWD }\end{array}$ \\
\hline
\end{tabular}

Data source: Ecowin. Authors' calculation.

For the Standard deviation, High levels mean higher than the euro. Mid-high being between the EMEs' average and the euro. 
TABle 6.16 PCA: Exchange Rate Changes. Period: 2000 - 2003

Number of obs $=781$

Number of comp. $=6$

Trace $=19$

Rotation: orthogonal varimax (Kaiser off)

$$
\text { Rho }=0.4624
$$

\begin{tabular}{lcccc} 
Component & Variance & Difference & Proportion & Cumulative \\
\hline Comp1 & 2.06574 & 0.258749 & 0.1087 & 0.1087 \\
Comp2 & 1.80699 & 0.330056 & 0.0951 & 0.2038 \\
Comp3 & 1.47693 & 0.319019 & 0.0777 & 0.2816 \\
Comp4 & 1.15792 & 0.000876506 & 0.0609 & 0.3425 \\
Comp5 & 1.15704 & 0.0356555 & 0.0609 & 0.4034 \\
Comp6 & 1.12138 &. & 0.059 & 0.4624
\end{tabular}

\begin{tabular}{lcccccc} 
Variable & Comp1 & Comp2 & Comp3 & Comp4 & Comp5 & Comp6 \\
\hline arg & & & & & 0.4633 & \\
brl & & & 0.5868 & & & \\
clp & & & 0.4544 & & & \\
cop & & & & 0.4656 & & \\
czk & 0.6209 & & & & & \\
huf & 0.6309 & & & & & \\
idr & & 0.3785 & & & 0.5799 & \\
inr & & & & & & \\
krw & & 0.4871 & & & & -0.4587 \\
mxp & & & 0.5703 & & & \\
myr & & & & & & \\
pen & & & & 0.6843 & & 0.5931 \\
php & & 0.4296 & & & 0.324 & \\
pln & 0.331 & & & & & 0.356 \\
rub & & & & & & \\
thb & & 0.5576 & & & & \\
tur & & & & & & \\
twd & & & & & & \\
zar & & & & & &
\end{tabular}

Data source: Ecowin. Author's estimations.

The results do not include data on the Chinese yuan due to zero variance of the variable. 
TABle 6.17 PCA: Exchange Rate Changes. Period: 2003-Aug, 2008. Rotated

\begin{tabular}{|c|c|c|c|c|c|}
\hline \multirow{2}{*}{\multicolumn{6}{|c|}{$\begin{array}{r}\begin{array}{r}\text { Number of obs }=1457 \\
\text { Number of comp. }=5 \\
\text { Trace }=20 \\
\text { Rho }=0.4853\end{array} \\
\text { Rotation: orthogonal varimax (Kaiser off) }\end{array}$}} \\
\hline & & & & & \\
\hline & Variance & \multicolumn{2}{|c|}{ Difference } & Proportion & Cumulative \\
\hline $\begin{array}{l}\text { Component } \\
\text { Comp1 }\end{array}$ & 2.55407 & \multicolumn{2}{|c|}{0.010451} & 0.1277 & 0.1277 \\
\hline Comp2 & 2.54362 & \multicolumn{2}{|c|}{0.437271} & 0.1272 & 0.2549 \\
\hline Comp3 & 2.10635 & \multicolumn{2}{|c|}{0.823811} & 0.1053 & 0.3602 \\
\hline Comp4 & 1.28254 & \multicolumn{2}{|c|}{0.0624857} & 0.0641 & 0.4243 \\
\hline Comp5 & 1.22005 & . & \multicolumn{2}{|c|}{0.061} & 0.4853 \\
\hline Variable & Comp1 & Comp2 & Comp3 & Comp4 & Comp5 \\
\hline $\arg$ & & & 0.4109 & & \\
\hline brl & & & 0.4785 & & \\
\hline chn & & & & 0.5954 & \\
\hline $\operatorname{clp}$ & & & & & 0.3302 \\
\hline cop & & & & & 0.4483 \\
\hline czk & & 0.5815 & & & \\
\hline huf & & 0.5351 & & & \\
\hline $\mathrm{idr}$ & 0.4423 & & & & \\
\hline inr & 0.3555 & & & & \\
\hline krw & 0.3925 & & & & \\
\hline $\operatorname{mxp}$ & & & 0.5126 & & \\
\hline myr & 0.3913 & & & & \\
\hline pen & & & & & 0.6146 \\
\hline php & 0.4349 & & & & \\
\hline pln & & 0.4436 & & & \\
\hline rub & & & & 0.6225 & \\
\hline thb & & & & & \\
\hline tur & & & & & \\
\hline twd & & & & 0.3296 & \\
\hline zar & & & & & \\
\hline
\end{tabular}

Data source: Ecowin. Author's estimations. 
TABle 6.18 PCA: Exchange Rate Changes. Period: Aug, 2008 - 2013

Number of obs $=1413$

Number of comp. $=4$

Trace $=20$

Rotation: orthogonal varimax (Kaiser off)

Rho $=0.5597$

\begin{tabular}{lcccc} 
Component & Eigenvalue & Difference & Proportion & Cumulative \\
\hline Comp1 & 5.32592 & 1.9281 & 0.2663 & 0.2663 \\
Comp2 & 3.39782 & 2.0225 & 0.1699 & 0.4362 \\
Comp3 & 1.37532 & 0.280467 & 0.0688 & 0.505 \\
Comp4 & 1.09485 &. & 0.0547 & 0.5597
\end{tabular}

\begin{tabular}{lcccc} 
Variable & Comp1 & Comp2 & Comp3 & Comp4 \\
\hline arg & & & 0.6336 & \\
brl & & & & \\
chn & & & -0.3844 & \\
clp & & & & \\
cop & & & 0.3446 & \\
czk & 0.394 & & & \\
huf & 0.4017 & & & \\
idr & & 0.3006 & & \\
inr & & 0.3102 & & \\
krw & & 0.3521 & & \\
mxp & 0.3315 & & & \\
myr & & 0.4557 & & \\
pen & & & & \\
php & & 0.3838 & & \\
pln & 0.4037 & & & 0.8599 \\
rub & & & & \\
thb & & 0.3044 & & \\
tur & 0.3329 & & & \\
twd & & 0.3848 & & \\
zar & 0.3653 & & &
\end{tabular}

Data source: Ecowin. Author's estimations. 
TABLE 6.19 Correlation of Emerging Currencies (2003-2013) (1/2)

\begin{tabular}{lccccccccccc} 
& Avg & ARG & BRL & CLP & CHN & COP & CZK & HUF & INR & IDR & KRW \\
\hline ARG & 0.09 & $\mathbf{1 . 0 0}$ & 0.08 & 0.10 & 0.01 & 0.07 & 0.01 & 0.03 & 0.04 & 0.05 & 0.07 \\
BRL & 0.29 & 0.08 & $\mathbf{1 . 0 0}$ & 0.36 & 0.00 & 0.37 & 0.37 & $\mathbf{0 . 4 3}$ & 0.20 & 0.09 & 0.20 \\
CLP & 0.28 & 0.10 & 0.36 & $\mathbf{1 . 0 0}$ & 0.09 & 0.37 & 0.30 & 0.33 & 0.26 & 0.18 & 0.20 \\
CHN & 0.12 & 0.01 & 0.00 & 0.09 & $\mathbf{1 . 0 0}$ & 0.03 & 0.06 & 0.06 & 0.11 & 0.10 & 0.10 \\
COP & 0.26 & 0.07 & 0.37 & 0.37 & 0.03 & $\mathbf{1 . 0 0}$ & 0.27 & 0.31 & 0.26 & 0.15 & 0.20 \\
CZK & 0.31 & 0.01 & 0.37 & 0.30 & 0.06 & 0.27 & $\mathbf{1 . 0 0}$ & $\mathbf{0 . 7 8}$ & 0.23 & 0.09 & 0.17 \\
HUF & 0.34 & 0.03 & $\mathbf{0 . 4 3}$ & 0.33 & 0.06 & 0.31 & $\mathbf{0 . 7 8}$ & $\mathbf{1 . 0 0}$ & 0.28 & 0.07 & 0.22 \\
INR & 0.28 & 0.04 & 0.20 & 0.26 & 0.11 & 0.26 & 0.23 & 0.28 & $\mathbf{1 . 0 0}$ & 0.25 & 0.33 \\
IDR & 0.19 & 0.05 & 0.09 & 0.18 & 0.10 & 0.15 & 0.09 & 0.07 & 0.25 & $\mathbf{1 . 0 0}$ & 0.28 \\
KRW & 0.26 & 0.07 & 0.20 & 0.20 & 0.10 & 0.20 & 0.17 & 0.22 & 0.33 & 0.28 & $\mathbf{1 . 0 0}$ \\
MYR & 0.26 & 0.04 & 0.12 & 0.24 & 0.21 & 0.20 & 0.15 & 0.20 & $\mathbf{0 . 4 2}$ & 0.35 & $\mathbf{0 . 4 3}$ \\
MXP & 0.30 & 0.07 & $\mathbf{0 . 5 4}$ & 0.34 & 0.01 & 0.30 & $\mathbf{0 . 4 2}$ & $\mathbf{0 . 5 1}$ & 0.25 & 0.06 & 0.21 \\
PEN & 0.17 & 0.04 & 0.17 & 0.19 & 0.02 & 0.22 & 0.14 & 0.17 & 0.15 & 0.05 & 0.11 \\
PHP & 0.24 & 0.03 & 0.13 & 0.17 & 0.11 & 0.20 & 0.16 & 0.19 & 0.34 & 0.31 & 0.38 \\
PLN & 0.36 & 0.04 & $\mathbf{0 . 4 3}$ & 0.37 & 0.09 & 0.31 & $\mathbf{0 . 7 5}$ & $\mathbf{0 . 7 6}$ & 0.32 & 0.14 & 0.25 \\
RUB & 0.15 & 0.00 & 0.05 & 0.07 & 0.07 & 0.06 & 0.02 & 0.02 & 0.06 & 0.08 & 0.07 \\
ZAR & 0.31 & 0.06 & $\mathbf{0 . 4 7}$ & 0.32 & 0.02 & 0.31 & $\mathbf{0 . 5 1}$ & $\mathbf{0 . 5 9}$ & 0.24 & 0.07 & 0.19 \\
TWD & 0.27 & 0.08 & 0.16 & 0.23 & 0.18 & 0.20 & 0.22 & 0.24 & 0.32 & 0.26 & $\mathbf{0 . 4 6}$ \\
THB & 0.19 & 0.03 & 0.11 & 0.16 & 0.09 & 0.11 & 0.17 & 0.18 & 0.22 & 0.18 & 0.20 \\
TUR & 0.31 & 0.04 & $\mathbf{0 . 4 6}$ & 0.33 & 0.03 & 0.35 & $\mathbf{0 . 4 4}$ & $\mathbf{0 . 5 1}$ & 0.26 & 0.13 & 0.22
\end{tabular}


TABLE 6.20 Correlation of Emerging Currencies' Exchange Rates (2003-2013) (2/2)

\begin{tabular}{lcccccccccc} 
& MYR & MXP & PEN & PHP & PLN & RUB & ZAR & TWD & THB & TUR \\
\hline ARG & 0.04 & 0.07 & 0.04 & 0.03 & 0.04 & 0.00 & 0.06 & 0.08 & 0.03 & 0.04 \\
BRL & 0.12 & $\mathbf{0 . 5 4}$ & 0.17 & 0.13 & $\mathbf{0 . 4 3}$ & 0.05 & $\mathbf{0 . 4 7}$ & 0.16 & 0.11 & $\mathbf{0 . 4 6}$ \\
CLP & 0.24 & 0.34 & 0.19 & 0.17 & 0.37 & 0.07 & 0.32 & 0.23 & 0.16 & 0.33 \\
CHN & 0.21 & 0.01 & 0.02 & 0.11 & 0.09 & 0.07 & 0.02 & 0.18 & 0.09 & 0.03 \\
COP & 0.20 & 0.30 & 0.22 & 0.20 & 0.31 & 0.06 & 0.31 & 0.20 & 0.11 & 0.35 \\
CZK & 0.15 & $\mathbf{0 . 4 2}$ & 0.14 & 0.16 & $\mathbf{0 . 7 5}$ & 0.02 & $\mathbf{0 . 5 1}$ & 0.22 & 0.17 & $\mathbf{0 . 4 4}$ \\
HUF & 0.20 & $\mathbf{0 . 5 1}$ & 0.17 & 0.19 & $\mathbf{0 . 7 6}$ & 0.02 & $\mathbf{0 . 5 9}$ & 0.24 & 0.18 & $\mathbf{0 . 5 1}$ \\
INR & $\mathbf{0 . 4 2}$ & 0.25 & 0.15 & 0.34 & 0.32 & 0.06 & 0.24 & 0.32 & 0.22 & 0.26 \\
IDR & 0.35 & 0.06 & 0.05 & 0.31 & 0.14 & 0.08 & 0.07 & 0.26 & 0.18 & 0.13 \\
KRW & $\mathbf{0 . 4 3}$ & 0.21 & 0.11 & 0.38 & 0.25 & 0.07 & 0.19 & $\mathbf{0 . 4 6}$ & 0.20 & 0.22 \\
MYR & $\mathbf{1 . 0 0}$ & 0.13 & 0.13 & $\mathbf{0 . 4 4}$ & 0.20 & 0.12 & 0.15 & 0.39 & 0.22 & 0.17 \\
MXP & 0.13 & $\mathbf{1 . 0 0}$ & 0.23 & 0.15 & $\mathbf{0 . 5 1}$ & 0.03 & $\mathbf{0 . 5 3}$ & 0.16 & 0.14 & $\mathbf{0 . 4 4}$ \\
PEN & 0.13 & 0.23 & $\mathbf{1 . 0 0}$ & 0.11 & 0.17 & 0.06 & 0.14 & 0.13 & 0.08 & 0.14 \\
PHP & $\mathbf{0 . 4 4}$ & 0.15 & 0.11 & $\mathbf{1 . 0 0}$ & 0.23 & 0.06 & 0.15 & 0.33 & 0.21 & 0.18 \\
PLN & 0.20 & $\mathbf{0 . 5 1}$ & 0.17 & 0.23 & $\mathbf{1 . 0 0}$ & 0.02 & $\mathbf{0 . 5 4}$ & 0.30 & 0.21 & $\mathbf{0 . 5 1}$ \\
RUB & 0.12 & 0.03 & 0.06 & 0.06 & 0.02 & $\mathbf{1 . 0 0}$ & $\mathbf{0 . 4 9}$ & -0.09 & -0.02 & $\mathbf{0 . 7 5}$ \\
ZAR & 0.15 & $\mathbf{0 . 5 3}$ & 0.14 & 0.15 & $\mathbf{0 . 5 4}$ & 0.02 & $\mathbf{1 . 0 0}$ & 0.18 & 0.15 & $\mathbf{0 . 5 2}$ \\
TWD & 0.39 & 0.16 & 0.13 & 0.33 & 0.30 & 0.08 & 0.18 & $\mathbf{1 . 0 0}$ & 0.23 & 0.20 \\
THB & 0.22 & 0.14 & 0.08 & 0.21 & 0.21 & 0.03 & 0.15 & 0.23 & $\mathbf{1 . 0 0}$ & 0.18 \\
TUR & 0.17 & $\mathbf{0 . 4 4}$ & 0.14 & 0.18 & $\mathbf{0 . 5 1}$ & 0.03 & $\mathbf{0 . 5 2}$ & 0.20 & 0.18 & $\mathbf{1 . 0 0}$
\end{tabular}

Data source: Ecowin. Authors' calculation.

The correlations are calculated based on the daily percentual changes of the variables. Values higher than 0.4 are in bold for ease of reading. 
Figure 6.30: Capital Account Openness: Average Index 2003-2013

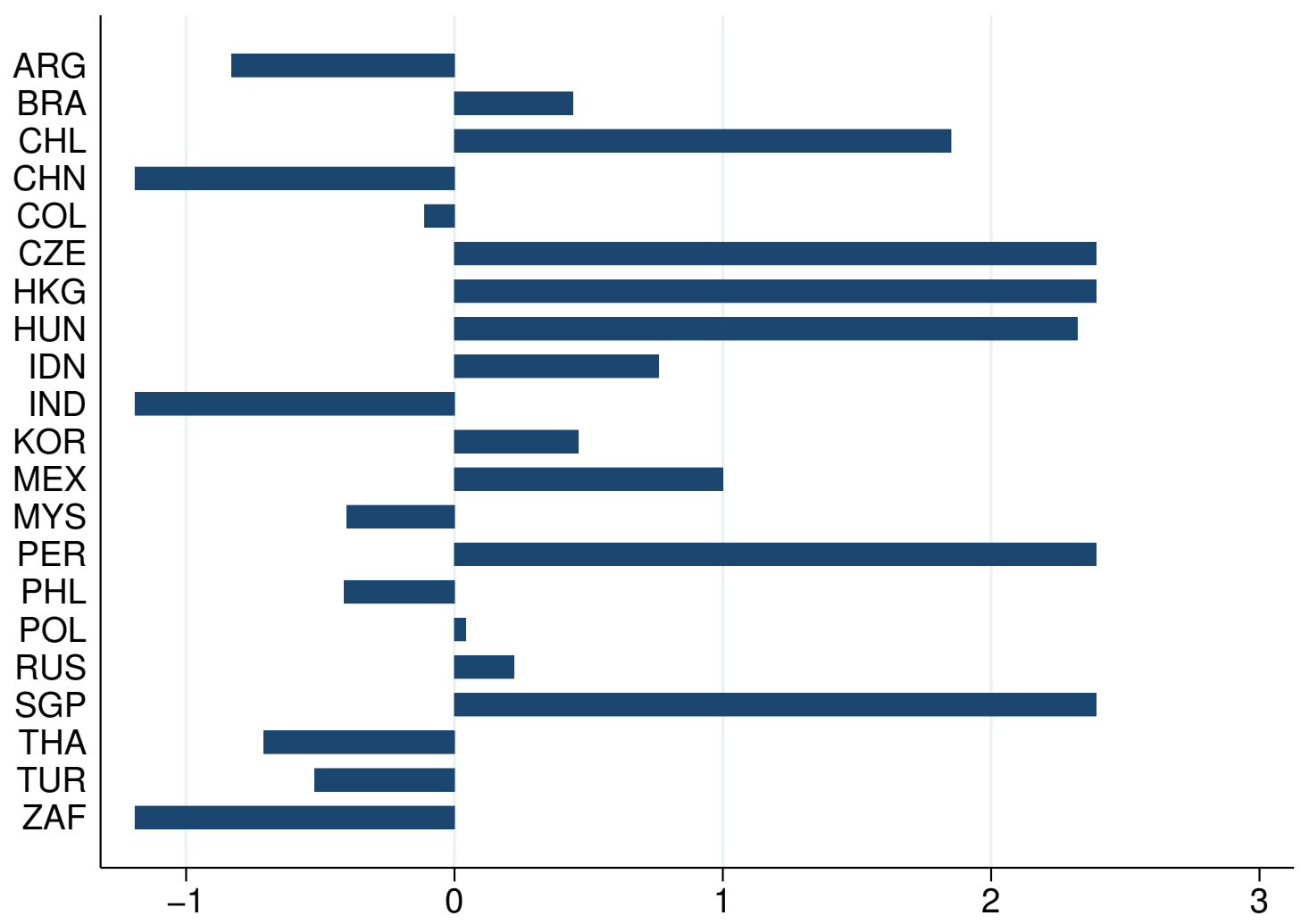

Data source: Chinn and Ito (2006) 
TABle 6.21 Regression Coefficients: Explaining Exchange Rate Patterns

\begin{tabular}{|c|c|c|c|c|c|c|}
\hline & $\begin{array}{c}\text { Capital } \\
\text { Account } \\
\text { Openn. }\end{array}$ & $\begin{array}{c}\text { Financial } \\
\text { Intergation } \\
(\% \text { GDP })\end{array}$ & $\begin{array}{c}\text { For. } \\
\text { Exch. } \\
\text { Mkt } \\
\text { (to GDP) }\end{array}$ & $\begin{array}{l}\text { Real } \\
\text { Int. } \\
\text { Rate } \\
\text { Diff }\end{array}$ & $\begin{array}{c}\text { Financialized } \\
\text { Integration }\end{array}$ & $\begin{array}{c}\text { Adj } \\
\text { R-squared }\end{array}$ \\
\hline \multirow{6}{*}{$\begin{array}{l}\text { Exchange } \\
\text { Rate } \\
\text { Volatility } \\
\text { (Std. Dev.) }\end{array}$} & 0.18 & & & & & 0.04 \\
\hline & $(0.203)$ & & & & & \\
\hline & & $\begin{array}{c}0.35 \\
(0,000)\end{array}$ & & & & 0.66 \\
\hline & & & $\begin{array}{c}8.80 \\
(0,000)\end{array}$ & & & 0.78 \\
\hline & & & & $\begin{array}{c}0.08 \\
(0.007)\end{array}$ & & 0.29 \\
\hline & & & & & $\begin{array}{c}2.89 \\
(0,000)\end{array}$ & 0.95 \\
\hline \multirow{7}{*}{$\begin{array}{l}\text { Freq. } \\
\text { Ext. } \\
\text { Exch. } \\
\text { Rate } \\
\text { Deprec. }\end{array}$} & 0.03 & & & & & -0.05 \\
\hline & $(0.705)$ & & & & & \\
\hline & & 0.13 & & & & 0.26 \\
\hline & & (0.011) & & & & \\
\hline & & & $\begin{array}{c}4.88 \\
(0.006)\end{array}$ & & & 0.55 \\
\hline & & & & $\begin{array}{c}0.07 \\
(0,000)\end{array}$ & & 0.64 \\
\hline & & & & & $\begin{array}{c}1.81 \\
(0,000)\end{array}$ & 0.88 \\
\hline \multirow{5}{*}{$\begin{array}{l}\text { Corr. } \\
\text { w/ the } \\
\text { VIX }\end{array}$} & $\begin{array}{c}0.04 \\
(0.394)\end{array}$ & & & & & -0.01 \\
\hline & & $\begin{array}{c}0.10 \\
(0.001)\end{array}$ & & & & 0.43 \\
\hline & & & $\begin{array}{c}2.94 \\
(0.001)\end{array}$ & & & 0.17 \\
\hline & & & & $\begin{array}{c}0.03 \\
(0.006)\end{array}$ & & 0.30 \\
\hline & & & & & $\begin{array}{c}0.98 \\
(0,000)\end{array}$ & 0.86 \\
\hline
\end{tabular}

Data in parenthesis represent the significance level $(\mathrm{P} i \mathrm{t})$. 


\section{Chapter 7}

\section{The Fragility of Emerging}

\section{Countries' Exchange Rates Since the 2000s: a Minskyan Analysis}

The exchange rates of a group of emerging market economies (EMEs) have undergone synchronized exchange rate dynamics, characterized by an important appreciation from 2003 to the Global Financial Crisis (GFC) and significant volatility and extreme depreciations in moments of turbulence in international financial markets. The literature on financialization argues that with the changes of finance at the international level, exchange rate dynamics would not be different than that of a financial assets' price. Heterodox exchange-rate literature considers some financialization-related innovations. Schulmeister explains the role of FX traders and their (technical) trading strategies, that results in alternating upwards and downward trends. Harvey explains investors' decision-making process under our current financial convention: it is mostly dependent on the forecast exchange rate that fluctuates according to the expected changing demand of foreign portfolio investors. Through these analyses the general characteristics of FX markets is explained: they are marked by ups and downs determined by portfolio investors expectations.

The behavior of exchange rates of EMEs (emerging currencies) is however, more specific. As seen in the last chapter, a part of these currencies have been following ups and downs 
whose alternation is more related to the international financial scenario than the countries' specific context, and were marked, since 2003, by a long-lasting cycle followed by extreme changes. Studies of the specific attributes of emerging currencies provide a better account for their dynamics than the mentioned heterodox approaches by demonstrating how their attributes explain the changing demand according to the international scenario ${ }^{1}$.

This chapter proposes an analysis that takes those attributes into account, using a framework focused on money managers' decisions and their balance-sheet constraints. Given the relevance of these investors' balance-sheets in interconnecting asset markets across advanced countries and EMEs, the analysis of their decisions results in a description of the mechanisms determining emerging currencies' fragility.

The Minskyan framework is chosen for the analysis for three main reasons. First, because the centrality of balance-sheets in the framework is in line with the role of money managers' balance-sheets in times of financialization in interconnecting markets, which determines exchange rates, as argued in Chapter Two. The dynamics of the liabilities side of balance-sheets are a well known part of Minsky's analyses due to the role of their ability to repay debt. However, the core of Minsky's analysis is on the interactions of liabilities with assets, which is the basis of the definition of margins of safety, that are based on income inflows (from the companies' activities and financial inflows) and debt repayment. Assets' dynamics are also important in the transmission of crisis given the relevance of a decrease of inflows due to bankruptcy of a firm in another one.

By focusing on both assets and liabilities, the Minskyan framework allows two essential attributes of emerging currencies respectively related to money managers' assets and liabilities to be taken into account: the non use of emerging currencies as reserve of value nor as denominator of financial contracts internationally, discussed in Chapter Three.

Secondly, Minsky's framework sheds light on the dynamics of the expansionary phase of the cycle, the moment when fragility is built. In Tymoigne and Wray's (2013) words: "in the Minskyan framework, the most relevant instability is upward" (p. 2). With this focus,

\footnotetext{
${ }^{1}$ The dynamics that emerge from emerging currencies attributes was detailed in Chapters Three and Five, and will be briefly mentioned in this chapter.
} 
Minsky's analysis explains not only exchange rate depreciation, but also its previous appreciation. Although both might be equally undesirable ${ }^{2}$, crisis episodes receive substantially more attention on the economic literature.

Thirdly, Minsky's framework is explicit on interactions among different agents. As shown in Chapter Three, the heterogeneity of agents is crucial for understanding exchange rates ups and downs. Heterogeneous agents are a main feature of the most recent mainstream models, as well as of most exchange-rates heterodox models, but they are not yet contemplated by the models that deal with the specificities of emerging currencies.

The structure of the chapter Following this introduction, Section 7.1 analyzes Minsky's financial instability hypothesis and its use in contexts other than its original one. Section 7.2 suggests how to transpose Minsky's framework to open economies and money managers' portfolio allocation decision, allowing the study of the demand for EMEs' assets. Section 7.3 concludes.

\subsection{The Financial Instability Hypothesis}

As "a post-Keynesian institutionalist", Minsky has always provided great attention to the institutional structure in which his analyses were inserted (Wolfson, 2002, p. 398). In the financial instability hypothesis, the institutional background is very specific: "a capitalist economy with expensive capital assets and a complex, sophisticated financial system" $\left(\right.$ Minsky, 1992) ${ }^{3}$. As production must be financed, capitalist economies are characterized by a system of borrowing and lending based upon 'margins of safety' (Minsky, 1993) - the 'cushions' between the cash commitments and the prospective cash receipts involved in the investment decision (Kregel, 2008). According to the desired margins of safety each firm (or, more generally, an economic unit) will have a combination of cash inflows and outflows, which is at the heart of Minsky's famous hedge, speculative and Ponzi characterization.

\footnotetext{
${ }^{2}$ The negative impacts of exchange rate 'misalignment' are presented in the Introduction.

${ }^{3}$ The importance of financial conditions in explaining crises is not exclusive to Minsky and is found in other heterodox authors' works. See Guttmann et al. (2015) for a review.
} 
The taxonomy of cash flows Hedge is the name given to units whose "flow of funds that result from the normal functioning of the assets it owns (...) are sufficient to fulfill current and future expected payment commitments due to liabilities" (Minsky, 1993, p. 80). Speculative units, on the other hand, are those that "expect the cash flows (...) to be less than the cash payment commitments in some, typically near-term, periods" (Minsky, 1986, p. 230). A Ponzi unit "is similar to a speculative financing unit in that, for some near-term periods, the cash payment commitments exceed the expected cash receipts on account of owned assets" and not even the interests on debt can be paid (Minsky, 1986, p. 231), demanding new debt to be issued (Minsky, 1993). A common and simple way Minsky's characterization is used is: hedge, when expected inflows cover outflows; speculative, when inflows cover at least interest payments; and Ponzi when neither the debt nor interests can be paid based on the expected inflows.

Although this "taxonomy of cash flows" (Minsky, 1986, p. 223) is customary, Minsky (1993) offers us a broader way of looking at the types of units. For being an enlarged form of seeing his framework, Minsky (1993) broadens the potential use of his framework to different contexts. A main point is that speculative and Ponzi are differentiated from hedge units for having an additional "element of uncertainty in financial relations" (Minsky, 1993, p. 80, italics added), creating a dependency on future market conditions - "the market terms that rule at the refunding date". This additional element impacts speculative and Ponzi units but not hedge units: "speculative- and Ponzi-financing units have to meet changing financial market conditions, whereas a hedge unit will be impervious to such changes" (Minsky, 1986, p. 231). Both speculative and Ponzi depend on future conditions and the differentiation between them is subtle: margins of safety are shrinked in the case of Ponzi, putting these units in a worst situation when financial conditions are not as good as expected.

The two theorems After differentiating the units, Minsky (1993) uses the typology to compose the financial instability hypothesis, divided into two theorems. The first theorem defines the fragility of the economic system based on the relative presence of each type of unit:

If hedge finance dominates, then the economy may well be an equilibrium seeking and containing system. In contrast, the greater the weight of speculative 
and Ponzi finance, the greater the likelihood that the economy is a deviation amplifying system. (p. 8)

The fragility of an economy is also determined by the institutions in place and by their ability to increase liquidity when needed. In Minsky's (1993, p. 81) words, fragility also depend on i) "the willingness and the ability of the authorities to refinance units at concessionary terms"; and ii) on "the in-place power of the authorities to sustain aggregate profits (cash flows to business) and aggregate wages (...)"

The second theorem of the financial instability hypothesis is the increase of fragility over periods of prolonged prosperity (Minsky, 1992). Alternatively, as put by Minsky (1993):

over a run of good times the structure of units among hedge, speculative and Ponzi financing changes, so that the weight of hedge financing decreases and the weight of speculative and Ponzi financing increases. (p. 8)

The evolution of Ponzi units results from the choice of margins of safety being somewhat dependent on the stability of the economic environment: in a run of good times, expectations are constantly being confirmed, leading units to reassess their prior decisions as too conservative and to reduce margins of safety. As summarized by Papadimitriou and Wray (1998):

It is precisely the apparent 'stability' that generates changes of expectations that leads to the adoption of financial positions that cannot be validated should events prove to be less favorable than expected - that is, the transformation from robust (hedge) arrangements to fragile (speculative) positions ${ }^{5}$. (p. 213)

In a nutshell, given profit-seeking behavior and evolving expectations, tranquility will motivate units to lower margins of safety moving the economy to a more fragile situation.

\footnotetext{
${ }^{4}$ Minsky (1992) indirectly references the importance of Big Bank and Big Government, the institutions responsible for the fact that Managerial Capitalism "did not exhibit the serious recessions and depressions of Finance Capitalism", the precedent phase on the author's characterization (Minsky, 1990, p. 23). It is interesting to highlight that Minsky's analysis of financial instability cannot be dissociated from his work on the four stages of the development of capitalism in the United States. See Chapter Two, page 18.

${ }^{5} \mathrm{It}$ is interesting to note that this change in expectations will not only affect productive units, but also partner institutions responsible for providing credit. In Minsky's (1993) words, "during a period dominated by hedge financing, the structure of financing terms and the performance of markets and institutions that trade in assets and refinance debts lead profit -seeking clients of banks and markets and the operators of banks and the operators in markets to substitute debt for equities and short-term debts for long-term debts" (p. 81).
} 
From a fragile situation a crisis can be triggered by any 'not-unusual' shock, or 'not-abnormal' event (Minsky, 1993, p. 81).

The role of the 'not-unusual' shock The emphasis on the shock being 'not-unusual' is meaningful: it is an event that can occur at any time, but that only leads to a crisis because the system is in a fragile situation when hit. As a consequence, the crisis is endogenous: it only occurs because the economy is fragile, and fragility is endogenously built. In Arestis and Glickman's (2002) words: "the reasons why a 'shocking' event can actually have the power to shock are emphatically endogenous" (p. 241). What is key is that the build-up of fragility that allowed the event to be shocking, is endogenous, although the event itself might be exogenous. Minsky et al. (1982) also considers possibilities in which the unfolding of the crisis is completely endogenous ${ }^{6}$.

The spread of the crisis When the 'not-unusual' surprise happens, speculative units are pushed into Ponzi, and hedge units can be pushed into speculative. These speculative positions are then pushed into Ponzi for a variety of reasons: "the terms on which finance is available become less favorable, (...) some expectations are revised, income flows that had been expected are not forthcoming, and so on" (Papadimitriou and Wray, 1998, p. 14). This spiral is such that "the net worth of Ponzi units will quickly evaporate" and units recur to "selling positions to make positions" (Minsky, 1992, p. 8), but when "everybody is a seller", asset prices collapse, worsening the situation further (Kregel, 2004, p. 577).

\subsubsection{Minsky's Framework Applied to an International Context}

Although created with a focus on the fragility of an economy based on the behavior of firms, the financial instability hypothesis has also been used in other contexts. While most of the

\footnotetext{
${ }^{6}$ The most important example of endogenous shock is the evolution of interest rates: "The upper turning point is completely endogenous once it is accepted that interest rates rise in an investment boom and that the successful functioning of the economy induces profit-seeking bankers and their customers to engage in speculative financial arrangements and to economize on holdings of money and protected assets" (Minsky et al., 1982, 33). The evolution of other variables can also trigger a crisis in a completely endogenous manner: "A break in the boom occurs whenever short- and long-term interest rates rise enough so that attenuation and reversals in present-value relations take place. Often this occurs after the increase in demand financed by speculative finance has raised interest rates, wages of labor, and prices of material so that profit margins and thus the ability to validate the past are eroded" (Minsky, 1986, p. 245).
} 
'new' analyses focus on cash inflows and maintain debt-related cash commitments, some studies keep the focus on inflows and outflows without necessarily relating them to debt. Minsky himself has used his typology referring to units as other than firms, especially to analyze the banking system. Minsky (1992) cites as examples of speculative units "governments with floating debt, corporations with floating issues of commercial paper, and banks"; Minsky (1993) mentions the United States as a Ponzi unit for having borrowed to pay the interest on outstanding debt; and Minsky (1986, p. 230) classifies units such as New York City and Brazil as Ponzi. However, it was after the exchange-rate crises in developing countries in the late 1990s that the enlarged versions of Minsky's framework increased considerably, being often applied to a context of international economies where countries are the units of interest.

These analyses highlight that Minsky's theories are implicitly targeted at financial crisis in closed economies (Dymski, 1999), which led Arestis and Glickman (2002) to argue that Minsky's work "predates the current era of financial liberalization". Indeed, regardless of Minsky's extensive analyzes of 'Money Manager capitalism' and of the late 1980's currency attacks, it cannot be said that open economies were the focus of his work. However, the enlargement of Minsky's theory to open economies is a logical evolution given the current context of liberalization and free capital mobility, where "the global economy can be considered as a closed system of capitalist systems" (Wolfson, 2002) ${ }^{7}$.

But how can Minsky's original framework be transposed to the analysis of other contexts? The methodology used in most of the literature consists of examining a situation from 'the lenses of Minsky's framework'. More precisely, these studies identify how the most important Minskyan elements ${ }^{8}$ manifest in the new context and which elements must be $\operatorname{added}^{9}$.

\footnotetext{
${ }^{7}$ Also see Kregel (2016).

${ }^{8}$ Wolfson (2002, p. 393) prefers the term "main themes of Minsky's (...) theory".

${ }^{9}$ In some of these studies, index of fragility are constructed.

Finally, it should be mentioned that part of the literature enlarging Minsky's framework include analysis based on indeces of fragility. De Paula and Alves Jr (2000), analyzing the effect of changes in the units' attitude in the balance of payments propose an index of external financial fragility based on a country's main BOP elements where current and potential foreign currency liabilities are compared to the country's payment capacity. The idea is that this index would indicate a potential need to resort to international capitals market to renegotiate outstanding financial positions. Schroeder (2002) proposes to track the evolution of fragility in Thailand during the 1990s based on an index that results from the transposition of a firm's balance-sheet to a national economy. The main elements taken into account are the rate of increase of profits, interest rates and growth, resulting in a hedge, a speculative or a Ponzi profile.
} 
The remainder of the section reviews the use of Minsky's framework in other contexts, specifically by identifying how key elements of the original analysis translate to an openeconomy context. The key Minskyan elements identified are: the taxonomy of units according to their margins of safety; the confirmation of expectations; the interconnection among units; the 'not-unusual' event; the debt-deflation and the spread of the crisis; and the related policy implications.

\subsubsection{The taxonomy of units}

The most famous Minskyan element is the taxonomy of units into different levels of margins of safety ${ }^{10}$. Different forms of classifying a hedge, a speculative or a Ponzi unit in an open economy context have been proposed, though there is consensus on the key role of units' exposition to exchange-rate risks on defining the taxonomy.

Arestis and Glickman (2002), studying the financial crisis in Asia in the late 1990s, argue that given the possibility of being funded in different currencies the classification of different financing-types becomes blurry. For instance, a firm that finances itself with a long-dated loan in a foreign currency is classified as a hedge unit domestically but not internationally due to its vulnerability to the exchange rate. To deal with this double source of risk, the authors suggest the inclusion of a fourth type of unit: the 'super-speculative', a unit that is Ponzi both domestically and internationally for having short-term funding in foreign currencies.

De Paula and Alves Jr (2000), studying the development of financial fragility in Brazil after the mid-1990s reforms, agree with the complexity imposed by the "sensitivity to exchange variations" (p. 10) and propose to differentiate units that do not run exchange-rate risks (hedge) from those that do, either with regards to their costs (importers) or revenues (exporters) $)^{11}$.

\footnotetext{
${ }^{10}$ Margins of safety define the behavior of units, that is based on expected cash inflows. If inflows turn out to be different than expected, units can move from one category to the other. In this sense, Minsky's taxonomy might also be seen as a classification of the unit's situation, that is not necessarily as favorable as it had previously desired.

${ }^{11}$ From a macro perspective, the result of agents' attitudes are reflected in the country's balance of payment, whose main elements are used to build an index of external financial fragility, in which actual and potential foreign currency liabilities are compared to its payment capacity. This index indicates a potential "need to resort to the international capital markets in order to renegotiate outstanding financial positions" (De Paula and Alves Jr, 2000, p. 11).
} 
Kregel (2004) analyzes developing countries' governments that borrow in foreign currency. It is a structural picture from the analysis of the fragility of the country's balance of payments. In order to repay debt, developing countries must use foreign exchange earnings, which can be of three types: current account surpluses, foreign exchange reserves (which were accumulated from prior current account surpluses), or more foreign debt. From the observation that net borrowing by developing countries are usually associated with a negative current account balance, debt service payment demands external borrowing, characterizing these countries as Ponzi ${ }^{12}$.

Although Kregel (2008) does not focus on open economy concerns, he offers a detailed discussion on margins of safety. The subprime financial crisis is the subject of analysis ${ }^{13}$ having the subprime mortgage obligations as the central units, whose fragility depends on the fragility of the securities that back them. There are three types of securities with very different cash inflow positions depending on their seniority: senior, intermediate, and residual. Intermediate security receives income only after the senior, and residual security only after the other two. These different levels of expected income determine margins of safety and their classification into hedge, speculative and Ponzi profiles - a Ponzi mortgage-backed security depends on income from a subprime loan.

Kregel's (2008) therefore differs from the other studies for having at the core of the classification of units a more uncertain type of income, instead of debt repayment. These analyses have in common the understanding of Ponzi units as the ones incurring in an additional element of uncertainty, which is in line with Minsky's (1993) broader reading of his taxonomy.

\footnotetext{
${ }^{12}$ The broad policy conclusion is on the essence behind Minsky profiles: to better manage its balance-sheet to match earning and commitments. Countries would have two options to overcome this situation. The first is to build 'real capital': to use foreign borrowing to enhance the share of exports in GDP, thus increasing foreign earnings. The second is to increase 'financial capital': to increase lenders' confidence about their own decisions, so they continue lending in an increasing rate. Kregel (2004) differentiates between using capital inflows to build real and financial capital, the former is related to the use of foreign lending in investments, ensuring an increase in the share of net exports to GDP, in a way that is later sufficient to pay for the lendings commitments. Financial capital, on the other hand, refers to increasing a lender's confidence so they continue to increase lending. Dymski (1999) also raised the importance of increasing real capital, arguing that capital flows can create imbalances in developing countries if they lack the proper institutional structure to channel flows to productive investments instead of to speculative investments.

${ }^{13}$ It is interesting to note that, according to Kregel (2008), the GFC was not Minskyan in the most pure sense because the decrease in the margins of safety was not due to changes in expectations (as in Minsky), but due to a miss-assessment of risks by the rating agencies.
} 


\subsubsection{The confirmation of expectations}

Another Minskyan element is the confirmation of expectations in a period of boom that has the major consequences of decreasing the margins of safety. In Wolfson's (2002) analysis of the Asian crisis, this point was studied in detail. Wolfson (2002, p. 395) mentions expectations concerning the continuity of the increase in profits ("as profits grew, expectations of further profits expanded, which led to further flows of funds"); the continuity of the exchange rate stability ("as funds poured into Asian markets few investors though it was necessary to hedge these investments, since exchange rates in these countries have been stable"); and the continuity of foreign investors' demand for EMEs' assets ("lending and investment to 'emerging market' became the hot new area in the 1990s").

When dealing with open economies, it is also important to have in mind the role of capital flows in confirming the optimistic expectations that were behind them. As put by Arestis and Glickman (2002, p. 242), an enhanced international position is "interpreted as evidence of economic health". Asset-price bubbles also lead to the confirmation of optimistic expectations. As argued by Dymski (1999, p. 9), "the more rapid the growth of a bubble, the more certain are participants that the sky will not fall, the more likely a crash". The author adds that in the context of open economies, asset-price bubbles could happen more often, as they can result from important capital inflows or, in an asset-buying economy (with capital outflows), be driven up by a bubble overseas.

\subsubsection{The interconnection among units}

In Minsky's original analysis, the interconnection among units takes place through balancesheets: the default of one puts the income of others at stake, pushing them into a situation of decreased margins of safety. This is at the heart of the propagation of a crisis. Wolfson (2002) underscores the role of carry trade operations funded in Japanese yen, creating a link between the Asian developing countries and the monetary stance in Japan. The author's analysis highlights that carry trading operations are analogous to the yield curve in Minsky's analysis, as both create an incentive for borrowing at low, short-term and lending at high, long-term rates. 


\subsubsection{The 'not-unusual' event}

The 'not-unusual' event is another important element of Minsky's analyses, that triggers a crisis if it occurs when the system is at a fragile situation. Wolfson's (2002) analysis mentions two events. The rumor of changes in the Japanese monetary stance was key because it directly affected the continuity of inflows of units: "Apparently, the rumor of increasing interest rates in Japan was a precipitating factor in the Asian financial crisis, as profits from the carry trade were threatened" (Wolfson, 2002, p. 396).

However, Wolfson draws more attention to the 'contagion' of the crisis from Thailand to other countries, through the interconnection of balance-sheets, that had an important role in reversing the until-then optimistic expectations. Although the "spread of financial crisis from one point to another" (Wolfson, 2002, p. 397) is clearly not what triggered the crisis in the first place, the author's inclination toward the contagion event might be due to it being an endogenous reaction (Wolfson, 2002, p. 395) - which is in line with Wolfson's (1994) definition of the not surprise event being an "endogenous reaction to the pressures building in the financial system" (p. 147). However, the explanation of the crisis through external events reveals that, in a world marked by important interconnections of different markets, the possibility of exogenous shocks cannot be denied.

\subsubsection{Debt-deflation or 'debt-exchange-rate' deflation}

Debt-deflation is a key element of Minsky's analysis that explains the spread of the crisis. Wolfson (2002) suggests that in the Asian crisis, the parallel to this situation was the 'debtexchange-rate interaction':

as investors fled financial markets in Asia and as exchange rates fell, (...) more loans were defaulted (...) investors fled financial markets, and the exchange rates fell further. Thus an interactive process developed that ultimately spiraled downward and intensified the crisis. (p. 395)

It is interesting to note that in the Asian case the change towards an open economy context resulted in an inversion of the initial focus of decreasing values of assets to increasing values of liabilities, which was especially important in this case given the currency mismatch. 


\subsubsection{Policy implications}

Finally, the correspondent of the lender-of-last-resort, the institution responsible for providing liquidity to avoid a crisis from taking place, has also been expanded to the context of open economies. Wolfson (2002) argues that the International Monetary Fund (IMF) can play such a role internationally given its ability to intervene with hard currency; while Arestis and Glickman (2002) believe that there is currently no institution to play this role of "Big Bank". The latter add that the role of "Big Government" to assure income inflows is also vacant in an international context.

With regards to policy implications, Arestis and Glickman (2002) and Wolfson (2002) conclude that, in an open economy, crises demand not only the lender-of-last-resort, but also capital controls. These allow countries to deal with problems of sudden capital outflows and also for hindering fragility for being built on, in Wolfson's (2002) words, "what is necessary for financial fragility to develop (...) is a lack of regulations and laws limiting foreign financial investment" (p. 397).

\subsubsection{Additional open economy elements}

Open economy crises have been explained through several elements from Minsky's framework, with the addition from other perspectives. The exchange rate, the monetary and economic conditions overseas, and the above mentioned capital controls were additional elements of concern in the reviewed literature. As discussed, exchange-rate considerations greatly impact the very taxonomy of units, given its decisive role in determining their fragility. Wolfson (2002, p. 396) concluded that "in addition to the characteristics of domestic financial fragility mentioned by Minsky, we should consider the exchange-rate risk to be an aspect of financial fragility in the global environment". To Dymski (1999, p. 3), open economy analysis "requires that Minsky's core framework be 'spatialized' - that is, it must take explicit account of spatial economic borders and foreign-exchange constraints". Arestis and Glickman (2002) highlight that the possibility of being funded in another currency shows the importance of the exchange and interest rates as the main 'novelties' of the enlarged Minskyan framework. Wolfson (2002, p. 395) also highlights the role of expected interest rates ("what become increasingly 
relevant for borrowers is the stance of monetary policy, and the direction of interest rates, in the country from which the loans are being made") and the economic situation in the country where capital is flowing from.

As this section illustrated, several authors have used Minsky's framework to study the rise of fragility in different contexts. This is usually done by identifying how the main elements of the Minskyan framework manifest themselves in the concerned context. Most elements have equivalents in the international context, and additional elements such as exchange rates, interest rates and capital controls were introduced.

\subsection{Emerging Currencies' Fragility}

In this section, the rise of fragility in emerging currencies is analyzed by transposing the elements studied above to the context of money managers' investment decisions as well as the causalities of the traditional phases of the cycle - its tranquility and trigger, the build up of fragility with self-feeding interactions, the 'not-unusual' event, and debt-deflation, that, in this case, is an asset/exchange-rate deflation. Policy implications are also discussed.

The section characterizes the key units of the analysis, the money managers and what defines their margins of safety, before presenting the analysis of the rise of fragility in the 2000s.

\subsubsection{The Economic Units: Money Managers}

Minsky's original analysis focuses on productive units in which assets and liabilities determine inflows and outflows; their financial commitments must be covered with income from either business activities or loans, with the constraint of having to meet these commitments. The decisions on the liability structure change according to expectations concerning future income, which are based on assessments of past and current activity. Each choice of liability structure has its respective margin of safety.

As discussed in Chapter Two, the rise of money managers is a marked feature of financialization, their decisions being crucial for understanding the dynamics of finance at 
the international level. Chapter Three demonstrated the importance of portfolio investors in determining exchange rates and that the analysis of their behavior is broadly recognized by the heterodox literature as well as by the most recent mainstream frameworks (behavior finance, micro-structure, carry trade $)^{14}$. As discussed in Chapter Six, the conditions of international financial markets have an impact on emerging currencies, hinting to the crucial role of money managers, these markets' key players, in determining emerging currencies. Thus, money managers are the central units in the analysis of emerging currencies.

In order to continue receiving funding, money managers must be successful in allocating portfolio - flows migrate to the successful fund managers (Minsky, 1990, p. 32). Money managers' survival constraint is maximizing profits, ensuring a return that is at least aligned with the return of other money managers. More than the return paid by an asset, money managers are interested in an asset's total returns, that consists not only of dividends distributed or interest paid, but also of capital gains (Minsky, 1990), that, in the context of international portfolio allocation, include exchange rate returns.

Exchange rate changes are also relevant given the new logic of finance at the international level. As argued in Chapter Two, and demonstrated from the empirical analyses of Chapter Five, emerging currencies' FX transactions are decoupled not only from the country's trade, but also from its financial integration. This reveals that assets are frequently bought and sold, which hints at gains from changes of their value (that include exchange rate returns) rather than from their returns - called a rise of speculation, according to Kaldor's (1939) definition.

The higher focus on exchange rate returns is in line with the increasing financialization of currencies, the rise of derivatives carry trading and the increase of foreign investors' exposure to emerging currencies with the rise of the use of instruments denominated in domestic currencies as equities (Kaltenbrunner and Painceira, 2014) ${ }^{15}$.

\footnotetext{
${ }^{14}$ Portfolio investment are included in mainstream models since the portfolio models, but their focus were rather on the relevance of interest rates, the behavior of investors being simplified.

${ }^{15}$ The profitability of canonical carry trade operations also depend on exchange rate returns. Their profitability is given by a higher interest rate return differential than the exchange rate depreciation of the target currency, or $i^{*}-i>e^{e}$ (Equation 3.24), which implies being reactive to exchange rate changes so as not to lose its returns, and profiting from appreciation of the target currency as a source of returns. The discussion on the rise of the focus on exchange rate returns is presented in Chapter Two, page 41.
} 
Due to their impact on returns, exchange rates gained relevance with the shift of attention from central decisions to assets. It is worth recalling that in the late-1990s crises exchange rates were fixed. The floating regime gives higher importance to the exchange rate through the impact of appreciation on money managers' returns. Exchange rates are also key in the dynamics that emerge from money managers decisions for being a mechanism through which a unit affects the other: money managers' decisions affect emerging currencies that affect the value of other money managers' assets. Interest rates were key in Minsky's original analysis and in analyses of the Asian crisis, but when central decisions concern assets instead of liabilities, interest rate lose part of their relevance to exchange rates ${ }^{16}$.

\subsubsection{Exchange Rates and Margins of Safety}

Margins of safety have the crucial function of connecting assets and liabilities. In Minsky's original analysis, they represent the cushion between the expected incoming cash from assets and the payment commitments relative to the funding of those assets. When Minsky' framework is transposed to the context of money managers, with the possibility of allocating their assets abroad, the exchange rate creates a currency mismatch of money managers' balance-sheets, being a main element of uncertainty of their inflows as liabilities are labeled in advanced countries' currencies, but their assets can be labeled in different currencies.

Money managers have three general possibilities for allocating their portfolio: i) in assets of the country where they have their funding from, ii) in assets of another advanced country, or iii) in assets labeled in emerging currencies (that are an increasing part of the EMES' assets. The exchange rate is the major difference among these three options, as a return and a risk variable. As demonstrated in the last chapter, the exchange rates of a group of EMEs vary in larger ranges than that of advanced countries' currencies, what, for money managers, means higher profit possibilities and higher risk of loosing capital. Accordingly, the exchange rate return and risk is not the same in the three cases.

In the first possibility, the money manager is not exposed to any exchange-rate risk and there is no currency mismatch, thus having the highest margin of safety, representing

\footnotetext{
${ }^{16}$ Interest rates still play a major role not only for determining part of money managers' returns (part being due to exchange rate returns), but also for hinting to the possible behavior of financial market participants.
} 
a hedge case. In the other two cases, units are exposed to exchange rates, which are the parallel to changes in financial markets conditions in Minsky (1993); because they have an additional element of uncertainty, margins of safety of these money managers are reduced. These are the cases of speculative and Ponzi units. In line with Minsky (1993), margins of safety are shrinked in Ponzi units, in this case, the third possibility, due to the higher frequency of extreme depreciationof emerging currencies (seen in Chapter Six), thus higher risks of loosing assets' value.

\subsubsection{Self-Feeding Interactions, Tranquility and the Build-up of Fragility}

In Minsky's original analysis, the expansionary phase of the cycle begins in a period of tranquility: In a profit-seeking strategy, firms change their liability structures to profit from new opportunities that arise from innovations or from a changed economic environment. They do that by constantly, over "each short period", reassessing the environment and their opportunities (Minsky, 1990, p. 33). As discussed in Chapter Two, innovations (in both technological and institutional terms) were key for increasing international investments in general and in EMEs in particular. However, over shorter periods, the main driver of expectations and decisions about investing in EMEs is the tranquility of the economic environment.

Exchange rate analyses focused on the specificities of emerging currencies highlight the role of uncertainty and liquidity preference internationally in determining capital flows to EMEs (as seen in Chapter Three). These analyses are centered in the fact that emerging currencies provide a lower liquidity premium than the ones of advanced countries. In the framework of the Keynesian equation on an asset's own rate of return, the liquidity premium $(l)$ is one of the attributes of a currency's returns $(r)$, together with its expected appreciation $(a)$, its quasi-rent or yield $(q)$, and its carrying costs $(c)$. Liquidity preference is a parameter that changes how the attribute liquidity is valued $(\beta)$. The return of emerging currencies and of currencies of advanced countries (*) are presented in Equations 3.33 and 3.34, respectively, reprinted from Chapter Three.

$$
\begin{gathered}
r=a+q-c+\beta l \\
r^{*}=a^{*}+q^{*}-c^{*}+\beta l^{*}
\end{gathered}
$$


The demand for emerging assets is analyzed through the difference between the return of EMEs' and advanced countries' assets $\left(r-r^{*}\right)$, in Equation 3.35, as suggested in Chapter Three. Given that the liquidity premium of emerging currencies is lower than the liquidity premium of advanced countries' currencies $\left(l<l^{*}\right)$, the differential between the two $\left(l-l^{*}\right)$ is structurally negative, having a negative impact on the returns differential. When liquidity preference $(\beta)$ decreases, this negative impact decreases, increasing the return differential $\left(r-r^{*}\right)$. This is in line with Biancareli's (2011) argument that cycles of liquidity preference determine flows for EMEs. Another way of seeing the impact of the lower liquidity premium is through the need to change one of the currency's attribute to attract flows to compensate their lower liquidity premium (as put by Andrade and Prates (2013)).

$$
r-r^{*}=(a+q-c)-\left(a^{*}+q^{*}-c^{*}\right)+\beta\left(l-l^{*}\right)
$$

In the early 2000s, in the aftermath of the Dotcom bubble, the return differential between the emerging currency and the one from advanced countries $\left(r-r^{*}\right)$ were increased by two changes. The decrease of interest rates in the US is one of them, represented by a fall of $q^{*}$. Indeed, the fall of U.S. interest rates led to a significant rise of the interest rate differential relatively to most EMEs - a differential that decreased in the following years, increasing again only after the collapse of Lehman Brothers ${ }^{17}$. A second change was in the tranquility of the international financial sphere (as seen from the fall of the VIX index since mid-2003 ${ }^{18}$ ), that can be represented by a decrease of $\beta$, and thus of $\beta\left(l-l^{*}\right)$. In addition, tranquility was also a feature of emerging currencies, whose last currency crises were in 2001 and 2002, in Turkey and Brazil ${ }^{19}$.

\subsubsection{Self-feeding interactions}

The special combination of higher return differential and tranquility caused an initial hike in demand for EMEs' assets, which in turn created the conditions for the expansionary

\footnotetext{
${ }^{17}$ Interest rate differentials are shown in Figure 6.25, in page 334.

${ }^{18}$ See Figure 6.12, in page 294.

Values lower than 20 are commonly considered as less stressful periods and values higher than 30 are associated with high uncertainty. The discussion on the use of the VIX index as an indicator of stress in financial market and thus uncertainty and liquidity preference is presented in Chapter Six, Section 6.3.2.

${ }^{19}$ See Figure 1.1, in page 4 for the path of emerging currencies since 2000.
} 
phase of the cycle through spirals of increasing price and increasing demand. These selffeeding interactions concern two of the currencies attributes: rising equity prices (that are part of $q$ ) and exchange rate appreciation $(a)$. The higher demand for any of the country's assets (including the currency itself) put appreciation pressure on the currency, leading to an expectation of further appreciation $(a)$ that increases the expected return differential $\left(r-r^{*}\right)$. If the higher demand is targeted at equity prices, the impact on return differential will be even greater, because there is expectation of capital gain not only from the appreciation $(a)$, but also from the stock price (thus, $q$ ).

A relatively small increase of demand for EMEs' assets might trigger these self-feeding interactions because of two structural attributes of EMEs. The first is the potential bias of the type of money manager attracted by EMEs, given the high volatility of some emerging currencies - such as the South African rand, the Brazilian real, the Hungarian forint, the Polish zloty, the Turkish lira, and, to a lesser extent, the Mexican peso and the Czech koruna $^{20}$ (demonstrated in Chapter Six). This attribute might attract investors who are more drawn to exchange rate returns, and that respond more quickly to a first exchange rate appreciation.

The small size of their markets vis-a-vis of the magnitude of foreign portfolio investors (associated with the monetary and financial asymmetries (Prates, 2005a), discussed in Chapter Three $^{21}$ ) is the second reason why these interactions might be more easily triggered in EMEs. With regards to FX markets, emerging currencies were involved in $8.4 \%$ of total FX transactions in 2013 and by the time of the first hike of demand for EMEs' assets, in the early 2000s, the participation of their currencies was half this value (seen in Chapter Five). With regards to the asymmetric size of EMEs' assets markets vis-a-vis of foreign portfolio investors, the proxy of the stock of foreign liabilities held in the form of equities in relation to the country's stock market capitalization makes the point clear. Foreign investors would have represented $45 \%$ of Hungary's stock market in the 2003-2011 period, and $42 \%$ of Mexico's - the share was also high in Korea, Czech Republic, Indonesia, Brazil and Peru (seen

\footnotetext{
${ }^{20}$ In several EMEs the exchange rate is not very volatile, presenting deviations that are significantly lower than the Euro/U.S. dollar pair.

${ }^{21}$ In this chapter's analysis, low liquidity refers to the small size of markets, although this is only one of different possible defining features. According to Carvalho (1992), liquidity is related to a market's density, permanence and organization. While density has to do with the size of the market itself, also permanence how long it is open - and how organized it is are features determining its liquidity.
} 
in Chapter Four) ${ }^{22}$. Because they are 'a small content' (as in Haldane's (2011) 'Big Fish Small Content' metaphor), the demand from a few money managers is enough for triggering self-feeding interactions.

With respect to the self-feeding mechanism between stock prices and exchange rates, a bi-directional causality of stock prices and exchange rates, that empirically supports the idea of this interaction, was found in almost half of the EMEs with floating exchange rates: Brazil, Hungary, India, Korea, Peru, Russia, Taiwan, and Thailand. The occurrence of the bi-directional impact depends mostly on the weight of equity financing in total foreign liabilities and on the size of the country's stock market ${ }^{23}$ (as seen in Chapter Four, Section $4.6)$.

Parallel to that, money managers that decide not to invest in EMEs (hedge or speculative money managers) are also propelled to do so because otherwise they would have lower returns than those that did (Ponzi money managers), which can decrease their funding. This pressure certainly existed in the 2000s: from 2003 to the GFC, emerging market returns, as proxied by the MSCI Emerging Market index, have grown 230\%, far outpacing returns in advanced countries as proxied by the S\&P 500, that grew $41 \%$ in the same period ${ }^{24}$.

\subsubsection{Tranquility and the evolution of assessments}

Whether a first surge of demand for EMEs' assets will be sustained depends on the extent that it can change the expectations of agents. In Minskyan analyses, a change in financial positions is triggered by "the apparent 'stability' that generates changes of expectations" (Papadimitriou and Wray, 1997, p.14).

The evolution of assessments in moments of tranquility is crucial for money managers' decrease of margins of safety in a structural basis. In the 2000s, stability was guaranteed in EMEs' FX markets with the first increase of demand from money managers, and the absence

\footnotetext{
${ }^{22}$ The ratio varies significantly across EMEs, the lowest being Chile's, where it represented $6 \%$ - see Figure 4.12 , in page 170 for the ratio of each EME.

${ }^{23}$ The occurrence of bi-directional causality also depends on the share of foreign investors in the stock markets, the size of the economies and of trade. The weight of equity financing in total foreign liabilities is high in Taiwan, South Africa, Korea, India, Brazil, Malaysia and Mexico, see Figure 4.8. See Figure 4.15 for the size of countries stock market.

${ }^{24}$ The estimation is done from April 17th, 2003 to September 12th, 2008, just before Lehman's collapse through Google Finance: www.google.com/finance.
} 
of crisis in EMEs' economies - in some EMEs, the boom of commodities prices also favored demand of their assets through an expected exchange rate appreciation ${ }^{25}$. Also important, the international financial environment was marked by tranquility from the aftermath of the the Dotcom bubble to the GFC, illustrated by the historically low values of the VIX index.

After an initial moment of tranquility, crisis become too far in memory ${ }^{26}$ and prior investment decisions are considered as excessively conservative and reviewed. With the tranquility of emerging currencies, money managers that did not invest in EMEs will deem this decision as too conservative. When including EMEs' assets (or currencies) in their portfolios, money managers are decreasing margins of safety and fueling the boom phase of the cycle.

The confirmation of expectations is important in the spiral of increasing fragility ${ }^{27}$. Through its impacts on assets' price and on exchange rate appreciation, and by guaranteeing the liquidity and stability of EMEs' FX markets, money managers' decisions to invest in EMEs' assets and currencies confirm their assessments that it is too conservative not to investing in EMEs, further feeding the cycle as other money managers also reassess their portfolio decisions.

A subsequent step in decreasing margins of safety is to further increase its exposure to emerging currencies through the leveraging possibilities of $F X$ derivatives. Speculative money managers are exposed to advanced countries exchange rates, while Ponzi money managers are exposed to the more volatile emerging currencies and they can also be more exposed through FX derivatives, which would be another type of Ponzi, or a 'super Ponzi' unit.

With the rise of this practice, emerging currencies receive an additional pressure, not through spot, but through future markets, strengthening the appreciation cycle and reaffirming money managers' decisions as sound.

The confirmation of expectations leads to the rise of a convention in favor of investing in EMEs, in the sense analyzed by Keynes and Orléan, discussed in Chapter Three. A major

\footnotetext{
${ }^{25}$ Note that the commodities boom is also associated with the rise of liquidity, and the commodities' financialization, discussed in Chapter Two.

${ }^{26}$ This aspect of temporarily abstracting from episodes of past crisis is reflected on (or even caused by) the use of econometric techniques that decrease the importance of old events vis-a-vis more recent ones, as is the case of estimating volatility with the EWMA (exponentially weighted moving average), where the weighting for older datum decreases exponentially.

${ }^{27}$ In Minsky's original analysis this spiral was observed in the fact that decisions for higher investments increased aggregate demand and profits, validating the decision itself.
} 
evidence of this is the increasing use of the BRIC acronym (suggested by O'Neill (2001)) by the financial media throughout the boom phase of the cycle, evoking excitement about investment opportunities in these countries (Fourcade, 2013).

Rating agencies also contributed to confirm money managers' assessment and the new convention with the classification of several EMEs' debt as investment grade: Russia in 2005, Brazil and Peru in 2008, India and Indonesia in 2011, Turkey in 2012, and the Philippines in 2013. Given that some funds only invest in assets of investment grade countries, the role of rating agencies is the same as in the subprime loans analyzed by Kregel (2008): they assume the function of estimating margins of safety, instead of money managers.

Another evidence is the spread of the decoupling thesis, according to which EMEs would not be affected by crisis in advanced countries in 2007, and the continuity of capital flows to EMEs despite the signs of crisis in the U.S. economy (mentioned in the Introduction Chapter).

Moreover, excitement about EMEs continued after the crisis, in the wake of the 'two speed recovery'. Even in 2010 there are signs of expectation of continuity of the favorable position towards EMEs, as shown in Goldman Sachs' (2010) estimation that the share of EMEs' equities in global equity portfolios would almost threefold in the next 20 years (from $13 \%$ in 2010 to $31 \%$ in 2030$)$.

\subsubsection{The reflect of the build-up of fragility in markets}

Pre-GFC low levels of the J. P. Morgan's Emerging Market Bonds Index (EMBI) - a major benchmark of the spread asked on EMEs' government bonds (see Figure 7.1) are evidence of the peak in the desirability for EMEs' assets.

EMEs' assets were not only more in-demand in this period, but their share in money managers' portfolio also increased. This demonstrates their changing margins of safety and is a direct evidence of the second theorem of the financial instability hypothesis when applied to the analyzed context. Goldman Sachs (2010) estimated that the share of EMEs' equities in the MSCI World Index ${ }^{28}$ had increased from $5 \%$ in 2000 to $13 \%$ in 2010 . Bonizzi (2013)

\footnotetext{
${ }^{28}$ MSCI's All Country World Index refers to global stock market activity.
} 
FIGURE 7.1: EMBI+, Selected EMEs

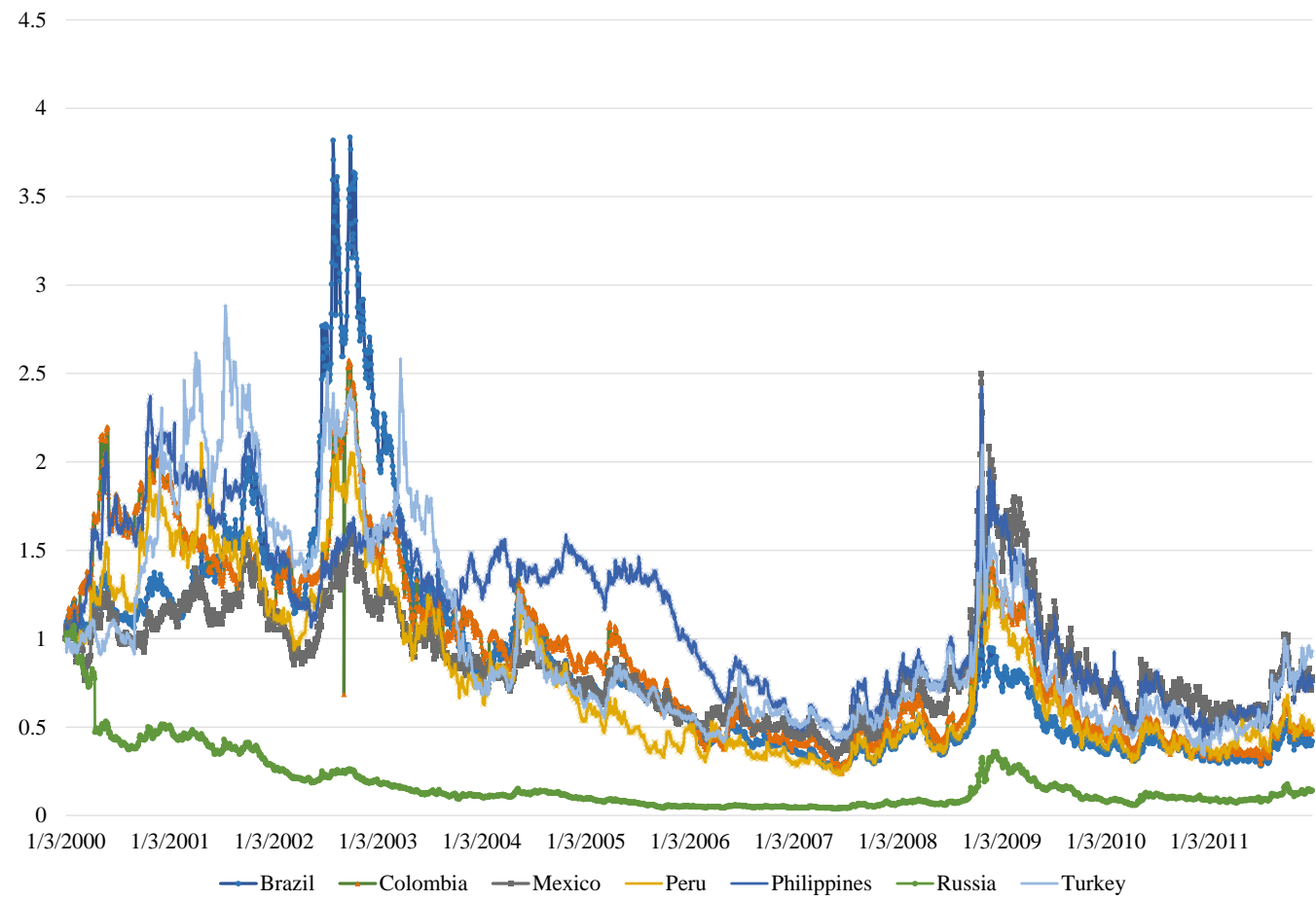

Source: JP Morgan

shows that the same pattern of increasing share of EMEs' assets is found in the portfolios of U.K. pension funds: by 2012, their share had nearly doubled from the 2001's level (6.5\%).

Stock exchange boom Stock prices boomed with the increasing focus of foreign investors on EMEs' assets. Figure 7.2 presents the evolution of the major stock exchange index of each EME from 2003 to 2011 (with yearly data). As observed, in many EMEs the rise of stock prices moved in tandem with the stock of foreign liabilities in the form of equities ${ }^{29}$. The similarity of the two is striking in most EMEs and demonstrates the strength of money managers' higher investment in pushing up EMEs' asset prices.

\footnotetext{
${ }^{29}$ The stock value presented in the figure includes not only the changes in new demand (flow), but also the change in stocks due to change of prices. The ideal for this measure would have been the amount of flows to these markets.
} 
FIGURE 7.2: Stock of Foreign Equity Liabilities and Stock Exchange Index: 2003-2011

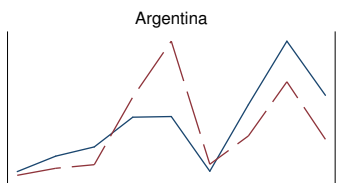

Colombia
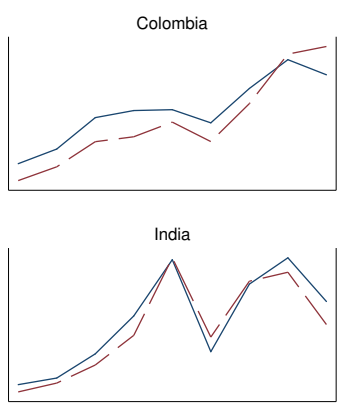

Peru

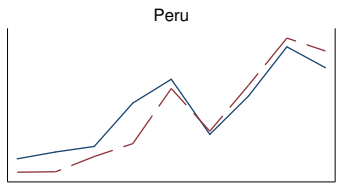

Thailand

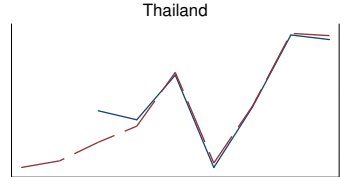

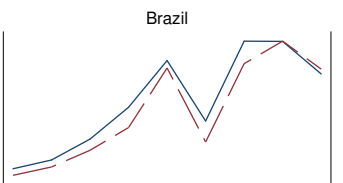
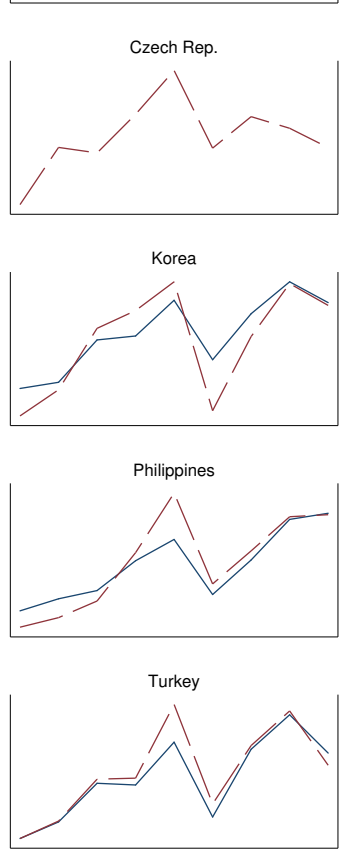
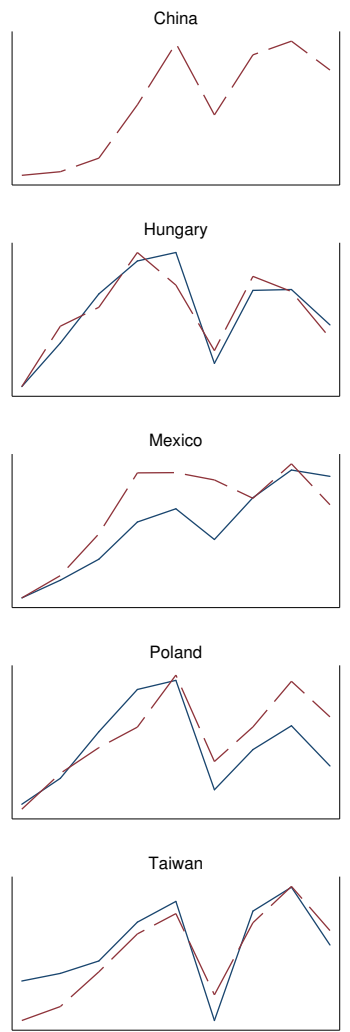
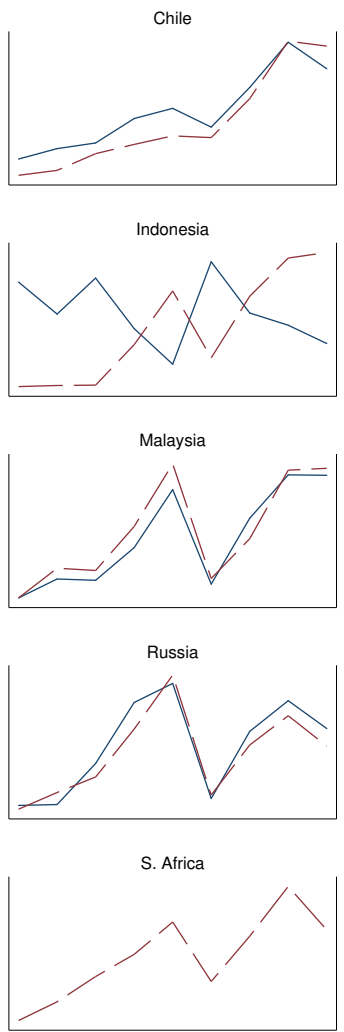

The stocks of foreign equity liabilities (Lane and Milesi-Ferretti, 2007) are presented in dashed red lines. Stock exchange indeces are presented in solid blue lines.

A result from money managers' decision of increasing exposure to EMEs is the increasingly similar pattern of EMEs' foreign liabilities, demonstrated in Chapter Four - and shown, for equities in Figure 4.9, through the N- or M-shaped curves of the series.

The boom of emerging currencies Not only EMEs' assets, but also their currencies inflate with higher investment. This interaction is evident in Figure 7.3: in many EMEs the higher stock of foreign portfolio liability is clearly associated with exchange rate appreciation (and the decrease of their stocks are associated with depreciation). This negative relationship is prominent for Brazil, India, the Philippines, Colombia, Korea, and Turkey.

Similar to what happened with EMEs' foreign liabilities, the external determination of exchange rates resulted in the different emerging currencies following similar patterns - the correlation with other emerging currencies is especially noteworthy for the Brazilian real, 
Figure 7.3: Stock of Foreign Portfolio Liabilities and Exchange Rates: 2003-2011

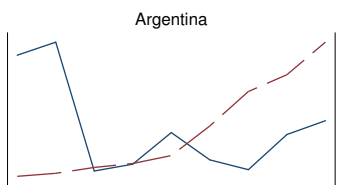

Colombia

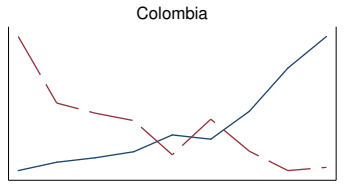

India

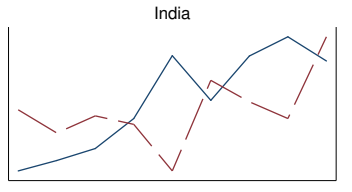

Peru

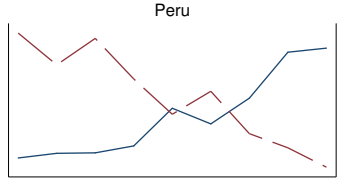

Thailand

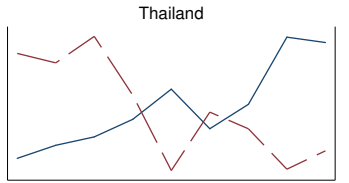

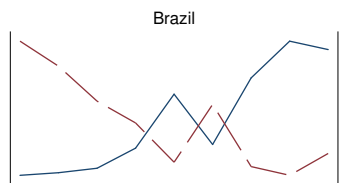

Czech Rep.

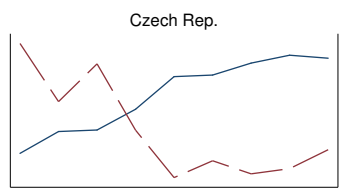

orea

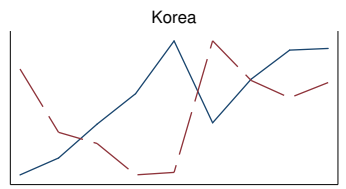

Philippines
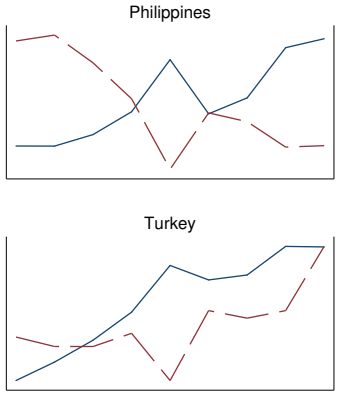

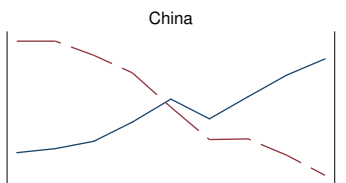

Hungary

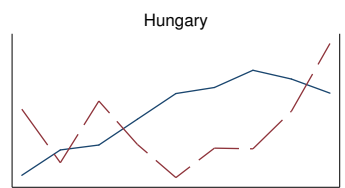

Mexico

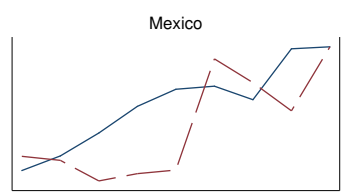

Poland

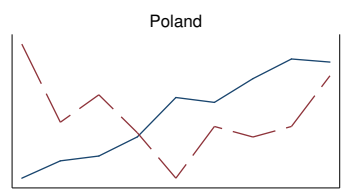

Taiwan

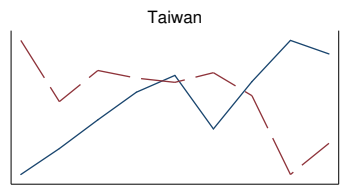

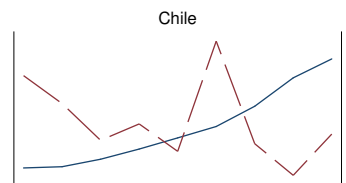

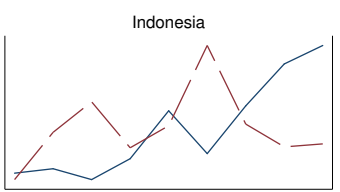

Malaysia
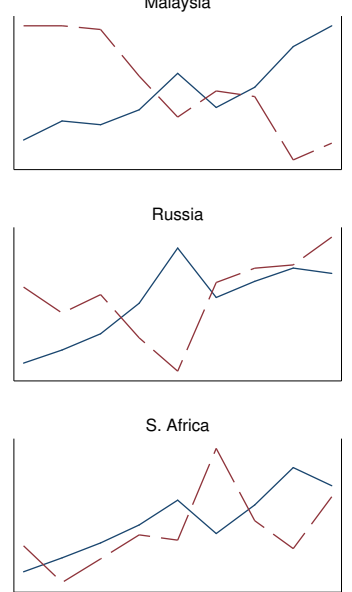

Exchange rates (Ecowin) are presented in dashed red lines. The stocks of foreign portfolio liabilities (Lane and Milesi-Ferretti, 2007) are presented in solid blue lines. Exchange rates are end-of-year values.

the Hungarian forint, the Mexican peso, the Polish zloty, the South African rand, and the Turkish lira, that are highly correlated with at least three currencies of other continents seen in Chapter Six, Section 6.4.2.

The fact that this correlation emerges from the high influence of international financial conditions (that determines the dynamics of all these currencies) is demonstrated through their high correlation with the VIX index - discussed in Chapter Six, Section 6.3.4.

Determined by money managers' investment decisions, the changing behavior of money managers potentially affects their own fragility, but certainly affects the fragility of emerging currencies. Due to the small sizes of these countries' assets in money managers' balancesheets, money managers' fragility brought by the higher exposure to EMEs might be limited. This remains to be analyzed. 
However, the fragility of (part of the) emerging currencies to international financial scenario is unambiguous. As showed, the interactions led by money managers' decisions to invest in EMEs result in exchange rate patterns that can be characterized as "deviation amplifying system", which is at the core of the first theorem of the financial instability hypothesis, and of Minsky's (1993) determination of a fragile situation.

By investing in EMEs, money managers put appreciation pressure in emerging currencies and increase the stock of foreign capital of these economies. Thus, in this situation, an event that would make them decide to sell EMEs' assets would have major impacts: given the significance of the stock to be sold, the exchange rate will be strongly impacted. Fragility is endogenously built, according to the discussed self-feeding interactions, the reassessments of decisions and the confirmation of these decisions. However, it is exogenous to the EMEs, depending mostly on money managers' decisions (EMEs interact to the extent that they do not pass by crises that would change the tranquil scenario). The fact that emerging currencies' fragility is endogenous to money managers' decisions, and exogenous to EMEs, explains why the emerging currencies that suffered the greatest depreciations with the GFC are the same that passed through the greatest appreciations until that point (as shown in Chapter Six), the turbulence at that moment not being related to the countries' fundamentals (Kaltenbrunner and Painceira (2014), Kohler (2010)).

\subsubsection{The end of the Boom Phase: Fragility and Exchange Rate Turbu- lence}

When fragility is at high levels a 'not-abnornal' or 'not-unusual' surprise event can cause a crisis. In the 2000s, the collapse of Lehman Brothers was a major event that caused substantial turbulence in EMEs' currencies. The economic scenario was marked by uncertainty and money managers sold their EMEs' assets, preferring to hold more liquid currencies those used as store of value (Andrade and Prates, 2013), and/or purchasing the (advanced countries') currencies needed to meet their financial obligations (Kaltenbrunner, 2015). In addition, by selling EMEs' assets, money managers reduced the currency mismatch of their balance-sheets and, with one less element of uncertainty, increased their margins of safety. 
Therefore their decisions that trigger the crisis are not associated to a deviation of the conventionally estimated value of the emerging currency (as in Orleéan and Harvey), but instead, to balance-sheet constraints - related to their assets, liabilities, or its currency mismatch. The importance of currency mismatches and its changing features since the Asian crisis are discussed in the conclusion.

The end of the booming phase of the cycle of tranquility and boom is followed by a sell-off of assets in an asset-exchange-rate deflation dynamic. As mentioned, exchange rates interconnect money managers: their decisions impact exchange rates, impacting other money managers' assets and expectations. Therefore, when some money managers sell their assets, they push for an exchange rate depreciation that decreases the value of other money managers portfolios (as measured in their funding currencies) and creates an expectation of further depreciation, leading other money managers to sell their EMEs' position, fueling the downward spiral further (this major turbulence of emerging currencies is illustrated in Figure 1.1, page 4, presented in daily data). This negative spiral is intensified given money managers' focus, and the reliance of their total returns on exchange rate returns.

With the major shock of Lehman's collapse, instability was installed: every event could trigger another major exchange rate depreciation and loss of capital, requiring money managers to react quickly, thus increasing turbulence. Nevertheless, the period of instability also included periods of demand hikes for EMEs' assets given the high return differential in emerging and in advanced economies (the latter having interest rates nearing the zero bound and a risk of recession) including by investing in emerging currencies.

The emerging currencies' crises seen since the mid-2000s were related to international crises, which does not exclude the possibility of crises triggered by a 'not-unusual' event related to the domestic sphere: once fragility is created, anything that changes money managers' expectations about the exchange rate path is a trigger. The specific trigger of the crisis (that can be varied) is not the point of the Minskyan analysis, as much as how fragility is created, allowing a crisis to take place. However, given EMEs' role in financialization, the smaller magnitude of their markets, and their exchange rate volatility (and related potential returns), they are structurally fragile to exchange-rate crisis related to the international sphere: In periods of tranquility money managers accumulate high amounts of EMEs' assets 
making these countries' exchange rates fragile to any event that affects money managers' decisions - that, due to the spread of their balance-sheets across markets around the globe, can be related to several countries.

\subsubsection{Policy Responses and Implications}

Given that fragility of emerging currencies is built in the expansionary period, it is in this period that policies to hinder the development of vulnerabilities are most needed. Accordingly, the analysis underscores the need for policies to limit self-feeding interactions. Three main policies can be useful in this specific goal: capital inflow controls, reserves of international assets, and derivatives management techniques.

Prudential regulation are complementary to these three and important in decreasing EMEs' vulnerabilities. The joint use of prudential regulation and capital controls is known as capital account regulation (cf. Ocampo (2003a)) or capital management techniques (cf. Epstein et al. (2003)). Examples of counter-cyclical prudential regulations are: limiting domestic firms and residents from borrowing in foreign currencies; imposing limits regarding the purpose of foreign debt (for instance, only allowing it for investment and foreign trade); or restricting foreign borrowing only to companies that have foreign currency reserves (Gallagher, 2012). The agents that are submitted to these policies vary in different countries they might be limited to banks or include a larger set of financial institutions. For being focused on balance-sheet mismatches of domestic units these are not analyzed in this chapter.

\subsubsection{Capital inflow controls}

Capital controls were implemented in several EMEs after the GFC (in 2009 and 2010), including in Argentina, Brazil, Colombia, Chile, Korea, Indonesia, Peru, Taiwan and Thailand (Ahmed and Zlate (2014); ECLAC (2011); Forbes et al. (2011); Gallagher (2012); Ocampo (2012); Prates and Fritz (2016)). Although their implementation was only done after the crisis, for following a new wave of flows, they indicate a sound concern, in line with the recommendations drawn from the Minskyan framework. 
Capital inflow controls have the objective to reduce the volatility of capital flows by reducing the total amounts received or by changing its composition towards longer maturities through the reduction of a specific type of capital. Their effects on limiting exchange rate appreciation are also beneficial given the problems of exchange-rate 'misalignment' (discussed in the Introduction Chapter).

Given the manifest vulnerabilities brought by capital account opening and the resulting loss of monetary policy independence (Flassbeck (2001); Rey (2015)), capital controls are also used to reconcile the use of monetary policies with domestic purposes even when exchange rates follow a floating regime (Oreiro, 2004). Broadly speaking, they help to insulate developing countries from "externally generated boom-bust cycles in capital markets (...) and the vulnerabilities they engender", thus the high economic and social costs generated by the marked business cycles of these countries (Ocampo, 2003b, p. 45).

The most common capital inflow controls are direct taxes and unremunerated reserve requirements (URR) on foreign-currency liabilities (which requires foreign investors to maintain a deposit in the Central Bank and imposes fees in case of early withdrawal).

The most broadly known cases of URR are those of Chile and Colombia in the 1990s, but they have also been recently used by Indonesia and Taiwan. These have the advantages of being a simple prudential incentive and penalizing short-term foreign-currency liabilities more heavily (Gallagher (2012); Ocampo (2003b)). Taxes are usually applied as a percentage of the amounts invested, as recently done by Brazil, South Korea and Thailand. In the case of Brazil they were adjusted when loopholes were found (see Fritz and Prates (2014) and Ramos (2010) for Brazil's case).

These options are traditionally considered to affect foreign investor decisions for being a cost, and thus a reduction of the investment returns. However, apart from decreasing returns of assets, capital controls also decrease foreign investors' expected total returns through their negative impact on the expected exchange rate return as investors anticipate that controls will discourage portfolio investment. According to this chapter's analysis, the effects of controls on expectations is a main transmission channel for halting the self-feeding spiral created by expectations. In other words, they reduce investors confidence on the continuity of the appreciation. It is indeed a central mechanism given the centrality of exchange rate returns 
in money managers' strategies (seen in Chapter Two) and the the magnitude of the returns of emerging currencies (seen in Chapter Six) ${ }^{30}$.

Capital controls are subject to criticisms ${ }^{31}$. However, the most often evoked criticisms are based on controversial issues: controls limit the benefits from capital account liberalization $^{32}$ and, depending on the market's features, they would not be effective ${ }^{33}$ (Ariyoshi et al. (2000); Carvalho and Garcia (2008); Neely (1999); Forbes (2003); Forbes (2005); Forbes (2007)). The inconclusiveness of the first debate was presented in Chapter Five ${ }^{34}$; the controversy on the effectiveness of capital controls will be presented in the following.

Capital controls were also said to only treat symptoms of inconsistent policies or distortions (Neely, 1999), although this argument is outdated in light of GFC-related events (when capital flew to the countries in crisis) and broader evidence of the high weight of external conditions in determining emerging currencies (as presented in the last chapter). Other concerns are minor, such as those related to distortion of the decision-making process by companies and individuals as they try to circumvent controls; implementation issues (Forbes, 2007); and the claim that they jointly limit desired flows and less desired ones (Ariyoshi et al., 2000), which is a design issue.

With the GFC, the IMF reviewed its position on capital controls (Roy and Ramos, 2012). IMF (2009, p. 8) stated that large capital inflows "can lead to sharp appreciations, often followed by abrupt reversals and strong effects on balance sheets" and Ostry et al. (2010) indicated circumstances when capital controls should be included in countries' toolkit. Additionally, the appropriate design of capital controls were analyzed (Ostry et al., 2011).

\footnotetext{
${ }^{30}$ For the controls implemented in Brazil in 2009 (IOF, in the Portuguese acronym), Ramos (2010) shows a marked change in expectations of domestic financial agents associated with the announcements of inflow controls.

${ }^{31}$ This criticisms are reflected in the constantly evolving position of international agencies towards controls and of its use worldwide (Gallagher, 2012).

${ }^{32}$ As markets are insulated from competition, capital controls would induce them to inefficiency (or reduce the discipline imposed by the market), and would increase firms' financial costs (Forbes (2003); Forbes (2005); Forbes (2007)).

Note that the evidence of increasingly similar path of EMEs' assets and currencies demonstrated in Chapter Six put questions on one possible gain from capital account opening, i.e. the reduction of international portfolio investors' risks. This was also argued by Longin and Solnik (1995).

${ }^{33}$ The effectiveness of capital controls depend on incentives and costs of circumvention (Ariyoshi et al., 2000); or, more precisely, on: "the development of domestic financial market and alternatives in overseas derivatives markets (...); the ability of authorities to monitor inflows; the penalties for avoidance; and, the most difficult to prevent, regulation loopholes" (Carvalho and Garcia, 2008, p. 72).

34 evidence of increasing co-movement among currencies demonstrated in Chapter Six indicates the decreasing gain of international investors from risk reduction with world-wide portfolio allocation
} 
However, controls are seen as a temporary instrument, while case studies show that these tools are needed on a permanent basis and in combination with prudential regulation (Fritz and Prates, 2014).

One criticism on capital controls raised by GFC-related interventions is that they can have adverse consequences in other economies as flows would be redirected to them, thus 'beggar-thy-neighbor effects' (Forbes et al. (2011); Ostry et al. (2010)). This argument reflects the effectiveness of controls in reducing flows and highlights the need of international coordination on their implementation (Forbes et al., 2011) and of reforming the international monetary system, which could enhance the vulnerability of all EMEs at once ${ }^{35}$.

The efficacy of capital controls is a long-dated empirical controversy ${ }^{36}$. From the extent literature, two studies should be highlighted for having very different methodologies. Epstein et al. (2003) provide a comprehensive analysis of seven experiences based on a detailed description of their context and conclude the effectiveness of all the cases. With a summary of 30 the results of studies weighted according to their econometric rigor, Magud and Reinhart (2006) conclude that inflow controls were effective in changing the composition of inflows towards longer maturities, in making monetary policy more independent, and in reducing exchange rate pressures.

However, the rigor of this analysis is not the best indicator of accuracy, given the complexity of the relationships and the numerous variables to be accounted for. One problem is the difficult task of exchange rate modeling (Williamson, 2000, ch. 4). Moreover, as this thesis has argued, these analyses should account for every market connected to money managers' balance-sheets, including considering possible changes in the financial scenario where money managers have assets ${ }^{37}$ and their funding. On the other hand, as a reduction of total returns and a marked shock in the confidence on the continuity of the exchange rate appreciation, capital inflow controls are only exempt from impact if every foreign investor had a free possibility of circumventing controls.

\footnotetext{
${ }^{35}$ See more on how the reform of the international monetary system could enhance the situation of all EMEs in the Conclusions Chapter.

${ }^{36}$ For references that found evidence of effectiveness of capital controls, and others that did not, specifically in Chile and Colombia, see Ocampo (2003a).

${ }^{37}$ Note that this is in line with the idea that capital controls have 'beggar-thy-neighbor effect' (Forbes et al., 2011).
} 


\subsubsection{Reserves}

The analysis done in this chapter also points to the need of accumulating important amounts of foreign assets, as done by most EMEs since the 2000s (see Chapter Five, Section 5.2.1). This policy has a precautionary reason: its use enables EMEs to protect themselves from crises as those seen in the late 1990s, and from halting appreciation and its inflationary pressures with the boom of capital inflows to EMEs in the 2000s.

As capital inflow controls, reserves could also avoid fragility from taking place by attenuating appreciation, thus affecting the continuity of the self-feeding cycle. Its effects through expectations are softer than that of capital controls that usually involve a notorious announcement. Nonetheless, governments' interventions in FX markets also reverberate among financial practitioners.

Accumulating large amounts of reserves imply significant sterilization costs ${ }^{38}$ depending on the interest differential between the EMEs and the advanced country - that has been positive and large for most EMEs ${ }^{39}$. Given these costs, reserves should be used in combination with policies of capital account management, which decrease the level of reserves needed, or be specifically combined with taxes on inflows, which reduces total costs with capital account management by raising recipes ${ }^{40}$. As put by Andrade and Prates (2013),

In times of boom, they [capital management techniques] control the destabilizing effects of short-term capital flows as well as the cost and risk of reserve accumulation; in times of bust, they reduce the minimum level of reserves needed to restrain speculative attacks and alleviate pressures on domestic interest rates. (p.

Accumulating reserves is also filled with inconsistencies. First, who profits from a country's large amount of reserves should be analyzed. If the policy results in more stable

\footnotetext{
${ }^{38}$ Ramos (2010) estimated the costs of reserves in Brazil (where both reserves and basic interest rates are high) at $1 \%$ of Brazilian GDP.

${ }^{39}$ The literature also considers opportunity costs, focusing on the returns of alternative investments (Aizenman and Marion, 2003) and the social cost of foreign reserves, that compares the cost of reserves with the costs that firms pay to hedge their borrowing (Rodrik, 2006).

For EMEs' interest rates see Figures 6.25 and 6.26 in the Appendix of Chapter Six.

${ }^{40}$ Ramos (2010) estimated that in Brazil in 2009/10 the revenues due to the tax on portfolio inflows amounted to $20 \%$ of the yearly sterilization costs.
} 
exchange rates and shields the country from turbulence, the whole economy benefits (the same can be said about a reserve-policy that has a mercantilist goal). If it is done to hedge external debt, its benefits are however concentrated on foreign portfolio investors (UNCTAD, 2007, ch. 4). According to the discussion done in this chapter, this is a relevant issue, as the attractiveness of a country is key in building fragility. In line with this idea, Kaltenbrunner and Painceira (2009) highlight the importance of the large amount of reserves held by Brazil on the attraction of volatile portfolio flows. Furthermore, by increasing the supply of government bonds, the policy created liquidity for international investors.

Second, by holding important amounts of reserves, EMEs move towards becoming international net creditors. They have the assets of advanced countries' governments and liabilities with these countries' investors, resulting in a contradictory situation: EMEs receive very volatile capital that demands protection to be built, which is done through sending capital abroad (that also increases the attraction of this type of capital). This inconsistency raises questions on the advantages of capital account opening.

With the GFC, reserves were not sufficient for shielding EMEs from major turbulence. There is a debate on whether they were appropriately used. Some authors argue that they were only modestly used (Aizenman and Hutchison, 2012), while others emphasize their role in absorbing part of the shock (Calvo et al., 2012). Indeed, a rather small part of reserves was sold in 2008, but this behavior of EMEs' central banks might hint to how valued reserves are for these countries and their fear of losing their investment grade ratings (that were granted based on these countries' high level of reserves; Prates (2015).

Despite costs and these inconsistencies, reserves of foreign assets are a much needed 'cushion' for counter-balancing money managers' excessive demand or supply at specific moments, which, as discussed, is key for attenuating the self-feeding interactions and the build up of fragile exchange rates.

As discussed in Chapter Five (Section 5.2.1.2), given the magnitude of EMEs' foreign liabilities, the increasingly short-term focus of money mangers, and the non-stable pattern of FDI in some EMEs, substantial amounts of reserves are needed. 


\subsubsection{Derivatives management techniques}

The analysis done in this chapter also indicates the need to intervene in FX derivatives markets. FX derivatives are a privileged locus of speculation for they leverage possibilities (as seen in Chapter Two) and, as shown in Chapters Six and Seven, they help explaining why some emerging currencies presented higher fragility than others. FX derivatives are, therefore, a third type of policy needed in EMEs. Intervention in FX derivatives is similar as that of reserves, authorities intervene in derivatives markets in the opposite position of money managers, but in the future segment of the FX markets. Swap operations have been used by Brazilian authorities since the return of inflows after the GFC (Prates and Farhi, 2009).

These should be complemented by regulation of FX derivatives instruments, which Fritz and Prates (2014) named 'derivatives management techniques' (DMTs). In 2010 and 2011 Brazilian authorities changed the regulation concerning derivatives. The increase of the financial tax on margin requirements for FX derivatives transactions was probably the most important change. As derivatives were used to circumvent previously imposed capital controls, the DMTs were key for restraining the appreciation of the currency, thus "mitigating the Brazilian governments economic policy dilemma regarding how to contain the growth rate and inflationary pressures without reinforcing exchange rate misalignment" (Fritz and Prates, 2014, p. 229). The authors conclude that DMTs are crucial for countries characterized by a high degree of financial openness and developed FX derivatives markets - the countries whose integration have more marked characteristics of financialization. the international environment the stock can be withdrawn, leading to a sudden exchange rate depreciation.

\subsection{Conclusions}

Minsky's framework was developed to analyze firms and its indebtedness and investment decisions, but has been proven useful in analyses of different situations. Each enlargement of the framework to other contexts resulted in a in-depth analysis of situations and the main agent in each of them, allowing the understanding of their decisions, of how their expectations evolve according to changes in the macro environment, and of the interactions among them 
and their environment. The result is a clear understanding of the resulting phenomenon and of the creation of fragility.

The review of Minsky's analysis and its transpositions to other contexts indicated the key role of the following elements in explaining how fragility is built: the identification of core units; their taxonomy according to the margins of safety of their expected cash inflows and outflows; the interconnection among units; the tranquility; the self-feeding interactions and the confirmation of expectations; the 'not-unusual' event; the 'debt'-deflation and the spread of the crisis.

In the analysis of the late-1990s crises, core units were often firms that engaged in operations characterized by currency mismatch. In the subprime crisis, mortgage-backed securities were at the central place. In the most recent dynamics, the manifest impact of the international financial scenario in emerging currencies highlights the need to analyze money managers' decisions. To do so, Minsky's framework was enlarged to one of open economies and the focus was shifted from the decisions of firms on its funding to those of money managers on their portfolio investments.

Money managers' decisions evolve according to changes in the macro environment that include the international context (as analyzed by the studies on the role of international liquidity cycles and liquidity preference), domestic assets and FX markets. In addition to being what first increases demand for EMEs' assets, tranquility is key for the evolution of money managers' assessments, which is a structural factor to the extent that it changes the ruling convention. For this reason, tranquility matters not only when it increases, but also for how long it lasts. For empirical tests, not only a decrease of the VIX index is meaningful, but also its maintenance at low levels for a long period (which does not facilitate empirical assessments, as discussed in Chapter Six, Section 6.3.4).

The analysis also underscored the changing dynamics of the demand for EMEs' assets, with the implementation of floating regimes and the rise of equity-financing. As asset prices and the currency in which they are labeled fluctuate according to demand, they create selffeeding interactions that result in the fragility of the currency to money managers' decisions - which, in turn, depend on the conditions of different markets around the world. 
When fragility is at high levels, a 'not-abnormal' event can lead to a sudden outflow and strong depreciation. By impacting the value of a currency, the exit of some money managers will impact others, that will reassess their positions and might withdraw from other countries to regroup their assets in the same currency as their liabilities - towards a situation of no currency mismatch in their balance-sheets. To do so, they decrease exposure to emerging currencies, which is an element of uncertainty.

The focus on money managers' decreasing currency mismatches is another part of explaining emerging currencies' depreciation with the collapse of the Lehman Brothers. It is a balance-sheet consideration, such as the need to meet financial obligations (that are not denominated in emerging currencies (Kaltenbrunner, 2015)) and the demand for currencies used as reserve of value internationally (which is not the case of emerging currencies(Andrade and Prates, 2013)). Note that while the latter two are focused, respectively, on the dynamics of liabilities and assets, the currency mismatch is the relationship between the two.

As with the other two explanations, it structurally affects EMEs, not from their currencies attributes, but from their insertion in the IMFS: they supply financial assets to money managers, who are funded in advanced countries' currencies, and they increasingly supply assets labeled in their own currency (as argued by Kaltenbrunner and Painceira (2014)). These dynamics are inserted in the context of financialization, specifically the rise of money managers, how they allocate their portfolio in markets across the globe, and their increasingly speculative behavior, focused on profiting from the exchange rate (as a consequence of the innovations that occurred, as currency financialization and carry trading).

In the late-1990s Asian crisis, currency mismatches were a characteristic of the balancesheets of domestic units. In the more recent crises, a shift of currency mismatch occurred from domestic economic units to international financial investors (Kaltenbrunner and Painceira, 2014). However, this change did not prevent emerging currencies from undergoing significant crises.

Balance-sheet considerations are still crucial to the stability of emerging currencies, regardless of the mismatch being on the "creditors" or on the "debtors" side.

As discussed in Chapter Four, the trend of increasing reliance on equity foreign financing instead of on debt is expected to be beneficial to the creditor, as risk is better shared among 
'creditors' and 'debtors'. However, equity financing has two potential sources of loss of involved capital: falling prices and exchange rate depreciation. Therefore, the investor is subject to higher vulnerability, accentuating its speculative behavior.

Such behavior is a problem when applied to the exchange rate. For domestic units, issuing equities might be better as its implications in moments of crisis are limited. However, that does not mean the domestic economy will not be impacted. On the contrary, the speculative behavior can bring exchange rate volatility. Whether an increase of equity financing, or its higher participation as a portfolio investment, are more associated with exchange rate volatility is an intriguing avenue for future research raised by the chapter.

With regards to the determination of exchange rates, the analysis concluded that because EMEs play a role as suppliers of financial assets in the current financialized world and have smaller assets' and FX markets, and floating exchange rate regimes, their exchange rates are fragile to the international financial sphere, and exhibit a cyclical pattern.

The combination of these features increases the role of exchange rate returns in money managers' total returns, intensifying the self-feeding interactions that build the appreciation phase of the cycle. This 'deviation-amplifying system' is backed by the decisions of money managers, whose balance-sheets considerations are related to several markets across the world, and therefore need to sell their EMEs' position for a broad range of events.

The idea of exchange rates marked by increasing deviations spurred by endogenous forces is clearly opposed to exchange rates that move to equilibrium, and of exchange rates that clear markets. It is an exchange rate determination that is specific to emerging currencies. As money managers have their liabilities in advanced countries, balance-sheet constraints in moments of crisis as the need to meet financial obligations (Kaltenbrunner, 2015), as well as the need to reduce currency mismatch lead to appreciation of their currencies. The same happens because these currencies are used as reserve of value, and thus there is more demand in case of turbulence (Prates, 2005a). The appreciation of the U.S. dollar (not only against emerging currencies, but also against the euro) amid the GFC is evidence in this sense.

A notable avenue for future research raised by the consideration of money managers' balance-sheets is an analysis of exchange rate dynamics differences in advanced countries and in EMEs. 
The exchange rate determination process suggested in this chapter does not concern every EME. As presented in Chapter Six, exchange rate dynamics are markedly different among EME. The group of countries that are more highly influenced by international financial markets includes Brazil, Hungary, Poland, South Africa, and Turkey.

In comparison to the exchange rate theories presented in Chapter Three, this analysis denotes a shift in focus from the attributes of emerging currencies, or from expected portfolio inflows, to the decisions of money managers. It does not contradict those models - a currency's liquidity premium and the process through which exchange rate forecasts are built help explaining money manager's behavior.

However, looking at exchange rates through their decisions may be a broader framework, where balance-sheet considerations are neatly accommodated, enabling the analysis of the role of events not related to the currencies' attributes or the countries' fundamentals. This framework is also in line with the context of financialization, as well as with the importance of money managers and their characteristics.

The analysis proposed in this chapter differs from other Minskyan analyses for focusing on the interrelation of two different systems: emerging currencies and financial markets of advanced countries. By demonstrating the importance of the conditions of the latter in determining the former, it demonstrates the subordinated place of emerging currencies in the international monetary and financial system. 


\section{Chapter 8}

\section{Conclusions}

The thesis is centered on how financialization influences emerging currencies' dynamics. The analysis has a theoretical and an empirical axis. Theoretically, it analyzed how different financialization-related phenomena impact exchange rate determination and how the transmission mechanisms brought about by this literature are taken into account by the exchange rate literature (in Chapters Two and Three, respectively).

Empirically, the financial integration of EMEs and their currencies' FX markets were subject to in-depth analyses that aimed at assessing the manifestation of financializationrelated phenomena in these countries (in Chapters Four and Five). The hypothesis of the impact of financialization on exchange rates was tested by comparing the different levels of financialization of a country's integration with the fragility of its exchange rates (as revealed by the presence of the exchange rate features of concern; in Chapter Six).

Based on the findings from the theoretical and empirical analyses, the thesis proposed to investigate exchange rates through Minsky's framework. The analysis presented is in line with the financialization-related phenomena, accounts for the specificities of EMEs and their currencies, and results in the exchange rate features found (in Chapter Seven). Through this framework, the mechanisms at place that determine exchange rate dynamics are presented in detailed form, allowing an assessment of how vulnerabilities are built, and accordingly, indicating policy implications. 
The main findings of the analyses developed in the thesis are presented in the Introduction Chapter. This chapter discusses the main contributions to both fields: financialization and exchange rates.

\subsection{Financialization and EMEs' Integration}

The term financialization is used in many different contexts as reference to various different phenomena. The review (presented in Chapter Two) indicated three main developments that are referred to as financialization, for a more precise use of the term:

i) the increasing importance of finance at the international level with the decoupling from its earlier functions and logic;

ii) the changes within the financial system, with the sophistication of finance through major innovations of products and usages, the increasing importance of markets, and the evolution of banks; and

iii) the changing relationship between finance and other economic sectors, with the increasing importance of the first and its associated class group, the rentiers.

From a focus on the international level, the thesis suggested a definition of financialization as the patrimonial and increasingly speculative logic of finance at the international level - as revealed from the innovations of usages and products and the amounts traded.

As analyzed, the major volumes traded internationally relative to the underlying productive economy led authors to argue that finance was no longer attached to its prior functions of financing trade and production, following its own logic. The 'excess' increase of finance was related to financial integration, that grew considerably with liberalization and materialized in important increases in the volumes traded on the financial account vis-a-vis the current account. The thesis refers to this phenomenon as the (re)emergence of a patrimonial logic of finance at the international level.

In addition, the analysis of the recent innovations of usages and products concluded that these are centered on exchange rate returns, what characterizes the patrimonial logic 
as increasingly speculative. This argument was confirmed by the marked rise of FX transactions vis-a-vis financial integration in both advanced countries and EMEs. These innovations include FX (foreign exchange) derivatives (a privileged locus for allowing leveraging one's exposure to exchange rate returns), and practices focused on exchange rate returns (as derivatives carry trading and currency financialization more broadly) or that are exposed to exchange rate returns (as canonical carry trading and equities or other instruments denominated in local currencies). As these practices and products are not used in every country or currency, financial integration has different rationales in different contexts, what requires the consideration of their features in analyses of their impacts. This is a major finding of the thesis and the argument underlying the empirical analyses.

The rise of money managers is a major change seen with financialization that pervades the three aforementioned developments. They are portfolio investors funded in advanced countries; small in numbers and managing the major amounts of liquidity available in these economies, they have a great impact on markets. As the thesis suggests, these institutions are key in determining exchange rates for creating a network, through their funding and portfolio allocation choices, where different countries' markets and currencies are interconnected through money managers' balance-sheets.

The thesis argues that with the integration of EMEs to this network, and the use of their assets and currencies in the most innovative practices, emerging currencies are now subject to money managers' decisions, which, based on their balance-sheet constraints, depend on conditions of the funding markets in advanced countries and markets where they have assets, across the globe.

Therefore, understanding the exchange rates of EMEs involves understanding the $d y$ namics of this network and of money managers balance-sheet constraints. This position is revealed in different methodological choices of the thesis, such as the utilization of stock data in empirical studies to characterize this network; and the Minskyan and the SFC approaches to discuss exchange rates emphasizing the decisions of money managers and how they interact with the economy more broadly. 


\subsection{Integration and Emerging Currencies' Dynamics}

Although all EMEs are subject to money managers' decisions for being, by definition, the developing countries that are the most financially integrated, their currencies' dynamics are not all the same, some presenting more turbulence than others. The thesis has raised the hypothesis that the different exchange rate dynamics are a result of a country's type of integration according to the mentioned different rationales.

To test this hypothesis, the thesis proposes an index that characterizes integration in regards to financialization. This is a strong contrast to analyses of financial integration, which are based on indicators of magnitude, and a clear consequence of the centrality of the changes of finance associated with financialization and of the importance given to country specific dynamics. The indicator of financialization of integration is based on measures of integration and of the magnitude of FX derivatives markets vis-a-vis the underlying economy: the stock of foreign assets and liabilities relative to i) GDP and ii) foreign trade; the weight of FX markets relative to iii) GDP and iv) foreign trade; and v) the importance of derivatives relative to spot FX contracts (as presented in Chapter Five). The analyses conducted concluded that the EMEs with the most financialized integration are: Brazil, Hungary, South Africa, and Turkey.

The level of financialization of integration was compared, in Chapter Six, to exchange rate features that characterize the concerned dynamic of turbulence - volatility and high frequency of extreme depreciations - and subordination to the international financial sphere. The index was also compared to emerging currencies' correlation with emerging currencies of other continents, reflecting the importance of the external component in their determination. Based on critical reviews of the methodologies used to estimate currencies features, these analyzes resulted in a rich depiction of emerging currencies.

The thesis thus tested the association of the currency features with the financialization level of the integration, revealing a strong relationship: a more financialized integration is related to exchange rates that are more subordinated to the international financial conditions and more volatile due to their higher frequency of extreme depreciations. The exchange rate features were also compared to measures of the magnitude of integration, revealing a 
higher explanatory power of the type of integration. These results are crucial for studies on exchange rates, on the determination of capital flows, and on the impacts of integration.

The correlation of exchange rates with the VIX and with other emerging currencies hints to the impacts of an external component in determining exchange rates, thus to a higher importance of push forces in determining the demand for these countries' assets. Although the analyses of the push vs. pull literature are focused on their impacts on capital flows (as shown in Chapter Six), their study using exchange rates is complementary and interesting, making use of more frequent data, it more precisely indicates the impact of the rapidly changing external conditions, especially given the increasing shot-term focus.

The higher explanatory power of the type, rather than the magnitude, of integration is most relevant for the literature that analyzes the impact of capital account liberalization and financial integration on an economy. As shown in Chapter Five, this literature measures integration through its size, but the focus on magnitudes overlooks impacts of the type of integration on growth through its impacts on exchange rates. Countries' integration is different, and, as shown, so are their impacts on exchange rates. To consider the type of integration also implies adding concerns over exchange rates, which are indeed an important transmission channel: in the case of turbulence of nominal rates, through its impact on uncertainty, and thus on investments (in the case of floating rates); and indirectly, for affecting the level of the real exchange rate, through its impacts on trade.

A broad implication of the empirical results on exchange rate theories is the need for theoretical frameworks that are in line with the countries' type of integration. In a small open economy that trades a commodity, the price of this good might be the most relevant variable in explaining the countries' exchange rate. In the case of EMEs, as the most turbulent exchange rates are the most correlated with the international sphere, the decisions of international portfolio investors are crucial in understanding exchange rate patterns. Accordingly, this result indicates the need to analyze exchange rates through the decisions of the main actors of international financial markets, the money managers. The higher turbulence of the currencies from highly integrated countries and where FX derivatives are important underscores the need to consider the role of derivatives FX markets and focus on exchange rate returns that might be behind the important magnitude of the FX markets. 
This is done in Chapter Seven through a Minskyan analysis, based on money managers' decision concerning the desired exchange rate exposure, that evolves with the macro environment. This analysis is a relevant contribution of the thesis to the use of Minsky's approach in other contexts: it suggests a form of transposing his original framework not only to the international sphere, but also presents the insights when units' decisions refer to assets, instead of liabilities - in this case, money managers' portfolio allocation decisions.

Investment in EMEs' assets and currencies are affected by the international condition by the impact of uncertainty. As emerging currencies offer lower liquidity premium, a decrease of uncertainty and liquidity preference positively impacts demand for emerging currencies. The tranquility of the currency's FX markets is also important. It is a feature that progressively increases demand, in tandem with the gradual distance to crisis. This is clear in a framework with heterogeneous agents: as crises become far in memory some money managers reassess prior decisions of avoiding more aggressive investment options as too conservative. Given the centrality of exchange rate returns in times of financialization and the findings on the volatility of emerging currencies, the more aggressive investment option for the money manager is the EME's asset. Accordingly, demand for EMEs' assets progressively increases as crisis are forgotten.

Given the small magnitude of EMEs' markets, a first hike of demand for their assets caused by any change in their relative return (including a change of liquidity preference internationally) triggers a self-feeding cycle of higher demand and appreciation: because the stability of EMEs' FX markets is ensured and their currencies appreciate, other money managers will reassess their decisions and increase their investments in these countries. In this mechanism, money managers' decisions are confirmed. As it continues, a convention favorable to EMEs emerges. With the expectation that the appreciation will continue, some money managers decide to further increase their exposure to emerging currencies by leveraging their positions with FX derivatives, fueling the appreciation trend further.

Fragility is built through the cycle of increasing appreciation. At this moment, any event that drives money managers to reassess their decisions can result in extreme depreciation. These events can be associated to the EMEs or to any other market where money managers have their assets or funding - in other words, they can be related to money managers' assets 
or liabilities or to a desire to decrease their balance-sheet mismatch; these reasons were named in the thesis as balance-sheet constraints. In this sense, the fact that EMEs are part of the broad network that connects markets around the globe increases the potential sources of shock.

The point of the analysis is less to identify one specific cause, but to discuss how fragility is installed allowing these events to impact emerging currencies. By discussing the buildup of fragility, the analysis argues that the fragility of emerging currencies is endogenous to the behavior of money managers, that, in turn, is based on emerging currencies' features of high volatility and is intensified with the availability of liquid derivatives FX markets. Their behavior, combined with the specific features of EMEs' insertion, allows a self feeding mechanism to install, and the build up of fragility that will end up with an extreme depreciation, or crisis. This is an important outcome of the thesis that contrasts with other exchange rate models.

This explanation of emerging currencies crisis diverges from those provided by the mainstream literature (reviewed in Chapter Three) revealing the role of foreign portfolio investors, instead of governments, in creating the very reasons for the crisis. Given the variety of policy options (discussed in Chapter Seven), if governments have a role to play in these crises it is not for having inappropriate policies that lead to misalignments, but for allowing fragility to take place - which is a 'negative decision'.

With regards to exchange rate determination more generally, the framework demonstrates that these fluctuate according to money managers decisions that are not necessarily related to the country in question, but to their balance-sheet constraints. This greatly contrasts with most exchange rate models.

The focus on investors' decisions differs from models solely focused on macro variables (as most traditional mainstream frameworks, including portfolio and carry trading models), but is similar to some heterodox approaches (Orléan, Schulmeister and Harvey) and the mainstream behavioral finance analyses. It however differs from these latter models for demonstrating that exchange rates can also be impacted by events that are external to the country in question. In this sense, it is similar to the heterodox approaches focused on the specificities of emerging currencies, which emphasize the role of international financial 
conditions (as Andrade, Prates and Kaltenbrunner), but it includes events other than the ones related to the advanced countries, such as events in another market where money managers have assets, as these impact their balance-sheets.

Another important point of divergence between the results of the suggested framework and the exchange rate theories is the equilibrium seeking behavior. As shown, with the self-feeding mechanism emerging currencies become a 'deviation amplifying system', whose trend depends on an external determinant. This strongly contrasts the idea of equilibrium seeking and market clearing pattern of exchange rates put forward by mainstream models (as analyzed in Chapter Three). Equilibrium-seeking mechanisms are also included in heterodox models (as technical trading in Schulmeister or as the deviation of a variable from its conventionally estimated value, in Orléan and Harvey), and this mechanism might be at place among emerging currencies. They are however subordinated to cycles depending on international conditions that are broader, resulting in larger swings of these currencies marked by major crisis.

Due to emerging currencies attributes and the characteristics of their countries' insertion, their dynamics are different than those of advanced countries and of other developing countries. Understanding emerging currencies' dynamics demand frameworks that allow its specificities to manifest. The thesis presented three main contributions in this sense.

The first is the modeling of key elements for explaining emerging currencies, such as liquidity premium and liquidity preference in the SFC framework, which allow their consideration in those models. The thesis has also suggested ways of modeling investors' expectation formation and FX trading strategies, which are crucial in times of financialization and allow important mechanisms to emerge.

Specifically regarding building models focused on explaining emerging currencies' dynamics, the second main contribution was the indication of the features to be accounted for by comparing currencies from advanced countries and from EMEs: a group of emerging currencies present higher volatility associated with their higher frequency of extreme depreciation, and their pattern are highly related to international financial markets. The thesis has also demonstrated that the source of this behavior is the financialized integration of their countries i.e, they are highly integrated and this integration has a stronger speculative logic. 
Thirdly, and most importantly, the thesis has presented a framework that details the mechanisms that lead to these exchange rate dynamics: a currency's demand depends on money managers' decisions on their desired exposure to exchange rate returns and the currencies' features; these decisions evolve with the macro environment; depending on the countries' integration features, it can trigger more or less important self-feeding mechanisms that characterize a fragile system. In line with financialization, their balance-sheets constraints depend on conditions of markets across the globe. Accordingly, various events can suddenly affect the demand of the currencies.

\subsection{Policy Implications}

Due to the hierarchical nature of the international monetary and financial systems (IMFS) emerging currencies are not subject to the same dynamics of central ones, being subordinated to the international financial conditions. The thesis has shown that the rise of financialization accentuates ties to the international conditions (including increasing volatility) if an EME's assets and currencies are included in money managers' portfolios through innovative strategies and products.

Two main alternatives emerge. The first is a reform of the IMFS similar to Keynes's suggestion of an 'International Clearing Union', a central bank of central banks that would issue a international currency, as the 'bancor', and liquidate countries' central banks position (Cintra and Prates, 2013). An international currency to denominate contracts and that allow countries to trade in their own currencies would decrease the asymmetries of the international monetary system where the U.S. dollar is the only currency that exercises the three functions of money, thus reducing the subordination of every other currency, including the ones from EMEs.

The second alternative includes country-level policies focused on decreasing fragility given the structural asymmetry. In this sense, the main options are: capital inflow controls, reserves of foreign assets and 'derivatives management techniques'. As argued in the last chapter, these policies decrease the impact of money managers' innovative strategies in 
building the fragility of emerging currencies. Accordingly, they could attenuate the deleterious impacts from the hierarchical nature of the IMFS, and are a crucial step in favoring long-term investments, trade, and growth through more stable exchange rates and monetary policy autonomy. 


\section{Bibliography}




\section{Bibliography}

Abdalla, I. S. and Murinde, V. (1997). Exchange rate and stock price interactions in emerging financial markets: evidence on India, Korea, Pakistan and the Philippines. Applied financial economics, 7(1):25-35.

Aglietta, M. (1999). La globalisation financière. L'économie mondiale, pages 52-67.

Aglietta, M. and Breton, R. (2001). Financial systems, corporate control and capital accumulation. Economy and Society, 30(4):433-466.

Ahmed, S. and Zlate, A. (2014). Capital flows to emerging market economies: a brave new world? Journal of International Money and Finance, 48:221-248.

Aizenman, J. and Hutchison, M. M. (2012). Exchange market pressure and absorption by international reserves: Emerging markets and fear of reserve loss during the 2008-2009 crisis. Journal of International Money and Finance, 31(5):1076-1091.

Aizenman, J. and Lee, J. (2007). International reserves: precautionary versus mercantilist views, theory and evidence. Open Economies Review, 18(2):191-214.

Aizenman, J. and Marion, N. (2003). The high demand for international reserves in the far east: What is going on? Journal of the Japanese and international Economies, 17(3):370400.

Akyüz, Y. (2012). The boom in capital flows to developing countries: Will it go bust again. Ekonomi-tek, 1(1):69-96.

Akyüz, Y. and Cornford, A. (2002). Capital flows to developing countries. Governing Globalization: Issues and Institutions, page 108. 
Alexander, S. S. (1952). Effects of a devaluation on a trade balance. Working paper, International Monetary Fund.

Amable, B. (2005). Les cinq capitalismes. Diversité des systèmes économiques et sociaux dans la mondialisation. Seuil. Collection Economie Humaine.

Andrade, R. P. and Prates, D. M. (2013). Exchange rate dynamics in a peripheral monetary economy: A Keynesian perspective. Journal of Post-Keynesian Economics, 35(3):399-416.

Arestis, P., Basu, S., and Mallick, S. (2005). Financial globalization: the need for a single currency and a global central bank. Journal of Post Keynesian Economics, 27(3):507-531.

Arestis, P. and Glickman, M. (2002). Financial crisis in Southeast Asia: dispelling illusion the minskyan way. Cambridge Journal of Economics, 26(2):237-260.

Arida, P. (2003a). Ainda a conversibilidade. Revista de Economia Política, 23(3):135-142.

Arida, P. (2003b). Por uma moeda plenamente conversível. Revista de economia política, $23(3): 151-154$.

Arida, P. (2004). Aspectos macroeconômicos da conversibilidade: uma discussão do caso brasileiro. BME̋F, São Paulo.

Ariyoshi, M. A., Kirilenko, M. A., Ötker, M. I., Laurens, M. B., Kriljenko, M. J. I. C., and Habermeier, M. K. F. (2000). Capital controls: country experiences with their use and liberalization. Number 190. International Monetary Fund.

Asensio, A., Charles, S., Lang, D., and Le Heron, E. (2011). Les développements récents de la macroéconomie post-keynésienne. Revue de la régulation. Capitalisme, institutions, pouvoirs, (10).

Avdjiev, S., McCauley, R. N., and Shin, H. S. (2015). Breaking free of the triple coincidence in international finance. Working Paper 524, Bank for International Settlements (BIS).

Baele, L., Ferrando, A., Hördahl, P., Krylova, E., and Monnet, C. (2004). Measuring financial integration in the euro area. Occasional Paper Series 14, European Central Bank.

Bagehot, W. (1873). Lombard Street: A description of the money market. King. 
Baker, D., Epstein, G., and Pollin, R. (1998). Globalization and Progressive Economic Policy. Cambridge University Press.

Baker, S. R., Bloom, N., and Davis, S. J. (2015). Measuring economic policy uncertainty. NBER Working Paper 21633, National Bureau of Economic Research.

Balassa, B. (1964). The purchasing-power parity doctrine: a reappraisal. The Journal of Political Economy, pages 584-596.

Barbosa, L. and Costa, S. (2010). Determinants of sovereign bond yield spreads in the euro area in the context of the economic and financial crisis. Working Paper 22, Banco de Portugal.

Basu, S. and Bundick, B. (2012). Uncertainty shocks in a model of effective demand. NBER Working Paper 18420, National Bureau of Economic Research.

Baumann, B. A. and Gallagher, K. P. (2013). Post-crisis capital account regulation in South Korea and South Africa. PERI Working Paper Series 230, University of Massachusetts Amherst, Political Economy Research Institute, Amherst.

Bekaert, G. and Harvey, C. R. (2000). Foreign speculators and emerging equity markets. The Journal of Finance, 55(2):565-613.

Bekaert, G., Harvey, C. R., and Lundblad, C. (2005). Does financial liberalization spur growth? Journal of financial Economics, 77(1):3-55.

Bekaert, G., Hoerova, M., and Duca, M. L. (2013). Risk, uncertainty and monetary policy. Journal of Monetary Economics, 60(7):771-788.

Berman, N., Martin, P., and Mayer, T. (2012). How do different exporters react to exchange rate changes? The Quarterly Journal of Economics, 127(1):437-492.

Bernanke, B. (2010). Rebalancing the global recovery. Electronic. Speech on the Sixth European Central Bank Central Banking Conference. Retrieved from: http://www. federalreserve.gov/newsevents/speech/bernanke20101119a.htm.

Bernanke, B. (2013). Transcript of chairman bernankes press conference: June 19, 2013. Online. Retrieved from http://www.federalreserve.gov/mediacenter/files/ FOMCpresconf20130619.pdf. 
Bernanke, B. and Gertler, M. (1989). Agency costs, net worth, and business fluctuations. The American Economic Review, pages 14-31.

Biancareli, A. M. (2007). Integração, ciclos e finanças domésticas: o Brasil na globalização financeira. PhD thesis, Universidade Estadual de Campinas (Unicamp).

Biancareli, A. M. (2011). Brazil, developing economies and private international capital flows: the (new) challenges in the post-crisis scenario. In 15th conference of the Research Network Macroeconomics and Macroeconomic Policies (FMM): From crisis to growth.

Bibow, J. (2009). The international monetary (non-)order and the "global capital flows paradox". In Finance-led capitalism? : Macroeconomic effects of changes in the financial sector, pages 219-248. Metropolis Verlag, Marburg.

BIS (2001). Triennial central bank survey of foreign exchange and derivatives market activity 2001.

BIS (2013). Triennial central bank survey of foreign exchange and derivatives market activity 2013.

Blanchard, O., DellAriccia, G., and Mauro, P. (2010). Rethinking macroeconomic policy. Staff Position Note 3, International Monetary Fund, Washington DC.

Blanchard, O. et al. (2012). Monetary policy in the wake of the crisis. In the Wake of the Crisis: Leading Economists Reassess Economic Policy, page 7.

Blanchard, O., Giavazzi, F., and Sa, F. (2005). International investors, the US current account, and the dollar. Brookings Papers on Economic Activity, 2005(1):1-65.

Blanchard, O., Ostry, J. D., Ghosh, A. R., and Chamon, M. (2015). Are capital inflows expansionary or contractionary? Theory, policy implications, and some evidence. IMF working Paper 226, International Monetary Fund.

Blecker, R. (2005). Financial globalization, exchange rates and international trade. Financialization in the World Economy, Northampton, MA and Cheltenham, UK: Edward Elgar, pages $183-209$. 
Bonizzi, B. (2013). Capital flows to emerging markets: Institutional investors and the postcrisis environment. Paper prepared for 17th FMM conference of the research network macroeconomics and macroeconomic policies, Berlin.

Borio, C. (2014). The financial cycle and macroeconomics: What have we learnt? Journal of Banking \& Finance, 45:182-198.

Borio, C. and Disyatat, P. (2011). Global imbalances and the financial crisis: Link or no link? BIS Working Papers 346, Bank for International Settlements.

Borio, C. and Disyatat, P. (2015). Capital flows and the current account: taking financing (more) seriously. BIS Working Paper 525, Bank for International Settlements.

Bourguinat, H. (1992). Finance internationale. Presses Universitaires de France (PUF).

Boyer, R. (2000). Is a finance-led growth regime a viable alternative to fordism? a preliminary analysis. Economy and Society, 29(1):111-145.

Boyer, R. (2004). Théorie de la régulation. 1. Les fondamentaux. La Découverte, Paris.

Boyer, R., Dehove, M., and Plihon, D. (2004). Les crises financières. La Documentation Française.

Brainard, W. C. and Tobin, J. (1968). Pitfalls in financial model building. The American Economic Review, 58(2):99-122.

Branson, W. H. (1974). Stocks and flows in international monetary analysis. In Ando, A., Herring, R., and Marston, R., editors, International aspects of stabilization policies, pages 27-51. Federal Reserve Bank of Boston.

Branson, W. H. (1981). Macroeconomic determinants of real exchange rates.

Bresser-Pereira, L. C. (2008). The Dutch disease and its neutralization: a ricardian approach. Revista de economia política, 28(1):47-71.

Bresser-Pereira, L. C. (2010). The global financial crisis and a new capitalism? Journal of Post Keynesian Economics, 32(4):499-534.

Brunnermeier, M. K. (2008). Deciphering the liquidity and credit crunch 2007-08. NBER Working Paper 14612, National Bureau of Economic Research. 
Brunnermeier, M. K., Nagel, S., and Pedersen, L. H. (2008). Carry trades and currency crashes. NBER Working Paper 14473, National Bureau of Economic Research.

Bruno, V. and Shin, H. S. (2015). Capital flows and the risk-taking channel of monetary policy. Journal of Monetary Economics, 71:119-132.

Burnside, C., Eichenbaum, M., Kleshchelski, I., and Rebelo, S. (2006). The returns to currency speculation. NBER Working Paper 14473, National Bureau of Economic Research.

Calderón, C. and Kubota, M. (2009). Does higher openness cause more real exchange rate volatility? Policy Research Working Paper Series 4896, World Bank.

Calvo, G., Leiderman, L., and Reinhart, C. (1993). Capital inflows and real exchange rate appreciation in Latin America: the role of external factors. Staff Papers-International Monetary Fund, pages 108-151.

Calvo, G. and Reinhart, C. (2002). Fear of floating. Quarterly Journal of Economics, 117(2):379-408.

Calvo, G. A., Izquierdo, A., and Loo-Kung, R. (2012). Optimal holdings of international reserves: self-insurance against sudden stop. NBER Working Paper 18219, National Bureau of Economic Research.

Calvo, S. G. and Reinhart, C. (1996). Capital flows to Latin America: is there evidence of contagion effects? Policy Research Working Paper 1619, World Bank.

Campbell, R., Koedijk, K., and Kofman, P. (2002). Increased correlation in bear markets. Financial Analysts Journal, 58(1):87-94.

Carneiro, R. (1999). Globalização financeira e inserção periférica. Economia e Sociedade, 13(4):57-92.

Carvalho, B. S. d. M. and Garcia, M. G. (2008). Ineffective controls on capital inflows under sophisticated financial markets: Brazil in the nineties. In Financial Markets Volatility and Performance in Emerging Markets, pages 29-96. University of Chicago Press.

Carvalho, F. J. C. (1992). Mr Keynes and the post keynesians. Edward Elgar. 
Carvalho, F. J. C. (2008). Macroeconomic policy with open capital accounts. Finance-led Capitalism?: Macroeconomic Effects of Changes in the Financial Sector, 11:273.

Carvalho, F. J. C. (2009). Macroeconomic policy with open capital accounts. In Hein, E., Niechoj, T., Spahn, P., and Truger, A., editors, Finance-led capitalism? : Macroeconomic effects of changes in the financial sector., pages 273-293. Metropolis Verlag, Marburg.

Cassel, G. (1916). The present situation of the foreign exchanges. The Economic Journal, 26(101):62-65.

Castro, J. D. (2016). Após maior alta em 5 anos dólar perde força com decisão de renan. Valor Econômico. Retrieved from http://www.valor.com.br/financas/4554883/ apos-maior-alta-em-5-anos-dolar-perde-forca-com-decisao-de-renan.

Caverzasi, E. and Godin, A. (2015). Post-keynesian stock-flow-consistent modelling: a survey. Cambridge Journal of Economics, 39(1):157-187.

Chang, R. and Velasco, A. (2001). A model of financial crises in emerging markets. Quarterly Journal of Economics, pages 489-517.

Chavance, B. et al. (2007). L'économie institutionnelle. La Découverte Paris.

Chesnais, F. (1997). La mondialisation du capital. Syros.

Chesnais, F. (2001). La théorie du régime d'accumulation financiarisé: contenu, portée et interrogations. In Article présenté au Forum de la régulation, pages 11-12.

Chesnais, F., de Brunhoff, S., and Plihon, D. (1996). La mondialisation financière: genèse, coût et enjeux. Syros.

Chicago Board Options Exchange, C. (2015). White Paper: The CBOE Volatility Index VIX. Online. Retrieved from https://www.cboe.com/micro/vix/vixwhite.pdf.

Chinn, M. D. and Ito, H. (2006). What matters for financial development? capital controls, institutions, and interactions. Journal of development economics, 81(1):163-192.

Chinn, M. D. and Ito, H. (2008). A new measure of financial openness. Journal of comparative policy analysis, 10(3):309-322. 
Chkili, W., Aloui, C., Masood, O., and Fry, J. (2011). Stock market volatility and exchange rates in emerging countries: A markov-state switching approach. Emerging Markets Review, 12(3):272-292.

Chkili, W. and Nguyen, D. K. (2014). Exchange rate movements and stock market returns in a regime-switching environment: Evidence for BRICS countries. Research in International Business and Finance, 31:46-56.

Christie-David, R. and Chaudhry, M. (2001). Currency futures, news releases, and uncertainty resolution. Global Finance Journal, 11(1):109-127.

Chuhan, P., Perez-Quiros, G., and Popper, H. (1996). International capital flows: do shortterm investment and direct investment differ? World Bank Publications, Washington.

Cintra, M. A. M. (1998). A reestruturação institucional do sistema financeiro americano (1980/95). Economia e Sociedade, 10:111-39.

Cintra, M. A. M. and Prates, D. M. (2013). Keynes e a hierarquia de moedas: possíveis lições para o Brasil, volume 1, pages 175-200.

Claessens, S., Dooley, M. P., and Warner, A. (1995). Portfolio capital flows: hot or cold? The World Bank Economic Review, 9(1):153-174.

Claessens, S., Laeven, M. L., Igan, D., and Dell'Ariccia, M. G. (2010). Lessons and policy implications from the global financial crisis. Number 10-44. International Monetary Fund.

Clark, P., Tamirisa, N., Wei, S.-J., Sadikov, A., and Zeng, L. (2004). Exchange rate volatility and trade flows-some new evidence. IMF Occasional Paper, 235.

Clévenot, M. and Héron, E. L. (2014). Renouveler la macroéconomie postkeynésienne? Les modèles stock-flux cohérent et multi-agents. introduction. Revue de la régulation. Capitalisme, institutions, pouvoirs, 16.

Cohen, B. J. (1998). The geography of money. Cornell University Press.

Cole, H. L. and English, W. B. (1992). Two-sided expropriation and international equity contracts. Journal of International Economics, 33(1-2):77-104. 
Corrêa, V. P., Messenberg, R. P., Silva, R. C., and Braga, J. d. M. (2012). Instability of capital inflows and financial assets returns in the Brazilian economy. In Paper Presented at the VIII International Conference of the Brazilian Keynesian Association (AKB), Sã0 Paulo. AKB.

Cottani, J. A., Cavallo, D. F., and Khan, M. S. (1990). Real exchange rate behavior and economic performance in LDCs. Economic Development and Cultural Change, 39(1):61-76.

Coudert, V. and Gex, M. (2008). Does risk aversion drive financial crises? Testing the predictive power of empirical indicators. Journal of Empirical Finance, 15(2):167-184.

Crotty, J. R. (1990). Owner-manager conflict and financial theories of investment instability: A critical assessment of Keynes, Tobin, and Minsky. Journal of Post Keynesian Economics, 12(4):519-542.

Da Silva, P. P. and Da Fonseca, M. R. R. (2015). A liberalizao financeira de facto da economia brasileira: um estudo de seus impactos atravs do modelo MS-VAR. Working paper, Florianopolis, Brazil.

Davidson, P. (2011). Post Keynesian macroeconomic theory. Edward Elgar Publishing, second edition.

De Carlo, L. T. (1997). On the meaning and use of kurtosis. Psychological methods, 2(3):292.

De Conti, B. M. (2011). Políticas cambial e monetária: os dilemas enfrentados por países emissores de moedas periféricas. PhD thesis, Universidade Estadual de Campinas.

De Conti, B. M. and Prates, D. M. (2014). The international monetary system hierarchy: determinants and current configuration. In FMM 18th Conference: "Inequality and the Future of Capitalism".

De Deos, S. S. (1998). Instabilidade financeira numa economia de mercado de capitais. Ensaios FEE, 19(2):38-61.

De Grauwe, P. and Grimaldi, M. (2006a). The exchange rate in a behavioral finance framework. Princeton University Press.

De Grauwe, P. and Grimaldi, M. (2006b). Exchange rate puzzles: a tale of switching attractors. European Economic Review, 50(1):1-33. 
De Paula, L. F. and Alves Jr, A. J. (2000). External financial fragility and the 1998-1999 Brazilian currency crisis. Journal of Post Keynesian Economics, pages 589-617.

De Paula, L. F., Fritz, B., and Prates, D. M. (2016). Keynes at the periphery: Currency hierarchy and challenges for economic policy in emerging economies. Online.

Dequech, D. (1999). Expectations and confidence under uncertainty. Journal of Post Keynesian Economics, 21(3):415-430.

Dequech, D. (2000). Fundamental uncertainty and ambiguity. Eastern Economic Journal, $26(1): 41-60$.

Dequech, D. (2001). Bounded rationality, institutions, and uncertainty. Journal of economic issues, 35(4):911-929.

Diamandis, P. F. and Drakos, A. A. (2011). Financial liberalization, exchange rates and stock prices: Exogenous shocks in four Latin America countries. Journal of Policy Modeling, 33(3):381-394.

Diamond, D. W. and Dybvig, P. H. (1983). Bank runs, deposit insurance, and liquidity. The journal of political economy, 91(3):401-419.

Disyatat, P. (2011). The bank lending channel revisited. Journal of money, Credit and Banking, 43(4):711-734.

Do Nascimento, P. F. and Macedo e Silva, A. C. (2016). Financeirização e crescimento: alguns experimentos stock-flow consistent. In Paper presented at the $42 n d$ ANPEC Meeting, number 85. Brazilian Association of Graduate Programs in Economics (ANPEC).

Dodd, R. (2002). The role of derivatives in the East Asian financial crisis. International capital markets: Systems in transition, page 447.

Dodd, R. (2005). Derivatives markets: sources of vulnerability in US financial markets. In Epstein, G., editor, Financialization and the world economy, pages 149-180. Edward Elgar Publishing.

Dollar, D. (1992). Outward-oriented developing economies really do grow more rapidly: evidence from 95 ldcs, 1976-1985. Economic development and cultural change, 40(3):523544. 
Dooley, M. and Hutchison, M. (2009). Transmission of the us subprime crisis to emerging markets: Evidence on the decoupling-recoupling hypothesis. Journal of International Money and Finance, 28(8):1331-1349.

Dornbusch, R. (1976). Expectations and exchange rate dynamics. The journal of political economy, pages 1161-1176.

Dornbusch, R. (1985). Purchasing power parity. Unpublished manuscript, National Bureau of Economic Research, Mass., USA.

Dornbusch, R. (2001). A primer on emerging market crises. NBER Working Paper 8326, National Bureau of Economic Research.

Dornbusch, R. and Fischer, S. (1980). Exchange rates and the current account. The American Economic Review, 70(5):960-971.

Dos Santos, C. H. (2005). A stock-flow consistent general framework for formal Minskyan analyses of closed economies. Journal of Post Keynesian Economics, 27(4):712-735.

Dos Santos, C. H. (2006). Keynesian theorising during hard times: stock-flow consistent models as an unexplored 'frontier' of keynesian macroeconomics. Cambridge Journal of Economics, 30(4):541-565.

Dos Santos, C. H. and Zezza, G. (2008). A simplified, 'benchmark', stock-flow consistent (sfc) post-keynesian growth model. Metroeconomica, 59(3):441-478.

Drine, I. and Rault, C. (2004). La PPA est-elle vérifiée pour les pays développés et en développement? Un ré-examen par l'économétrie des panels non stationnaires. Economie internationale, 1(97):49-80.

Duménil, G. and Lévy, D. (2003). Économie marxiste du capitalisme. La Découverte.

Dymski, G. A. (1999). Asset bubbles and Minsky crises in East Asia: A spatialized minsky approach. Research paper, University of California, Department of Economics.

Eatwell, J. and Taylor, L. (2001). Global finance at risk: the case for international regulation. New Press. 
ECLAC (2011). Economic survey of Latin America and the Caribbean 2010-2011. Technical report, Economic Commission for Latin America and the Caribbean (ECLAC).

Edison, H. and Reinhart, C. M. (2001). Stopping hot money. Journal of Development Economics, 66(2):533-553.

Edison, H. and Warnock, F. E. (2003). A simple measure of the intensity of capital controls. Journal of Empirical Finance, 10(1):81-103.

Edwards, S. (2001). Capital mobility and economic performance: Are emerging economies different? NBER Working Paper 8076, National Bureau of Economic Research.

Eichengreen, B. (1990). Trends and cycles in foreign lending. Technical report, National Bureau of Economic Research.

Eichengreen, B. (2001). Capital account liberalization: What do cross-country studies tell us? The World Bank Economic Review, 15(3):341-365.

Eichengreen, B. (2007). The real exchange rate and economic growth. Social and Economic Studies, pages 7-20.

Eichengreen, B. and Gupta, P. (2015). Tapering talk: the impact of expectations of reduced federal reserve security purchases on emerging markets. Emerging Markets Review, 25:115.

Eichengreen, B. and Leblang, D. (2003). Capital account liberalization and growth: was Mr. Mahathir right? International Journal of Finance \& Economics, 8(3):205-224.

Eichengreen, B., Rose, A. K., and Wyplosz, C. (1994). Speculative attacks on pegged exchange rates: an empirical exploration with special reference to the european monetary system. NBER Working Paper 4898, National Bureau of economic research.

Eichengreen, B., Rose, A. K., and Wyplosz, C. (1996). Contagious currency crises. NBER Working Paper 5681, National bureau of economic research.

Eichengreen, B. J., Mussa, M., and Dell'Ariccia, G. (1998). Capital Account Liberalization: Theoretical and Practical Aspects. International Monetary Fund. 
Engel, C. (1996). The forward discount anomaly and the risk premium: A survey of recent evidence. Journal of empirical finance, 3(2):123-192.

Engel, C. and Morley, J. C. (2001). The adjustment of prices and the adjustment of the exchange rate. NBER Working Paper 8550, National Bureau of Economic Research.

Epstein, G. (2005). Financialization And The World Economy. Edward Elgar Publishing, Massachusetts.

Epstein, G., Grabel, I., and Jomo, K. S. (2003). Capital management techniques in developing countries: An assessment of experiences from the 1990s and lessons for the future.

Epstein, G. and Power, D. (2003). Rentier incomes and financial crises: an empirical examination of trends and cycles in some OECD countries. Canadian Journal of Development Studies/Revue canadienne d'tudes du dveloppement, 24(2):229-248.

Erdemlioglu, D., Laurent, S., and Neely, C. J. (2012). Econometric modeling of exchange rate volatility and jumps. Working Paper 8, Federal Reserve Bank of St. Louis.

Evans, M. D. and Lyons, R. K. (1999). Order flow and exchange rate dynamics. Working Paper 8, National bureau of economic research.

Evans, M. D. and Lyons, R. K. (2005). Meese-rogoff redux: Micro-based exchange rate forecasting. NBER Working Paper 11042, National Bureau of Economic Research.

Everitt, B. and Skrondal, A. (1998). Cambridge dictionary of statistics. Cambridge University Press, fourth edition.

Fama, E. F. (1970). Efficient capital markets: A review of theory and empirical work. The Journal of Finance, 25.

Farhi, M. (1998). O futuro no presente: um estudo dos mercados de derivativos financeiros. $\mathrm{PhD}$ thesis, Universidade Estadual de Campinas (UNICAMP). Instituto de Economia.

Farhi, M. (1999). Derivativos financeiros: hedge, especulação e arbitragem. Economia e Sociedade, 8(2):13.

Farhi, M. (2006). O impacto dos ciclos de liquidez no brasil: mercados financeiros, taxa de câmbio, preços e política monetária. Política econômica em foco, 7:152-183. 
Farhi, M. (2010). Sistema financeiro e desenvolvimento no Brasil, chapter 5. Atitude.

Fawley, B. W. and Neely, C. J. (2013). Four stories of quantitative easing. Review, 95.

Fazzari, S., Ferri, P., and Greenberg, E. (2008). Cash flow, investment, and keynes-minsky cycles. Journal of Economic Behavior \& Organization, 65(3):555-572.

Feldstein, M. (1999). A self-help guide for emerging markets. Scholarly articles, Harvard University Department of Economics.

Fernandes, A. V. (2008). Microestrutura do mercado cambial brasileiro. Master's thesis, PUC-Rio.

Fernandez-Arias, E. (1996). The new wave of private capital inflows: push or pull? Journal of development economics, 48(2):389-418.

Ferrari Filho, F., Jayme Junior, F. G., Lima, G. T., Oreiro, J. L., and de Paula, L. F. (2005). Uma avaliação crítica da proposta de conversibilidade plena do real. Revista de economia política., 25(1):133-151.

Fischer, S. (1997). Capital account liberalization and the role of the IMF. Technical report, International Monetary Fund (IMF), Washington, DC.

Fischer, S. (2001). Opening remarks at the IMF/World Bank International Reserves.

Flassbeck, H. (2001). The exchange rate: economic policy tool or market price? Discussion Papers 157, United Nations Conference on Trade and Development, Geneva.

Flassbeck, H. and La Marca, M., editors (2007). Coping with globalized finance: Recent Challenges and Long-term Perspectives. United Nations Conference on Trade and Development, New York and Geneva. Retrieved from: http://unctad.org/en/Docs/gds20072_en.pdf.

Fleming, J. M. (1962). Domestic financial policies under fixed and under floating exchange rates. Staff Papers-International Monetary Fund, 9(3):369-380.

Flood, R. P. and Garber, P. M. (1984). Collapsing exchange-rate regimes: some linear examples. Journal of international Economics, 17(1):1-13.

Flood, R. P. and Garber, P. M. (1987). Gold monetization and gold discipline. In The Reconstruction of International Monetary Arrangements, pages 183-211. Springer. 
Flood, R. P. and Marion, N. (1998). Perspectives on the recent currency crisis literature. Working Paper 6380, National Bureau of Economic Research.

Flood, R. P. and Rose, A. K. (1995). Fixing exchange rates a virtual quest for fundamentals. Journal of Monetary Economics, 36(1):3-37.

Forbes, K. J. (2003). One cost of the Chilean capital controls: Increased financial constraints for smalles traded firms. NBER Working Paper 9777, National Bureau of Economic Research.

Forbes, K. J. (2005). Capital controls: mud in the wheels of market efficiency. Working Paper 4454, MIT Sloan School of Management.

Forbes, K. J. (2007). The microeconomic evidence on capital controls: no free lunch. In Edwards, S., editor, Capital Controls and Capital Flows in Emerging Economies: Policies, Practices and Consequences, pages 171-202. University of Chicago Press.

Forbes, K. J. (2010). Why do foreigners invest in the united states? Journal of International Economics, 80(1):3-21.

Forbes, K. J., Fratzscher, M., Kostka, T., and Straub, R. (2011). Bubble thy neighbor: direct and spillover effects of capital controls. In 12th Jacques Polak Annual Research Conference.

Forbes, K. J. and Warnock, F. E. (2012). Capital flow waves: Surges, stops, flight, and retrenchment. Journal of International Economics, 88(2):235-251.

"Foreign Exchange Regime" (2015). Central Bank of the Republic of China (Taiwan). Retrieved from http: //www. cbc.gov . tw/ct . asp? xItem=856\&CtNode=480\&mp=2.

Fourcade, M. (2013). The material and symbolic construction of the brics: Reflections inspired by the ripe special issue. Review of International Political Economy, 20(2):256267.

Frank, N. and Hesse, H. (2009). Financial spillovers to emerging markets during the global financial crisis. Number 9-104. International Monetary Fund.

Frankel, J. A. et al. (1987). Monetary and portfolio-balance models of exchange rate determination. University of California, Berkeley, Department of Economics. 
Frankel, J. A. and Froot, K. A. (1985). Using survey data to test some standard propositions regarding exchange rate expectations.

Frenkel, R. and Rapetti, M. (2014). The real exchange rate as a target of macroeconomic policy. In Calcagno, A., Dullien, S., Márquez-Vel'azquez, A., Maystre, N., and Priewe, J., editors, Rethinking Development Strategies after the Financial Crisis, volume I, chapter 6, pages 81-92. UNCTAD and HTW Berlin, New York and Geneva.

Friedman, M. (1953a). The case for flexible exchange rates. In Essays in Positive Economics, pages 157-203. Chicago University Press, Chicago.

Friedman, M. (1953b). The methodology of positive economics. In Essays in Positive Economics. Chicago University Press, Chicago.

Fritz, B. and Prates, D. M. (2014). The new IMF approach to capital account management and its blind spots: lessons from Brazil and South Korea. International Review of Applied Economics, 28(2):210-239.

Gagnon, J. and Chaboud, A. (2007). What can the data tell us about carry trades in japanese yen? Discussion Paper 899, FRB International Finance.

Galati, G. and Melvin, M. (2004). Why has FX trading surged? explaining the 2004 triennial survey. BIS Quarterly Review.

Gallagher, K. P. (2012). Regaining Control? Capital Controls and the Global Financial Crisis, pages 109-138. Oxford University Press.

Garcia, M. G. and Urban, F. (2004). O mercado interbancário de câmbio no Brasil. Working Paper 509, [PUC], Rio de Janeiro.

Garcia, P. and Soto, C. (2004). Large hoardings of international reserves: are they worth it. Working Paper 299, Central Bank of Chile.

Garcia-Herrero, A. and Wooldridge, P. D. (2007). Global and regional financial integration: progress in emerging markets. BIS Quarterly Review, September.

Gavin, M. (1989). The stock market and exchange rate dynamics. Journal of international money and finance, 8(2):181-200. 
Ghosh, A. R., Qureshi, M. S., Kim, J. I., and Zalduendo, J. (2014). Surges. Journal of International Economics, 92(2):266-285.

Giovannini, A. and Jorion, P. (1989). The time variation of risk and return in the foreign exchange and stock markets. The Journal of Finance, 44(2):307-325.

Goda, T. and Lysandrou, P. (2014). The contribution of wealth concentration to the subprime crisis: a quantitative estimation. Cambridge Journal of Economics, 38(2):301-327.

Goda, T., Onaran, Ö., and Stockhammer, E. (2014). A case for redistribution? income inequality and wealth concentration in the recent crisis. Working Paper 17, Center for Research in Economics and Finance, EAFIT University, Medellín.

Godley, W. (2012). Macroeconomics without equilibrium or disequilibrium. Springer.

Godley, W. and Lavoie, M. (2003). Two-country stock-flow-consistent macroeconomics using a closed model within a dollar exchange regime. Working Paper 10, University of Cambridge, Centre for Financial Analysis \& Policy.

Godley, W. and Lavoie, M. (2005). Simple open economy macro with comprehensive accounting: a two country model. Working Paper 20, University of Cambridge, Centre for Financial Analysis \& Policy.

Godley, W. and Lavoie, M. (2007). Monetary economics. Palgrave Macmillan Basingstoke.

Goldman Sachs (2010). EM equity in two decades: a changing landscape. Global economics paper, Goldman Sachs.

Goldstein, M. and Mussa, M. (1993). The integration of world capital markets. In Changing capital markets: implications for monetary policy. Jackson Hole, Wyoming.

Gorton, G. B. (2008). The panic of 2007. Technical report, National Bureau of Economic Research.

Gradojevic, N., Neely, C. J., et al. (2008). The dynamic interaction of order flows and the cad/usd exchange rate. Working Paper 6, Federal Reserve Bank of St. Louis.

Granger, C. W. (1969). Investigating causal relations by econometric models and crossspectral methods. Econometrica: Journal of the Econometric Society, pages 424-438. 
Granger, C. W., Huangb, B.-N., and Yang, C.-W. (2000). A bivariate causality between stock prices and exchange rates: evidence from recent asianflu? The Quarterly Review of Economics and Finance, 40(3):337-354.

Grilli, V. and Milesi-Ferretti, G. M. (1995). Economic effects and structural determinants of capital controls. IMF Staff Papers, 42(3):517-551.

Guttmann, R. (2008). A primer on finance-led capitalism and its crisis. Revue de la Rgulation, $3(4): 119$.

Guttmann, R. et al. (2015). The heterodox notion of structural crisis. Review of Keynesian Economics, 3(2):194-212.

Gyntelberg, J. and Remolona, E. M. (2007). Risk in carry trades: a look at target currencies in asia and the pacific. BIS Quarterly Review.

Haldane, A. (2011). The big fish small pond problem. In Institute for New Economic Thinking Annual Conference, volume 9, Bretton Woods, New Hampshire.

Han, L.-M., Kling, J. L., and Sell, C. W. (1999). Foreign exchange futures volatility: Dayof-the-week, intraday, and maturity patterns in the presence of macroeconomic announcements. Journal of Futures Markets, 19(6):665-693.

Harvey, J. T. (1998). Heuristic judgement theory. Journal of Economic Issues, 32(1):47-64.

Harvey, J. T. (2001). Exchange rate theory and the fundamentals. Journal of Post Keynesian Economics, 24(1):3-15.

Harvey, J. T. (2009). Currencies, capital flows and crises: A post Keynesian analysis of exchange rate determination. Routledge.

Haseeb, K. and Makdisi, S. A. (1982). Arab Monetary Integration: Issues and Prerequisites. Routledge Kegan \& Paul.

Hayes, M. G. (2003). Investment and finance under fundamental uncertainty. PhD thesis, University of Sunderland.

Heath, A., Galati, G., and McGuire, P. (2007). Evidence of carry trade activity. BIS Quarterly Review. 
Hein, E. (2011). Distribution, financialisation and the financial and economic crisis: Implications for post-crisis economic policies. Working Paper 9, Institute for International Political Economy Berlin.

Helleiner, E. (1996). States and the reemergence of global finance: from Bretton Woods to the 1990s. Cornell University Press.

Helleiner, G. K. (1997). Capital account regimes and the developing countries. International Monetary and Financial Issues for the 1990s, 8:1-25.

Henry, P. B. (2006). Capital account liberalization: Theory, evidence, and speculation. NBER Working Paper 12698, National Bureau of Economic Research.

Hesse, H., Frank, N., and González-Hermosillo, B. (2008). Transmission of liquidity shocks: Evidence from the 2007 subprime crisis. Working Paper 200, IMF.

Ho, L.-C. and Huang, C.-H. (2015). The nonlinear relationships between stock indexes and exchange rates. Japan and the World Economy, 33:20-27.

Hodge, D. (2008). Economics, realism and reality: a comparison of Mäki and Lawson. Cambridge Journal of Economics, 32(2):163-202.

Hoffmann, A. (2013). Carry trades and speculative manias: evidence from central and eastern europe. Journal of Post Keynesian Economics, 36(1):15-30.

Hofmann, B. and Bogdanova, B. (2012). Taylor rules and monetary policy: A global 'great deviation'? BIS Quarterly Review September.

Hofmann, B. and Takáts, E. (2015). International monetary spillovers. BIS Quarterly Review, page 105 .

Hoti, S. (2004). An empirical evaluation of international capital flows for developing countries. Mathematics and Computers in Simulation, 64(1):143-160.

Hudson, M. (2008). Trends that cant go on forever, wont: financial bubbles, trade and exchange rates. In Hein, E., Niechoj, T., Spahn, P., and Truger, A., editors, Finance-led capitalism, pages 249-272. Metropolis, Marburg/Lahn, second edition. 
Ibarra, C. A. (2010). Exporting without growing: investment, real currency appreciation, and export-led growth in mexico. The Journal of International Trade 85 Economic Development, 19(3):439-464.

IMF (2001). World Economic Outlook. International Monetary Fund, Washington, DC.

IMF (2004). Classification of Exchange Rate Arrangements and Monetary Policy Frameworks. International Monetary Fund.

IMF (2009). Initial lessons of the crisis. Paper prepared by the research, monetary and capital markets, and strategy, policy, and review departments, International Monetary Fund, Washington DC.

IMF (2014). Annual Report on Exchange Arrangements and Exchange Restriction. International Monetary Fund, Washington DC.

Isard, P. (1977). How far can we push the "law of one price"? The American Economic Review, 67(5):942-948.

Jeanne, O. (1996). Les modèles de crise de change: un essai de synthèse en relation avec la crise du franc de 1992-1993. Économie \& Prévision, 123(2-3):147-162.

Jeanne, O. (2007). International reserves in emerging market countries: too much of a good thing? Brookings papers on Economic activity, 2007(1):1-55.

Jeanne, O., Subramanian, A., and Williamson, J. (2012). Who needs to open the capital account. Peterson Institute, Washington, D.C.

Kahneman, D. (2011). Thinking, fast and slow. Macmillan, New York.

Kahneman, D. and Tversky, A. (2000). Choices, values, and frames. Cambridge University Press, New York.

Kaldor, N. (1939). Speculation and economic stability. The Review of Economic Studies, $7(1): 1-27$.

Kaltenbrunner, A. (2010). International financialization and depreciation: the Brazilian real in the international financial crisis. Competition \& Change, 14(3-4):296-323. 
Kaltenbrunner, A. (2011). Currency internationalisation and exchange rate dynamics in emerging markets: a post Keynesian analysis of Brazil. PhD thesis, SOAS, University of London, London.

Kaltenbrunner, A. (2015). A post keynesian framework of exchange rate determination: a Minskyan approach. Journal of Post Keynesian Economics, 38(3):426-448.

Kaltenbrunner, A. and Painceira, J. P. (2009). New forms of external vulnerability: Brazil in the global financial crisis. Research on money and finance.

Kaltenbrunner, A. and Painceira, J. P. (2014). Developing countries' changing nature of financial integration and new forms of external vulnerability: the Brazilian experience. Cambridge Journal of Economics, 39(5):1281-1306.

Kaltenbrunner, A. and Painceira, J. P. (2015). Developing countries' changing nature of financial integration and new forms of external vulnerability: the brazilian experience. Cambridge Journal of Economics, 39(5):1281-1306.

Kaminsky, G. L. and Reinhart, C. M. (1999). The twin crises: the causes of banking and balance-of-payments problems. American economic review, 89(3):473-500.

Keynes, J. M. (1936). General theory of employment, interest and money. Harcourt Brace.

Klitgaard, T. and Weir, L. (2004). Exchange rate changes and net positions of speculators in the futures market. Economic Policy Review, 10(1).

Koedijk, K. G., Schafgans, M. M., and De Vries, C. G. (1990). The tail index of exchange rate returns. Journal of International Economics, 29(1):93-108.

Koepke, R. (2015). What drives capital flows to emerging markets? A survey of the empirical literature. Munich Personal RePEc Archive Working Paper 62770, Institute of International Finance, University of Wurzburg, Munich.

Kohler, M. (2010). Exchange rates during financial crises. BIS Quarterly Review, March.

Kokenyne, A., Veyrune, R., Habermeier, K. F., and Anderson, H. (2009). Revised system for the classification of exchange rate arrangements. Working Paper 211, International Monetary Fund (IMF). 
Kolenikov, S. and Angeles, G. (2004). The use of discrete data in PCA: theory, simulations, and applications to socioeconomic indices. Working Paper, Carolina Population Center, University of North Carolina, Chapel Hill.

Kose, M. A., Prasad, E., Rogoff, K. S., and Wei, S.-J. (2006). Financial globalization: a reappraisal. NBER Working Paper 12484, National Bureau of Economic Research.

Koulakiotis, A., Kiohos, A., and Babalos, V. (2015). Exploring the interaction between stock price index and exchange rates: an asymmetric threshold approach. Applied Economics, 47(13):1273-1285.

Kouri, P. J. (1976). The exchange rate and the balance of payments in the short run and in the long run: A monetary approach. The Scandinavian Journal of Economics, pages 280-304.

Kraay, A. (1998). In search of the macroeconomic effects of capital account liberalization. Unpublished manuscript, World Bank. Retrieved from http://siteresources.worldbank. org/DEC/Resources/22237_CALMacroEffects_Manuscript.pdf.

Kregel, J. (1996). Riscos e implicações da globalização financeira para a autonomia de políticas nacionais. Economia e Sociedade, 7:29-49.

Kregel, J. (2004). Can we create a stable international financial environment that ensures net resource transfers to developing countries? Journal of Post Keynesian Economics, 26(4):573-590.

Kregel, J. (2008). Using Minsky's cushions of safety to analyze the crisis in the us subprime mortgage market. International Journal of Political Economy, 37(1):3-23.

Kregel, J. (2016). Minsky's financial instability analysis. In The Rejuvenation of Political Economy, chapter 12, page 242. Routledge.

Krippner, G. R. (2005). The financialization of the american economy. Socio-Economic Review, 3(2):173-208.

Krueger, A. O. (1983). Exchange-rate determination. Cambridge University Press.

Krugman, P. (1979). A model of balance-of-payments crises. Journal of money, credit and banking, 11(3):311-325. 
Krugman, P. (2001a). Crises: the next generation. Tel Aviv: Razin.

Krugman, P. (2012 (2001)b). What happened to asia? In Sato, R., Ramachandran, R. V., and Mino, K., editors, Global competition and integration, volume 4, chapter 14, page 315. Springer Science \& Business Media.

Krugman, P. and Miller, M. (1993). Why have a target zone? Carnegie-Rochester Conference Series on Public Policy, 38:279-314.

Krugman, P. R. (1985). Is the strong dollar sustainable?

Kubelec, C. and Sá, F. (2010). The geographical composition of national external balance sheets: 1980-2005. Working Paper 384, Bank of England.

Kyle, A. S. and Xiong, W. (2001). Contagion as a wealth effect. The Journal of Finance, 56(4):1401-1440.

Lane, P. R. (2001). The new open economy macroeconomics: a survey. Journal of international economics, 54(2):235-266.

Lane, P. R. and Milesi-Ferretti, G.-M. (2000). External capital structure: theory and evidence. Working Paper 152, International Monetary Fund.

Lane, P. R. and Milesi-Ferretti, G. M. (2001). The external wealth of nations: measures of foreign assets and liabilities for industrial and developing countries. Journal of international Economics, 55(2):263-294.

Lane, P. R. and Milesi-Ferretti, G. M. (2007). The external wealth of nations mark II: Revised and extended estimates of foreign assets and liabilities, 1970-2004. Journal of International Economics, 73(2):223-250.

Lang, D. and De Peretti, C. (2009). A strong hysteretic model of Okuns law: theory and a preliminary investigation. International Review of Applied Economics, 23(4):445-462.

Lang, D. and Setterfield, M. (2006). History versus equilibrium? on the possibility and realist basis of a general critique of traditional equilibrium analysis. Journal of Post Keynesian Economics, 29(2):191-209. 
Lapavitsas, C. (2009). Financialisation, or the search for profits in the sphere of circulation. Ekonomiaz, 72(03):98-119.

Lavoie, M. (2000). A post Keynesian view of interest parity theorems. Journal of Post Keynesian Economics, 23(1):163-179.

Lavoie, M. (2014). Post-Keynesian Economics: New Foundations. Edward Elgar Publishing.

Lavoie, M. and Daigle, G. (2011). A behavioural finance model of exchange rate expectations within a stock-flow consistent framework. Metroeconomica, 62(3):434-458.

Lazonick, W. and O'sullivan, M. (2000). Maximizing shareholder value: a new ideology for corporate governance. Economy and Society, 29(1):1335.

Le Cacheux, J. and Touzé, V. (2003). Vieillissement et richesse des nations. Revue de l'OFCE, 3(86):4791.

Lee, J. (2004). Insurance value of international reserves: an option pricing approach. IMF Working Paper 175.

Levine, R. and Zervos, S. (1996). Stock market development and long-run growth. The World Bank Economic Review, 10(2):323-339.

Loko, B. and Diouf, M. A. (2009). Revisiting the determinants of productivity growth: What's new? Working Paper 225, International Monetary Fund.

Longin, F. and Solnik, B. (1995). Is the correlation in international equity returns constant: 1960-1990? Journal of international money and finance, 14(1):3-26.

Lux, T. and Marchesi, M. (2000). Volatility clustering in financial markets: a microsimulation of interacting agents. International journal of theoretical and applied finance, 3(04):675702.

MacDonald, R. (1995). Long-run exchange rate modeling: a survey of the recent evidence. Staff Papers-International Monetary Fund, pages 437-489.

MacDonald, R. (2007). Exchange rate economics: theories and evidence. Psychology Press. 
Macedo e Silva, A. C. and Dos Santos, C. H. (2011). Peering over the edge of the short period? the keynesian roots of stock-flow consistent macroeconomic models. Cambridge Journal of Economics, 35(1):105-124.

Magud, N. and Reinhart, C. M. (2006). Capital controls: an evaluation. NBER Working Paper 11973, National Bureau of Economic Research.

Mäki, U. (2003). 'The methodology of positive economics' (1953) does not give us the methodology of positive economics. Journal of Economic Methodology, 10(4):495-505.

Margeirsson, O. (2015). Foreign direct investment: A focused literature. Working Paper 104, Binzagr Institute for Sustainable Prosperity, Exeter.

Markowitz, H. M. (1968). Portfolio selection: efficient diversification of investments, volume 16. Yale University Press.

McCauley, R. N. and Scatigna, M. (2011). Foreign exchange trading in emerging currencies: more financial, more offshore. BIS Quarterly Review, March.

McCombie, J. S. (1993). Economic growth, trade interlinkages, and the balance-of-payments constraint. Journal of Post Keynesian Economics, 15(4):471-505.

McKinnon, R. I. (1966). Portfolio balance and international payments adjustments. Stanford University, Research Center in Economic Growth.

McKinnon, R. I. (1973). Money and capital in economic development. Brookings Institution Press.

McKinnon, R. I. (1982). Currency substitution and instability in the world dollar standard. The American Economic Review, 72(3):320-333.

Meade, J. E. (1951). The balance of payments, volume 432. Oxford University Press London.

Meese, R. A. and Rogoff, K. (1983). Empirical exchange rate models of the seventies: Do they fit out of sample? Journal of international economics, 14(1):3-24.

Melitz, J. and Owen, R. (1983). How much simplification is wise in modelling exchange rates? In De Grauwe, P. and Peeters, T., editors, Exchange Rates in Multicountry Econometric Models, pages 1-20. Macmillan. 
Miles, M. A. (1978). Currency substitution, flexible exchange rates, and monetary independence. The American Economic Review, 68(3):428-436.

Milesi-Ferretti, G.-M. and Tille, C. (2011). The great retrenchment: international capital flows during the global financial crisis. Economic Policy, 26(66):289-346.

Minsky, H. P. (1975). John Maynard Keynes. Columbia University Press New York.

Minsky, H. P. (1988). Money manager capitalism, fiscal independence and international monetary reconstruction. Hyman P. Minsky Archive Papers 431, The Levy Economics Institute.

Minsky, H. P. (1990). Schumpeter: finance and evolution. Evolving technology and market structure, pages 51-74.

Minsky, H. P. (1992). The financial instability hypothesis. Hyman P. Minsky Archive Papers 74, The Levy Economics Institute.

Minsky, H. P. (1993). On the non-neutrality of money. Federal Reserve Bank of New York Quarterly Review, 18(1):77-82.

Minsky, H. P. (1995). Longer waves in financial relations: financial factors in the more severe depressions II. Journal of Economic Issues, 29(1):83-96.

Minsky, H. P. (2008 (1986)). Stabilizing an Unstable Economy. McGraw Hill Professional.

Minsky, H. P., Kindleberger, C., and Laffargue, J.-P. (1982). The financial-instability hypothesis: capitalist processes and the behavior of the economy. In Financial Crises: Theory, history, and policy, pages 13-43. Cambridge University Press.

Miotti, L. and Plihon, D. (2001). Libéralisation financière, spéculation et crises bancaires. Économie internationale, 85(1):3-36.

Mishkin, F. (2006). The next great globalization.

Missio, F. J., Jayme Júnior, F. G., Britto, G., and Oreiro, L. J. (2015). Real exchange rate and economic growth: New empirical evidence. Metroeconomica, 66(4):686-714.

Moguillansky, G. (2002). Investment and financial volatility in Latin America. Cepal Review. 
Moosa, I. A. (2004). An empirical examination of the post keynesian view of forward exchange rates. Journal of Post Keynesian Economics, 26(3):395-418.

Mundell, R. A. (1963). Capital mobility and stabilization policy under fixed and flexible exchange rates. Canadian Journal of Economics and Political Science/Revue canadienne de economiques et science politique, 29(04):475-485.

Mundell, R. A. (2001). On the history of the Mundell-Fleming Model. Keynote speech. Staff Papers Special 47, International Monetary Fund.

Mussa, M. (1976). The exchange rate, the balance of payments and monetary and fiscal policy under a regime of controlled floating. The Scandinavian Journal of Economics, pages $229-248$.

Nam, R. and Kumar, M. (2015). India sets inflation target in monetary policy overhaul. Reuters. Retrieved from http://in.reuters.com/article/2015/03/02/ india-rbi-idINKBNOLYOB320150302.

Neely, C. J. (1999). An introduction to capital controls. Federal Reserve Bank of St. Louis Review, 81(November/December 1999).

Obstfeld, M. (1986). Rational and self-fulfilling balance-of-payments crises. The American Economic Review, 76(1):72-81.

Obstfeld, M. (1994). The logic of currency crises. NBER Working Paper 4640, National Bureau of Economic Research.

Obstfeld, M. (1996). Models of currency crises with self-fulfilling features. European economic review, 40(3):1037-1047.

Obstfeld, M. (1997). Destabilizing effects of exchange-rate escape clauses. Journal of International Economics, 43(1):61-77.

Obstfeld, M. (2002). Exchange rates and adjustment: perspectives from the new open economy macroeconomics. Technical Report 9118, National Bureau of Economic Research.

Obstfeld, M. (2009). International finance and growth in developing countries: What have we learned? Technical report, National Bureau of Economic Research. 
Obstfeld, M. (2015). Trilemmas and trade-offs: living with financial globalisation. Paper commissioned for the Asian monetary policy forum, Singapore, Bank for International Settlements (BIS).

Obstfeld, M. and Rogoff, K. (1995). Exchange rate dynamics redux. Journal of Political Economy, 103(3):624-660.

Obstfeld, M. and Rogoff, K. (2000). New directions for stochastic open economy models. Journal of international economics, 50(1):117-153.

Obstfeld, M. and Rogoff, K. (2001). The six major puzzles in international macroeconomics: is there a common cause? In NBER Macroeconomics Annual 2000, Volume 15, pages 339-412. MIT press.

Obstfeld, M., Shambaugh, J. C., and Taylor, A. M. (2009). Financial instability, reserves, and central bank swap lines in the panic of 2008. NBER Working Paper 14826, National Bureau of Economic Research.

Ocampo, J. A. (2003a). Capital account and countercyclical prudential regulations in developing countries. In From Capital Surges to Drought, pages 217-244. Springer.

Ocampo, J. A. (2003b). International asymmetries and the design of the international financial system. Critical Issues in Financial Reform: A View from the South. Transaction Publishers, New Brunswick, NJ, pages 45-74.

Ocampo, J. A. (2012). The case for and experience with capital account regulations. Regulating Global Capital Flows for Long-Run Development, Boston: Boston University, pages $13-22$.

OECD (2002). Foreign Direct Investment for Development. Organisation for Economic Cooperation and Development, Paris.

OECD (2008). OECD Benchmark Definition of Foreign Direct Investment. Organisation for Economic Co-operation and Development.

O'Neill, J. (2001). Building better global economic brics. Goldman Sachs Global Economics Paper 66. Retrieved from: http://www.content.gs.com/our-thinking/ archive/archive-pdfs/build-better-brics.pdf. 
Oreiro, J. L. (2004). Autonomia de política econômica, fragilidade externa e equilíbrio do balanço de pagamentos. Revista Economia e Sociedade, 13(2):1-22.

Orhangazi, O. (2008). Financialisation and capital accumulation in the non-financial corporate sector: A theoretical and empirical investigation on the US economy: 1973-2003. Cambridge Journal of Economics, 32(6):863-886.

Orléan, A. (1999). Le pouvoir de la finance. Odile Jacob.

Orléan, A. (2004). Efficience, finance comportementale et convention: une synthèse théorique. Les crises financières, Rapport du Conseil d'Analyse Economique, 50:241-270.

Ostry, J. D., Ghosh, A. R., Habermeier, K. F., Chamon, M., Qureshi, M. S., and Reinhardt, D. (2010). Capital inflows: The role of controls. IMF Staff Position Note 4, International Monetary Fund, Washington DC.

Ostry, J. D., Ghosh, A. R., Habermeier, K. F., Laeven, L., Chamon, M., Qureshi, M. S., and Kokenyne, A. (2011). Managing capital inflows: What tools to use? IMF Working Paper 6, International Monetary Fund, Washington DC.

Palley, T. (2007). Financialization: what it is and why it matters. Working Paper 525, The Levy Economics Institute.

Palma, J. G. (2012). How the full opening of the capital account to highly liquid financial markets led Latin America to two and a half cycles of 'mania, panic and crash'. Cambridge Working Papers in Economics 1201, Faculty of Economics, University of Cambridge, UK.

Pan, M.-S., Fok, R. C.-W., and Liu, Y. A. (2007). Dynamic linkages between exchange rates and stock prices: Evidence from East Asian markets. International Review of Economics \& Finance, 16(4):503-520.

Papadimitriou, D. B. and Wray, L. R. (1997). A tribute to hyman p. minsky. Journal of Economic Issues, 31(2):491-492.

Papadimitriou, D. B. and Wray, L. R. (1998). The economic contributions of Hyman Minsky: varieties of capitalism and institutional reform. Review of Political Economy, 10(2):199225. 
Pastr, O. (2007). The new banking economics. Edward Elgar.

Perry, J. (2008). Hungary eliminates euro-based trading range for its currency. The Wall Street Journal. http://www.wsj.com/articles/SB120397086361591431.

Phylaktis, K. and Ravazzolo, F. (2002). Measuring financial and economic integration with equity prices in emerging markets. Journal of International Money and Finance, 21(6):879903.

Phylaktis, K. and Ravazzolo, F. (2005). Stock prices and exchange rate dynamics. Journal of International Money and Finance, 24(7):1031-1053.

Plihon, D. (1995). Liquidité et investissement : une lecture Keynesienne des mutations financierés recentes et de leurs consequences. Economies et socites, 29(11):57-91.

Plihon, D. (1997). Les enjeux de la globalisation financiér. In La mondialisation au-delá des mythes, pages 69-79. La Decouverte, Paris.

Plihon, D. (2010). Les taux de change. La Decouverte, Paris.

Plihon, D. (2010 [2003]). Le nouveau capitalisme. La Decouverte, Paris, third edition.

Plihon, D., Couppey-Soubeyran, J., and Saïdane, D. (2006). Les banques: acteurs de la globalisation financière. La documentation française.

Plihon, D. and Ponssard, J. P. (2002). La monté en puissance des fonds d'investissement: quels enjeux pour les entreprises? Documentation française.

Polak, J. J. (1957). Monetary analysis of income formation and payments problems. Technical Report 1, International Monetary Fund.

Pollin, R. (2007). The resurrection of the rentier. New Left Review, pages 140-153.

Prasad, E., Rogoff, K., Wei, S.-J., and Kose, M. A. (2003). Effects of financial globalisation on developing countries: Some empirical evidence. Economic and Political Weekly, pages 4319-4330.

Prates, D. M. (2002). Crises financeiras dos países 'emergentes': uma interpretação heterodoxa. PhD thesis, Unicamp. 
Prates, D. M. (2005a). As assimetrias do sistema monetário e financeiro internacional. Revista de economia contemporânea, 9(2):263-288.

Prates, D. M. (2005b). Resenha crítica-a literatura convencional sobre crises financeiras nos países" emergentes": os modelos desenvolvidos nos anos 90. Estudos Econômicos (São Paulo), 35(2):359-385.

Prates, D. M. (2007). A alta recente dos preços das commodities. Revista de Economia Política, 27(3):323-344.

Prates, D. M. (2009). Os determinantes das taxas de câmbio nominal e real no Brasil no período 2003-2007. In Ferreira, F. and Meireles, B., editors, Ensaios Sobre Economia Financeira. BNDES, Rio de Janeiro.

Prates, D. M. (2015). O regime de câmbio flutuante no Brasil: 1999-2012: Especificidades e dilemas. Instituto de Pesquisa Econômica Aplicada.

Prates, D. M. and Biancareli, A. M. (2009). Panorama do ciclo de crédito recente: condicionantes e características gerais: projeto de estudos sobre as perspectivas da indústria financeiras brasileira e o papel dos bancos públicos.

Prates, D. M. and Cunha, A. M. (2013). Controles de capitais e o perfil do passivo externo brasileiro: tendências recentes e perspectivas. Indicadores Econômicos FEE, 40(4).

Prates, D. M. and Farhi, M. (2009). A crise financeira internacional, o grau de investimento e a taxa de câmbio do real. Working Paper 164, Universidade Estadual de Campinas (Unicamp), Instituto de Economia.

Prates, D. M. and Farhi, M. (2015). The shadow banking system and the new phase of the money manager capitalism. Journal of Post Keynesian Economics, 37(4):568-589.

Prates, D. M. and Farhi, M. (2016). Playing it again: new financial innovations and renewed financial fragility. Manuscript submitted for publication.

Prates, D. M. and Fritz, B. (2016). Beyond capital controls: regulation of foreign currency derivatives markets in theRepublic of Korea and Brazil after the Global Financial Crisis. CEPAL Review, (118). 
Priewe, J. (2014). An asset price theory of exchange rates. Technical report, HTW Berlin University of Applied Sciences.

Pusch, T. (2012). The role of uncertainty in the euro crisis: A reconsideration of liquidity preference theory. No 31, Discussion Papers from University of Hamburg, 31, Zentrum für Ökonomische und Soziologische Studien.

Quinn, D. (1997). The correlates of change in international financial regulation. American Political Science Review, 91(03):531-551.

Quinn, D., Schindler, M., and Toyoda, A. M. (2011). Assessing measures of financial openness and integration. IMF Economic Review, 59(3):488-522.

Ramos, R. A. (2010). How to prevent exchange rate misalignments: Costs and benefits of capital account management and reserve accumulation in the case of Brazil. Master's thesis, HTW Berlin.

Ramos, R. A. (2012). Financial flows and exchange rates: Challenges faced by developing countries. IPC-IG Working Paper 97, International Policy Centre for Inclusive Growth, Brasilia.

Ranciere, R. and Jeanne, M. O. (2006). The optimal level of international reserves for emerging market countries: formulas and applications. International Monetary Fund.

Rapetti, M. (2013). The real exchange rate and economic growth: some observations on the possible channels. Working Paper 11, Department of Economics, University of Massachusetts, Amherst.

Rapetti, M., Skott, P., and Razmi, A. (2012). The real exchange rate and economic growth: are developing countries different? International Review of Applied Economics, 26(6):735753.

Razmi, A., Rapetti, M., and Skott, P. (2009). The real exchange rate as an instrument of development policy. Working Paper 7, University of Massachusetts, Amherst.

Reinhart, C. M. and Reinhart, V. R. (2008). Capital flow bonanzas: An encompassing view of the past and present. Technical report, National Bureau of Economic Research. 
Reisen, H. and Soto, M. (2001). Which types of capital inflows foster developing-country growth? International finance, 4(1):1-14.

Rey, H. (2015). Dilemma not trilemma: the global financial cycle and monetary policy independence. NBER Working Paper 21162, National Bureau of Economic Research.

Reyes, L. and Mazier, J. (2014). Financialized growth regime: lessons from stock flow consistent models. Working Paper 16.

Rime, D. R. and Schrimpf, A. (2013). The anatomy of the global FX market through the lens of the 2013 triennial survey. BIS Quarterly Review, December.

Rodrik, D. (1998). Who needs capital-account convertibility? Essays in international finance, pages $55-65$.

Rodrik, D. (2006). The social cost of foreign exchange reserves. International Economic Journal, 20(3):253-266.

Rodrik, D. (2008). The real exchange rate and economic growth. Brookings papers on economic activity, 2008(2):365-412.

Rodrik, D. and Velasco, A. (1999). Short-term capital flows. NBER Working Paper 7364, National bureau of economic research.

Roger, S. (2010). Inflation targeting turns 20. Finance and Development, 47(1):46-49.

Rogoff, K. (1996). The purchasing power parity puzzle. Journal of Economic literature, $34(2): 647-668$

Rogoff, K. (1999). International institutions for reducing global financial instability. NBER Working Paper 7265, National Bureau of Economic Research.

Rossi, P. L. (2014). Institutionality of the foreign exchange market and exchange rate policy in Brazil. Economia e Sociedade, 23(3):645-667.

Rossi, P. L. (2016). Taxa de câmbio e politíca cambial no Brasil: teoria, instucionalidade, papel da arbitragem e da especulação. São Paulo.

Rotheim, R. (2003). New Keynesian Economics/Post Keynesian Alternatives. Routledge. 
Roy, R. and Ramos, R. A. (2012). IMF article IV reports: An analysis of policy recommendations. IPC-IG Working Paper 86, International Policy Centre for Inclusive Growth, Brasilia.

Samuelson, P. A. (1964). Theoretical notes on trade problems. The Review of Economics and Statistics, pages $145-154$.

Sarno, L. and Taylor, M. P. (1999). Hot money, accounting labels and the permanence of capital flows to developing countries: an empirical investigation. Journal of Development Economics, 59(2):337-364.

Schindler, M. (2009). Measuring financial integration: a new data set. IMF Staff Papers, pages $222-238$.

Schroeder, S. K. (2002). A Minskian analysis of financial crisis in developing countries. Technical report, Schwartz Center for Economic Policy Analysis (SCEPA), The New School.

Schulmeister, S. (1987). An essay on exchange rate dynamics. Discussion Papers 8, WZB Berlin Social Science Center, Berlin.

Schulmeister, S. (1988). Currency speculation and dollar fluctuations. Banca Nazionoie del Lavoro Quarterly Review, (167):343-366.

Schulmeister, S. (2008). Components of the profitability of technical currency trading. $A p$ plied Financial Economics, 18(11):917-930.

Schulmeister, S. (2009). On the manic-depressive fluctuations of speculative prices. In Hein, E., Niechoj, T., Spahn, P., and Truger, A., editors, Finance-led Capitalism, MetropolisVerlag, Marburg, pages 309-335. Metropolis Verlag, Marburg, second edition.

Serieux, J. (2008). Financial liberalization and domestic resource mobilization in africa: An assessment. Working Paper 45, International Poverty Centre.

Shaw, E. (1973). Financial deepening in economic development. New York.

Shin, H. S. (2014). The second phase of global liquidity and its impact on emerging economies. In Volatile Capital Flows in Korea, pages 247-257. Springer. 
Shin, H. S. (2016). Global liquidity and procyclicality. In World Bank conference, "The state of economics, the state of the world".

Smithin, J. (2002). Interest parity, purchasing power parity," risk premia," and post keynesian economic analysis. Journal of Post Keynesian Economics, 25(2):219-235.

$$
\begin{array}{lccccc}
\text { "Société } & \text { payée } & \text { pour } & \text { s'endetter" } & \text { (2016). Le } & \text { Monde. } \\
\text { trieved } & \text { from } & \text { http://www.lemonde.fr/economie/article/2016/09/07/ } \\
\text { sanofi-premiere-societe-francaise-payee-pour-s-endetter_4993852_3234.html. }
\end{array}
$$

Solow, R. M. (1956). A contribution to the theory of economic growth. The quarterly journal of economics, pages 65-94.

STATA (2016). Stata Manual, Correlate. STATA, 13th edition. Retrieved in: http://www. stata.com/manuals13/rcorrelate.pdf.

Stockhammer, E. (2004). Financialisation and the slowdown of accumulation. Cambridge Journal of Economics, 28(5):719-741.

Stockhammer, E. (2008). Some stylized facts on the finance-dominated accumulation regime. Competition \& Change, 12(2):184-202.

Stockhammer, E. (2009). The finance-dominated accumulation regime, income distribution and the present crisis. Working Paper Series 127, Vienna University of Economics and Business, Vienna.

Stockhammer, E. (2010). Financialization and the global economy. Working paper, Political Economy Research Institute.

Sula, O. and Willett, T. D. (2009). The reversibility of different types of capital flows to emerging markets. Emerging Markets Review, 10(4):296-310.

Taleb, N. N. (2007). The black swan: The impact of the highly improbable. Random House.

Tang, K. and Xiong, W. (2010). Index investment and financialization of commodities. NBER Working Paper 6, National Bureau of Economic Research.

Taylor, A. M. and Taylor, M. P. (2004). The purchasing power parity debate. The Journal of Economic Perspectives, 18(4):135-158. 
Taylor, L. (2004). Exchange rate indeterminacy in portfolio balance, Mundell-Fleming and uncovered interest rate parity models. Cambridge Journal of Economics, 28(2):205-227.

Taylor, L. (2009a). Reconstructing macroeconomics: Structuralist proposals and critiques of the mainstream. Harvard University Press.

Taylor, M. P. (2009b). Long-run purchasing power parity and real exchange rates: introduction and overview. Applied Economics Letters, 16(1):1-4.

Tobin, J. (1965). The theory of portfolio selection. The theory of interest rates, pages 3-51.

Tridico, P. (2012). Financial crisis and global imbalances: its labour market origins and the aftermath. Cambridge Journal of Economics, 36(1):17-42.

Tymoigne, E. and Wray, L. R. (2013). The rise and fall of money manager capitalism: Minsky's half century from World War Two to the Great Recession. Routledge.

UNCTAD (2007). Trade and Development Report. United Nations Conference on Trade and Development.

UNCTAD (2009). Trade and Development Report. United Nations Conference on Trade and Development.

UNCTAD (2010). World Investment Report. United Nations Conference on Trade and Development.

UNCTAD (2012). Dont blame the physical markets: financialization is the root cause of oil and commodity price volatility. Policy Brief 25, United Nations Conference on Trade and Development.

UNCTAD (2015). Trade and Development Report. United Nations Conference on Trade and Development.

Ventura, A. and Garcia, M. (2012). Mercados futuro e à vista de câmbio no brasil: o rabo abana o cachorro. Revista Brasileira de Economia, 66(1):21-48.

"VIX Index" (2013). Chicago Board Options Exchange (CBOE). Retrieved from http: //www.cboe.com/micro/vix/vixintro.aspx. 
"Volatile" (2015). Oxford Dictionaries. Retrieved from http://www.oxforddictionaries . com.

"VSTOXX Index" (2013). STOXX. Retrieved from http://www.stoxx.com/indices/ index_information.html?symbol=V2TX.

Weeks, J. (2012). Trade balance and the exchange rate in argentina: An analytical and empirical exercise. Online.

Weiss, M. A. and Prates, D. M. (2015). Análise empírica dos determinantes dos fluxos de capitais financeiros para os países emergentes e em desenvolvimento. Working paper, AKB (Brazilian Keynesian Association).

Westerhoff, F. et al. (2009). Exchange rate dynamics: A nonlinear survey. Handbook of research on complexity, pages $287-325$.

"What is happening to the Japanese yen?" (2011). The Guardian. Retrieved from https: //www.theguardian.com/business/2011/mar/17/japan-yen-question-and-answer.

Willett, T. D., Budiman, A., Denzau, A., Jo, G.-J., Ramos, C., Thomas, J., et al. (2001). The falsification of four popular hypotheses about international financial behavior during the asian crisis. The World Economy.

Williamson, J. (1990). What washington means by policy reform. Latin American adjustment: How much has happened.

Williamson, J. (2000). Exchange rate regimes for emerging markets: reviving the intermediate option. Peterson Institute.

Williamson, J. (2009). Exchange rate economics. Open Economies Review, 20(1):123-146.

Wolfson, M. H. (1994). Financial Crises: Understanding the Postwar U.S. Experience. M.E. Sharpe.

Wolfson, M. H. (2002). Minsky's theory of financial crises in a global context. Journal of Economic Issues, 36(2):393-400.

World Bank (2015). World development indicators 2015. World Bank Publications. 
Wray, L. R. (2009). The rise and fall of money manager capitalism: a Minskian approach. Cambridge Journal of Economics, 33(4):807-828.

Yang, S.-Y. and Doong, S.-C. (2004). Price and volatility spillovers between stock prices and exchange rates: empirical evidence from the G-7 countries. International Journal of Business and Economics, 3(2):139. 